PROGRAMA DE DOCTORADO EN CIENCIA E INGENIERÍA AGROALIMENTARIA Y DE BIOSISTEMAS

TESIS DOCTORAL:

\title{
CARACTERIZACIÓN MECÁNICA DE LA MADERA ESTRUCTURAL DE ALERCE DEL JAPÓN (LARIX KAEMPFERI (LAMB.) CARR.) E INFLUENCIA DE LA ÉPOCA DE CORTA EN SUS PROPIEDADES
}

\author{
Presentada por \\ MARÍA JOSÉ BARRIOLA BARAIBAR \\ para optar al grado de \\ Doctora por la Universidad de Valladolid \\ Dirigida por: \\ JOSÉ RAMÓN AIRA ZUNZUNEGUI \\ MARÍA TERESA DE TROYA FRANCO \\ 2019
}




\section{Agradecimientos}

Siempre he considerado que las cosas no valen por el tiempo que duran, sino por las huellas que dejan. Y así ha sido en mi caso la huella que ha dejado "la madera en mi vida". Un material que me ha dado calor, cobijo y sobre todo una forma de vivir y sentir mi relación con la naturaleza.

Una de las personas que más ha influido en la materialización de esta tesis doctoral es mi padre, que junto con mi madre que me ayuda cada día desde donde esté, han hecho que sea una persona privilegiada por haber tenido la oportunidad de recibir una educación basada en la colaboración, el esfuerzo, el respeto y la humildad. Ellos, marcaron el camino para forjar mi personalidad, mientras me contaban tantísimas historias alrededor del fuego en la cocina de mi casa. En ella, se quemaba la madera de haya y roble de los montes de Leitza, cortada en invierno teniendo muy presente la fase lunar. Y todo ello me ha enseñado a no olvidar nunca mis orígenes por muy lejos que quiera llegar.

Del mismo modo, deseo dedicar unas palabras de agradecimiento a mis dos hermanos y familia, por hacerme crecer como persona con las importantísimas lecciones de vida que me han dado y que jamás olvidaré.

Y cómo no, a mi marido Javier y a mis hijos Ander y Eider, que me han acompañado en este camino muchas veces difícil. Ellos me han ayudado a creer que "todo parece imposible hasta que se hace".

En el transcurso de todos estos años, debo hacer una mención especial al Viceconsejero de Formación Profesional de Euskadi Jorge Arévalo, quien ha creído en este trabajo desde el momento en que comenzó su andadura. Ha sido él quien que me ha brindado su apoyo incondicional durante el transcurso de esta tesis doctoral, y me ha enseñado que "debemos trabajar desde el sentimiento más profundo de lo inimaginable"

De modo general, quiero dar las gracias por todo el apoyo económico, material y administrativo recibido al Gobierno Vasco, a la Diputación Foral de Gipuzkoa, al Gobierno de Navarra y a Secoma (Servicios Comerciales de la Madera de Gipuzkoa).

Quiero mostrar mi gratitud a mis directores de tesis José Ramón Aira y Mayte de Troya que han estado presentes en la realización de esta meta y de este sueño que es tan importante para mí, por sus palabras motivadoras, sus conocimientos, sus consejos y su dedicación.

Por su parte, no puedo dejar de agradecer a título particular a:

Los compañeros y a la dirección del Centro Integrado de Formación Profesional Bidasoa de Irún, y a todos los compañeros de Tknika, centro de Investigación en Innovación Aplicada para la Formación Profesional en el País Vasco, que han sido los que han padecido mis locuras luneras en el transcurso de estos años. 
A Julian Unanue y Bixente Dorronsoro porque aportando apoyo institucional el uno y profesionalidad y experiencia el otro, habéis dado vida y sentido a una pasión por la madera que muchos compartimos.

A Juan Mari Zubizarreta y a Joxe Miguel Larrañaga, porque estéis donde estéis, siempre recordaré vuestro apoyo e ilusión,.

A la Guardería Forestal de Gipuzkoa, Joxe Manuel, Inaxio, Rober, Imanol, Joxe Angel, Aitzol, Fermín, Mikel, Maitane, y a Xabi y Alejo, celadores de Bera y Lesaka, con los que he compartido muchas horas de trabajo, y sin los cuales hubiera sido imposible realizar esta tesis.

A dos todo terreno, los hermanos Txomin y Xabi Bikuña, operarios forestales cualificados y colaboradores en cualesquiera otras labores. Han sido compañeros y amigos, desde que esto empezó y una parte insustituible de esta pequeña familia de trabajos de campo.

A los transportistas Joseba, Aitor y Unai, que con su paciencia al seguir las indicaciones para que en cada momento fuera más fácil la ejecución del trabajo, han sabido acompañarnos en este camino.

Al centro tecnológico Cesefor, Sergio, José Luis, y en especial a Edgar, por vuestra cercanía, apoyo y por haberme ofrecido la posibilidad de conocer el interior de vuestros laboratorios, así como por hacerme partícipe de los diversos proyectos de toda índole en los que trabajáis.

AI INIA, Instituto Nacional de Investigaciones Agrarias, y en particular a Mayte de Troya, por su apoyo y sus enseñanzas en materia de durabilidad de la madera.

A toda la familia de la serrería Larrañaga de Azpeitia, por su amabilidad y por la absoluta disponibilidad que ha mostrado en la realización de todos los trabajos, desde descargas a deshoras, ocupación de campa por largos períodos de tiempo, facilidades para la ejecución de nuestras labores en aserradero, paciencia en el procesado de la madera y elaboración de las probetas de ensayo.

A todas las asociaciones, fundaciones, universidades y personas que han colaborado y trabajado conmigo durante estos años: Ernst Zürcher, Jairo Restrepo, personal de Hazi, Ademan, Arotzgi, Serrería Aleman, Maderas Santesteban, Serrería Errekondo, así como a los profesionales del sector de la madera que he podido conocer a lo largo de este periodo.

Si me preguntaran con qué me quedo de esta tesis doctoral, respondería que con las personas. Con todas aquellas que, muchas veces sin conocerme de nada, se han volcado en ayudarme. Ellas han sido el reflejo de que lo importante no es lo que se promete sino lo que se cumple.

Esta tesis no hubiera sido posible sin la generosidad de nuestros mayores que me han permitido entrar hasta la cocina de sus casas, sus talleres y que me han ofrecido su tiempo y compartido experiencias de vidas personales. Con ellas he aprendido la existencia de un ingente conocimiento y patrimonio sobre la madera acumulado de generación en generación, basado en la experiencia y la relación de la madera y el 
bosque desde el inicio de la humanidad. A partir de este conocimiento, he tratado de aunar la tradición y la innovación en mi quehacer profesional y he aprendido que de cara al futuro, el desafío consiste en recuperar y cambiar las buenas prácticas del pasado modernizándolas. Esto ha hecho posible que este trabajo haya sido una experiencia inolvidable.

Quiero dar gracias a la vida por darme tantas posibilidades, lecciones y recompensas, por enseñarme a reconocer el pasado, valorar el presente y preparar el futuro y porque me ha permitido aprender a sonreir y a ayudar a otros, sin esperar nada a cambio.

Porque es a través de la experiencia en tu día a día, cuando te das cuenta que cada persona tiene un espacio en tu vida, pero que lo realmente importante es cuidar a esas personas poco comunes y extraordinarias, que dejan huella, sacan lo mejor de nosotros y nos recuerdan que este mundo merece la pena. 


\title{
DIRECTORES
}

\author{
JOSÉ RAMÓN AIRA ZUNZUNEGUI \\ Doctor Ingeniero de Montes \\ Profesor Ayudante Doctor \\ Departamento de Construcción y Tecnología Arquitectónicas (DCTA) \\ Escuela Técnica Superior de Arquitectura (ETSAM) \\ Universidad Politécnica de Madrid (UPM)
}

\section{MARÍA TERESA DE TROYA FRANCO}

Doctora en Ciencias Biológicas

Científico titular

Departamento de Productos Forestales

Centro de Investigación Forestal (CIFOR)

Instituto Nacional de Investigación y Tecnología Agraria y Alimentaria (INIA) 


\section{Universidad deValladolid}

\section{AUTORIZACIÓN DEL DIRECTOR/A DE TESIS}

Impreso $1 \mathrm{~T}$

(Art. 7.2 de la Normativa para la presentación y defensa de la Tesis Doctoral en la UVa)

D./Da: José Ramón Aira Zunzunegui, con D.N.I./Pasaporte 45683161D

Profesor/a del departamento de: Construcción y Tecnología Arquitectónicas.

Centro: Escuela Técnica Superior de Arquitectura (Universidad Politécnica de Madrid).

Dirección a efecto de notificaciones: C/ Juan Sebastián Elcano, Nº, 4ª A, 49020, Zamora. e-mail: joseramon.aira@upm.es

como Director(a) de la Tesis Doctoral titulada: "Caracterización mecánica de la madera estructural de alerce del Japón (Larix kaempferi (Lamb.) Carr.) e influencia de la época de corta en sus propiedades".

realizada por D./Da: María José Barriola Baraibar.

alumno/a del Programa de Doctorado en: Doctorado en Ciencia e Ingeniería Agroalimentaria y de Biosistemas.

autoriza su presentación, considerando que:

La estudiante ha desarrollado una labor de formación, y un trabajo experimental y teórico de manera rigurosa y científica obteniendo como resultado una tesis doctoral que reúne todas las características, desde el punto de vista de la investigación, propias de este tipo de documento. Como demostración de su calidad se han publicado 2 artículos en 2 revistas científicas indexadas, con índice JCR, pertenecientes a los cuartiles Q2 y Q3 respectivamente.

Valladolid, 12 de julio de 2019

El/La Director/a de la Tesis,

$\begin{array}{ll}\text { AIRA } & \begin{array}{l}\text { Firmado digitalmente } \\ \text { por AIRA ZUNZUNEGUI } \\ \text { JOSE RAMON- }\end{array} \\ \text { ZUNZUNEGUI } & \text { 45683161D } \\ \text { JOSE RAMON } & \text { Fecha: 2019.07.12 } \\ \text { 45683161D } & 11: 10: 42+02^{\prime} 0^{\prime} \\ \text { Fdo.: José Ramón Aira Zunzunegui }\end{array}$


Universidad deValladolid

\section{AUTORIZACIÓN DEL DIRECTOR/A DE TESIS}

Impreso $1 \mathrm{~T}$

(Art. 7.2 de la Normativa para la presentación y defensa de la Tesis Doctoral en la UVa)

Da Ma Teresa de Troya Franco, con D.N.I./Pasaporte 50802565G

Científico Titular, Investigador Responsable del Laboratorio de Protección de Maderas del Departamento de Productos Forestales, del Centro de Investigación Forestal (CIFOR) del Instituto Nacional de Investigación y Tecnología Agraria y Alimentaria (INIA)

Dirección a efecto de notificaciones: Ctra. De la Coruña km 7,5, 28040-Madrid. e-mail troya@inia.es

como Co-Directora de la Tesis Doctoral titulada "Caracterización mecánica de la madera estructural de alerce del Japón (Larix kaempferi (Lamb.) Carr.) e influencia de la época de corta en sus propiedades".

realizada por Da: María José Barriola Baraibar.

alumna del Programa de Doctorado en: Doctorado en Ciencia e Ingeniería Agroalimentaria y de Biosistemas.

autoriza su presentación, considerando que:

La estudiante ha desarrollado una labor de formación, y un trabajo experimental y teórico de manera rigurosa y científica obteniendo como resultado una tesis doctoral que reúne todas las características, desde el punto de vista de la investigación, propias de este tipo de documento. Como demostración de su calidad se han publicado 2 artículos en 2 revistas científicas indexadas, con índice JCR, pertenecientes a los cuartiles Q2 y Q3 respectivamente.

Valladolid, 12 de julio de 2019

La Directora de la Tesis,

Firmado digitalmente por DE TROYA FRANCO MARIA TERESA - DNI 508025656

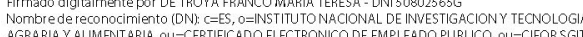

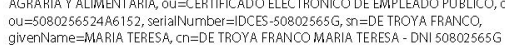

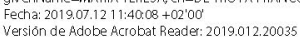

Fdo.: Teresa de Troya Franco 


\section{ÍNDICE}

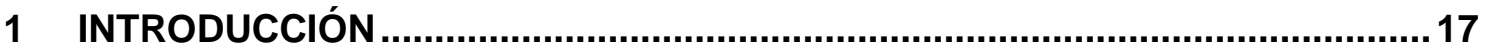

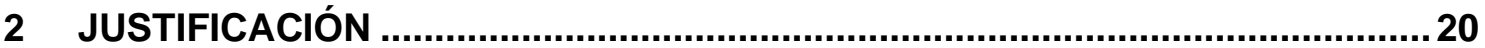

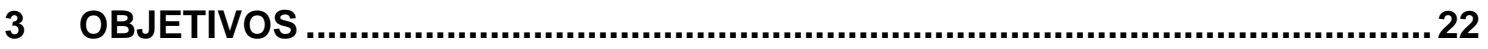

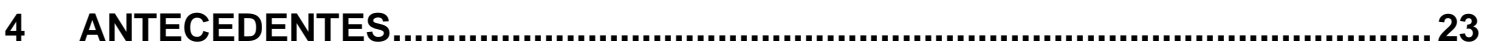

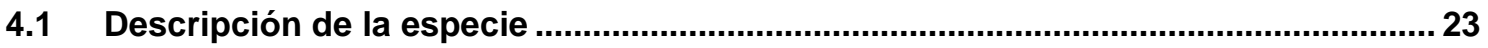

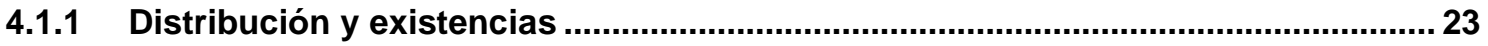

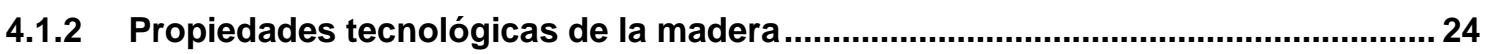

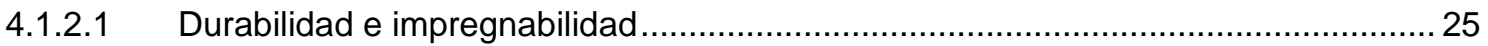

4.2 Herramientas de clasificación de madera aserrada para uso estructural ................. 26

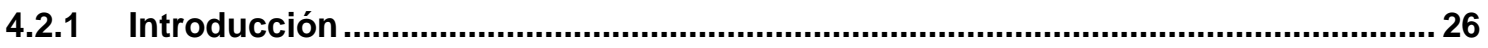

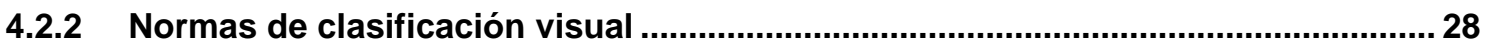

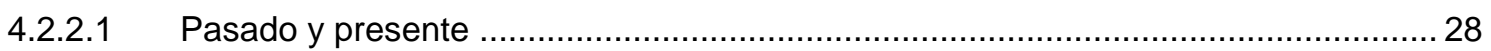

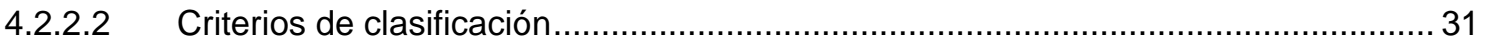

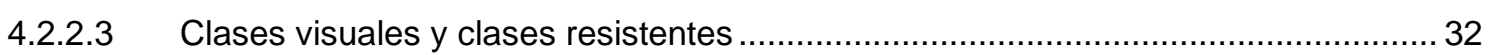

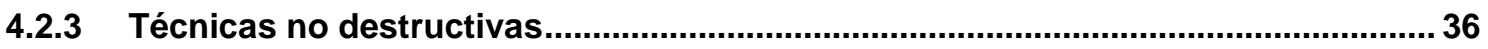

4.2.3.1 Métodos basados en ondas de impacto y ultrasonidos ............................................. 38

4.2.3.1.1 Sistemática del método de medición del tiempo de paso de una onda sonora ..... 40

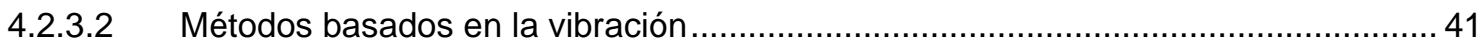

4.2.3.2.1 Sistemática del método de medición de la frecuencia de vibración........................ 43

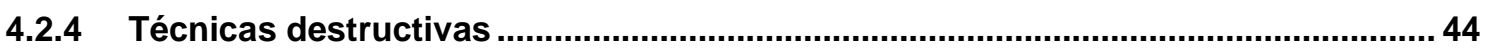

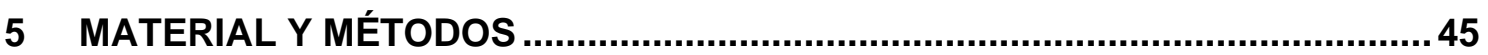

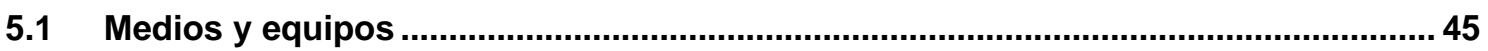

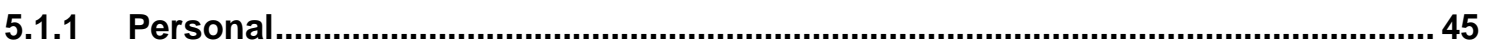

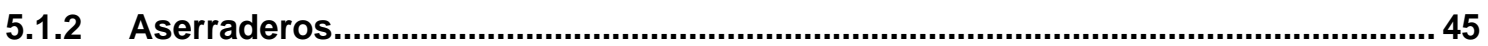

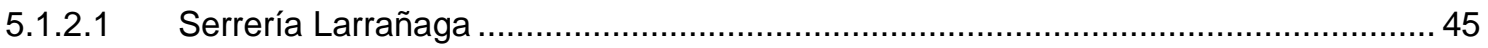

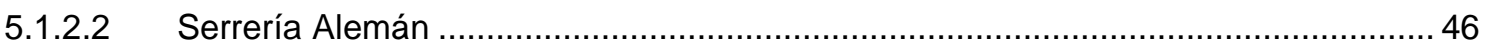

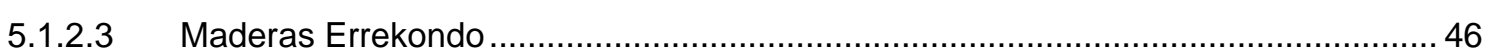

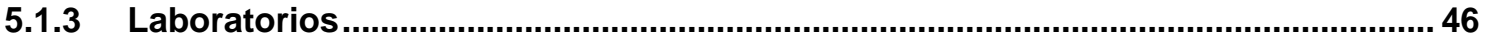

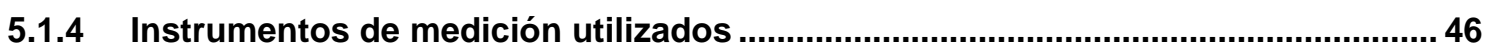

5.1.4.1 Instrumentos utilizados en los trabajos de monte ................................................. 46

5.1.4.2 Aparatos utilizados en aserradero y laboratorios ................................................... 47

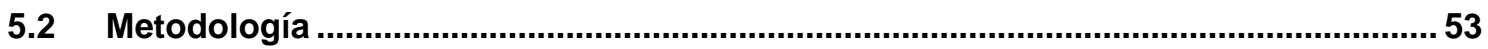

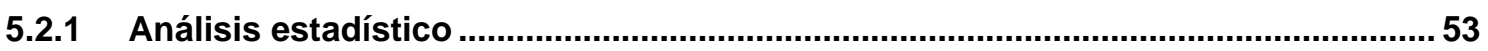

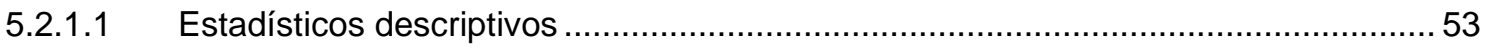




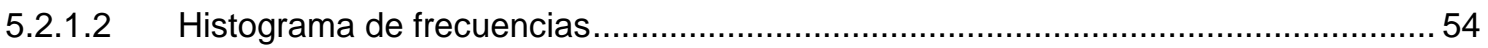

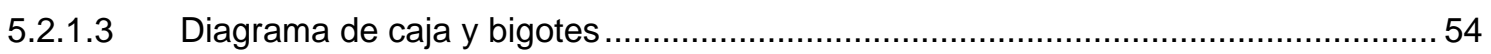

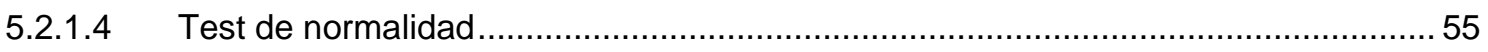

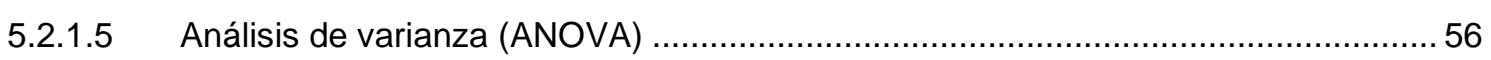

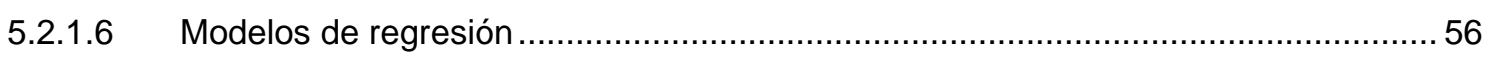

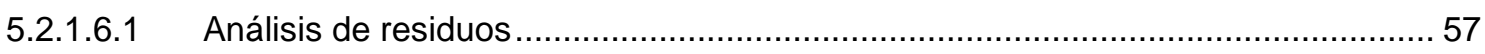

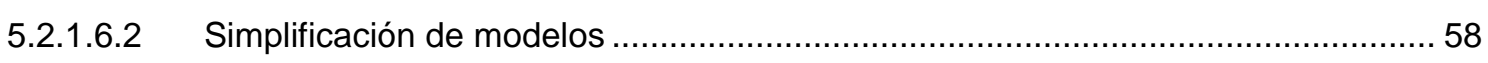

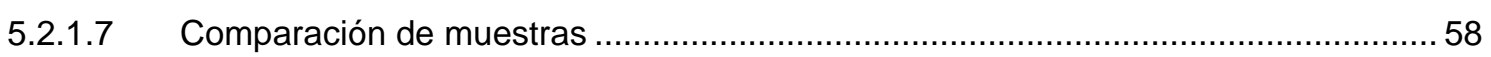

5.2.2 Consideraciones normativas y tamaño de la muestra ............................................58

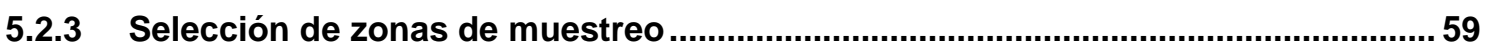

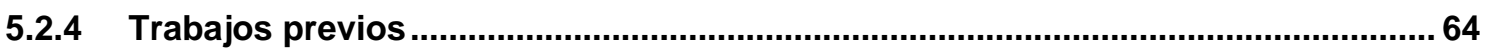

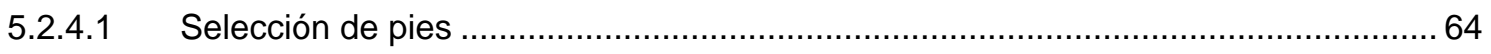

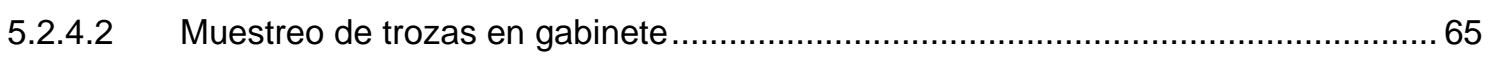

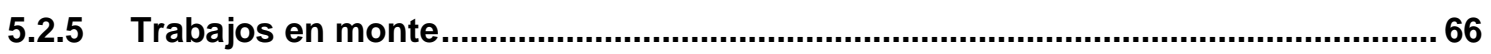

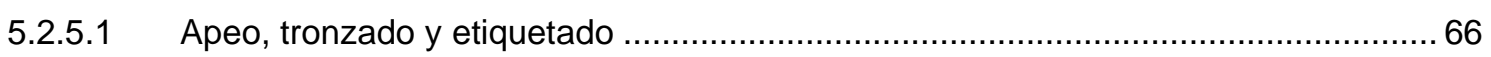

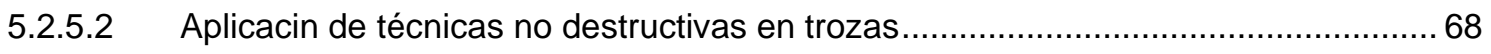

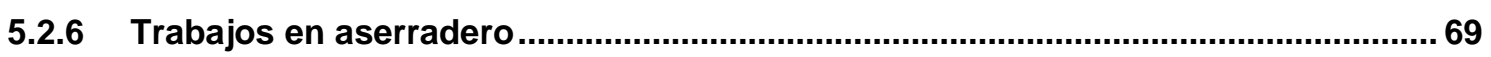

5.2.6.1 Medición de singularidades de la madera en trozas ................................................... 69

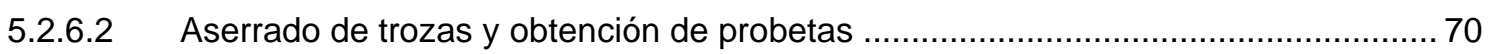

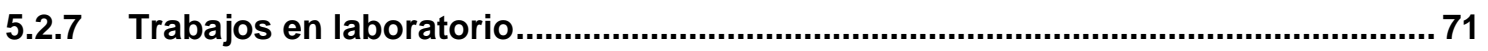

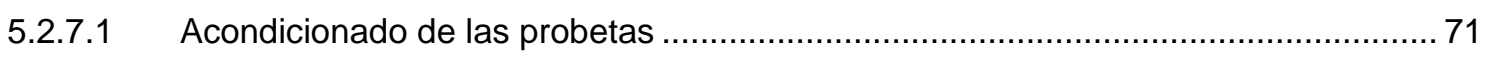

5.2.7.1.1 Control de las dimensiones, peso y humedad de las probetas................................ 71

5.2.7.2 Medición de singularidades de la madera en probetas ......................................... 72

5.2.7.3 Aplicación de técnicas no destructivas en probetas en seco....................................... 73

5.2.7.4 Caracterización mecánica de la madera mediante ensayos destructivos ................. 74

5.2.7.4.1 Determinación de las propiedades mecánicas. Ensayos de flexión ........................ 74

5.2.7.4.2 Determinación de las propiedades físicas ....................................................... 80

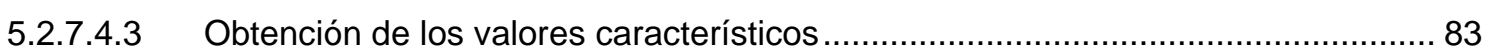

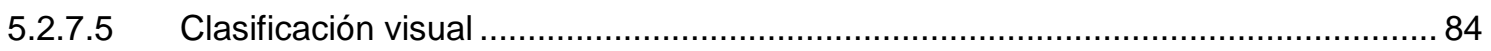

5.2.7.6 Obtención de modelos analíticos para determinar las propiedades mecánicas....... 85

5.2.7.7 Evaluación de la influencia de la altura de la troza en el árbol ................................... 86

5.2.7.8 Relación de MOED con MOR, MOE y MOEG ...................................................... 87

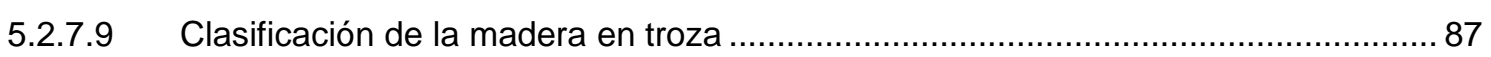

5.2.7.10 Influencia de la época de corta en las propiedades............................................. 87

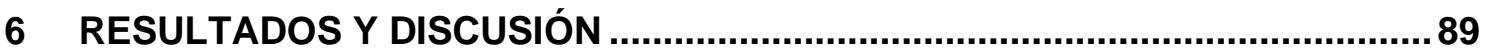

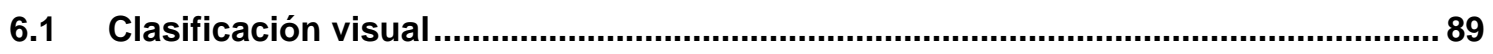

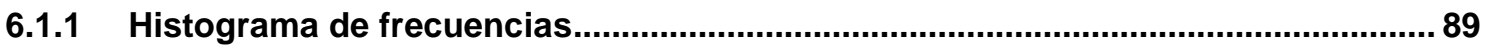

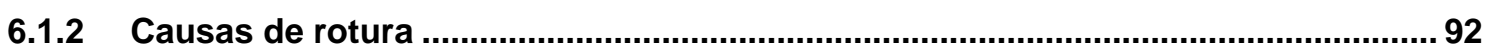

6.1.3 Influencia de la sección y procedencia en el MOR, MOE y densidad ..................... 93 


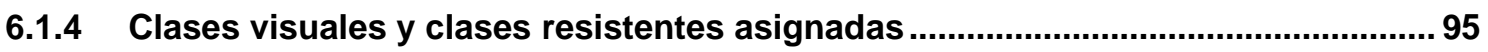

6.1.5 Comparación con normas de clasificación visual existentes ..............................100

6.2 Modelos analíticos para determinar las propiedades mecánicas ........................... 100

6.3 Evaluación de la influencia de la altura de la troza del árbol .................................. 108

6.3.1 Resistencia a flexión (MOR) a diferentes alturas del árbol ..................................... 109

6.3.2 Módulo de elasticidad local (MOE) a diferentes alturas del árbol ..........................112

6.3.3 Densidad al 12\% a diferentes alturas del árbol ..................................................113

6.3.4 Rendimientos de clasificación según altura del árbol ...........................................115

6.4 Relación de MOED con MOR, MOE y MOEG en troza y probeta ..............................116

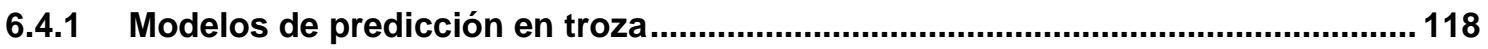

6.4.2 Modelos de predicción en probeta aserrada seca ................................................119

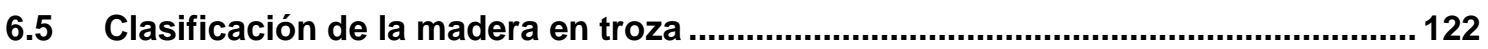

6.6 Influencia de la época de corta en las propiedades .................................................. 123

6.6.1 Nociones sobre el movimiento de agua en las plantas........................................... 123

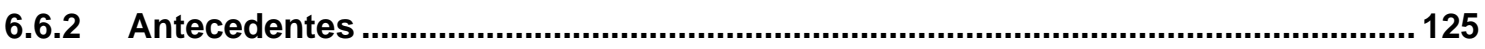

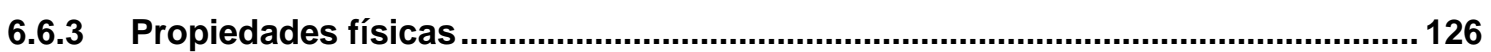

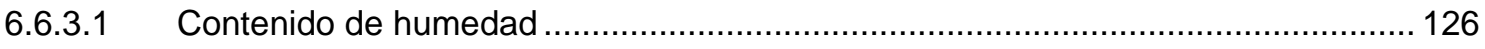

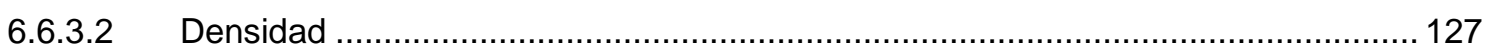

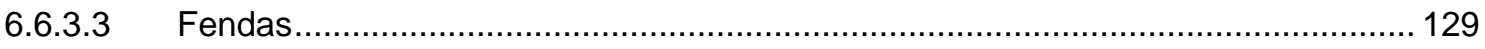

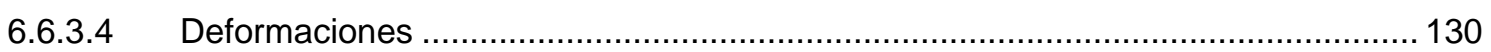

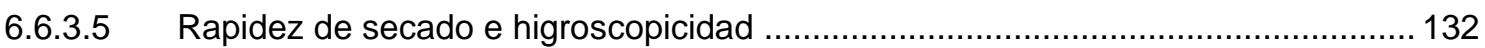

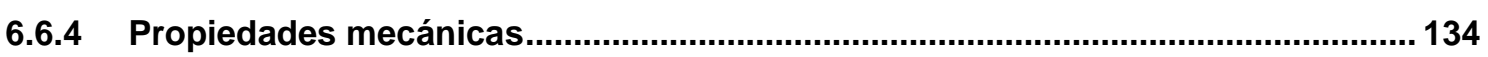

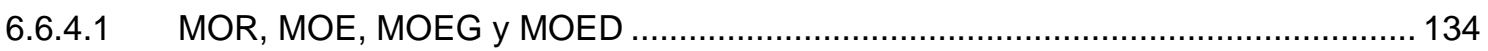

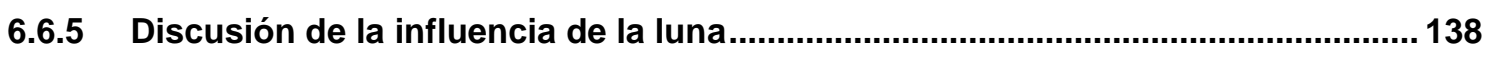

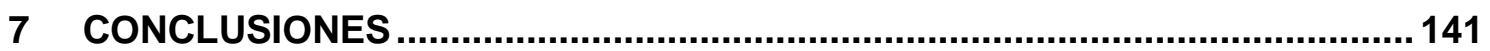

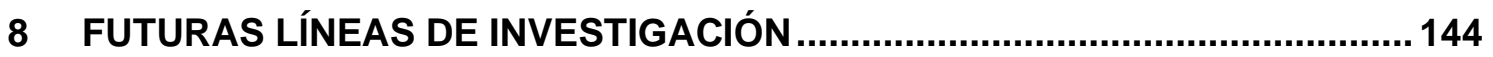

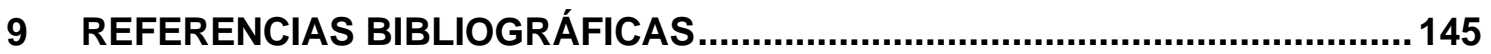

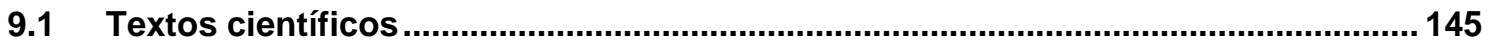

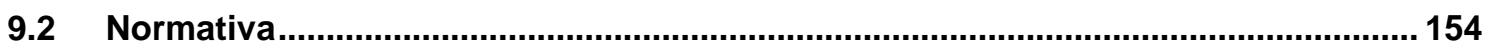

ANEXO I. LA INFLUENCIA DE LA LUNA. SABIDURÍA POPULAR.........................156

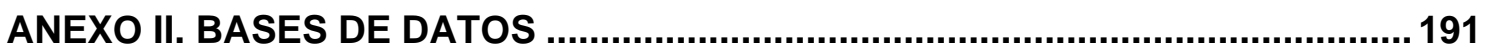

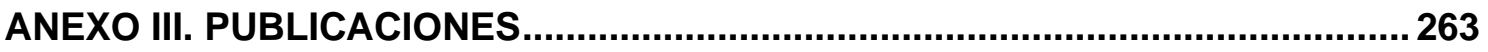




\section{Índice de figuras}

Figura. 4.1: Mapa de distribución actual de especies de alerce en las comunidades autónomas

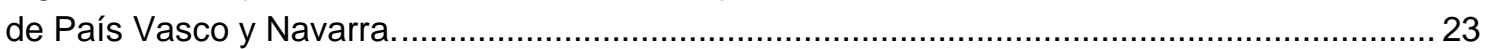

Figura. 5.1 Personal de la Diputación Foral de Gipuzkoa. ..................................................... 45

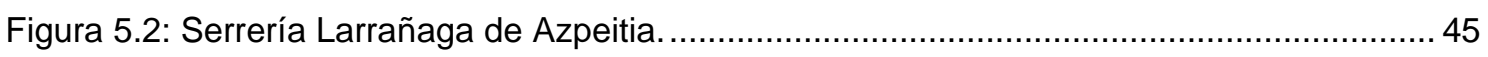

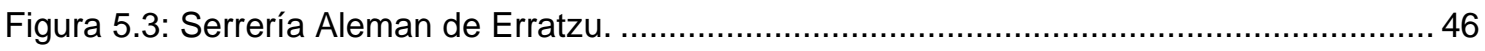

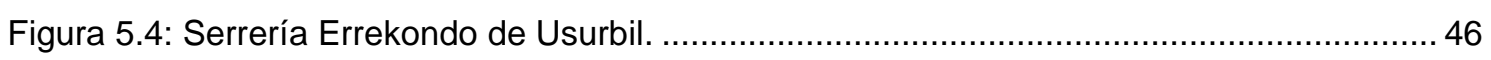

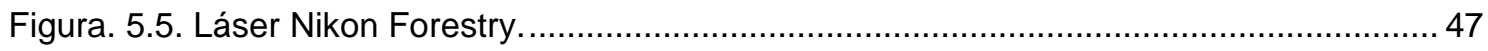

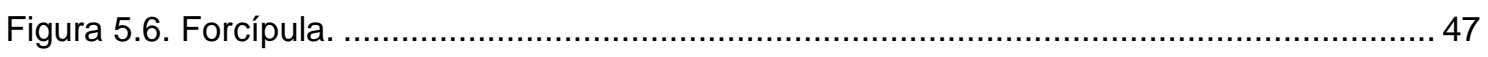

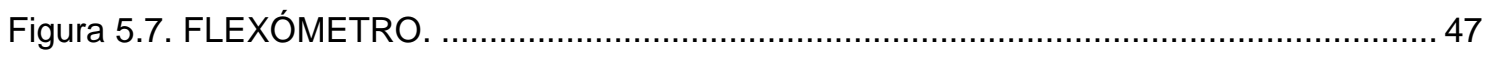

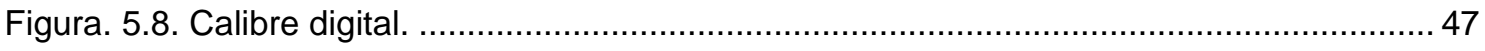

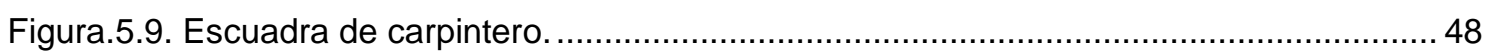

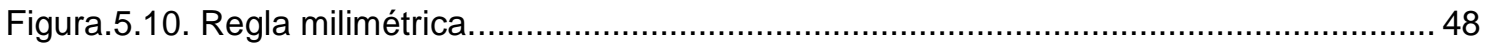

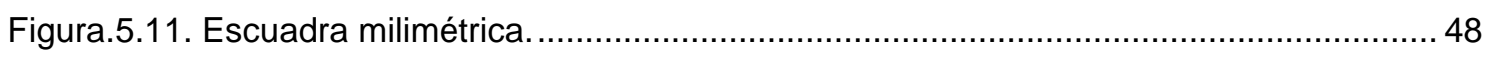

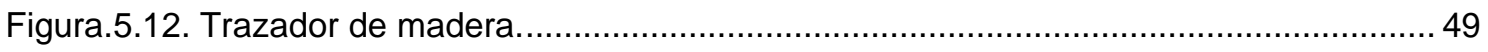

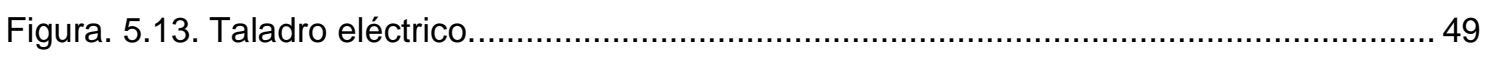

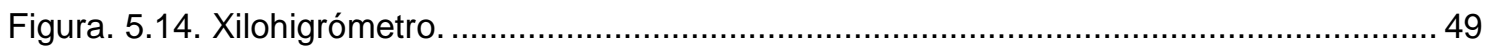

Figura. 5.15. Equipo de ultrasonidos Microsend Timer realizando mediciones en vigas. .......... 50

Figura. 5.16. Equipo de medición, software y balanza de la casa Fakopp................................50

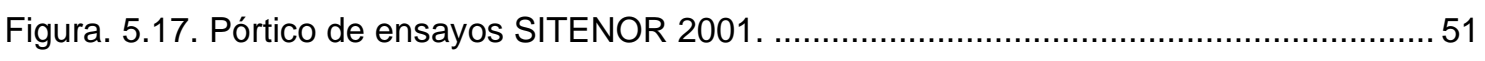

Figura. 5.18. Cintas métricas, flexómetro ……................................................................... 51

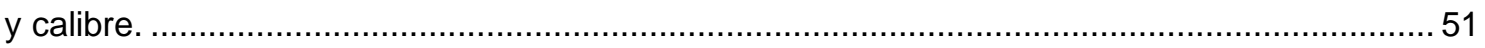

Figura. 5.19. Cámara de acondicionamiento. ................................................................ 51

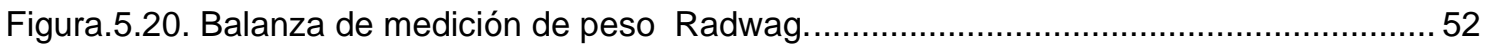

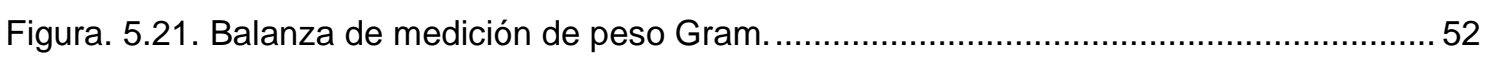

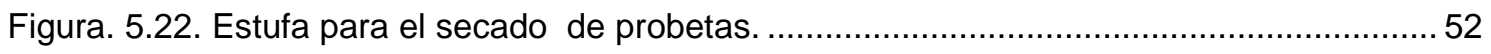

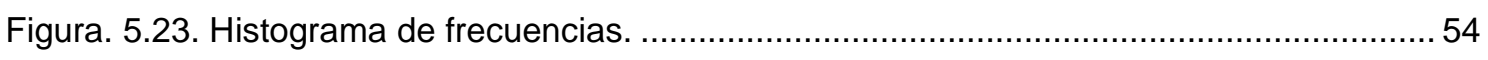

Figura. 5.24. Diagrama de caja y bigotes. .................................................................... 55

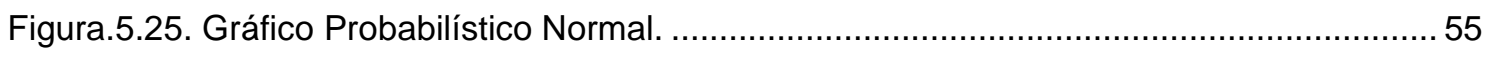

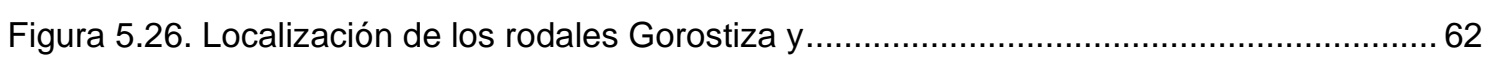

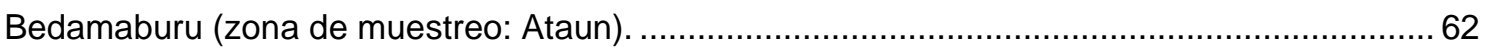

Figura 5.27. Localización de los rodales Gizonzabal y Otzaurte .............................................. 63

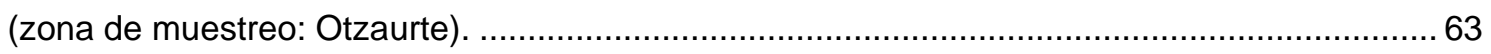

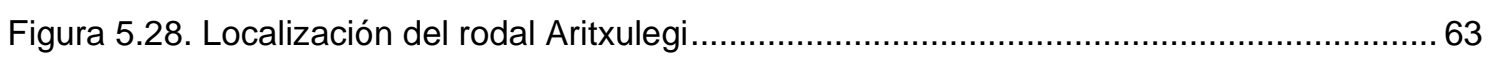

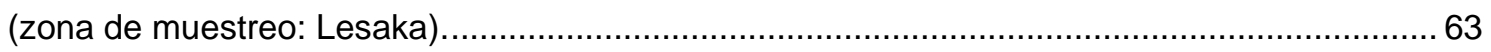

Figura. 5.29. Localización del rodal de Labeaga (Bera de Bidasoa). ........................................ 64

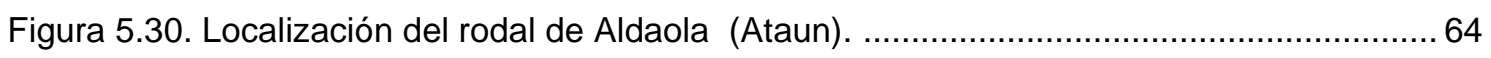

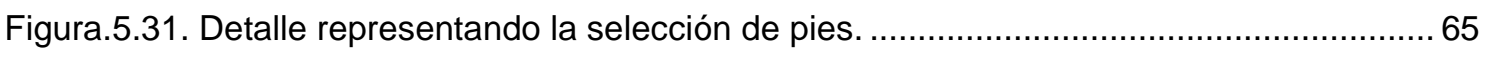

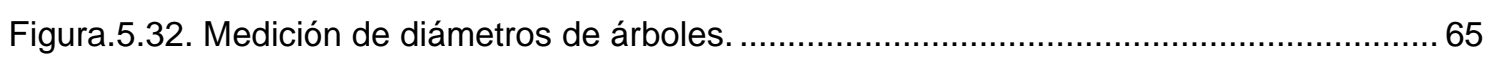




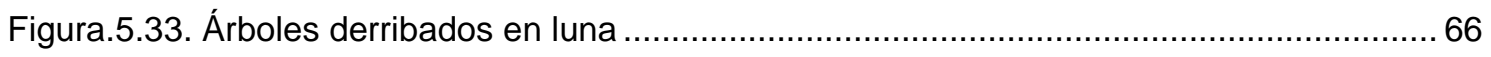

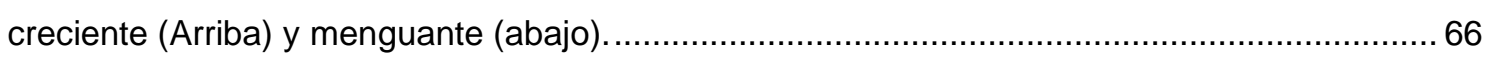

Figura.5.34. Detalle de placas serigrafiadas para identificación de probetas. ............................67 67

Figura. 5.35. Incorporación de placas serigrafiadas en trozas de árboles. ................................67 67

Figura 5.36. Esquema de utilización de las técnicas no destructivas en una troza de madera. 68

Figura. 5.37. Evaluación de trozas mediante técnicas no destructivas. .....................................68

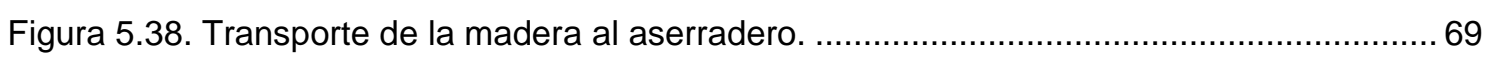

Figura. 5.39. Medición de singularidades de las trozas en aserradero. ...................................... 69

Figura. 5.40. Medición de singularidades de las trozas en aserradero. ...................................... 69

Figura. 5.41. Supervisión de la trazabilidad de las trozas y de la madera aserrada durante su

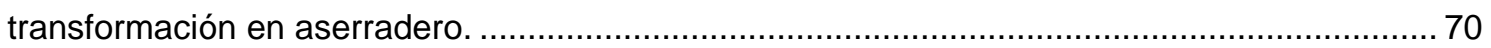

Figura. 5.42. Preparación de lotes de probetas para transporte a laboratorio. .......................... 70

Figura.5.43. Detalle de probetas en el exterior del laboratorio............................................ 70

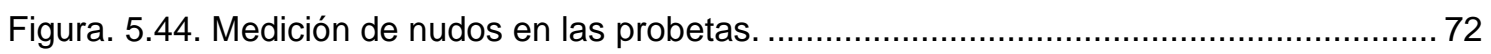

Figura 5.45. Sistemática en la medición del tiempo de paso de una onda sonora mediante el

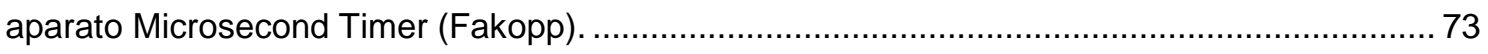

Figura 5.46. Sistemática en la medición de la frecuencia de vibración mediante un analizador de

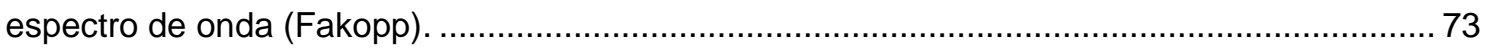

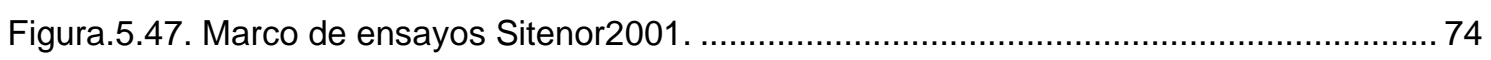

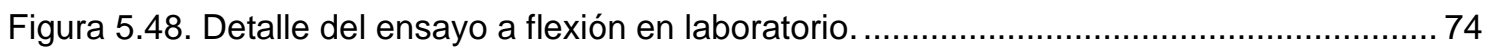

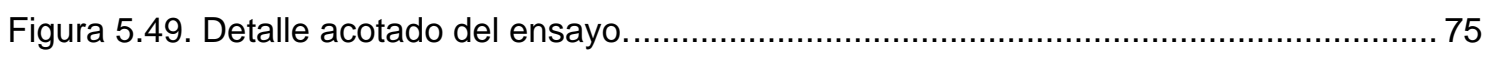

Figura 5.50. Dispositivo de ensayo para la medición del módulo de elasticidad......................... 75

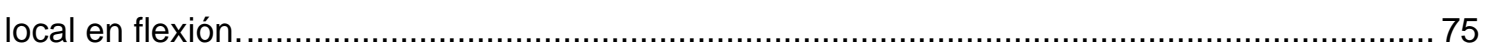

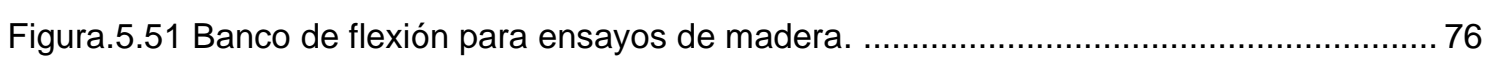

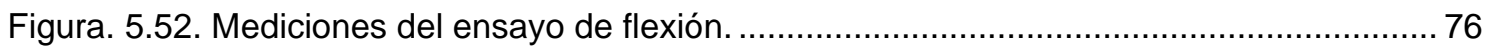

Figura.5.53. Gráfico de carga-deformación dentro de los márgenes de deformación elástica. . 77

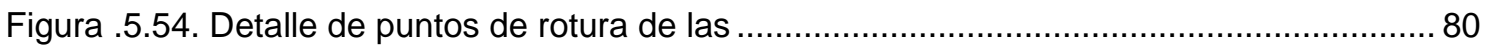

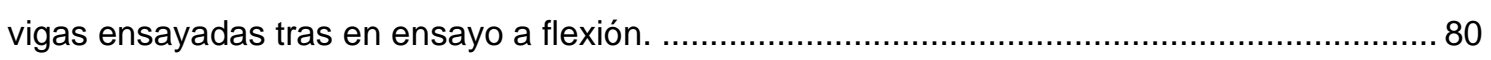

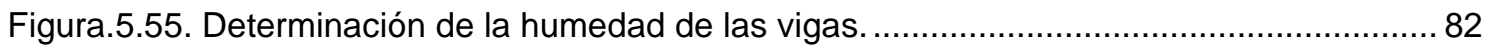

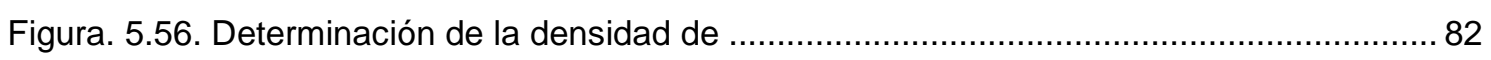

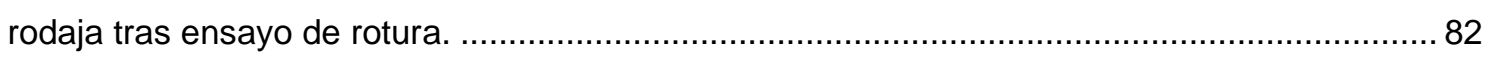

Figura. 5.57. Introducción de probetas en estufa para el cálculo de la densidad en seco......... 83

Figura 6.1. Histograma de frecuencias de las variables mecánicas y la densidad. .................... 89

Figura 6.2. Gráfico probabilístico Normal de las variables mecánicas y la densidad. ................ 90

Figura 6.3. Histograma de frecuencias de las singularidades más relevantes........................... 91

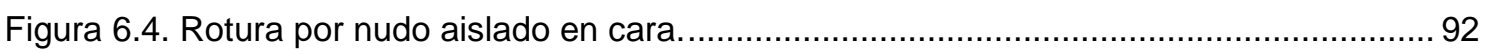

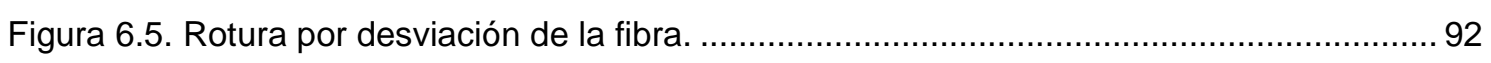

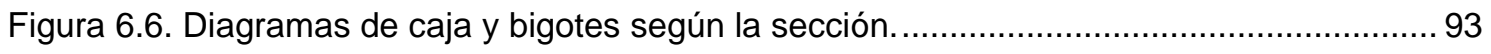

Figura 6.7. Diagramas de caja y bigotes según la procedencia. ............................................. 94

Figura 6.8. Gráficos para verificar la homocedasticidad de los residuos. ............................... 107

Figura 6.9. Gráficos para verificar la independencia de los residuos. .................................. 108 
Figura 6.10. Diagrama de caja y bigotes del MOR a diferentes alturas del árbol. ................... 109

Figura 6.11. Relación entre el MOR y la altura del árbol. .................................................... 110

Figura 6.12. Diagrama de caja y bigotes del MOE a diferentes alturas del árbol..................... 112

Figura 6.13. Diagrama de caja y bigotes de la densidad $12 \%$ a diferentes alturas del árbol. 113

Figura 6.14. Relación porcentaje probetas clasificadas como MEG-1 y altura DEL ÁRBOL... 115

Figura 6.15. Relación porcentaje probetas clasificadas como MEG-2 y altura del árbol. ........ 116

Figura 6.16. Relación en troza entre el MOR corregido por sección y el MOED obtenido por

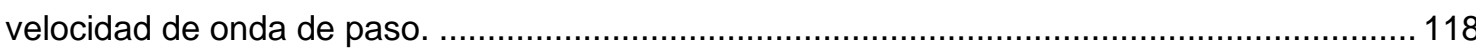

Figura 6.17. Relación en troza entre el MOE sin corregir por humedad y el MOED obtenido por

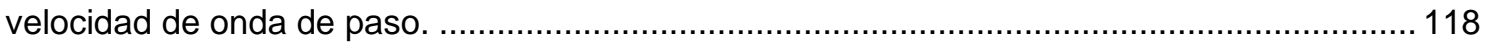

Figura 6.18. Relación en troza entre el MOEG sin corregir por humedad y el MOED obtenido por

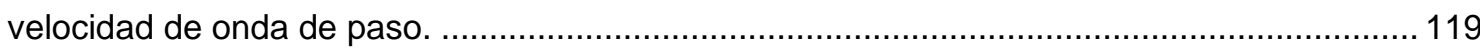

Figura 6.19. Relación en probeta seca entre el MOR corregido por sección y el MOED obtenido

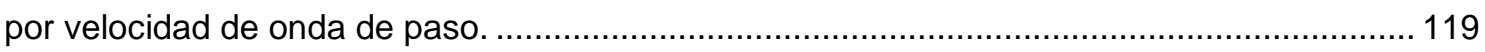

Figura 6.20. Relación en probeta seca entre el MOE sin corregir por humedad y el MOED

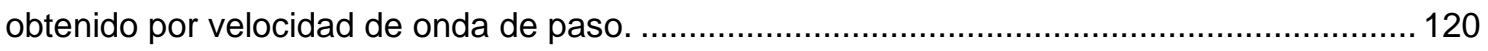

Figura 6.21. Relación en probeta seca entre el MOED sin corregir por humedad y el MOED

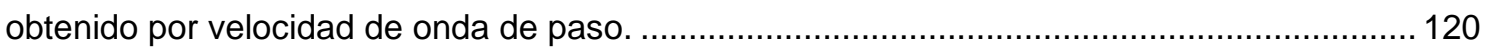

Figura 6.22. Relación en probeta seca entre el MOR corregido por sección y el MOED obtenido

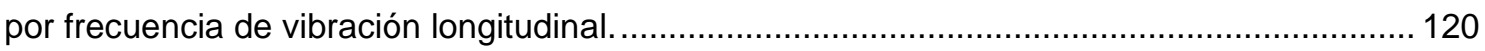

Figura 6.23. Relación en probeta seca entre el MOE sin corregir por humedad y el MOED

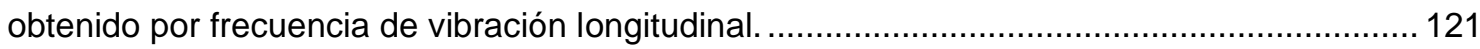

Figura 6.24. Relación en probeta seca entre el MOEG sin corregir por humedad y el MOED

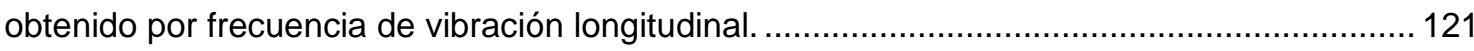

Figura 6.25. Análisis gráfico de la influencia de la época de corta en el contenido de humedad. 127

Figura 6.26. Análisis gráfico de la influencia de la época de corta en la densidad sin corregir. 128

Figura 6.27. Análisis gráfico de la influencia de la época de corta en la densidad corregida por

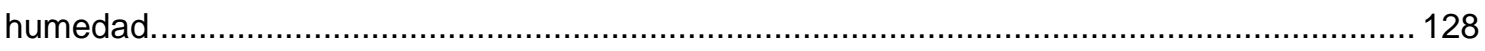

Figura 6.28. Análisis gráfico de la influencia de la época de corta en el ancho de fenda. ........ 129

Figura 6.29. Análisis gráfico de la influencia de la época de corta en la profundidad ............... 130

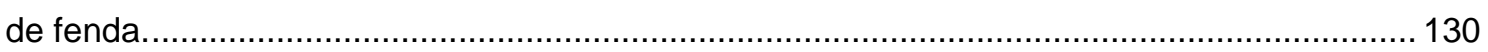

Figura 6.30. Análisis gráfico de la influencia de la época de corta en la curvatura .................. 131

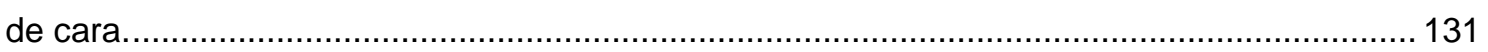

Figura 6.31. Análisis gráfico de la influencia de la época de corta en la curvatura ................... 131

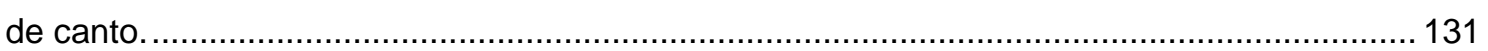

Figura 6.32. Análisis gráfico de la influencia de la época de corta en el alabeo. ..................... 131

Figura 6.33. Análisis gráfico de la influencia de la época de corta en la RAPIDEZ DE secado. 132

Figura 6.34. Análisis gráfico de la influencia de la época de corta en la higroscopicidad. ........ 132

Figura 6.35. Análisis gráfico de la influencia de la época de corta en el MOR sin corregir...... 135 
Figura 6.36. Análisis gráfico de la influencia de la época de corta en el MOR corregido por

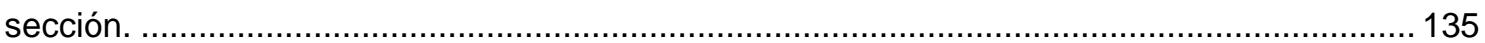

Figura 6.37. Análisis gráfico de la influencia de la época de corta en el MOE sin corregir...... 135 Figura 6.38. Análisis gráfico de la influencia de la época de corta en el MOE corregido por

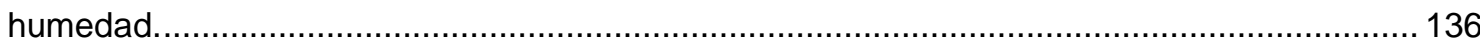

Figura 6.39. Análisis gráfico de la influencia de la época de corta en el MOEG sin corregir. .. 136 Figura 6.40. Análisis gráfico de la influencia de la época de corta en el MOEG corregido por humedad. 136

Figura 6.41. Análisis gráfico de la influencia de la época de corta en el MOED_vev sin corregir. 137

Figura 6.42. Análisis gráfico de la influencia de la época de corta en el MOED_vev corregido por

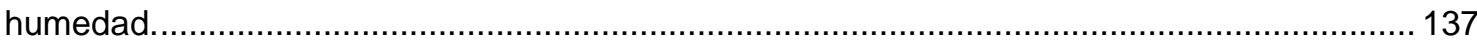

Figura 6.43. Análisis gráfico de la influencia de la época de corta en el MOED_ves sin corregir. 137

Figura 6.44. Análisis gráfico de la influencia de la época de corta en el MOED_ves corregido por humedad. 138

\section{Índice de tablas}

Tabla 4.1: Datos sobre existencias por clases diamétricas en la comunidad autónoma de País Vasco y Navarra (territorios que incluyen las muestras objeto del estudio). .............................. 24 Tabla 4.2: Clases visuales y clases resistentes asignadas a determinadas especies en las

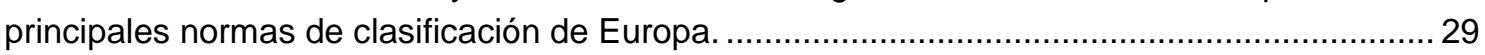

Tabla 4.3: Tabla de clases resistentes para coníferas establecida en la norma europea EN 338 : 2016 basadas en ensayos de flexión de canto. .35

Tabla 5.1: Zonas de muestreo seleccionadas para la madera de alerce del Japón y características generales.

Tabla 5.2: Número, dimensiones y procedencia de las probetas ensayadas. …......................... 62

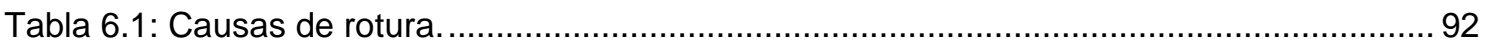

Tabla 6.2: Especificaciones para las clases resistentes MEG-1 y MEG-2 ............................... 96

Tabla 6.3: Longitud total máxima de las piezas según norma UNE-EN 14081-1:2016.............97

Tabla 6.4: Deformación máxima (en $\mathrm{mm}$ ) en $2 \mathrm{~m}$ de longitud según norma UNE-EN 14081-

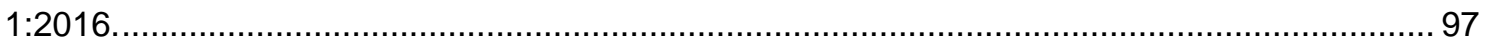

Tabla 6.5. Piezas de cada sección clasificadas como MEG-1, MEG-2 y rechazadas. ............... 98

Tabla 6.6. Valores característicos del MOR, MOE y densidad de la clase visual MEG-1.......... 99

Tabla 6.7. Valores característicos del MOR, MOE y densidad de la clase visual MEG-2 ..........99

Tabla 6.8. Valores medios y coeficientes de variación de las variables explicativas y estimadas. 101

Tabla 6.9. Coeficientes de los modelos de regresión para estimar el MOEH, MOEGн y MORs. 103

Tabla 6.10. Coeficientes de los modelos de regresión para estimar el $\mathrm{MOE}_{12}, \mathrm{MOEG}_{12}$ y $\mathrm{MOR}_{\mathrm{Kh}}$. 103

Tabla 6.11. Valores $P$ de los modelos de regresión múltiple. 105 
Tabla 6.12. Modelos analíticos para estimar el $\mathrm{MOE}_{H}, \mathrm{MOE}_{12}, \mathrm{MOEG} \mathrm{H}_{\mathrm{H}}, \mathrm{MOEG}_{12}$, MORs y MORKh. 106

Tabla 6.13. Rendimiento de clasificación según la altura del árbol.

Tabla 6.14. Coeficientes de determinación $\left(r^{2}\right)$ obtenidos entre los módulos de elasticidad dinámicos (MOED) corregidos a la humedad del ensayo destructivo $\mathrm{H} \%$, y las variables MOR, MOE y MOEG sin corregir. 117

Tabla 6.15: Porcentajes de clasificación por clase visual en función de la velocidad de paso de la onda de choque. 122

Tabla 6.16: Calidades visuales en troza y porcentajes de clasificación visual por calidades visuales en las piezas de madera aserradas.

Tabla 6.17: Análisis analítico de la influencia de la época de corta en el contenido de humedad.

Tabla 6.18: Análisis analítico de la influencia de la época de corta en la densidad. 127

Tabla 6.19: Análisis analítico de la influencia de la época de corta en las fendas. 129

Tabla 6.20: Análisis analítico de la influencia de la época de corta en las deformaciones por secado.

Tabla 6.21: Análisis analítico de la influencia de la época de corta en el MOR, MOE, MOEG 134 y MOED. 134

Tabla 6.22: Resumen de diferencias estadísticamente significativas entre probetas de creciente y de menguante. 139 


\section{Resumen}

En el presente trabajo de investigación se llevó a cabo la caracterización mecánica de la madera estructural de alerce del Japón (Larix kaempferi (Lamb.) Carr.). Además, se analizó la influencia de la época de corta de la madera, en relación con las fases lunares, sobre las propiedades físicas y mecánicas de la misma.

La muestra consistió en un total de 370 piezas de madera aserrada (de 225 pies

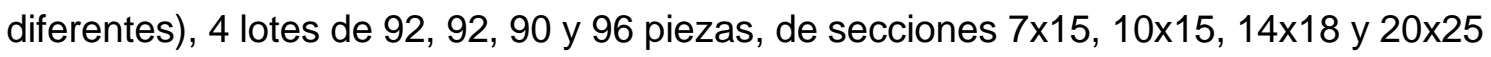
$\mathrm{cm}$, respectivamente. Para la obtención de los lotes se establecieron 5 zonas de muestreo, 3 de ellas localizadas en la provincia de Gipuzkoa y 2 en la región de Navarra, representativas de la industria de madera estructural de esta especie a nivel nacional. De los sobrantes del mecanizado de probetas, se obtuvieron 140 tablas con las que se analizó la influencia de la época de corta en el proceso de secado, bajo cubierta y al aire. Se realizaron ensayos mecánicos destructivos en laboratorio para determinar las propiedades caracterizadoras del material: rigidez (MOE), resistencia (MOR), y densidad ( $12 \%$ de humedad). Además, se realizaron mediciones de singularidades de la madera y ensayos no destructivos sobre las trozas en húmedo (tras el tronzado en monte), y sobre las probetas finales secas (antes de ejecutar los ensayos mecánicos).

Considerando los parámetros visuales se elaboró una tabla de clasificación visual para la madera estructural de alerce del Japón de procedencia española, obteniendo 2 clases visuales denominadas MEG-1 (Madera Estructural de Gran Escuadría-1) y MEG-2 (Madera Estructural de Gran Escuadría-2). Los valores característicos de resistencia, rigidez y densidad de la clase MEG-1 fueron $\mathrm{f}_{\mathrm{k}}=31,80 \mathrm{MPa}, \mathrm{E}_{0, \text { mean }}=13.082 \mathrm{MPa}$, y $\rho_{\mathrm{k}}$ $=465,6 \mathrm{~kg} / \mathrm{m}^{3}$, asignándose una clase resistente C30. Los valores característicos de la clase MEG-2 fueron $f_{k}=24,55 \mathrm{MPa}, E_{0, \text { mean }}=12.320 \mathrm{MPa}$, y $\rho_{\mathrm{k}}=469,1 \mathrm{~kg} / \mathrm{m}^{3}$, asignándose una clase resistente C24. Para la estimación de la rigidez (MOE y MOEG) y de la resistencia (MOR), se realizaron modelos analíticos considerando conjuntamente parámetros no destructivos y visuales. La estimación del MOEG $\left(r^{2}=0,66\right)$ alcanzó un ajuste ligeramente mayor que la estimación del $\operatorname{MOE}\left(r^{2}=0,56\right)$, y mucho mayor que la estimación del MOR $\left(r^{2}=0,44\right)$.

Respecto a las trozas, se observó una clara relación entre el MOR y la altura del árbol, de modo que la resistencia de la probeta disminuía cuanto mayor era la altura de la troza de procedencia. Se elaboró una tabla de clasificación visual en troza, estableciendo 3 calidades (Superior, Media e Inferior) que se relacionaron directamente con las clases visuales (MEG-1 y MEG-2) de las probetas finales.

En relación a la época de corta, se encontraron diferencias estadísticamente significativas entre las probetas de creciente (pies cortados entre 2 y 5 días tras la luna nueva) y las probetas de menguante (pies cortados entre 2 y 5 días tras la luna llena). Concretamente, las probetas de creciente presentaron menor densidad, mayor rapidez de secado, mayor higroscopicidad, y menor módulo de elasticidad dinámico (aplicando para su obtención el método de frecuencia de vibración longitudinal). 


\section{INTRODUCCIÓN}

Desde hace siglos, la madera ha sido un bien fundamental para el hombre por sus múltiples aplicaciones. Así, por ejemplo, uno de los principales hitos en la Historia de la Humanidad y clave para su progreso, fue la invención de la rueda hacia el final del Neolítico (hacia el quinto milenio a. C., aproximadamente), cuando sus primeros modelos fueron hechos con este material.

Durante miles de años el hombre se ha servido de la madera para cubrir sus necesidades más diversas, tales como leña para protegerse y para cocinar, para fabricar herramientas y utensilios, armas para cazar, muebles, etc.

Otro de los usos esenciales de la madera a lo largo de la historia ha sido el de material básico con el que proporcionarse cobijo, gracias a sus múltiples propiedades de resistencia, durabilidad, versatilidad, disponibilidad, etc., toda vez que la madera es uno de los mejores materiales para tal menester, y casi el único a su disposición y de fácil elaboración a lo largo de milenios.

Su resistencia, calidad, seguridad, calor que proporciona y su color, quedan patentes en todas y cada una de las construcciones que utilizan este noble material, cuyos resultados son, además, visualmente insuperables.

Hasta nuestros días han llegado ejemplos de monumentos arquitectónicos de la Humanidad realizados en madera hace cientos de años, tales como la Ciudad Prohibida de Pekín (China), construida en el siglo XV, señalada como la mayor colección de estructuras de madera antiguas que se conserva en el mundo; o el Taj Mahal, construido en el siglo XVII en la India, una de las Siete Maravillas del Mundo moderno, sustentada sobre pilares de madera, al igual que la ciudad italiana de Venecia.

Pero sin irnos geográficamente tan lejos, la madera es uno de los elementos clave en los sistemas constructivos de la Alhambra de Granada (S. XIII), ya sea en soportes, ornamentación u otros elementos. En éstas y otras obras grandiosas, la madera aporta una plasticidad y una vistosidad únicas.

Estos y muchos otros ejemplos convienen en señalar que la madera es un material que, bien utilizado, es capaz, no solo de resistir a la perfección el paso del tiempo, si no, además, de seguir impresionando siglos después de su utilización.

A lo largo de la historia, y aún en la actualidad, el bosque ha permitido la supervivencia de las poblaciones rurales gracias al aprovechamiento de los recursos forestales.

A su vez, los avances tecnológicos que se han desarrollado en los últimos años, han permitido acabar con uno de los mitos existentes acerca de las limitaciones del material 
de madera en la construcción: aquél que señalaba que el uso de la madera estaba ligado a construcciones muy pequeñas y tradicionales. Hoy en día, se desarrollan permanentemente, y ante nuestros ojos, obras de ingeniería absolutamente vanguardistas realizadas con madera mejorada tecnológicamente.

Es con la aparición de las construcciones de madera laminada, de los tableros contrachapados, de partículas y de fibras, etc., productos todos ellos derivados de la madera junto con el descubrimiento de su buen comportamiento frente al fuego, cuando la madera recupera un campo de aplicación propio de sus características.

Así en Estados Unidos, Canadá, países del norte de Europa, etc. la madera extiende rápidamente su uso en el campo de la vivienda unifamiliar y como material protagonista de proyectos en los que se requieren grandes luces libres junto con calidades decorativas difíciles de alcanzar por sus competidores como el hormigón y acero. (Arriaga y Argüelles, 1993).

Por el contrario, en España durante el último siglo la madera ha perdido importancia a nivel constructivo a favor de otros materiales como el hormigón o el acero. La brillantez de los nuevos materiales, unido a la escasa tecnificación de los productos de madera, provocaron un cambio de tendencia en el uso de los materiales constructivos.

Podemos decir que los datos sobre el uso de la madera en los últimos años indican que la madera ha vuelto a formar parte de las nuevas construcciones, sobre todo en viviendas, así como en grandes instalaciones deportivas, de ocio, etc., representando un porcentaje importante de las mismas.

Así, en los países industrializados, el consumo anual de madera es superior a 1000 millones de toneladas (Manrique, 2010), mientras que, en los países en vía de desarrollo, se estima que el consumo es de magnitud comparable a la anterior. Esto hace que en todo el mundo se utilicen unos 2000 millones de toneladas de madera con fines estructurales al año (Alares,1992). Este auge, es debido principalmente a cuatro factores:

- Tecnológico y técnico: Con los nuevos productos de madera, más tecnificados (madera laminada encolada, madera microlaminada, madera estructural empalmada con finger-joint, los diferentes tableros derivados de la madera para fines estructurales, los procesos de tratamiento de la madera que mejoran la durabilidad natural propia de la madera, etc.), los arquitectos y aparejadores ya cuentan con un material de fácil montaje y que resuelven con rapidez gran cantidad de problemas constructivos.

- Ecológico: La madera es el material constructivo más ecológico que existe, ya que es un material natural, que necesita poca energía para ser transformado y además almacena $\mathrm{CO}_{2}$ de la atmósfera en su interior. También se debe tener en cuenta la aparición de las nuevas certificaciones de los productos de madera (PEFC y FSC), que garantizan que los productos de madera certificados 
provienen de montes gestionados de manera sostenible, eliminando en parte el concepto equivoco de que cortar y usar madera resulta perjudicial para el medio ambiente. Ha sido la divulgación de las ventajas de usar la madera como material ecológico y renovable frente a otros materiales más contaminantes y no renovables, la que ha contribuido de forma vital en que la madera sea más solicitada en obras públicas y por particulares.

- Económico: Una estructura bien diseñada y dimensionada puede ser más barata que una estructura de hormigón o de acero.

- Estético: Por su calidez, apariencia y múltiples opciones de acabado, cada vez es más demandada.

Otro punto relevante es el incremento durante los últimos años de las exigencias de calidad a los productos de madera estructural. Surge la necesidad imperante de satisfacer el cumplimiento de nuevas reglamentaciones, como el Código Técnico de la Edificación y la directiva de productos de la construcción, con el Marcado CE. Ambas normativas obligan a todos los fabricantes a declarar los valores de resistencia y rigidez de cada pieza de madera estructural que coloquen en el mercado y que a su vez se vaya a incorporar a una edificación. Por ello, resulta primordial abordar todas las carencias existentes actualmente en la caracterización de especies de madera de origen español. 


\section{JUSTIFICACIÓN}

Cada país ha desarrollado estándares nacionales para clasificar estructuralmente la madera de sus masas forestales, estableciendo su propia clasificación y nomenclatura estructural. Debido a la gran variedad de especies de madera, orígenes y diferentes reglas de clasificación, se recomienda utilizar el sistema europeo de clasificación de madera para uso estructural. La madera de sección rectangular se clasifica en categorías (clases de resistencia) según tres propiedades clave: resistencia, rigidez y densidad. Las clases de resistencia y sus propiedades se indican en la norma EN 338:2016.

Bajo el actual sistema europeo existen dos sistemas para la clasificación estructural de la madera, la clasificación visual y la clasificación mecánica.

La clasificación visual consiste en medir las singularidades de la madera, que afectan a su resistencia y rigidez, como los nudos, la inclinación de la fibra, la anchura de los anillos de crecimiento, la médula, las grietas, etc. La transformación válida de las calidades visuales a las clases de resistencia correspondientes se definen en la norma española UNE 56544:2011 y en la norma europea EN 1912:2012. Sin embargo, en España sólo 4 especies de coníferas están asignadas a una clase resistente: Pino laricio (Pinus nigra Arn. var. Salzmannii), pino silvestre (Pinus sylvestris L.), pino radiata (Pinus radiata D. Don) y pino pinaster (Pinus pinaster Ait.), limitando el acceso de cualquier otra especie maderable al mercado de la madera estructural.

La clasificación mecánica requiere la evaluación mediante técnicas no destructivas (NDT) de cada pieza, pero la diferencia es que la madera es clasificada por una máquina que mide una o más propiedades físico-mecánicas llegando a rendimientos clasificatorios mayores que con la clasificación visual.

A partir de los datos físico-mecánicos obtenidos en los ensayos de rotura (resistencia a flexión, módulo de elasticidad global y local, y densidad) y de su posterior correlación y limitación con los defectos de la madera medidos en cada una de las piezas sometidas a rotura, se obtiene la herramienta para llevar a cabo una clasificación visual. De la relación de dichos datos y de los diferentes parámetros físicos obtenidos mediante ensayos no destructivos, se determinan las diferentes herramientas de clasificación mecánica.

En España es necesario realizar trabajos de investigación tanto para aumentar el número de especies maderables clasificadas por clasificación visual, como para adaptar y calibrar los dispositivos de clasificación mecánica basadas en métodos no destructivos. 
Cabe señalar que numerosas investigaciones han demostrado la capacidad predictiva de las técnicas no destructivas a la hora de evaluar diversas características físicomecánicas de la madera (Acuña et al., 2006; Divos and Tanaka, 1997; Arriaga et al., 2012; Llana et al., 2018; Montero et al., 2015; Crespo et al., 2017). En este sentido, son varios los autores que han recomendado la utilización de métodos mixtos para la clasificación estructural y obtención de propiedades mecánicas, basados en la combinación de NDT y en la medición de parámetros visuales (Casado et al., 2012; Arriaga et al., 2014).

Durante los últimos años, las masas de pino radiata están siendo atacadas por una plaga de hongos (Phytophora ramorum) que está causando importantes daños forestales y enormes pérdidas económicas, debido a que esta especie constituye el motor de la industria maderera en la franja norte de la península, especialmente en el País Vasco y en Navarra. Las condiciones ambientales de alta humedad y temperaturas suaves favorecen la proliferación de estos patógenos, condiciones cada vez más frecuentes por el avance del conocido cambio climático.

La creciente preocupación ha provocado que se busquen especies de coníferas que pudieran ser alternativas capaces de sustituir con garantías aquellas masas forestales afectadas, manteniendo los turnos de corta reducidos que se vienen aplicando en la zona. En este contexto, una de las especies candidatas es el alerce del Japón (Larix kaempferi (Lamb.) Carr.) cuya utilidad en construcción está sobradamente demostrada en edificaciones emblemáticas japonesas (Yamabiko Dome en Matsumoto, The Nagano 'M Wave' arena en Nagano, Mokuzai Nakagai Kaikan edificio de oficinas en Osaka, o Mizu-no-Machiya Nanokamachi-Gotenzeki en Yamagata). En Europa, esta especie solo está clasificada en el Reino Unido (norma BS 4978:2007+A2:2017).

Mediante este trabajo de investigación se pretende caracterizar mecánicamente la madera de alerce del Japón para que se presente como una alternativa viable a utilizar en la construcción con madera.

Se pretende, además, estudiar la posible influencia de la época de corta, y concretamente de la fase lunar, en las propiedades físicas y mecánicas de la madera.

La influencia que la fase lunar existente en el momento del apeo de un árbol, tiene sobre las propiedades de la madera que luego se obtiene, es un tema que posiblemente se haya debatido a lo largo de los siglos por nuestros antecesores, pero sólo en las dos últimas décadas puede decirse que se haya iniciado su estudio de forma rigurosa y científica.

En el presente trabajo de investigación se analizará, desde un punto de vista estrictamente científico, la influencia de la época de corta en las propiedades mecánicas y físicas de la madera. Se podrá de este modo ratificar o refutar algunas de las afirmaciones ancestrales arraigadas en el acervo cultural, que han pervivido a lo largo de los siglos con la única herramienta de la transmisión oral intergeneracional. 


\section{OBJETIVOS}

En el presente trabajo de investigación se pretende obtener una clasificación visual del alerce del Japón para su inclusión en las normas de clasificación nacionales y europeas. El establecimiento de clases resistentes requiere la realización de ensayos mecánicos destructivos para conocer las propiedades del material.

A su vez, se aplicarán técnicas no destructivas que, combinadas con parámetros visuales, permiten desarrollar modelos analíticos para la estimación de las variables de rigidez y resistencia. Los ensayos no destructivos ofrecerán información necesaria para el desarrollo futuro de la clasificación mecánica de esta especie.

Los ensayos no destructivos se llevarán a cabo en troza, tras el tronzado en monte, y en las probetas finales secas, antes de los ensayos mecánicos. La información adquirida de este modo es muy relevante para la aplicación industrial del producto final, ya que permite establecer criterios de calidad del material en una etapa muy temprana del proceso de transformación.

Finalmente, se pretende averiguar la influencia de la época de corta de la madera, en relación con las fases lunares, sobre las propiedades de la misma. Concretamente, se estudiarán las propiedades mecánicas de resistencia y rigidez, y las propiedades físicas de densidad, contenido de humedad, aparición de fendas, deformaciones y rapidez de secado e higroscopicidad. 


\section{ANTECEDENTES}

\subsection{DESCRIPCIÓN DE LA ESPECIE}

\subsubsection{DISTRIBUCIÓN Y EXISTENCIAS}

El alerce del Japón ha sido utilizado fundamentalmente en Gipuzkoa, donde su extensión superó las 9.000 ha. Hace años fue utilizado como alternativa al pino radiata (Pinus radiata D. Don) que resultó muy afectado de las heladas de 1956. Sus crecimientos no han satisfecho las expectativas que se tenían con la especie habiéndose dejado de utilizar prácticamente en la actualidad (Aunós, 2008). De una forma más dispersa, la especie se ha utilizado en repoblaciones desde Galicia a Cataluña (Gracia, 2004).

En el País Vasco el alerce del Japón se utilizó en masas mezcladas con haya (Fagus sylvatica L.) para la restauración de hayedos. Su preferencia por suelos profundos exige una labor preparatoria del suelo en profundidad, bien mediante ahoyados mecanizados o mediante subsolados, según las características de la estación. Además, su elevada sensibilidad a daños por herbívoros exige una protección de la nueva masa, bien de carácter perimetral o individual, si se quiere compatibilizar la superficie arbolada con otros usos. Pese a todo ello, tal y como se indica en la figura 4.1, es en Navarra y en Gipuzkoa donde se detectan actualmente un gran número de existencias de esta especie. Esta especie presenta un elevado potencial para producir productos de alto valor añadido como la madera estructural y la madera de carpintería para revestimientos.

En la tabla 4.1, se detallan las clases diamétricas de esta especie pertenecientes a la comunidad autónoma del País Vasco.

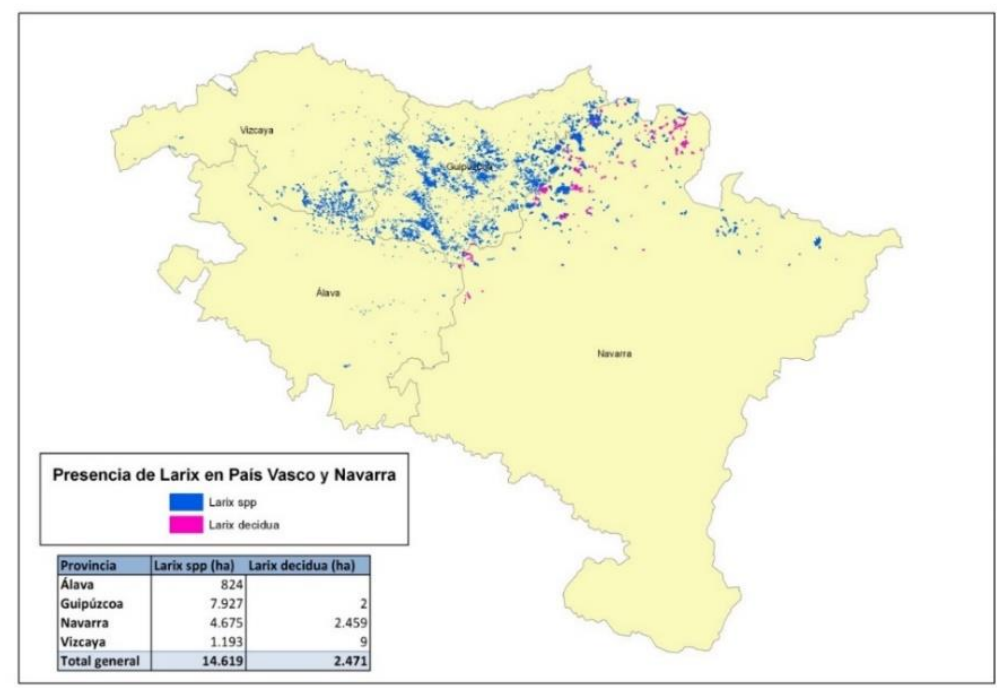

FIGURA. 4.1: MAPA DE DISTRIBUCIÓN ACTUAL DE ESPECIES DE ALERCE EN LAS COMUNIDADES AUTÓNOMAS DE PAÍS VASCO Y NAVARRA. 
Fuente: Elaboración propia a partir del Mapa Forestal de España a escala 1:50.000 (MFE50). MAGRAMA.

TABLA 4.1: DATOS SOBRE EXISTENCIAS POR CLASES DIAMÉTRICAS EN LA COMUNIDAD AUTÓNOMA DE PAÍS VASCO Y NAVARRA (TERRITORIOS QUE INCLUYEN LAS MUESTRAS OBJETO DEL ESTUDIO).

\begin{tabular}{|c|c|c|c|}
\hline CD & VCC Gipuzkoa $\left(\mathbf{m}^{\mathbf{3}}\right)$ & VCC Vizcaya $\left(\mathbf{m}^{\mathbf{3}}\right)$ & VCC Navarra $\left(\mathbf{m}^{\mathbf{3}}\right)$ \\
\hline 10 & 10.448 & 411 & 16.490 \\
\hline 15 & 28.379 & - & 96.259 \\
\hline 20 & 95.857 & 2.897 & 195.272 \\
\hline 25 & 217.582 & 10.896 & 281.385 \\
\hline 30 & 378.698 & 45.378 & 238.218 \\
\hline 35 & 307.371 & 70.105 & 54.563 \\
\hline 40 & 107.721 & 63.036 & 9.927 \\
\hline 45 & 30.720 & 13.927 & 14.537 \\
\hline 50 & 10.121 & 2.845 & 7.727 \\
\hline 55 & 1.754 & 1.712 & - \\
\hline TOTAL & $\mathbf{1 . 1 8 8 . 6 5 1}$ & $\mathbf{2 1 5 . 6 0 5}$ & $\mathbf{9 1 4 . 3 7 8}$ \\
\hline
\end{tabular}

Fuente: Elaboración propia. Datos obtenidos a partir del tercer Inventario Forestal Nacional y tercer Mapa Forestal Español. 2006.

En la actualidad, si bien existe material de base identificado en el Catálogo Nacional de Materiales de Base, aún suele recurrirse a la importación de semillas y plantas.

En el caso del alerce japonés, a pesar de su reducida distribución en las montañas del centro de la isla de Honshu, su utilización en repoblaciones en diferentes partes del mundo ha puesto de manifiesto que las fuentes de semillas más septentrionales y a mayor altitud dan lugar a progenies con un endurecimiento más temprano y una mayor resistencia al frío (Shearer, 2008). La resistencia del alerce europeo (Larix decidua Mill.) a la nieve, al frío, a las heladas y al viento, lo convierten en una especie muy interesante para su uso en estaciones de alta montaña con un fin protector, sobre todo de estabilización de suelos. Su carácter caducifolio le limita para el uso en repoblaciones de protección frente a aludes. No obstante, los mediocres resultados obtenidos en nuestro país, comparado con el pino uncinata (Pinus uncinata Mill), no han avalado su empleo futuro en la estabilización de suelos y lucha contra la erosión (Aunós, 2008).

\subsubsection{PROPIEDADES TECNOLÓGICAS DE LA MADERA}

A continuación, se hace una breve descripción de la madera de esta especie, alerce del Japón, según Vignote (2014), en su documento "Principales maderas de coníferas en España. Características, tecnología y aplicaciones".

La madera de alerce del Japón es muy semejante a la de alerce europeo. La albura es blanco-amarillenta claramente diferenciada del duramen marrón-rojizo. Anillos de crecimiento bien diferenciados a veces de contorno algo ondulado. Tiene textura fina y es de fibra recta. 
La madera proveniente de masas naturales de alerce del Japón es en cuanto a peso específico muy parecida a la del alerce europeo, quizás ligeramente menos pesada 0,50 a $0,55 \mathrm{~kg} / \mathrm{m}^{3}$. En cambio, la madera procedente de las repoblaciones europeas de esta especie es más ligera (450 a $550 \mathrm{~kg} / \mathrm{m}^{3}$ al $12 \%$ de humedad) y sensiblemente más blanda.

En general, las características mecánicas de esta madera son muy similares a las de la madera de alerce europeo de densidad comparable, es decir, si ha crecido en zona llana. De todas maneras, la dureza es inferior.

Tanto las características tecnológicas como las aplicaciones de esta madera son similares a las del alerce europeo, y en general similares a la de los pinos españoles.

Sus aplicaciones más importantes están en la construcción, tanto de edificios como naval, y en menor medida en ebanistería.

\subsubsection{DURABILIDAD E IMPREGNABILIDAD}

Reseñar que la durabilidad natural para la mayor parte de las especies de madera quedan definidas en la Norma Europea UNE EN 350-2: 1995. La madera de alerce del Japón sí aparece en dicha clasificación, pero solo ha quedado caracterizada para madera procedente de América del Norte, siendo la clasificación presentada la siguiente:

- Hongos: clase 3-4. Medianamente durable - Poco durable.

- Hylotrupes: Clase S. Sensible.

- Anóbidos: Clase S. Sensible.

- Termitas: Clase S. Sensible.

- Impregnabilidad:

- Duramen: Clase 4. No impregnable: Prácticamente imposible de impregnar. Después de $3 \mathrm{~h}$ a $4 \mathrm{~h}$ de tratamiento bajo presión sólo se absorben pequeñas cantidades de producto. Penetraciones longitudinales y laterales mínimas.

- Albura: Clase 2v. Medianamente impregnable: Fácil de impregnar. Normalmente no es posible una impregnación completa, pero después de $2 \mathrm{~h}$ ó $3 \mathrm{~h}$ de tratamiento a presión se puede alcanzar una penetración de más de $6 \mathrm{~mm}$. Presenta además una gran diversidad de comportamiento.

Estos datos de durabilidad difieren con las valoraciones de los industriales que utilizan dicha madera, tanto en España como en otros países de Europa, que se refieren a dicha madera como una especie durable, resistente frente a hongos e insectos. 


\subsection{HERRAMIENTAS DE CLASIFICACIÓN DE MADERA ASERRADA PARA USO ESTRUCTURAL}

\subsubsection{INTRODUCCIÓN}

Dentro del sector europeo de la madera, el conocimiento de las propiedades de los diversos productos estructurales de muy diferentes especies forestales se realiza siguiendo unos protocolos de trabajo ya definidos por el Comité Técnico (TC 124), el competente en materia normalizadora de los productos destinados al mercado estructural e incluido a su vez en el Comité Europeo de Normalización (Sáenz, 2011).

La caracterización de la madera de acuerdo con los postulados y metodologías descritas en las normas dictadas por el TC 124, se ha convertido en una necesidad de supervivencia competitiva dentro del mercado estructural, ya que la inexistencia de datos homologados sobre una determinada madera imposibilita su libre mercado en el ámbito europeo.

Dentro de este proceso normalizador se ha trabajado en la unificación de normas que permitan la libre circulación de los productos y que aseguran su calidad, logrando un marco normativo con exigencias comunes en toda la Unión Europea (Sáenz, 2011). En este marco se establecen las diferentes metodologías a seguir para llevar a cabo los ensayos a flexión, la medición de las diferentes singularidades de la madera, el desarrollo de nuevas normas de clasificación o nuevas metodologías de clasificación mecánica.

En este marco se han disparado las necesidades de investigación, desarrollo e innovación, y así lo demuestran las numerosas líneas de investigación abiertas en nuestro país, tanto en el ámbito de caracterización como de clasificación, con una clara vocación de responder a las necesidades surgidas en el sector y de satisfacer los requisitos de seguridad planteados en la normativa.

Existen varios métodos de clasificación de madera para uso estructural. Los más habituales son el ensayo mecánico estructural de tipo destructivo, la clasificación visual y la clasificación mecánica. El primero se conoce comúnmente como técnica destructiva, y es el que aporta una mayor exactitud a la hora de obtener las propiedades de resistencia y rigidez de la madera, así como su densidad.

La clasificación visual y la clasificación mecánica se basan en las denominadas Técnicas No Destructivas (NDT), que permiten estimar de forma individualizada (pieza a pieza) las propiedades resistentes de la madera, sin necesidad de alterar de forma permanente sus propiedades físicas y mecánicas. Ambos métodos requieren, para su desarrollo, la realización de ensayos mecánicos estructurales de tipo destructivo de la especie y procedencia a caracterizar. 
La clasificación visual se basa en un proceso de caracterización, donde se definen, relacionan y delimitan la influencia de las singularidades presentes en la madera con valores de resistencia y rigidez de la misma.

Una de las principales desventajas que tiene una clasificación visual es que subestima la calidad resistente de la madera, situándose siempre del lado de la seguridad, además de ser un proceso lento de clasificación (requiere el manejo de la pieza para visualizar sus cuatro caras), que siempre queda sujeto a la decisión final de un clasificador.

Actualmente existen numerosas normas de clasificación visual resistente en Europa. Esto se debe en gran parte a la heterogeneidad de la madera como material constructivo, ya que en cada país o zona geográfica se detectó la disponibilidad y uso de diferentes especies o grupos de especies, diferentes requisitos dimensionales, diferentes calidades del material disponible, e incluso diferentes prácticas y costumbres históricas. Esto llevó a que cada país o zona geográfica decidiera cubrir las necesidades derivadas de sus usos y costumbres teniendo en cuenta la diversidad presente en su territorio.

El empleo de una clasificación mecánica consiste en medir una variable y relacionarla de la forma más estrecha posible con una variable clasificadora (en casi todos los casos con el módulo de elasticidad), de tal modo que, cuanto mayor sea esa relación entre factores y más fácil de medir sea el estimador, mejor será la técnica.

Existe una gran diversidad de métodos de clasificación mecánica, aunque todos exigen grandes esfuerzos en la caracterización del producto de forma inicial y en la obtención de correlaciones estadísticas entre los diferentes parámetros mecánicos y/o físicos, y los valores de resistencia y rigidez. Así se consigue obtener una clasificación instantánea y mecanizada. Según el método de clasificación mecánica escogido, puede resultar necesaria la toma de muestras continuas durante la producción para controlar e incluso reajustar favorablemente los parámetros de clasificación establecidos en la máquina.

Por otra parte, en ambos métodos es necesario delimitar el alcance de la aplicación, es decir, la especie o grupos de especies a valorar, y sus procedencias geográficas, tanto para la obtención de las tablas de clasificación visual, como para el ajuste de los parámetros de las maquinas.

El objetivo final de ambos sistemas, basados en técnicas no destructivas, es obtener una herramienta de clasificación que permita declarar unos valores de resistencia y rigidez a cada pieza de madera estructural clasificada, sin necesidad de tener que someter a rotura dichas piezas.

Actualmente en España generalmente se hace uso del método de clasificación visual por dos motivos esencialmente: los escasos volúmenes de producción, y la escasa 
tecnificación de los procesos industriales de la industria maderera que deriva en una escasez de máquinas de clasificación mecánica con parámetros ajustados a las especies y distribuciones españolas.

\subsubsection{NORMAS DE CLASIFICACIÓN VISUAL}

\subsubsection{PASADO Y PRESENTE}

La clasificación visual de la madera en función de su aspecto exterior ha sido, y es, el método más usado para decidir sobre la calidad mecánica de la madera. Una de las primeras normas de clasificación visual de la madera estructural data de 1923 y fue desarrollada y publicada por el Forest Products Laboratory de Madison (Estados Unidos). Hacia 1950 tuvieron su desarrollo normas similares en Europa, apareciendo las primeras versiones de las normas alemanas (DIN), inglesa (BSI), francesa (AFNOR), etc. (Fernández Golfín et al., 2001).

Por su parte en España la madera aserrada empezó siendo clasificada por su aspecto, donde los criterios de clasificación están basados en la apariencia estética y los defectos de la madera penalizaba atendiendo al grado de aparición en la superficie (Arriaga et al., 2003).

Estas primeras clasificaciones estéticas atendían a los usos y costumbres de la zona de explotación y comercialización, ligándose así a especies y procedencias. Un ejemplo que ha perdurado en el tiempo es la clasificación para el pino silvestre procedente del sistema ibérico, que tipifica cinco calidades, especial, primera, segunda, tercera, y cuarta o construcción.

En general se trata de una clasificación incompleta, que puede dar lugar a muchos conflictos entre comprador y vendedor (Vignote et al., 1999). Por esta razón se desarrolló en 1995 la Norma UNE 56545:1995 que establecía cuatro calidades visuales de calidad según el aspecto: especial, $1^{\circ}, 2^{\circ} \mathrm{A}, 2^{\circ} \mathrm{B}, 3^{\circ}$ y $4^{\circ}$. Estas normas delimitaban los tamaños y/o la presencia de singularidades típicas de la madera, teniéndolos únicamente en cuenta por temas puramente estéticos y/o funcionales. Dicha norma no llego a implantarse en la industria, siendo posteriormente anulada. Actualmente existen diferentes normas europeas que pretenden poner criterios de clasificación comunes que regulen en mejor medida el mercado de la madera dentro de la Unión Europea, como la EN 942:2007, útil para madera en elementos de carpintería.

La primera norma española de clasificación visual de la madera aserrada según su resistencia estructural (actual UNE 56544: 2011) se remonta al año 1996. El desarrollo de esta norma española ha sido siempre paralelo a la antigua norma marco europea EN 518:1996, ahora sustituida por la norma armonizada EN 14081-1: 2016, por lo que se puede asegurar que la normativa española cumple en estos momentos con todos los requisitos que se establecen a nivel europeo para la clasificación visual de la madera según su resistencia. 
Respecto a la situación actual en el continente europeo, son numerosos los estudios realizados, lo que ha permitido la caracterización y fijación de tablas de clasificación para las principales maderas comercializadas a nivel estructural. Esencialmente se han determinado a nivel nacional o a nivel de grandes extensiones geográficas de características muy similares con distribución por diferentes países.

Es por lo tanto cada país o grupo de países quienes establecen en sus correspondientes normas de clasificación, las diferentes calidades visuales (clases visuales) por especie o grupo/s de especies caracterizadas, donde se delimitan los criterios de clasificación visual y se asignan los valores de resistencia y rigidez a cada una de ellas. Este proceso se suele realizar mediante la asignación directa por especie y clase visual de las denominadas clases resistentes (establecidas en la Norma Europea UNE EN 338: 2016, tales como la C18, C22, C24, C30, etc.). Esto es posible ya que cada clase resistente lleva asociados unos valores característicos de la resistencia, rigidez y densidad, tal y como se establece en la Norma UNE EN 338: 2016.

La estructura de todas las normas de clasificación suele ser bastante similar:

- Inicialmente se hace una breve descripción de los defectos que deben ser analizados y se establece la metodología de medición por la que se ha optado en cada caso.

- La metodología de medición de las singularidades de la madera suele variar de unas normas a otras, pero en la mayor parte de los casos optan por alguna de las opciones que plantea la Norma Europea EN 1310:1997, tal y como establece la norma EN 14081-1: 2016, como es para el caso de los nudos, fendas, desviaciones de fibra y deformaciones.

- Seguidamente se fijan las diferentes tablas de clasificación para cada especie o grupo de especies analizadas. Cada tabla contiene los valores límite para cada una de las singularidades analizadas y para cada una de las diferentes calidades (clases visuales) que se hayan fijado, en la mayor parte de los casos de una a tres.

- Y finalmente, y no en todos los casos, la asignación a cada calidad (clase visual) de la correspondiente clase resistente. Esto se debe a que no todas las normas optan por recoger en su propia norma de clasificación dicha opción, ya que existe una norma, la EN 1912: 2012, que recoge la asignación de clases resistentes de todas las especies o grupos de especies, calidades y normas de clasificación, existentes a nivel europeo, e incluso de fuera de Europa, como es el caso de la norma estadounidense y canadiense.

A continuación, en la tabla 4.2, se hace un breve resumen de las principales normas de clasificación establecidas en Europa:

TABLA 4.2: CLASES VISUALES Y CLASES RESISTENTES ASIGNADAS A DETERMINADAS ESPECIES EN LAS PRINCIPALES NORMAS DE CLASIFICACIÓN DE EUROPA. 


\begin{tabular}{|c|c|c|c|c|c|c|}
\hline Procedencia & $\begin{array}{l}\text { País que } \\
\text { publica la } \\
\text { norma de } \\
\text { clasificación }\end{array}$ & $\begin{array}{c}\text { Norma de } \\
\text { clasificación }^{1)}\end{array}$ & $\begin{array}{l}\text { Especie } \\
\text { (nombre } \\
\text { comercial) }\end{array}$ & Nombre científico & Calidad & $\begin{array}{l}\text { Clase } \\
\text { resistente }\end{array}$ \\
\hline \multirow{12}{*}{ España } & \multirow{12}{*}{ España } & \multirow{11}{*}{ UNE 56544²) } & \multirow{3}{*}{ Pino radiata } & \multirow{3}{*}{ Pinus insignis } & ME-1 & $\mathrm{C} 24$ \\
\hline & & & & & ME-2 & C18 \\
\hline & & & & & MEG & $\mathrm{C} 22$ \\
\hline & & & \multirow{2}{*}{ Pino marítimo } & \multirow{2}{*}{ Pinus pinaster } & $\mathrm{ME}-1$ & $\mathrm{C} 24$ \\
\hline & & & & & ME-2 & C18 \\
\hline & & & \multirow{3}{*}{ Pino silvestre } & \multirow{3}{*}{ Pinus sylvestris } & ME-1 & C27 \\
\hline & & & & & ME-2 & C18 \\
\hline & & & & & MEG & $\mathrm{C} 22$ \\
\hline & & & \multirow{3}{*}{ Pino laricio } & \multirow{3}{*}{ Pinus nigra } & $\mathrm{ME}-1$ & C30 \\
\hline & & & & & ME-2 & C18 \\
\hline & & & & & MEG & C22 \\
\hline & & UNE 56546 & Eucalipto & $\begin{array}{l}\text { Eucalyptus globulus } \\
\text { (Hasta } 20 \times 7 \mathrm{~cm})\end{array}$ & MEF & D40 \\
\hline \multirow{15}{*}{ Francia } & \multirow{15}{*}{ Francia } & \multirow{15}{*}{ NF B 52001} & \multirow{3}{*}{$\begin{array}{l}\text { Abeto blanco } \\
\text { Picea } \\
\text { Abeto douglas }\end{array}$} & \multirow{3}{*}{$\begin{array}{c}\text { Abies alba }^{3} \\
\text { Picea abies }^{3)} \\
\text { Pseudotsuga menziesii }\end{array}$} & ST-I & C30 \\
\hline & & & & & ST-II & C24 \\
\hline & & & & & ST-III & C18 \\
\hline & & & \multirow{4}{*}{$\begin{array}{l}\text { Pino silvestre } \\
\text { Pino marítimo } \\
\text { Pino laricio }\end{array}$} & \multirow{4}{*}{$\begin{array}{l}\text { Pinus sylvestris }{ }^{4)} \\
\text { Pinus pinaster }{ }^{4,5)} \\
\text { Pinus nigra }\end{array}$} & ST-I & C30 \\
\hline & & & & & ST-II & $\mathrm{C} 24$ \\
\hline & & & & & ST-III & C18 \\
\hline & & & & & ST-IV & C14 \\
\hline & & & \multirow[b]{2}{*}{ Chopo } & \multirow{2}{*}{ 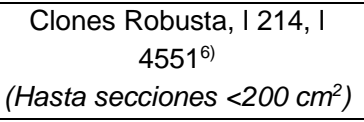 } & ST-III & C18 \\
\hline & & & & & ST-II & $\mathrm{C} 24$ \\
\hline & & & \multirow{3}{*}{ Roble } & \multirow{3}{*}{ Quercus robur-petrea } & 1 & D30 \\
\hline & & & & & 2 & D24 \\
\hline & & & & & 3 & D18 \\
\hline & & & \multirow{3}{*}{ Alerce } & \multirow{3}{*}{$\begin{array}{c}\text { Larix decidua } \\
\left(\text { Hasta secciones }<200 \mathrm{~cm}^{2}\right)\end{array}$} & ST-I & $\mathrm{C} 27$ \\
\hline & & & & & ST-II & $\mathrm{C} 24$ \\
\hline & & & & & ST-III & C18 \\
\hline \multirow{4}{*}{$\begin{array}{l}\text { Norte y } \\
\text { Noroeste de } \\
\text { Europa }\end{array}$} & \multirow{4}{*}{$\begin{array}{l}\text { Países } \\
\text { nórdicos }\end{array}$} & \multirow{4}{*}{$\begin{array}{l}\text { INSTA } 142 \\
\text { (madera de } \\
\text { grandes } \\
\text { escuadrías) }\end{array}$} & \multirow{4}{*}{$\begin{array}{c}\text { Pino silvestre } \\
\text { Abeto blanco } \\
\text { Picea } \\
\text { Alerce }\end{array}$} & & T3 & C30 \\
\hline & & & & Abies alba & T2 & $\mathrm{C} 24$ \\
\hline & & & & Picea abies & T1 & C18 \\
\hline & & & & & T0 & C14 \\
\hline & & & Pino silvestre & Pinus sylvestris & $\mathrm{S} 13$ & C30 \\
\hline Centro, norte y & Alemania y & $\begin{array}{l}\text { (madera } \\
\text { (mad4-1 }\end{array}$ & Abeto blanco & Abies alba & S10 & $\mathrm{C} 24$ \\
\hline de Europa & Austria & escuadrada) & $\begin{array}{l}\text { Picea } \\
\text { Alerce }\end{array}$ & $\begin{array}{l}\text { Picea abies } \\
\text { Larix decidua }\end{array}$ & S7 & C16 \\
\hline
\end{tabular}

1) Existen además de las indicadas en la presente tabla numerosas normas de clasificación de otros países, como Portugal (pino marítimo), Irlanda (picea noruega y picea de Sitka), república checa (abeto), Reino Unido, Canadá y Estados Unidos (que establecen una gran variedad de coníferas y frondosas), etc.

2) Las clases visuales ME-1 y ME-2 corresponden a piezas de grosor menor o igual a $7 \mathrm{~cm}$ y la MEG para piezas de grosor superior a $7 \mathrm{~cm}$.

3) El abeto blanco y la picea procedente de Francia solo se puede clasificar como $\mathrm{C} 30$ en piezas con secciones inferiores a $200 \mathrm{~cm}^{2}$

4) Las piezas de madera de pinos de Francia con secciones inferiores a $160 \mathrm{~cm}^{2}$ no se pueden clasificar como ST-I (C30).

5) En el caso concreto del pino marítimo todas las piezas clasificadas como ST-I (C30) son reclasificadas como ST-II (C24).

En cuanto a la norma actual UNE 56544: 2011 para madera de coníferas de procedencia española, conviene remarcar que, las clases visuales ME-1 y ME-2 para madera de pinos procedentes de España solo son útiles para piezas de grosor inferior o igual a 7 $\mathrm{cm}$, mientras que la clase visual MEG es válida para piezas de un grosor mayor a $7 \mathrm{~cm}$. En cuanto a la norma española para frondosas existe una única clase visual, la MEF, que únicamente se puede aplicar a piezas de un grosor máximo de $60 \mathrm{~mm}$ y una anchura 
máxima de $200 \mathrm{~mm}$. Se puede decir que con las normas de clasificación españolas existentes sólo quedan cubiertas parte de las necesidades más generales de la industria de la madera. Así, actualmente en España solamente se encuentran caracterizadas 4 especies de coníferas (Pinus nigra Arn. var. Salzmannii, Pinus sylvestris L., Pinus radiata D. Don, Pinus pinaster Ait.) y 2 especies de frondosas (Eucalyptus globulus Labill., y Castanea sativa Mill.), que representan un pequeño fragmento de las especies maderables que se pueden utilizar a nivel estructural.

Especies minoritarias como el roble del país (Quercus sp.), alerce (Larix sp.), abeto blanco (Abies alba Mill.), abeto Douglas (Pseudotsuga menziesii (Mirb.) Franco), ciprés de Lawson (Chamaecyparis lawsoniana (A. Murray) Parl.), y no tan minoritarias, como el chopo (Populus sp.), no se encuentran recogidas en la actual normativa española, aunque en algunos casos concretos se están acometiendo actualmente.

Si comparamos además con otras normas de clasificación se detecta la ausencia de variedad de calidades visuales para piezas estructurales con secciones actualmente demandadas en el mercado estructural español, ya que para piezas de un grosor superior a $7 \mathrm{~cm}$ únicamente existe la clase visual MEG (equivalente para todas las especies incluidas a una C22). Este hecho también es de vital importancia ya que una norma con diferentes calidades se convierte en una herramienta de estratificación y valorización de los productos estructurales, abriendo un abanico de posibilidades que se adapta en mayor medida a la flexibilidad tan demandada por arquitectos e ingenieros.

Si además tenemos en cuenta la entrada en vigor del Marcado CE de madera estructural maciza $(31 / 12 / 11)$, que obliga a todos los fabricantes a declarar los valores de resistencia y rigidez de cada pieza de madera estructural que coloquen en el mercado, resulta primordial abordar todas estas carencias existentes actualmente en la caracterización de especies españolas.

En esta situación se encontraba el alerce japonés del norte de España, que una vez detectada y analizada la necesidad imperante de caracterizar dicha madera, FP Euskadi a través de Tknika (Centro de Innovación e Investigación Aplicada para la Formación Profesional del País Vasco), Secoma (Servicios Comerciales de la madera de Gipuzkoa) el Departamento de Desarrollo Económico e Infraestructuras del Gobierno Vasco, la Diputación Foral de Gipuzkoa y el Gobierno de Navarra decidieron abordar dicho estudio contando con la experiencia y apoyo de Cesefor, así como con parte de su industria.

El objetivo era obtener tablas de clasificación que fuesen incluidas dentro de la norma española para coníferas, la UNE 56544: 2011, que habilitaran a todo el sector maderero a clasificar visualmente dicha madera por su resistencia. Con la incorporación además de la evaluación de las denominadas técnicas no destructivas basadas en métodos acústicos se pretendía demostrar la viabilidad en el uso de una nueva metodología de clasificación que reduciría el número de rechazos durante la clasificación.

\subsubsection{CRITERIOS DE CLASIFICACIÓN}


La clasificación visual se basa en la evaluación y medición de determinadas singularidades de la madera, ligadas a la propia anatomía de la madera (nudos, fendas, desviaciones de la fibra, entrecascos, etc.), al aserrado de las propias piezas (gemas, daños de mecanizado), a alteraciones de tipo biológico (azulados, pudriciones, ataques de insectos, muérdago, etc.) y a ciertas deformaciones derivadas en gran medida por su secado (curvaturas, alabeos y atejados). Consiste, por lo tanto, en la medición y control de todos aquellos criterios que limitan en cierta medida los valores de resistencia, rigidez, y densidad, y que pueden ser evaluados visualmente.

En cuanto a los factores más determinantes, son los nudos el factor que más influye en los valores de resistencia y rigidez, mientras que la desviación de la fibra es la propiedad de mayor influencia sobre el comportamiento geométrico de la madera (curvaturas y alabeos).

Además del análisis de la influencia de dichos criterios en la madera en rollo y en la madera aserrada, con mayor influencia negativa sobre esta última, se puede interpretar que el aserrado influye negativamente a causa de la discontinuidad producidas en las fibras y al desajuste de tensiones a lo largo de la pieza de madera y alrededor de los nudos.

Respecto a las diferencias en el procedimiento de medición de las singularidades de la madera entre unas y otras normas de clasificación, se encuentran principalmente en la metodología de medición de nudos, criterio que como ya se ha comentado es de elevada relevancia y a la vez el criterio que posiblemente mayor dificultad presenta a la hora de clasificar, por las múltiples formas en las que puede presentarse en una pieza aserrada en función del corte recibido.

Por otra parte, conviene remarcar que es la norma EN 14081-1: 2016 la que establece los requisitos para las características que reducen la resistencia en las normas de clasificación, indicando las singularidades que se han de tener en cuenta y que por lo tanto deben ser incluidas en la norma de clasificación, estableciendo en casos específicos valores umbrales máximos.

\subsubsection{CLASES VISUALES Y CLASES RESISTENTES}

El siguiente paso en cualquier norma de clasificación, tras establecer la sistemática a seguir para la evaluación y control de las singularidades presentes en las piezas de madera, es el establecimiento de las calidades (clases visuales), es decir, la relación de los valores limitantes y las singularidades de la madera aserrada que ha de cumplir una pieza de madera de una determinada especie y procedencia. 
El surgimiento del establecimiento de una tipificación de los valores de resistencia y rigidez de la madera estructural no se debe sino a una necesidad de asemejar y establecer unas bases comunes para todos los países de la Unión Europa.

Este sistema de clases resistentes tipifica los valores de resistencia en una serie de grupos o intervalos de resistencia. Cada grupo de resistencia se codifica con la siguiente nomenclatura, $C$ (para coníferas) y $D$ (para frondosas), seguido de dos dígitos que corresponden al valor característico de la resistencia a flexión (percentil 5).

La única especie que no cumple estos criterios es la madera de chopo, que se incluye dentro de la asignación de clases resistentes como si fuera una conífera, debido a que presenta un comportamiento más parecido a éstas.

Cada clase resistente lleva consigo unos valores característicos de resistencia y rigidez: de flexión, de tensión paralela y perpendicular, de compresión paralela y perpendicular, de cortante, de módulo de elasticidad paralelo y perpendicular; además de unos valores característicos de densidad.

Para establecer una clase resistente para una especie o grupo de especies es necesario evaluar y determinar sus valores característicos respecto a la resistencia a flexión, al módulo de elasticidad local y a la densidad.

La menor clase resistente de las tres características será la que fije la clase resistente de la especie o grupo de especies caracterizada/s, pudiendo a posteriori asignar no solo los valores característicos correspondientes a las tres propiedades evaluadas, sino también el resto de valores característicos asociados. La norma europea que regula y desarrolla el sistema de clases resistentes de la madera es la norma EN 338: 2016 que se puede ver en la tabla 4.3.

La sistemática, en definitiva, no es otra que aplicar a cada combinación de especie, procedencia y calidad, independientemente del método de clasificación, una determinada clase resistente. En el ámbito europeo es la norma EN 1912: 2012 la que establece las asignaciones de clases resistentes sobre las combinaciones de especie, procedencia y calidad.

La enorme ventaja que presenta este procedimiento es que permite calcular y proyectar con las propiedades mecánicas de una clase resistente determinada, independientemente del tipo de especie de madera que luego se utilice. Por otra parte, el comercio de la madera se optimiza ya que, por un lado, los stocks de los almacenistas se reducen (podrán vender sólo aquella madera que les resulta rentable sin necesidad de mantener una amplia oferta con distintas calidades) y se amplía la oferta al poder obtener para una misma resistencia diferentes combinaciones de especie-calidad, y por otro lado, el usuario final dispondrá de más información y una mayor oferta, teniendo la seguridad de comprar un producto con unos valores mínimos de resistencia (Adell, 2005). 
La única norma europea que contempla la clasificación estructural del alerce del Japón es la norma de clasificación visual de coníferas del Reino Unido (BS 4978:2007+A2:2017). La calidad SS tiene asignada una clase resistente C24, y la calidad GS, una clase resistente C16.

En cambio, el alerce europeo se encuentra incluido en normas de clasificación visual de numerosos países (Alemania, Austria, República Checa, Países Nórdicos, Países Bajos, Francia, Reino Unido e Italia). 
TABLA 4.3: TABLA DE CLASES RESISTENTES PARA CONÍFERAS ESTABLECIDA EN LA NORMA EUROPEA EN 338: 2016 BASADAS EN ENSAYOS DE FLEXIÓN DE CANTO.

\begin{tabular}{|c|c|c|c|c|c|c|c|c|c|c|c|c|c|}
\hline \multirow{2}{*}{ Valores característicos } & & \multicolumn{12}{|c|}{ Coníferas } \\
\hline & & C14 & C16 & C18 & $\mathrm{C} 20$ & $\mathrm{C} 22$ & $\mathrm{C} 24$ & $\mathrm{C} 27$ & C30 & C35 & C40 & C45 & C50 \\
\hline \multicolumn{14}{|l|}{ Propiedades de resistencia (en $\mathrm{N} / \mathrm{mm}^{2}$ ) } \\
\hline Flexión & $f_{\mathrm{m}, \mathrm{k}}$ & 14 & 16 & 18 & 20 & 22 & 24 & 27 & 30 & 35 & 40 & 45 & 50 \\
\hline Tracción paralela & $t_{\mathrm{t}, 0, \mathrm{k}}$ & 7,2 & 8,5 & 10 & 11,5 & 13 & 14,5 & 16,5 & 19 & 22,5 & 26 & 30 & 33,5 \\
\hline Tracción perpendicular & $f_{\mathrm{t}, 90, \mathrm{k}}$ & 0,4 & 0,4 & 0,4 & 0,4 & 0,4 & 0,4 & 0,4 & 0,4 & 0,4 & 0,4 & 0,4 & 0,4 \\
\hline Compresión paralela & $f_{\mathrm{c}, 0, \mathrm{k}}$ & 16 & 17 & 18 & 19 & 20 & 21 & 22 & 24 & 25 & 27 & 29 & 30 \\
\hline Compresión perpendicular & $f_{\mathrm{c}, 90, \mathrm{k}}$ & 2,0 & 2,2 & 2,2 & 2,3 & 2,4 & 2,5 & 2,6 & 2,7 & 2,7 & 2,8 & 2,9 & 3,0 \\
\hline Cortante & $f_{\mathrm{v}, \mathrm{k}}$ & 3,0 & 3,2 & 3,4 & 3,6 & 3,8 & 4,0 & 4,0 & 4,0 & 4,0 & 4,0 & 4,0 & 4,0 \\
\hline \multicolumn{14}{|l|}{ Propiedades de rigidez (en kN/mm2) } \\
\hline Módulo de elasticidad paralelo medio & $\mathrm{E}_{0, \text { mean }}$ & 7 & 8 & 9 & 9,5 & 10 & 11 & 11,5 & 12 & 13 & 14 & 15 & 16 \\
\hline Módulo de elasticidad paralelo $5^{\circ}$ percentil & $\mathrm{E}_{0,05}$ & 4,7 & 5,4 & 6,0 & 6,4 & 6,7 & 7,4 & 7,7 & 8,0 & 8,7 & 9,4 & 10,0 & 10,7 \\
\hline $\begin{array}{l}\text { Módulo de elasticidad perpendicular } \\
\text { medio }\end{array}$ & $E_{90, \text { mean }}$ & 0,23 & 0,27 & 0,30 & 0,32 & 0,33 & 0,37 & 0,38 & 0,40 & 0,43 & 0,47 & 0,50 & 0,53 \\
\hline Módulo de elasticidad transversal medio & $\mathrm{G}_{\text {mean }}$ & 0,44 & 0,5 & 0,56 & 0,59 & 0,63 & 0,69 & 0,72 & 0,75 & 0,81 & 0,88 & 0,94 & 1,00 \\
\hline \multicolumn{14}{|l|}{ Densidad (en kg/m³) } \\
\hline Densidad característica & $\rho_{\mathrm{k}}$ & 290 & 310 & 320 & 330 & 340 & 350 & 360 & 380 & 390 & 400 & 410 & 430 \\
\hline Densidad media & $\rho_{\text {mean }}$ & 350 & 370 & 380 & 400 & 410 & 420 & 430 & 460 & 470 & 480 & 490 & 520 \\
\hline
\end{tabular}

Fuente: Norma EN 338: 2016 


\subsubsection{TÉCNICAS NO DESTRUCTIVAS}

Un patrón común a todas las normas de clasificación visual es su elevado conservadurismo, que las lleva a eficiencias clasificadoras (porcentaje de acierto) que difícilmente superan el 50\%. En España y para el pino laricio (Pinus nigra Arnold) la efectividad de la norma UNE 56544: 2011 es tan solo del 53\% (Fernández Golfín, 2000). Esto quiere decir que las normas de clasificación visual subestiman fuertemente la calidad mecánica del material y, por tanto, el beneficio económico del productor (Fernández Golfín et al., 2001).

Buscando un mayor grado de eficacia y objetividad en la predicción de la calidad mecánica del material, las investigaciones sobre nuevos métodos clasificatorios se orientaron hacia nuevos métodos de clasificación mecánica.

La Norma UNE-EN 14081-1:2016, y sus sucesivas partes, establecen el método normalizado para la utilización de dichas máquinas de clasificación mecánica. La misma define la clasificación mecánica como el proceso mediante el cual puede clasificarse una pieza de madera con una máquina que detecta, de forma no destructiva, y con el control visual que eventualmente pudiera precisarse, una o más propiedades de la madera, en calidades a las que pueden asignarse valores de resistencias, rigidez y densidad.

En este campo se abre un enorme abanico de líneas de investigación tan extenso como necesario. Las posibilidades y tiempos que ofrece una clasificación visual es muy limitada cuando hablamos de grandes producciones, que requieren altos rendimientos, por lo que se antoja necesario incorporar una clasificación mecánica en el proceso.

Inicialmente los nuevos métodos de clasificación se centraron en la clasificación mecánica por máquina, conocida como "Machine Stress Grading o Rating (MSR)". Habitualmente estas máquinas se basan en la determinación de la elasticidad o rigidez de la madera y en la posterior predicción de su resistencia mediante el uso de relaciones conocidas entre ambas variables.

La utilización de la elasticidad o de la rigidez de la madera como predictor de la resistencia se basa en su relación con el módulo de resistencia a flexión (MOR) y en su facilidad de medición a ritmo elevado.

El descubrimiento de la utilización de nuevos y diversos métodos y técnicas para determinar el módulo de elasticidad o rigidez de la madera es el origen de los nuevos métodos de clasificación automática que existen y se están desarrollando en la actualidad. 
Dentro de este nuevo grupo se pueden destacar dos nuevos tipos de técnicas: las que se basan en la determinación del módulo de elasticidad mediante métodos acústicos, basados en la medición de la velocidad de propagación de ondas acústicas o en la medición de la frecuencia de vibración; y los que se basan en la localización y medición de los defectos presentes en la madera y de su densidad y humedad mediante la combinación de técnicas de radiofrecuencia (microondas) y de absorción de radiaciones ionizantes.

Otros métodos y técnicas con escasa implantación en la industria maderera europea, son las basadas en la resistencia a la penetración de una varilla y la resistencia a la extracción de un tornillo. El resistógrafo también resulta una técnica muy utilizada, aunque sus aplicaciones en la práctica se encuentran más relacionadas con el diagnóstico de daños que con la caracterización de las propiedades mecánicas.

Otras técnicas son la termografía, que permite detectar con alta sensibilidad los cambios de temperatura, el georradar, que detecta discontinuidades internas en el material mediante campos electromagnéticos, o los rayos $\mathrm{X}$, que detectan singularidades internas de la madera como nudos, bolsas de resina o desviación de la fibra.

En el presente trabajo nos centraremos en los métodos acústicos, utilizando dos métodos, uno basado en la medición de la velocidad de paso de una onda sonora, y el segundo, en la medición de la frecuencia de vibración longitudinal que provoca una onda sonora a su paso por una pieza de madera.

La aplicación de métodos acústicos para la clasificación y evaluación de las propiedades de la madera no cuenta con el mismo grado de desarrollo tecnológico que posee en otros materiales, como el hormigón, sin embargo, existe una dilatada experiencia de uso (se aplica desde hace más de 50 años) y existen pocos, pero potentes grupos de investigación dedicados a su estudio.

Fueron Ross y Pellerin, de la Washington State University en Estados Unidos, quienes usaron por primera vez las ondas de impacto para determinar el módulo de elasticidad dinámico de probetas libres de defectos. Se obtuvo un alto grado de predicción midiendo el tiempo de propagación y relacionándolo con la elasticidad del material (Iñiguez et al., 2007).

Los métodos acústicos se emplean además para la clasificación y detección de las singularidades de la madera en múltiples campos. Existiendo desde grandes equipos de alto rendimiento para líneas de producción (Machado et al., 2004) a pequeños y ligeros equipos portátiles diseñados para su utilización en campo y laboratorio (Iñiguez, 2007). Actualmente en España es la técnica que más se está investigando en el sector de la madera. 


\subsubsection{MÉTODOS BASADOS EN ONDAS DE IMPACTO Y ULTRASONIDOS}

Los métodos acústicos pueden emplear dos tipos de ondas, una onda ultrasónica (frecuencias superiores a los $20 \mathrm{kHz}$ ) y una onda sónica (frecuencias comprendidas entre los $20 \mathrm{~Hz}$ y $20 \mathrm{kHz}$ ) generada, por ejemplo, mediante el impacto con un martillo. En el primer caso, a la técnica se le denomina ultrasonidos, mientras que la segunda ondas de impacto. Pese a todo ello los ultrasonidos son un caso particular de ondas de impacto, que debido a su importancia suelen ser tratados de modo independiente (Iñiguez, 2007).

Con estas técnicas la capacidad resistente de la madera se puede estimar a partir de la velocidad de la onda sónica, puesto que la presencia de singularidades propias de la madera como la medula, nudos, degradaciones internas, etc., hacen que la velocidad de transmisión de las ondas generadas sea diferente de la que presentan en el material sin defectos. En definitiva, la velocidad de propagación será mayor cuanto menor sea la presencia de defectos en la madera debido a que, por ejemplo, las fendas, las desviaciones e la fibra generales o las locales producidas por los nudos provocan la interrupción de la continuidad de la transmisión de la onda y por tanto retardan su llegada al receptor (Goiar R. de Oliveira et al., 2002).

Como ejemplo de equipos de ultrasonidos, se pueden destacar por su amplia utilización el Sylvatest ${ }^{\circledR}$, que trabaja por transmisión ultrasónica con un generador de $30 \mathrm{kHz}$ de frecuencia, y el Ultrasonic Timer de la casa Fakopp $(45 \mathrm{kHz})$.

Como ejemplo de equipos de ondas de impacto para madera, se puede citar el dispositivo portátil denominado "Microsecond Timer" de la casa Fakopp. Este equipo utiliza el principio de transmisión directa de una onda acústica y calcula el tiempo de propagación de dicha onda entre dos puntos de distancia conocida (Iñíguez, 2007). Este mecanismo fue uno de los seleccionados en el presente trabajo para los ensayos en troza y en las piezas aserradas.

Para los ultrasonidos, Íñiguez (2007), señala que las relaciones lineales que se obtienen en madera entre la velocidad de propagación de los ultrasonidos en la dirección longitudinal y las propiedades mecánicas, dan coeficientes de determinación del orden de 0,45 a 0,75, aproximadamente (Sandoz, 1989, Machado et al., 1998), llegando incluso a valores de 0,98 en probetas libres de defectos (Pellerín et al., 2002). 
También hay que insistir en que normalmente los mejores coeficientes de determinación se obtendrán cuando se relaciona la velocidad de ultrasonidos (o mejor, el módulo de elasticidad dinámico) y el módulo de elasticidad del material, ya que la predicción de la resistencia suele ser sensiblemente más baja, debido a la presencia de defectos locales que, siendo registrados en su magnitud, limitan significativamente la carga máxima soportada (Iñíguez, 2007). Este hecho puede extrapolarse a los métodos basados con ondas de impacto.

En una investigación realizada por Kessel sobre 450 piezas de madera de pícea, (Picea abies (L.) Karst.), de gruesa escuadría (100x120 mm y 120 × $240 \mathrm{~mm}$ ), el coeficiente de determinación que obtuvo es del 0,50 (valor muy elevado dada la bibliografía analizada) entre la velocidad de transmisión y la tensión de rotura a flexión, y con el módulo de elasticidad de 0,67 (Kessel et al., 1998).

Existen también experiencias de interés en la aplicación de este método en la madera aserrada de coníferas españolas del género Pinus (Hermoso et al., 2003), y en secciones de gran escuadría (Arriaga et al., 1992; Arriaga et al., 2005).

Íñiguez (2007), obtuvo regresiones lineales simples entre el módulo de elasticidad dinámico determinado a partir de la velocidad de una onda ultrasónica y el módulo de elasticidad global con un coeficiente de determinación de 0,74 , para especies de procedencia española como el pino silvestre y el pino laricio. Saenz (2011), obtuvo regresiones entre módulo de elasticidad local y módulo de elasticidad dinámico con un coeficiente de determinación del 0,62, y del 0,72 entre el módulo de elasticidad global y el módulo de elasticidad dinámico, para madera de chopo (populus $x$ euramericana I214), haciendo para ello uso de dos aparatos diferentes, uno de la casa Sylvatest y otro de la casa Fakopp, obteniendo correlaciones del mismo orden.

Con ondas de impacto, Fernández et al., (2009), realizaron estudios con madera de abeto Douglas obteniendo regresiones entre el módulo de elasticidad global y el módulo de elasticidad dinámico con un coeficiente de determinación del 0,75 , haciendo uso del aparato "Microsecond Timer".

En este trabajo se plantea además su utilización para la clasificación tanto de la madera en troza. INIA (2011), obtuvo regresiones entre las mismas variables con un coeficiente de determinación de 0,60 con el mismo aparato, y para madera de grandes escuadrías de pino radiata.

Cesefor por último, y también con este aparato, ha obtenido regresiones entre el módulo de elasticidad global y el módulo de elasticidad dinámico con coeficientes de determinación del 0,78, para madera de grandes escuadrías de pino silvestre (procedente de los montes de Soria y Burgos. 
También se obtuvieron coeficientes de determinación de hasta el 0,5 entre la resistencia a flexión y el módulo de elasticidad dinámico, valores muy esperanzadores para el uso de dicha técnica. Por otra parte para madera de gran escuadría de roble americano (Quercus rubra L.) obtuvo valores de 0,56 entre el módulo de elasticidad global y el dínámico.

\subsection{SISTEMÁTICA DEL MÉTODO DE MEDICIÓN DEL TIEMPO DE PASO DE UNA ONDA SONORA}

Este ensayo consiste en la medición en microsegundos, del tiempo que tarda en llegar la onda sonora desde un extremo al otro de la probeta (tiempo de paso). Esta variable está influenciada por tres factores: el material con que se trabaja (en nuestro caso madera), la longitud de la pieza, y las propiedades del propio material. Es este tercer factor del que más desconocemos su influencia, por lo que interesa analizar y evaluar la misma.

En este estudio se ha utilizado el Microsecond Timer de la casa Fakopp. Utiliza dos palpadores o sensores, uno que hace funciones de emisor y el otro de receptor. Se produce una onda acústica por excitación mecánica mediante un golpe sobre uno de los sensores (emisor). El emisor y el receptor se clavan en las testas en caso de las trozas o de la madera aserrada. A continuación, se golpea con un martillo en el emisor, el aparato registra el tiempo en microsegundos que la onda sonora tarda en recorrer la distancia entre el emisor y el receptor.

La presión de contacto entre el palpador y el material es determinante en la intensidad de la señal recibida, existiendo un requerimiento mínimo (Divos, 2005). De ahí la ventaja del método utilizado en este proyecto, ya que los palpadores se clavan, con lo que se asegura el pleno contacto entre medios, además la presión siempre es la suficiente, es constante y se evita el tener que hacer previamente orificios en la madera.

La velocidad de propagación $\left(V_{H}\right)$ de la onda sónica a través de la madera, a la humedad en que se ha realizó el ensayo, se obtuvo de:

$$
V_{H}=I / t
$$

\section{Donde:}

$\boldsymbol{V}_{\boldsymbol{H}}$ es la velocidad de propagación de la onda sónica en $\mathrm{m} / \mathrm{s}$.

I es la distancia recorrida entre los sensores o palpadores (longitud de la pieza) en metros.

$\boldsymbol{t}$ es el tiempo que tarda la onda sónica en atravesar la pieza de madera en segundos. 
Con respecto a la humedad, la casa Fakopp determina por ejemplo que su efecto es importante por debajo del punto de saturación de las fibras (entorno al 30\%). Por encima del punto de saturación no cambia demasiado porque las fibras son responsables de la propagación de las ondas. Pese a ello, no ofrece ninguna fórmula de corrección de la humedad.

La corrección por humedad de la velocidad ejecutada a una humedad de la probeta $\mathrm{H} \%$ $\left(\mathrm{V}_{\mathrm{H}}\right)$, distinta de la humedad de referencia del $12 \%\left(\mathrm{~V}_{12}\right)$, se lleva a cabo considerando que por cada $1 \%$ de humedad de ensayo por encima del $12 \%$, la velocidad obtenida era inferior en un 1\%. Para ello se aplicó la expresión siguiente:

$$
V_{12}=V_{H}(1+0,01(H-12))
$$

Esta relación es recomendada habitualmente por los fabricantes y también en investigaciones realizadas recientemente sobre el tema (Íñiguez-González et al., 2015).

Una vez que se obtiene la velocidad de propagación a humedad real de cada pieza de madera, se calcula el módulo de elasticidad dinámico $\left(\mathrm{MOE}_{\mathrm{d}}\right)$ mediante la siguiente expresión:

$$
M O E_{d}=V_{H}^{2} \rho_{H}
$$

\section{Donde:}

$M O E_{d}$ es el módulo de elasticidad dinámico en $\mathrm{N} / \mathrm{m}^{2}$.

$\boldsymbol{V}_{\boldsymbol{H}}$ es la velocidad de propagación de la onda ultrasónica a través de la madera al contenido de humedad real de la pieza en $\mathrm{m} / \mathrm{s}$.

$\boldsymbol{\rho}_{\boldsymbol{H}}$ es la densidad de la pieza en al contenido de humedad real de la pieza en $\mathrm{kg} / \mathrm{m}^{3}$.

\subsubsection{MÉTODOS BASADOS EN LA VIBRACIÓN}

La utilización del método de análisis de vibraciones consiste en medir la frecuencia natural de vibración de una pieza y, a partir de ella, estimar sus propiedades resistentes. Dicha vibración se puede provocar, por ejemplo, mediante el impacto de un martillo, o de una bola de acero, en un extremo.

El módulo de elasticidad dinámico de un material puede ser determinado mediante la medición de la frecuencia natural de vibración de una pieza prismática de dimensiones conocidas y de su densidad. La relación matemática existente entre estas variables, se enuncia suponiendo que se trate de medios solidos: homogéneos, isótropos y perfectamente elásticos; sin embargo, esta expresión puede aplicarse también a sistemas heterogéneos, como la madera o el hormigón, cuando las dimensiones de la 
pieza son grandes en relación al tamaño de los elementos constituyentes del material (Malhotra et al., 2003).

Uno de los posibles métodos para determinar las frecuencias fundamentales consiste exactamente en golpear la probeta con un martillo. El impacto hace que la pieza comience a vibrar en su frecuencia natural. La amplitud y frecuencia de la vibración de resonancia son obtenidas utilizando un analizador de espectro que determina las frecuencias relativas mediante la transformada rápida de Fourier.

Por tanto, la utilización del método de análisis de vibraciones consiste en medir la frecuencia natural de vibración de una pieza y a partir de ella, estimar sus propiedades resistentes.

Una de las numerosas aplicaciones prácticas de este método se centra en la evaluación del estado de la estructura de pasarelas y puentes de madera (Wang et al., 2005a y 2005b). También hay experiencias de su aplicación para la estimación de forjados en edificios históricos, en las que se llega a coeficientes de determinación de la rigidez de $\mathrm{R}^{2}=0,97$ (ROSS et al., 2001).

En España este método se ha comenzado a aplicar en madera especialmente en las últimas décadas. Íñiguez (2007), obtuvo coeficientes de determinación entre módulo de elasticidad dinámico y el módulo de elasticidad global para la madera de pino silvestre y pino laricio de 0,76 . Fernández et al., (2009), obtuvieron coeficientes de determinación de 0,82 en madera de abeto Douglas. Sáenz (2011) utilizó también este método con madera de chopo (Populus $x$ euramericana I-214), obteniendo un coeficiente de determinación de 0,88 para el módulo de elasticidad global, y de 0,58 para el módulo de elasticidad local.

Villanueva (2009) analizó en Cesefor la relación entre el módulo de elasticidad dinámico y el módulo de elasticidad local para rollizos de sabina (Juniperis thurifera, L.) obteniendo un coeficiente de determinación de únicamente 0,12 , siendo mejora mediante regresión múltiple (inclusión de variables independientes como la densidad, conicidad y densidad) hasta obtener un coeficiente de 0,43.

En otro estudio llevado a cabo por Cesefor con pino silvestre de gran escuadría procedente de Soria y Burgos, se obtuvieron coeficientes de determinación entre los módulos de elasticidad global y dinámico de 0,72, y de 0,56 entre la resistencia a flexión y el módulo de elasticidad dinámico.

Por otra parte, en el estudio realizado por la misma entidad para la madera de gran escuadría de roble americano se obtuvieron coeficientes de determinación de 0,52 entre los módulos de elasticidad global y dinámico. 


\subsection{SISTEMÁTICA DEL MÉTODO DE MEDICIÓN DE LA FRECUENCIA DE VIBRACIÓN}

Para la medición de dicho parámetro se utiliza también el lector de la frecuencia de vibración de la casa Fakopp.

La probeta se coloca sobre dos apoyos rígidos situados en los extremos, los apoyos contendrán en su parte superior unas bandas de vinilo las cuales aseguraban la vibración libre de la probeta. A continuación, se coloca en una de las testas un micrófono, necesario para la posterior obtención de la frecuencia de resonancia.

Una vez se encuentra en posición, la probeta se procede al ensayo y se golpea con un martillo en el extremo opuesto al del micrófono, cada golpeo da una lectura de frecuencia en hercios.

Conocida la frecuencia de vibración longitudinal y la longitud de la pieza se puede determinar la velocidad de propagación ( $V$ ), como:

$$
V=2 I f
$$

Donde:

$V$ es la velocidad de propagación en $\mathrm{m} / \mathrm{s}$.

$\boldsymbol{f}$ es la frecuencia de vibración longitudinal en hercios.

I longitud de la pieza en metros.

A continuación, el módulo de elasticidad dinámico $\left(\mathrm{MOE}_{d}\right)$ para madera se calcula como:

$$
M O E_{d}=(2 I f)^{2} \rho_{H}
$$

\section{Donde:}

$M O E_{d}$ es el módulo de elasticidad dinámico en $\mathrm{N} / \mathrm{m}^{2}$.

$\boldsymbol{f}$ es la frecuencia de vibración longitudinal en hercios.

I longitud de la pieza en metros.

$\boldsymbol{\rho}_{\boldsymbol{H}}$ es la densidad de la pieza en $\mathrm{kg} / \mathrm{m}^{3}$.

La corrección por humedad de la velocidad obtenida mediante esta metodología se lleva a cabo del mismo modo que la corrección de la velocidad obtenida por la medición del tiempo de paso de una onda de impacto, siguiendo las investigaciones realizadas recientemente (Íñiguez-González et al., 2015). 


\subsubsection{TÉCNICAS DESTRUCTIVAS}

Las técnicas destructivas se fundamentan en la rotura de las piezas para la determinación de sus características, principalmente mecánicas. Con este tipo de ensayos, lo que se pretende, es determinar el módulo de rotura y el módulo de elasticidad de las piezas principalmente y comparar los resultados con los valores obtenidos por otros métodos menos exactos y fiables, como los métodos no destructivos de tipo mecánico (para su posible incorporación posterior como método de clasificación mecánica), o como los métodos de control de singularidades existentes en las piezas de madera, para su posterior delimitación y obtención de herramientas de clasificación visual (ya sean de tipo manual, tablas de clasificación, o de tipo mecánico).

Las normas europeas más importantes referentes a la determinación de las propiedades estructurales de la madera estructural de sección transversal rectangular (maciza), son las siguientes:

- Norma EN 384:2016. Madera estructural. Determinación de los valores característicos de las propiedades mecánicas y la densidad.

- Norma EN 408:2011 + A1:2012. Estructuras de madera. Madera aserrada y madera laminada encolada para uso estructural. Determinación de algunas propiedades físicas y mecánicas. 


\section{MATERIAL Y MÉTODOS}

\subsection{MEDIOS Y EQUIPOS}

Los medios y equipos utilizados durante las diferentes fases del desarrollo experimental se dividen en los grupos I, II y III, en función del equipo humano y las instalaciones de los dos laboratorios que han colaborado en los trabajos de investigación.

\subsubsection{PERSONAL}

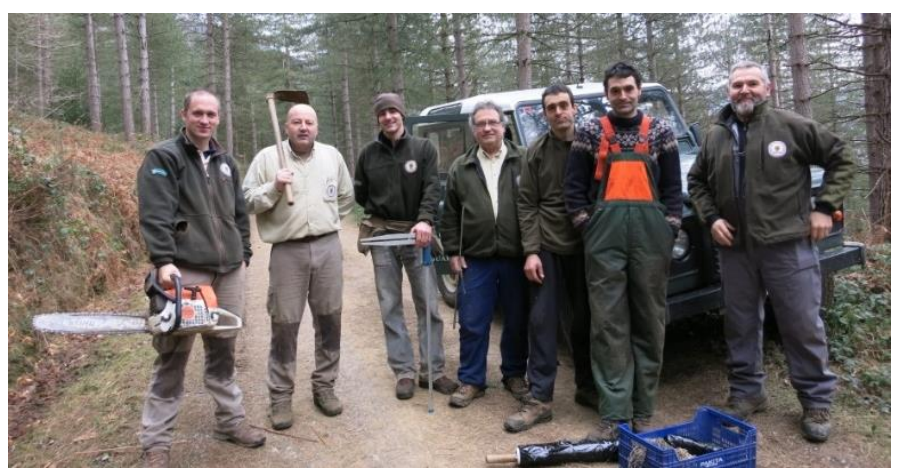

El grupo I está constituido por el servicio de guarderío de la Diputación Foral de Gipuzkoa, Gobierno de Navarra y personal de la Fundación Hazi, tal y como se indica en la Figura 5.1.

FIGURA. 5.1 PERSONAL DE LA DIPUTACIÓN FORAL DE GIPUZKOA.

\subsubsection{ASERRADEROS}

El grupo II, está constituido por las empresas Larrañaga, Errekondo y Maderas Alemán de las comunidades autónomas del País Vasco y Navarra.

\subsubsection{SERRERÍA LARRAÑAGA}

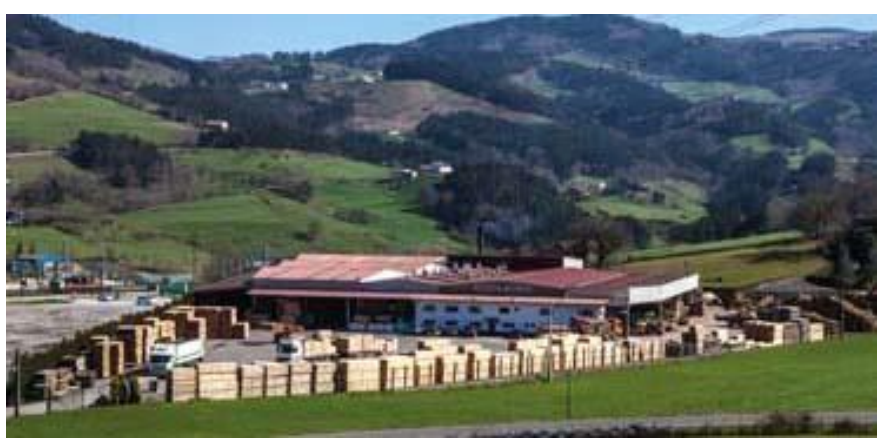

Situada en Azpeitia, Gipuzkoa, fue creada en el año 1993, pero asienta sus raíces tiempo atrás de la mano del fundador José Miguel Larrañaga Urrestarazu. En la figura 5.2 se puede ver una imagen de las instalaciones de la empresa.

FIGURA 5.2: SERRERÍA LARRAÑAGA DE AZPEITIA.

Larrañaga es una empresa familiar dedicada también a la explotación forestal de los bosques del entorno y utilizan la madera de pino radiata, pero también trabajan el alerce y el abeto para madera estructural y restauración. Entre sus productos destacan las maderas para embalaje, madera estructural, madera para carpintería y mueble, así como los restos y residuos para la producción de energía. 


\subsubsection{SERRERÍA ALEMÁN}

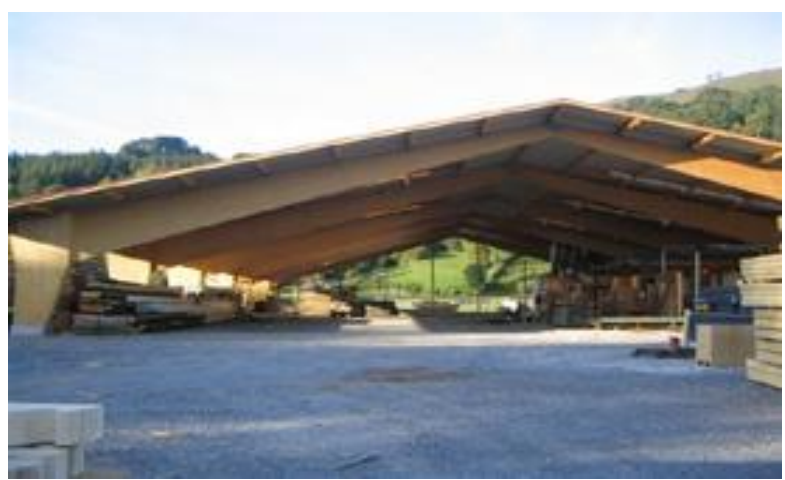

FIGURA 5.3: SERRERÍA ALEMAN DE ERRATZU.

\subsubsection{MADERAS ERREKONDO}

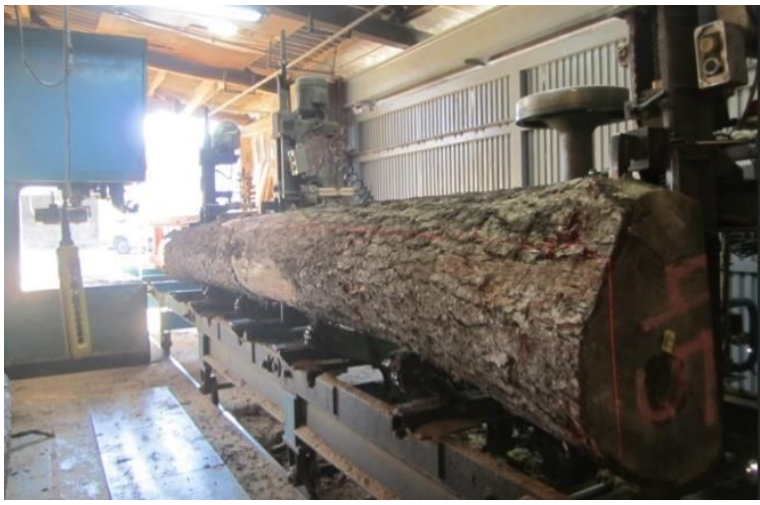

Errekondo es una empresa con una trayectoria profesional en el mundo de la madera con más de 60 años de experiencia. Realiza todo tipo de estructuras como vallados, parrillas, suelos, etc. Utiliza especies de madera de roble, pino, alerce, abeto Douglas, abeto blanco y cedro, Acacia. En la figura 5.4. podemos ver la sierra de carro que siguen utilizando en la empresa.

FIGURA 5.4: SERRERÍA ERREKONDO DE USURBIL.

\subsubsection{LABORATORIOS}

El grupo III, está constituido por el personal del Centro de Servicios y Promoción Forestal y de su Industria de Castilla y León (Cesefor).

\subsubsection{INSTRUMENTOS DE MEDICIÓN UTILIZADOS}

Los instrumentos de medición que se han utilizado son los siguientes:

\subsubsection{INSTRUMENTOS UTILIZADOS EN LOS TRABAJOS DE MONTE}

- Cintas métricas o flexómetros de $5 \mathrm{~m}$ y $8 \mathrm{~m}$ de longitud, con precisión 1,0 mm.

- Localizador GPS.

- Hipsómetros.

- Láser Nikon Forestry Pro utilizado para medir la altura a nivel del mar. 
En las figuras 5.5 y 5.6, se indican dos aparatos de medición que se han utilizado en los trabajos realizados en monte (Láser Nikon Forestry y la forcípula).

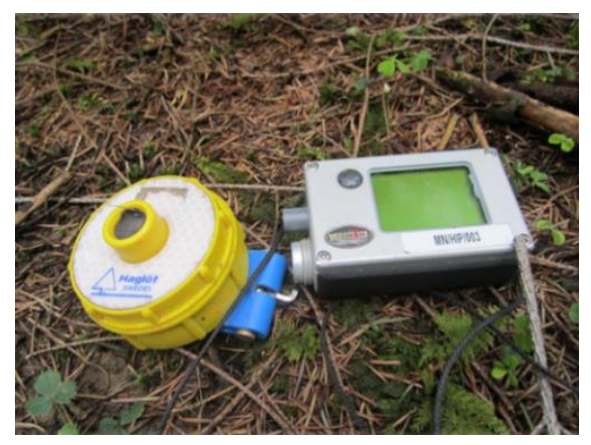

FIGURA. 5.5. LÁSER NIKON FORESTRY.

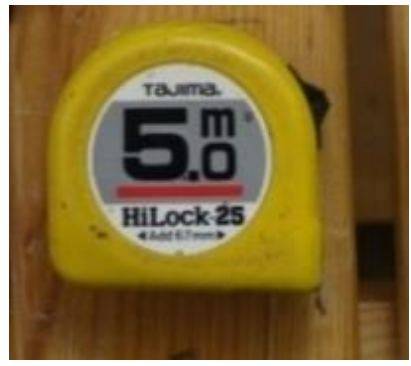

FIGURA 5.7. FLEXÓMETRO.

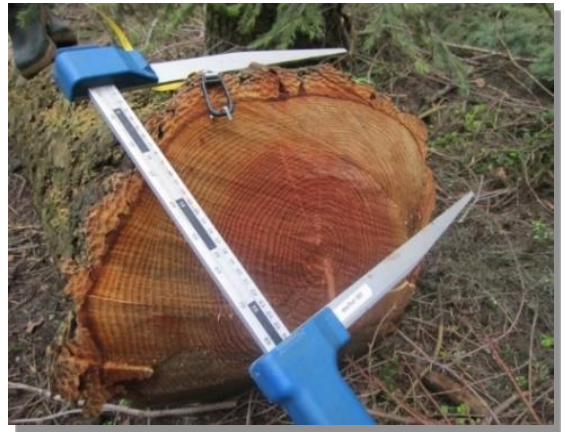

FIGURA 5.6. FORCÍPULA.

En la figura 5.7, se detalla cómo se realiza el paso de onda en la madera cuando se procede a la medición de la velocidad.

\subsubsection{APARATOS UTILIZADOS EN ASERRADERO Y LABORATORIOS}

Los equipos utilizados para determinar las dimensiones, la localización y el tamaño de las singularidades de las piezas son los siguientes:

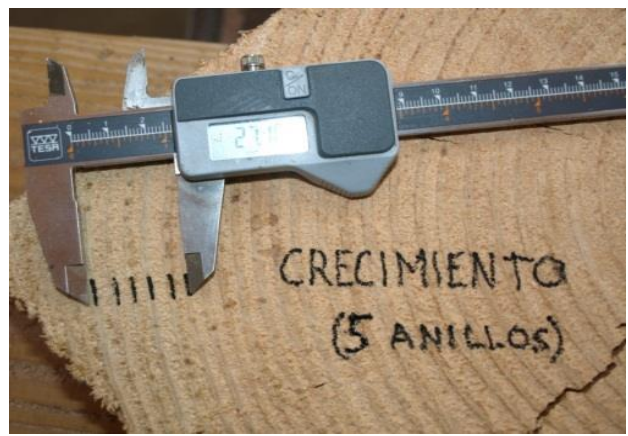

Calibre digital marca TESA, modelo electrónico, representado en la figura 5.8.

FIGURA. 5.8. CALIBRE DIGITAL. 


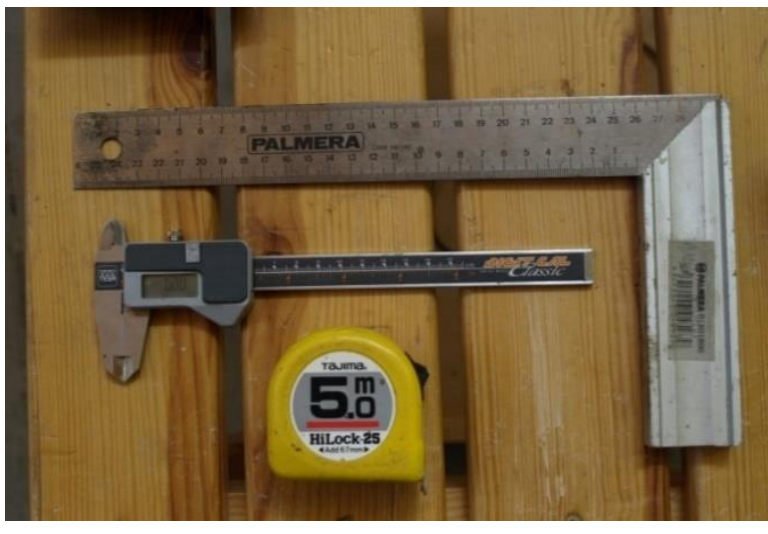

Escuadra de carpintero de $30 \mathrm{~cm}$, visible en la figura 5.9 y utilizada para marcar y señalar las secciones correspondientes a los lugares de apoyo para el ensayo mecánico de flexión.

FIGURA.5.9. ESCUADRA DE CARPINTERO.

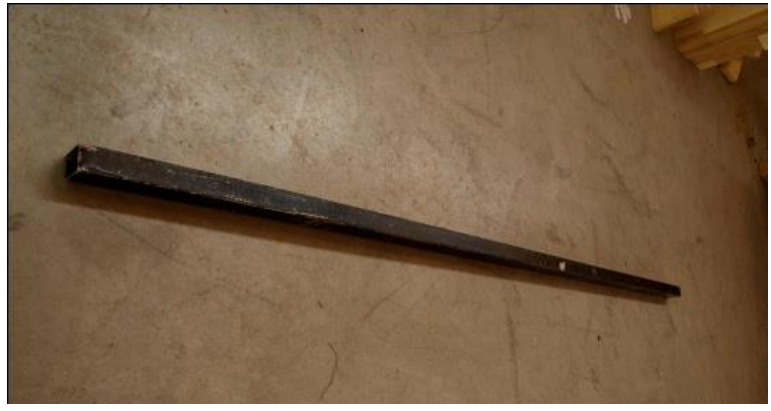

Perfil o regla metálica de 2 metros de longitud, representada en la figura 5.10 y empleada para evaluar las deformaciones de las piezas durante la clasificación visual.

FIGURA.5.10. REGLA MILIMÉTRICA.

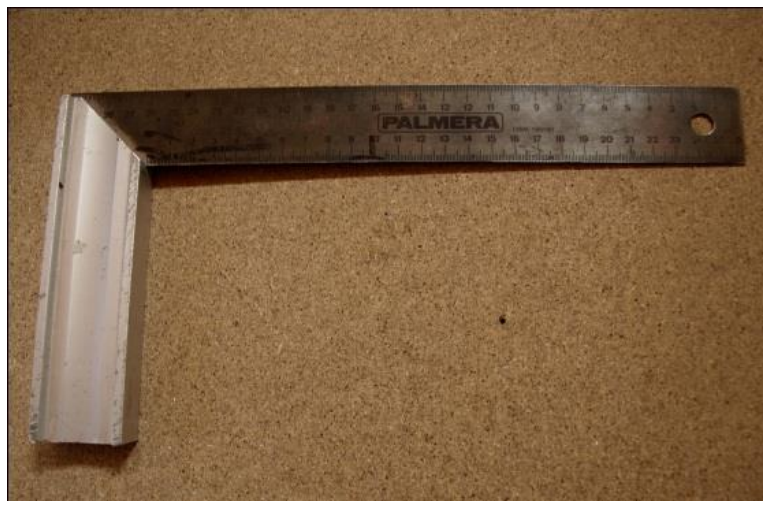

Escuadra milimetrada de $\mathbf{3 0 0} \mathbf{~ m m}$, con precisión $1 \mathrm{~mm}$, utilizada para medir la profundidad y anchura de las fendas tal y como se puede observar en la figura 5.11 .

FIGURA.5.11. ESCUADRA MILIMÉTRICA. 


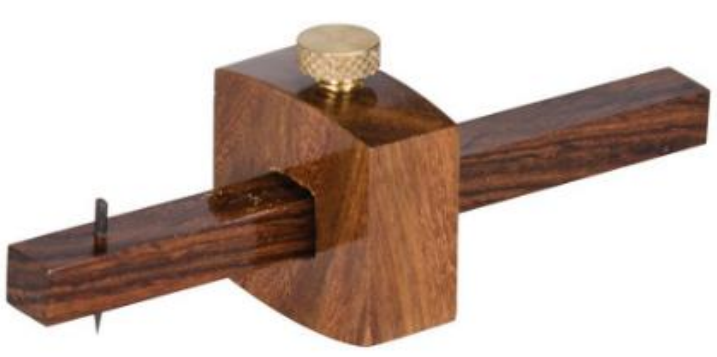

Trazador de madera, que se utiliza para determinar la desviación general de la fibra de acuerdo a la norma UNE-EN 1309-3: 2018. A continuación, en la figura 5.12 se representa un detalle del trazador utilizado para realizar las mediciones.

FIGURA.5.12. TRAZADOR DE MADERA.

Taladro eléctrico marca Makita, representado en la figura 5.13, modelo HP347DWE; utilizado para realizar los orificios donde se alojan los palpadores del equipo de ultrasonidos. Herramienta con la que se han mecanizado y preparado las piezas a ensayar en el ensayo a flexión.

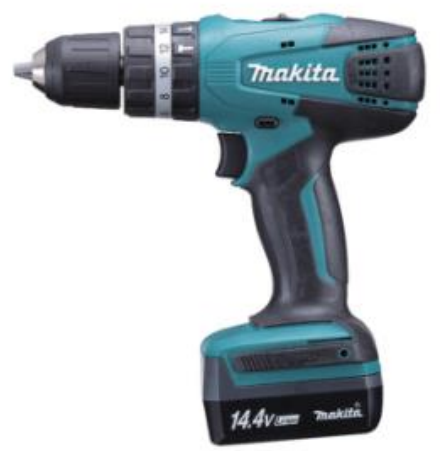

FIGURA. 5.13. TALADRO ELÉCTRICO.

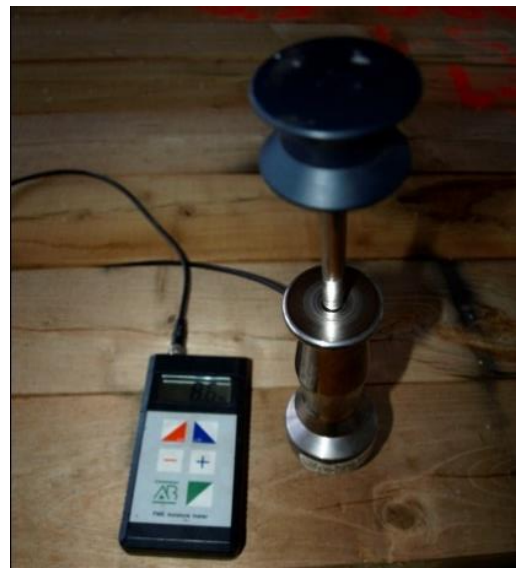

Xilohigrómetro marca BROOKHUIS, modelo FM Moisture meter y resolución de décima, utilizado en la determinación del contenido de humedad de las probetas siguiendo el procedimiento descrito en la norma UNE-EN 13183-2: 2002. A continuación, en la figura 5.14 , se observa un detalle de medición realizado con este instrumento de medición.

FIGURA. 5.14. XILOHIGRÓMETRO.

Equipo de ultrasonidos Microsecond Timer, representado en la figura 5.15 está diseñado específicamente para madera, por la empresa FAKOPP, para medir el tiempo 
de propagación de una onda de impacto. La señal es generada por un golpe de martillo en el sensor de inicio, y la unidad muestra el tiempo de propagación medido. Al medir la distancia entre los dos sensores, la velocidad puede ser calculada, de manera que se puede utilizar para detectar zonas podridas ocultas o agujeros entre los dos sensores.
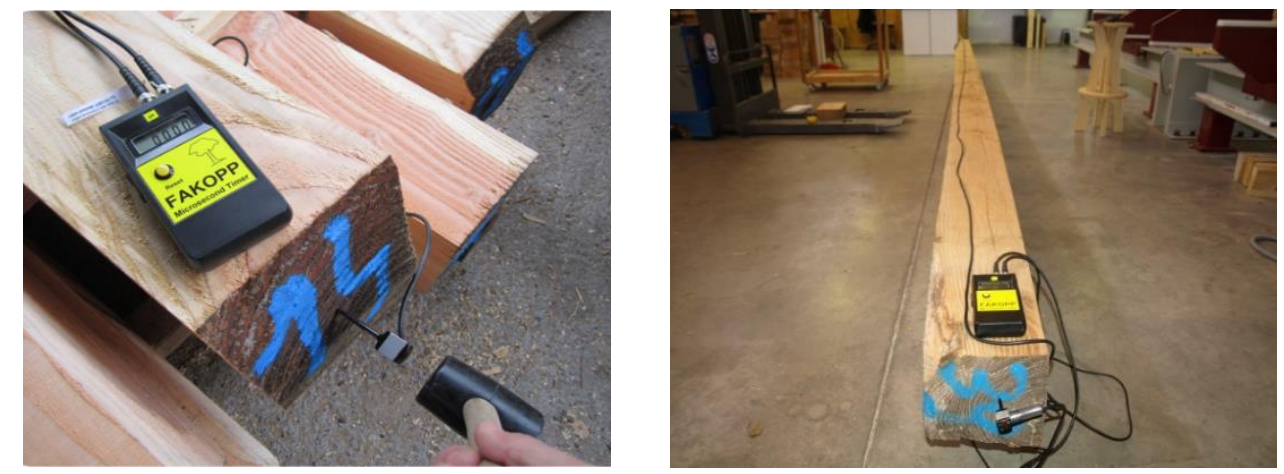

FIGURA. 5.15. EQUIPO DE ULTRASONIDOS MICROSEND TIMER REALIZANDO MEDICIONES EN VIGAS.

Equipo de medición de frecuencia sonora, de la casa Fakopp. Este equipo cuenta con software específico (FFT Analizer), una balanza industrial de $400 \mathrm{~kg}$ de capacidad con resolución de gramo (marca Brookhuis) y un micrófono para recoger la frecuencia. Este equipo ha sido desarrollado por el Laboratorio de Técnicas No Destructivas de la Madera de la Universidad del Oeste de Hungría en Sopron, y está comercializado por la empresa Fakopp Enterprise. A continuación, en la figura 5.16, se indican unos detalles de este equipo de medición.
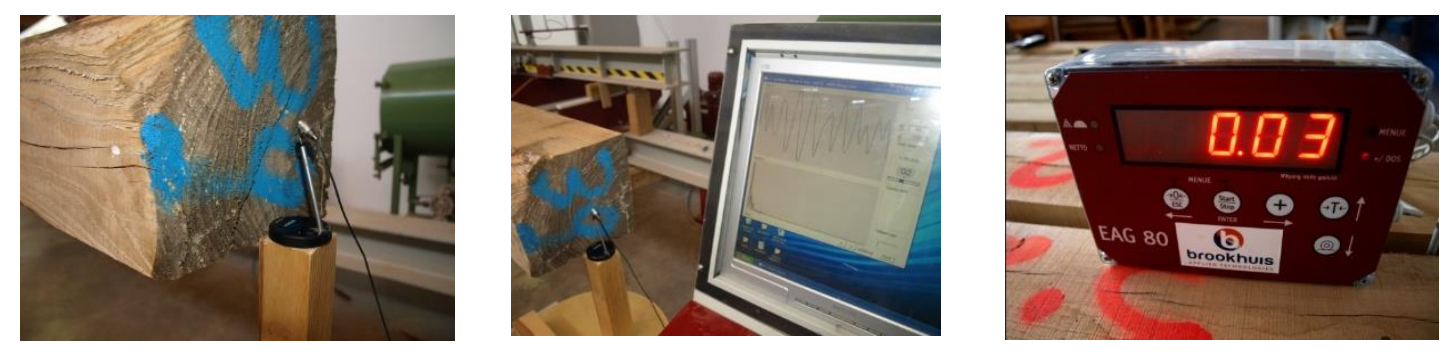

FIGURA. 5.16. EQUIPO DE MEDICIÓN, SOFTWARE Y BALANZA DE LA CASA FAKOPP.

Pórtico de ensayos mecánicos. En la figura 5.17 se ve representado este pórtico de ensayos marca SITENOR 2001, específicamente diseñado para los ensayos mecánicos conforme a la norma UNE-EN 408:2011+A1:2012. En flexión permite ensayar piezas de directriz recta de hasta $8 \mathrm{~m}$ de longitud. Se trata de un pórtico hidráulico, dotado de célula de carga: de 500 kN de capacidad, y resolución de 10 Newton. Igualmente posee varios extensómetros o deformadores de diversos recorridos. 

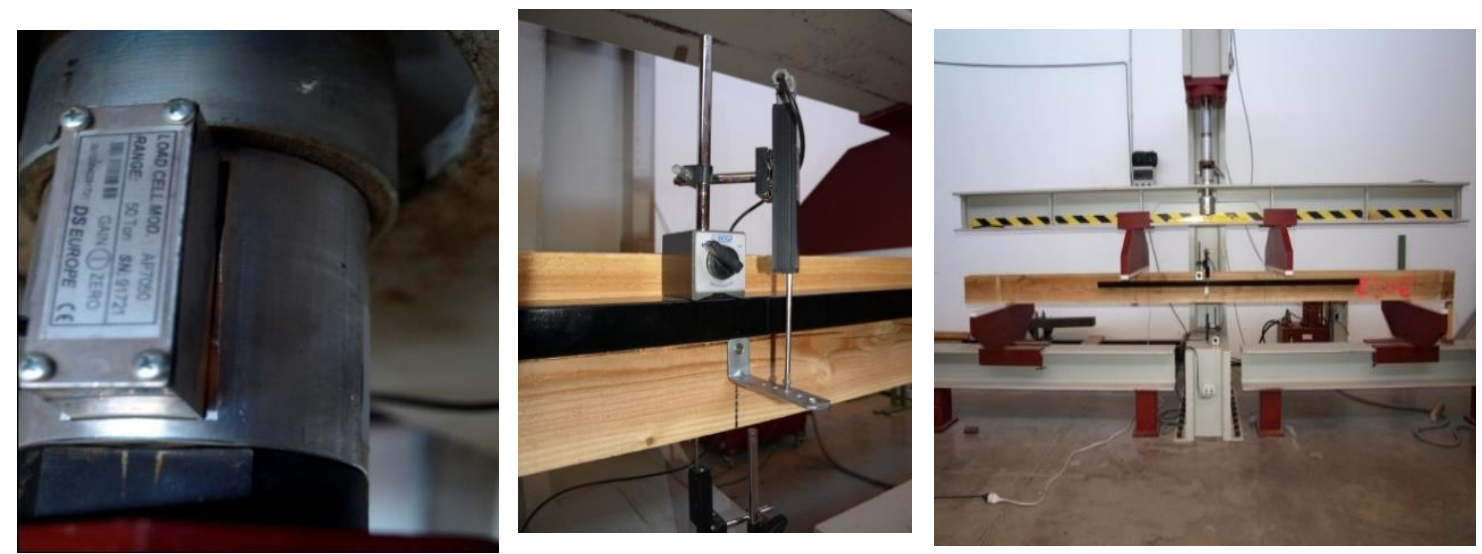

FIGURA. 5.17. PÓRTICO DE ENSAYOS SITENOR 2001.

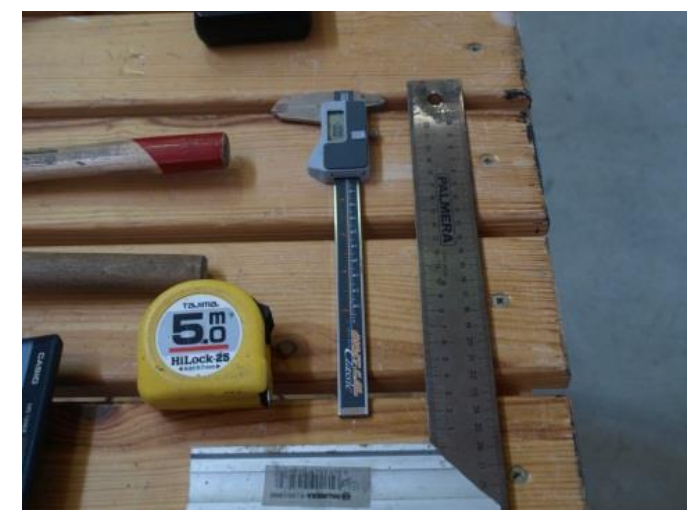

FIGURA. 5.18. CINTAS MÉTRICAS, FLEXÓMETRO

Y CALIBRE.

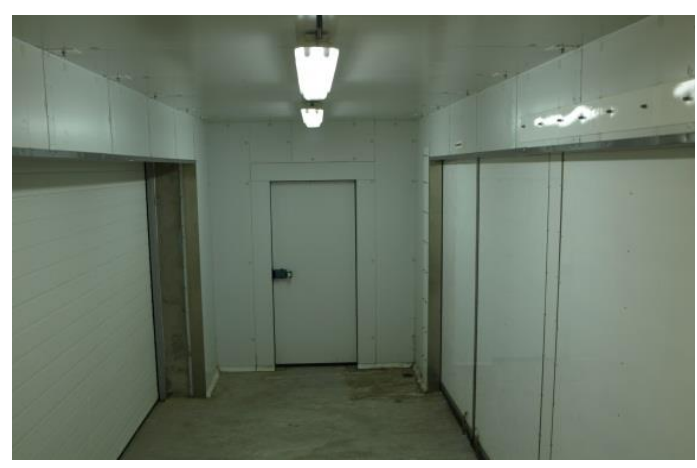

FIGURA. 5.19. CÁMARA DE ACONDICIONAMIENTO.

Balanzas. Para calcular mediante pesado tanto la densidad como la humedad de las probetas, se han utilizado en esta investigación dos balanzas electrónicas: balanza marca RADWAG, modelo WLC 10/A2 con una capacidad de $10000 \mathrm{~g}$ y una precisión de $0,1 \mathrm{~g}$; y balanza marca GRAM, serie DM, con capacidad de $10000 \mathrm{~g}$. En las figuras 5.20 y 5.21, se pueden observar las balanzas utilizadas para las mediciones de peso realizadas con las probetas. 


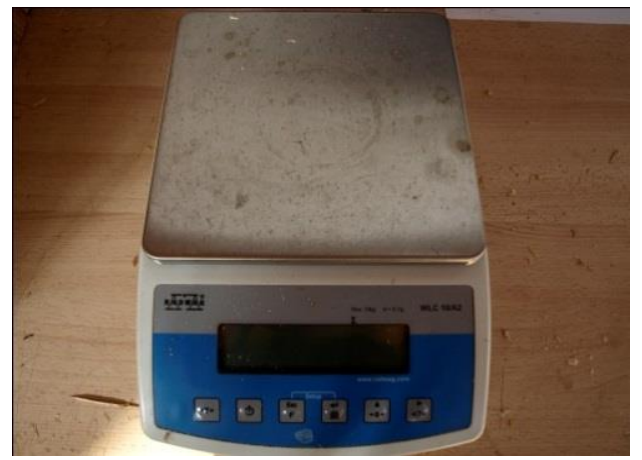

FIGURA.5.20. BALANZA DE MEDICIÓN DE PESO RADWAG.

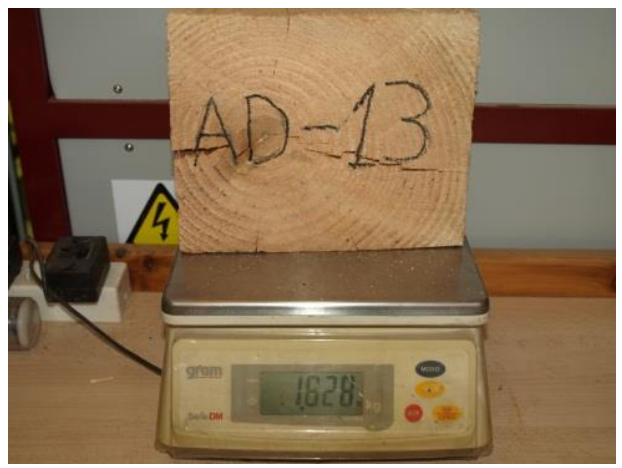

FIGURA. 5.21. BALANZA DE MEDICIÓN DE PESO GRAM.

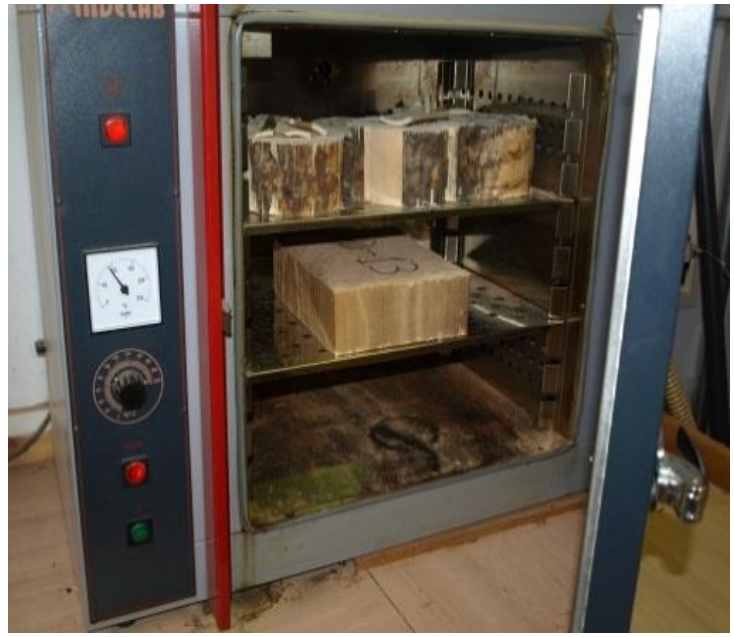

Estufa. La estufa empleada para el secado de las probetas a $103 \pm 2{ }^{\circ} \mathrm{C}$, para determinar el contenido de humedad según la norma UNE-EN 13183-1/AC: 2004, fue una estufa electrónica y programable de la marca Indelab, de circulación forzada. Con una capacidad de $125.000 \mathrm{~cm}^{3}$ y regulación de temperaturas entre 0 y $200^{\circ} \mathrm{C}$. En la figura 5.22 , se indica un detalle de las probetas en el momento del secado de las mismas.

FIGURA. 5.22. ESTUFA PARA EL SECADO

DE PROBETAS.

Todos los equipos de ensayo se encontraban convenientemente calibrados conforme a la periodicidad requerida en cada caso (anual), y de acuerdo a los manuales de calidad del laboratorio. 


\subsection{METODOLOGÍA}

\subsubsection{ANÁLISIS ESTADÍSTICO}

Se describen a continuación los conceptos y métodos estadísticos más relevantes que se han utilizado en este trabajo. El software estadístico que se ha empleado es Statgraphics 18.

\subsubsection{ESTADÍSTICOS DESCRIPTIVOS}

La estadística descriptiva consiste en una técnica matemática encargada de la organización, síntesis y descripción de los datos recogidos con el apoyo de tablas, medidas numéricas o gráficas. A continuación, se muestran los estadísticos descriptivos empleados.

\section{Media aritmética}

$$
\begin{gathered}
\overline{\mathrm{y}}=\frac{1}{n} \sum_{i=1}^{n} y_{i}(\text { distribución normal }) \\
\overline{\mathrm{y}}=\frac{1}{n} \sum_{i=1}^{n} \ln y_{i}(\text { distribución logarítmica) }
\end{gathered}
$$

Donde $n$ es el número total de probetas analizadas de la muestra, e $y_{i}$ es el valor individual de variable $y$ de cada probeta.

\section{Desviación típica}

$$
\begin{gathered}
s_{y}=\sqrt{\frac{1}{n-1} \sum_{i=1}^{n}\left(y_{i}-\bar{y}\right)^{2}}(\text { distribución normal }) \\
s_{y}=\sqrt{\frac{1}{n-1} \sum_{i=1}^{n}\left(\ln y_{i}-\bar{y}\right)^{2}}(\text { distribución logarítmica })
\end{gathered}
$$

Donde $n$ es el número total de probetas analizadas de la muestra, $y_{i}$ es el valor individual de la variable $y$ de cada probeta, e ȳ es la media aritmética. 


\section{Coeficiente de variación}

$$
C V=\frac{s_{y}}{\bar{y}}
$$

Donde $s_{y}$ es la desviación típica de la variable aleatoria $y$, e $\bar{y}$ es la media aritmética.

\subsubsection{HISTOGRAMA DE FRECUENCIAS}

Consiste en la representación gráfica de una variable aleatoria en forma de barras, figura 5.23. En el eje vertical se representan las frecuencias, es decir, la cantidad de la muestra que se ubica en un determinado rango de valores indicados en el eje horizontal. Sirve para obtener una vista general de la distribución de la muestra respecto a una variable cuantitativa discreta.

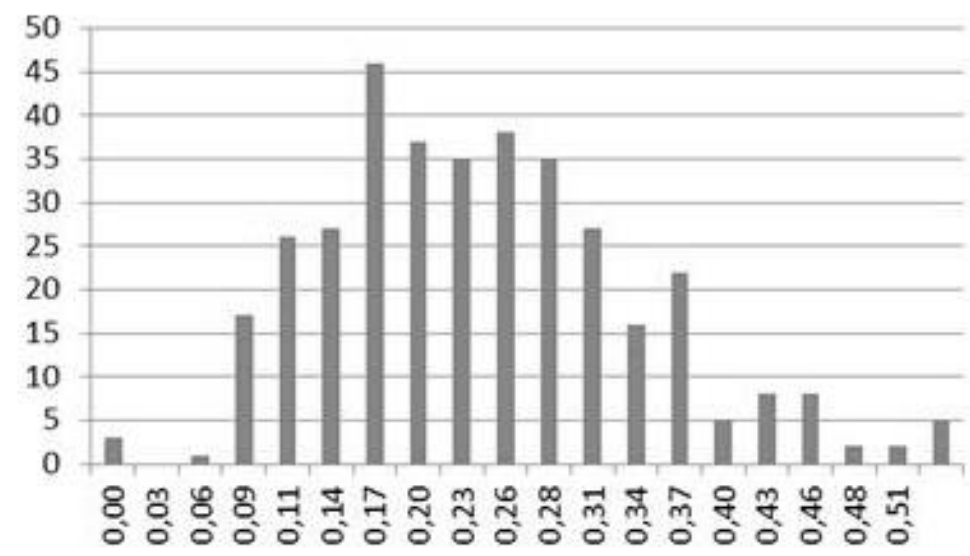

FIGURA. 5.23. HISTOGRAMA DE FRECUENCIAS.

\subsubsection{DIAGRAMA DE CAJA Y BIGOTES}

Es una forma de mostrar gráficamente grupos de datos numéricos a través de sus cuartiles, figura 5.24. La gráfica consiste en una caja rectangular, donde los lados más largos muestran el recorrido intercuartílico. La caja está dividida por un segmento vertical que indica donde se posiciona la mediana y por lo tanto su relación con los cuartiles primero y tercero (el segundo cuartil coincide con la mediana). La caja se ubica a escala sobre un segmento que tiene como extremos los valores mínimo y máximo de la variable. Las líneas que sobresalen de la caja se llaman bigotes. Estos bigotes tienen un límite de prolongación, de modo que los valores que no se encuentren dentro de este rango son identificados individualmente mediante puntos, denominándose valores atípicos (outliers). 


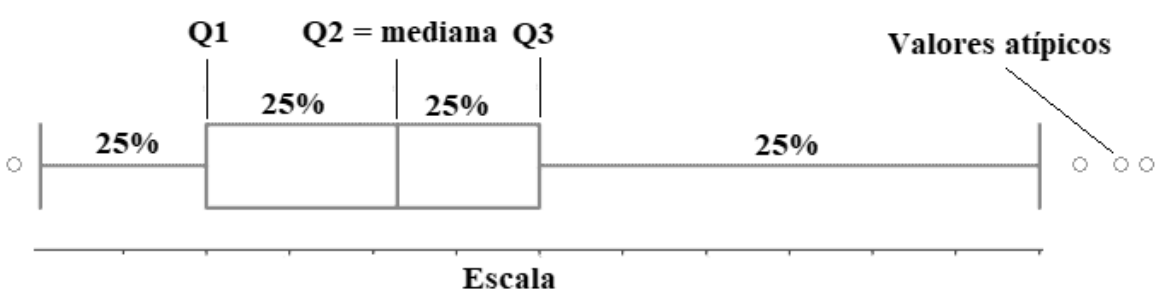

FIGURA. 5.24. DIAGRAMA DE CAJA Y BIGOTES.

\subsubsection{TEST DE NORMALIDAD}

Es muy útil conocer la distribución de las variables aleatorias que se pretenden estudiar. Para ello es frecuente realizar pruebas (tests) de normalidad de los datos antes de abordar un análisis más complejo. El test de normalidad se puede realizar tanto gráfica como numéricamente. Comprobar que se verifica la hipótesis de normalidad resulta necesario para que el resultado de algunos análisis sea fiable como, por ejemplo, el análisis de varianza.

En la verificación gráfica puede emplearse el Gráfico Probabilístico Normal, donde la diagonal representa la ubicación teórica de los datos en el caso de que éstos sigan una distribución normal, figura 5.25 .

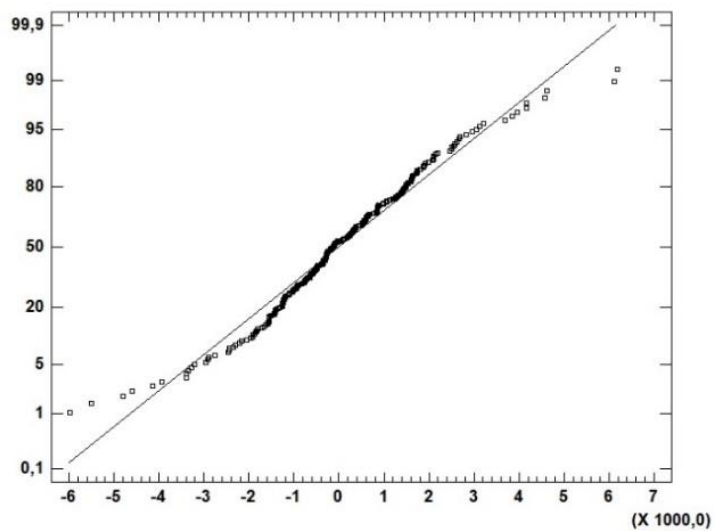

FIGURA.5.25. GRÁFICO PROBABILÍSTICO NORMAL.

Para comprobar la normalidad de una distribución numéricamente existen varias pruebas. En este trabajo se utilizó el test no paramétrico de Kolmogorov-Smirnov (K-S) por resultar más adecuado que otros al analizar muestras grandes y mostrar una menor sensibilidad a las variaciones en las observaciones extremas (Vega, 2013).

El test K-S compara la función de distribución acumulada de los datos observados de la muestra con la distribución esperada si los datos siguiesen una distribución normal. Si la diferencia observada es adecuadamente grande, la prueba rechazará la hipótesis de normalidad de la población. 
En el contraste de hipótesis, la hipótesis nula, $H_{0}$, considera que la distribución de la variable seleccionada proviene de una distribución normal; y la hipótesis alternativa, $H_{1}$, considera que no proviene de una distribución normal. Si el valor- $P$ obtenido en el test K-S es mayor o igual que el nivel de significación (en este trabajo se ha considerado un nivel de significación de 0,05 ), no es posible rechazar la hipótesis nula. Por tanto, según este test, se puede establecer que la distribución de los datos observados es normal.

\subsubsection{ANÁLISIS DE VARIANZA (ANOVA)}

Un análisis de varianza (ANOVA) es una metodología muy utilizada para comparar diferentes grupos y determinar si existen diferencias entre los mismos. Se averigua si existen diferencias estadísticamente significativas entre las medias de las poblaciones o si, por el contrario, no existen diferencias entre las medias y las diferencias encontradas se deben a las limitaciones del muestreo (Gorgas et al., 2011).

Para ello, se utiliza el test- $F$ donde el estadístico $F$ (razón- $F$ ) se obtiene al estimar la variación de los datos entre las muestras ("entre grupos"), y dividirla por la estimación de la variación de los datos dentro de las muestras ("dentro de grupos").

En el contraste de hipótesis, la hipótesis nula, $H_{0}$, considera que las medias de las muestras son iguales; y la hipótesis alternativa, $H_{1}$, considera que al menos una de ellas es distinta. Si el valor- $P$ obtenido en el test- $F$ es mayor o igual que el nivel de significación $(0,05)$, no es posible rechazar la hipótesis nula, y por tanto no existe diferencia estadísticamente significativa entre las muestras.

En cambio, cuando el valor- $P$ es menor que el nivel de significación, se rechaza la hipótesis nula y, por tanto, existe una diferencia estadísticamente significativa entre las muestras. En esta situación, si se quiere determinar qué muestras son diferentes de otras, se utiliza una Prueba de Múltiples Rangos que consiste en un procedimiento de comparación múltiple, dos a dos, para determinar qué medias son significativamente diferentes de las otras. El método empleado para discriminar entre las medias es el procedimiento de diferencia mínima significativa (LSD) de Fisher (con este método hay un riesgo del 5,0\% al decir que cada par de medias es significativamente diferente, cuando la diferencia real es igual a 0 ).

\subsubsection{MODELOS DE REGRESIÓN}

Un modelo de regresión simple trata de explicar la relación que existe entre la variable dependiente, $y$, y una única variable explicativa, $x$. El modelo de regresión múltiple consiste en la extensión del modelo simple a $k$ variables explicativas.

En el modelo de regresión múltiple las variables se pueden relacionar mediante una función de tipo lineal de la siguiente forma: $y=a_{0}+a_{1} x_{1}+a_{2} x_{2}+\ldots+a_{k} x_{k}+\varepsilon$; siendo $a_{0}, a_{1}, \ldots a_{k}$ los parámetros desconocidos que se estiman, y $\varepsilon$ el error aleatorio 0 perturbación. La variable dependiente que se quiere predecir se denomina $y$. Las variables $x_{1}, x_{2}, \ldots x_{k}$ son las variables explicativas. 
En el modelo de regresión los parámetros desconocidos son estimados por mínimos cuadrados, resultando la ecuación estimada de regresión: $\hat{y}=\hat{a}_{0}+\hat{a}_{1} x_{1}+\hat{a}_{2} x_{2}+\ldots+$ $\hat{a}_{k} x_{k}$; siendo cada coeficiente $\hat{a}_{i}$ el efecto sobre la respuesta cuando la variable aumenta una unidad y las demás variables permanecen constantes, y âo el valor de la respuesta ajustada cuando todas las variables explicativas toman el valor cero.

Como indicativo cuantitativo del ajuste global de un modelo de regresión se emplea el coeficiente de determinación, $r^{2}$, que se obtiene mediante la razón entre la suma de cuadrados de la regresión y la suma de cuadrados total. Su valor varía entre 0 y 1 , y representa la proporción de la variación de la variable, $y$, explicada por el modelo de regresión. Cuanto más cerca esté de 1 , mayor es la variación de y explicada por el modelo de regresión, y, por tanto, mejor es la ecuación analítica de ajuste. En ocasiones, también se utiliza el coeficiente de correlación, $r$.

\subsection{ANÁLISIS DE RESIDUOS}

Para que un modelo de regresión sea adecuado es necesario realizar un análisis final de los residuos de modo que éstos cumplan las condiciones de normalidad (distribución normal), homocedasticidad (varianza de los errores constante) e independencia (de los residuos respecto de la toma de datos).

Para verificar la normalidad numéricamente se realizó el test de Kolmogorov-Smirnov (K-S) según se ha comentado anteriormente. Una de las condiciones deseables para acercarse al cumplimiento de la normalidad de residuos, es que las variables explicativas sigan también una distribución normal.

Para averiguar si se cumple la homocedasticidad se elaboró una gráfica que representa los residuos estudentizados (cada residuo i-ésimo es dividido por la desviación estándar de todos los residuos salvo el i-ésimo) en el eje vertical, y los valores estimados en el eje horizontal. El análisis de esta gráfica indica que se verifica la hipótesis de varianza de los residuos constante, cuando no existe un aumento o disminución de los residuos de forma sistemática a medida que aumenta el valor estimado, es decir, cuando el gráfico no muestra ningún patrón.

Para determinar la independencia de residuos se utilizó el contraste de Durbin-Watson (D-W). De este modo, se examinaron los residuos para determinar si eran independientes de la toma de datos, es decir, si existía alguna correlación significativa basada en el orden en el que se presentaban en el archivo de datos. Este contraste considera la hipótesis nula, $H_{0}$, de independencia de residuos, de modo que cuando el valor- $P$ es mayor o igual que 0,05 se puede considerar que los residuos son independientes con un nivel de confianza del $95 \%$. Cuando el valor-Pes menor que 0,05 no se puede considerar la independencia de residuos por lo que es recomendable visualizar gráficamente el valor de los residuos obtenidos frente al número de fila (de los datos de entrada) para detectar la posible existencia de algún patrón. 


\subsection{SIMPLIFICACIÓN DE MODELOS}

Con el objeto de simplificar los modelos de regresión múltiple se trató de averiguar si era posible eliminar alguna de las variables explicativas.

Para ello, se realizaron contrastes de significación individuales, es decir, para cada uno de los coeficientes $\left(a_{i}\right)$ que acompaña a cada variable explicativa $\left(x_{i}\right)$, se realizó un contraste de hipótesis utilizando el estadístico $T$. La hipótesis nula considerada, $H_{0}$, fue que el coeficiente asociado a la variable explicativa es cero, $a_{i}=0$, y la hipótesis alternativa, $H_{1}$, que el resto de coeficientes eran distintos de cero, $a_{i} \neq 0$. De este modo, si el valor- $P$ es mayor o igual que 0,05 se acepta la hipótesis nula y por tanto es posible eliminar la variable explicativa correspondiente.

\subsubsection{COMPARACIÓN DE MUESTRAS}

Para analizar la influencia del periodo de corta con las propiedades de la madera se compararon entre sí las muestras cosechadas (cortadas) en luna creciente y en luna menguante.

La comparación de ambas muestras se realizó gráfica y analíticamente. Gráficamente se elaboraron histogramas de frecuencias enfrentados de las dos muestras, así como diagramas de caja y bigotes. Analíticamente se estudió la existencia de diferencias estadísticamente significativas en la distribución de la muestra y en las medias.

Para comparar la distribución de las dos muestras se ejecutó una prueba de Kolmogorov-Smirnov (K-S). Esta prueba se realiza calculando la distancia máxima entre las distribuciones acumuladas de las dos muestras. El contraste de hipótesis considera la hipótesis nula, $H_{0}$, de igualdad de distribución de ambas muestras, de modo que cuando el valor- $P$ es mayor o igual que 0,05 se puede considerar que no hay diferencias estadísticamente significativas entre las dos distribuciones, con un nivel de confianza del 95\%.

Para comparar las medias de las dos muestras se ejecutó una prueba T que construye los intervalos de confianza para cada media y para la diferencia entre las medias. EI contraste de hipótesis considera la hipótesis nula, $H_{0}$, de igualdad de medias de ambas muestras asumiendo que las varianzas de ambas son iguales. Cuando el valor- $P$ es mayor o igual que 0,05 se puede considerar que no hay diferencias estadísticamente significativas entre las dos medias, con un nivel de confianza del 95\%.

\subsubsection{CONSIDERACIONES NORMATIVAS Y TAMAÑO DE LA MUESTRA}

Las muestras para los ensayos deben ser representativas de la población a analizar. La madera debe representar la procedencia, las dimensiones y las calidades reales que serán clasificadas en la fabricación. 
Tal y como queda reflejado en el documento de aclaraciones en la caracterización estructural de madera aserrada emitido por AENOR, 2011, del Comité Técnico de Normalización Madera y Corcho- Subcomite 6 "Estructuras de madera", una muestra es un lote de piezas de una especie con la misma procedencia y la misma sección. En lo que se refiere a la procedencia de una muestra, ésta debe estar ligada a una localización geográfica de características comunes. Las muestras pueden tomarse de aserradero, siempre que la producción de éste proceda de una zona geográfica de características comunes.

La muestra consistió en un total de 370 piezas de madera aserrada, 4 lotes de 92, 92, 90 y 96 piezas, de modo que se pudieran obtener dos clases visuales y por lo tanto dos clases resistentes. Con este muestreo, cada clase visual estaría compuesta por una submuestra de 4 lotes que contenían al menos 40 piezas cada, una vez excluidos los rechazos. Al tratarse de 4 lotes, la norma UNE-EN 384:2016 establece un factor de ajuste $k_{n}$ de valor 0,97 para la obtención del MOE y de la densidad, y 0,95 para la obtención del MOR.

\subsubsection{SELECCIÓN DE ZONAS DE MUESTREO}

Para la obtención de los lotes se establecieron 5 zonas de muestreo, 3 de ellas localizadas en la provincia de Gipuzkoa y 2 en la región de Navarra, representativas de la industria de alerce del Japón a nivel nacional. Las serrerías colaboradoras fueron Serrería Larrañaga y Serrería Errekondo en Gipuzkoa, y Serrería Alemán en Navarra.

A la hora de seleccionar la muestra se consideraron las secciones habituales, el método de aserrío, así como los tamaños mínimos y máximos utilizados habitualmente en la industria de la madera estructural de alerce del Japón. Las secciones establecidas, a las que se aplicarían las reglas de clasificación durante su fabricación, y los aserraderos elegidos, representan aproximadamente el 95\% de la producción de madera estructural de esta especie.

Las plantaciones seleccionadas tuvieron como requisito mínimo el tratarse de masas adultas con presencia de pies con un diámetro normal mínimo en torno a los $30 \mathrm{~cm}$, valor establecido por la propia industria maderera para el aprovechamiento de los pies.

Para el análisis de la posible influencia de la época de corta en las propiedades físicomecánicas de la madera, las probetas objeto de estudio corresponden a dos fases lunares distintas (la mitad de los árboles fueron derribados en luna creciente y la otra mitad en luna menguante). Los días de luna creciente la luna era ascendente y en los días de luna menguante, la luna era descendente. 
Se contó con un total de 225 pies de los que se obtuvieron 4 trozas de cada pie. Las probetas de madera aserrada se sacaron a razón de 2 probetas de cada pie, de modo que cada una de las 2 probetas, de un mismo pie, procedía de trozas distintas. Las características de las zonas de muestreo seleccionadas se muestran en la tabla 5.1. 
TABLA 5.1: ZONAS DE MUESTREO SELECCIONADAS PARA LA MADERA DE ALERCE DEL JAPÓN Y CARACTERÍSTICAS GENERALES.

\begin{tabular}{|c|c|c|c|c|c|c|c|}
\hline \multicolumn{3}{|c|}{ LOCALIZACIÓN DE LAS ZONAS DE CORTA } & \multicolumn{2}{|l|}{ COTAS } & \multirow[b]{2}{*}{ EXPOSICIÓN } & \multirow{2}{*}{\multicolumn{2}{|c|}{ COORDENADAS }} \\
\hline $\begin{array}{l}\text { TERMINO } \\
\text { MUNICIPÀL }\end{array}$ & $\begin{array}{l}\text { MUP - } \\
\text { RODAL - } \\
\text { PARAJE }\end{array}$ & $\begin{array}{l}\text { RODAL O } \\
\text { PARAJE }\end{array}$ & $\begin{array}{l}\text { EXTREMAS } \\
\text { RODAL }\end{array}$ & $\begin{array}{l}\text { ZONA DE } \\
\text { APEO }\end{array}$ & & & \\
\hline \multirow[b]{2}{*}{ LESAKA ${ }^{1}$ (Navarra) } & \multirow{2}{*}{$\begin{array}{l}\text { MUP 566, } \\
\text { "ZALAKO } \\
\text { ERREKA- } \\
\text { ENDARAKO } \\
\text { ERREKA y } \\
\text { OTSANGO“. }\end{array}$} & \multirow{2}{*}{$\begin{array}{l}\text { Rodal } \\
\text { ARITXULEGI }\end{array}$} & $565 \mathrm{~m}$ & \multirow[b]{2}{*}{$650-700 \mathrm{~m}$} & $\begin{array}{l}\text { Predominante } \\
\text { Norte }\end{array}$ & $x$ & 599827 \\
\hline & & & $712 \mathrm{~m}$ & & N-NW & Y & 4788645 \\
\hline $\begin{array}{l}\text { BERA }^{1} \text { DE BIDASOA } \\
\text { (Navarra) }\end{array}$ & $\begin{array}{l}\text { MUP 639, } \\
\text { "SATA } \\
\text { BÁRBARA Y } \\
\text { LABEAGA". } \\
\text { Rodal } \\
\text { LABEAGA }\end{array}$ & $\begin{array}{l}\text { Rodal } \\
\text { LABEAGA }\end{array}$ & $650 \mathrm{~m}$ & $450-500$ & OESTE & $x$ & 436897 \\
\hline \multirow{4}{*}{ ATAUN' (Gipuzkoa) } & \multirow{4}{*}{$\begin{array}{l}\text { MUP } 2.015 .2 \\
\text { "AITZARTE" }\end{array}$} & \multirow{2}{*}{$\begin{array}{l}\text { Rodal } \\
\text { BEDAMABURU }{ }^{2}\end{array}$} & $650 \mathrm{~m}$ & \multirow{2}{*}{$710-740 \mathrm{~m}$} & \multirow{2}{*}{ SUR } & $x$ & 569387 \\
\hline & & & $755 \mathrm{~m}$ & & & $Y$ & 475974 \\
\hline & & \multirow{2}{*}{$\begin{array}{l}\text { Rodal } \\
\text { GOROSTIZA }\end{array}$} & $535 \mathrm{~m}$ & \multirow{2}{*}{$595-905 \mathrm{~m}$} & \multirow{2}{*}{ OESTE } & $x$ & 568701 \\
\hline & & & $755 \mathrm{~m}$ & & & Y & 4760535 \\
\hline \multirow[b]{2}{*}{$\begin{array}{l}\text { LA PARZONERÍA } \\
\text { GENERAL (Gipuzkoa) }\end{array}$} & \multirow{2}{*}{$\begin{array}{l}\text { MUP } 3.070 .2 \\
\text { "LA } \\
\text { PARZONERÍA } \\
\text { GENERAL DE } \\
\text { GIPUZKOA Y } \\
\text { ALAVA" }\end{array}$} & \multirow[b]{2}{*}{$\begin{array}{l}\text { Rodal } \\
\text { ALDAOLA }^{1}\end{array}$} & $805 \mathrm{~m}$ & \multirow[b]{2}{*}{$825-860 \mathrm{~m}$} & \multirow[b]{2}{*}{ SUR } & $x$ & 557587 \\
\hline & & & $900 \mathrm{~m}$ & & & Y & 4754130 \\
\hline \multirow{2}{*}{$\begin{array}{l}\text { LA PARZONERÍA DE } \\
\text { GIPUZKOA } \\
\text { (Gipuzkoa) }\end{array}$} & \multirow{2}{*}{$\begin{array}{l}\text { MUP } 3.070 .1 \\
\text { "LA } \\
\text { PARZONERÍA } \\
\text { DE } \\
\text { GIPUZKOA" }\end{array}$} & \multirow{2}{*}{$\begin{array}{l}\text { Rodal } \\
\text { GIZONZABAL }\end{array}$} & $695 \mathrm{~m}$ & \multirow[b]{2}{*}{$700-705 \mathrm{~m}$} & $\begin{array}{l}\text { Predominante } \\
\text { Norte }\end{array}$ & $x$ & 561261 \\
\hline & & & $708 \mathrm{~m}$ & & $\begin{array}{l}\text { Todos los } \\
\text { vientos }\end{array}$ & Y & 4754685 \\
\hline \multirow[b]{2}{*}{$\begin{array}{l}\text { LA PARZONERÍA } \\
\text { GENERAL (Gipuzkoa) }\end{array}$} & \multirow{2}{*}{$\begin{array}{l}\text { MUP } 3.070 .2 \\
\text { "LA } \\
\text { PARZONERÍA } \\
\text { GENERAL DE } \\
\text { GIPUZKOA Y } \\
\text { ALAVA" }\end{array}$} & \multirow[b]{2}{*}{$\begin{array}{l}\text { Rodal } \\
\text { OTZAURTE }{ }^{1,3}\end{array}$} & $650 \mathrm{~m}$ & \multirow[b]{2}{*}{$675-700 \mathrm{~m}$} & \multirow[b]{2}{*}{ ESTE } & $x$ & 560513 \\
\hline & & & $725 \mathrm{~m}$ & & & Y & 4754339 \\
\hline \multicolumn{8}{|c|}{$\begin{array}{l}\text { 1) Se reseña en negrita el nombre con el que denominarán las zonas de muestreo en adelante, en este documento. } \\
\text { 2) Los rodales Bedamaburu y Gorostiza se consideraron como una misma zona de muestreo, denominada Ataun, debido a su } \\
\text { proximidad. } \\
\text { 3) Los rodales Gizonzabal y Outzaurte se consideraron como una misma zona de muestreo, denominada Outzaurte, debido a } \\
\text { su proximidad. }\end{array}$} \\
\hline
\end{tabular}


El número de probetas, dimensiones y procedencia de las mismas, se muestran en la tabla 5.2.

TABLA 5.2: NÚMERO, DIMENSIONES Y PROCEDENCIA DE LAS PROBETAS ENSAYADAS.

\begin{tabular}{|c|c|c|c|c|c|c|c|}
\hline Lote & Provincia & Rodal & Serrería & $\begin{array}{l}\text { Número } \\
\text { probetas }\end{array}$ & $\begin{array}{c}\text { Anchura } \\
\text { (cm) }\end{array}$ & $\begin{array}{c}\text { Altura } \\
\text { (cm) }\end{array}$ & $\begin{array}{l}\text { Longitud } \\
\text { (cm) }\end{array}$ \\
\hline \multirow{2}{*}{1} & \multirow{2}{*}{ Gipuzkoa } & Ataun & Larrañaga & 45 & \multirow{2}{*}{7} & \multirow{2}{*}{15} & \multirow{2}{*}{300} \\
\hline & & Aldaola & Larrañaga & 47 & & & \\
\hline \multirow{2}{*}{2} & \multirow{2}{*}{ Gipuzkoa } & Ataun & Larrañaga & 45 & \multirow{2}{*}{10} & \multirow{2}{*}{15} & \multirow{2}{*}{300} \\
\hline & & Aldaola & Larrañaga & 47 & & & \\
\hline \multirow{2}{*}{3} & \multirow{2}{*}{ Navarra } & Bera & Alemán & 45 & \multirow{2}{*}{14} & \multirow{2}{*}{18} & \multirow{2}{*}{400} \\
\hline & & Lesaka & Alemán & 45 & & & \\
\hline \multirow{2}{*}{4} & \multirow{2}{*}{ Gipuzkoa } & Otzaurte & Errekondo & 50 & \multirow{2}{*}{20} & \multirow{2}{*}{25} & \multirow{2}{*}{500} \\
\hline & & Otzaurte & Larrañaga & 46 & & & \\
\hline
\end{tabular}

Respecto a la ubicación de las parcelas de muestreo, se presentan a continuación los mapas de localización en las figuras 5.26, 5.27, 5.28, 5.29 y 5.30 de los rodales indicados en la tabla 4.

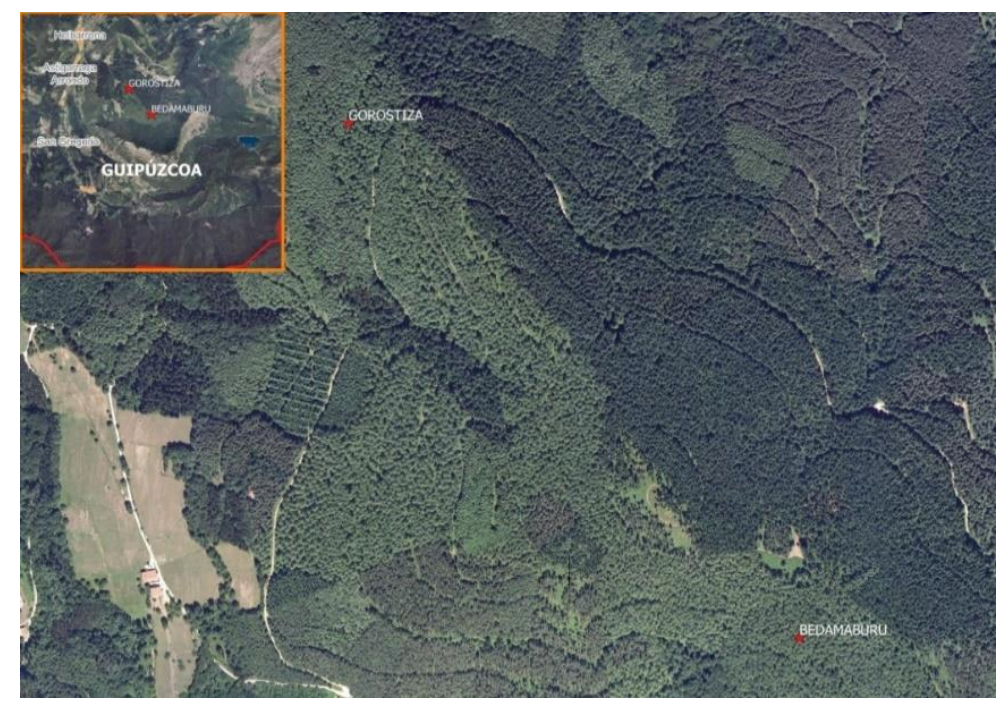

FIGURA 5.26. LOCALIZACIÓN DE LOS RODALES GOROSTIZA Y BEDAMABURU (ZONA DE MUESTREO: ATAUN). 


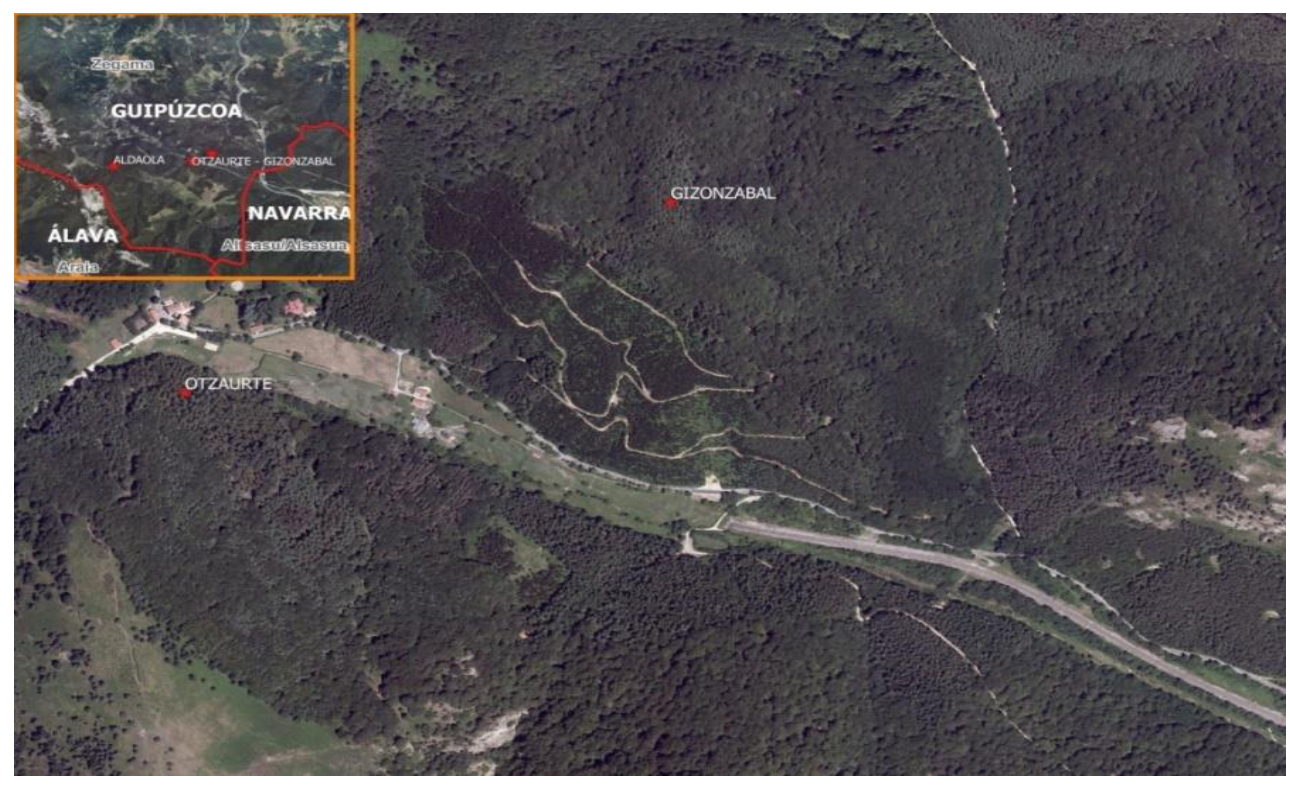

FIGURA 5.27. LOCALIZACIÓN DE LOS RODALES GIZONZABAL Y OTZAURTE (ZONA DE MUESTREO: OTZAURTE).

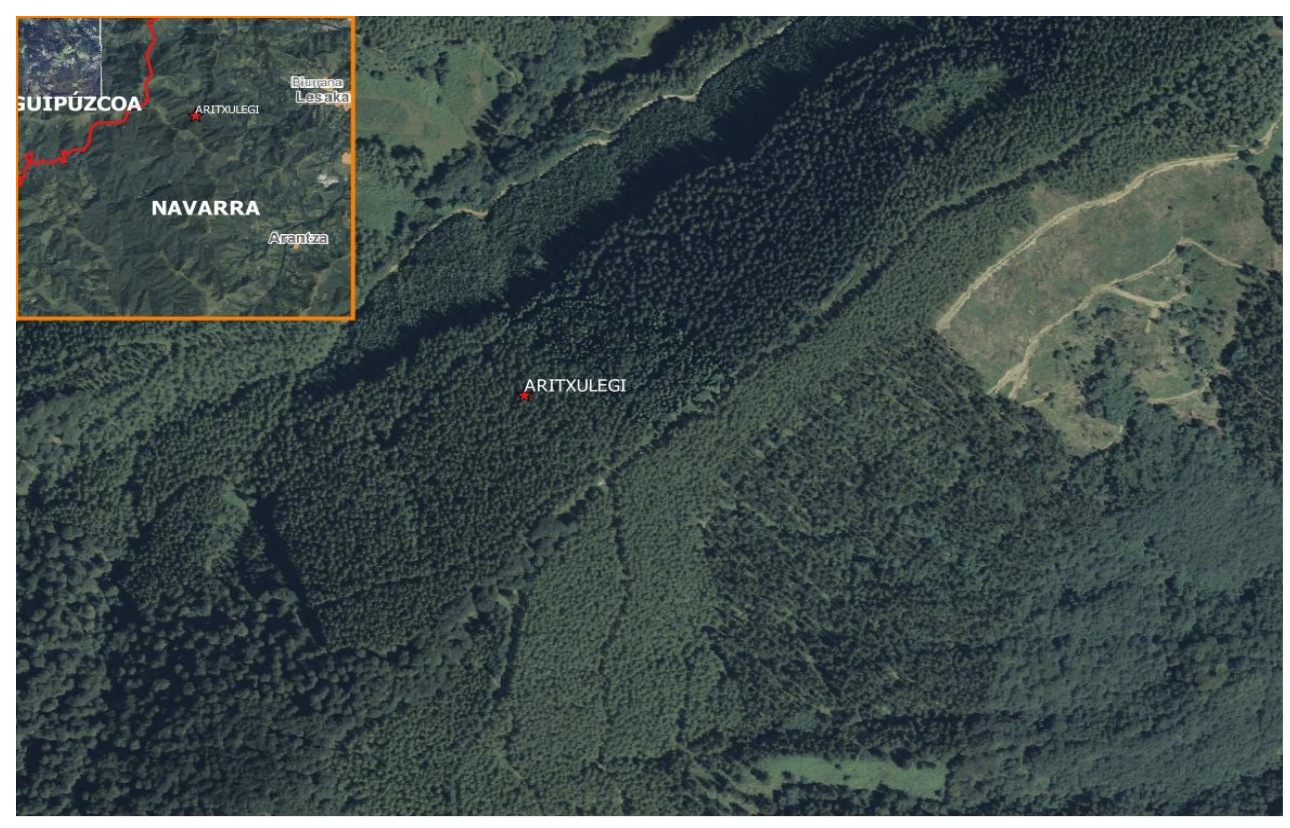

FIGURA 5.28. LOCALIZACIÓN DEL RODAL ARITXULEGI (ZONA DE MUESTREO: LESAKA). 


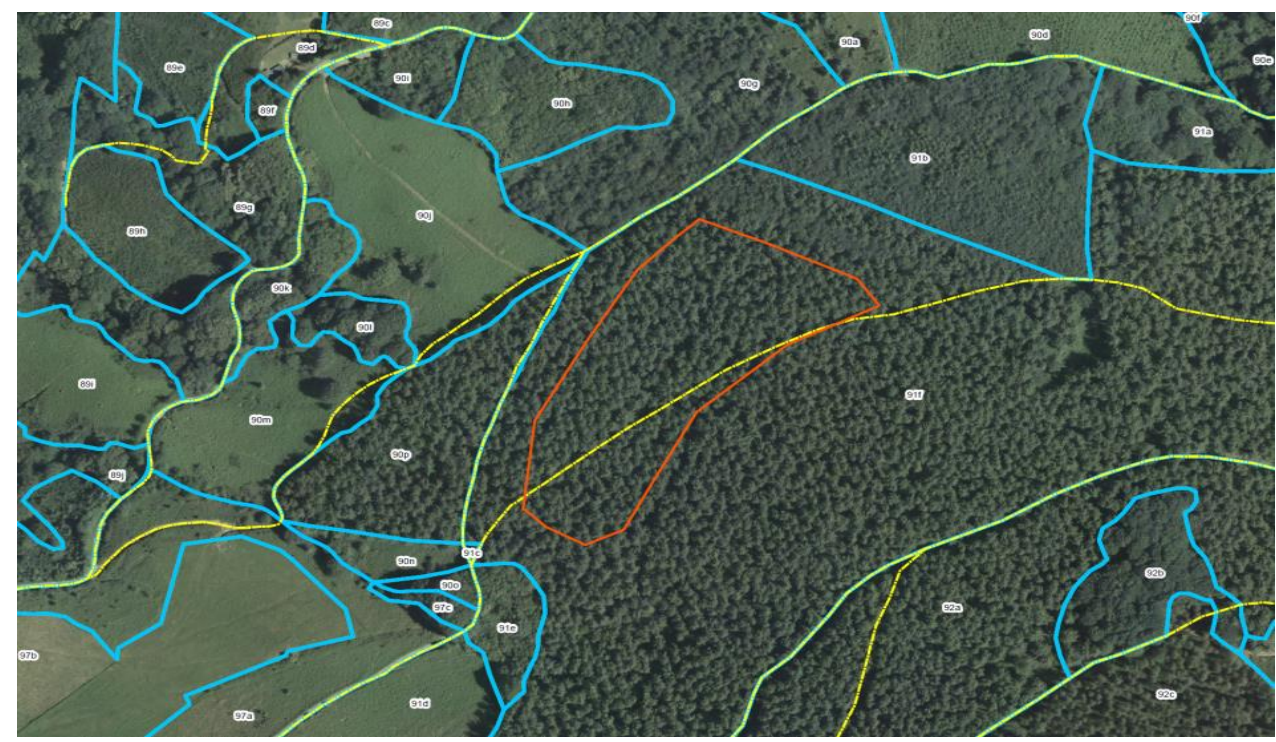

FIGURA. 5.29. LOCALIZACIÓN DEL RODAL DE LABEAGA (BERA DE BIDASOA).

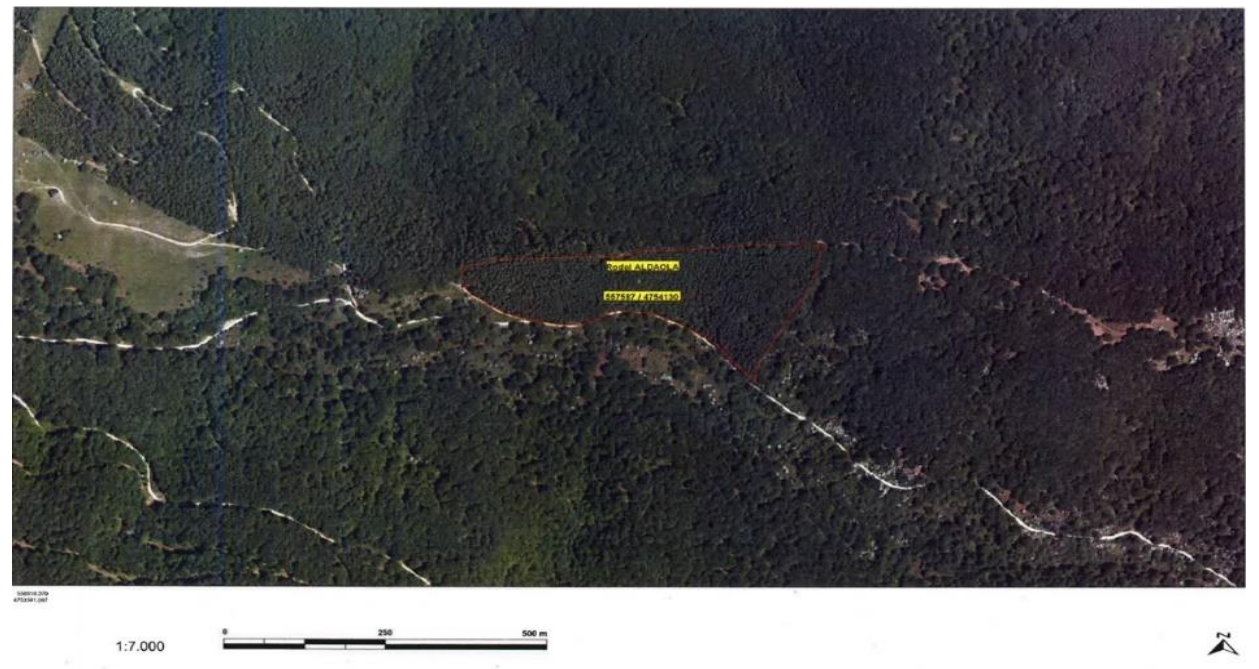

FIGURA 5.30. LOCALIZACIÓN DEL RODAL DE ALDAOLA (ATAUN).

\subsubsection{TRABAJOS PREVIOS}

\subsubsection{SELECCIÓN DE PIES}

La selección de pies fue pie a pie, de forma aleatoria, y distantes unos de otros con el objeto de no dejar grandes aberturas en los montes seleccionados y realizando una entresaca adecuada a la edad de la población. Sólo se rechazaron pies por motivos de sanidad o fuertes curvaturas que impidieran su posterior aprovechamiento para uso estructural. En ningún momento se tuvo en cuenta el grado de nudosidad, desviación de la fibra, conicidad, etc. En todos los casos se tomaron los diámetros normales de los pies. En las figuras 5.31 y 5.32, se representan cómo se realizaron la selección de pies, el marcado de árboles con spray y la medición de los mismos. 
Según Zhu et al., (2000), el límite entre madera juvenil y madera madura varía entre una edad de 15 y 21 años para el alerce del Japón, dependiendo de la procedencia y lugar de plantación. En este trabajo de investigación todos los pies seleccionados provenían de masas de edad comprendida entre 55 y 80 años, por lo que las probetas se pueden considerar constituidas por madera madura.

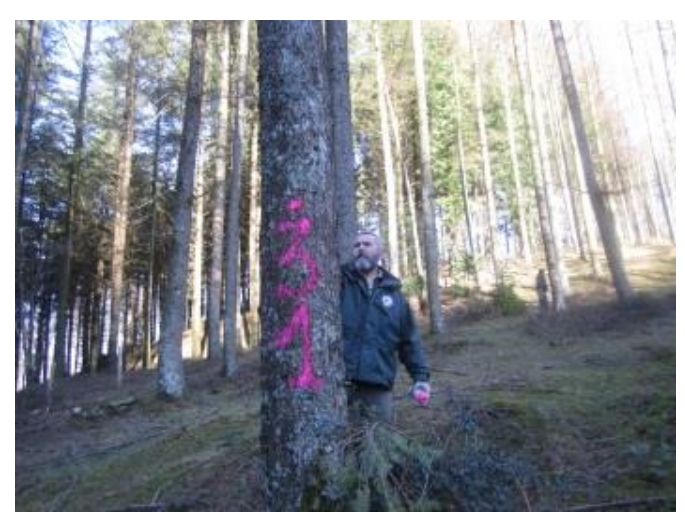

FIGURA.5.31. DETALLE REPRESENTANDO LA SELECCIÓN DE PIES.

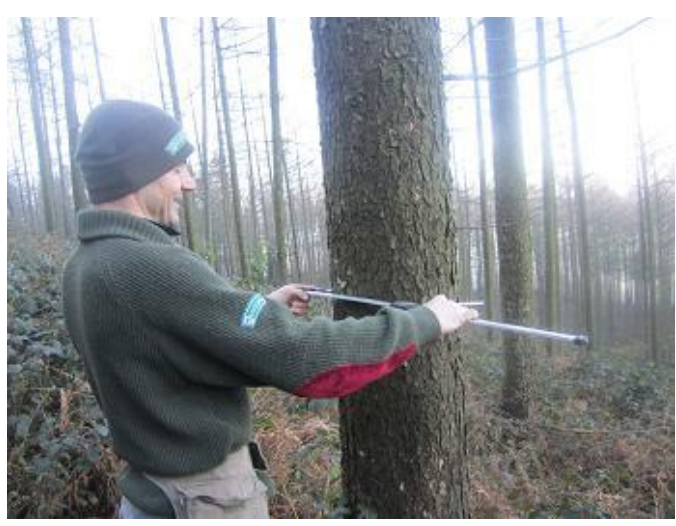

FIGURA.5.32. MEDICIÓN DE DIÁMETROS DE ÁRBOLES.

\subsubsection{MUESTREO DE TROZAS EN GABINETE}

El siguiente paso fue la selección de trozas en gabinete, el cual vino influenciado por la muestra de madera aserrada que se deseaba obtener. Fueron las características dimensionales de las piezas las que determinaron la tipología de trozas a adquirir a partir de los pies seleccionados. Para cada sección fijada las trozas debían presentar un diámetro mínimo concreto a lo largo de toda su longitud (longitud de la pieza de madera aserrada).

Este trabajo de muestreo fue desarrollado en gabinete, previamente al apeado de los pies. Para ello se utilizaron los datos tomados en campo en el momento de la selección y marcado de pies.

El muestreo de trozas dependió por lo tanto de las características dasométricas de las plantaciones seleccionadas y del tamaño concreto de los pies.

A partir de los requisitos establecidos la distribución de las trozas dentro de los pies fue del mismo modo aleatoria. Las trozas se tomaron a diferentes alturas, pudiendo utilizar trozas que tuvieran un diámetro mínimo en punta delgada de $25 \mathrm{~cm}$, criterio establecido por la industria para su incorporación en proceso de aserrado para las piezas de inferior sección. La toma a diferentes alturas permitió el posterior análisis de la evolución de la calidad de la madera en la altura de los pies. 
En este proceso fue determinante lograr mantener la proporción de todas las variables que pudieran influir en las características físico-mecánicas a analizar en el estudio de la posible influencia de la época de corta entre la muestra procedente de la madera apeada en luna menguante y en luna creciente. Fue necesario lograr un equilibrio en cada monte respecto al tamaño de las piezas de madera aserrada y la altura de las trozas donde obtenerse.

\subsubsection{TRABAJOS EN MONTE}

\subsubsection{APEO, TRONZADO Y ETIQUETADO}
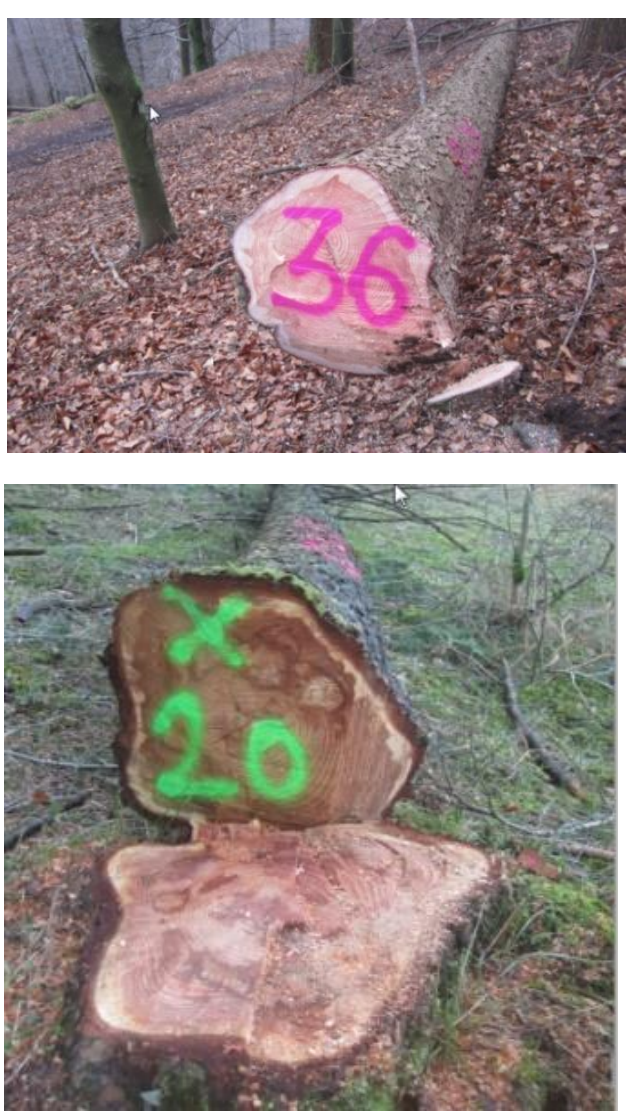

El apeo de los pies se llevó a cabo en dos tiempos. El $50 \%$ de los pies de cada zona de muestreo se apearon en días con luna creciente (entre 2 y 5 días después de la aparición de la luna nueva), y el otro $50 \%$ con luna menguante (entre 2 y 5 días después de la aparición de la luna llena).

Para los días de luna creciente la luna era ascendente y en los días de fase de luna menguante, correspondía a días de luna descendente. Los árboles derribados en las dos distintas fases lunares se identificaron de manera diferente tal y como se puede ver en la figura 5.33 .

FIGURA.5.33. ÁRBOLES DERRIBADOS EN LUNA

CRECIENTE (ARRIBA) Y MENGUANTE (ABAJO).

En ambos procesos se siguieron en todo momento los criterios establecidos por el muestreo de trozas realizado en gabinete. Para asegurar la trazabilidad de cada una de las trozas y que en ningún caso se perdiera la información en el transcurso del proyecto, se utilizaron etiquetas de plástico codificadas previamente mediante un trabajo previo de identificación y colocación de placas serigrafiadas en gabinete, tal y como viene indicado en la figura 5.34. 


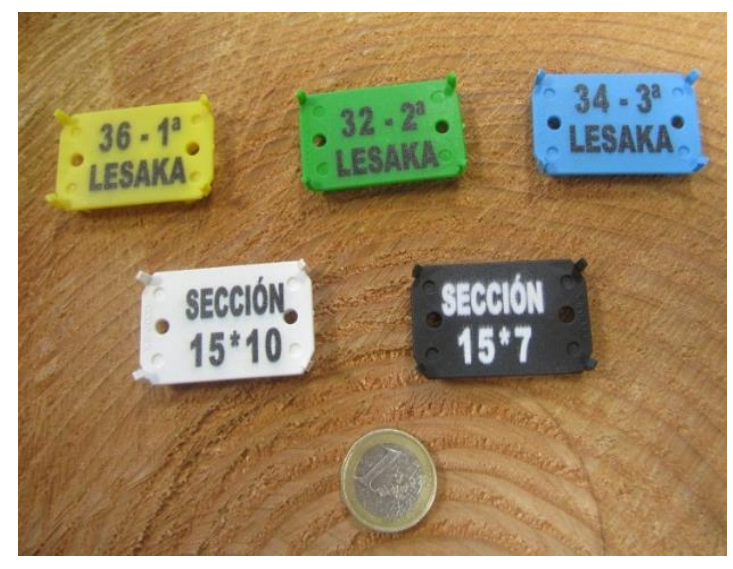

FIGURA.5.34. DETALLE DE PLACAS SERIGRAFIADAS PARA IDENTIFICACIÓN DE PROBETAS.
A cada troza se le colocaron dos etiquetas, una con la identificación de la zona de muestreo, el número de árbol y la troza seleccionada dentro del árbol; y una segunda etiqueta donde se indicaba la sección a obtener en el aserrado. De este modo, las etiquetas de color blanco o negro identificaban la sección a obtener del rollo; y las etiquetas de otros colores identificaban la troza de la que procedía el rollo (1 $\left.{ }^{\mathrm{a}}-4^{\mathrm{a}}\right)$.

Las trozas de las cuales se iban a sacar probetas de sección $7 \times 15 \mathrm{~cm}$, tenían una

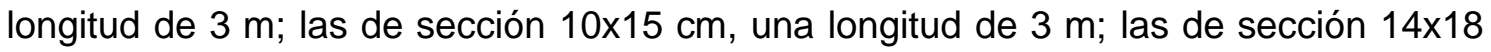
$\mathrm{cm}$, una longitud de $4 \mathrm{~m}$; y las de sección $20 \times 25 \mathrm{~cm}$, una longitud de $5 \mathrm{~m}$.

Las placas, tal y como se puede observar en la figura 5.35, se colocaron en ambas caras de la troza mediante martillo, lo que permitió un fuerte anclaje y que en ninguno de los casos se perdiera la trazabilidad en las piezas hasta su incorporación en aserradero.
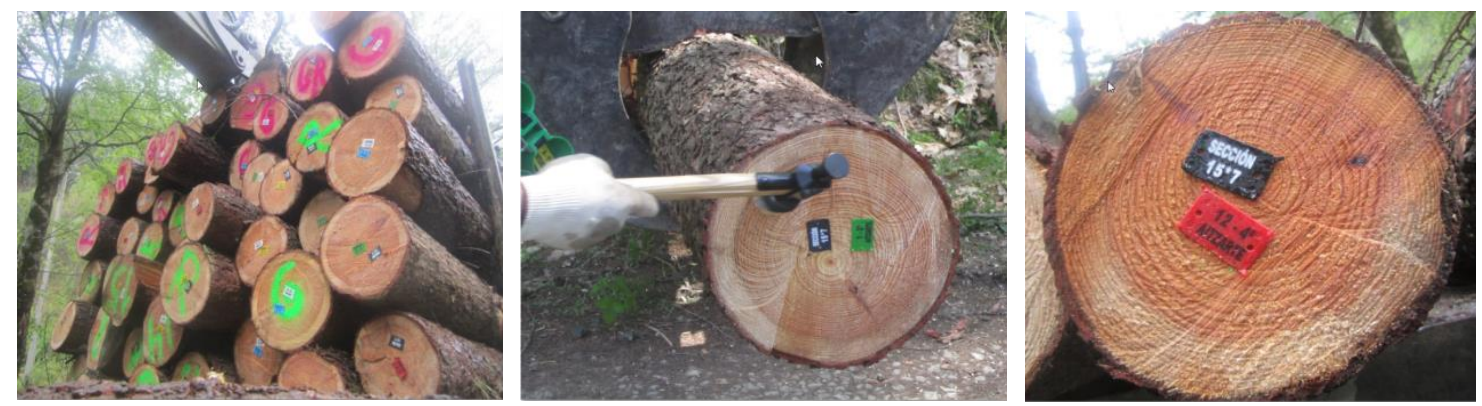

FIGURA. 5.35. INCORPORACIÓN DE PLACAS SERIGRAFIADAS EN TROZAS DE ÁRBOLES. 


\subsubsection{APLICACION DE TÉCNICAS NO DESTRUCTIVAS EN TROZAS}

El siguiente paso fue la evaluación de la trozas mediante la aplicación del ensayo no destructivo tal y como se indica en las figuras 5.36 y 5.37 , que registra el tiempo de paso, en la longitud total de la troza, de una onda sonora haciendo uso para ello del equipo Microsecond Timer de la casa Fakopp.

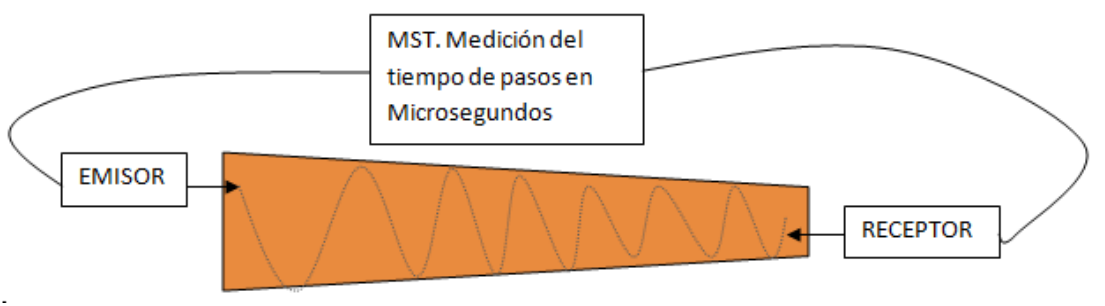

FIGURA 5.36. ESQUEMA DE UTILIZACIÓN DE LAS TÉCNICAS NO DESTRUCTIVAS EN UNA TROZA DE MADERA.

La metodología fue de tres repeticiones del ensayo de testa a testa y medición de la distancia entre sensores.
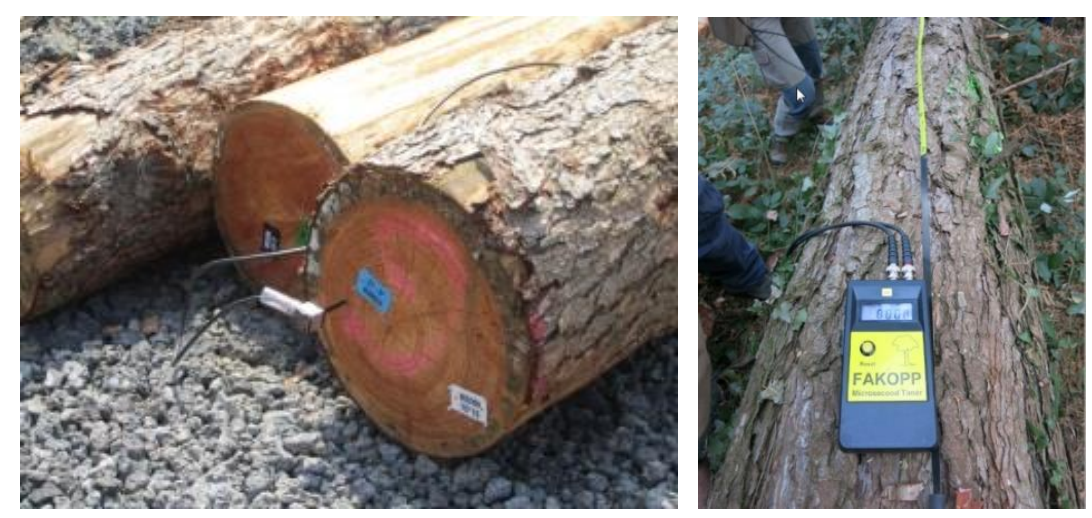

FIGURA. 5.37. EVALUACIÓN DE TROZAS MEDIANTE TÉCNICAS NO DESTRUCTIVAS.

La madera se quedó almacenada en monte, aproximadamente unos 8 meses, lo que permitió un secado progresivo de la madera en rollo. Posteriormente a esta fase del proyecto las trozas fueron transportadas hasta los diferentes aserraderos seleccionados como se puede apreciar en la figura 5.38. 

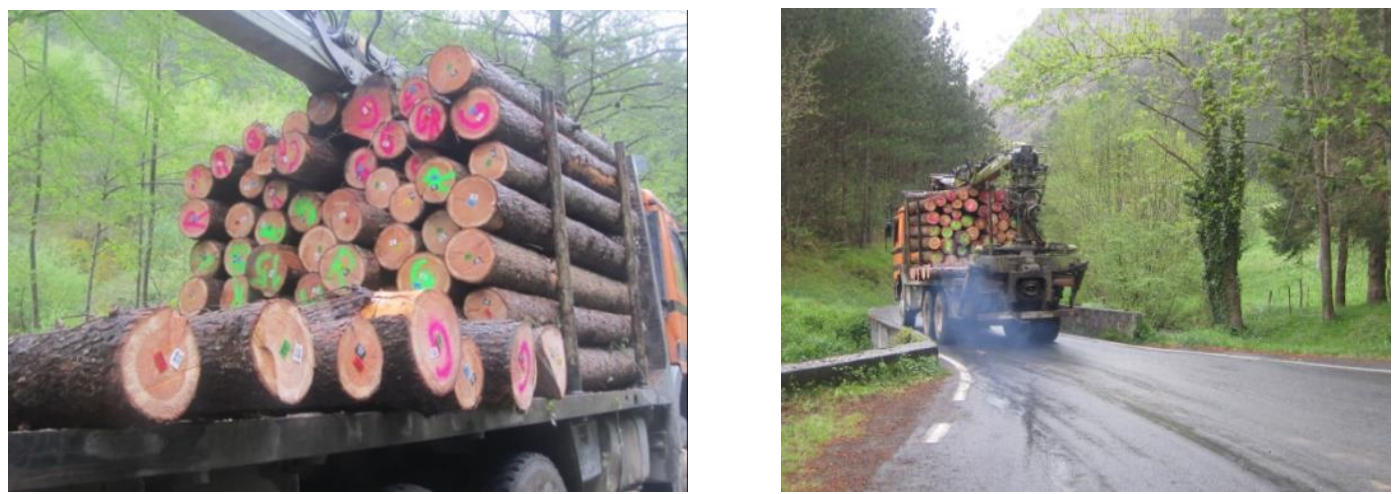

FIGURA 5.38. TRANSPORTE DE LA MADERA AL ASERRADERO.

\subsubsection{TRABAJOS EN ASERRADERO}

Las trozas seleccionadas se transportaron hasta las diferentes serrerías, donde fueron procesadas para obtener las piezas de ensayo. El aserrado se realizó siguiendo la metodología de trabajo tradicional para la obtención de madera estructural.

\subsubsection{MEDICIÓN DE SINGULARIDADES DE LA MADERA EN TROZAS}

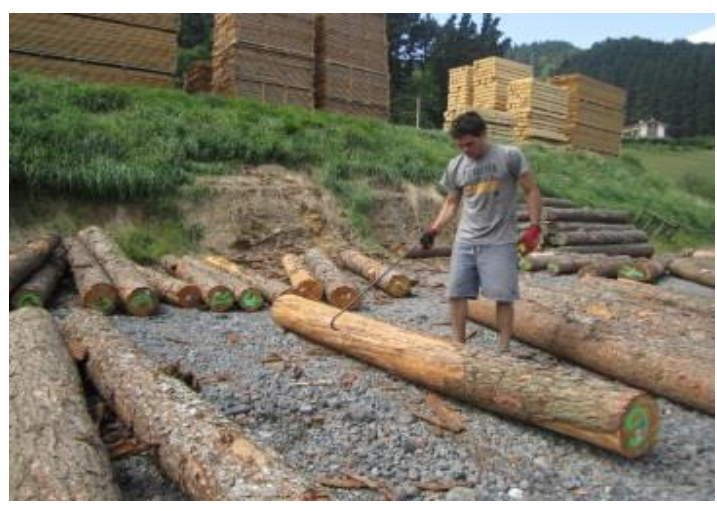

FIGURA. 5.39. MEDICIÓN DE SINGULARIDADES DE LAS TROZAS EN ASERRADERO.

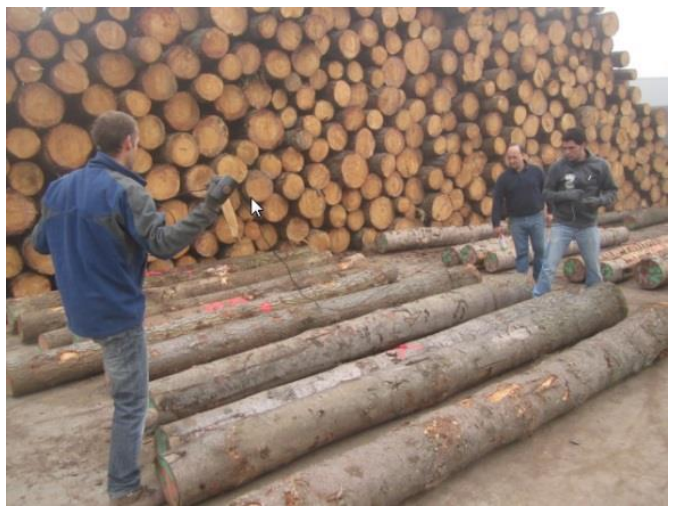

FIGURA. 5.40. MEDICIÓN DE SINGULARIDADES DE LAS TROZAS EN ASERRADERO.
Previamente al trabajo de aserrado se llevó a cabo una medición de las singularidades de la madera en trozas, como se observa en las figuras 5.39 y 5.40. Para ello, se midieron a lo largo de la longitud los siguientes parámetros:

№ de verticilos y distancia entre verticilos. Nudos por verticilo y tamaño máximo del nudo en cada uno de ellos.

Desviación de la fibra en caso de detectarse visualmente.

Curvaturas.

Heridas, perforaciones $u$ otros defectos de tipo biótico. 


\subsubsection{ASERRADO DE TROZAS Y OBTENCIÓN DE PROBETAS}

Se procedió al aserrado de cada una de las trozas siguiendo para ello las propias indicaciones que quedaban reflejadas en las etiquetas de las trozas. Inmediatamente después de pasar por la sierra de carro y obtener la pieza de madera aserrada éstas fueron identificadas mediante spray con el mismo código que el de la troza. En la figura 5.41 se puede ver cómo se realizó esta identificación de probetas.
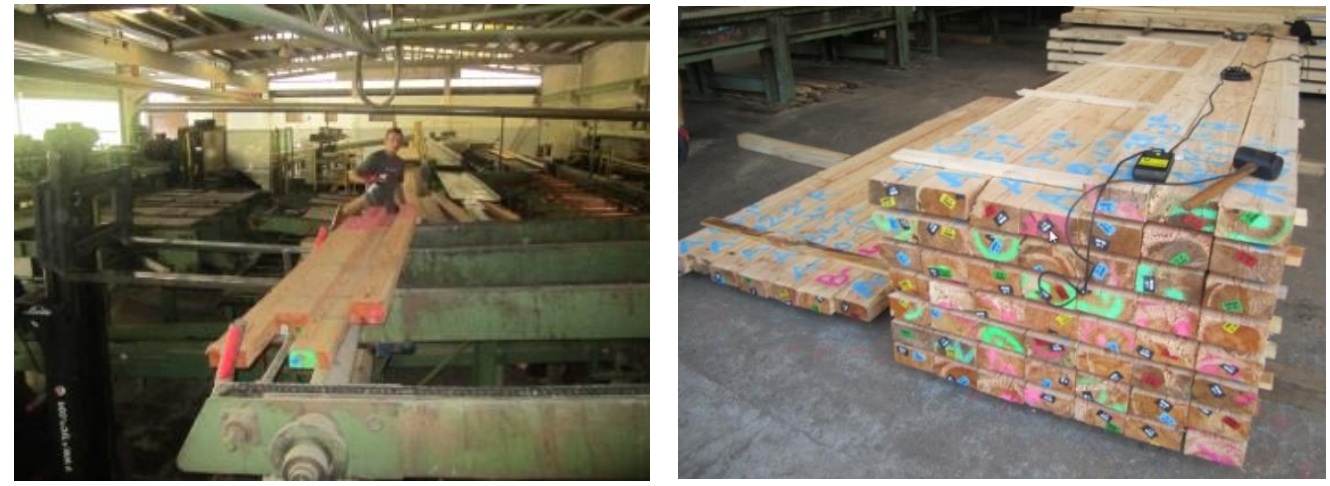

FIGURA. 5.41. SUPERVISIÓN DE LA TRAZABILIDAD DE LAS TROZAS Y DE LA MADERA ASERRADA DURANTE SU TRANSFORMACIÓN EN ASERRADERO.

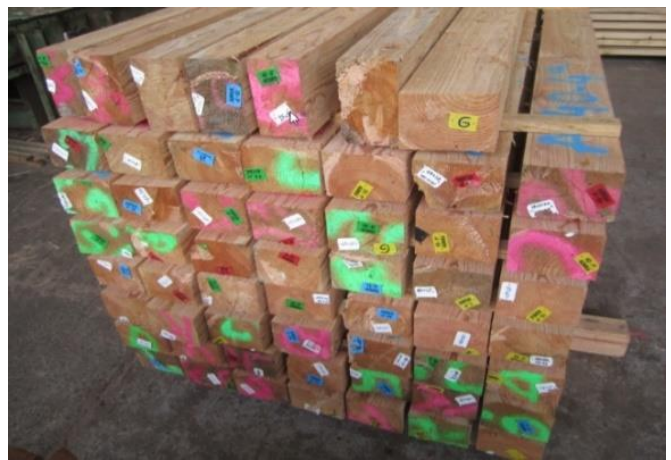

FIGURA. 5.42. PREPARACIÓN DE LOTES DE PROBETAS PARA TRANSPORTE A LABORATORIO.

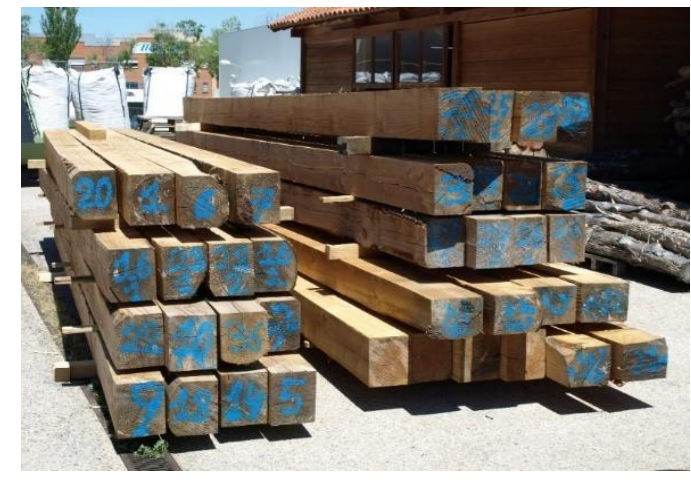

Posteriormente todos los paquetes de madera aserrada conformados fueron enviados al laboratorio de Cesefor, pudiéndose ver en la figura 5.43 .

La madera aserrada, pudiéndose ver en la figura 5.42, fue apilada conformando paquetes con piezas de sección similar, haciendo uso de rastreles para permitir la circulación del aire y el secado de la madera.

FIGURA.5.43. DETALLE DE PROBETAS EN EL EXTERIOR DEL LABORATORIO. 


\subsubsection{TRABAJOS EN LABORATORIO}

\subsubsection{ACONDICIONADO DE LAS PROBETAS}

Las vigas se almacenaron al aire bajo cubierta durante aproximadamente 2 meses para ir reduciendo su humedad. Periódicamente se controló su humedad mediante xilohigrómetro, con capacidad de medición hasta una profundidad de $4 \mathrm{~cm}$ (estimación por el método de la resistencia eléctrica). Una vez se detectaron contenidos de humedad próximos al $30 \%$, los lotes se introdujeron de forma separada en la cámara de acondicionado, primeramente, el de menor escuadría, después en el de escuadría intermedia y así sucesivamente.

De este modo, los lotes de menor escuadría presentaban valores de humedad más próximos a la humedad de referencia del ensayo (12\% de humedad), dando así tiempo a los lotes más húmedos de reducir el contenido de humedad de forma natural.

La normativa de ensayo UNE-EN 408: $2011+$ A1: 2012 indica que la madera se deberá acondicionar en cámara de acondicionado bajo determinadas condiciones, $(20 \pm 2)^{\circ} \mathrm{C}$ y $(65 \pm 5) \%$ de temperatura y humedad respectivamente.

No obstante, el documento de aclaraciones en la caracterización estructural de madera aserrada, AENOR, 2011, del comité técnico madera y corcho-subcomité 6 "Estructuras de madera", indica respecto al acondicionamiento de probetas, "que cuando sea difícil alcanzar el acondicionado de la madera (como en el caso de algunas frondosas de alta densidad), se debe mencionar este hecho. Es decir, se acepta que no siempre es posible el acondicionamiento en cámara".

Este hecho conviene tenerlo en cuenta, ya que las probetas de alerce del Japón presentaron gran dificultad a la hora de intentar alcanzar contenidos de humedad próximos al $12 \%$, tal y como se observó durante el acondicionado de dicha madera, y en los valores de humedad obtenidos finalmente por desecación de la madera, detectándose valores de humedad si cabe más alejados en las piezas de mayor escuadría.

En aquellas piezas en que no se logró la humedad de referencia se recogió tal hecho y se tuvo en cuenta a la hora de llevar a cabo las correcciones sobre los parámetros físico mecánicos debidas a la variación de la humedad detectada respecto a la humedad de referencia (12\%).

\subsection{CONTROL DE LAS DIMENSIONES, PESO Y HUMEDAD DE LAS PROBETAS}

Para el control de las dimensiones reales de las piezas tras su acondicionado se realizaron medidas tanto en altura como en anchura, tomando tres medidas de cada una de ellas (dos en los extremos y otra en la parte central de la pieza), utilizando como dimensión de referencia la media de las tres. 
Una vez controladas las dimensiones se realizó el pesado de las piezas. Para ello se utilizó una báscula de $150 \mathrm{~kg}$ de capacidad y $100 \mathrm{~g}$ de precisión.

Por último, se midió la humedad de la madera en su parte central, con una profundidad de $4 \mathrm{~cm}$, haciendo uso de un xilohigrómetro de estimación por el método de la resistencia eléctrica con precisión de $0,1 \%$ de humedad. El punto de medición se tomó siempre sobre una sección libre de defectos, tales como nudos, entrecascos, etc. Se analizó así la proximidad de las piezas de madera a la humedad de referencia.

\subsubsection{MEDICIÓN DE SINGULARIDADES DE LA MADERA EN PROBETAS}

Se procedió al control y medición de todas las singularidades existentes en las piezas de madera, de acuerdo a la norma UNE-EN 1309-3:2018, anotando su localización a lo largo de la longitud de la pieza, ya fuera en el tercio central, zona donde previsiblemente se produciría la rotura de la pieza y en la que la distribución de momentos es constante, o en los tercios exteriores. Las singularidades presentadas en la zona del tercio central se utilizaron para la obtención de la herramienta de clasificación visual.

En el caso concreto de los nudos, se diferenció entre nudos detectados en las caras de las piezas y nudos detectados en los cantos. Los nudos detectados en el tercio central se midieron tanto por su tamaño absoluto como por su tamaño relativo, es decir, como la relación entre el tamaño del nudo y la superficie en la que se encontraban, por ser ésta la metodología más utilizada en las normas de clasificación existentes. De este modo, no solo se tiene en cuenta el tamaño del nudo sino también la proporción de la sección que se ve afectada por el mismo, efecto de mayor relevancia que el propio tamaño del nudo.

Se midieron las siguientes singularidades tal y como se señala en la figura 5.44: nudos de cara, nudos de canto, anillos de crecimiento, fendas, acebolladuras, entrecascos, desviación de la fibra, gemas, médula, alteraciones biológicas, deformaciones y daños de mecanizado.
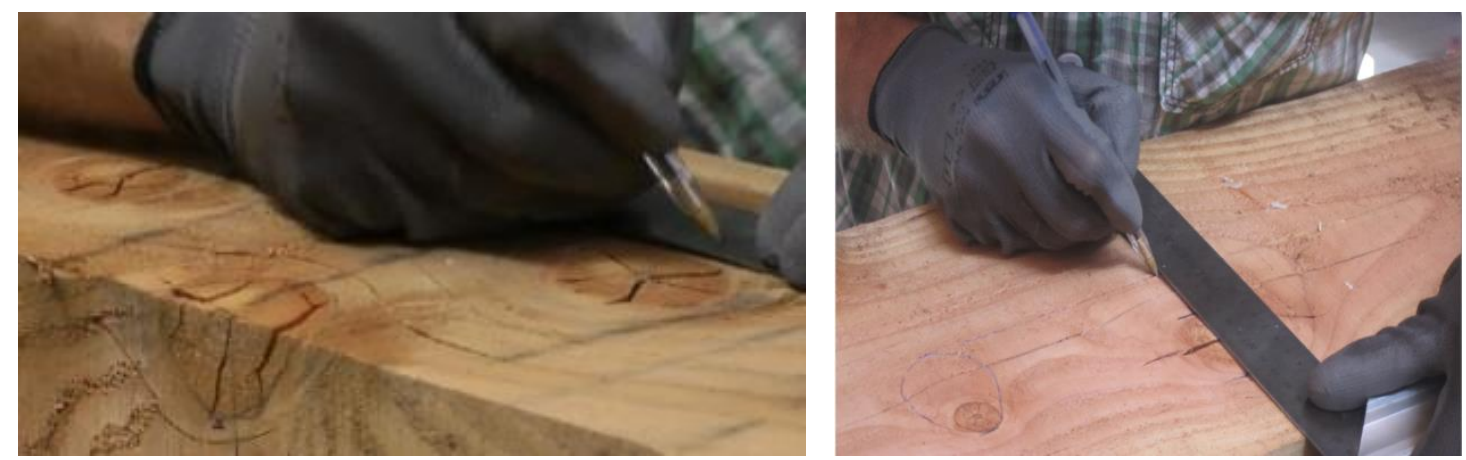

FIGURA. 5.44. MEDICIÓN DE NUDOS EN LAS PROBETAS. 


\subsubsection{APLICACIÓN DE TÉCNICAS NO DESTRUCTIVAS EN PROBETAS EN SECO}

Una vez realizada la clasificación visual, se procedió a ensayar las vigas con los equipos de ensayos no destructivos.

En la figura 5.45 se indica cómo se realizó en laboratorio el ensayo en vigas.

Para determinar las propiedades mecánicas del material se emplearon dos dispositivos distintos, el Microsecond Timer de Fakopp que está basado en el tiempo de paso de una onda de impacto testa a testa (utilizado anteriormente); y un analizador de espectro de onda (también de la casa Fakopp) basado en la frecuencia natural de vibración, indicado en la figura 5.46 .
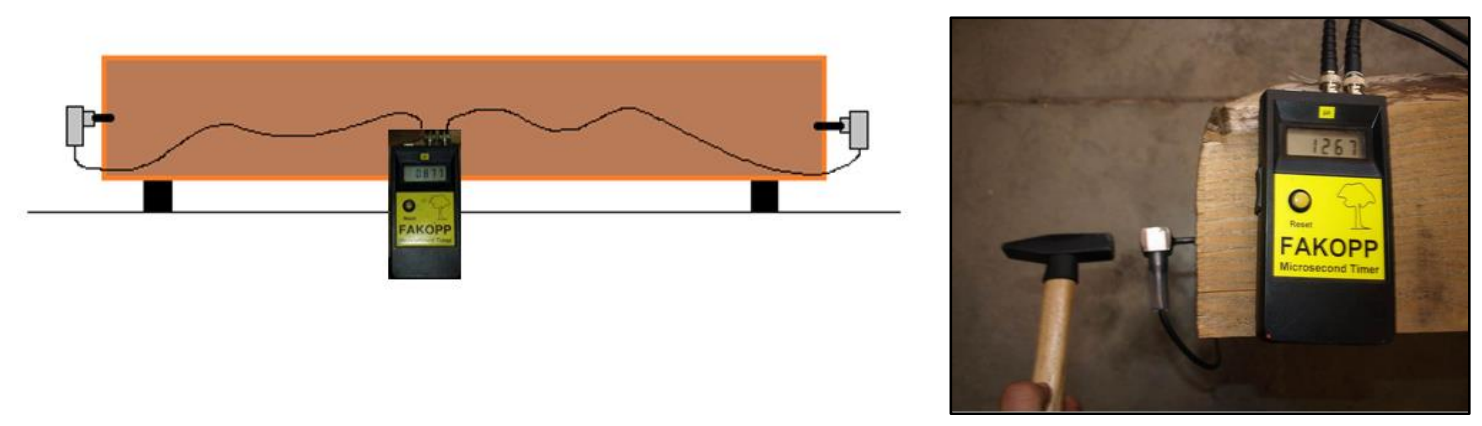

FIGURA 5.45. SISTEMÁTICA EN LA MEDICIÓN DEL TIEMPO DE PASO DE UNA ONDA SONORA MEDIANTE EL APARATO MICROSECOND TIMER (FAKOPP).
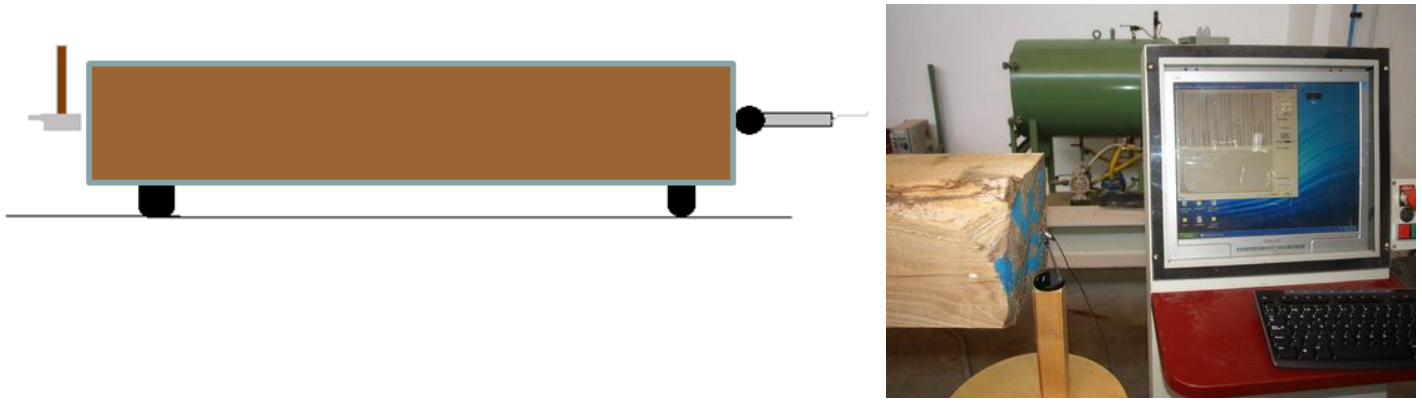

FIGURA 5.46. SISTEMÁTICA EN LA MEDICIÓN DE LA FRECUENCIA DE VIBRACIÓN MEDIANTE UN ANALIZADOR DE ESPECTRO DE ONDA (FAKOPP).

Una vez realizados los ensayos basados en técnicas acústicas se procedió a la realización de los ensayos mecánicos. 


\subsubsection{CARACTERIZACIÓN MECÁNICA DE LA MADERA MEDIANTE ENSAYOS DESTRUCTIVOS}

\subsection{DETERMINACIÓN DE LAS PROPIEDADES MECÁNICAS. ENSAYOS DE FLEXIÓN}

El protocolo de ensayo se realizó según la Norma UNE-EN 408: 2011 + A1: 2012.

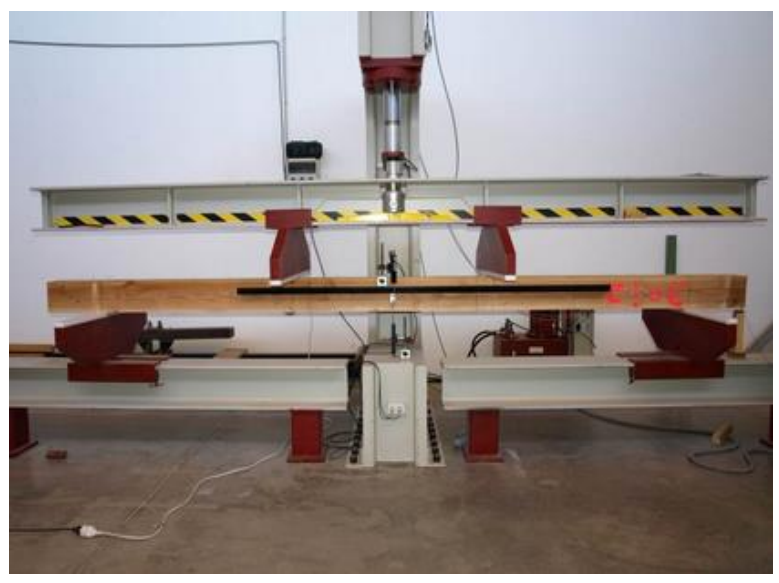

Cesefor dispone en su laboratorio de un Marco de ensayos Sitenor2001, indicados en las figuras 5.47 y 5.48 , con capacidad de $500 \mathrm{kN}$ de fuerza y dotada de dos extensómetros para la medición, de modo continuo, de la flecha de las vigas durante el ensayo. Todos los aparatos de medida disponían de su certificado de calibración.

FIGURA.5.47. MARCO DE ENSAYOS SITENOR2001.

Los ensayos mecánicos tuvieron por objeto determinar los siguientes parámetros: módulo de elasticidad global y local en flexión estática, y módulo de rotura en flexión, que junto con la densidad son los parámetros que determinan los valores característicos de los diferentes lotes de madera.

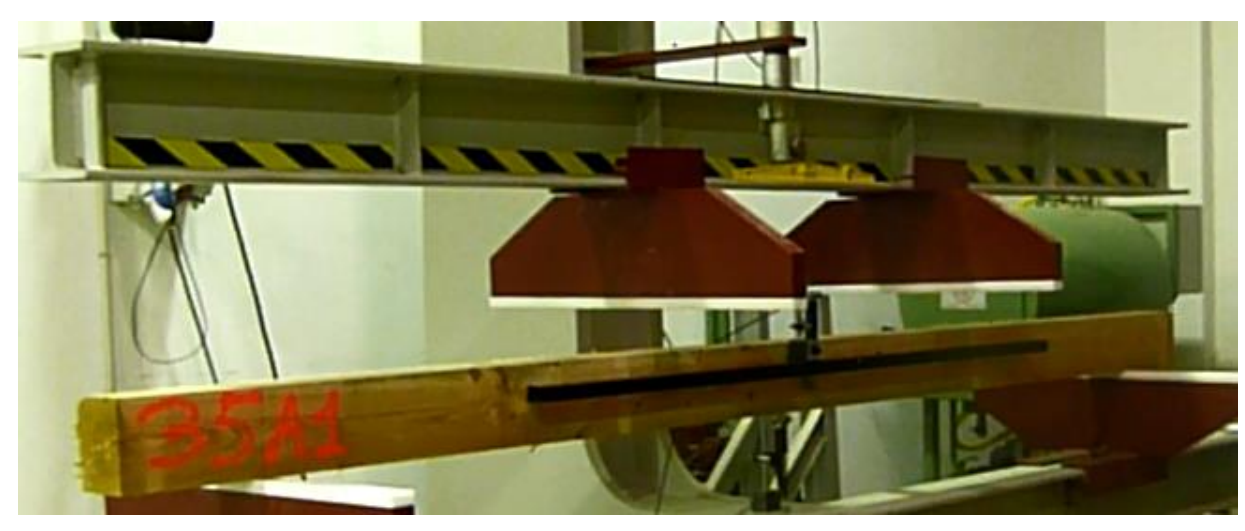

FIGURA 5.48. DETALLE DEL ENSAYO A FLEXIÓN EN LABORATORIO.

La longitud de cada una de las piezas fue al menos 19 veces el alto (cara o anchura) de la sección de la misma, tal y como establece la norma. El procedimiento del ensayo se inició con la colocación de la probeta sobre dos puntos simétricos de apoyo con una luz igual a 18 veces la altura de la pieza, y sometiendo a la pieza a dos cargas puntuales, simétricamente colocadas en los tercios de la luz y por lo tanto con separación entre apoyos de 6 veces la altura de la pieza. Se indica el detalle en la figura 5.49. 


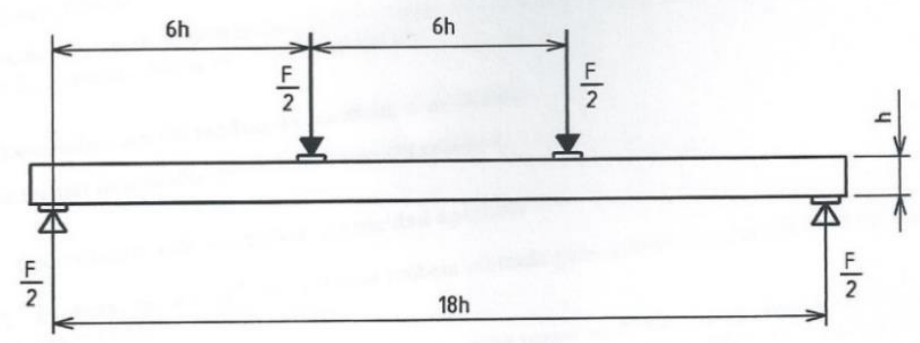

FIGURA 5.49. DETALLE ACOTADO DEL ENSAYO.

Fuente: Norma UNE-EN 408: $2011+$ A1: 2012.

El módulo de elasticidad global mide la deformación en la parte central y por la parte inferior de la pieza, considerando toda la longitud. En cambio, el módulo de elasticidad local mide la deformación de la pieza en el tercio central y en su línea neutra, donde la deformación es debida únicamente a momentos flectores al no existir esfuerzo cortante. En el presente estudio, se optó por medir tanto el módulo de elasticidad local como el global.

En ambos casos la deformación se midió mediante la utilización de extensómetros. Para el módulo de elasticidad global el extensómetro se colocó en el centro de la pieza, en la parte inferior.

Para el módulo elasticidad local primero fue necesario colocar una percha en uno de sus cantos, soportada en unos clavos puestos en la línea neutra (formando un segmento de longitud igual a 5 veces el ancho de la probeta), representado en detalles en las figuras 5.49 y 5.50 y el extensómetro en una chapa colocada en la parte central de la pieza, de tal modo que el extremo del flexómetro apoyara sobre la percha y así se midiera la deformación producida en la línea neutra.

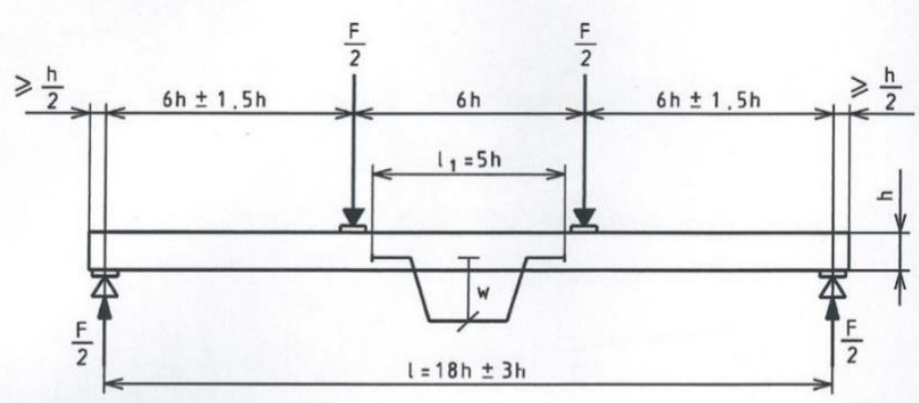

FIGURA 5.50. DISPOSITIVO DE ENSAYO PARA LA MEDICIÓN DEL MÓDULO DE ELASTICIDAD LOCAL EN FLEXIÓN. 
Cada 0,25 segundos de ensayo el equipo guardó una medición, con la fuerza que registraba la célula de carga y la deformación que se había producido en cada extensómetro. Al final y para ambos casos se obtuvo una serie de registros fuerzadeformación, a partir de los cuales se determinó el módulo de elasticidad global y local.

Una vez colocados todos los dispositivos tal y como se observa en la figura 4.53, se comenzó a ejercer lentamente la presión, siempre con una velocidad constante que no debía superar en ningún momento los $0,003 \mathrm{~h} \mathrm{~mm} / \mathrm{s}$ y que la carga máxima a aplicar no debía ser superior a $0,4 F_{\max }$, no debiendo dañar en ningún momento la probeta. La presión se mantuvo hasta alcanzar una carga (dentro del tramo elástico del material) suficiente para obtener la gráfica deformación-fuerza.

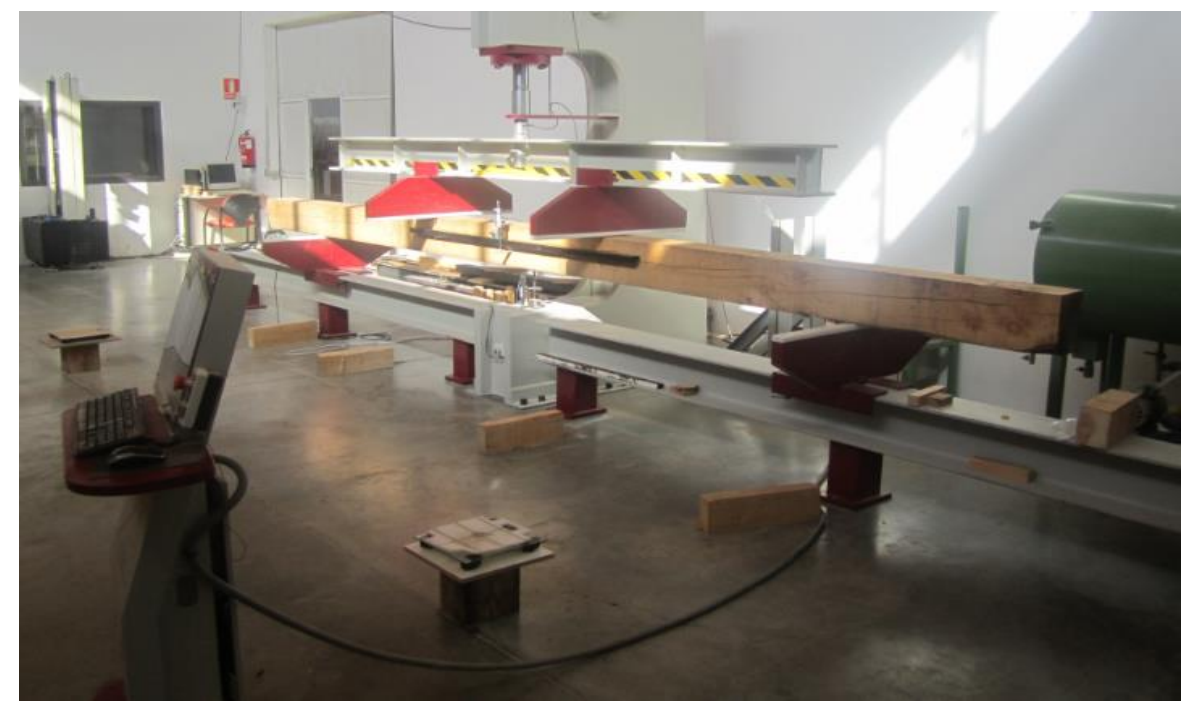

FIGURA.5.51 BANCO DE FLEXIÓN PARA ENSAYOS DE MADERA.

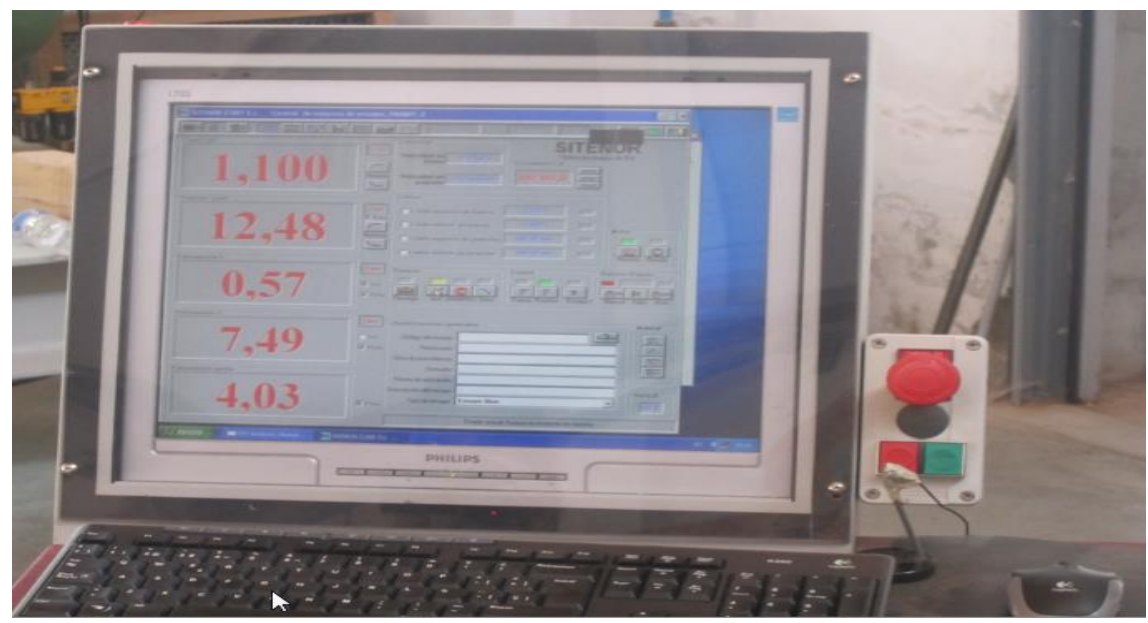

FIGURA. 5.52. MEDICIONES DEL ENSAYO DE FLEXIÓN.

A partir de los valores de deformación-carga, como se representan en la figura 4.54 obtenidos para cada uno de los módulos de elasticidad se debe buscar el tramo más largo de cada sección que de un coeficiente de correlación de 0,99 o mejor. 
La Norma UNE-EN 408: 2011 + A1: 2012, establece como requisito mínimo incluir el tramo comprendido entre el $0,2 F_{\max }$ y $0,3 F_{\max }$, siendo $F_{\max }$ la carga media de rotura. En el presente trabajo se optó por analizar el tramo comprendido entre el 0,1 y $0,4 F_{\text {max }}$, siempre y cuando se cumplieran las condiciones anteriormente nombradas, con el objetivo de recoger un tramo aún más representativo, indicado en la figura 5.53.
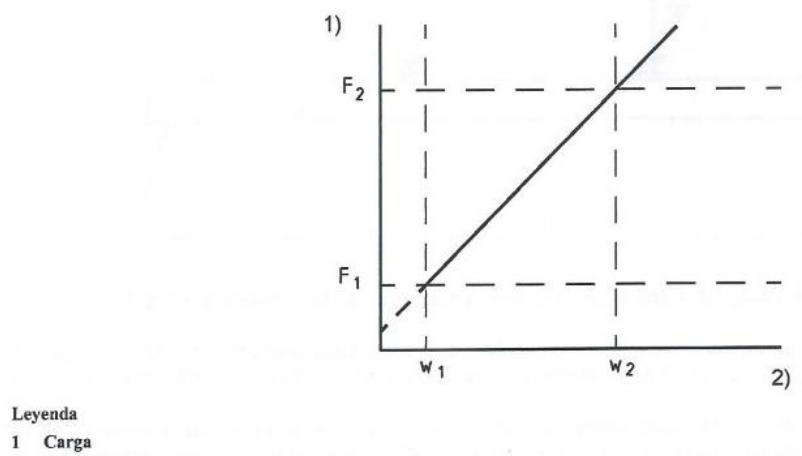

2 Deformación

FIGURA.5.53. GRÁFICO DE CARGA-DEFORMACIÓN DENTRO DE LOS MÁRGENES DE DEFORMACIÓN ELÁSTICA.

Fuente: Norma UNE-EN 408: $2011+$ A1: 2012.

-Obtención del módulo de elasticidad global de canto a flexión (MOEG)

El módulo de elasticidad global en flexión (MOEG) se obtuvo, tal y como define la norma UNE-EN 408: 2011 + A1: 2012, de:

$$
M O E G=\frac{l^{3}\left(F_{2}-F_{1}\right)}{b h^{3}\left(w_{2}-w_{1}\right)}\left[\left(\frac{3 a}{4 l}\right)-\left(\frac{a}{l}\right)^{3}\right]
$$

\section{Donde:}

$\boldsymbol{F}_{2}-\boldsymbol{F}_{1}$ es el incremento de la carga en el tramo recto de la curva de carga/deformación, en newtons, correspondiente al tramo comprendido entre el $10 \%$ y el $40 \%$ de la fuerza de rotura.

$\boldsymbol{w}_{2}-\boldsymbol{w}_{1}$ es el incremento de deformación correspondiente a $F_{2}-F_{1}$, en milímetros. I es la luz de la pieza en milímetros.

b es el ancho de la sección de la pieza, o la menor dimensión de la sección transversal de la pieza, en milímetros.

\footnotetext{
${ }^{1}$ En la norma UNE-EN 408: 2011 + A1: 2012, queda definida con la abreviatura $E_{m, g}$.
} 
$\boldsymbol{h}$ es la altura de la sección de la pieza, o la mayor dimensión de la sección transversal de la pieza, en milímetros.

a es la distancia entre un punto de carga y el apoyo más próximo en milímetros.

-Obtención del módulo de elasticidad local de canto a flexión (MOE)²:

El módulo de elasticidad local en flexión (MOE) se obtuvo, tal y como define la norma UNE-EN 408: 2011 + A1: 2012, de:

$$
M O E=\frac{a l_{1}^{2}\left(F_{2}-F_{1}\right)}{16 I\left(w_{2}-w_{1}\right)}
$$

\section{Donde:}

$\boldsymbol{F}_{2}-\boldsymbol{F}_{1}$ es el incremento de la carga en el tramo recto de la curva de carga/deformación, en newtons, correspondiente al tramo comprendido entre el $10 \%$ y el $40 \%$ de la fuerza de rotura.

$W_{2}-W_{1}$ es el incremento de deformación correspondiente a $F_{2}-F_{1}$, en milímetros.

$L$ es la luz de la pieza en milímetros.

$\boldsymbol{A}$ es la distancia entre un punto de carga y el apoyo más próximo en milímetros. I es el momento de inercia en milímetros elevados a la cuarta potencia.

La Norma UNE-EN 384:2016, establece para la determinación de los valores característicos un contenido de humedad de referencia que corresponde a una humedad ambiental del $65 \%$ y una temperatura de $20^{\circ} \mathrm{C}$, lo que supone una humedad del $12 \%$, por ello todos aquellos ensayos que no se hayan realizado a dicha humedad de referencia deberán ser corregidos, dada la influencia de la humedad respecto a los módulos de elasticidad. La corrección propuesta por dicha norma para ambos módulo de elasticidad (MOE y MOEG) es de un 1\% por cada variación del $1 \%$ del contenido de humedad. En este ajuste, aquellas probetas cuyo contenido de humedad sea mayor del $18 \%$ (extremo superior del intervalo de humedad de referencia propuesto para la humedad de la madera durante el ensayo) deben corregirse como si tuvieran un contenido de humedad del $18 \%$ y no desde su contenido real de humedad, tal y como indica además el documento de aclaraciones en la caracterización estructural de madera aserrada, AENOR, 2011, del comité técnico madera y corcho-subcomité 6 "Estructuras de madera".

- Determinación de la resistencia a flexión estática (MOR)3:

La metodología para la determinación de la resistencia a flexión estática se basa en un ensayo de idéntica configuración que el descrito para la determinación de los módulos

\footnotetext{
2 En la norma UNE-EN 408: $2011+\mathrm{A} 1: 2012$, queda definida con la abreviatura $E_{m, l}$.

${ }^{3}$ En la norma UNE-EN 408: $2011+$ A1: 2012, queda definida con la abreviatura $f_{m}$.
} 
de elasticidad global y local, es por ello que normalmente, al igual que en el presente trabajo, se opte por, una vez finalizados los ensayos para la determinación de los módulos de elasticidad, continuar aumentando la carga de la pieza hasta su rotura.

Debiendo cumplir que la carga se mantenga constante y la carga máxima (punto de rotura) se alcance en $(300 \pm 120) \mathrm{s}$, tal y como establece la Norma UNE-EN 408: 2011 $+\mathrm{A} 1: 2012$.

En cada ensayo se anotó el tiempo de ensayo hasta la rotura de cada probeta, dejando constancia de la desviación obtenida en aquellas probetas que difirieron en más de 120 $\mathrm{s}$ respecto al objetivo de $300 \mathrm{~s}$.

La resistencia a flexión estática (MOR) se obtuvo mediante la expresión:

$$
M O R=\frac{a F_{\max }}{2 W}
$$

\section{Donde:}

a es la distancia entre un punto de carga y el apoyo más próximo en milímetros.

$\boldsymbol{F}_{\max }$ es la carga máxima en newtons.

$W$ es el módulo resistente de la sección, en milímetros elevados a la tercera potencia.

Conviene reseñar que la metodología de ensayo está concebida para obtener una rotura en el tercio central de la pieza, es decir en la sección de la pieza que queda dentro de los puntos de carga y donde mayor es el momento flector, además de mantenerse constante, hecho que facilita a posteriori la determinación de la resistencia a flexión estática de cada pieza.

Es por ello que aquellas roturas que se produjeron fuera del tercio central fueron controladas y anotadas midiendo su distancia al punto de carga más próximo. En estos casos la tensión real a la que se produce la rotura no es la correspondiente al momento máximo sino al momento en la sección de rotura fuera del tercio central, de ahí que el valor real en dichas condiciones se calcula mediante una expresión diferente a la [13].

Por otra parte, para la determinación de los valores característicos no resulta necesario aplicar ningún tipo de corrección por el contenido de humedad, dada la escasa influencia de la misma en la resistencia a flexión de la madera en los contenidos de humedad de referencia de la norma UNE-EN 384:2016. En cambio, sí deben ser corregidos a un canto o altura de referencia de $150 \mathrm{~mm}$, por lo que para alturas inferiores a $150 \mathrm{~mm}$ y densidad menor o igual a $700 \mathrm{~kg} / \mathrm{m}^{3}$, los valores obtenidos se dividieron por el factor $\mathrm{kh}$ cuya expresión se indica a continuación:

$$
k_{h}=\left(\frac{150}{h}\right)^{0,2}
$$




\section{Donde:}

$\boldsymbol{h}$ es el canto de la pieza en milímetros.

Debido a que las secciones más pequeñas de las probetas analizadas $(7 \times 15 \mathrm{~cm})$ tenían un canto de $150 \mathrm{~mm}$, esta corrección tuvo que aplicarse de manera muy puntual en alguna probeta que tenía un canto ligeramente inferior, pero no resultó relevante en cuanto a la obtención del MOR de la muestra.

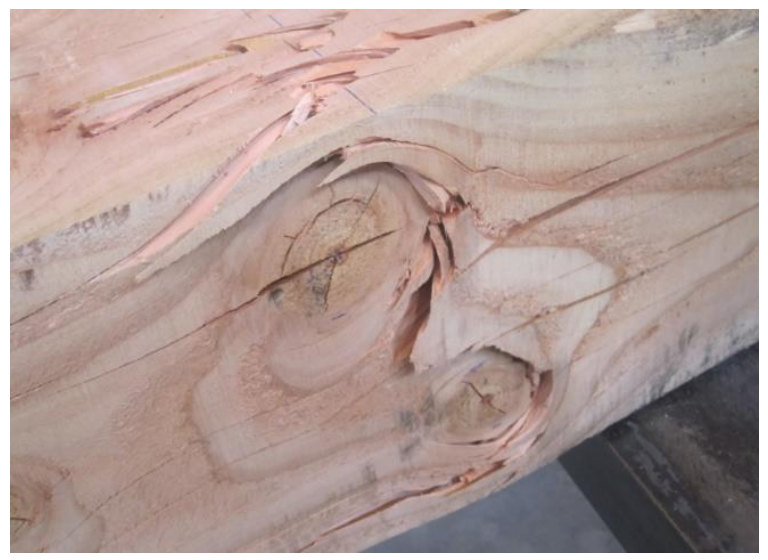

Análisis visual de la sección de rotura: Una vez finalizado el ensayo de flexión se analizó visualmente la sección de rotura de la pieza, midiendo y anotando la singularidad de la madera que previsiblemente ha provocado la rotura de la pieza (nudos, desviación de la fibra, etc.), tal y como se indica en la figura 5.54 .

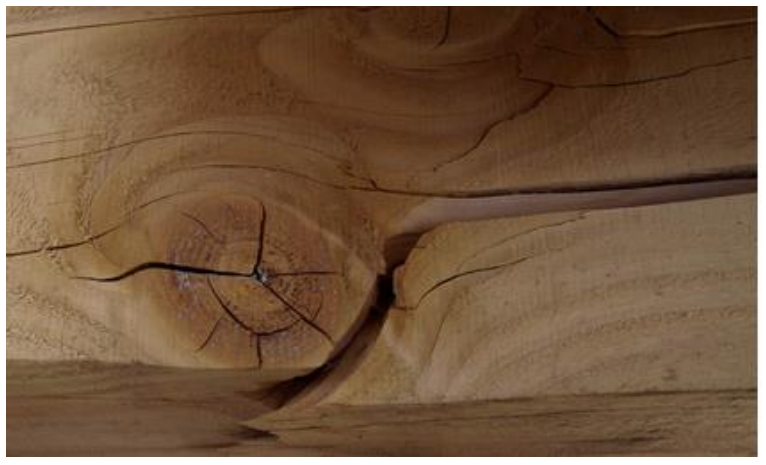

FIGURA .5.54. DETALLE DE PUNTOS DE ROTURA DE LAS VIGAS ENSAYADAS TRAS EN ENSAYO A FLEXIÓN.

\subsection{DETERMINACIÓN DE LAS PROPIEDADES FÍSICAS}

Posteriormente se procedió a extraer una rebanada de sección completa lo más próxima posible al punto de rotura y libre de defectos, tales como nudos, entrecascos, bolsas de resina, etc. Para ello se hizo uso de una motosierra eléctrica, así como de una escuadradora. El grosor de dicha rebanada fue aproximadamente de unos $5 \mathrm{~cm}$.

Cada rebanada fue identificada con el número de la viga de la que provenía. Se midieron todas las dimensiones de la pieza (longitud, anchura y espesor), para así obtener el 
volumen de la pieza. Posteriormente se obtuvo el peso húmedo, haciendo uso de una balanza analítica de precisión de 0,001 g.

A continuación, se introdujeron las rebanadas en estufas de secado a $103^{\circ} \mathrm{C}$ de temperatura. Al cabo de 24 horas se extrajeron y se pesaron nuevamente las probetas, y así sucesivamente a intervalos de 2 horas de duración, hasta que alcanzaron un peso constante, es decir se ha alcanzado el peso anhidro en la probeta. Esto se consigue cuando la diferencia de masa entre dos pesadas sucesivas sea menor del $0,1 \%$. Todo ello se realizó conforme a la norma UNE-EN 13183-1/AC: 2004.

\section{- Determinación de la humedad:}

La determinación de la humedad es necesaria ya que es un parámetro que influye directamente sobre los valores de resistencia y rigidez obtenidos para cada una de las piezas. Por ello la norma de ensayo establece una humedad de referencia para presentar y poder comparar los resultados, que no es otra que la humedad correspondiente a unas condiciones habituales en el uso de la madera, $20{ }^{\circ} \mathrm{C}$ y $65 \%$ de humedad, lo que corresponde a un contenido de humedad del $12 \%$ en la madera.

A continuación, en la figura 5.55 se representa una imagen de medición de la humedad de la probeta.

El contenido de humedad, medido en porcentaje de humedad, se obtiene de:

$$
H=\left(\frac{P_{h}-P_{0}}{P_{0}}\right) 100
$$

Donde:

$\boldsymbol{H}$ es el contenido de humedad de la probeta en tanto por ciento.

$\boldsymbol{P}_{\boldsymbol{h}}$ es el peso húmedo de la probeta en gramos.

$\boldsymbol{P}_{0}$ es el peso anhidro de la probeta en gramos.

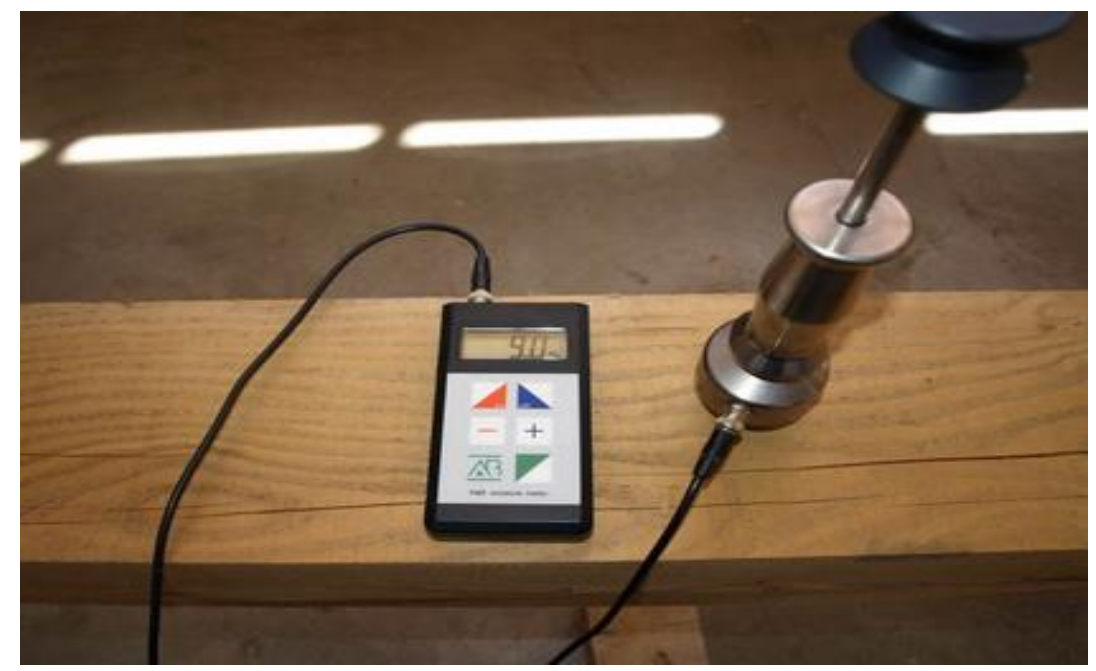




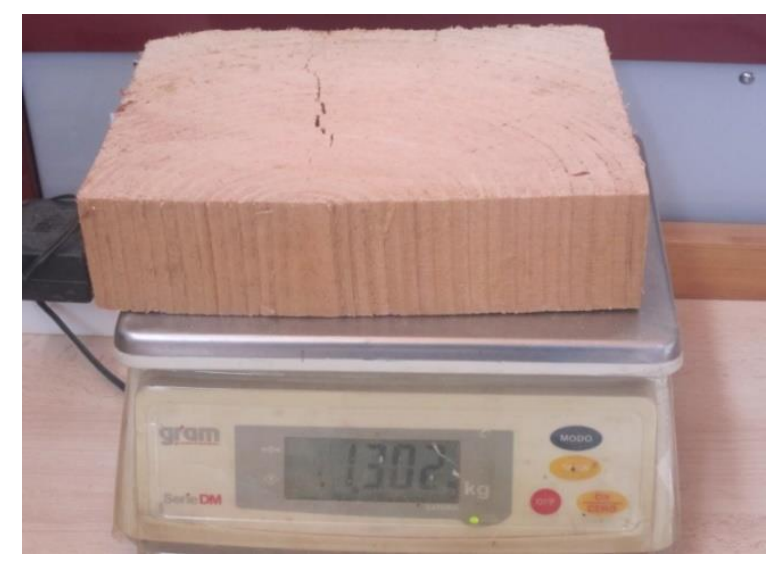

FIGURA. 5.56. DETERMINACIÓN DE LA DENSIDAD DE RODAJA TRAS ENSAYO DE ROTURA.

\section{Determinación de la densidad:}

Desde el punto de vista de la clasificación de la madera aserrada el valor que se necesita es el de la densidad normal (humedad al 12\%) estimada por el cociente peso/volumen medido a la humedad en las condiciones del laboratorio y corregida para el $12 \%$ de humedad.

A partir del volumen y del peso húmedo obtenido se calculó la densidad medida, tal y como se puede comprobar en la figura 5.56, para una determinada humedad que más adelante fue corregida a una humedad de referencia del $12 \%$, representada en la figura 5.57 tal y como establece la norma UNE-EN 384: 2016 . Se redujo el valor en un $0,5 \%$ por cada $1 \%$ de disminución en el contenido de la misma, o lo que es lo mismo, se aplicó la siguiente fórmula:

$$
\rho_{12}=\rho_{H}(1-0,005(H-12))
$$

\section{Donde:}

$\boldsymbol{\rho}_{12}$ es la densidad corregida al $12 \%$ de humedad.

$\boldsymbol{P}_{\mathbf{H}}$ es la densidad correspondiente a la humedad de la madera cuando se hizo el ensayo.

$\boldsymbol{H}$ es la humedad de la madera cuando se hizo el ensayo. 


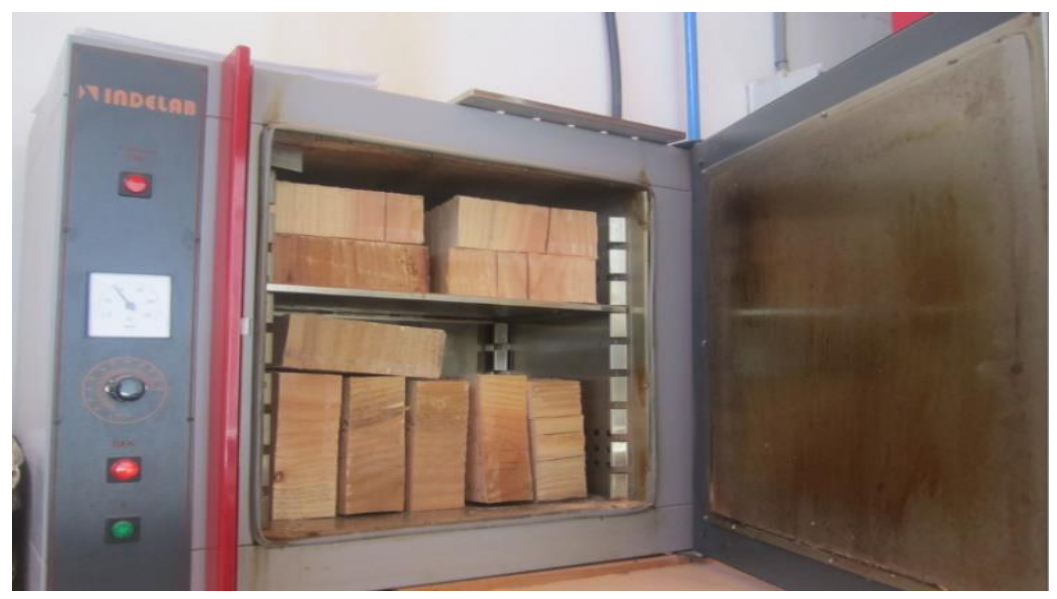

FIGURA. 5.57. INTRODUCCIÓN DE PROBETAS EN ESTUFA PARA EL CÁLCULO DE LA DENSIDAD EN SECO.

\subsection{OBTENCIÓN DE LOS VALORES CARACTERÍSTICOS}

El valor del percentil del $5 \%$ del $\operatorname{MOR}\left(f_{05, i}\right)$ y de la densidad $\left(\rho_{05, i}\right)$, así como el valor medio del MOE $\left(\bar{E}_{i}\right)$, de cada lote (submuestra $l$ ) se obtuvieron aplicando la norma UNEEN 14358:2016. Para la obtención del valor medio y la desviación típica del MOR, esta norma indica ecuaciones distintas dependiendo de si los datos se ajustan mejor a una distribución normal o a una distribución log-normal. En cambio, para el valor medio y la desviación típica del MOE y de la densidad, la norma indica directamente las ecuaciones de una distribución normal. Con estas consideraciones, el valor característico (percentil $5 \%$ ) se obtuvo mediante las siguientes expresiones:

\section{con distribución log-normal:}

$$
\boldsymbol{m}_{k}=\exp \left(\bar{y}-k_{s}(n) s_{y}\right)
$$

con distribución normal:

$$
\boldsymbol{m}_{\boldsymbol{k}}=\left(\overline{\mathrm{y}}-\boldsymbol{k}_{\boldsymbol{s}}(\boldsymbol{n}) \boldsymbol{s}_{\boldsymbol{y}}\right)
$$

\section{Donde:}

$\boldsymbol{m}_{\boldsymbol{k}} \quad$ valor del percentil del $5 \%$ parámetro estimado $\left(f_{05, i} \rho_{05, i} \bar{E}_{i}\right)$ de cada lote (submuestra i).

$\bar{y} \quad$ es el valor medio.

$\boldsymbol{s}_{\boldsymbol{y}} \quad$ es la desviación típica.

$\boldsymbol{k}_{\boldsymbol{s}}(\boldsymbol{n})$ toma el valor de $(6,5 n+6) /(3,7 n-3)$, siendo $n$ el número de probetas.

Los valores obtenidos se utilizaron posteriormente para obtener el valor característico del $\operatorname{MOR}\left(f_{k}\right)$, el MOE característico medio $\left(E_{0, \text { mean }}\right)$ y la densidad característica $\left(\rho_{k}\right)$ 
aplicando las formulaciones de la norma UNE-EN 384:2016 que se muestran a continuación:

$$
f_{k}=\min \left(1,2 f_{05, i, \min }, \frac{\sum_{i=1}^{n_{S}} n_{i} f_{05, i}}{n}\right) \cdot k_{n}
$$

\section{Donde:}

$\boldsymbol{f}_{05, i} \quad$ es el valor del $5 \circ$ percentil de la resistencia de la submuestra $i$.

$\boldsymbol{f}_{05, i, \min }$ es el menor valor del $5^{\circ}$ percentil de las resistencia de las $i$-submuestras.

$n_{\boldsymbol{s}} \quad$ es el número de submuestras.

$\boldsymbol{n}_{\boldsymbol{i}} \quad$ es el número de probetas de la submuestra $i$.

n es el número total de probetas.

$\boldsymbol{k}_{\boldsymbol{n}} \quad$ es un factor de ajuste del número de submuestras. Al tratarse de 4 lotes, toma el valor de 0,95.

$$
E_{0, \text { mean }}=\frac{\min \left(1,1 \overline{\mathrm{E}}_{i, \min }, \frac{\sum_{i=1}^{n_{S}} n_{i} \overline{\mathrm{E}}_{i}}{n}\right) \cdot k_{n}}{0,95}
$$

\section{Donde:}

$\overline{\mathbf{E}}_{\boldsymbol{i}} \quad$ es el valor medio del módulo de elasticidad de la submuestra $i$.

$\overline{\mathbf{E}}_{i, \min }$ es el menor valor medio del módulo de elasticidad de las $i$-submuestras.

$\boldsymbol{n}_{\boldsymbol{s}} \quad$ es el número de submuestras.

$\boldsymbol{n}_{\boldsymbol{i}} \quad$ es el número de probetas de la submuestra $i$.

n es el número total de probetas.

$\boldsymbol{k}_{\boldsymbol{n}} \quad$ es un factor de ajuste del número de submuestras. Al tratarse de 4 lotes, toma el valor de 0,95 .

$$
\rho_{k}=\min \left(1,1 \rho_{05, i, \min }, \frac{\sum_{i=1}^{n_{s}} n_{i} \rho_{05, i}}{n}\right) \cdot k_{n}
$$

\section{Donde:}

$\boldsymbol{\rho}_{05, i}$ es el valor del $5^{\circ}$ percentil de la resistencia de la submuestra $i$.

$\boldsymbol{\rho}_{05, \boldsymbol{i}, \min }$ es el menor valor del $5^{\circ}$ percentil de las densidades de todas las muestras.

$\boldsymbol{n}_{\boldsymbol{s}} \quad$ es el número de submuestras.

$\boldsymbol{n}_{\boldsymbol{i}} \quad$ es el número de probetas de la submuestra $i$.

n es el número total de probetas.

$\boldsymbol{k}_{\boldsymbol{n}}$ es un factor de ajuste del número de submuestras. Al tratarse de 4 lotes, toma el valor de 0,97.

\subsubsection{CLASIFICACIÓN VISUAL}


Inicialmente se analizó la distribución de los valores de resistencia, rigidez y densidad obtenidos en la muestra total, así como la distribución de las diferentes singularidades medidas, para posteriormente y con el objeto de obtener 2 clases resistentes, dividir la muestra en 2. Las 2 submuestras debían estar conformadas por 4 lotes (cada uno de ellos correspondiente con cada una de las secciones) y contener al menos 40 piezas, para que le muestra fuese estadísticamente representativa. Para cada una de las submuestras se calcularon los valores característicos de resistencia $\left(f_{k}\right)$, módulo de elasticidad medio $\left(E_{0, \text { mean }}\right)$ y densidad $\left(\rho_{k}\right)$.

Según la norma UNE-UNE 338:2016, una población se asigna a una clase resistente cuando los valores característicos $\left(f_{k}, E_{0 \text {,mean } \mathrm{y}} \rho_{k}\right)$ son iguales o mayores que los indicados en la propia norma para dicha clase resistente, de modo que los 3 valores deben verificar dicha condición.

Con el objeto de que el presente estudio no se quedase en una mera caracterización sin aplicación práctica en la industria, se procedió al análisis posterior de las tablas de clasificación obtenidas para evaluar si las clases resistentes establecidas eran competitivas, desde un punto de vista mecánico, y si la clasificación realizada se ajustaba al porcentaje de rechazos de la realidad industrial. Si no se cumplían ambos requisitos, se determinó la necesidad de modificar los criterios de clasificación tantas veces como fuese necesario hasta encontrar un resultado adecuado al material ensayado y a las necesidades de mercado.

Una vez obtenidos los criterios de clasificación se compararon con los existentes en otras normas de clasificación. Concretamente con las normas francesa NF B 52-0011:2011, italiana UNI 11035-2:2010, inglesa BS 4978:2007+A2:2017, y española UNE 56544:2011.

\subsubsection{OBTENCIÓN DE MODELOS ANALÍTICOS PARA DETERMINAR LAS PROPIEDADES MECÁNICAS}

Con el objetivo de obtener los parámetros mecánicos principales (MOEG, MOE y MOR) se elaboraron modelos analíticos basándose en las mediciones de las singularidades de la madera y en los ensayos no destructivos realizados sobre las piezas aserradas en seco (después del acondicionado).

En los modelos se consideró la totalidad de la muestra, es decir, los valores de todas las probetas ensayadas, independientemente de que éstas tuviesen clasificación visual estructural o fuesen de rechazo.

Para ello, se realizaron varios modelos de regresión múltiple, con un nivel de confianza del 95\%. Se consideraron las variables dependientes siguientes:

- MOE sin corregir por humedad $\left(\mathrm{MOE}_{\mathrm{H}}\right)$.

- MOE corregido al $12 \%$ de humedad $\left(\mathrm{MOE}_{12}\right)$.

- MOEG sin corregir por humedad $\left(\mathrm{MOEG}_{H}\right)$. 
- MOEG corregido al $12 \%$ de humedad $\left(\mathrm{MOEG}_{12}\right)$.

- MOR sin corregir por tamaño $\left(M_{S}\right)$.

- MOR corregido por tamaño (MOR $\mathrm{Kh})$.

Para la obtención de modelos analíticos de las variables dependientes, se consideraron las variables explicativas que se muestran a continuación:

- Longitud de la probeta, en cm (LON).

- Densidad de la probeta sin corregir por humedad, en $\mathrm{kg} \cdot \mathrm{m}^{-3}\left(\mathrm{DEN}_{\mathrm{H}}\right)$.

- Densidad de la probeta corregida al $12 \%$ de humedad, en $\mathrm{kg} \cdot \mathrm{m}^{-3}\left(\mathrm{DEN}_{12}\right)$.

- Velocidad de onda vibratoria sin corregir por humedad, en $\mathrm{m} \cdot \mathrm{s}^{-1}\left(\mathrm{VEV}_{\mathrm{H}}\right)$.

- Velocidad de onda vibratoria corregida al $12 \%$ de humedad, en $\mathrm{m}^{-1}\left(\mathrm{VEV}_{12}\right)$.

- Velocidad de onda sonora sin corregir por humedad, en $\mathrm{m} \cdot \mathrm{s}^{-1}\left(\mathrm{VES}_{\mathrm{H}}\right)$.

- Velocidad de onda sonora corregida al $12 \%$ de humedad, en $\mathrm{m}^{-1} \mathrm{sES}_{12}$ ).

- MOE dinámico obtenido a partir de la velocidad de onda vibratoria sin corregir por humedad, en $\mathrm{N} \cdot \mathrm{mm}^{-2}$ (MOEDVEVH).

- MOE dinámico obtenido a partir de velocidad de onda vibratoria corregida al $12 \%$ de humedad, en $\mathrm{N} \cdot \mathrm{mm}^{-2}$ (MOEDVEV12).

- MOE dinámico obtenido a partir de la velocidad de onda sonora sin corregir por humedad, en $\mathrm{N} \cdot \mathrm{mm}^{-2}$ (MOEDVESH).

- MOE dinámico obtenido a partir de velocidad de onda sonora corregida al $12 \%$ de humedad, en $\mathrm{N} \cdot \mathrm{mm}^{-2}$ (MOEDVES12).

- Relación diámetro nudo en cara/altura de la pieza + relación diámetro nudo en canto/espesor de la pieza (NUD).

- Desviación de la fibra, en \% (DOF).

- Anchura unitaria de los 5 anillos de crecimiento internos, en mmanillo-1 (WOR).

Aplicando el test de normalidad K-S, todas las variables indicadas seguían una distribución normal excepto $\mathrm{VES}_{\mathrm{H}}$ que fue necesario hacer la transformación a Ln(VES $\left.S_{H}\right), M_{V E S H}$ que se hizo la transformación a $L n\left(M O E D_{V E S H}\right)$, y DOF que se hizo la transformación a (DOF) ${ }^{11 / 20}$.

\subsubsection{EVALUACIÓN DE LA INFLUENCIA DE LA ALTURA DE LA TROZA EN EL ÁRBOL}

Dado el muestreo realizado, en que se llegó a contar en la gran mayoría de los pies con dos piezas de madera aserrada procedentes de dos trozas de diferentes alturas del árbol, se procedió al análisis de la influencia la altura del árbol en las variables caracterizadoras.

Además, se analizó el rendimiento clasificatorio, en relación a las clases visuales establecidas en este trabajo, en función de la altura del árbol. 


\subsubsection{RELACIÓN DE MOED CON MOR, MOE Y MOEG}

Se realizaron análisis de regresión simple (dos a dos) para averiguar las relaciones entre los módulos de elasticidad dinámicos (MOED), los módulos de elasticidad estáticos (MOE y MOEG) y el módulo de resistencia a flexión (MOR).

Estas relaciones se utilizaron para establecer modelos de predicción de la rigidez y de la resistencia en función de mediciones no destructivas, tanto en troza, como en probeta aserrada y seca.

\subsubsection{CLASIFICACIÓN DE LA MADERA EN TROZA}

En base a los parámetros medidos de las singularidades de la madera en troza, y a los resultados de los ensayos no destructivos aplicados en troza, se establecieron unas directrices para realizar una primera evaluación de la calidad de la madera.

\subsubsection{INFLUENCIA DE LA ÉPOCA DE CORTA EN LAS PROPIEDADES}

Finalmente se procedió al análisis de la existencia o no de diferencias significativas en diferentes propiedades de la madera entre la muestra cortada en época de luna creciente (entre 2 y 5 días tras la aparición de la luna nueva) y en época de luna menguante (entre 2 y 5 días tras la aparición de la luna llena). Las propiedades que se analizaron fueron las siguientes:

- Propiedades físicas: contenido de humedad, densidad, fendas, deformaciones, y rapidez de secado e higroscopicidad.

- Propiedades mecánicas: MOR, MOE, MOEG y MOED (el MOED se obtuvo a partir de ensayos no destructivos sobre probeta en seco).

El material de ensayo utilizado para estimar las propiedades mecánicas y físicas fueron las mismas probetas objeto de estudio en este proyecto de investigación. Sin embargo, para analizar el la rapidez de secado y la higroscopicidad se consideraron tablas sobrantes del mecanizado de las probetas mencionadas.

Concretamente, se estudiaron un total de 140 tablas: 35 tablas procedentes de pies cortados en luna creciente y de dimensiones aproximadas $4 \times 10 \times 200 \mathrm{~cm}, 35$ tablas procedentes de pies cortados en luna menguante y de dimensiones aproximadas 4x10x200 cm, 35 tablas procedentes de pies cortados en luna creciente y de dimensiones aproximadas $4 \times 10 \times 300 \mathrm{~cm}$, y 35 tablas procedentes de pies cortados en luna menguante y de dimensiones aproximadas $4 \times 10 \times 300 \mathrm{~cm}$.

Las tablas de longitud $200 \mathrm{~cm}$ se secaron en exterior bajo cubierta durante 3 meses, tomando mediciones del peso de las mismas cada 15 días. Finalmente se introdujeron en la cámara de acondicionado, aproximadamente otros 15 días, hasta alcanzar una humedad de referencia del $12 \%$. Al secar bajo cubierta estas tablas se pretendía conocer si existe alguna diferencia en la rapidez de secado entre las tablas cortadas en luna creciente y las cortadas en luna menguante. 
Las tablas de longitud $300 \mathrm{~cm}$ se secaron siguiendo el mismo procedimiento pero al aire libre. Con ello, se pretendía conocer si existe alguna diferencia en la higroscopicidad de las tablas procedentes de lunas diferentes. Es decir, en el proceso de ajuste del contenido de humedad hacia la humedad de equilibrio higroscópico, las tablas perderían humedad en periodos sin lluvias y la aumentarían en los momentos lluviosos. 


\section{RESULTADOS Y DISCUSIÓN}

\subsection{CLASIFICACIÓN VISUAL}

\subsubsection{HISTOGRAMA DE FRECUENCIAS}

En la figura 6.1 se muestra el histograma de frecuencias para las variables MOR, MOEG, MOE y densidad al $12 \%$ de todas las probetas. En todas ellas se realizó un test de normalidad K-S para verificar que efectivamente seguían una distribución normal. Además, la normalidad se verificó visualmente mediante el trazado de un Gráfico Probabilístico Normal mostrado en la figura 6.2.
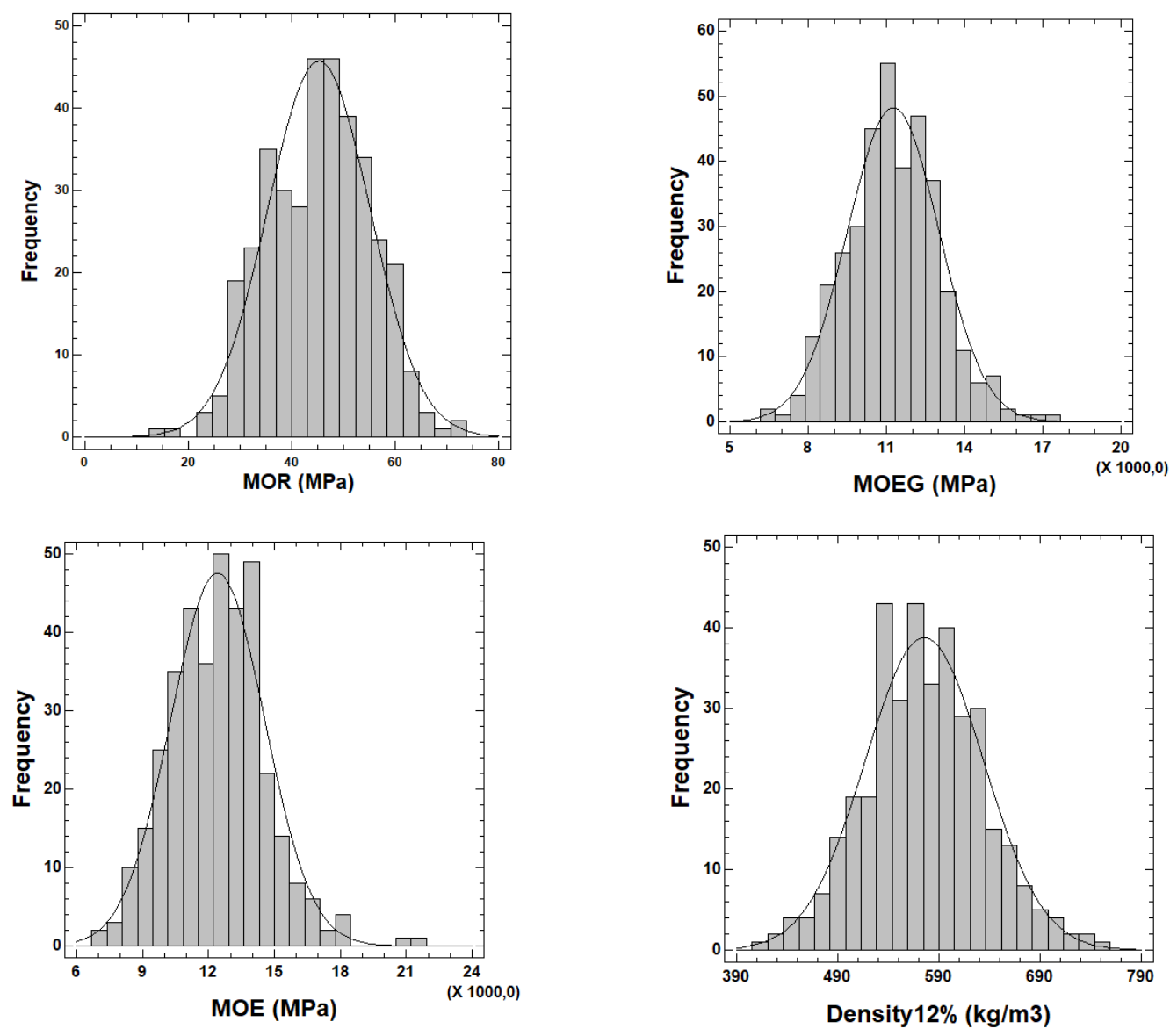

FIGURA 6.1. HISTOGRAMA DE FRECUENCIAS DE LAS VARIABLES MECÁNICAS Y LA DENSIDAD. 

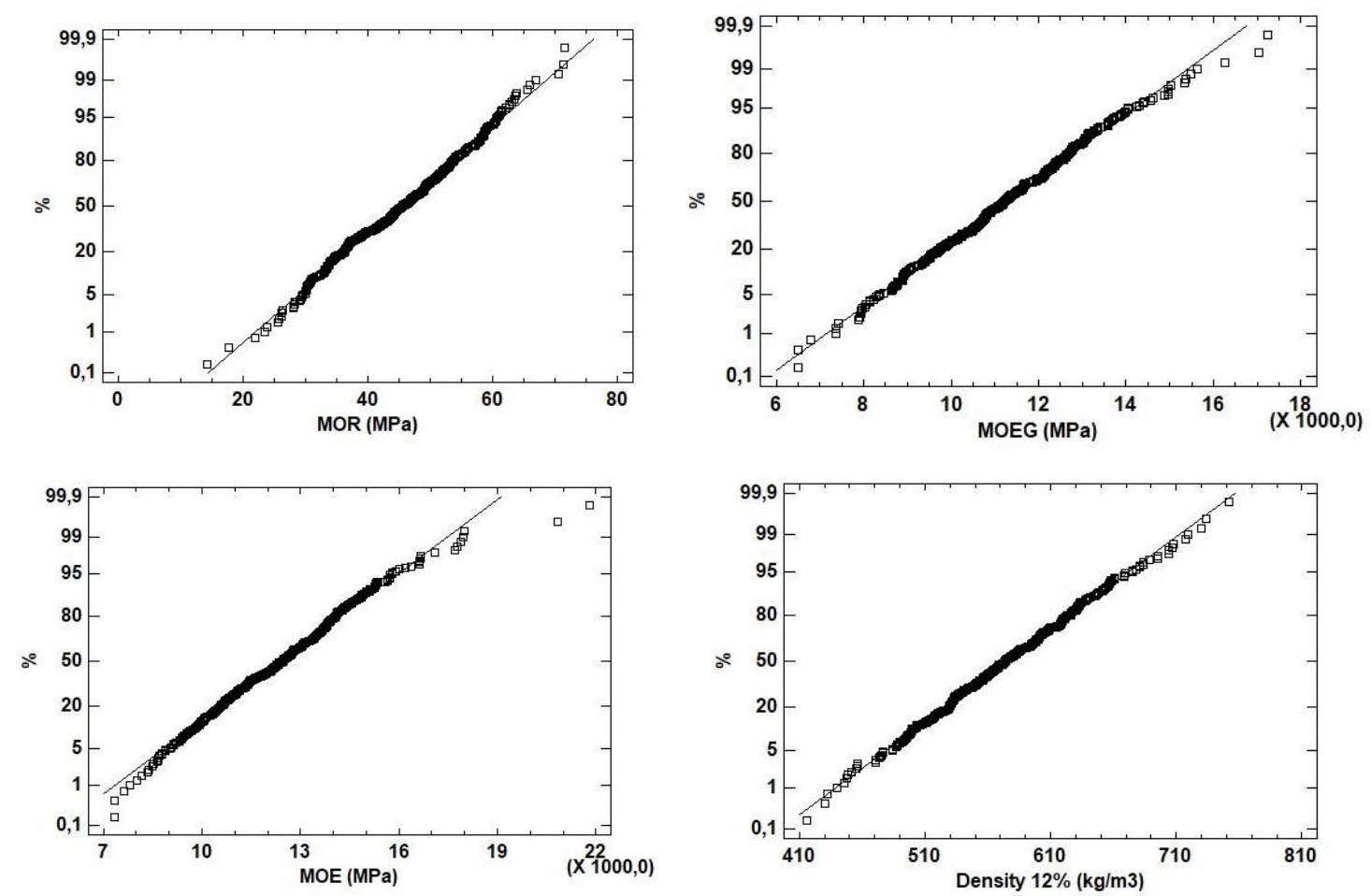

FIGURA 6.2. GRÁFICO PROBABILÍSTICO NORMAL DE LAS VARIABLES MECÁNICAS Y LA DENSIDAD.

El comportamiento del alerce de Japón a flexión es excelente superando generalmente a muchas otras coníferas utilizadas para madera estructural. El $85 \%$ de las muestras analizadas tenía una resistencia (MOR) superior a $30 \mathrm{MPa}$, el $35 \%$ una superior a 50 $\mathrm{MPa}$, llegando a detectarse valores de hasta $72 \mathrm{MPa}$. En cuanto a rigidez (MOE), el $90 \%$ de las piezas superaban los $9 \mathrm{GPa}$, el $75 \%$ superaban los 10,5 GPa, llegando a valores de 21,8 GPa. Respecto a la densidad, se trata de una conífera especialmente densa ya que el $90 \%$ de las piezas superaba los $500 \mathrm{~kg} / \mathrm{m}^{3}$, llegando a valores de 752 $\mathrm{kg} / \mathrm{m}^{3}$.

En la figura 6.3 se muestra el histograma de frecuencias de las singularidades de la madera más relevantes de las probetas clasificadas visualmente. El principal defecto que presentaba la madera eran los nudos, detectándose una elevada presencia de nudos agrupados, tanto en canto (51\% de las piezas) como en cara (85\%). Esto denota que se trata de una especie fuertemente verticilada con un número elevado de ramas por verticilo.

Alrededor del $90 \%$ de las piezas tenía una desviación de la fibra inferior al $10 \%$ que es un indicador de la calidad estructural de la madera. En cuanto al espesor de los 5 primeros anillos de crecimiento, el $85 \%$ de las piezas presentaba un crecimiento superior a $2 \mathrm{~cm} /$ anillo lo que denota un fuerte crecimiento en los primeros años. 

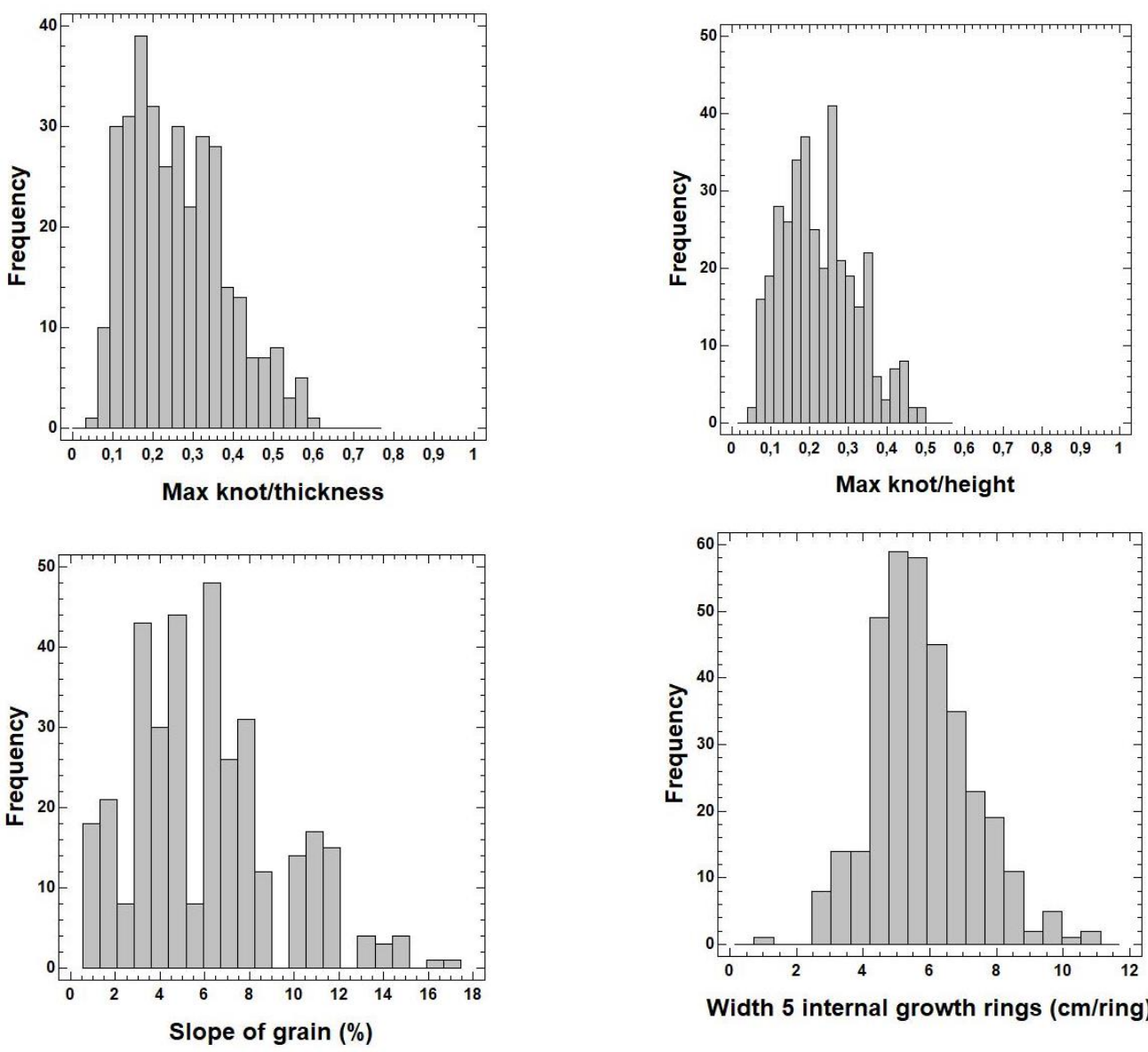

FIGURA 6.3. HISTOGRAMA DE FRECUENCIAS DE LAS SINGULARIDADES MÁS RELEVANTES. 


\subsubsection{CAUSAS DE ROTURA}

En cuanto a los motivos que provocaron la rotura en las piezas de madera, se muestran en la tabla 6.1.

TABLA 6.1: CAUSAS DE ROTURA.

\begin{tabular}{|l|l|}
\hline Causa de rotura & Porcentaje (\%) \\
\hline Sin apuntar & 1,4 \\
\hline Rotura limpia sin defectos aparente & 25 \\
\hline Rotura por nudo de cara & 9,1 \\
\hline Rotura nudos agrupados en cara & 1,4 \\
\hline Rotura por nudo de canto & 32,2 \\
\hline Rotura por nudo agrupado en canto & 9,4 \\
\hline Rotura por nudo de cara + nudo de canto & 10 \\
\hline Rotura por cortante & 1,9 \\
\hline Rotura por desviación de la fibra & 10,3 \\
\hline Bolsa de resina, separación de anillos & 0,5 \\
\hline
\end{tabular}

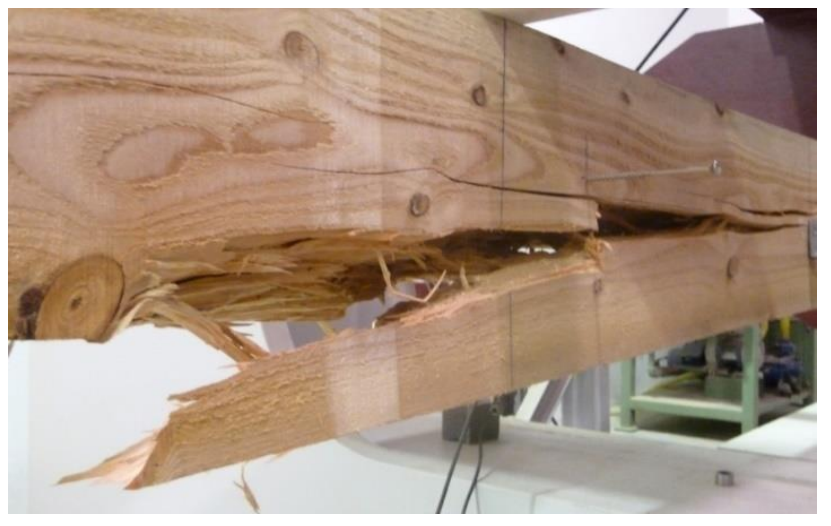

FIGURA 6.4. ROTURA POR NUDO AISLADO EN CARA.

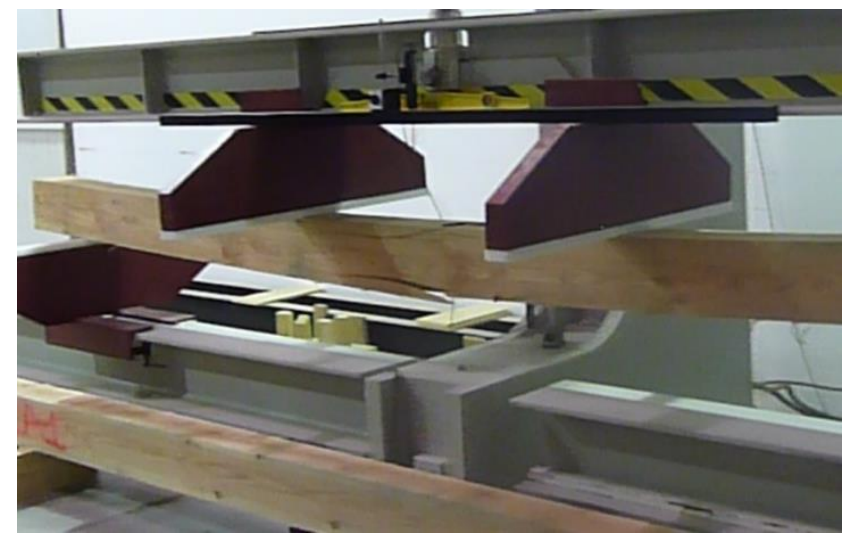

FIGURA 6.5. ROTURA POR DESVIACIÓN DE LA FIBRA.
En el ensayo mecánico a flexión, el principal motivo de rotura fueron los nudos localizados en canto, aislados o agrupados, alcanzando esta rotura el $41,6 \%$ de las piezas. Un $80 \%$ se produjo por nudos localizados en canto, un $10 \%$ por nudos combinados de cara y canto, y un $10 \%$ por nudos en cara, figura 6.4.

El segundo motivo de rotura, en porcentaje, fue la desviación de la fibra con un $10,3 \%$ de las roturas totales, figura 6.5 . 
Cabe destacar el elevado número de piezas cuya rotura se produjo de forma limpia, sin defecto aparente, aproximadamente un $25 \%$, que denotan la excelente calidad de la madera. Alguna de estas piezas si presentaron nudos en el canto pero con un tamaño reducido.

\subsubsection{INFLUENCIA DE LA SECCIÓN Y PROCEDENCIA EN EL MOR, MOE Y DENSIDAD}

Se analizó si existían diferencias estadísticamente significativas en las variables caracterizadoras (MOR, MOE y Densidad12\%) en función de la sección y de la procedencia. Para este análisis se tomaron los valores corregidos de las variables caracterizadoras, es decir, el MOR corregido por sección, el MOE corregido por humedad, y la densidad corregida por humedad.

Para ello se elaboraron diagramas de caja y bigotes y se construyó (para cada variable) una tabla ANOVA donde el valor- $P$ indica que cuando su valor es menor que 0,05 , existe una diferencia estadísticamente significativa entre las medias de todas las variables (con un nivel de significación del 5\%), figuras 6.6 y 6.7. Finalmente, para determinar qué variables eran significativamente diferentes de otras se realizaron Pruebas de Múltiples Rangos.

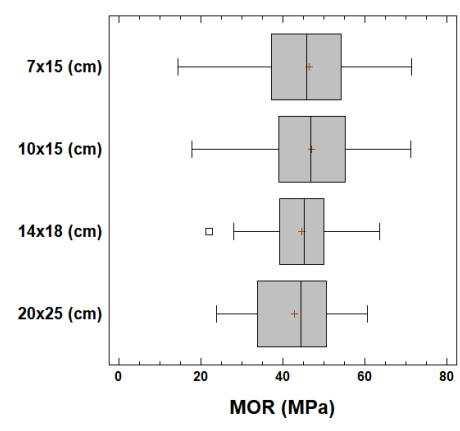

razón-F: 3,47 / valor-P: 0,0164

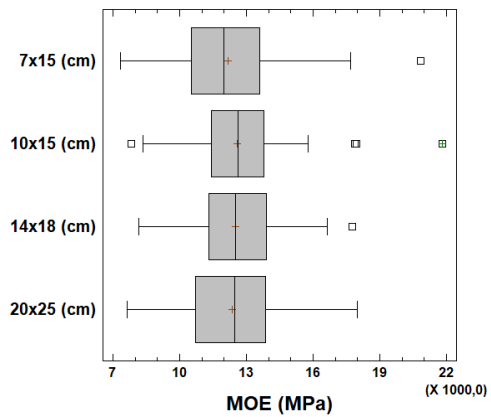

razón-F: 0,71 / valor-P: 0,5479

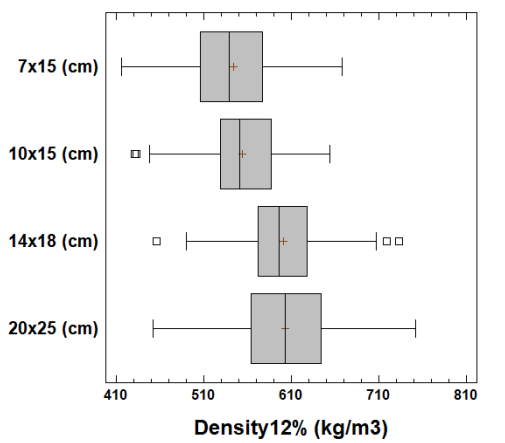

razón-F: 33,27 / valor-P: 0,0000

FIGURA 6.6. DIAGRAMAS DE CAJA Y BIGOTES SEGÚN LA SECCIÓN.

Respecto al MOR, existen diferencias significativas entre las 4 secciones ensayadas, apareciendo dos grupos homogéneos entre sí, uno formado por las secciones 14x18 y $20 \times 25$, y otro por las secciones $7 \times 15,10 \times 15$ y $14 \times 18$.

En el diagrama de caja y bigotes se muestra cómo a pesar de que todas las secciones tienen medianas similares, las probetas de menor sección tienen un rango mucho mayor así como una mayor simetría en los cuartiles Q2 y Q3 respecto a la mediana, que las probetas de mayor sección. 
Los valores del MOE son más homogéneos y no existen diferencias significativas entre las 4 secciones. Al ser la razón- $F$ menor que la unidad $(0,71)$, indica que la varianza "entre grupos" es incluso menor que la varianza "dentro de grupos". Aparecen únicamente algunos valores atípicos en las secciones $7 \times 15,10 \times 15$ y $14 \times 18$ que son poco relevantes.

En lo que se refiere a la densidad, existen diferencias significativas entre las 4 secciones mostrando claramente 2 grupos homogéneos; por un lado las secciones menores de $7 \times 15$ y $10 \times 15$, y por otro lado las secciones mayores de $14 \times 18$ y $20 \times 25$, que presentan densidades mayores que el anterior.

Esta circunstancia puede ser debida a que las masas muestreadas de alerce de Japón tienen crecimientos rápidos hasta los $40-50$ años. A partir de esa edad el crecimiento es más lento, y por tanto, mayor la densidad de las paredes celulares que se van formando. Las piezas de secciones mayores (14x18 y 20x25) provienen mayoritariamente de trozas inferiores incorporando en la sección un porcentaje más alto de madera de mayor densidad que las piezas de secciones menores (7x15 y 10x15). Además, pese a que las piezas de secciones menores se obtienen de cualquier troza, muchas de ellas provienen de las trozas superiores donde la proporción de madera juvenil respecto a la sección total es más elevada.

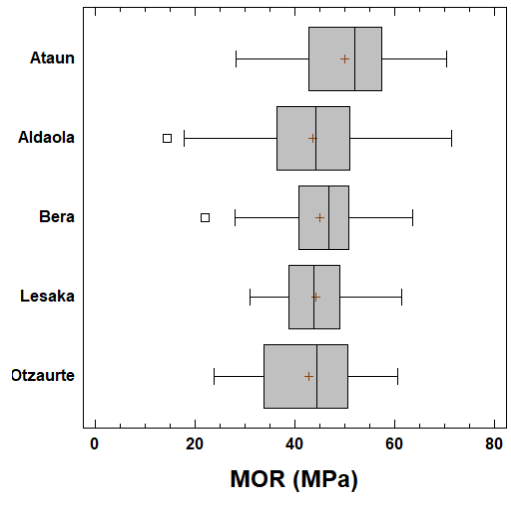

razón-F: 7,89 / valor-P: 0,0000

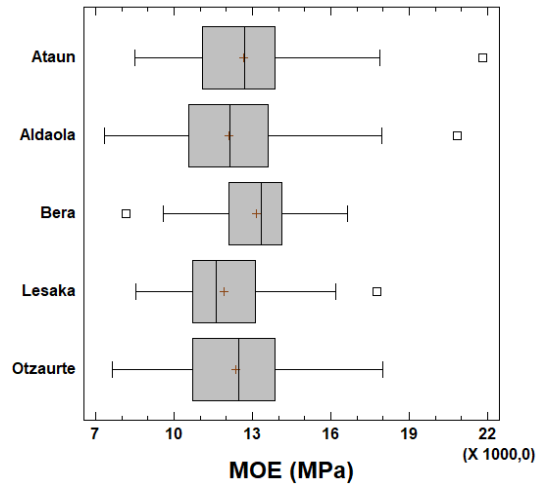

razón-F: 2,78 / valor-P: 0,0268

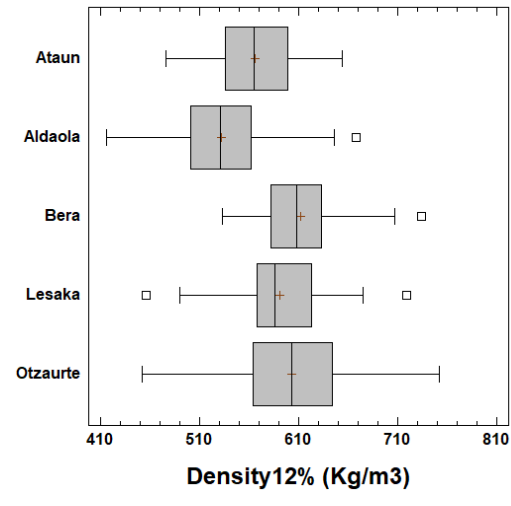

razón-F: 32,12 / valor-P: 0,0000

FIGURA 6.7. DIAGRAMAS DE CAJA Y BIGOTES SEGÚN LA PROCEDENCIA.

Respecto al MOR, existen diferencias significativas entre las 5 procedencias ensayadas. Sin embargo aparecen 2 grupos homogéneos bastante dispares, uno formado por las procedencias Aldaola, Bera, Lesaka y Otzaurte, entre los que no existen diferencias significativas; y otro formado únicamente por la precedencia Ataun, que indica valores de resistencia mayores que el resto. 
Los valores del MOE también muestran diferencias significativas entre las 5 procedencias. Al ser la razón- $F$ ligeramente mayor que la unidad $(2,78)$, indica que esta diferencia no es excesivamente acusada. Aparecen 2 grupos homogéneos, uno formado por las procedencias Aldaola, Lesaka, Otzaurte y Ataun; y otro formado por las precedencias Bera y Ataun, siendo este segundo grupo el que muestra valores de rigidez ligeramente mayores.

En lo que se refiere a la densidad, existen claramente diferencias significativas entre las 5 procedencias apareciendo hasta 3 grupos homogéneos diferentes. El primero estaría formado únicamente por la procedencia Aldaola, el segundo únicamente por la procedencia Ataun, y el tercero por las procedencias Lesaka, Otzaurde y Bera. El tercer grupo es el que muestra valores de densidad más altos, y el primero más bajos.

El análisis realizado indica que existen diferencias estadísticamente significativas entre las diferentes secciones y las diferentes procedencias. Sin embargo, también revela que no existe una evidencia estadística de que una misma sección, o una misma procedencia, sea claramente diferente del resto considerando las 3 variables caracterizadoras (MOR, MOE y densidad).

\subsubsection{CLASES VISUALES Y CLASES RESISTENTES ASIGNADAS}

Se establecen 2 clases visuales para la madera estructural de alerce del Japón, denominadas MEG-1 (Madera Estructural de Gran Escuadría-1) y MEG-2 (Madera Estructural de Gran Escuadría-2), cuyos requisitos se indican en la tabla 6.2. 
TABLA 6.2: ESPECIFICACIONES PARA LAS CLASES RESISTENTES MEG-1 Y MEG-2.

\begin{tabular}{|c|c|c|c|c|c|}
\hline \multicolumn{4}{|c|}{ Criterios de calidad } & MEG-1 & MEG-2 \\
\hline \multicolumn{4}{|c|}{ Diámetro de nudos en cara } & $\leq 1 / 4$ de "h" & $\leq 1 / 2$ de "h" \\
\hline \multicolumn{4}{|c|}{ Diámetro de los nudos sobre canto } & $\leq 1 / 3$ de "b" & $\leq 3 / 5$ de "b" \\
\hline \multicolumn{4}{|c|}{ Anchura de anillos de crecimiento ${ }^{1)}$} & $\leq 11 \mathrm{~mm} /$ anillo & $\leq 11 \mathrm{~mm} /$ anillo \\
\hline \multirow{3}{*}{ Fendas } & \multirow{2}{*}{\multicolumn{2}{|c|}{$\begin{array}{l}\text { De } \\
\text { contracción }{ }^{23)}\end{array}$}} & Pasantes & No se admite & No se admite \\
\hline & & & $\begin{array}{l}\text { No pasantes } \\
\text { (profundidad) }\end{array}$ & $\begin{array}{l}<1 / 2 \text { de "b" se admite. } \\
\geq 1 / 2 \text { de "b" se admite si } \\
\text { la longitud es menor o } \\
\text { igual que el menor de } \\
\text { los valores: } 1 / 4 \text { de la } \\
\text { longitud de la pieza y } 1 \\
\text { metro. }\end{array}$ & $\begin{array}{l}<1 / 2 \text { de "b" se admite. } \\
\geq 1 / 2 \text { de "b" se admite } \\
\text { si longitud es menor o } \\
\text { igual que el menor de } \\
\text { los valores: } 1 / 4 \text { de la } \\
\text { longitud de la pieza y } \\
1 \text { metro. }\end{array}$ \\
\hline & \multicolumn{3}{|c|}{$\begin{array}{l}\text { De rayo, de heladura, de } \\
\text { abatimiento }\end{array}$} & No se admite & No se admite \\
\hline \multicolumn{4}{|c|}{ Acebolladuras } & No se admite & No se admite \\
\hline \multicolumn{4}{|c|}{ Bolsas de resina y Entrecasco } & No se admite & $\leq 3 / 2$ de "h" \\
\hline \multicolumn{4}{|c|}{ Desviación de la fibra } & $\leq 1: 11(9,1 \%)$ & $\leq 1: 6(16,7 \%)$ \\
\hline \multicolumn{4}{|c|}{ Madera de reacción } & $\begin{array}{l}\leq 1 / 5 \text { de la sección o de } \\
\text { la superficie externa de } \\
\text { la pieza }\end{array}$ & $\begin{array}{l}\leq 2 / 5 \text { de la sección } 0 \\
\text { de la superficie } \\
\text { externa de la pieza }\end{array}$ \\
\hline \multirow{2}{*}{\multicolumn{2}{|c|}{ Gemas }} & Longit & & $\leq 1 / 3$ de "L" & $\leq 1 / 3$ de "L" \\
\hline & & Anchu & y espesor & $\leq 1 / 4$ de "b" & $\leq 1 / 3$ de "b" \\
\hline \multicolumn{4}{|c|}{ Médula1) } & Se admite & Se admite \\
\hline \multirow{3}{*}{\multicolumn{2}{|c|}{$\begin{array}{l}\text { Alteraciones } \\
\text { biológicas }\end{array}$}} & Pudric & & No se admite & No se admite \\
\hline & & Insectc & xilófagos & No se admite & No se admite \\
\hline & & Azulad & & Se admite & Se admite \\
\hline \multirow{4}{*}{\multicolumn{2}{|c|}{$\begin{array}{l}\text { Deformaciones } \\
\text { máximas } \text { 2) 3) 4) }^{\text {4) }}\end{array}$}} & Curvat & a de cara & $\begin{array}{l}\leq 10 \mathrm{~mm} \text { (para } 2 \mathrm{~m} \text { de } \\
\text { longitud) }\end{array}$ & $\begin{array}{l}\leq 10 \mathrm{~mm} \text { (para } 2 \mathrm{~m} \text { de } \\
\text { longitud) }\end{array}$ \\
\hline & & Curvat & a de canto & $\begin{array}{l}\leq 8 \mathrm{~mm} \text { (para } 2 \mathrm{~m} \text { de } \\
\text { longitud) }\end{array}$ & $\begin{array}{l}\leq 8 \mathrm{~mm} \text { (para } 2 \mathrm{~m} \text { de } \\
\text { longitud) }\end{array}$ \\
\hline & & Alabeo & & $\begin{array}{l}\leq 1 \mathrm{~mm} \text { (por cada } 25 \mathrm{~mm} \\
\text { de "h") }\end{array}$ & $\begin{array}{l}\leq 1 \mathrm{~mm} \text { (por cada } 25 \\
\mathrm{~mm} \text { de "h") }\end{array}$ \\
\hline & & Atejad & o abarquillado & Sin limitación & Sin limitación \\
\hline \multicolumn{6}{|c|}{ Notas: } \\
\hline 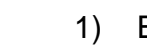 & \multicolumn{5}{|c|}{ Estas características solo se consideran cuando se comercializa en húmedo. } \\
\hline 2) & \multicolumn{5}{|c|}{ Estas características no se consideran cuando la clasificación se efectúa en húmedo. } \\
\hline 3) & \multicolumn{5}{|c|}{ Referidas a una humedad del $20 \%$. } \\
\hline 4) & \multicolumn{5}{|c|}{$\begin{array}{l}\text { Pueden aceptarse deformaciones mayores siempre que no afecten a la estabilidad de la } \\
\text { construcción (por que puedan corregirse durante la fase del montaje) y exista un acuerdo expreso al } \\
\text { respecto entre el suministrador y el cliente. }\end{array}$} \\
\hline
\end{tabular}


Para determinar los criterios de clasificación de las fendas y de las deformaciones máximas se consideraron las limitaciones indicadas en la norma UNE-EN 14081$1: 2016$, tablas 6.3 y 6.4 .

TABLA 6.3: LONGITUD TOTAL MÁXIMA DE LAS PIEZAS SEGÚN NORMA UNE-EN 14081-1:2016.

\begin{tabular}{|c|c|c|}
\hline Tipo & $\begin{array}{c}\text { Longitud máxima admitida } \\
\text { correspondiente a las clases resistes } \\
\text { inferiores o iguales a C18 }\end{array}$ & $\begin{array}{c}\text { Longitud máxima admitida } \\
\text { correspondiente a las clases resistes } \\
\text { superiores a } C 18^{2)}\end{array}$ \\
\hline \multirow[b]{2}{*}{ Fendas no pasantes } & \multicolumn{2}{|c|}{ Las fendas que profundicen menos de la mitad pueden despreciarse } \\
\hline & $\begin{array}{l}\text { No mayores que } 1,5 \mathrm{~m} \circ 1 / 2 \text { de la longitud } \\
\text { de la pieza, la que sea menor }\end{array}$ & $\begin{array}{l}\text { No mayores que } 1 \mathrm{~m} 1 / 4 \text { de la longitud de } \\
\text { la pieza, la que sea menor }\end{array}$ \\
\hline Fendas pasantes & $\begin{array}{l}\text { No mayores que } 1 \mathrm{~m}^{1 / 4} \text { de la longitud de } \\
\text { la pieza, la que sea menor. Si están en los } \\
\text { extremos, la longitud no debe ser mayor } \\
\text { que dos veces el ancho de la pieza. }\end{array}$ & $\begin{array}{l}\text { Solo se admiten en los extremos y si son } \\
\text { de longitud no mayor que el ancho de la } \\
\text { pieza. }\end{array}$ \\
\hline
\end{tabular}

Nota: La longitud de las fendas es función del contenido de humedad, y en consecuencia, las limitaciones anteriores son únicamente aplicables al momento de la clasificación.

1) Los límites admisibles tanto para la profundidad como para la longitud de las fendas se refieren a la suma acumulada en una misma cara de una pieza de madera.

2) Según la norma UNE-EN 338:2016.

TABLA 6.4: DEFORMACIÓN MÁXIMA (EN MM) EN 2 M DE LONGITUD SEGÚN NORMA UNE-EN 14081-1:2016.

\begin{tabular}{|c|c|c|}
\hline Tipo & $\begin{array}{c}\text { Desviación máxima admisible } \\
\text { para clases resistentes inferiores } \\
\text { o iguales a } \mathrm{C18}^{2)}\end{array}$ & $\begin{array}{c}\text { Desviación máxima admisible } \\
\text { para clases resistentes } \\
\text { superiores a } C 18^{2}\end{array}$ \\
\hline Curvatura de cara & 20 & 10 \\
\hline Curvatura de canto & 12 & 8 \\
\hline Alabeo & $2 \mathrm{~mm} / 25 \mathrm{~mm}$ de anchura & $1 \mathrm{~mm} / 25 \mathrm{~mm}$ de anchura \\
\hline Abarquillado & Sin limitación & Sin limitación \\
\hline $\begin{array}{l}\text { Para otras longitud } \\
\text { Según la norma UI }\end{array}$ & $\begin{array}{l}\text { xtrapolarse las deformaciones. } \\
2016 \text {. }\end{array}$ & \\
\hline
\end{tabular}


La clasificación resultante de piezas de cada lote como MEG-1, MEG-2 y rechazo, se detalla en la tabla 6.5 .

TABLA 6.5. PIEZAS DE CADA SECCIÓN CLASIFICADAS COMO MEG-1, MEG-2 Y RECHAZADAS.

\begin{tabular}{|c|c|c|c|c|c|}
\hline Lote & Sección & Procedencia & Clase visual & $\begin{array}{l}\text { № de } \\
\text { piezas }\end{array}$ & Rechazos (\%) \\
\hline \multirow{3}{*}{1} & \multirow{3}{*}{$15 \times 7$} & \multirow{3}{*}{ Gipuzkoa } & MEG-1 & 40 & \multirow{3}{*}{4,3} \\
\hline & & & MEG-2 & 48 & \\
\hline & & & Rechazos & 4 & \\
\hline \multirow{3}{*}{2} & \multirow{3}{*}{$15 \times 10$} & \multirow{3}{*}{ Gipuzkoa } & MEG-1 & 40 & \multirow{3}{*}{5,4} \\
\hline & & & MEG-2 & 47 & \\
\hline & & & Rechazos & 5 & \\
\hline \multirow{3}{*}{3} & \multirow{3}{*}{$18 \times 14$} & \multirow{3}{*}{ Navarra } & MEG-1 & 47 & \multirow{3}{*}{1,1} \\
\hline & & & MEG-2 & 42 & \\
\hline & & & Rechazos & 1 & \\
\hline \multirow{3}{*}{4} & \multirow{3}{*}{$25 \times 20$} & \multirow{3}{*}{ Gipuzkoa } & MEG-1 & 52 & \multirow{3}{*}{4,2} \\
\hline & & & MEG-2 & 40 & \\
\hline & & & Rechazos & 4 & \\
\hline
\end{tabular}

Con los criterios de clasificación visual establecidos fue necesario rechazar 14 piezas de 370 piezas ensayadas, lo que equivale a un porcentaje de rechazo del 3,8\%. Este rechazo tan reducido permite considerar que el rendimiento de clasificación es muy elevado y bien ajustado a las condiciones habituales de fabricación. El 48,4\% de las piezas se clasificó como MEG-1 y el 47,8\% como MEG-2.

De cada uno de los lotes conformados por muestras clasificadas como MEG-1 y MEG2 se determinaron los valores característicos de MOR, MOE y densidad. Los resultados obtenidos se muestran en las tablas 6.6 y 6.7 .

Para analizar si los datos de resistencia se ajustaban mejor a una distribución normal o a una distribución log-normal, para cada lote se realizó una prueba de bondad de ajuste de Kolmogorov-Smirnov. Se observó que los lotes 2 y 4, de las probetas asignadas como MEG-2, se ajustaban mejor a una distribución log-normal, al igual que sucede en otras investigaciones llevadas a cabo con Larix gmelinii del noreste de China (Wanli et al., 2012). 
TABLA 6.6. VALORES CARACTERÍSTICOS DEL MOR, MOE Y DENSIDAD DE LA CLASE VISUAL MEG-1.

\begin{tabular}{|c|c|c|c|c|}
\hline Lote & $\begin{array}{c}\text { Número de } \\
\text { probetas MEG- } \\
1\end{array}$ & $\begin{array}{c}f_{05, i} \\
(\mathrm{CoV})\end{array}$ & $\begin{array}{c}\bar{E}_{i}(\mathrm{MPa}) \\
(\mathrm{CoV})\end{array}$ & $\begin{array}{c}\rho_{05, i}\left(\mathrm{~kg} / \mathrm{m}^{3}\right) \\
12 \% \text { de humedad } \\
(\mathrm{CoV})\end{array}$ \\
\hline 1 & 40 & $\begin{array}{c}34,18 \\
(0,29) \text { normal }\end{array}$ & $\begin{array}{l}12.691 \\
(0,20)\end{array}$ & $\begin{array}{l}439,2 \\
(0,10)\end{array}$ \\
\hline 2 & 40 & $\begin{array}{c}31,77 \\
(0,29) \text { normal }\end{array}$ & $\begin{array}{l}12.798 \\
(0,15)\end{array}$ & $\begin{array}{l}463,9 \\
(0,08)\end{array}$ \\
\hline 3 & 47 & $\begin{array}{c}33,63 \\
(0,18) \text { normal }\end{array}$ & $\begin{array}{l}12.706 \\
(0,16)\end{array}$ & $\begin{array}{l}525,6 \\
(0,07)\end{array}$ \\
\hline 4 & 52 & $\begin{array}{c}34,08 \\
(0,23) \text { normal }\end{array}$ & $\begin{array}{l}13.013 \\
(0,14)\end{array}$ & $\begin{array}{l}482,6 \\
(0,10)\end{array}$ \\
\hline & & $f_{k}(M P a)$ & $\begin{array}{l}E_{0, \text { mean }} \\
(\mathrm{MPa})\end{array}$ & $\begin{array}{c}\rho_{k}\left(\mathrm{~kg} / \mathrm{m}^{3}\right) \\
12 \% \text { humedad }\end{array}$ \\
\hline & & 31,80 & 13.082 & 465,6 \\
\hline \multicolumn{2}{|c|}{$\begin{array}{l}\text { Clase resistente } \\
\text { UNE-EN } 338\end{array}$} & $\mathrm{C} 30$ & C35 & C50 \\
\hline
\end{tabular}

TABLA 6.7. VALORES CARACTERÍSTICOS DEL MOR, MOE Y DENSIDAD DE LA CLASE VISUAL MEG-2.

\begin{tabular}{|c|c|c|c|c|}
\hline Lote & $\begin{array}{l}\text { Número de } \\
\text { probetas MEG- } \\
2\end{array}$ & $\begin{array}{c}f_{05, i} \\
(\mathrm{CoV})\end{array}$ & $\begin{array}{c}\bar{E}_{i}(\mathrm{MPa}) \\
(\mathrm{CoV})\end{array}$ & $\begin{array}{c}\rho 05, i\left(\mathrm{~kg} / \mathrm{m}^{3}\right) \\
12 \% \text { de humedad } \\
(\mathrm{CoV})\end{array}$ \\
\hline 1 & 48 & $\begin{array}{c}25,63 \\
(0,22) \text { normal }\end{array}$ & $\begin{array}{l}11.847 \\
(0,16)\end{array}$ & $\begin{array}{l}465,5 \\
(0,09)\end{array}$ \\
\hline 2 & 47 & $\begin{array}{c}26,93 \\
(0,07) \text { log-normal }\end{array}$ & $\begin{array}{c}12.372 \\
(0,19)\end{array}$ & $\begin{array}{l}467,8 \\
(0,09)\end{array}$ \\
\hline 3 & 42 & $\begin{array}{c}26,59 \\
(0,20) \text { normal }\end{array}$ & $\begin{array}{l}12.295 \\
(0,15)\end{array}$ & $\begin{array}{l}502,6 \\
(0,09)\end{array}$ \\
\hline 4 & 40 & $\begin{array}{c}24,04 \\
(0,07) \text { log-normal }\end{array}$ & $\begin{array}{l}11.730 \\
(0,19)\end{array}$ & $\begin{array}{l}504,1 \\
(0,10)\end{array}$ \\
\hline & & $f_{k}(M P a)$ & $\begin{array}{l}E_{0, \text { mean }} \\
(\mathrm{MPa})\end{array}$ & $\begin{array}{c}\rho_{k}\left(\mathrm{~kg} / \mathrm{m}^{3}\right) \\
12 \% \text { humedad }\end{array}$ \\
\hline & & 24,55 & 12.320 & 469,1 \\
\hline \multicolumn{2}{|c|}{$\begin{array}{l}\text { Clase resistente } \\
\text { UNE-EN } 338\end{array}$} & $\mathrm{C} 24$ & C30 & C50 \\
\hline
\end{tabular}

Una vez obtenidos los valores de resistencia, rigidez y densidad ( $f_{k}, E_{0, \text { mean }}$ y $\left.\rho_{k}\right)$ para cada clase visual, el menor de ellos es el que determina la clase resistente a la que se puede asignar una población (según la norma UNE-EN 338:2016). Así, a la denominación MEG-1 se le asignaría una clase resistente C30, y a la denominación MEG-2, una clase resistente C24. 


\subsubsection{COMPARACIÓN CON NORMAS DE CLASIFICACIÓN VISUAL EXISTENTES}

Comparando los criterios de clasificación establecidos con la norma francesa NF B 52001-1:2011 para el alerce europeo (Larix decidua), a priori se puede indicar que las limitaciones en cuanto al tamaño y disposición de los nudos, que es la singularidad que más incide en la calidad estructural de la madera (Bunetti et al., 2016; Moriguchi et al., 2016; Jung-Kwon et al., 2016; Takashi and Takeo, 1999), son similares, aunque no iguales, en las clases visuales ST-I y MEG-1, y en las clases ST-II y MEG-2. Estas semejanzas se evidencian también en la similitud de asignación de clases resistentes ya que la ST-I equivale a una C27 y la ST-II a una C24 (según la norma EN 1912:2012).

La norma de clasificación italiana UNI 11035-2:2010 establece para el alerce europeo una clase visual S2 y mejor (que es una agrupación de las clases S1 y S2), asimilable a la MEG-2, que se corresponde con una clase resistente C22 (según la norma EN 1912:2012). En general, esta norma tiene un bajo rendimiento clasificatorio e infravalora la capacidad resistente de esta especie según los resultados de un trabajo de investigación llevado a cabo con madera de los Alpes italianos y franceses, donde se obtuvieron mediante clasificación mecánica asignaciones resistentes de C30/C24/C18/R (Bunetti et al., 2016).

La norma de clasificación inglesa BS 4978:2007+A2:2017 establece, en el mejor de los casos, una clase visual SS para el alerce europeo y para el alerce de Japón que se corresponde con una clase resistente C24 (según la norma EN 1912:2012). En este sentido, cabe señalar que la norma inglesa utiliza un sistema de medición de nudos diferente de la norma europea (EN 1309-3:2018) que dificulta enormemente su comparación objetiva con el resto.

Respecto a la norma de clasificación española UNE 56544:2011, los criterios de clasificación visual para la clase MEG, establecida para diferentes especies del género Pinus, se ajustan en gran medida a las limitaciones establecidas en la clase visual MEG2, para el alerce de Japón, excepto para los nudos de cara donde la limitación se ha fijado en 1/2 en lugar de 2/3; y para los nudos de canto, donde la limitación se ha fijado en $3 / 5$ en lugar de $2 / 3$.

\subsection{MODELOS ANALÍTICOS PARA DETERMINAR LAS PROPIEDADES MECÁNICAS}

En la tabla 6.8 se muestran los valores medios y los coeficientes de variación (CV) de las variables explicativas y estimadas obtenidos en la fase experimental. 
TABLA 6.8. VALORES MEDIOS Y COEFICIENTES DE VARIACIÓN DE LAS VARIABLES EXPLICATIVAS Y ESTIMADAS.

\begin{tabular}{|c|c|c|c|c|}
\hline Variable & Unidad & $\begin{array}{l}\text { Media } \\
\text { (CV) }\end{array}$ & Valor mínimo & $\begin{array}{c}\text { Valor } \\
\text { máximo }\end{array}$ \\
\hline MOE $_{H}$ & $\mathrm{~N} / \mathrm{mm}^{2}$ & $\begin{array}{c}11.893 \\
(0,18)\end{array}$ & 6.910 & 20.790 \\
\hline $\mathrm{MOE}_{12}$ & $\mathrm{~N} / \mathrm{mm}^{2}$ & $\begin{array}{l}12.407 \\
(0,17)\end{array}$ & 7.324 & 21.815 \\
\hline MOEG $_{H}$ & $\mathrm{~N} / \mathrm{mm}^{2}$ & $\begin{array}{c}10.779 \\
(0,16) \\
\end{array}$ & 6.143 & 16.264 \\
\hline $\mathrm{MOEG}_{12}$ & $\mathrm{~N} / \mathrm{mm}^{2}$ & $\begin{array}{c}11.248 \\
(0,16) \\
\end{array}$ & 6.493 & 17.240 \\
\hline MORs & $\mathrm{N} / \mathrm{mm}^{2}$ & $\begin{array}{l}45,25 \\
(0,22)\end{array}$ & 14,35 & 71,58 \\
\hline MOR $_{K h}$ & $\mathrm{~N} / \mathrm{mm}^{2}$ & $\begin{array}{l}45,23 \\
(0,22)\end{array}$ & 14,35 & 71,48 \\
\hline LON & $\mathrm{cm}$ & $\begin{array}{c}383 \\
(0,23)\end{array}$ & 285 & 629 \\
\hline DEN $_{H}$ & $\mathrm{~kg} / \mathrm{m}^{3}$ & $\begin{array}{c}598 \\
(0,10)\end{array}$ & 427 & 780 \\
\hline $\mathrm{DEN}_{12}$ & $\mathrm{~kg} / \mathrm{m}^{3}$ & $\begin{array}{c}575 \\
(0,10)\end{array}$ & 416 & 752 \\
\hline VEV $_{H}$ & $\mathrm{~m} / \mathrm{s}$ & $\begin{array}{l}4.355 \\
(0,07)\end{array}$ & 2.721 & 5.126 \\
\hline $\operatorname{VEV}_{12}$ & $\mathrm{~m} / \mathrm{s}$ & $\begin{array}{l}4.678 \\
(0,08)\end{array}$ & 2.885 & 5.686 \\
\hline VES $_{H}$ & $\mathrm{~m} / \mathrm{s}$ & $\begin{array}{l}4.746 \\
(0,07)\end{array}$ & 3.915 & 7.504 \\
\hline VES $_{12}$ & $\mathrm{~m} / \mathrm{s}$ & $\begin{array}{l}5.101 \\
(0,08)\end{array}$ & 3.871 & 8.445 \\
\hline MOED $_{V E V H}$ & $\mathrm{~N} / \mathrm{mm}^{2}$ & $\begin{array}{c}11.396 \\
(0,17)\end{array}$ & 4.059 & 17.205 \\
\hline MOED $_{\mathrm{VEV} 12}$ & $\mathrm{~N} / \mathrm{mm}^{2}$ & $\begin{array}{c}12.654 \\
(0,18)\end{array}$ & 4.427 & 18.653 \\
\hline MOED $_{\mathrm{VESH}}$ & $\mathrm{N} / \mathrm{mm}^{2}$ & $\begin{array}{l}13.491 \\
(0,16)\end{array}$ & 8.521 & 32.042 \\
\hline MOED $_{\mathrm{VES} 12}$ & $\mathrm{~N} / \mathrm{mm}^{2}$ & $\begin{array}{l}15.016 \\
(0,19)\end{array}$ & 8.524 & 38.040 \\
\hline NUD & --- & $\begin{array}{c}0,48 \\
(0,42)\end{array}$ & 0,00 & 1,03 \\
\hline DOF & $\%$ & $\begin{array}{c}5,93 \\
(0,57)\end{array}$ & 0,00 & 19,00 \\
\hline WOR & $\mathrm{mm} /$ anillo & $\begin{array}{c}5,79 \\
(0,27)\end{array}$ & 1,20 & 12,81 \\
\hline
\end{tabular}


En una investigación realizada con 20 ejemplares de alerce del Japón procedentes del este de Canadá (Fowler et al., 1988), se obtuvo un MOE de $12.380 \mathrm{~N} / \mathrm{mm}^{2}(0,24)$ similar al obtenido en el presente trabajo. En otra investigación sobre 126 ejemplares de alerce del Japón, también procedentes del este de Canadá (Chui y MacKinnon-Peters, 1995), se obtuvieron valores de MOE de $8.440 \mathrm{~N} / \mathrm{mm}^{2}(0,29)$, MOR 39,51 N/mm $(0,30)$, densidad $442 \mathrm{~kg} / \mathrm{m}^{3}(0,09)$, y tasa de crecimiento $5,77 \mathrm{~mm} /$ anillo $(0,28)$. En este caso, los valores son ligeramente inferiores a los de este trabajo, excepto el ancho de los anillos de crecimiento, que es el mismo.

En un estudio experimental realizado con 600 ejemplares de alerce del Japón procedentes de Japón (Takeda y Hasizume, 1999), se obtuvo una densidad de 570 $\mathrm{kg} / \mathrm{m}^{3}(0,10)$, similar a la obtenida en este trabajo. También se obtuvo un MOED de $12.950 \mathrm{~N} / \mathrm{mm}^{2}(0,09)$ por el método de vibración longitudinal, similar al obtenido en este trabajo.

En otra investigación realizada sobre 50 ejemplares de alerce del Japón y 45 de alerce europeo procedentes de Bélgica, sin distinción entre madera juvenil y madera madura (Charron et al., 2003), se obtuvo una densidad de $526 \mathrm{~kg} / \mathrm{m}^{3}(0,15)$, un MOE de 8.600 $\mathrm{N} / \mathrm{mm}^{2}(0,33)$ y un MOR de $81,5 \mathrm{~N} / \mathrm{mm}^{2}(0,33)$ para el alerce del Japón; y una densidad de $642 \mathrm{~kg} / \mathrm{m}^{3}(0,12)$, un MOE de $12.000 \mathrm{~N} / \mathrm{mm}^{2}(0,30)$ y un MOR de 112,00 N/mm $(0,20)$ para el alerce europeo. La densidad obtenida en este trabajo fue similar a la del alerce del Japón, el MOE similar a la del alerce europeo, y el MOR inferior a cualquiera de ellos. Estos resultados dan una idea de la importancia que tiene la procedencia del material de ensayo debido a la variabilidad que existe entre ellas.

En cuanto a los coeficientes de variación obtenidos, están dentro de la normalidad al tratarse de madera, y en ninguno de los casos se supera el $27 \%$ salvo en las variables NUD y DOF donde se aprecia una variabilidad de resultados más elevada.

En las tablas 6.9. y 6.10 se muestran los coeficientes de determinación $\left(r^{2}\right)$ y los coeficientes de correlación ( $r$ ) de los modelos de regresión más representativos. En estos modelos no se ha considerado la combinación de variables NDT con variables visuales, con el objeto de obtener inicialmente información del aporte independiente de cada una de ellas.

En las tablas 6.9. y 6.10 se muestra el coeficiente de determinación $\left(r^{2}\right)$ ajustado ya que valora con mayor exactitud la información aportada por cada una de las variables explicativas. 
TABLA 6.9. COEFICIENTES DE LOS MODELOS DE REGRESIÓN PARA ESTIMAR EL MOE ${ }_{\mathrm{H}}$, MOEG $_{\mathrm{H}}$ Y MOR

\begin{tabular}{|c|c|c|c|}
\hline $\begin{array}{l}\text { Variables estimadas } \\
\text { Variables explicativas }\end{array}$ & $\begin{array}{l}\mathrm{MOE}_{\mathrm{H}} \\
\mathrm{r}^{2}(\mathrm{r})\end{array}$ & $\begin{array}{c}\text { MOEG }_{H} \\
r^{2}(r)\end{array}$ & $\begin{array}{l}\text { MORs } \\
r^{2}(r)\end{array}$ \\
\hline $\mathrm{VEV}_{\mathrm{H}}$ & $0,43(0,66)$ & $0,42(0,65)$ & $0,20(0,45)$ \\
\hline $\operatorname{Ln}\left(\mathrm{VES}_{\mathrm{H}}\right)$ & $0,24(0,49)$ & $0,18(0,42)$ & $0,15(0,39)$ \\
\hline $\mathrm{VEV}_{\mathrm{H}}+\mathrm{DEN}_{\mathrm{H}}+\mathrm{LON}$ & $0,55(0,74)$ & $0,62(0,79)$ & $0,34(0,58)$ \\
\hline $\mathrm{Ln}\left(\mathrm{VES}_{\mathrm{H}}\right)+\mathrm{DEN}_{\mathrm{H}}+\mathrm{LON}$ & $0,38(0,62)$ & $0,48(0,69)$ & $0,23(0,48)$ \\
\hline MOEDVEVH & $0,50(0,71)$ & $0,62(0,79)$ & $0,19(0,44)$ \\
\hline Ln(MOEDVESH) & $0,38(0,62)$ & $0,46(0,68)$ & $0,17(0,41)$ \\
\hline MOEDVEVH + LON & $0.56(0.75)$ & $0.63(0.79)$ & $0.34(0.58)$ \\
\hline Ln(MOEDVESH $)+$ LON & $0.38(0.62)$ & $0.48(0.69)$ & $0.23(0.48)$ \\
\hline NUD + DOF $11 / 20+$ WOR & $0,09(0,30)$ & $0,16(0,40)$ & $0,19(0,44)$ \\
\hline
\end{tabular}

TABLA 6.10. COEFICIENTES DE LOS MODELOS DE REGRESIÓN PARA ESTIMAR EL MOE ${ }_{12}, M_{O}$ EGG $_{12}$ Y MOR $_{\mathrm{KH}}$.

\begin{tabular}{|c|c|c|c|}
\hline $\begin{array}{l}\text { Variables estimadas } \\
\text { Variables explicativas }\end{array}$ & $\begin{array}{l}\mathrm{MOE}_{12} \\
\mathrm{r}^{2}(\mathrm{r})\end{array}$ & $\begin{array}{l}\text { MOEG }_{12} \\
r^{2}(r)\end{array}$ & $\begin{array}{c}\text { MOR }_{K h} \\
r^{2}(r)\end{array}$ \\
\hline $\mathrm{VEV}_{12}$ & $0,28(0,53)$ & $0,39(0,62)$ & $0,11(0,33)$ \\
\hline VES $_{12}$ & $0,11(0,33)$ & $0,15(0,39)$ & $0,04(0,20)$ \\
\hline $\mathrm{VEV}_{12}+\mathrm{DEN}_{12}+\mathrm{LON}$ & $0,41(0,64)$ & $0,56(0,75)$ & $0,22(0,47)$ \\
\hline $\mathrm{VES}_{12}+\mathrm{DEN}_{12}+\mathrm{LON}$ & $0,25(0,50)$ & $0,39(0,62)$ & $0,13(0,36)$ \\
\hline MOEDvEv12 & $0,38(0,62)$ & $0,56(0,75)$ & $0,13(0,36)$ \\
\hline MOEDVES12 & $0,21(0,46)$ & $0,31(0,56)$ & $0,06(0,24)$ \\
\hline MOEDVEV12 + LON & $0.42(0.65)$ & $0.56(0.75)$ & $0.22(0.47)$ \\
\hline MOEDVES12 + LON & $0.20(0.45)$ & $0.33(0.57)$ & $0.10(0.32)$ \\
\hline NUD + DOF $11 / 20+$ WOR & $0,08(0,28)$ & $0,15(0,39)$ & $0,19(0,44)$ \\
\hline
\end{tabular}

Tanto el MOE como el MOEG sin corregir por humedad $\left(\mathrm{MOE}_{H}\right.$ y $\mathrm{MOEG}_{H}$ ) se estiman con mayor exactitud que el MOE y el MOEG corregidos por humedad ( $\mathrm{MOE}_{12}$ y $\mathrm{MOEG}_{\mathrm{H}}$ ). Lo mismo sucede con el MOR sin corregir por tamaño (MORs) respecto al MOR corregido por tamaño (MOR $\mathrm{Mh}_{\mathrm{n}}$ ).

Todas las piezas ensayadas tenían un porcentaje de duramen superior al $80 \%$. Esto dificultó mucho el secado hasta el contenido de humedad de referencia del $12 \%$, especialmente en las probetas más grandes $(20 \times 25 \mathrm{~cm})$. En general, en el momento de realizar los ensayos mecánicos las probetas tenían un contenido medio de humedad del $19,4 \%$, obtenido mediante secado de rebanada en estufa. El contenido de humedad obtenido con xilohigrómetro fue de 15,8\%. Este valor es inferior debido a que la medición se realizó a una profundidad de $4 \mathrm{~cm}$, y en las probetas de sección grande el gradiente de humedad, desde el centro de la probeta hasta el exterior, puede ser relevante. 
Por otra parte, la norma UNE-EN 384:2016 indica una corrección del módulo de elasticidad (MOE y MOEG) únicamente en el tramo comprendido entre el 12 y el $18 \%$. Como la corrección por humedad empleada en los métodos no destructivos considera todo el intervalo (desde la humedad de la probeta hasta la humedad de referencia del $12 \%)$, sin tener en cuenta límites superiores, parece que la corrección de humedad realizada en los métodos no destructivos no se ajusta perfectamente al alerce de Japón debido a su elevado porcentaje de duramen y la consecuente dificultad de secado a las condiciones de referencia.

Otro resultado importante es que se consigue una mejor estimación del MOEG que del MOE, circunstancia lógica y esperable porque tanto las variables obtenidas por NDT como por análisis visual vienen determinadas por propiedades presentes en la totalidad de la pieza, y no solo en el tercio central.

Respecto a las metodologías NDT, a la hora de estimar cualquiera de las variables dependientes, el método de frecuencia de vibración longitudinal se mostró mucho más eficiente que el de velocidad de paso de onda sónica. Esta circunstancia ha sido constatada también por otros autores previamente (Martins et al., 2017; Marchal and Jacques, 1999).

Si no se consideran las variables visuales, la combinación de las variables módulo de elasticidad dinámico obtenido por vibración longitudinal (MOEDVEv) y longitud de la pieza (LON), ofrece los ajustes más adecuados para estimar cualquiera de las variables dependientes.

Las variables explicativas basadas en parámetros visuales no influyen prácticamente en la determinación del $\mathrm{MOE}$, resultado obtenido también en otras investigaciones anteriores (Vega et al., 2011). Lo hacen en mayor medida en la determinación del MOEG, pero son mucho más relevantes en la estimación del MOR. Cabe destacar que la anchura unitaria de los 5 anillos de crecimiento internos (WOR) resultó estadísticamente insignificante en todos los modelos de regresión analizados.

En cuanto a los coeficientes de determinación $\left(\mathrm{r}^{2}\right)$, en estudios realizados en los últimos años sobre coníferas se obtuvieron regresiones entre el MOEG y el MOED (utilizando el método de frecuencia de vibración longitudinal con diferentes dispositivos) de 0,76 para madera de pino silvestre y pino laricio (Llana et al., 2018); 0,82 para madera de abeto Douglas (Fernández et al., 2009); 0,77 para madera de pino radiata (Arriaga et al., 2014; Yang et al., 2015); 0,78 para madera de pino taeda (Yang et al., 2017); ó 0,77 para madera de pino del sur (Arriaga et al., 2014). En el presente trabajo el valor obtenido fue de 0,62 , que se encuentra en el rango inferior a los valores encontrados en la bibliografía científica, pero dentro de valores aceptables. 
Utilizando la misma metodología NDT se encontraron también valores $r^{2}$ de 0,27 para las relaciones entre el MOR y el MOED (Dahlen et al., 2018). Estos valores son también ligeramente superiores a los observados en esta investigación, con valores de 0,19 (en el mejor de los casos).

En base a los resultados obtenidos, la utilización de métodos NDT resulta apropiada por sí sola para estimar los valores de rigidez, pero a la hora de estimar el MOR es recomendable utilizar el apoyo de variables visuales para mejorar el modelo analítico.

Una vez observada la influencia de los parámetros NDT y los parámetros visuales, para cada una de las variables dependientes se realizó un modelo de regresión con la combinación de todas las variables explicativas.

Para estimar cada variable dependiente se fueron eliminando las variables explicativas, estadísticamente no significativas, realizando contrastes de significación individuales. Cuando el valor $P$ de una variable explicativa era igual o superior a 0,05 , significaba que se podía eliminar del modelo de regresión múltiple porque no era estadísticamente significativa con un nivel de confianza del $95 \%$.

La Tabla 6.11 muestra los valores $P$ obtenidos. Los números en negrita se corresponden con las variables explicativas que mejor explican la variabilidad de las variables estimadas y, por lo tanto, deben incluirse en el modelo analítico.

TABLA 6.11. VALORES P DE LOS MODELOS DE REGRESIÓN MÚLTIPLE.

\begin{tabular}{|c|c|c|c|c|c|c|c|}
\hline $\begin{array}{l}\text { Variables } \\
\text { explicativas } \\
\text { Variables } \\
\text { estimadas }\end{array}$ & VEV $_{H}$ & DEN $_{H}$ & LON & MOEDVEVH $_{\text {VE }}$ & NUD & DOF $^{11 / 20}$ & WOR \\
\hline MOE $_{\mathrm{H}}$ & 0.3353 & 0.1256 & 0.0000 & 0.0005 & 0.1593 & 0.2662 & 0.3483 \\
\hline MOEG $_{H}$ & 0.3853 & 0.3130 & 0.0591 & 0.0931 & 0.0039 & 0.0000 & 0.9706 \\
\hline MORs & 0.7887 & 0.6403 & 0.0000 & 0.0943 & 0.0000 & 0.0112 & 0.6208 \\
\hline $\begin{array}{l}\text { Variables } \\
\text { explicativas } \\
\text { Variables } \\
\text { estimadas }\end{array}$ & VEV $_{12}$ & $\mathrm{DEN}_{12}$ & LON & MOED $_{\mathrm{VEV} 12}$ & NUD & $\mathrm{DOF}^{11 / 20}$ & WOR \\
\hline $\mathrm{MOE}_{12}$ & 0.8221 & 0.9308 & 0.0000 & 0.0779 & 0.0037 & 0.0830 & 0.7849 \\
\hline MOEG $_{12}$ & 0.2570 & 0.1469 & 0.1178 & 0.3497 & 0.0011 & 0.0000 & 0.6875 \\
\hline MOR $_{\mathrm{Kh}}$ & 0.2676 & 0.0888 & 0.0000 & 0.6667 & 0.0000 & 0.0030 & 0.4273 \\
\hline
\end{tabular}

Las variables explicativas que no fueron estadísticamente significativas en la estimación de cada variable dependiente fueron eliminadas gradualmente, dando el resultado final de los modelos analíticos que se muestran en la tabla 6.12. Aunque el MOED no fue estadísticamente significativo en algunos modelos, se incluyó en todos ellos para mejorar el ajuste de la regresión $\left(r^{2}\right)$ utilizando además la combinación de variables explicativas NDT y visuales. 


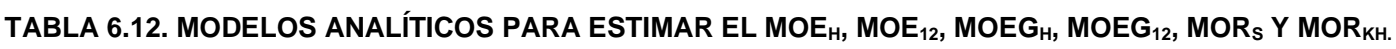

\begin{tabular}{|c|c|c|}
\hline Ecuación & $r^{2}(r)$ & $\begin{array}{c}\text { Error } \\
\text { absoluto } \\
\text { medio }\end{array}$ \\
\hline $\mathrm{MOE}_{\mathrm{H}}=4406.1000-6.1743 \cdot \mathrm{LON}+0.8642 \cdot \mathrm{MOEDVEVH}$ & $\begin{array}{c}0.56 \\
(0.75)\end{array}$ & 1019.140 \\
\hline $\begin{array}{l}\mathrm{MOE}_{12}=7420,7800-5,4319 \cdot \mathrm{LON}+0,6138 \cdot \mathrm{MOEDVEV} 12- \\
1449,9000 \cdot \mathrm{NUD}\end{array}$ & $\begin{array}{c}0,44 \\
(0,66)\end{array}$ & 1196,240 \\
\hline $\begin{array}{l}\text { MOEGH }=4445,9000+0,6517 \cdot M O E D_{V E V H}-299,8710 \cdot D O^{11 / 20} \\
689,5080 \cdot N U D\end{array}$ & $\begin{array}{c}0,66 \\
(0,81)\end{array}$ & 740,414 \\
\hline $\begin{array}{l}\text { MOEG }_{12}=5509,7300+0,5548 \cdot M O E D_{V E V} 12-344,4210 \cdot \text { DOF }^{11 / 20} \text { - } \\
\text { 844,8230.NUD }\end{array}$ & $\begin{array}{c}0,60 \\
(0,77)\end{array}$ & 827,698 \\
\hline $\begin{array}{l}\text { MORs }=44,2778-0,0497 \cdot \mathrm{LON}+0,0026 \cdot \mathrm{MOEDVEVH}- \\
1,1820 \cdot \mathrm{DOF}^{11 / 20}-14,1492 \cdot \mathrm{NUD}\end{array}$ & $\begin{array}{c}0,44 \\
(0,66)\end{array}$ & 5,815 \\
\hline $\begin{array}{l}\mathrm{MOR}_{\mathrm{Kh}}=51.0908-0.0391 \cdot \mathrm{LON}+0.0016 \cdot \mathrm{MOEDVEV}_{12}- \\
\text { 1.4352. }\end{array}$ & $\begin{array}{c}0.35 \\
(0.59)\end{array}$ & 6.300 \\
\hline
\end{tabular}

Se observa como los modelos de regresión obtenidos alcanzaron coeficientes de determinación aceptables para la estimación del MOE y del MOEG, sin considerar la corrección por humedad; y del MOR, sin considerar la corrección por tamaño. Cuando se realizaron las correcciones pertinentes, tanto en las variables dependientes como en las explicativas, los modelos analíticos alcanzaron peores estimaciones.

En la etapa final del estudio se analizaron los residuos para verificar los modelos de regresión múltiple mostrados en la tabla 10. La normalidad de los residuos se comprobó numéricamente mediante el test $\mathrm{K}-\mathrm{S}$, obteniendo los valores siguientes: $\mathrm{MOE}_{\mathrm{H}}$ (valor- $P$ $=0,1497), \mathrm{MOE}_{12}($ valor $-P=0,2981), \mathrm{MOEG}_{\mathrm{H}}($ valor $-P=0,2415), \mathrm{MOEG}_{12}$. (valor- $P=$ $0,2456)$, MOR $_{S}($ valor $-P=0,9945)$ y MOR Kh $($ valor $-P=0,5714)$. Por tanto, se puede establecer que la distribución de residuos de todos los modelos analíticos se ajusta a una distribución normal con un nivel de significación del 5\%.

Para verificar la homocedasticidad (o varianza de los residuos constante) se representaron gráficamente los residuos estudentizados (Residues) frente a los valores estimados (Estimated values), figura 6.8. 

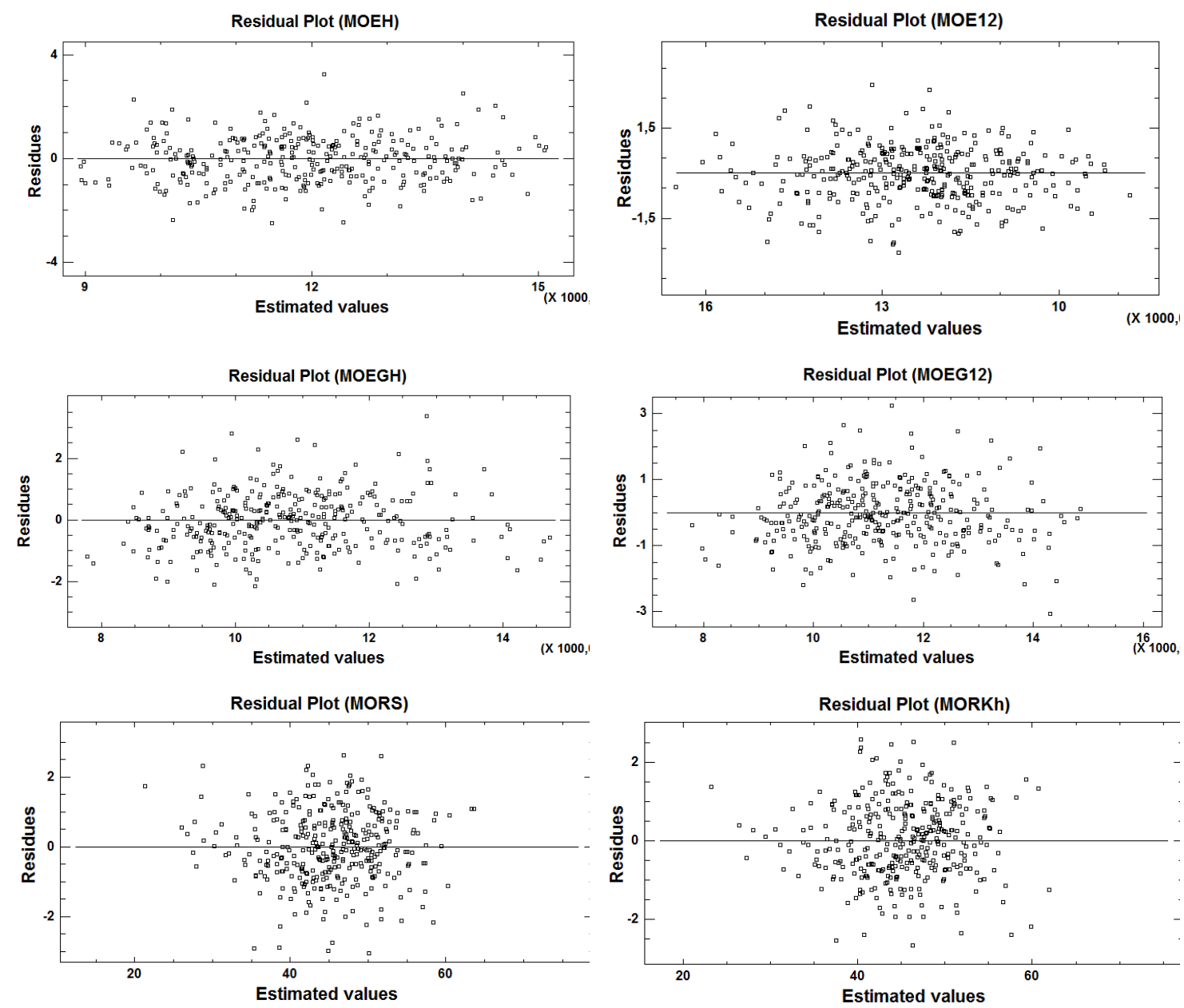

FIGURA 6.8. GRÁFICOS PARA VERIFICAR LA HOMOCEDASTICIDAD DE LOS RESIDUOS.

En ningún caso apreció un patrón definido (el tamaño de los residuos no aumentaba o disminuía de forma sistemática a medida que aumentaba la variable dependiente), por lo que se comprobó gráficamente el cumplimiento de la hipótesis de homocedasticidad para todos los modelos analíticos $\left(\mathrm{MOE}_{\mathrm{H}}, \mathrm{MOE}_{12}, \mathrm{MOEG} \mathrm{H}_{\mathrm{H}}, \mathrm{MOEG} \mathrm{G}_{12}, \mathrm{MOR}_{\mathrm{S}}\right.$ y $\left.\mathrm{MOR}_{\mathrm{Kh}}\right)$.

Finalmente, mediante el estadístico D-W se examinaron los residuos para determinar si eran independientes de la toma de datos. Se obtuvieron los valores siguientes: $\mathrm{MOE}_{\mathrm{H}}$ (estadístico $\mathrm{D}-\mathrm{W}=1,8123$; valor- $P=0,0381$ ), $\mathrm{MOE}_{12}$ (estadístico $\mathrm{D}-\mathrm{W}=1,5561$, valor$P=0,0000$ ), $\mathrm{MOEG}_{\mathrm{H}}$ (estadístico $\mathrm{D}-\mathrm{W}=1,9496$; valor- $P=0,3175$ ), $\mathrm{MOEG}_{12}$ (estadístico $\mathrm{D}-\mathrm{W}=1,7666$, valor $-P=0,0136$ ), $\mathrm{MOR}_{\mathrm{S}}$ (estadístico $\mathrm{D}-\mathrm{W}=2,0606$; valor $-P=0,7161$ ) y

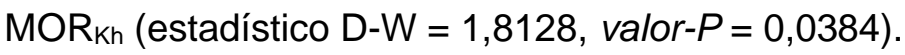

Todos los modelos analíticos mostraron valores mayores o iguales que 0,05 excepto los modelos para estimar el $\mathrm{MOE}_{\mathrm{H}}, \mathrm{MOE}_{12}, \mathrm{MOEG}_{12}$ y $\mathrm{MOR}_{\mathrm{kh}}$ por lo que no era posible determinar la independencia de los residuos en estos casos. Para verificarla, se trazaron las gráficas del valor de los residuos obtenidos frente al número de fila para detectar la posible existencia de algún patrón, figura 6.9. 

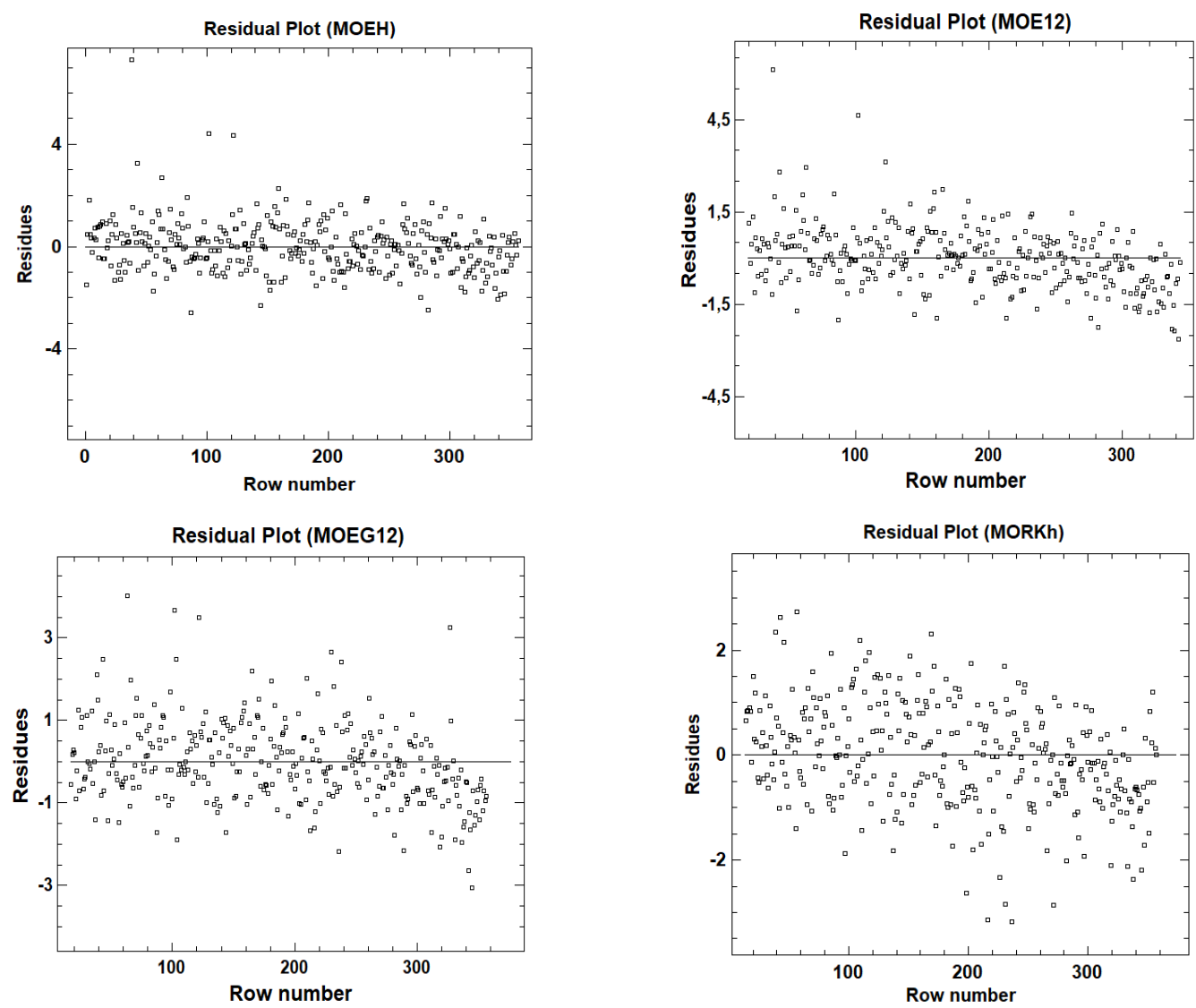

FIGURA 6.9. GRÁFICOS PARA VERIFICAR LA INDEPENDENCIA DE LOS RESIDUOS.

Según se observa, no existen patrones marcados que relacionen los residuos obtenidos con la posición en la entrada de datos por lo que se aceptó la independencia de los mismos en todos los modelos analíticos.

\subsection{EVALUACIÓN DE LA INFLUENCIA DE LA ALTURA DE LA TROZA DEL ÁRBOL}

Las propiedades físicas y mecánicas de la madera tienen una gran variabilidad debida a factores fenotípicos y genotípicos, no solo entre poblaciones de la misma especie sino también en árboles individuales. La variación de estas propiedades dentro de un mismo individuo no es tan evidente, ya que es el resultado de un complejo sistema de factores interrelacionados que modifican los procesos fisiológicos involucrados en la formación de la madera (Rodrigo et al., 2013).

La influencia de la troza respecto a la altura del árbol se estudió mediante un análisis de la varianza entre las diferentes muestras obtenidas a diferentes alturas del árbol, para las variables caracterizadoras (densidad, MOR y MOE), con el objeto de conocer si existían diferencias significativas en las medias debidas al factor altura. 
En el contraste de hipótesis, la hipótesis nula, $H_{0}$, consideraba que la variable caracterizadora era igual en todas las alturas del árbol.

Posteriormente, cuando era adecuado, se definieron, mediante regresión simple, ecuaciones analíticas que relacionaban la altura del árbol y cada una de las variables caracterizadoras. Para el análisis se consideró la altura de la que provenía cada troza, con el valor promedio de cada variable caracterizadora para esa altura.

\subsubsection{RESISTENCIA A FLEXIÓN (MOR) A DIFERENTES ALTURAS DEL ÁRBOL}

La figura 6.10 muestra el diagrama de caja y bigotes y la tabla ANOVA del MOR a diferentes alturas del árbol.

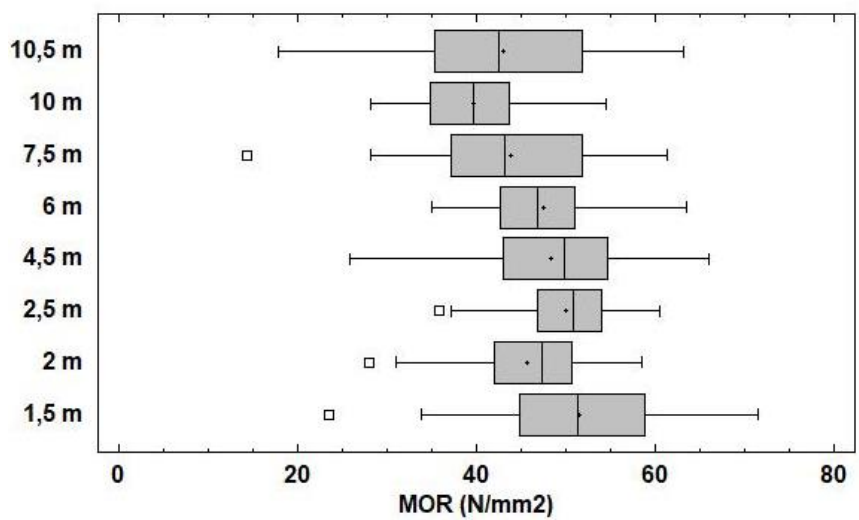

Tabla ANOVA

\begin{tabular}{|l|l|l|l|l|l|}
\hline Fuente & Suma de Cuadrados & GI & Cuadrado Medio & Razón-F & Valor-P \\
\hline Entre grupos & 4091,85 & 7 & 584,55 & 6,98 & 0,0000 \\
\hline Intra grupos & 25954,8 & 310 & 83,7252 & & \\
\hline Total (Corr.) & 30046,7 & 317 & & & \\
\hline
\end{tabular}

FIGURA 6.10. DIAGRAMA DE CAJA Y BIGOTES DEL MOR A DIFERENTES ALTURAS DEL ÁRBOL.

La tabla ANOVA muestra una razón- $F$ de 6,98 y un valor- $P$ de 0,0000 . Puesto que el valor-P es menor que 0,05 ; existe una diferencia estadísticamente significativa entre las medias de las 8 alturas consideradas, con un nivel del 5\% de significación.

La figura 6.11 muestra la relación entre el MOR y la altura del árbol mediante un análisis de regresión simple. 


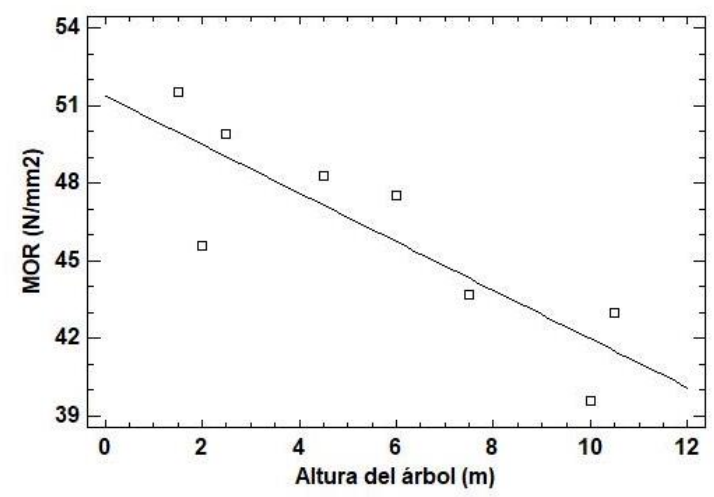

Coeficiente de Correlación $=-0,844736$

R-cuadrada $=71,3579$ porciento

MOR $(\mathrm{N} / \mathrm{mm} 2)=51,3576-0,93844^{\star}$ Altura $(\mathrm{m})$

FIGURA 6.11. RELACIÓN ENTRE EL MOR Y LA ALTURA DEL ÁRBOL.

Se observa una clara tendencia a reducir el MOR a medida que la troza proviene de una altura mayor del árbol. La mejor aproximación consiste en una recta con un $r^{2}$ de 0,71 que indica que la altura de la que procede la troza, de la cual se mecanizan las probetas, influye en gran medida en la resistencia a flexión. Además, es posible averiguar esta relación mediante la ecuación analítica del modelo.

$$
\operatorname{MOR}\left(\mathrm{N} / \mathrm{mm}^{2}\right)=51,3576-0,93844 \cdot \text { Altura }(\mathrm{m})
$$

Según se ha comentado previamente, la principal causa de rotura es la presencia de nudos, aislados o agrupados, y la desviación de la fibra. La fuerte relación que existe entre la altura del árbol y la resistencia a flexión podría deberse a que en las partes inferiores del árbol se han producido podas naturales o se han realizado tratamientos selvícolas consistentes en podas tempranas para favorecer el crecimiento en altura de los pies. Tras las podas, el fuste sigue creciendo en grosor hasta que la discontinuidad de la fibra, provocada por la inserción de ramas en el tronco, desaparece en los nuevos tejidos. El resultado es que en estas trozas se pueden obtener piezas estructurales con menor presencia de nudos, y por tanto, con menor desviación local de la fibra.

Por otra parte, el incremento del porcentaje de madera juvenil en la sección transversal, o sección resistente del fuste, debido a la conicidad del árbol y a la proximidad a la copa, justificaría también este resultado. En este sentido cabe señalar que el propio funcionamiento mecánico del árbol en el monte requiere la existencia de una diferencia de capacidad resistente entre las partes bajas del fuste y las partes altas, en respuesta a un reparto óptimo de resistencia según las acciones que recibe. Así, desde un punto de vista mecánico, el fuste se comporta como un voladizo vertical sometido a las acciones del viento que provocan que éste trabaje a flexión. Las secciones inferiores del fuste deberán tener una sección resistente mayor que las secciones superiores, para soportar los momentos más altos, o en caso de tener la misma sección, disponer de una capacidad resistente mayor. Lo mismo sucede si se considera que las secciones inferiores del tronco están sometidas a esfuerzos de compresión mayores que las secciones superiores, debido al peso propio de la copa y del fuste. 
En un estudio realizado con probetas de pino marítimo procedente de Portugal, se determinó una reducción del MOR según se aumenta la altura del árbol, en las partes intermedias y más alejadas de la médula en dirección radial. En la parte cercana a la médula se observó un ligero descenso del MOR únicamente en la zona alta del árbol. Se observó también un aumento del MOR en la dirección radial según se aumenta la distancia a la médula. Estos se justificaron por la creciente presencia de madera juvenil causada por la conicidad del árbol y la proximidad a la copa (Machado y Cruz, 2005). En el estudio se utilizaron probetas prismáticas libres de defectos de dimensiones $2 \times 2 \times 3,4 \mathrm{~cm}$.

En otro estudio llevado a cabo en los pirineos españoles en madera de abeto blanco (Abies alba Mill.) procedente del pirineo español (Rodrigo et al., 2013), se trazaron líneas de igual MOR en función de la altura del árbol y de la distancia a la médula. En la parte cercana a la médula el MOR prácticamente no variaba en función de la altura, en la parte intermedia el MOR decrecía con la altura del árbol pero con un gradiente poco acusado, y en parte exterior el MOR decrecía con un gradiente incluso menos acusado. En dirección radial, también se observó un aumento desde el anillo 0 hasta aproximadamente los anillos 40-50, un posterior descenso con un gradiente poco acusado hasta los anillos 70-75, y un descenso con un gradiente más acusado hasta el anillo exterior. En el estudio se utilizaron probetas prismáticas libres de defectos de dimensiones $2 \times 2 \times 3 \mathrm{~cm}$.

En base a las investigaciones analizadas se puede concluir que se produce un descenso generalizado del MOR con la altura del árbol al igual que ocurre en el presente estudio. 


\subsubsection{MÓDULO DE ELASTICIDAD LOCAL (MOE) A DIFERENTES ALTURAS DEL ÁRBOL}

La figura 6.12 muestra el diagrama de caja y bigotes y la tabla ANOVA del MOE a diferentes alturas del árbol.

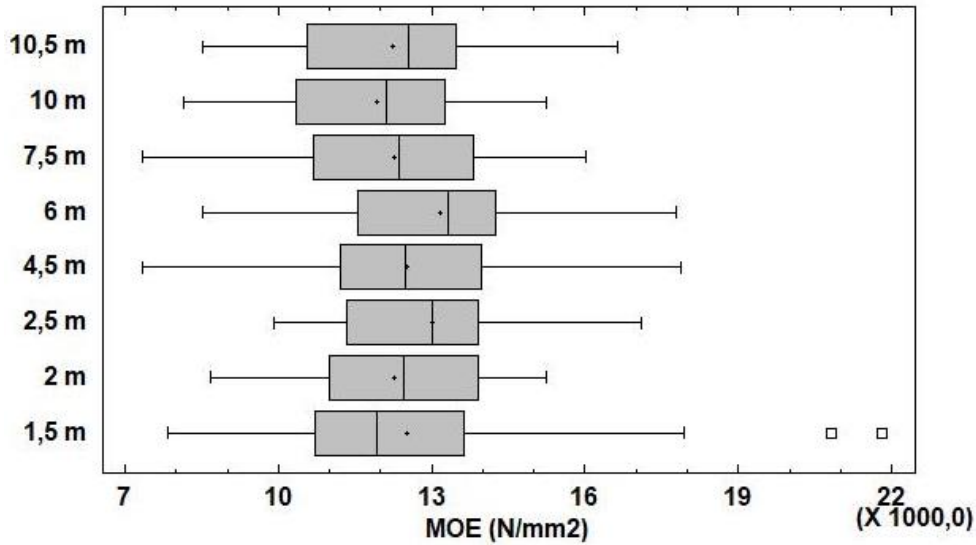

Tabla ANOVA
\begin{tabular}{|l|l|l|l|l|l|}
\hline Fuente & Suma de Cuadrados & GI & Cuadrado Medio & Razón-F & Valor-P \\
\hline Entre grupos & $4,1267 \mathrm{E} 7$ & 7 & $5,89528 \mathrm{E} 6$ & 1,29 & 0,2544 \\
\hline Intra grupos & $1,4024 \mathrm{E} 9$ & 307 & $4,56809 \mathrm{E} 6$ & & \\
\hline Total (Corr.) & $1,44367 \mathrm{E} 9$ & 314 & & & \\
\hline
\end{tabular}

FIGURA 6.12. DIAGRAMA DE CAJA Y BIGOTES DEL MOE A DIFERENTES ALTURAS DEL ÁRBOL.

La tabla ANOVA muestra una razón- $F$ de 1,29 y un valor- $P$ de 0,2544 . Puesto que el valor-P es mayor o igual que 0,05 ; no existen diferencias estadísticamente significativas entre las medias de las 8 alturas consideradas, con un nivel del $5 \%$ de significación. Este resultado indica que no se puede considerar que la altura del árbol influya decisivamente en el MOE, por lo que no se procedió a buscar relaciones analíticas mediante modelos de regresión entre ambos factores.

En el estudio realizado con probetas de pino marítimo (Pinus pinaster Ait.) procedente de Portugal (Machado y Cruz, 2005), se obtuvieron los mismos resultados con el MOE que se indicaron anteriormente para el MOR, aludiendo a la misma casuística.

En las investigaciones realizadas con abeto blanco procedente de los pirineos españoles (Rodrigo et al., 2013) se trazaron igualmente líneas de igual MOE en función de la altura del árbol y de la distancia a la médula. En la parte cercana a la médula el MOE descendía ligeramente entre 0 y $5 \mathrm{~m}$ de altura, se mantenía constante entre los 5 y los 12 metros de altura, y volvía a aumentar ligeramente hasta el final de la altura del árbol. En la parte intermedia el MOE descendía paulatinamente hasta el final de la altura del árbol. En la parte exterior el MOE seguía un trazado similar a la parte cercana a la médula, disminuyendo primero y aumentando después pero con un gradiente mucho más suave. En dirección radial el MOE seguía una tendencia similar a la indicada para el MOR. 
Por tanto, en base a las investigaciones analizadas se puede concluir que se produce un descenso generalizado del $\mathrm{MOE}$ con la altura del árbol pero que se aprecia especialmente en la parte intermedia en dirección radial.

En el diseño experimental de este trabajo se utilizaron probetas de tamaño estructural, con presencia de madera juvenil o no, que responden a una situación real donde las probetas de mayor sección abarcaban casi la sección completa del pie. No se utilizaron probetas pequeñas libres de defectos, obtenidas de una posición conocida, tal y como se ha indicado en las investigaciones anteriores. Mediante las probetas pequeñas es posible obtener información independiente de la influencia de la altura y de la influencia de la distancia a la médula, aunque su utilidad tenga un carácter más teórico que de aplicación práctica directa.

\subsubsection{DENSIDAD AL 12\% A DIFERENTES ALTURAS DEL ÁRBOL}

La figura 6.13 muestra el diagrama de caja y bigotes y la tabla ANOVA de la densidad a una humedad del $12 \%$ a diferentes alturas del árbol.

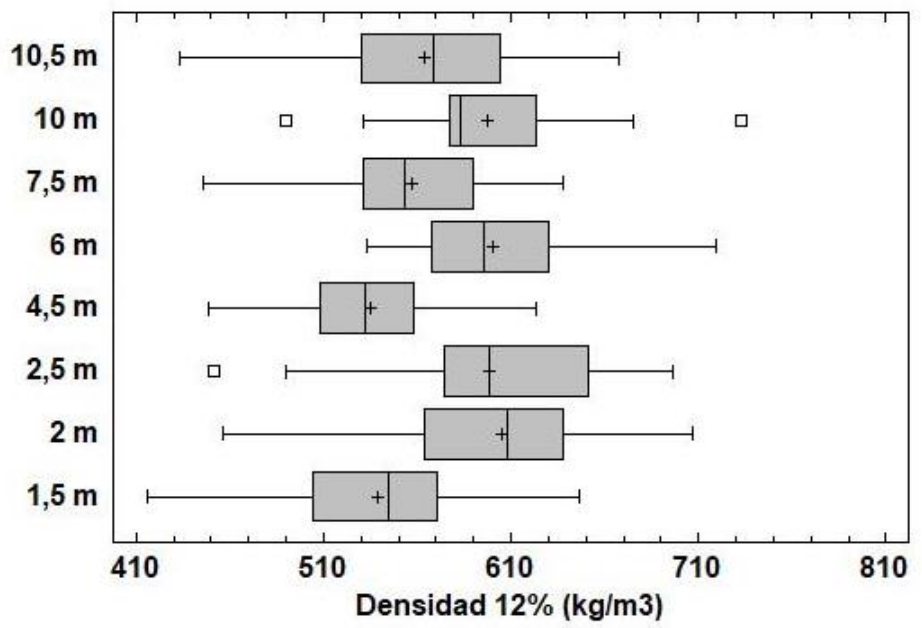

Tabla ANOVA
\begin{tabular}{|l|l|l|l|l|l|}
\hline Fuente & Suma de Cuadrados & GI & Cuadrado Medio & Razón-F & Valor-P \\
\hline Entre grupos & 223039, & 7 & 31862,7 & 12,87 & 0,0000 \\
\hline Intra grupos & 760204, & 307 & 2476,23 & & \\
\hline Total (Corr.) & 983242, & 314 & & & \\
\hline
\end{tabular}

FIGURA 6.13. DIAGRAMA DE CAJA Y BIGOTES DE LA DENSIDAD 12\% A DIFERENTES ALTURAS DEL ÁRBOL.

La tabla ANOVA indica una razón- $F$ de 12,87 y un valor- $P$ de 0,0000 . Puesto que el valor-P es menor que 0,05 ; existe una diferencia estadísticamente significativa entre las medias de las 8 alturas consideradas, con un nivel del 5\% de significación. 
Sin embargo, pese a que existen diferencias significativas, no es posible establecer una relación analítica adecuada (mediante modelos de regresión) ya que la densidad no sigue una tendencia marcada a aumentar o disminuir en función de la altura del árbol, figura 13.

La variación de la densidad a lo largo de la dirección longitudinal de un pie depende de la especie y de su procedencia (Zobel y Van Buijtenen, 1989).

En un estudio llevado a cabo con probetas de sección transversal completa de pino silvestre y picea común procedentes del sur de Finlandia (Repola, 2006), se observó que la densidad disminuía bruscamente con la altura en el pino. Sin embargo, la dependencia vertical de la densidad en el abeto era baja e irregular, disminuyendo primero y aumentando después, lo que coincidió con otras investigaciones llevadas a cabo con picea común (Hakkila 1979, Frimpong-Mensah 1987) y otras especies de abeto (Spurr et al., 1954, Wahlgren et al., 1966, Heger 1974).

Investigaciones realizadas con pino taeda (Pinus taeda L.) en distintas regiones del sureste de Estados Unidos (Antony et al., 2010), mostraron una tendencia de la densidad a disminuir de manera no lineal. Para ello se utilizaron probetas de secciones transversales enteras del tronco.

Otro estudio realizado con probetas de alerce europeo procedentes de Turquía (Ay et al., 2012) muestra un decrecimiento lineal de la densidad desde 0 hasta 6 metros de altura, una densidad prácticamente constante entre 6 y 15 metros, y nuevamente un descenso a partir de los 15 metros. Se analizaron probetas pequeñas libres de defectos de $2 \times 2 \times 3 \mathrm{~cm}$ secadas en estufa a un contenido de humedad del $12 \%$.

En el llevado a cabo en los pirineos en madera de abeto blanco (Abies alba Mill.) procedente del pirineo español (Rodrigo et al., 2013), se observó un ligero decrecimiento de la densidad con la altura, apreciable especialmente en las zonas intermedias en dirección radial. Además se analizó también la variación de la densidad en la dirección radial mostrando un aumento hasta aproximadamente los 40-50 primeros anillos, y un posterior descenso hasta el anillo exterior. Se utilizaron probetas pequeñas libres de defectos de sección transversal 2x2×4 cm.

Los resultados obtenidos en el presente trabajo, es decir, una dependencia irregular entre la densidad y la altura del árbol, coinciden con los estudios realizados sobre abetos en probetas de sección transversal completa, donde no se ha tenido en consideración la distancia a la médula en dirección radial. Estos resultados son lógicos y no comparables estrictamente con los resultados llevados a cabo con probetas pequeñas libres de defectos ya que, según se ha comentado anteriormente, mediante las probetas pequeñas es posible diferenciar la influencia de la altura y de la distancia a la médula, y con probetas mayores esta influencia deja de ser independiente. 


\subsubsection{RENDIMIENTOS DE CLASIFICACIÓN SEGÚN ALTURA DEL ÁRBOL}

A continuación, se presentan en la tabla 6.13 los rendimientos de clasificación obtenidos en las diferentes alturas de extracción de las piezas. Una pieza se considera clasificada cuando verifica al menos las exigencias para ser clasificada con la clase menos resistente, es decir, como MEG-2.

TABLA 6.13. RENDIMIENTO DE CLASIFICACIÓN SEGÚN LA ALTURA DEL ÁRBOL.

\begin{tabular}{|c|c|c|c|}
\hline \multirow{2}{*}{ Altura } & \multicolumn{2}{|c|}{ Distribución por calidades } & $\begin{array}{c}\text { Rendimiento } \\
\text { clasificación total }\end{array}$ \\
\cline { 2 - 3 } & MEG1 & MEG2 & (\%) \\
\cline { 2 - 3 } & Rendimiento (\%) & Rendimiento (\%) & 100 \\
\hline 1,5 & 81,8 & 18,2 & 100 \\
\hline 2 & 63,0 & 37,0 & 100 \\
\hline 2,5 & 83,9 & 16,1 & 100 \\
\hline 4,5 & 61,4 & 38,6 & 99 \\
\hline 6 & 46,2 & 51,3 & 96 \\
\hline 7,5 & 29,1 & 65,5 & 98 \\
\hline 10 & 44,0 & 52,0 & 97 \\
\hline 10,5 & 4,7 & 88,4 & \multicolumn{2}{c|}{} \\
\hline 1 & Recoge el porcentaje de piezas que cumplen al menos con los criterios de \\
clasificación establecidos de la clase visual inferior, es decir la clase visual MEG-2 \\
\hline
\end{tabular}

Se aprecia que todas las piezas obtenidas de trozas de altura inferior a 6 metros obtienen una clasificación estructural. A partir de 6 metros de altura aparecen algunos rechazos de piezas que no tienen un aprovechamiento estructural.

Para obtener una información gráfica de estos porcentajes, en las figuras 6.14 y 6.15 se muestra la relación entre el porcentaje de éxito de piezas clasificadas para la clase visual MEG-1 y MEG-2, y la altura del árbol.

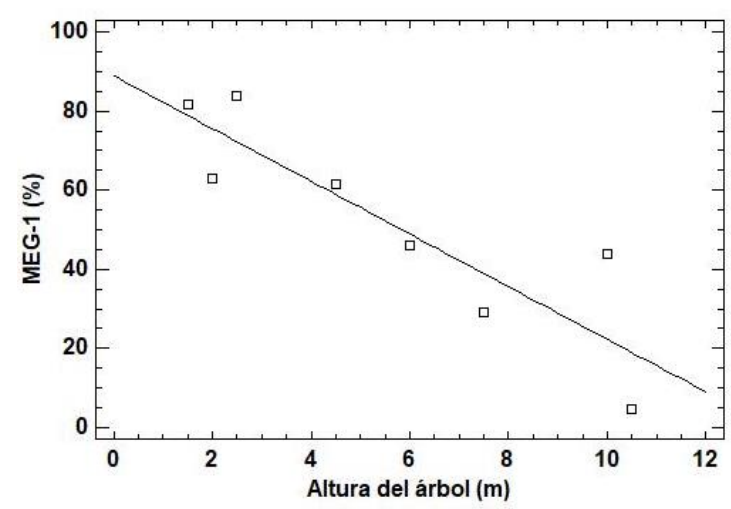

FIGURA 6.14. RELACIÓN PORCENTAJE PROBETAS CLASIFICADAS COMO MEG-1 Y ALTURA DEL ÁRBOL. 


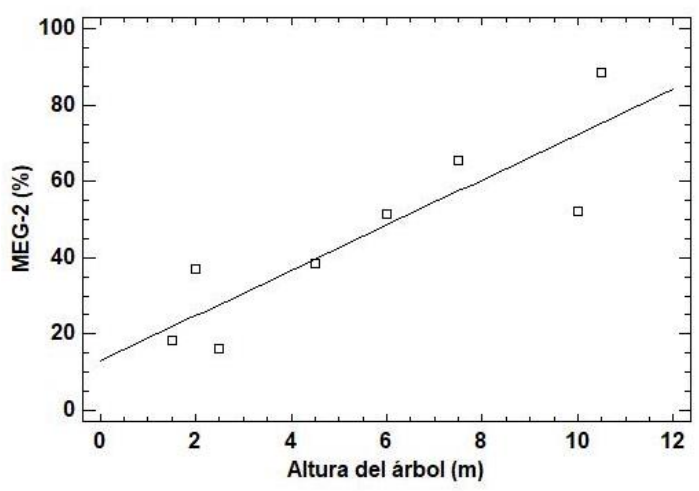

Coeficiente de Correlación $=0,873859$

R-cuadrada $=76,363$ porciento

MEG2 $(\%)=12,8807+5,93381^{*}$ Altura

FIGURA 6.15. RELACIÓN PORCENTAJE PROBETAS CLASIFICADAS COMO MEG-2 Y ALTURA DEL ÁRBOL.

Se aprecia como las probetas que proceden de trozas inferiores tienen más probabilidad de ser clasificadas como MEG-1, y según se incrementa la altura del árbol aumenta también la probabilidad de ser clasificadas como MEG-2.

Este resultado sigue la misma línea de conclusiones obtenidas anteriormente donde la resistencia a flexión (MOR) disminuye al aumentar la altura del árbol, y por tanto, la clasificación tenderá a una clase resistente menor.

\subsection{RELACIÓN DE MOED CON MOR, MOE Y MOEG EN TROZA Y PROBETA}

En la tabla 6.14 se presentan los diferentes coeficientes de determinación obtenidos en los modelos de regresión realizados para buscar la relación entre los módulos de elasticidad dinámicos (MOED), calculados a partir de métodos no destructivos, y las variables de resistencia (MOR) y rigidez (MOE y MOEG), determinadas a partir de ensayos destructivos en laboratorio.

La humedad de las probetas no se conocía en el momento de realizar los ensayos no destructivos sobre troza, sin embargo, se sabía que la humedad era superior al $30 \%$ (punto de saturación de la fibra). Los parámetros no destructivos se corrigieron a la humedad $\mathrm{H} \%$ que tenía la probeta en el momento de realizarse el ensayo destructivo, considerando el intervalo de humedad desde $30 \%$ hasta $\mathrm{H} \%$.

En el momento de realizar los ensayos no destructivos sobre pieza aserrada en seco (probeta seca), la humedad se correspondía con la humedad $\mathrm{H} \%$ porque se realizaban secuencialmente el ensayo no destructivo y el ensayo destructivo. Por tanto, no se aplicó ningún factor de corrección en estas mediciones no destructivas.

Los valores de rigidez (MOE y MOEG) no se corrigieron por humedad. Tampoco se aplicaron correcciones por humedad en el MOR, aunque sí se consideró la corrección por sección que, según se ha comentado previamente, tiene muy poca incidencia en los 
resultados ya que se tuvo que aplicar a muy pocas piezas y con modificaciones de los valores de resistencia insignificantes.

Todas las variables seguían una distribución normal excepto el módulo de elasticidad dinámico obtenido mediante la velocidad de onda de paso (MOEDVEs). Por ello fue necesario normalizarla utilizando la función logaritmo neperiano.

TABLA 6.14. COEFICIENTES DE DETERMINACIÓN $\left(R^{2}\right)$ OBTENIDOS ENTRE LOS MÓDULOS DE ELASTICIDAD DINÁMICOS (MOED) CORREGIDOS A LA HUMEDAD DEL ENSAYO DESTRUCTIVO H\%, Y LAS VARIABLES MOR, MOE Y MOEG SIN CORREGIR.

\begin{tabular}{|l|c|c|c|c|}
\cline { 2 - 5 } \multicolumn{1}{c|}{} & $\begin{array}{c}\text { Momento de } \\
\text { aplicación de los } \\
\text { métodos no } \\
\text { destructivos }\end{array}$ & MOR & MOE & MOEG \\
\hline \multirow{2}{*}{$\begin{array}{c}\text { Ln (MOED } \\
\text { Velocidad onda de paso }\end{array}$} & $\begin{array}{c}\text { Troza } \\
\text { (en monte) }\end{array}$ & 0,17 & 0,33 & 0,32 \\
\cline { 2 - 5 } & $\begin{array}{c}\text { Probeta seca } \\
\text { (en laboratorio) }\end{array}$ & 0,17 & 0,38 & 0,46 \\
\hline $\begin{array}{l}\text { MOED } \\
\text { Frecuencia de vibración }\end{array}$ & $\begin{array}{c}\text { Probeta seca } \\
\text { (en laboratorio) }\end{array}$ & 0,19 & 0,50 & 0,62 \\
\hline
\end{tabular}

En general, se puede observar como el grado de predicción disminuye conforme la pieza de madera aserrada presenta mayor grado de humedad, así como la materia prima se encuentra en menor grado de transformación.

Además, el método que mejor resultados logra en laboratorio es el de medición de la frecuencia de vibración, con unos resultados que demuestran una elevada viabilidad para su uso e incorporación en nuevos métodos de clasificación mecánica.

Para ambas metodologías y momentos de aplicación de los métodos no destructivos, las correlaciones más significativas se han detectado para explicar el módulo de elasticidad global (MOEG).

Respecto al MOE y el MOEG, se puede observar como el grado de predicción es menor en las trozas que en las probetas secas. Este resultado tiene sentido porque en las trozas se ha aplicado una corrección por humedad y en las probetas no. Además, según se ha comentado en apartados anteriores, esta corrección por humedad no es del todo acertada en esta especie por su alto porcentaje de duramen. 
En el caso del MOR, el grado de predicción no varía sustancialmente entre las trozas y las probetas secas, por lo que viene a corroborar que la humedad no tiene una influencia determinante en este parámetro (al determinarse por ensayo mecánico de flexión), tal y como se indica en la norma UNE-EN 384:2016.

Seguidamente se muestra en las figuras 6.16 a 6.24 los modelos de predicción obtenidos en troza y en probeta seca, mediante las metodologías de medición de velocidad de onda de paso y medición de frecuencia de vibración longitudinal. En troza se aplica solamente la primera metodología (velocidad de onda de paso), mientras que en probeta seca se aplican ambas metodologías.

\subsubsection{MODELOS DE PREDICCIÓN EN TROZA}

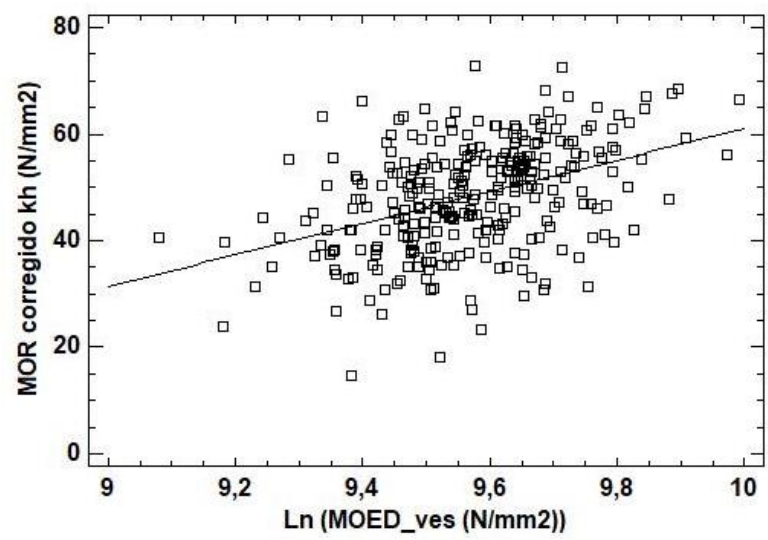

Coeficiente de Correlación $=0,412853$

R-cuadrada $=17,0448$ porciento

MOR corregido $\mathrm{kh}\left(\mathrm{N} / \mathrm{mm}^{2}\right)=-235,27+$ 29,628* Ln (MOED_ves $\left(\mathrm{N} / \mathrm{mm}^{2}\right)$ )

FIGURA 6.16. RELACIÓN EN TROZA ENTRE EL MOR CORREGIDO POR SECCIÓN Y EL MOED OBTENIDO POR VELOCIDAD DE ONDA DE PASO.

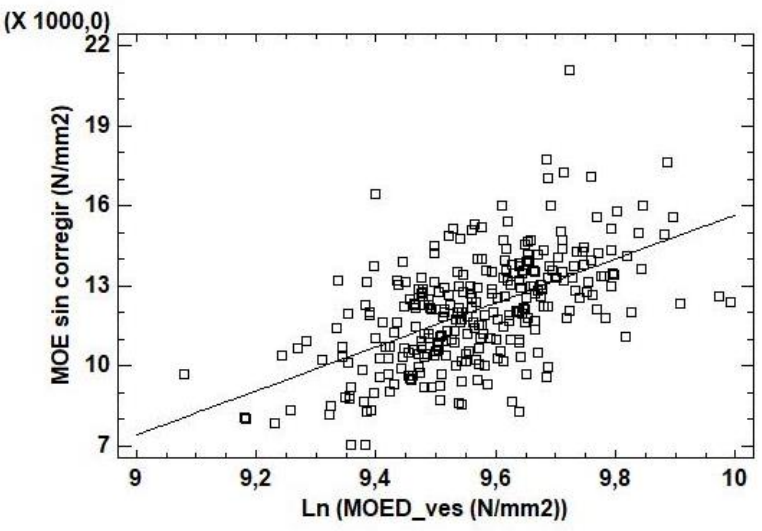

Coeficiente de Correlación $=0,571654$

R-cuadrada $=32,6789$ porciento

MOE sin corregir $\left(\mathrm{N} / \mathrm{mm}^{2}\right)=-66848$ $8250,86^{\star} \operatorname{Ln}\left(\right.$ MOED_ves $\left(\mathrm{N} / \mathrm{mm}^{2}\right)$ )

FIGURA 6.17. RELACIÓN EN TROZA ENTRE EL MOE SIN CORREGIR POR HUMEDAD Y EL MOED OBTENIDO POR VELOCIDAD DE ONDA DE PASO. 


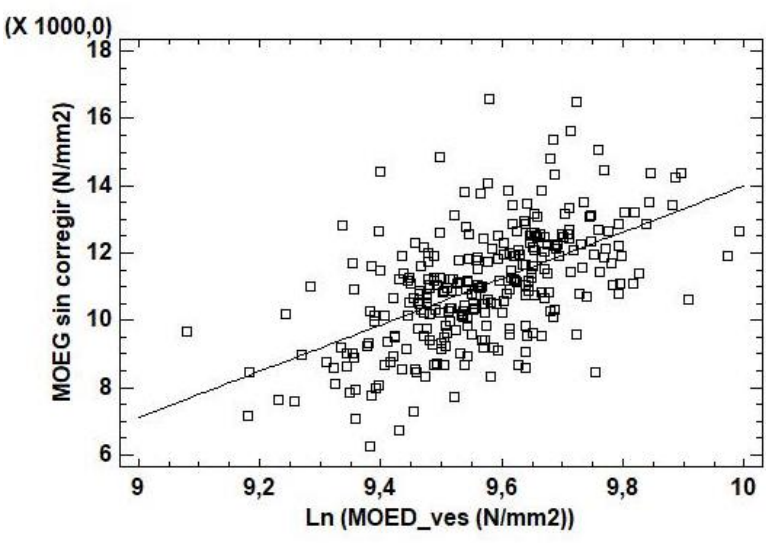

FIGURA 6.18. RELACIÓN EN TROZA ENTRE EL MOEG SIN CORREGIR POR HUMEDAD Y EL MOED OBTENIDO POR VELOCIDAD DE ONDA DE PASO.

Analizando los coeficientes de determinación, solo es posible aceptar el uso de las ecuaciones para obtener los valores de rigidez (MOE y MOEG).

\subsubsection{MODELOS DE PREDICCIÓN EN PROBETA ASERRADA SECA}

En las figuras 19-24 se muestran las relaciones entre el módulo de elasticidad dinámico obtenido a partir de los parámetros no destructivos (velocidad de onda de impacto y frecuencia de vibración longitudinal), y las variables caracterizadoras MOR, MOE y densidad.

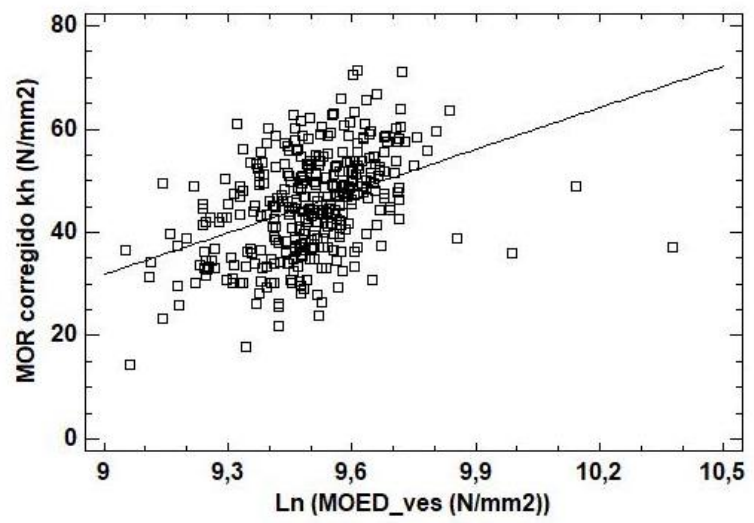

Coeficiente de Correlación $=0,4087$

R-cuadrada $=16,7036$ porciento

MOR corregido $\mathrm{kh}\left(\mathrm{N} / \mathrm{mm}^{2}\right)=-210,547+$ 26,9287* Ln (MOED_ves (N/mm²))

FIGURA 6.19. RELACIÓN EN PROBETA SECA ENTRE EL MOR CORREGIDO POR SECCIÓN Y EL MOED OBTENIDO POR VELOCIDAD DE ONDA DE PASO. 


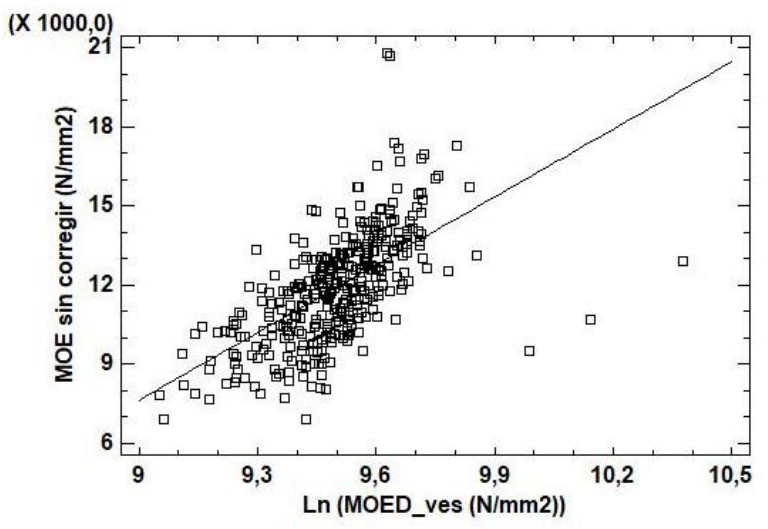

Coeficiente de Correlación $=0,614836$

R-cuadrada $=37,8023$ porciento

MOE sin corregir $\left(\mathrm{N} / \mathrm{mm}^{2}\right)=-69404+$

$8559,09 * \operatorname{Ln}\left(\right.$ MOED_ves $\left(\mathrm{N} / \mathrm{mm}^{2}\right)$ )

FIGURA 6.20. RELACIÓN EN PROBETA SECA ENTRE EL MOE SIN CORREGIR POR HUMEDAD Y EL MOED OBTENIDO POR VELOCIDAD DE ONDA DE PASO.

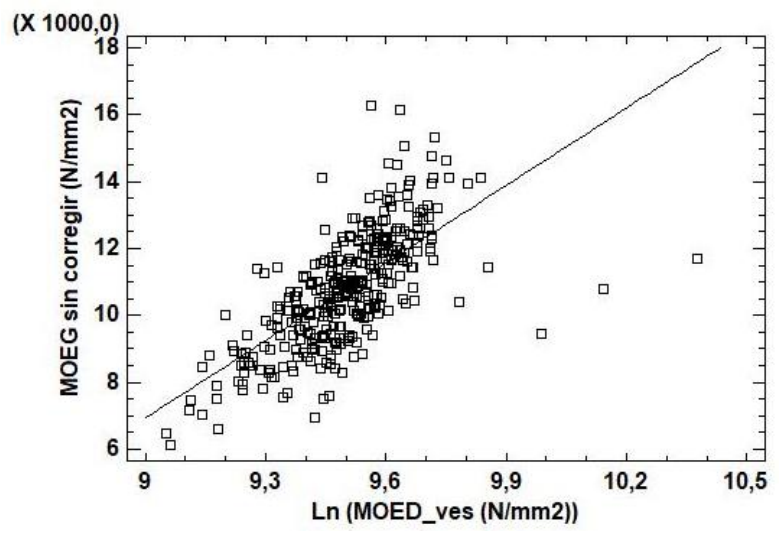

Coeficiente de Correlación $=0,681085$

R-cuadrada $=46,3877$ porciento

MOEG sin corregir $\left(\mathrm{N} / \mathrm{mm}^{2}\right)=-62605,7+$ $7726,05^{\star} \operatorname{Ln}\left(\right.$ MOED_ves $\left(\mathrm{N} / \mathrm{mm}^{2}\right)$ )

FIGURA 6.21. RELACIÓN EN PROBETA SECA ENTRE EL MOED SIN CORREGIR POR HUMEDAD Y EL MOED OBTENIDO POR VELOCIDAD DE ONDA DE PASO.

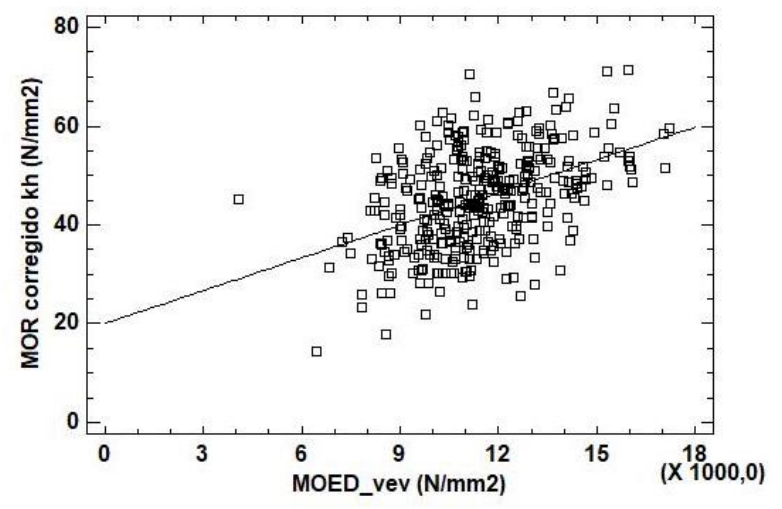

Coeficiente de Correlación $=0,438965$

R-cuadrada $=19,2691$ porciento

MOR corregido $\mathrm{kh}\left(\mathrm{N} / \mathrm{mm}^{2}\right)=20,0358+$ $0,0022107^{\star}$ MOED_vev $\left(\mathrm{N} / \mathrm{mm}^{2}\right)$

FIGURA 6.22. RELACIÓN EN PROBETA SECA ENTRE EL MOR CORREGIDO POR SECCIÓN Y EL MOED OBTENIDO POR FRECUENCIA DE VIBRACIÓN LONGITUDINAL. 


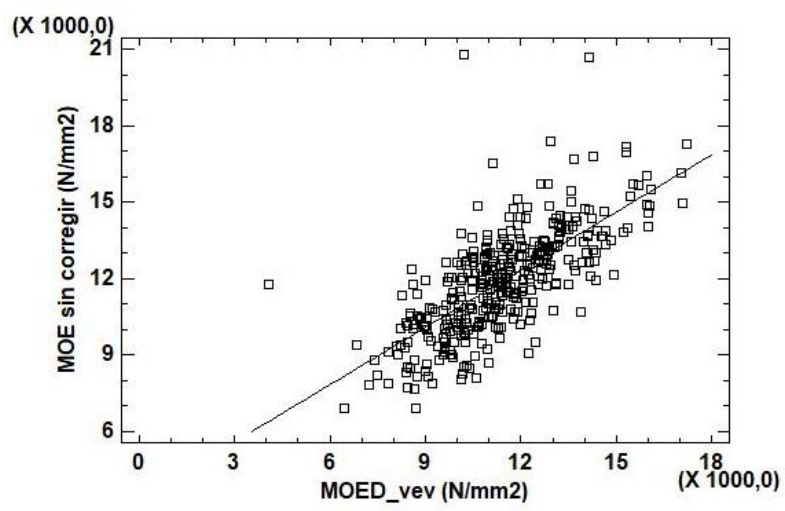

Coeficiente de Correlación $=0,707556$

R-cuadrada $=50,0636$ porciento

MOE sin corregir $\left(\mathrm{N} / \mathrm{mm}^{2}\right)=3312,75+$ $0,752868 *$ MOED_vev $\left(\mathrm{N} / \mathrm{mm}^{2}\right)$

FIGURA 6.23. RELACIÓN EN PROBETA SECA ENTRE EL MOE SIN CORREGIR POR HUMEDAD Y EL MOED OBTENIDO POR FRECUENCIA DE VIBRACIÓN LONGITUDINAL.

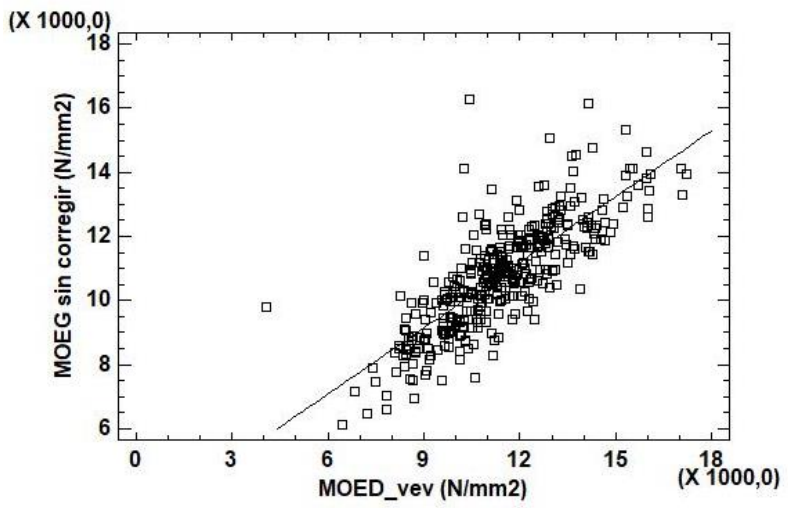

\author{
Coeficiente de Correlación $=0,790189$ \\ R-cuadrada $=62,4398$ porciento
}

MOEG sin corregir $\left(\mathrm{N} / \mathrm{mm}^{2}\right)=2970,57+$ $0,685136 \star M O E D \_v e v\left(\mathrm{~N} / \mathrm{mm}^{2}\right)$

FIGURA 6.24. RELACIÓN EN PROBETA SECA ENTRE EL MOEG SIN CORREGIR POR HUMEDAD Y EL MOED OBTENIDO POR FRECUENCIA DE VIBRACIÓN LONGITUDINAL.

Analizando los coeficientes de determinación, solo es posible aceptar el uso de las ecuaciones para obtener los valores de rigidez (MOE y MOEG), aunque la mejor predicción se corresponde con el método de frecuencia de vibración longitudinal. 


\subsection{CLASIFICACIÓN DE LA MADERA EN TROZA}

Se analizó también el grado de predicción de la velocidad de paso de la onda sonora en troza como método de estimación de la posibilidad de éxito de clasificación en una u otra calidad visual de las piezas de madera aserrada a obtener.

Para ello se estimó, en cada lote, la velocidad media de las ondas sonoras obtenidas, utilizando posteriormente este parámetro como criterio de la calidad de las trozas para calcular el grado de éxito de clasificación en función de éste, tabla 6.15.

TABLA 6.15: PORCENTAJES DE CLASIFICACIÓN POR CLASE VISUAL EN FUNCIÓN DE LA VELOCIDAD DE PASO DE LA ONDA DE CHOQUE.

\begin{tabular}{|c|c|c|c|c|c|c|}
\cline { 2 - 6 } \multicolumn{1}{c|}{} & Longitud & \multirow{2}{*}{$\begin{array}{c}\text { Velocidad } \\
\text { troza }(\mathbf{m})\end{array}$} & \multicolumn{2}{c|}{ Velocidades < media } & \multicolumn{2}{c|}{ Velocidades > media } \\
\cline { 4 - 7 } & & & $\begin{array}{c}\text { MEG-2 y } \\
\text { Rechazo }\end{array}$ & MEG-1 & $\begin{array}{c}\text { MEG-2 y } \\
\text { Rechazo }\end{array}$ & MEG-1 \\
\hline Trozas de $\mathbf{2 5} \times \mathbf{2 0} \mathbf{~ c m}$ & 5 & 4.444 & $80 \%$ & $20 \%$ & $20 \%$ & $80 \%$ \\
\hline Trozas de $\mathbf{1 8} \times \mathbf{1 4} \mathbf{~ c m}$ & 4 & 4.600 & $62 \%$ & $38 \%$ & $38 \%$ & $62 \%$ \\
\hline Trozas de $\mathbf{1 5} \times \mathbf{1 0} \mathbf{~ c m}$ & 3 & 4.550 & $49 \%$ & $51 \%$ & $51 \%$ & $49 \%$ \\
\hline Trozas de $\mathbf{1 5} \mathbf{7} \mathbf{~ c m}$ & 3 & 4.579 & $37 \%$ & $63 \%$ & $63 \%$ & $37 \%$ \\
\hline
\end{tabular}

El método es solamente factible para secciones grandes de la pieza aserrada con una fiabilidad del $80 \%$. Esto se debe a que la sección de la pieza representa en mayor medida las características totales de la troza, y por lo tanto, es más cercana la relación entre la velocidad de paso medida en troza y la calidad visual de la pieza aserrada a obtener.

Este resultado invalida la metodología de velocidad de paso de onda de choque, de cara a ser utilizada en el sistema de clasificación en troza (que se realiza posteriormente), lo que obliga a elaborar la clasificación en base únicamente a parámetros visuales.

Establecer un criterio de clasificación visual en troza resulta de gran utilidad para conocer la calidad estructural de la madera recién tronzada. Se establecieron, así, unos parámetros de medición visual sobre troza que permitiesen determinar a priori su calidad estructural. Para ello, se relacionaron las trozas, en las cuales se habían realizado mediciones de singularidades, con la clasificación visual (MEG-1 y MEG-2) de las probetas que se mecanizaron posteriormente de esas trozas, tabla 6.16. Ello fue posible gracias al sistema minucioso de trazabilidad que se desarrolló en todo el proceso de transformación de la madera. 
TABLA 6.16: CALIDADES VISUALES EN TROZA Y PORCENTAJES DE CLASIFICACIÓN VISUAL POR CALIDADES VISUALES EN LAS PIEZAS DE MADERA ASERRADAS.

\begin{tabular}{|c|c|c|c|}
\hline \multirow[b]{2}{*}{ Criterio de clasificación } & \multicolumn{3}{|c|}{ Calidades visuales (trozas) } \\
\hline & Inferior & Superior & Media \\
\hline Distancia entre verticilos & $<100 \mathrm{~cm}$ & $>150 \mathrm{~cm}$ & \multirow{5}{*}{$\begin{array}{l}\text { No cumple alguno de los } \\
\text { requisitos establecidos } \\
\text { en las dos calidades } \\
\text { inferior o superior }\end{array}$} \\
\hline Máximo nudo en troza & $>4 \mathrm{~cm}$ & $<4 \mathrm{~cm}$ & \\
\hline Máximo número de nudos por verticilo & 4 o mas & 3 o menos & \\
\hline Desviación de la fibra & $<16,6 \%$ & $<10 \%$ & \\
\hline Entrecascos & $\begin{array}{l}\text { Se admite si son de } \\
\text { reducido tamaño }\end{array}$ & $\begin{array}{l}\text { Se admite si son de } \\
\text { reducido tamaño }\end{array}$ & \\
\hline Calidades visuales (piezas aserradas) & \multicolumn{3}{|c|}{ Resultados de clasificación } \\
\hline MEG-1 & $33 \%$ & $80 \%$ & $50 \%$ \\
\hline MEG-2 & $62 \%$ & $20 \%$ & $47 \%$ \\
\hline Rechazos & $5 \%$ & $0 \%$ & $3 \%$ \\
\hline
\end{tabular}

Los parámetros visuales que se utilizaron fueron la distancia entre verticilos, el diámetro máximo del nudo en troza, el máximo número de nudos por verticilo, la desviación de la fibra, y la presencia de entrecasco.

Se establecen 3 niveles de calidad de madera en troza: "Superior", "Media" e "Inferior". Las características de cada una de ellas se muestran en la tabla 6.16.

Se observa que las probetas obtenidas de trozas clasificadas previamente como "Superior", tienen un porcentaje del $80 \%$ de alcanzar una clasificación MEG-1, un 20\% de alcanzar una clasificación MEG-2, y un 0\% de resultar rechazadas para uso estructural. Las probetas obtenidas de trozas clasificadas previamente como "Media", tienen un porcentaje del 50\% de alcanzar una clasificación MEG-1, un 47\% de alcanzar una clasificación MEG-2, y un 3\% de resultar rechazadas para uso estructural. Finalmente, las probetas obtenidas de trozas clasificadas previamente como "Inferior", tienen un porcentaje del 33\% de alcanzar una clasificación MEG-1, un 62\% de alcanzar una clasificación MEG-2, y un 5\% de resultar rechazadas para uso estructural.

Cabe indicar que con los criterios de clasificación establecidos en troza se consigue que cada calidad recoja aproximadamente $1 / 3$ de la muestra total analizada.

\subsection{INFLUENCIA DE LA ÉPOCA DE CORTA EN LAS PROPIEDADES}

\subsubsection{NOCIONES SOBRE EL MOVIMIENTO DE AGUA EN LAS PLANTAS}

El movimiento de agua en las plantas se rige por gradientes de potencial hídrico y está provocado por el fenómeno de la transpiración, que se define como el proceso de pérdida de agua por evaporación que se produce en su mayor proporción a través de los estomas de las hojas. 
El agua es absorbida del suelo por las raíces y transportada en forma líquida por el xilema hacia las hojas. En este proceso, las raíces se comportan como un osmómetro, al favorecer la entrada de agua en los vasos xilemáticos por ósmosis (disponen de células con mayor concentración de solutos que el suelo circundante) y originar una presión hidrostática en el interior del cilindro central (Azcón-Bieto y Talón 2013). Así, la presión necesaria para mover la columna de agua desde las raíces hasta las hojas se genera por la suma de la presión positiva, generada por las raíces, y la presión negativa, creada por las hojas.

El vapor de agua fluye de la hoja a la atmósfera mediante difusión a través de los estomas. Éstos son poros situados en la superficie foliar que permiten el intercambio de gases y cuyo diámetro varía por modificaciones en la turgencia de las células oclusivas. La principal función de los estomas es la regulación de la pérdida de agua por transpiración y la absorción de $\mathrm{CO}_{2}$, necesario para la realización del proceso fotosintético (Azcón-Bieto y Talón 2013).

La luz y la concentración intercelular de $\mathrm{CO}_{2}$ controlan la abertura de los estomas de modo que una concentración baja de $\mathrm{CO}_{2}$, en el interior de las hojas, normalmente aumenta la abertura de los estomas; mientras que una elevada concentración de $\mathrm{CO}_{2}$, la reduce. Sin embargo, la regulación de la abertura estomática es muy compleja, ya que los estomas responden a una diversidad amplia de influencias ambientales, como la intensidad luminosa, temperatura, concentración de $\mathrm{CO}_{2}$, viento, etc.; e influencias endógenas, como la producción y liberación de hormonas en raíces y hojas. Todos estos factores actúan a través de complejos sistemas interconectados difíciles de predecir en su conjunto (Azcón-Bieto y Talón 2013).

El xilema es el tejido a través del cual el agua asciende por el tallo desde las raíces hasta las hojas. El transporte de agua en el xilema depende del gradiente de potencial hídrico y de las características anatómicas de sus tejidos conductores. En gimnospermas, el agua asciende por el tallo a través de las traqueidas, que están formadas por paredes de células muertas dispuestas en filas verticales en forma de huso, formando conductos cerrados con membranas oblicuas con las que se unen de forma vertical. Las traqueidas poseen paredes terminales adelgazadas, que se superponen con las células contiguas, y punteaduras, tanto en las paredes laterales como en las terminales, a través de las cuales fluye el agua y que actúan como pequeñas válvulas. Las células de las traqueidas pierden el citoplasma durante su maduración, y poseen paredes celulares muy lignificadas y relativamente rígidas. Las traqueidas se extienden hacia las raíces y las hojas, donde se ramifican repetidamente (Azcón-Bieto y Talón 2013).

Aunque en el último siglo se han propuesto muchas teorías para explicar la ascensión de la savia ya que ha sido un tema que ha generado mucha controversia, actualmente la teoría de mayor aceptación es la de tensión-cohesión del agua. Ésta explica que cuando el agua se halla confinada en tubos con un diámetro estrecho y paredes humedecibles (tales como las traqueidas xilemáticas), al aplicar una presión (negativa o positiva) desde la parte superior, ésta se transmitirá a través de la columna de agua sin que se pierda el contacto entre las moléculas de agua (fuerzas de cohesión) ni con 
la pared del tubo (fuerzas de adhesión). De este modo, si se aplica una presión negativa (succión) en el extremo superior de la columna, el agua se moverá hacia arriba (AzcónBieto y Talón 2013).

En base a la teoría tensión-cohesión, las traqueidas encierran columnas de agua continuas que se extienden desde los nervios foliares hasta el xilema de las raíces más pequeñas. Mediante el proceso de traspiración se crea un gradiente de potencial hídrico a través del mesófilo foliar, que hace que el agua desaparezca en los extremos de los nervios foliares. La pérdida de agua a ese nivel genera una presión negativa en las columnas del xilema que provocan el movimiento ascendente del agua (Azcón-Bieto y Talón 2013).

El floema es el tejido conductor encargado del transporte de nutrientes generados en las partes aéreas fotosintéticas, hacia las partes que actúan como sumidero. Normalmente, durante el desarrollo vegetativo, el transporte tiene lugar hacia los ápices del tallo y la raíz; mientras que durante la fructificación, los frutos acumulan la mayor parte de los azucares exportados desde las hojas próximas. En gimnospermas los elementos conductores son las células cribosas (Azcón-Bieto y Talón 2013).

Comúnmente se denomina savia bruta al flujo transportado por el xilema desde las raíces hasta las hojas, y está formada por agua, sales minerales inorgánicas y fitorreguladores, que las raíces absorben del suelo a través de los pelos radicales. Se denomina savia elaborada al flujo que circula por el floema desde las hojas hasta los sumideros. Está compuesta principalmente por agua, azucares, aminoácidos, vitaminas, ácidos orgánicos, minerales disueltos y fitorreguladores. En las hojas, la savia bruta se convierte en savia elaborada mediante el proceso de fotosíntesis.

El xilema es la sección del tronco que constituye la madera propiamente dicha, por lo que será, principalmente, el comportamiento de sus tejidos el que interesa en este trabajo.

\subsubsection{ANTECEDENTES}

La posible influencia de la fase lunar en las diferentes propiedades de la madera constituye una temática antigua como lo refleja Theophrastus de Eresos (372-287 a.C.) en Historia de las Plantas (Vol 1, 3), donde se afirma que hay un periodo adecuado para apear los árboles indicando además que si se cortan al comienzo de la luna menguante, la madera es más dura y menos propensa a pudrirse.

Este conocimiento popular ha llegado a nuestros días, donde en algunas localidades se aplican directrices temporales para la ejecución de actividades selvícolas en función de las fases lunares y del uso posterior de la madera (Zürcher 2000).

Las investigaciones llevadas a cabo anteriormente sobre este tema se han centrado principalmente en estudiar determinadas propiedades físicas de la madera, como el contenido de humedad, la densidad, la pérdida de agua durante el secado y el comportamiento higroscópico. La importancia del agua como factor decisivo ha sido descrito en varios estudios (Seeling 1998, Seeling 2000, Bariska y Rösch 2000, Zürcher 2003, Ikeda 2006, Bues and Kretschmar 2008, Zürcher et al., 2010, Zürcher et al., 2012). 
En los últimos años aparecen algunas investigaciones focalizadas en el abeto de Noruega (Picea abies (L.) Karst) (Jahn, 1982; Triebel, 1998; Seeling and Herz, 1998; Rösch, 1999, Bariska and Rösch, 2000; Niemz, 2000; Seeling, 2000; Zurcher, 2003; Bues, 2008; y Zurcher, 2009). Más concretamente, 3 investigaciones casi simultáneas y en diferentes ciudades, analizaron la influencia de la fase lunar en las propiedades de la madera en 120 pies de abeto de Noruega en Dresde (Triebel 1998), 60 pies en Friburgo (Seeling and Herz 1998; Seeling, 2000), y 30 pies en Zúrich (Rösch 1999; Bariska and Rösch 2000). En ninguno de los trabajos mencionados se pudo afirmar de forma significativa la influencia de la fase lunar en las propiedades estudiadas. Sin embargo, los datos procedentes y recogidos de estos 30 árboles por Rösch en 1999 fueron reanalizados por Zürcher et al., (Zürcher y Mandallaz 2001; Zürcher 2003) encontrándose diferencias significativas con respecto a la densidad de la madera, así como en la pérdida de agua y contracción.

Generalmente, los resultados publicados en la bibliografía científica no siguen una dirección única, ya que en ocasiones se han obtenido relaciones significativas entre la influencia de la luna y alguna de las propiedades físicas, y en otras no se han encontrado tales relaciones. La forma de plantear el diseño experimental, de analizar los datos estadísticos, y la posible influencia de múltiples factores externos, dificultan la obtención de resultados independientes que muestren solamente la influencia de la fase lunar.

En el presente trabajo, para analizar la influencia del periodo de corta con las propiedades de la madera, se compararon entre sí las muestras obtenidas en luna creciente (pies apeados 3-5 días tras luna nueva) y en luna menguante (pies apeados 3-5 días tras luna llena). La comparación de ambas se realizó gráficamente, mediante histogramas de frecuencias y diagramas de caja y bigotes, y analíticamente, estudiando diferencias estadísticamente significativas en la distribución de las muestras y en las medias.

\subsubsection{PROPIEDADES FÍSICAS}

\subsubsection{CONTENIDO DE HUMEDAD}

En la tabla 6.17 y en la figura 6.25 se muestran los resultados del análisis estadístico realizado.

TABLA 6.17: ANÁLISIS ANALÍTICO DE LA INFLUENCIA DE LA ÉPOCA DE CORTA EN EL CONTENIDO DE HUMEDAD.

\begin{tabular}{|l|c|c|c|c|}
\cline { 2 - 5 } \multicolumn{1}{c|}{} & Comparación & Test & p-valor & Diferencias estadísticamente significativas \\
\hline \multirow{2}{*}{$\begin{array}{l}\text { Contenido de } \\
\text { humedad }\end{array}$} & Distribución & Kolmogorov Smirnov & 0,0216 & Sí \\
\cline { 2 - 5 } & Media & T-test & 0,5022 & No \\
\hline
\end{tabular}



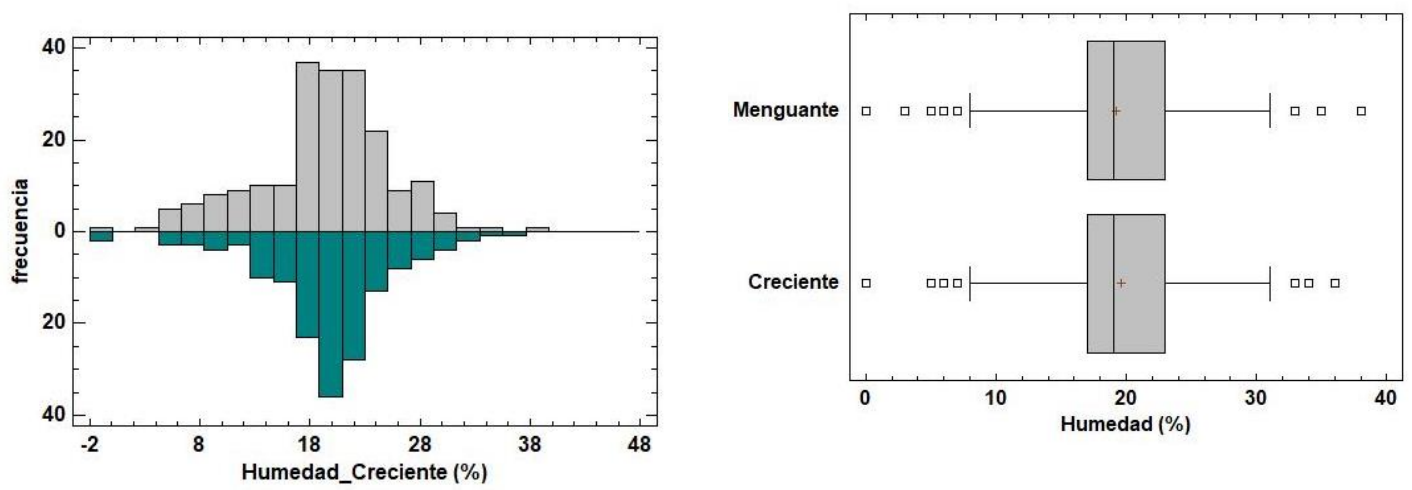

FIGURA 6.25. ANÁLISIS GRÁFICO DE LA INFLUENCIA DE LA ÉPOCA DE CORTA EN EL CONTENIDO DE HUMEDAD.

Respecto a la humedad, se encontraron diferencias significativas en la distribución pero no en la media. Estas diferencias se producen porque las probetas de menguante tienen un rango de humedad mayor, presentando algunas de ellas humedades en torno al $38 \%$. Por tanto, este resultado no muestra claramente diferencias en cuanto a la humedad, pese a que la media en las probetas de creciente sea ligeramente mayor.

En el caso de la madera de abeto de Noruega, los estudios de Zürcher (2003 y 2009) mostraron relaciones significativas entre la época de corta y la proporción de agua en el lumen celular, mientras que Seeling (2000) observó una relación escasa, si bien significativa, respecto al contenido en humedad.

Por el contrario, en los trabajos de Bariska (2000) y Bues (2008), efectuados con la misma especie, no se obtuvieron valores suficientes para establecer la misma posible influencia. Tampoco pudo establecer relaciones significativas Ikeda (2006), analizando el comportamiento de la madera de la Cryptomeria (Cryptomeria japonica D. Don).

\subsubsection{DENSIDAD}

En la tabla 6.18 y en las figuras 6.26 y 6.27 se muestran los resultados del análisis estadístico realizado.

TABLA 6.18: ANÁLISIS ANALÍTICO DE LA INFLUENCIA DE LA ÉPOCA DE CORTA EN LA DENSIDAD.

\begin{tabular}{|l|c|c|c|c|}
\cline { 2 - 5 } \multicolumn{1}{c|}{} & Comparación & Test & p-valor & $\begin{array}{c}\text { Diferencias estadísticamente } \\
\text { significativas }\end{array}$ \\
\hline \multirow{2}{*}{ Densidad H\% } & Distribución & Kolmogorov Smirnov & 0,0372 & Sí \\
\cline { 2 - 5 } & Media & T-test & 0,0096 & Sí \\
\hline \multirow{2}{*}{ Densidad 12\% } & Distribución & Kolmogorov Smirnov & 0,0191 & Sí \\
\cline { 2 - 5 } & Media & T-test & 0,0044 & Sí \\
\hline
\end{tabular}



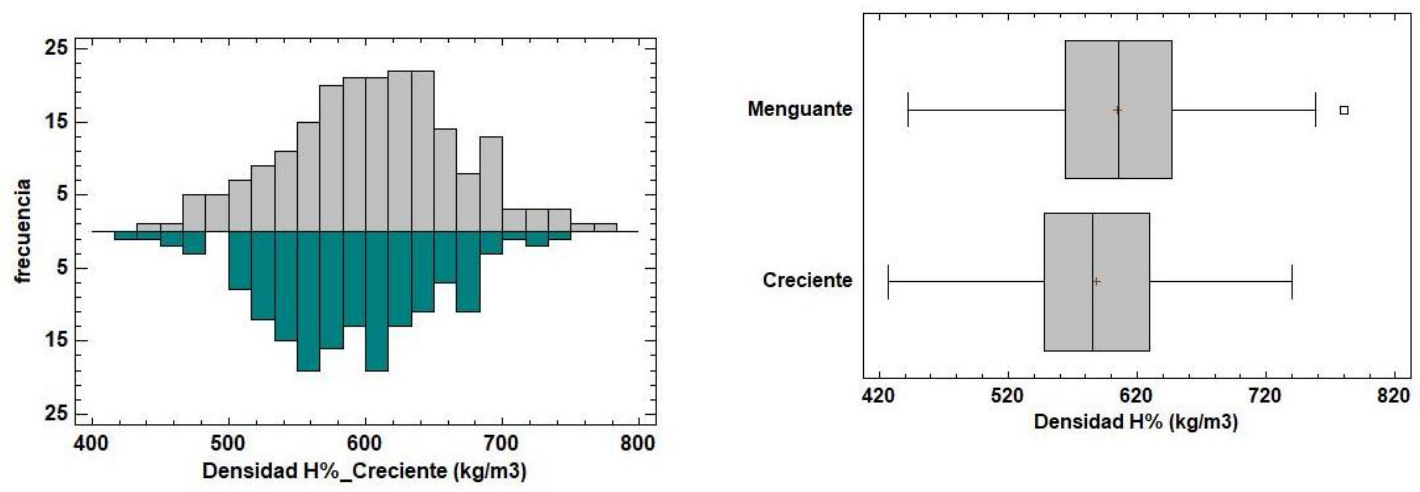

FIGURA 6.26. ANÁLISIS GRÁFICO DE LA INFLUENCIA DE LA ÉPOCA DE CORTA EN LA DENSIDAD SIN CORREGIR.

Densidad corr $12 \%$ Menguante $(\mathrm{kg} / \mathrm{m} 3)$
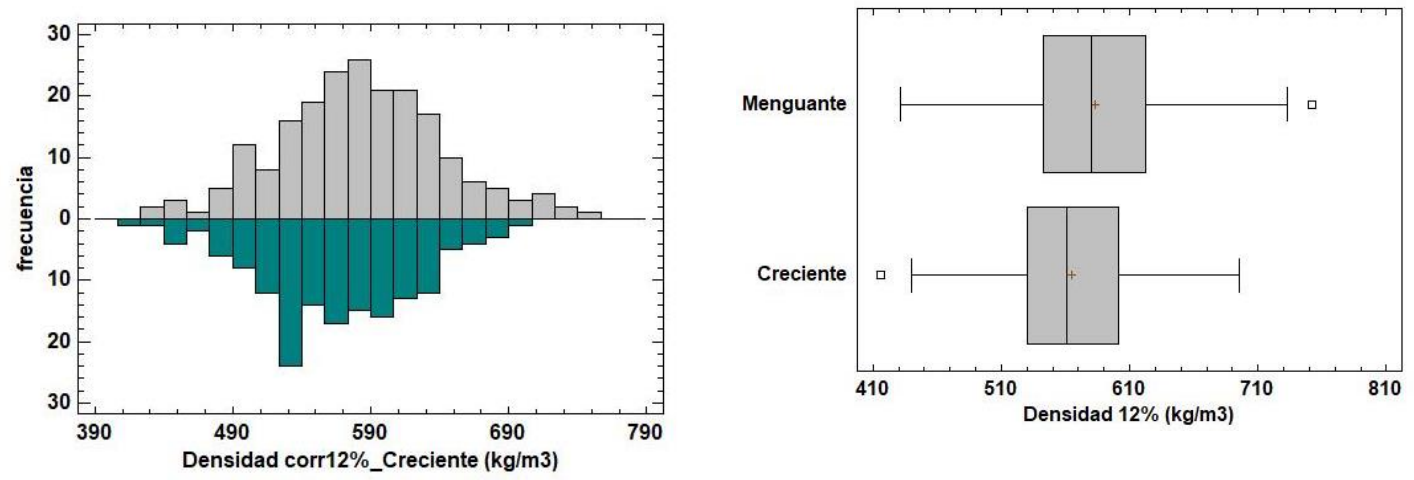

FIGURA 6.27. ANÁLISIS GRÁFICO DE LA INFLUENCIA DE LA ÉPOCA DE CORTA EN LA DENSIDAD CORREGIDA POR HUMEDAD.

Según se observa en los resultados, respecto a la densidad existen diferencias estadísticamente significativas, tanto en la distribución como en la comparación de medias. Las distribuciones se corresponden con muestras claramente distintas. Por tanto, se puede afirmar que la densidad, tanto a humedad $\mathrm{H} \%$ como a humedad $12 \%$, es mayor en las probetas obtenidas en luna menguante que en las obtenidas en luna creciente.

El posible efecto sobre la densidad también fue estudiado por Zürcher et al., (Zürcher y Mandallaz 2001, Zürcher 2003, Zürcher et al., 2010, Zürcher et al., al. 2012) detectando un cambio sistemático de esta variable en función de las diferentes fases lunares. Los resultados publicados en 2010 se basaron en muestras de cerca de 600 árboles de cuatro procedencias diferentes, y se concluyó que, en el caso del abeto noruego, el valor mayor de densidad se corresponde con el periodo de 3,5 días a partir del día de la luna llena, es decir, los primeros días de luna menguante. 
Este periodo coincide con la corta de árboles de luna menguante que se realizó para el presente trabajo, y también coinciden los resultados obtenidos en el mismo (densidad mayor en probetas de menguante).

Seeling (2000) llegó a los mismos resultados con probetas de abeto de noruega, obteniendo las muestras más densas a partir de las probetas de los árboles apeados en la fase de luna menguante.

Sin embargo, otros estudios no han encontrado relación entre todas las fases lunares con propiedades físicas tales como densidad o encogimiento (Villasante et al., 2010).

\subsubsection{FENDAS}

En la tabla 6.19 y en la figuras 6.28 y 6.29 se muestran los resultados del análisis estadístico realizado.

TABLA 6.19: ANÁLISIS ANALÍTICO DE LA INFLUENCIA DE LA ÉPOCA DE CORTA EN LAS FENDAS.

\begin{tabular}{|l|c|c|c|c|}
\cline { 2 - 5 } \multicolumn{1}{c|}{} & Comparación & Test & p-valor & $\begin{array}{c}\text { Diferencias } \\
\text { estadísticamente } \\
\text { significativas }\end{array}$ \\
\hline \multirow{2}{*}{ Anchura fenda } & Distribución & Kolmogorov Smirnov & 0,0000 & Sí \\
\cline { 2 - 5 } & Media & T-test & 0,8940 & No \\
\hline \multirow{2}{*}{ Profundidad fenda } & Distribución & Kolmogorov Smirnov & 0,1932 & No \\
\cline { 2 - 5 } & Media & T-test & 0,4884 & No \\
\hline
\end{tabular}

Ancho fenda_Menguante (mm)
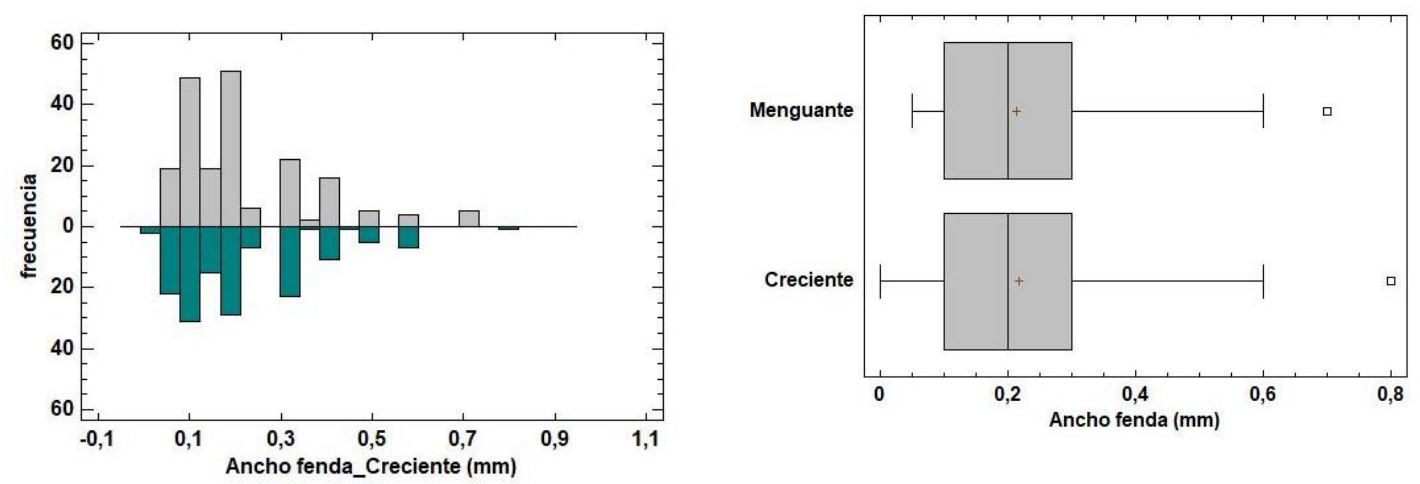

FIGURA 6.28. ANÁLISIS GRÁFICO DE LA INFLUENCIA DE LA ÉPOCA DE CORTA EN EL ANCHO DE FENDA. 

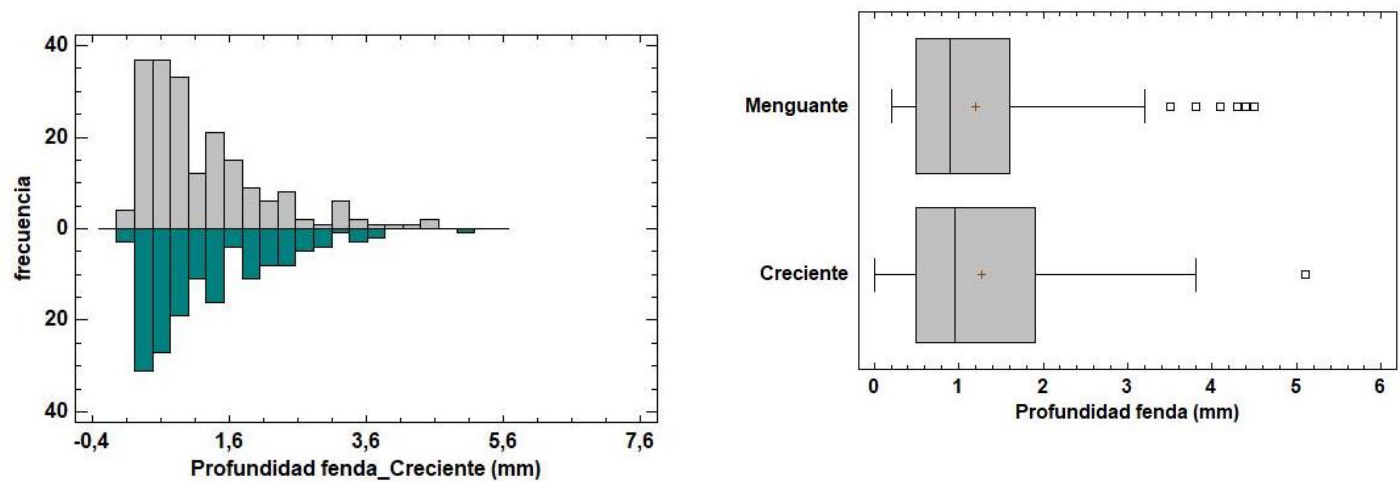

FIGURA 6.29. ANÁLISIS GRÁFICO DE LA INFLUENCIA DE LA ÉPOCA DE CORTA EN LA PROFUNDIDAD

DE FENDA.

En base a los resultados se puede determinar que no existen diferencias estadísticamente significativas en las fendas de las probetas de creciente y de las probetas de menguante. En la tabla 18 se muestra que hay diferencias en la distribución de la anchura de la fenda en ambas muestras, pero observando la figura 28 , se aprecia que ésta diferencia es debida a que la anchura máxima de la muestra de luna menguante es de $0,7 \mathrm{~mm}$, y la de luna creciente de $0,8 \mathrm{~mm}$; siendo el resto de anchuras bastante similares en ambas muestras.

\subsubsection{DEFORMACIONES}

En la tabla 6.20 y en las figuras $6.30,6.31$ y 6.32 se muestran los resultados del análisis estadístico realizado.

TABLA 6.20: ANÁLISIS ANALÍTICO DE LA INFLUENCIA DE LA ÉPOCA DE CORTA EN LAS DEFORMACIONES POR SECADO.

\begin{tabular}{|l|c|c|c|c|}
\cline { 2 - 5 } \multicolumn{1}{c|}{} & Comparación & Test & p-valor & $\begin{array}{c}\text { Diferencias } \\
\text { estadísticamente } \\
\text { significativas }\end{array}$ \\
\hline \multirow{2}{*}{ Curvatura cara } & Distribución & Kolmogorov Smirnov & 0,0000 & Sí \\
\cline { 2 - 5 } & Media & T-test & 0,6727 & No \\
\hline \multirow{2}{*}{ Curvatura canto } & Distribución & Kolmogorov Smirnov & 0,0001 & Sí \\
\cline { 2 - 5 } & Media & T-test & 0,1194 & So \\
\hline \multirow{2}{*}{ Alabeo } & Distribución & Kolmogorov Smirnov & 0,0028 & No \\
\cline { 2 - 5 } & Media & T-test & 0,1139 & \\
\hline
\end{tabular}



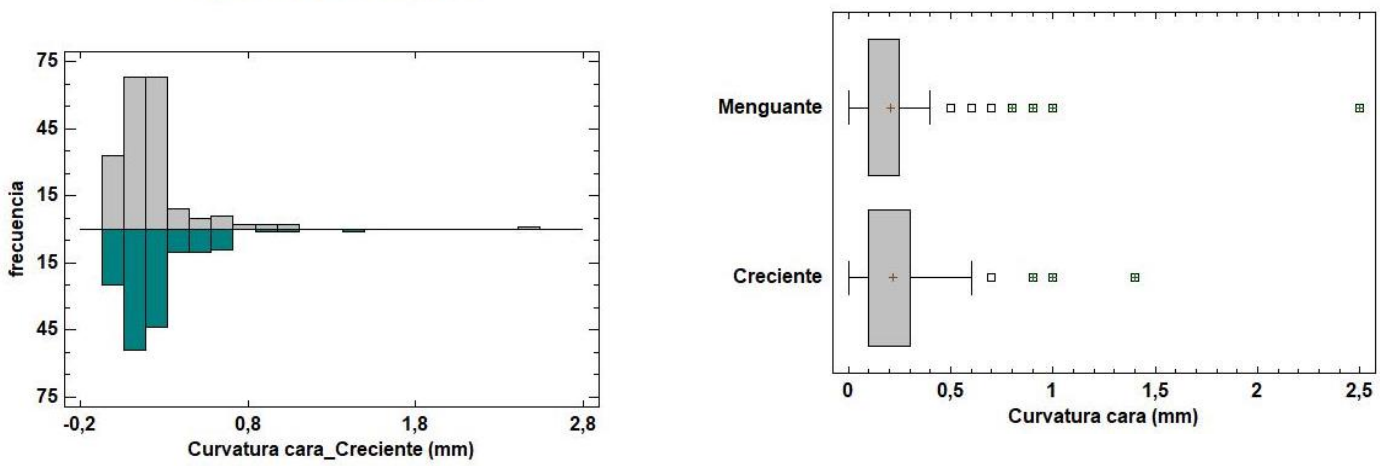

FIGURA 6.30. ANÁLISIS GRÁFICO DE LA INFLUENCIA DE LA ÉPOCA DE CORTA EN LA CURVATURA DE CARA.

Curvatura canto_Menguante $(\mathrm{mm})$
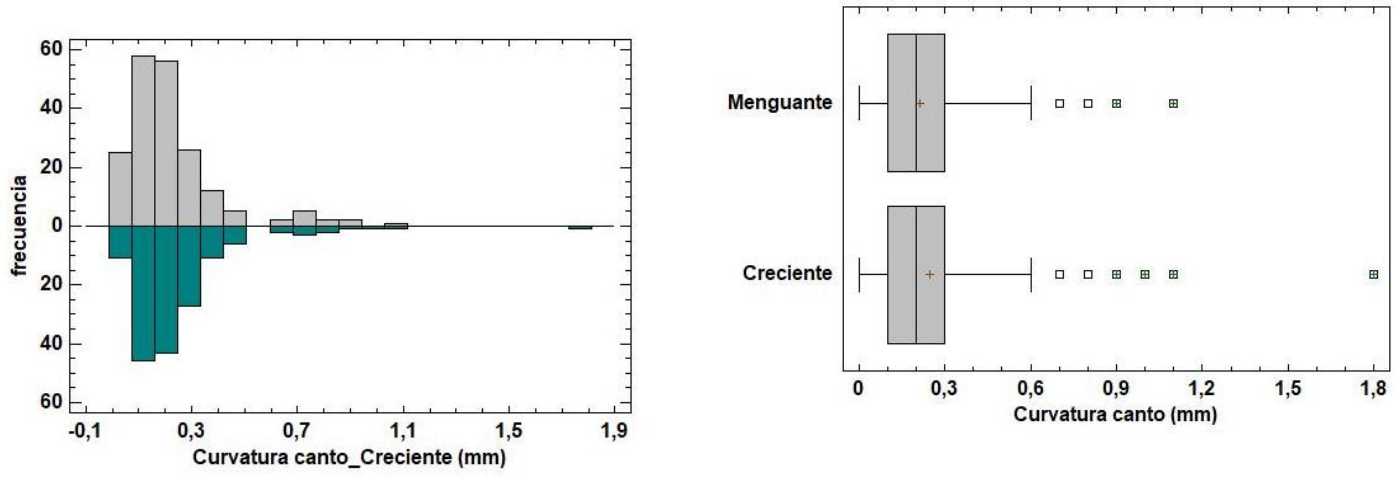

FIGURA 6.31. ANÁLISIS GRÁFICO DE LA INFLUENCIA DE LA ÉPOCA DE CORTA EN LA CURVATURA DE CANTO.

Alabeo_Menguante (mm)
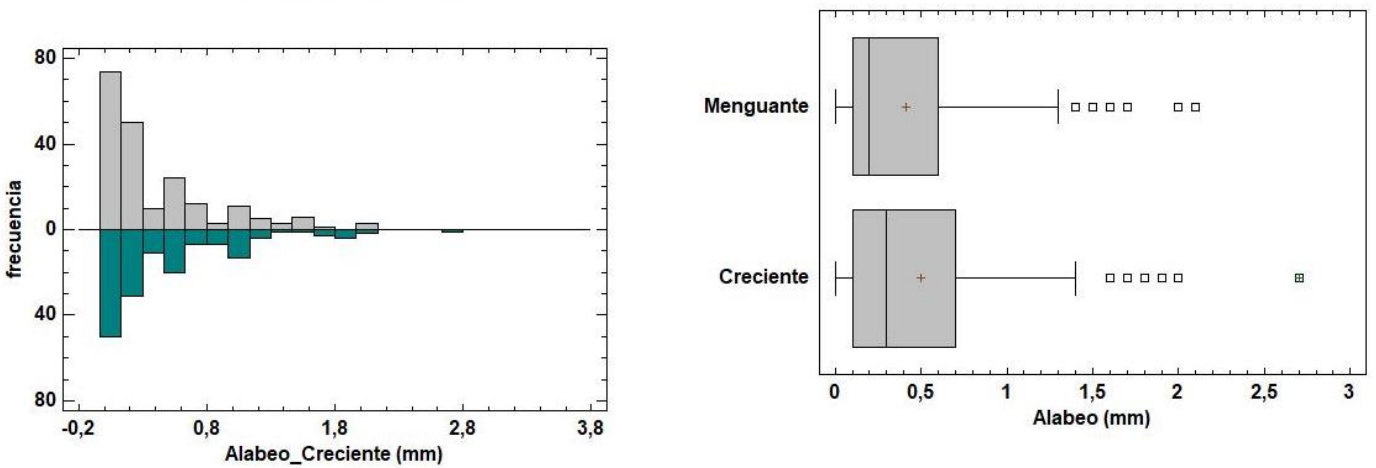

FIGURA 6.32. ANÁLISIS GRÁFICO DE LA INFLUENCIA DE LA ÉPOCA DE CORTA EN EL ALABEO. 
Analizando los resultados se puede determinar que no existen diferencias estadísticamente significativas en las deformaciones de las probetas de creciente y de las probetas de menguante. En la tabla 19 se muestra que hay diferencias en la distribución de todos los parámetros contemplados (curvatura de cara, curvatura de canto y alabeo), pero observando las figuras 30,31 y 32 , se aprecia que éstas diferencias son debidas principalmente a que alguna probeta aislada de creciente se deformó excesivamente en comparación con el resto, seguramente debido a que estaba en una zona de elevadas tensiones de crecimiento. Éste caso atípico no se puede considerar representativo para la comparación de ambas muestras.

\subsubsection{RAPIDEZ DE SECADO E HIGROSCOPICIDAD}

En la figura 6.33 se muestra la evolución del secado de las tablas en exterior bajo cubierta, y en la figura 6.34 la evolución del secado de las tablas en exterior. El proceso de secado fue el mismo en todas las tablas. Inicialmente se mantuvieron al exterior durante 3 meses (unas bajo cubierta y otras al aire) para observar el secado natural, y posteriormente se introdujeron en cámara de acondicionamiento, alrededor de 15 días, hasta alcanzar el $12 \%$ de humedad de referencia.

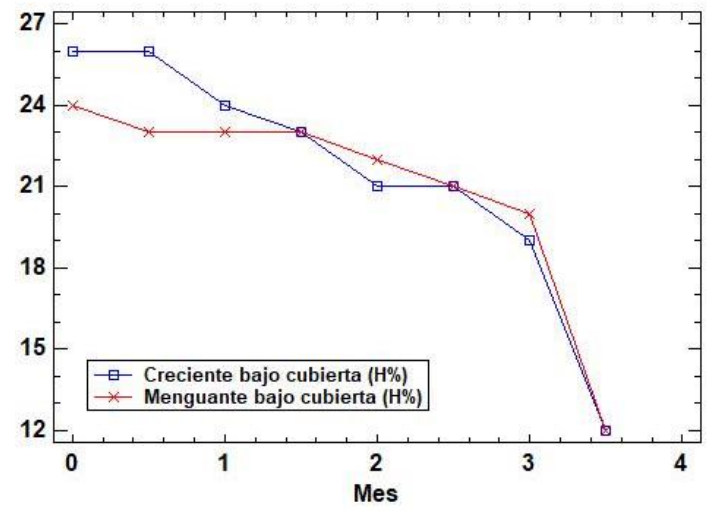

FIGURA 6.33. ANÁLISIS GRÁFICO DE LA INFLUENCIA DE LA ÉPOCA DE CORTA EN LA RAPIDEZ DE SECADO.

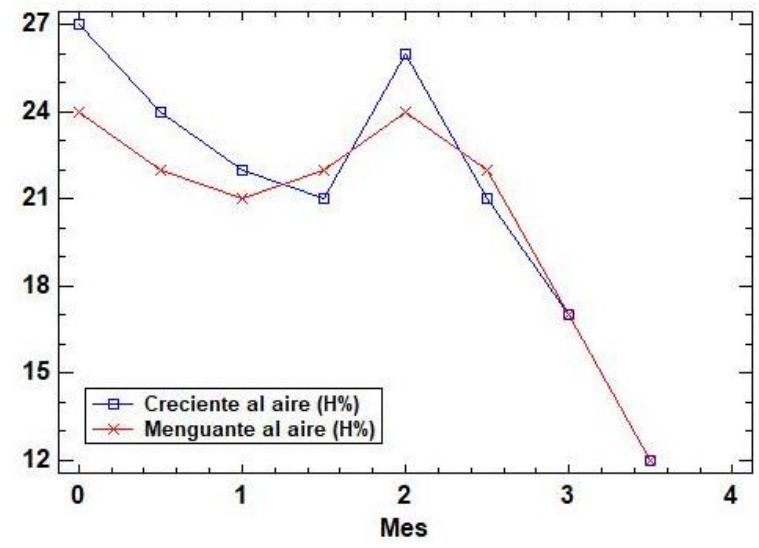

FIGURA 6.34. ANÁLISIS GRÁFICO DE LA INFLUENCIA DE LA ÉPOCA DE CORTA EN LA HIGROSCOPICIDAD. 
En ambas gráficas se aprecia como las tablas cortadas en creciente tienen un contenido de humedad inicial ligeramente superior. Este resultado concuerda con el obtenido anteriormente con la humedad de las probetas, aunque la diferencia entre medias no fue suficiente como para considerarla estadísticamente significante.

En la figura 6.33 se aprecia como las probetas de creciente parten de una humedad superior a las de menguante ( $26 \%$ frente a $24 \%$, aunque según se ha indicado anteriormente esta diferencia no es estadísticamente significativa). Durante el primer mes y medio, las probetas de creciente secan más rápidamente hasta que se igualan en humedad con las de menguante (en torno al 23\%). A partir de ese momento, la velocidad de secado de ambas probetas es más pareja aunque se aprecia que las probetas de creciente secan ligeramente más rápido, ya que justo antes de ser introducidas en la cámara de acondicionamiento (al mes 3) alcanzan una humedad inferior a las probetas de menguante (19\% frente a $20 \%)$.

Por tanto, en base al análisis de la gráfica mostrada en la figura 6.33, es posible concluir que existe una diferencia entre la rapidez de secado de ambas muestras, y más concretamente, que las probetas de creciente secan más rápidamente que las de menguante.

Con respecto a la higroscopicidad (capacidad de absorber o emitir humedad al aire), en la figura 6.34 se aprecia claramente como las probetas de creciente son más sensibles a los cambios de humedad exterior, secándose más rápido cuando hay un tiempo soleado, e incrementando su humedad, también a mayor velocidad, con tiempo lluvioso (periodo de lluvias ocurrido a los 2 meses).

Por tanto, en base al análisis de la gráfica de la figura 6.34, es posible concluir que existe una diferencia entre la higroscopicidad de ambas muestras, y más concretamente que las probetas de creciente tienen una mayor higroscopicidad que las de menguante, porque varían su contenido de humedad más rápidamente al variar la humedad del aire exterior.

En el caso del abeto de Noruega, Zürcher et al., (Zürcher y Mandallaz 2001, Zürcher 2003, Zürcher et al., 2010) encontraron relaciones significativas entre el momento de la tala y la proporción de agua perdida durante el proceso de secado, de modo que el valor de menor pérdida de agua se correspondía con el período sinódico de 3,5 días a partir del día de la luna llena, es decir, los primeros días de la luna menguante. Este resultado concuerda con el resultado obtenido de este trabajo.

En otros estudios realizados sobre abeto de Noruega se encontraron también relaciones significativas entre la pérdida de agua y las fases lunares (Seeling 1998, Bariska 2000, Niemz 2000, Seeling 2000). Además, Ikeda (2006) llega a resultados similares trabajando con madera de Cryptomeria. 


\subsubsection{PROPIEDADES MECÁNICAS}

\subsubsection{MOR, MOE, MOEG Y MOED}

En la tabla 6.21 y en las figuras 6.35 a 6.44 se muestran los resultados del análisis estadístico realizado.

TABLA 6.21: ANÁLISIS ANALÍTICO DE LA INFLUENCIA DE LA ÉPOCA DE CORTA EN EL MOR, MOE, MOEG Y MOED.

\begin{tabular}{|c|c|c|c|c|}
\hline & Comparación & Test & p-valor & $\begin{array}{l}\text { Diferencias } \\
\text { estadísticamente } \\
\text { significativas }\end{array}$ \\
\hline \multirow{2}{*}{ MOR sin corregir } & Distribución & Kolmogorov Smirnov & 0,4040 & No \\
\hline & Media & T-test & 0,1266 & No \\
\hline \multirow{2}{*}{ MOR corregido Kh } & Distribución & Kolmogorov Smirnov & 0,5057 & No \\
\hline & Media & T-test & 0,1319 & No \\
\hline \multirow{2}{*}{ MOE sin corregir } & Distribución & Kolmogorov Smirnov & 0,9753 & No \\
\hline & Media & T-test & 0,9982 & No \\
\hline \multirow{2}{*}{ MOE corregido $12 \%$} & Distribución & Kolmogorov Smirnov & 0,9995 & No \\
\hline & Media & T-test & 0,9305 & No \\
\hline \multirow{2}{*}{ MOEG sin corregir } & Distribución & Kolmogorov Smirnov & 0,7863 & No \\
\hline & Media & T-test & 0,5558 & No \\
\hline \multirow{2}{*}{ MOEG corregido $12 \%$} & Distribución & Kolmogorov Smirnov & 0,5649 & No \\
\hline & Media & T-test & 0,6578 & No \\
\hline \multirow{2}{*}{ MOED_vev sin corregir } & Distribución & Kolmogorov Smirnov & 0,0607 & No \\
\hline & Media & T-test & 0,0382 & Sí \\
\hline \multirow{2}{*}{ MOED_vev corregido $12 \%$} & Distribución & Kolmogorov Smirnov & 0,0523 & No \\
\hline & Media & T-test & 0,0616 & No \\
\hline \multirow{2}{*}{ MOED_ves sin corregir } & Distribución & Kolmogorov Smirnov & 0,6914 & No \\
\hline & Media & T-test & 0,9565 & No \\
\hline \multirow{2}{*}{ MOED_ves corregido $12 \%$} & Distribución & Kolmogorov Smirnov & 0,7629 & No \\
\hline & Media & T-test & 0,8040 & No \\
\hline
\end{tabular}


MOR sin corr_Menguante (N/mm2)
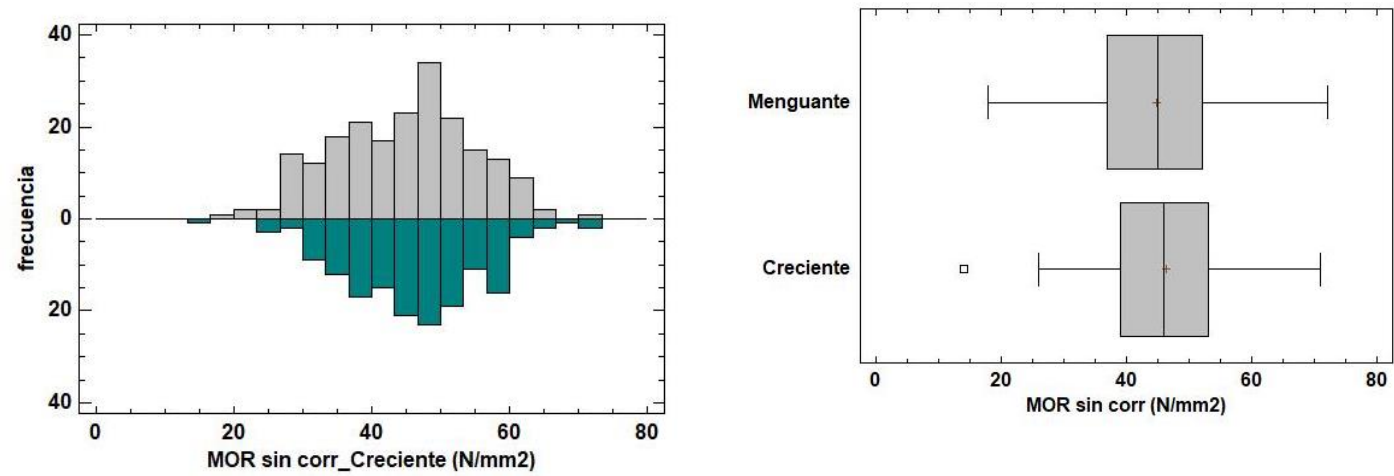

FIGURA 6.35. ANÁLISIS GRÁFICO DE LA INFLUENCIA DE LA ÉPOCA DE CORTA EN EL MOR SIN CORREGIR.

MOR corrKh_Menguante (N/mm2)
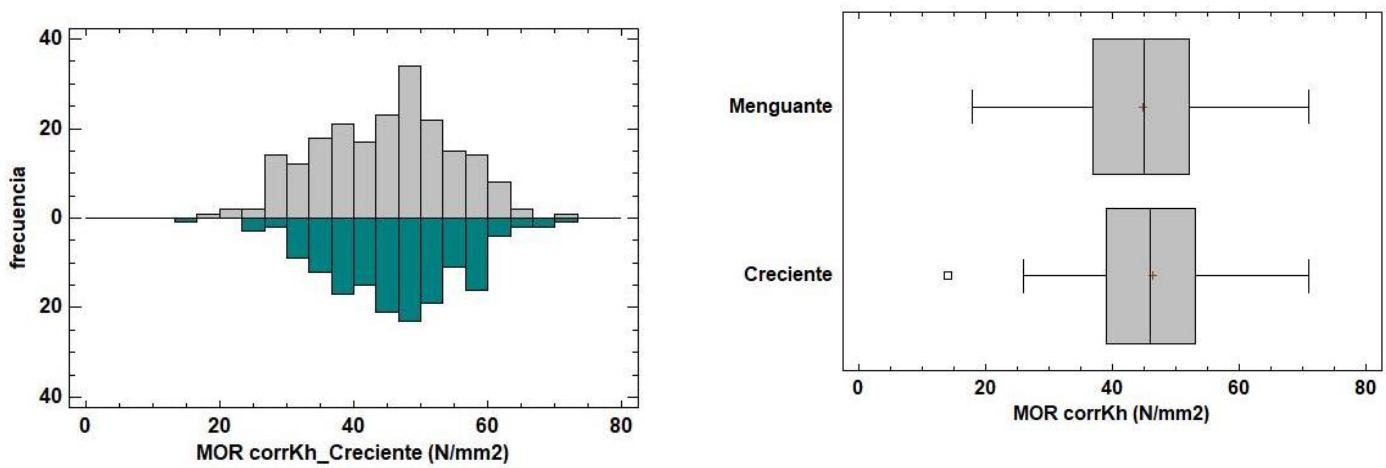

FIGURA 6.36. ANÁLISIS GRÁFICO DE LA INFLUENCIA DE LA ÉPOCA DE CORTA EN EL MOR CORREGIDO POR SECCIÓN.

MOE sin corr_Menguante (N/mm2)
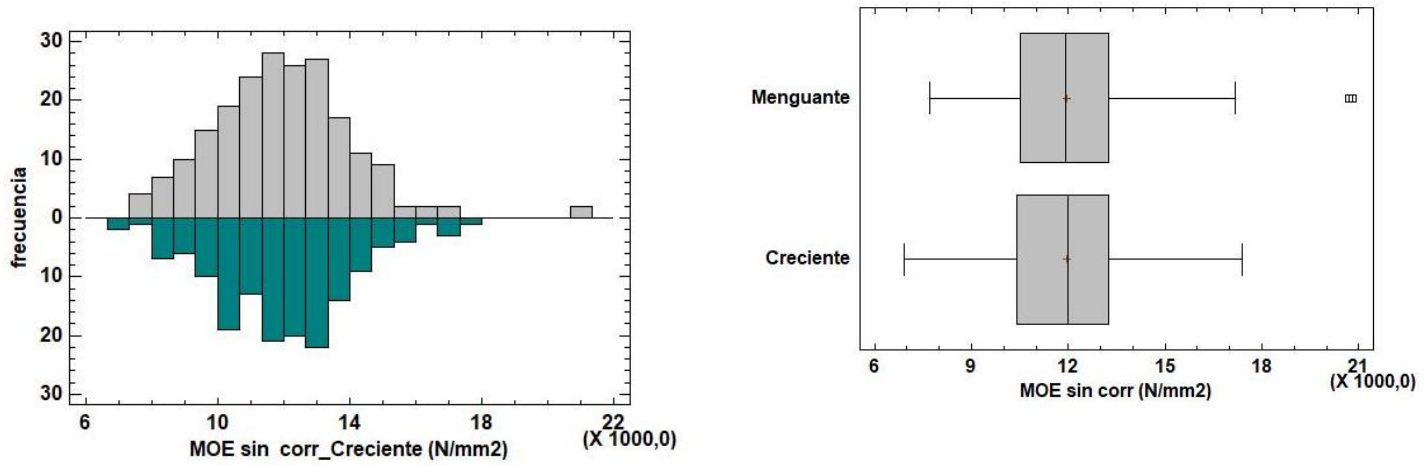

FIGURA 6.37. ANÁLISIS GRÁFICO DE LA INFLUENCIA DE LA ÉPOCA DE CORTA EN EL MOE SIN CORREGIR. 

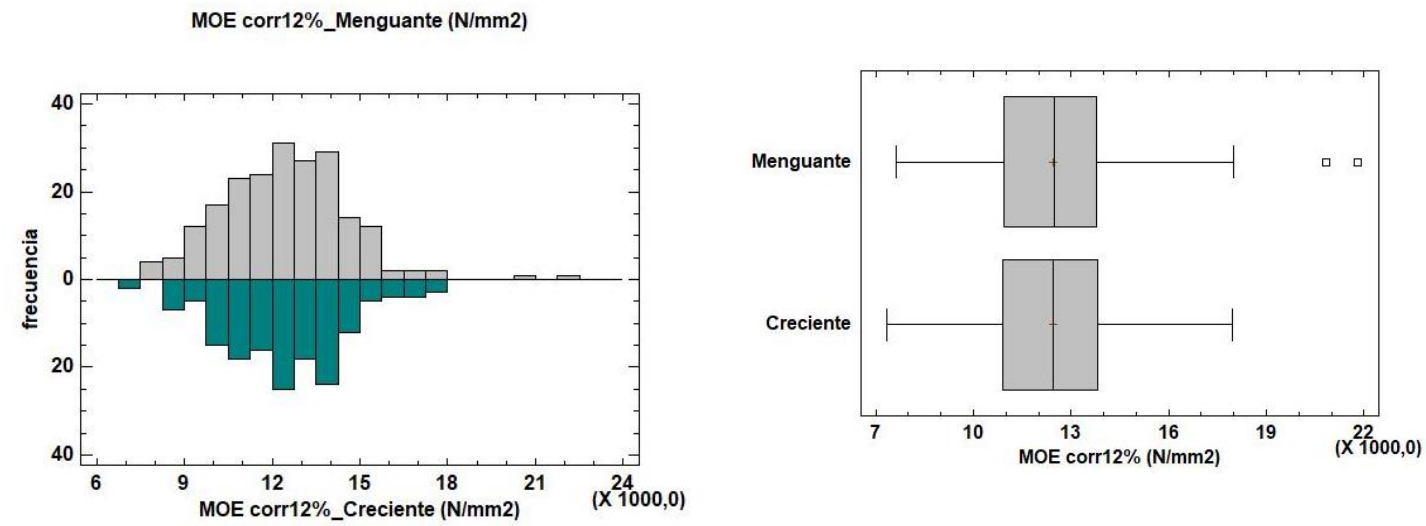

FIGURA 6.38. ANÁLISIS GRÁFICO DE LA INFLUENCIA DE LA ÉPOCA DE CORTA EN EL MOE CORREGIDO POR HUMEDAD.
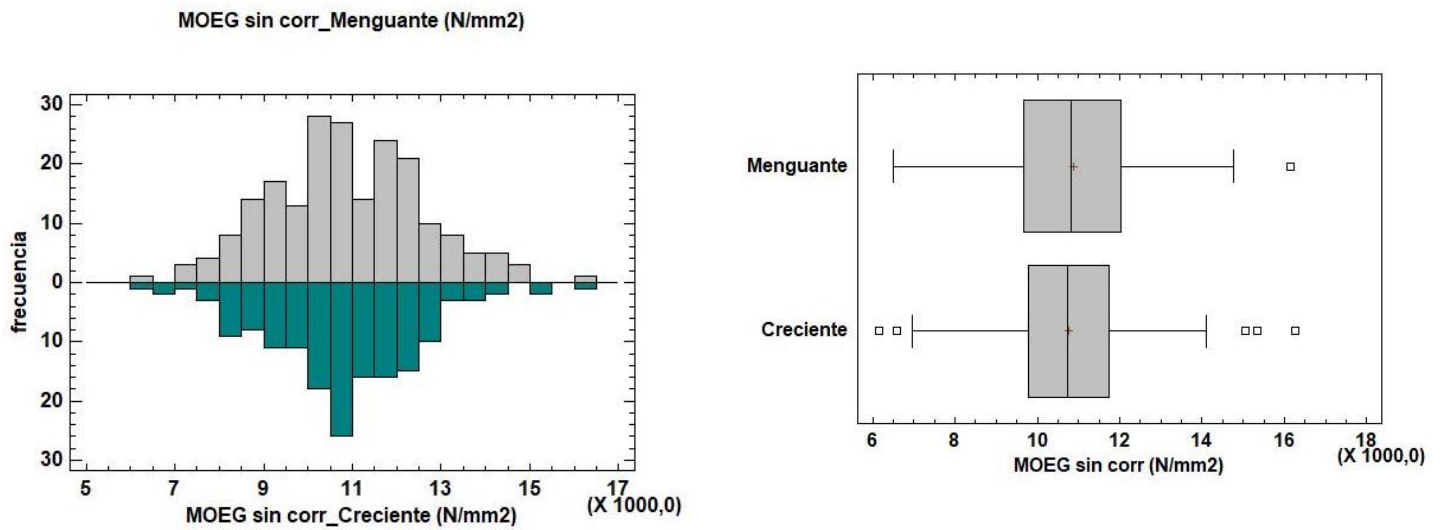

FIGURA 6.39. ANÁLISIS GRÁFICO DE LA INFLUENCIA DE LA ÉPOCA DE CORTA EN EL MOEG SIN CORREGIR.

MOEG corr12\%_Menguante (N/mm2)
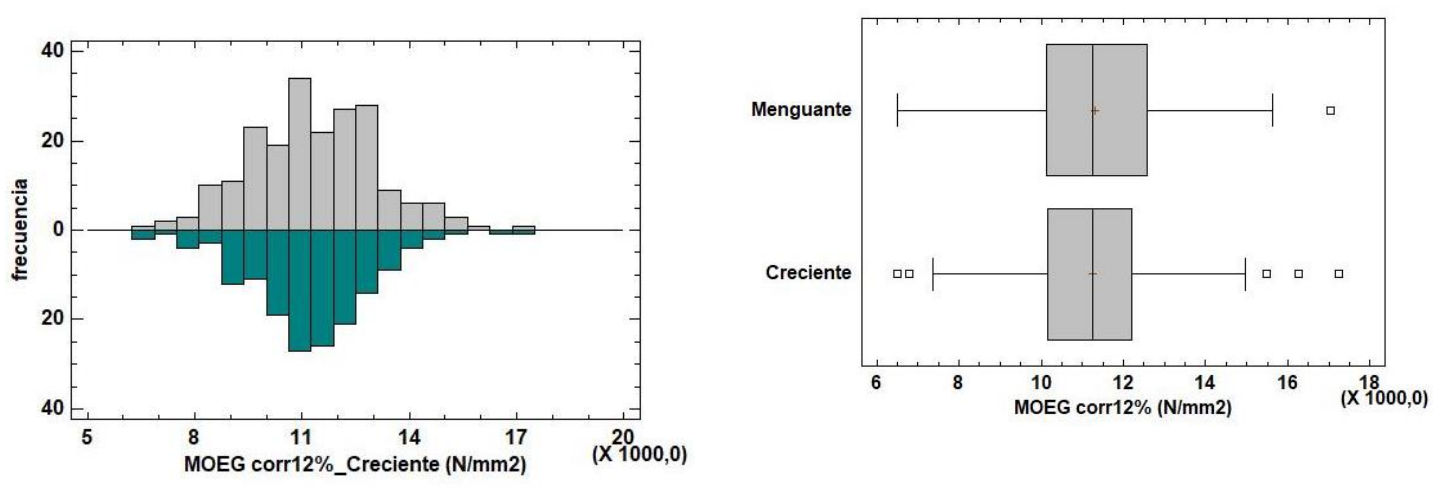

FIGURA 6.40. ANÁLISIS GRÁFICO DE LA INFLUENCIA DE LA ÉPOCA DE CORTA EN EL MOEG CORREGIDO POR HUMEDAD. 

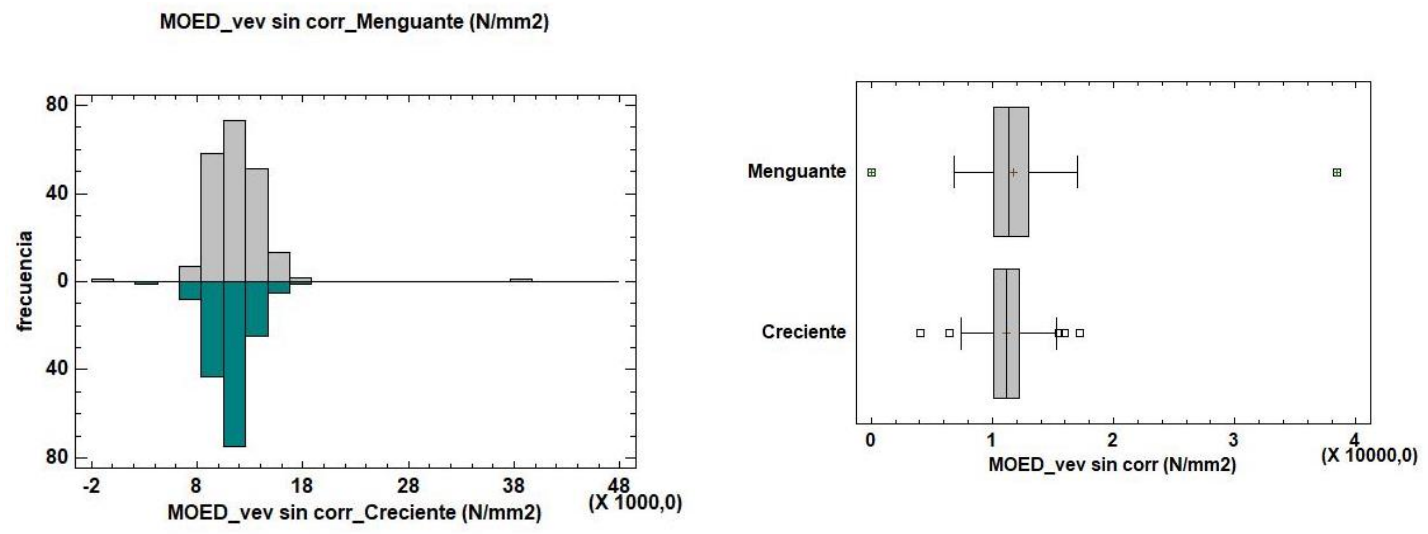

FIGURA 6.41. ANÁLISIS GRÁFICO DE LA INFLUENCIA DE LA ÉPOCA DE CORTA EN EL MOED_VEV SIN CORREGIR.
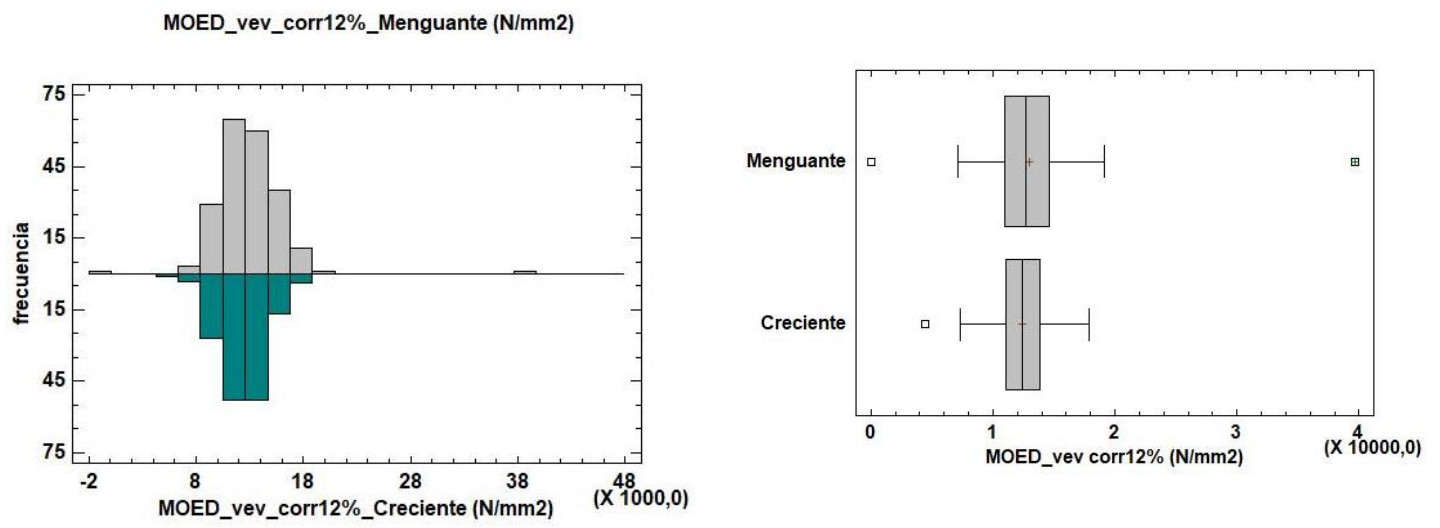

FIGURA 6.42. ANÁLISIS GRÁFICO DE LA INFLUENCIA DE LA ÉPOCA DE CORTA EN EL MOED_VEV CORREGIDO POR HUMEDAD.

MOED_ves sin corr_Creciente (N/mm2)
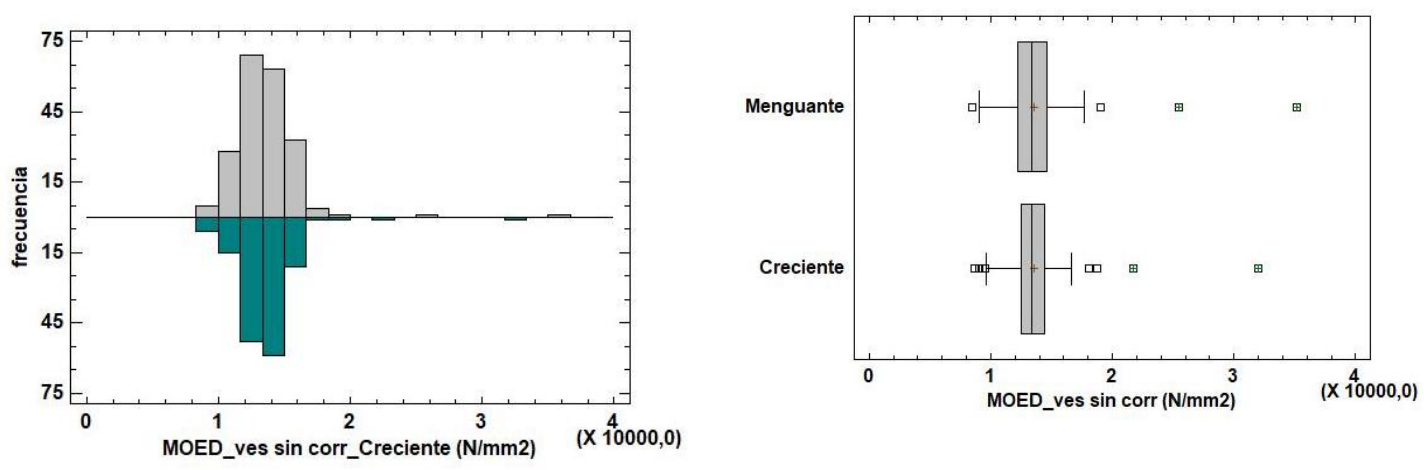

FIGURA 6.43. ANÁLISIS GRÁFICO DE LA INFLUENCIA DE LA ÉPOCA DE CORTA EN EL MOED_VES SIN CORREGIR. 
MOED_ves corr12\%_Menguante (N/mm2)
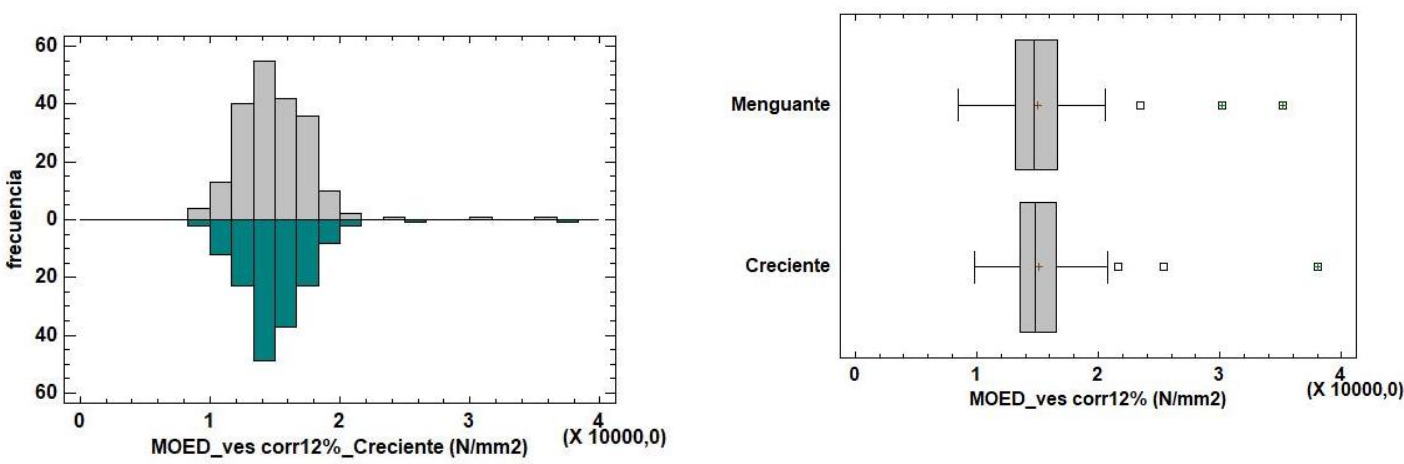

FIGURA 6.44. ANÁLISIS GRÁFICO DE LA INFLUENCIA DE LA ÉPOCA DE CORTA EN EL MOED_VES CORREGIDO POR HUMEDAD.

En general, no se encontraron diferencias estadísticamente significativas entre las propiedades mecánicas de ambas muestras. Únicamente aparecieron diferencias entre las medias del MOED_VEv sin corregir que es lógico de acuerdo a los resultados obtenidos respecto a las propiedades físicas. Así, en la figura 6.41 se aprecia que las probetas de menguante tienen mayor MOED_VEv sin corregir lo cual es debido a que el módulo de elasticidad dinámico, obtenido por el método de vibración longitudinal, es directamente proporcional a la densidad de la probeta (ecuación [5] del presente documento), y según se ha visto en apartados anteriores, las probetas de menguante tienen una mayor densidad que las de creciente.

Al aplicar la corrección por humedad, el MOED_VEV corregido 12\% deja de indicar diferencias significativas. No obstante, el $P$-valor $(0,0616)$ es muy bajo y cercano a 0,05 por lo que se podría decir que el MOED_vev muestra diferencias significativas independientemente de que se realice la corrección por humedad o no, aludiendo a la misma explicación anterior.

Resultados similares se obtuvieron en un estudio preliminar a este trabajo, donde se analizó la influencia de la época de corta en las propiedades mediante ensayos no destructivos sobre probetas de alerce del Japón procedentes del País Vasco. Para ello se midió la velocidad de onda de impacto mediante el dispositivo Microsecond Timer de la casa Fakopp. No se encontraron diferencias entre las propiedades mecánicas de MOE y MOR (Íñiguez-González et al., 2015).

\subsubsection{DISCUSIÓN DE LA INFLUENCIA DE LA LUNA}

Como resumen de los resultados, se han encontrado diferencias significativas en las propiedades físicas: densidad, rapidez de secado e higroscopicidad; y en las propiedades mecánicas: módulo de elasticidad dinámico (cuando éste se obtiene por el método de frecuencia de vibración longitudinal). Concretamente, las probetas de creciente presentaron menor densidad, mayor rapidez de secado, mayor higroscopicidad, y menor módulo de elasticidad dinámico, tabla 6.22. 
TABLA 6.22: RESUMEN DE DIFERENCIAS ESTADÍSTICAMENTE SIGNIFICATIVAS ENTRE PROBETAS DE CRECIENTE Y DE MENGUANTE.

\begin{tabular}{|l|c|c|}
\hline Propiedad & Probetas de creciente & Probetas de menguante \\
\hline Densidad & menor & mayor \\
\hline Rapidez de secado & mayor & menor \\
\hline Higroscopicidad & mayor & menor \\
\hline MOED_vev & menor & mayor \\
\hline
\end{tabular}

La densidad está relacionada con la masa y el volumen de modo que ante una masa constante, un aumento de volumen provoca una reducción de la densidad. En relación al volumen, estudios llevados a cabo con abeto noruego en los que se midió el diámetro en pie, mediante extensometría, bajo condiciones controladas e independientes de factores diarios como la luz, la temperatura o la humedad (en invernadero), descubrieron que el ritmo lunar sinódico provocaba fluctuaciones en el diámetro debido a que la luna influye en el flujo de agua en diferentes partes del árbol (Zürcher, et al., 1998). Estos mismos resultados fueron obtenidos por Barlow et al., (2010).

Analizando los resultados obtenidos en este trabajo y en investigaciones anteriores, respecto a la densidad y a la variación del diámetro de los árboles, se podría intuir que las probetas de creciente tienen menor densidad porque los pies se encuentran más "hinchados" en el momento de ser apeados, es decir, la presión de agua en el interior de sus tejidos vegetales es mayor que la de los pies cortados en luna menguante. Así, considerando una misma masa de las probetas en creciente y en menguante, las probetas de creciente ocuparán más volumen una vez secadas y, por tanto, tendrían menor densidad.

Por otra parte, la teoría de tensión-cohesión, explicada previamente, indica que el agua es conducida en el interior de las traqueidas ocupando la sección completa del conducto, sin cavitar ni despegarse de las paredes, debido a las fuerzas de cohesión entre moléculas y de adhesión con las paredes, respectivamente. Se podría relacionar la actividad de movimiento de savia bruta con la presión ejercida sobre las paredes laterales mediante el Principio de Benoulli de dinámica de fluidos. Éste establece que dentro de un flujo que fluye a presión por un conducto, las regiones del flujo que fluyen a mayor velocidad ejercen una menor presión sobre las paredes laterales del conducto que las regiones que fluyen a menor velocidad. Por ello, continuando con el razonamiento, cabe pensar que en luna menguante, donde los tejidos están menos "hinchados", la presión sobre los conductos laterales es menor debido a que la savia bruta está circulando con mayor velocidad y, por tanto, la intensidad de transpiración sería mayor.

Cabe introducir en este punto un estudio llevado a cabo por Barlow et al., (2010) donde se analizó la relación que existía entre la variación de la acción gravitatoria debida a la acción conjunta de la luna y el sol, la variación de la intensidad de transpiración, y la variación del diámetro de los pies. 
Para los pies de abeto de Noruega se realizó un análisis de Cosinor que permitía comparar la variación rítmica de estos 3 parámetros a lo largo de 3 días consecutivos (17, 18 y 19) del mes de julio de 1988. En la gráfica mostrada del análisis se puede observar como las horas de mayor acción gravitatoria coinciden con las horas de mayor diámetro, y a su vez, de menor transpiración. Lo mismo sucede con las horas de menor acción gravitatoria, que coinciden con las de menor diámetro y de mayor transpiración. Los máximos y mínimos no coinciden exactamente, ya que existe un pequeño desfase entre ellos. El periodo de fluctuación de los 3 parámetros coincidía con la duración de un día lunar. De este modo, los autores constataron que existía una relación entre la fluctuación de la acción gravitatoria y el diámetro de los pies, así como entre la fluctuación gravitatoria y la transpiración.

Aunque el estudio realizado por Barlow et al., (2010) no es comparable con el realizado en el presente trabajo porque ambos aluden a espacios temporales distintos (fluctuación en un día y fluctuación en varios días), parece lógico pensar que el aumento de la acción gravitatoria contribuya, de alguna manera, a reducir la intensidad de transpiración, y que a su vez, ésta provoque la disminución de la velocidad del flujo, aumentando, a su vez, el diámetro de los pies (por el Principio de Bernoulli).

Finalmente, siguiendo con el razonamiento anterior, la mayor presión del fluido sobre las paredes laterales de las traqueidas no solo provocaría que las probetas de creciente tuviesen menor densidad una vez secadas, sino también que las oquedades internas de los tejidos conductores fuesen ligeramente mayores, y por tanto, reaccionasen con mayor rapidez al intercambio de agua con el exterior, lo que justificaría que tengan una mayor rapidez de secado e higroscopicidad.

Sin embargo, hay que considerar que los mecanismos de activación de la transpiración son muy complejos y dependen de múltiples factores, no solo de la acción gravitatoria o de la intensidad lumínica, por lo que el razonamiento esgrimido anteriormente no es más que una suposición, realizada en base a principios sencillos, siendo por ello necesario realizar investigaciones posteriores de mayor calado y más específicas, que se escapan del objeto de este trabajo. 


\section{CONCLUSIONES}

Para la realización de este trabajo de caracterización mecánica y de análisis de la influencia del periodo de corta en las propiedades del alerce del Japón (Larix kaempferi (Lamb.) Carr.), se han estudiado 370 probetas de dicha especie, con 4 secciones diferentes $(7 \times 15,10 \times 15,14 \times 18$, y 20x25 cm), sobre las cuales se han realizado ensayos no destructivos (en troza húmeda y en probeta seca) y ensayos destructivos (en probeta seca). Además, se ha estudiado el proceso de secado, bajo cubierta y al aire, de 140 tablas de la misma especie. Se detallan a continuación las conclusiones obtenidas:

- El comportamiento del alerce de Japón a flexión es excelente superando generalmente a muchas otras coníferas utilizadas para madera estructural. El 85\% de las muestras analizadas tiene una resistencia (MOR) superior a $30 \mathrm{MPa}$, el $90 \%$ una rigidez (MOE) superior a $9 \mathrm{MPa}$, y el $90 \%$ una densidad al $12 \%$ superior a 500 $\mathrm{kg} / \mathrm{m}^{3}$.

- Desde un punto de vista mecánico, debido al carácter verticilado de esta especie, el principal defecto que presenta la madera son los nudos, detectándose una elevada presencia de nudos agrupados tanto en canto (51\% de las piezas) como en cara (85\%). La mayoría de las piezas (alrededor del 90\%) tienen una desviación de la fibra reducida (por debajo del 10\%). Por ello, la causa principal de rotura en el ensayo de flexión son los nudos, $62,1 \%$, seguidos por la desviación de la fibra en una proporción mucho menor, 10,3\%.

- Todas las piezas ensayadas tenían un porcentaje de duramen superior al 80\%, con un promedio del $90 \%$. Esto dificultó mucho el secado hasta el contenido de humedad de referencia del 12\%, especialmente en las probetas de mayor sección. En general, en el momento de realizar los ensayos mecánicos, las probetas tenían un contenido medio de humedad del $19,4 \%$, obtenido mediante secado de rebanada en estufa; y del $15,8 \%$, obtenido con xilohigrómetro.

- Se elaboró una tabla de clasificación visual para la madera estructural de alerce del Japón de procedencia española, obteniendo 2 clases visuales denominadas MEG1 (Madera Estructural de Gran Escuadría-1) y MEG-2 (Madera Estructural de Gran Escuadría-2). El rendimiento clasificatorio es muy elevado, con un porcentaje de rechazo de tan solo el 3,8\%. El 48,4\% de las piezas se clasifica como MEG-1, y el $47,8 \%$, como MEG-2.

- Los valores característicos de resistencia, rigidez y densidad de la clase MEG-1 son $f_{k}=31,80 \mathrm{MPa}, E_{0, \text { mean }}=13.082 \mathrm{MPa}$, y $\rho_{k}=465,6 \mathrm{~kg} / \mathrm{m}^{3}$, asignándose una clase resistente C30. Los valores característicos de la clase MEG-2 son $f_{k}=24,55 \mathrm{MPa}$, $E_{0, \text { mean }}=12.320 \mathrm{MPa}$, y $\rho_{k}=469,1 \mathrm{~kg} /{ }^{\mathrm{m} 3}$, asignándose una clase resistente C24. 
- Se realizaron modelos analíticos, considerando conjuntamente parámetros no destructivos y visuales, para la estimación de la rigidez (MOE y MOEG) y de la resistencia (MOR). La estimación del MOEG $\left(r^{2}=0,66\right)$ alcanzó un ajuste ligeramente mayor que la estimación del $\operatorname{MOE}\left(r^{2}=0,56\right)$, y mucho mayor que la estimación del MOR $\left(r^{2}=0,44\right)$. En todos los casos los modelos muestran peores estimaciones al aplicar las correcciones pertinentes (por humedad para la rigidez, y por tamaño para la resistencia). Esto puede ser debido a que la corrección por humedad propuesta para las mediciones no destructivas, no se ajusta perfectamente al alerce del Japón por su alto porcentaje de duramen.

- La utilización de métodos no destructivos resulta apropiada por sí sola para estimar los valores de rigidez (MOE y MOEG), obteniendo relaciones aceptables entre el módulo de elasticidad dinámico y la rigidez, tanto en troza como en probeta seca. Sin embargo, a la hora de estimar la resistencia (MOR), es recomendable utilizar además el apoyo de parámetros visuales para mejorar la estimación. Dentro de los métodos no destructivos empleados, el método de frecuencia de vibración longitudinal es más eficiente que el método de velocidad de paso de onda de impacto, mostrando una mejor viabilidad para la clasificación mecánica.

- Se observó una clara relación entre el MOR y la altura del árbol, de modo que la resistencia de la probeta se reduce cuanto mayor es la altura de la troza de procedencia. Se estableció una ecuación lineal entre ambos parámetros con un buen ajuste $\left(r^{2}=0,71\right)$. Para el resto de parámetros caracterizadores (MOE y densidad al $12 \%$ ), no fue posible encontrar una relación coherente con la altura. Esto es debido a que las probetas utilizadas eran de tamaño estructural real, con 4 secciones transversales diferentes, que podían contener parte o la totalidad de la sección del tronco, y que, por tanto, no tenían capacidad para aislar la variación de las variables caracterizadores en dirección longitudinal, de su posible variación en dirección radial.

- La utilización de la velocidad de onda de impacto como método de predicción de la calidad en troza, no es de aplicación, siendo solo fiable en las probetas de mayor sección porque éstas representan mejor las características de la troza completa. En consecuencia, se elaboró una tabla de clasificación visual en troza, considerando únicamente parámetros visuales, donde se establecieron 3 calidades: Superior, Media e Inferior. Las probetas obtenidas de trozas clasificadas como Superior, tienen un porcentaje del $80 \%$ de alcanzar una clasificación MEG-1, y un 20\% de alcanzar una clasificación MEG-2. Las probetas obtenidas de trozas clasificadas como Media, tienen un porcentaje del 50\% de alcanzar MEG-1, un 47\% de alcanzar MEG-2, y un 3\% de resultar rechazadas para uso estructural. Finalmente, las probetas obtenidas de trozas clasificadas como Inferior, tienen un porcentaje del $33 \%$ de alcanzar MEG-1, un 62\% de alcanzar MEG-2, y un 5\% de resultar rechazadas para uso estructural. 
- Se encontraron diferencias estadísticamente significativas entre las probetas de creciente (pies cortados entre 2 y 5 días tras la luna nueva) y las probetas de menguante (pies cortados entre 2 y 5 días tras la luna llena). Concretamente, las probetas de creciente presentan menor densidad, mayor rapidez de secado, mayor higroscopicidad, y menor módulo de elasticidad dinámico (cuando éste se obtiene por el método de frecuencia de vibración longitudinal). Para explicar el fundamento de las diferencias encontradas es necesario realizar investigaciones futuras más específicas y de mayor envergadura. 


\section{FUTURAS LÍNEAS DE INVESTIGACIÓN}

Durante el proceso de elaboración de este trabajo han ido surgiendo ideas sobre otras líneas de investigación, que desarrollen los resultados obtenidos y los complementen, o incluso, que aborden directamente nuevas temáticas para alcanzar visiones más profundas y científicas sobre algunos aspectos concretos. Se enumeran a continuación algunas líneas de investigación que podrían desarrollarse en el futuro:

- Establecer ecuaciones de corrección por humedad específicas para el alerce del Japón para distintos dispositivos de ensayos no destructivos. Comparar los resultados con otras especies con alto porcentaje de duramen, y con mediciones realizadas de duramen a duramen

- Analizar mediante probetas pequeñas la evolución de las variables caracterizadoras (MOR, MOE y densidad al 12\%) para el alerce del Japón, tanto en dirección longitudinal (según la altura del árbol), como en dirección radial. Establecer relaciones entre estas variaciones cuando se utilizan probetas mayores de tamaño estructural.

- Establecer relaciones fiables, mediante técnicas no destructivas y parámetros visuales, que permitan evaluar y relacionar la calidad estructural de la madera en todas las etapas de la línea de producción, es decir, en pie, en troza, y en probeta seca.

- Desarrollar la clasificación mecánica del alerce del Japón mediante la metodología de frecuencia de vibración, longitudinal y/o transversal, sobre probeta en seco.

- Analizar la relación de la época de corta con la actividad fisiológica de las plantas, aislando posibles variables influyentes con respuestas concretas. Se pretende entender mejor las respuestas fisiológicas relativas a la intensidad de transpiración, actividad fotosintética, movimiento de savia, activación de la respiración, etc.; ante agentes externos específicos como intensidad lumínica, acción gravitatoria, fotoperiodo, velocidad del viento, temperatura, humedad del aire, necesidades vegetativas, etc. Estudiar este tipo de relaciones para espacios temporales distintos, es decir, diariamente, mensualmente, trimestralmente, anualmente, en función de las fases lunares, etc. 


\section{REFERENCIAS BIBLIOGRÁFICAS}

\subsection{TEXTOS CIENTÍFICOS}

- ACUÑA L., DÍEZ M., CASADO M. 2006. Los ultrasonidos y la calidad de la madera estructural. Aplicación a Pinus pinaster Ait. CIDEU 2:7-26.

- ADELL F.J. (2005). Comparación de las normas de clasificación de madera estructural española (UNE 56544) y alemana (DIN 4074) para madera de pino silvestre (Pinus sylvestris L.) de procedencia alemana. Proyecto final de carrera. Escuela Técnica Superior de Ingenieros de Montes. Universidad Politécnica de Madrid.

- ALARES MARTíN, J.M., GUINDEO CASASÚS A., LÍAN ORTEGA, L. C., PERAZA ORAMAS, C. 1992. Estructuras de madera. UNED. Escuela de la edificación.

- ANTONY F., SCHIMLECK L.R., DANIELS, R.F., CLARK III, A., HALL D.B. 2010. Modeling the longitudinal variation in wood specific gravity of planted loblolly pine (Pinus taeda) in the United States. Canadian Journal of Forest Research 40: 24392451. DOI: 10.1139/X10-187.

- ARguelles R., ARRIAGA F. CONGRESO FORESTAL ESPAÑOL - Lourizán 1.993. Ponencias y comunicaciones. Tomo IV.

- ARRIAGA F., GARCÍA L., GEBREMEDHIN K. G., PERAZA F. 1992. Grading and load carrying capacity of old omber beams. International Summer Meeting, American Society of Agricultural Engineers. Paper no 92 4068. American Society of Agricultural Engineers, ASAE. Charlotte, North Carolina, USA. 21 -24 jun. 1992.

- ARRIAGA F., PERAZA, F.; ESTEBAN, M. 2003. Madera aserrada estructural. Editorial AITIM. $159 \mathrm{p}$.

- ARRIAGA F., ESTEBAN M., RELEA E. 2005. Evaluación de la capacidad portante de piezas de gruesa escuadría de madera de conífera en estructuras existentes. Materiales de Construcción. Vol. 55, no 280. P. 43-52.

- ARRIAGA F., ÍÑIGUEZ-GONZÁLEZ G., ESTEBAN M., DIVOS F. 2012. Vibration method for grading of large cross-section coniferous timber species. Holzforschung. Vol. 66, pp. 381-387. DOI: 10.1515/HF.2011.167.

- ARRIAGA F., ÍÑIGUEZ G., ESTEBAN M. 2014. Assessment of strength and stiffness properties using longitudinal stress wave on structural gross cross section timber of radiata pine (Pinus radiata D. Don). Proceedings of the 14th International Symposium on Non-destructive Testing of Wood. Shaker Verlag, Germany, pp. 101-110.

- ARRiagA F., MONTON J., SEgUES E., íÑIGUEZ-GONZÁleZ G. 2014. Determination of the mechanical properties of radiata pine timber by means of longitudinal and transverse vibration methods. Holzforschung. 68(3):299-305. DOI: 10.1515/hf-2013-0087.

- ARRIAGA F., ÍÑIGUEZ G., ESTEBAN M. 2014. Assessment of strength and stiffness properties using longitudinal stress wave on structural gross cross section timber of radiata pine (Pinus radiata D. Don). Proceedings of the 14th International 
Symposium on Non-destructive Testing of Wood. Shaker Verlag, Germany, pp. 101-110.

- AUNÓS A. (2008). Selvicultura de Larix spp. : Compendio de Selvicultura aplicada en España (Serrada R., Montero G., Reque J.A., eds.). Instituto Nacional de Investigación y Tecnología Agraria y Agroalimentaria. Madrid. pp. 259-266.

- AY N., TOPALOGLU E., AKPINAR E. 2012. The effects of stem height on the physical properties of European larch (Larix decidua Mill.) wood. Innovations in Forest Industry and Engineering Design, November 15-17, Yundola, Bulgaria.

- AZCÓN-BIETO J. Y TALÓN M. 2013. Fundamentos de fisiología vegetal. º edición. Publicacions i edicions Universitat de Barcelona. ISBN 978-84-475-3230-8.

- BARISKA M., ROSCH P. 2000. Felling date and shrinkage behavior of Norway spruce. Schweiz. Z. Forstwes. 151(11): 439-443.

- BARLOW, P. W., MIKULECKY, M., \& STRESTIK, J. (2010). Tree-stem diameter fluctuates with the lunar tides and perhaps with geomagnetic activity. Protoplasma, 247(1-2), 25-43. http://dx.doi.org/10.1007/s00709-010-0136-6.

- BROENDEGAARD, VJ. (1985) Ethnobotany: plants in traditions, history and popular medicine-tree felling and moon phases: superstition or folk-visdom? In: Contributions to ethnomedicine, ethnobotany and ethnozoology. Verl. Mensch und Leben, Berlin, vol 6, pp 82-92 (in German).

- BROWN F.A., CHOW CS. 1973. Lunar-correlated variations in water uptake by bean seeds. Biol Bull 145:265-278.

- BUES C.T., KRETSCHMAR, K. 2008. Moisture content and insect infestation at timber of Norway spruce (Picea abies [L.] Karst.), which was harvested at specific moon phases. Forst. Holz. 63(9): 32-36.

- BUNETTI M., BURATO P., CREMONINI C., NEGRO F., NOCETTI M., ZANUTTINI R. 2016. Visual and machine grading of larch (Larix decidua Mill.) structural timber from the Italian Alps. Materials and Structures. 49:2681-2688. DOI: 10.1617/s11527-015-0676-5.

- BURMESTER A. (1978A). Annual variations in shrinkage and swelling of Oak wood in living trees. Holz Roh-Werkst 36:157-161 (in German).

- BURMESTER A. (1978B). Annual variations of physical wood properties in an Oak tree (Quercus robur L.). Holz Roh-Werkst 36:315-321 (in German).

- CASADO M., ACUÑA L., BASTERRA L.A., RAMÓN-CUETO G., VECILLA D. 2012. Grading of structural timber of Populus x euramericana clone I.214. Holzforschung. Vol. 66, pp. 633, 633-638. DOI: 10.1515/hf-2011-0153.

- CHARRON S., JOUREZ B., MARCHAL M., HÉBERT J. 2003. Étude comparative des caractéristiques physiques et mécaniques du bois des mélèzes d'Europe (Larix decidua Mill.), du Japon (Larix kaempferi (Lambert) Carr.) et de leur hybride (Larix $x$ eurolepis Henry). Biotechnol. Agron. Soc. Environ. 7 (1), 5-16.

- CHUI Y.H. AND MACKINNON-PETERS G. 1995. Wood properties of exotic larch grown in eastern Canada and north-eastern United States. The Forestry Chronicle. Vol. 71, No. 5. pp. 639-646.

- COLUNGA VILLAR A. (2008). Determinación de la capacidad resistente de madera estructural de Populus sp. Mediante métodos no destructivos. Proyecto fin de carrera. Ingeniería de Montes, ETSIIAA de Palencia. Universidad de Valladolid. 
- CRESPO J., AIRA J.R., VÁZQUEZ C., GUAITA M. 2017. Comparative Analysis of the Elastic Constants Measured via Conventional, Ultrasound, and 3-D Digital Image Correlation Methods in Eucalyptus globulus Labill. Bioresources. Vol. 12, №2, pp. 3728-3743. DOI: 10.15376/biores.12.2.3728-3743.

- DAHLEN J., MONTES C., EBERHARDT T.L., AUTY D. 2018. Probability models that relate non-destructive test methods to lumber design values of plantation loblolly pine. Forestry. 00, 1-12. DOI: 10.1093/forestry/cpy001.

- DELIVEZ A. (1984). Influencia de diversos factores en la calidad de la madera de uso estructural de Pinus sylvestris L. Revista de Investigación Agraria, 1 (2). P. 4153.

- DIVOS F., TANAKA T. 1997. Lumber Strength Estimation by Multiple Regression. Holzforschung. 51(5):467-471.

- DIVOS F.(2005). Course in Non-Destructive Testing of Wood. Apuntes y presentaciones del curso. Madrid 13 - 16 junio 2005. ETS Ingenieros de montesETS Arquitectura, UPM, Madrid.

- DORDA G. (2004). Sun, earth, moon-the influence of gravity on the development of organic structures. Part II: the influence of the moon. Sudetendeutsche Akademie der Wissenschaften und Künste, München, vol 25, pp 29-44.

- DUVOISIN J., Lab: Laborantzako liburua edo bi aita semeen solasak laborantzaren gainean. Baiona, 1858 (ed. facsímil, Donostia, 1978).

- ENDRES K.P., SCHAD W.(1997). Biology of the moon. Moon periodicities and life rhythms. S. Hirzel Verlag, Stuttgart, 308 pp (in German).

- FERNANDEZ-GOLFIN J.I., DIEZ M.R. 2000. Caracterización de la madera de Pinus nigra subsp salzmanii. Memoria fin de proyecto. Documento interno.

- FERNANDEZ-GOLFín J.I., DIEZ M. R., HERMOSO E. 2001. Análisis y estado del arte de la técnica de clasificación mecánica por máquina de la madera aserrada estructural (Revisión). Revista de Investigación Agraria, 10 (1). P. 5-20.

- FERNANDEZ-GOLFÍN J. L.; DIEZ M. R.; HERMOSO E.; MIER, R. (2003). Manual de clasificación de madera. AITIM. ISBN: 84-87381-26-X.

- FERNANDEZ ORDIZ, A., SANCHEZ M., SANTACLARA O., GUATIA M. 2009. Los métodos sónicos y la calidad estructural de madera aserrada. Aplicación a Pseudotsuga menziesii. $5^{\circ}$ Congreso Forestal Español. 21 -25 sep.

- FERNÁNDEZ A., SÁNCHEZ M., SANTACLARA O., GUAITA M. 2009. Los métodos sónicos y la calidad estructural de madera aserrada. Aplicación a Pseudotsuga menziesii. 5ำ Congreso Forestal Español.

- FOWLER D.P., SIMPSON J.D., PARK Y.S. AND SCHNEIDER M.H. 1988. Yield and Wood Properties of 25-year-old Japanese Larch of Different Provenance in Eastern Canada. The Forestry Chronicle. Scientific Technical Articles. December 1988, pp. 475-479.

- FROMPONG-MENSAH K. 1987. Fibre length and basic density variation in the wood of Norway spruce (Picea abias [L.] Karst.) from northern Norway. Communications of the Norwegian Forest Research Institute 40(1): 1-25.

- GÄUMANN E.(1930). Research on the influence of the felling time on the wood properties of Norway Spruce and Silver Fir. 2. Teil. Beiheft Nr.5, Zeitschriften des Schweizerischen Forstvereins, 155 pp (in German). 
- GOIA R. DE OliveiRA F., PLETZ E., SALES A. 2002. Assessment of mechanical properties of Wood using an ultrasonic Technique. $13^{\text {th }}$ International Symposium on Nondestructive Testing of Wood.

- gORJAS GARcía J., CARDIEL LÓPEZ N., ZAMORANO CALVO J. 2011. Estadística básica para el estudiante de ciencias. Departamento de Astrofísica y Ciencias de la Atmósfera. Facultad de Ciencias Físicas. Universidad Complutense de Madrid.

- GRACIA C. (2004). Inventari Ecològic i Forestal de Catalunya. Catalunya. CREAF, Barcelona.

- HAKKILA P. 1966. Investigation on the basic density of Finnish pine, spruce and birch wood. Communicationes Instituti Forestalis Fenniae 61(5). 98 p.-1979. Wood density surveys and dry weight tables for pine, spruce andbirch stems in Finland. Communicationes Instituti Forestalis Fenniae 96(3). 59 p.

- HAUSER A. (1973). Rural rules. A Swiss collection with comments.Artemis Verlag, Zürich, 710 pp (in German).

- HEGER L. 1974. Longitudinal variation of specific gravity in stems of black spruce. Balsam fir, and lodgepole pine. Canadian Journal of Forest Resource 4(3): 321326.

- HERMOSO E., FERNANDEZ GOLFín J. I., DIEZ M. R. 2003. Análisis del factor de altura $k_{h}$ en la madera aserrada estructural de pino silvestre. Revista de Investigación Agraria, 11 (2). P- 441-448.

- HOLZKNECHT K. (2002). Electrical potential in the sapwood of Norway spruce (Picea abies L.) and stone pine (Pinus cembra L.) and their relationship with climate and lunar phase. Phd thesis G0443. Physiology, Universitaet Innsbruck, Naturwissenschaftliche Fakultaet, Institut fuer Botanik, 124 pp (in German, English summary).

- HOLZKNECHT K., ZÜRCHER E. (2006). Tree stems and tides-a new approach and elements of reflexion. Schweiz Z Forstwes 157(6):185-190.

- IKEDA K. (2006). Green moisture content of sugi (Cryptomeria japonica) felled at the new of the moon and the full of the moon in every month. Bull. Shizuoka Prefecture Forestry Forest Prod. Res. 34: 25-30.

- instituto NACIONAL DE INVESTIGACIÓN Y TECNOLOGía AGRARÍA Y ALIMENTARIA (INIA). 2011. Informe del desarrollo del proyecto sobre caracterización mecánica de vigas de gruesa escuadría de pino radiata del País Vasco. Mesa Intersectorial de la Madera y Diputación Foral de Bizkaia.

- IÑIGUEZ G. (2007). Clasificación mediante técnicas no destructivas y evaluación de las propiedades mecánicas de la madera aserrada de coníferas de gran escuadría para uso estructural. Tesis Doctoral. Escuela Técnica Superior de Ingenieros de Montes. Universidad Politécnica de Madrid.

- IINIIGUEZ G., ARRIAGA F., ESTEBAN M., LLANA D.F. 2015. Reference conditions and modification factors for the standardization of non-destructive variables used in the evaluation of existing timber. Construction and Building Materials. 101, 11661171. DOI: 10.1016/j.conbuildmat.2015.05.128. 
- IINIIGUEZ-GONZÁLEZ G., BARRIOLA M.J., ZURCHER E. 2015. Influence of the moon phase on stress wave velocity and structural timber properties. General Technical Report FPL-GTR-239. Proceedings: 19th International Nondestructive Testing adn Evaluation of Wood Symposium.

- JAHN E. (1982). Studies on the attack of spruce trees by bark beetles in connection with moon phases during the period of cutting. Anz.Schaedlingskd. Pflanzenschutz Umweltschutz 55(10):145-149.

- JUNG-KWON O., KWANG-MO K., JUN-JAE L. 2010. Use of adjacent knot data in predicting bending strength of dimensión lumber by x-ray. Wood and Fiber Science. 42 (1), pp. 10-20.

- KESSEL M.H., PLINKE B., AUGUSTIN R., HUSE M.1998. Streght grading of construction timber with large cross sections. Proceedings of the $5^{\text {th }}$ Word Conference on Timber Engineering. Montreaux, Switzerland. 17-20 august 1998. Vol. 1. 557-562.

- KLEIN G. (2007). Farewell to the internal clock. A contribution in the field of chronobiology. Springer, New York, 116 pp Kleinhoonte A (1932) Research on the autonomous movements of the primary leaves of Canavalia ensiformis DC. Jahrbücher für wissenschaftliche Botanik 75:679-725 (in German).

- LLANA D F., INIGUEZ-GONZALEZ G., MONTON J., ARRIAGA, F. 2018. In-situ density estimation by four nondestructive techniques on Norway spruce from builtin Wood structures. Holzforschung. 72(10): 871-879. DOI: 10.1515/hf-2018-0027.

- MACHADO J.S., SARDINA R., CRUZ H. 1998. Evaluation of lengthwise variation of mechanical properties by ultrasound. Proceedings of the $5^{\text {th }}$ World Conference on Timber Engineering. Montreaus, Switzerland. 17- 20 August 1998. Vol. 2. P. 304311.

- MACHADO J.S., SARDINHA R.A., CRUZ H P. 2004. Evaluation of legthwise variation of knots in meritime pine timber by acousto-ultrasonic scanning. Wood Science and technology, 38 (4). P. 277-284.

- MACHADO J.S., CRUZ H.P. 2005. Within stem variation of Maritime pine timber mechanical properties. Holz als Roh-und Werkstoff 63 (2): 154-159.

- MANRIQUE F.J. (2010). Determinación de la capacidad resistente en madera estructural de escuadría de Populus $x$ euramericana i-214 mediante métodos de vibración inducida y ultrasonido. Proyecto fin de carrera. Ingeniería de montes, ETSIIAA de Palencia. Universidad de Valladolid.

- MALHOTRA V. M., CARINO N.J. 2003. Handbook on Nondestructive Testing of Concrete. CRC Press, $2^{\text {nd }}$ edition. 384 p.

- MARCHAL M. and JACQUES D. 1999. Évaluation de deux méthodes acoustiques de détermination du module délasticité de bois de mélèze hybride jeune (Larix $x$ eurolepis Henry) - comparaison avec une méthode normalisée en flexion statique. Ann. For. Sci. 56: 333-343.

- MARTIN VICENTE R. (2009). Determinación de la capacidad resistente en madera estructural de populus $x$ euramericana $\mathrm{I}-214$ mediante ultrasonidos. Proyecto final de carrera. Ingeniería de Montes, ETSIA de Palencia. Universidad de Valladolid. 
- MARTINS C.E.J., DÍAS A.M.P.G., MARQUES A.F.S., DÍAS A.M.A. 2017. NonDestructive methodologies for assessment of the mechanical properties of new utility poles. Bioresources. 12(2), 2269-2283. DOI: 10.15376/biores.12.2.22692283.

- MONTON J. (2012). Clasificación estructural de la madera de Pinus radiata D. Don. Procedente de Cataluña mediante métodos no destructivos y su aplicabilidad en la diagnosis estructural. Tesis Doctoral. Escola tècnica superior d'arquitectura de barcelona. Universitat Politècnica de Catalunya.

- MONTERO M.J., DE LA MATA J., ESTEBAN M., HERMOSO E. 2015. Influence of moisture content on the wave velocity to estimate the mechanical properties of large cross-section pieces for structural use of scots pine from Spain. maderas-Ciencia y Tecnología. Vol. 17, 2, pp. 407-420. DOI: 10.4067/S0718-221X2015005000038.

- MORIGUCHI K., SCHIBATA N., IMAI M., YAMANOUCHI M., YOSHIDA T. 2016. Optimizing the parameters of a knot assesment model base don the visual grading of JAS of lumber. The Japan Wood Research Society. J-Stage. Vol 62, No 4, p. 133145. DOI: 10.2488/jwrs.62.133.

- NAVI P., HEGER F. (2005). Thermo-hydromechanical behavior of wood. Presses Polytechniques et Universitaires Romandes, Lausanne, 298 pp (in French).

- NIEMZ P., KUCERA L.J. 2000. Influence of the felling date in essential properties of Norway spruce-An investigation of published theses. Schweiz. Z. Forstwes. 151(11):444-450.

- PAUNGER J., THOMAS P., 1996. Vivir con la luna.

- PELLERIN R.F., ROSS, R.J. 2002. Nondestructive evaluation of wood. Forest Products Society. Madison, WI, USA. 210 p.

- PEMÁN GARCíA J., NAVARRO R., NICOLÁS JL., PRADA M.A, SERRADA R. 2012. Producción y manejo de semillas y plantas forestales Tomo I, Publisher: Organismo Autónomo Parques Nacionales, P.707-717.

- REPOLA J. 2006. Models for vertical wood density of Scots pine, Norway spruce and Birch stems, and their application to determine average wood density. Silva Fennica 40 (4): 673-685.

- RESTREPO J. 2003. El sol nocturno en los trópicos y su influencia en la agricultura.

- RODRIGo B.G., estebAN, L.G. DE PALACIOS, P., FERNÁNDEZ, F.G., CASASÚS, A.G. 2013. Variation throughout the tree stem in the physicalmechanical properties of the wood of Abies alba Mill. from the Spanish Pyrenees. Madera y Bosques 19 (2): 87-107.

- RÖSCH P. (1999). Research on the influence of the moon phase-related felling date on the drying process and shrinkage of Norway Spruce-wood (Picea abies Karst.). Diploma thesis, Swiss Federal Institute of Technology, Wood Sciences, Zürich, 42 pp (in German, English summary).

- ROSS R. J., HUNT, M. O., WANG, X., SOLTIS L. A. 2001. Floor vibration: a possible assessment method for historic buildings. APT Bulletin, The Journal of Presrvation Technology. Vol. XXII, 2-3. P. 23-25.

- SÁENZ GONZALEZ, C. (2008). Caracterización mecánica de rollizos descortezados de Pinus nigra para uso estructural. Trabajo fin de carrera. Ingeniería técnica forestal, EUIA Soria. Universidad de Valladolid. 
- SÁENZ GONZALEZ C. (2011). Caracterización físico mecánica y estructural de madera de Populus $x$ euramericana l-214. Respuesta a ensayos no destructivos. Trabajo fin de carrera. Ingeniería de montes, ETSIIAA de Palencia. Universidad de Valaldolid.

- SEELING U. (1998). Doesn't non-wood shrink and burn?. AFZ/Der Wald, Allg. Forst Z. Waldwirtschaft Umweltvorsorge. 53(26): 1599-1601.

- SEELING U. (2000). Selected wood properties of Norway spruce Picea abies (L.) Karst and its dependence on the date of felling. Schweiz. Z. Forstwes. 151(11): 451458.

- SHEARER R.C., 2008. Larix P. Mill. En: The woody plant seed manual (Bonner F.T., Karrfalt R.P., eds.). United States Department of Agriculture, Forest Service, Agriculture Handbook 727, Washington. pp. 637-647.

- SPURR, S.H. \& HSIUNG, W.-Y. 1954. Growth rate and specific gravity in conifers. Journal of Forestry 52(3): 191-200.

- TAKASHI T., TAKEO H. 1999. Differences of tensile strength distribution between mechanically high-grade and low-grade Japanese larch lumber II: Effect of knots on tensile strength dsitribution. Journal of Wood Science. 45:207-212. DOI: 10.1007/BF01177727.

- TAKEDA T. and HASHIZUME T. 1999. Differences of tensile strength distribution between mechanically high-grade and low-grade Japanese larch lumber I: Effect of length on the strength of lumber. Journal of Wood Science, 45:200-206.

- TRIEBEL J. (1998). Moon phase-dependent tree-felling-a literature survey and research on some properties of Norway Spruce (Picea abies Karst.). Technical University of Dresden, Forest Sciences, Tharandt, $108 \mathrm{pp}$ (in German).

- VEGA A., DIESTE A., GUAITA M., MAJADA J., BAÑO V. 2011. Modelling of the mechanical properties os Castanea sativa Mill. structural timber by a combination of non-destructive variables and visual grading parameters. European Journal of Wood and Wood Products. DOI: 10.1007/s00107-012-0626-7.

- VEGA A. (2013). Caracterización mecánica de la madera estructural de Castanea sativa Mill. Clasificación visual y evaluación mediante métodos no destructivos. Dissertation. Universidad de Santiago de Compostela.

- VIGNOTE S., JIMENÉZ F.J. 1999. Tecnología de la madera. Ministerio de Agricultura, Pesca y Alimentación (MAPA). ISBN: 84-491-0293-6.

- VIGNOTE S., JIMÉMEZ F.J. 2006. Tecnología de la madera. Ediciones Mundi Prensa. ISBN: 84-8476-263-7.

- VIGNOTE S. (2014). Principales maderas de coníferas en España características, tecnología y aplicaciones.

- VILlanueVA J. L. (2009). Caracterización mecánica de rollizos de Sabina (Juniperus thurifera L.) de Castilla y León. Prueba de clasificación visual y evaluación mediante resonancia. Proyecto final de carrera. Escuela Técnica Superior de Ingeniería Agraria de Lleida. Universidad de Lleida.

- VILLASANTE A., VIGNOTE, S., FERRER D. 2010. Influence of the Lunar Phase of Tree Felling on Humidity, Weight Densities, and Shrinkage in Hardwoods (Quercus humilis). Forest Products Journal. 60(5): 415-419. 
- VOGT K.A., BEARD KH., HAMMANN S., O'HARA PALMIOTTO J., VOGT D.J., SCATENA F.N., HECHT B.P. 2002. Indigenous knowledge informing management of tropical forests: the link between rhythms in plant secondary chemistry and lunar cycles. Ambio 31(6):485-490.

- WAHLGREN H.E., HART, A.C. \& MAEGLIN, R.R. 1966. Estimating tree specific gravity of Maine conifers. USDA Forest Service, Forest Products Laboratory, Research Paper FPL-61. $22 \mathrm{p}$.

- WANG X., WACKER J.P., MORISON A.M., FORSMAN J.W., ERIKSON J.R., ROSS, R J. 2005a. Nondestructive assessment of single-span timber bridges using a vibration-based method. USDA Forest Service, Research Paper FPL-RP-627. Forest Products Laboratory. P. 113-121.

- WANG X., WACKER J.P., ROSS R.J., BRASHAW B.K.; VALTARO R.2005B. Development of flexural vibration techniques to rapidly asses the structural health of timber bridges systems. Proceedings of the $14^{\text {th }}$ International Symposium on Nondestructive Testing of Wood. Hannover, 2-4 May 2005. Published by Shaker Verlag, Germany. P. 113-121.

- WANLI L., HAIQING R., ZHAOHUI W., XIUQIN L. 2012. Mechanical grading of structural Larch dimensión lumber. Key Engineering Materials. Vol. 517, pp. 683688. DOI: 10.4028/www.scientific.net/KEM.517.683.

- WAZNY J., K. J. KRAJEWSKI, 1984. Seasonal changes in the resistance of Scots pine to wood-destroying fungi. Holz Roh- Werkst. 42(2):55-58.

- YANG B.Z., SEALE R.D., SHMULSKY R., DAHLEN J., WANG X. 2015. Comparison of non-destructive testing methods for evaluating no. 2 southern pine lumber: part A, modulus of elasticity. Wood and Fiber Science. 47(4), pp. 375-384.

- YANG B.Z., SEALE R.D., SHMULSKY R., DAHLEN J., WANG X. 2017. Comparison of non-destructive testing methods for evaluating no. 2 southern pine lumber: part B, modulus of rupture. Wood and Fiber Science. 49(2), pp. 134-145.

- ZOBEL B.J. AND J. P. VAN BUIJTENEN. 1989. Wood variation: its causes and control. Springer Verlag, Berlin, Germany. $363 p$.

- ZHU JJ., NAKANO T., HIRAKAWA Y (2000). Effects of radial growth rate on selected indices for juvenile and mature wood of the Japanese larch. J Wood Sci 46:417-422.

- ZÜRCHER E., CANTIANI M-G., SORBETTI GUERRI F., MICHEL D. 1998. Tree stem diameters fluctuate with tide. Nature 392:665-666.

- ZÜRCHER E.(2000). Moon-related traditions in forestry and corresponding phenomena in tree biology. Schweiz. Z. Forstwes. 151(11): 417-424.

- ZÜRCHER E., MANDALLAZ D. 2001. Lunar synodic rhythm and wood properties: traditions and reality. Experimental results on Norway Spruce (Picea abies Karst.). In: Proceedings of the 4th international symposium, Tree Biology and Development. Isabelle Quentin Publication, Montreal, pp 244-250.

- ZÜRCHER E. (2003). Drying and weathering behavior of Norway spruce Picea abies Karst wood felled according to moon phases. Schweiz. Z. Forstwes. 154(9): 351359. 
- ZÜRCHER E. (2008). Les Plantes et la Lune-traditions et phe'nome'nes. In: Halle' F (ed) Aux Origines des Plantes-Des plantes anciennes a' la botanique du XXle' sie'cle. Arthe'me Fayard, Paris, pp 388-411.

- ZURCHER E., SCHLAEPFER R., CONEDERA M., GIUDICI F. 2009. Looking for differences in wood properties as a function of the felling date: Lunar phasecorrelated variations in the drying behavior of Norway Spruce (Picea abies Karst.) and Sweet Chestnut (Castanea sativa Mill.). Trees-Structure and Function 24:3141. Published online. August 26, 2009. DOI:10.1007/s00468-009-0376-2.

- ZÜRCHER E., SCHLAEPFER R., CONEDERA M., GIUDICI F. 2010. Looking for differences in wood properties as a function of the felling date: lunar phasecorrelated variations in the drying behavior of Norway Spruce (Picea abies Karst.) and Sweet Chestnut (Castanea sativa Mill.). Trees-Structure and Function. 24(1): 31-41.

- ZÜRCHER E., ROGENMOSER C., SOlEIMANY KARTALAEI A., RAMBERT D. 2012. Reversible Variations in Some Wood Properties of Norway Spruce (Picea abies Karst.), Depending on the Tree Felling Date. In: Spruce: Ecology, Management and Conservation. Eds. Nowak, K.I. and Strybel, H.F. Nova Science Publishers, Hauppauge, New York 2012; 75-94. 


\subsection{NORMATIVA}

- AENOR 2011. Documento de aclaraciones en la caracterización estructural de madera aserrada. Comité Técnico de Normalización madera y Corcho- Subcomité 6: "Estructuras de madera".

- BS 4978:2007+A2:2017. Visual strength grading of softwood. Specification. Instituto de Normalización Británico (BSI), Londres, Reino Unido.

- Código Técnico de la Edificación. Ministerio de Vivienda. 2006.

- Directiva 89/106/CE de productos de construcción. 1989.

- EN 518:1996. Structural timber grading. Requirements for visual strength grading standards. Comité Europeo de Normalización (CEN), Bruselas, Bélgica.

- EN 942:2007. Timber in joinery. General requirements. Comité Europeo de Normalización (CEN), Bruselas, Bélgica.

- EN 1309-3:2018. Round and sawn timber. Methods of measurements. Features and biological degradations. Comité Europeo de Normalización (CEN), Bruselas, Bélgica.

- EN 1310:1997. Round and sawn timber. Method of measurement of features. Comité Europeo de Normalización (CEN), Bruselas, Bélgica.

- EN 1912:2012. Structural Timber. Strength classes. Assignment of visual grades and species. Comité Europeo de Normalización (CEN), Bruselas, Bélgica.

- EN 14081-1:2016. Timber structures. Strength graded structural timber with rectangular cross section. General requirements. Comité Europeo de Normalización (CEN), Bruselas, Bélgica.

- NF B 52001-1:2018. Regles d'utilization du bois dans construction. Classement visual pour l'emploi en structures des bois sciés francais résineux et feuillus. Asociación Francesa de Normalización (AFNOR), París, Francia.

- UNE 56544:2011. Clasificación visual de la madera aserrada para uso estructural. Madera de coníferas. Asociación Española de Normalización (UNE), Madrid, España.

- UNE 56546:2013. Clasificación visual de la madera aserrada para uso estructural. Madera de frondosas. Asociación Española de Normalización (UNE), Madrid, España.

- UNE-EN 338:2016. Madera estructural. Clases resistentes. Asociación Española de Normalización (UNE), Madrid, España.

- UNE-EN 384:2016 Madera estructural. Determinación de los valores característicos de las propiedades mecánicas y la densidad. Asociación Española de Normalización (UNE), Madrid, España.

- UNE-EN 408:2011+A1:2012. Estructuras de madera. Madera aserrada y madera laminada encolada para uso estructural. Determinación de algunas propiedades físicas y mecánicas. Asociación Española de Normalización (UNE), Madrid, España.

- UNE-EN 1309-3:2018. Madera aserrada y madera en rollo. Métodos de medida. Asociación Española de Normalización (UNE), Madrid, España. 
- UNE-EN 13183-1/AC:2004. Contenido de humedad de una pieza de madera aserrada. Parte 1: Determinación por el método de secado en estufa. Asociación Española de Normalización (UNE), Madrid, España.

- UNE-EN 13183-2: 2002. Contenido de humedad de una pieza de madera aserrada. Parte 2: Estimación por el método de resistencia eléctrica. Asociación Española de Normalización (UNE), Madrid, España.

- UNE-EN 14081-1:2016. Estructuras de madera. Madera estructural con sección transversal rectangular clasificada por su resistencia. Parte 1: Requisitos generales. Asociación Española de Normalización (UNE), Madrid, España.

- UNE-EN 14081-2:2019. Estructuras de madera. Madera estructural con sección transversal rectangular clasificada por su resistencia. Parte 2: Clasificación mecánica. Requisitos complementarios para el ensayo inicial de tipo. Asociación Española de Normalización (UNE), Madrid, España.

- UNE EN 14081-3:2012+A1:2019. Estructuras de madera. Madera estructural con sección transversal rectangular clasificada por su resistencia. Parte 3: Clasificación mecánica. Requisitos complementarios para el control de producción en fábrica. Asociación Española de Normalización (UNE), Madrid, España.

- UNE-EN 14358:2016. Estructuras de madera. Determinación y verificación de los valores característicos. Asociación Española de Normalización (UNE), Madrid, España.

- UNI 11035-2:2010. Classificazione a vista dei legnami secondo la resistenza mecanica. Ente Nacional Italiano de Unificación (UNI), Roma, Italia. 


\section{ANEXO I.}

LA INFLUENCIA DE LA LUNA. SABIDURÍA POPULAR

Índice

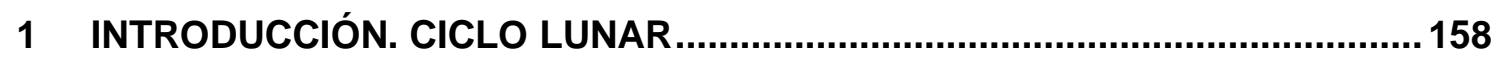

2 LA INFLUENCIA DE LAS FASES LUNARES EN ARBOLES Y PLANTAS

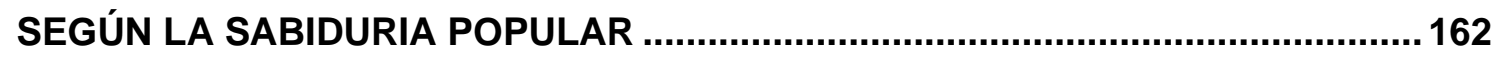

3 EPOCA ADECUADA PARA LA CORTA DE MADERA EN EL PAIS VASCO Y

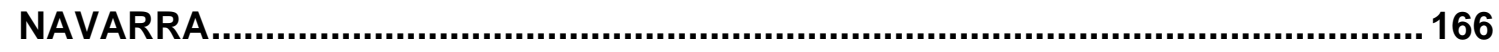

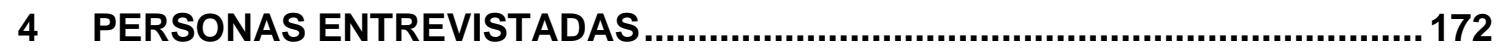




\section{Índice de figuras y tablas}

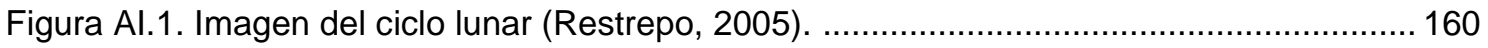

Figura Al.2. Flujos de savia según la fase lunar (Restrepo, 2005)....................................... 163

Figura Al.3. Detalle de los periodos extensivos de "aguas arriba" y "aguas abajo" en la fase lunar

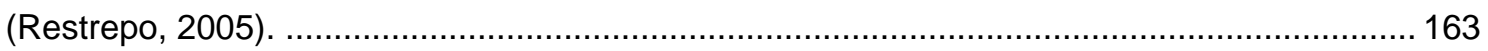

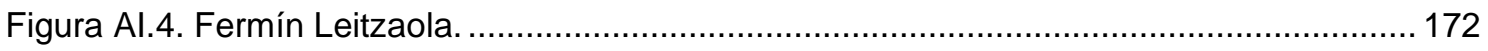

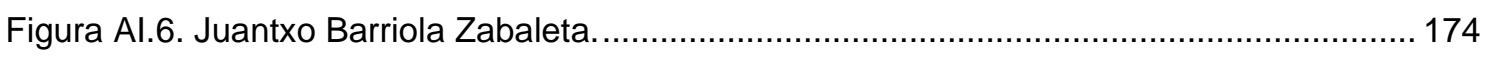

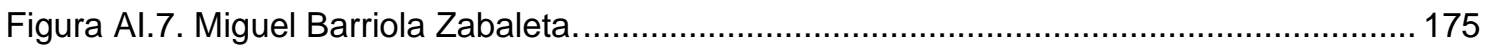

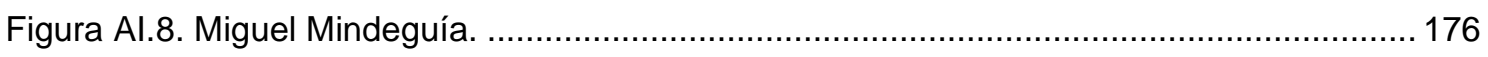

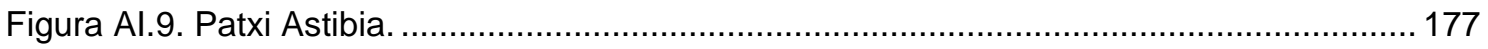

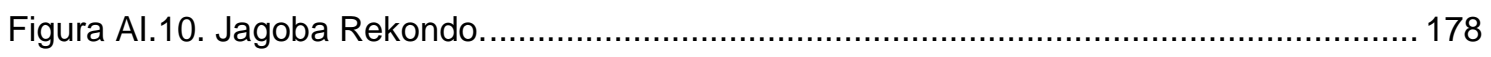

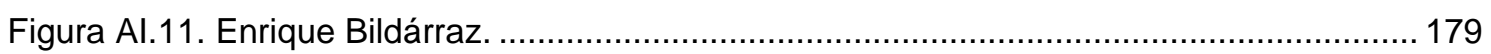

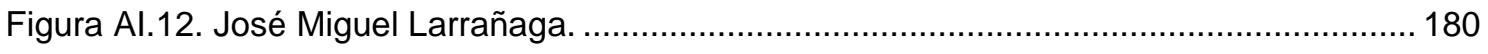

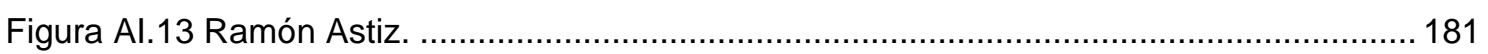

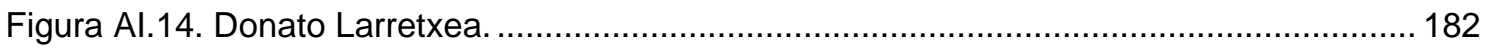

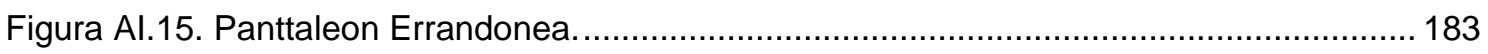

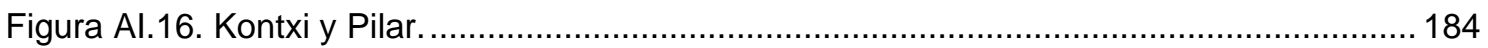

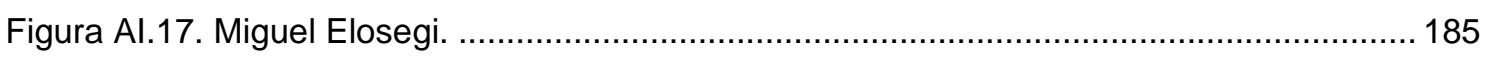

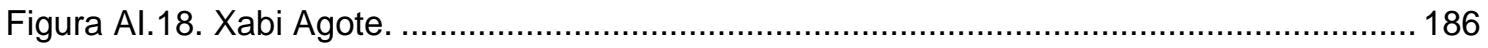

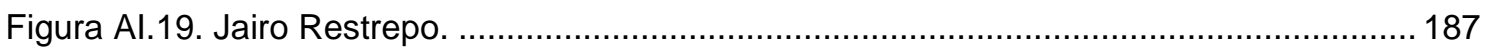

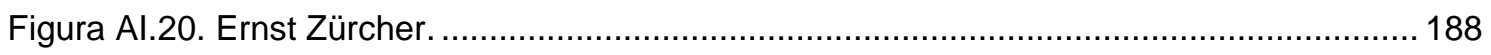

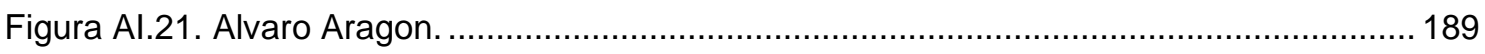

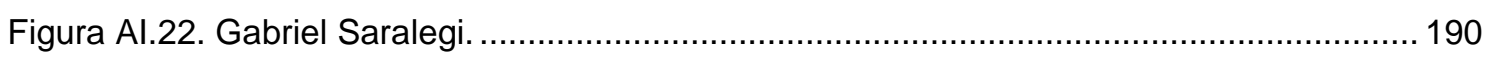

Tabla Al.1. Cortas de madera adecuadas según fase lunar y especie. .................................171 


\section{INTRODUCCIÓN. CICLO LUNAR}

En todo el mundo, los agricultores, artesanos y granjeros han observado cuidadosamente las fases de la luna, especialmente durante la siembra, cosecha 0 recolección de plantas y este acervo cultural y transmisión oral ha perdurado durante siglos hasta nuestros días.

Gaius Plinius Secundus, o Plinio el Viejo (23-79 dC), fue un conocido autor y respetado naturalista que escribió Naturalis Historia, el estudio más completo de la historia natural para sobrevivir del Imperio Romano. Durante su vida, aconsejó a los granjeros romanos que recolectaran fruta en la luna llena para el mercado, ya que pesaría más y la recogieran en la luna nueva para consumo personal, ya que esa fruta almacenaría mejor. Plinio también recomendó que se cortaran los árboles madereros en la luna nueva (Cole, 2010).

El rey Luis XIV aprobó una orden real durante su reinado indicando que la tala de madera sólo debería ocurrir durante una luna menguante (el período de tiempo después de la luna llena) entre la caída de las hojas y la nueva estación de crecimiento. En ocasiones, estas recomendaciones y órdenes quedan reflejadas incluso en la legislación forestal (Triebel, 2000).

Las prácticas tradicionales relacionadas con el uso de madera en Europa todavía existen hoy en día, especialmente en las industrias artesanales y en la producción de productos especiales como cajas de queso, barriles de vino, tejas de madera, chimeneas de madera y madera para instrumentos musicales.

La influencia que ejerce la luna sobre diferentes aspectos biológicos es un tema tratado desde antiguo y queda reflejado en escritos, desde Theophrastus (372-287 a.C) a Catón el antiguo (234-149 a.C.). Uno de los efectos que más interés presenta en el ámbito forestal es la posible relación entre la época de tala de un árbol y las características de la madera obtenida.

En el País Vasco, ya en la agricultura ancestral, la observación del sol, la luna y otros astros eran prácticas habituales. Esta observación, junto con la experiencia, han sido el origen de la sabiduría popular trasmitida de generación en generación, quedando en la actualidad reminiscencias de aquellos conocimientos.

Este acervo de sabiduría popular, es parte de la cultura local relacionada con las faenas del campo en general y con las relacionadas con el mundo de la madera en particular, sea para su utilización en la construcción, como fuente energética, etc., si bien debe indicar que dicho conocimiento o convencimiento, se ha obtenido empíricamente a lo largo de las décadas y los siglos.

No debe olvidarse que estos conocimientos empíricos se obtuvieron cuando no existían los modernos sistemas de producción y tratamiento de los productos, en el tiempo en que todo estaba al albur de lo que la propia naturaleza podía ofrecer. 
Hoy en día, la denominada agricultura biodinámica procura la práctica, la persistencia y el buen hacer de todos aquellos conocimientos basados en esta antigua conexión existente entre las energías del cielo y de la tierra. Así, es ya habitual encontrar en el mercado calendarios lunares biodinámicos que orientan sobre los mejores momentos para la realización de las diversas labores del huerto, dependiendo de las fases lunares, aspectos planetarios, etc.

Para comprender los calendarios lunares es necesario conocer cómo transcurren las fases de la luna, la cual precisa de 29 días, 12 horas y 44 minutos para culminar su recorrido celeste alrededor de la tierra, y comienza con la Luna Nueva.

A la secuencia dinámica de la aparición completa de todas las fases de la luna se le denomina "ciclo lunar". En términos de tiempo, el periodo que transcurre entre dos mismas fases consecutivas de la luna se denomina "mes sinódico" y constituye la base de los primeros calendarios de la humanidad.

Los fenicios disponían de un calendario lunar para celebrar la llegada de cada luna nueva. Ellos suponían que los planetas estaban subordinados al sol (Arochi, 1987).

Los babilonios tenían un año lunar de 354 días. Se regían por un año de doce meses lunares y posteriormente agregaron un mes adicional, para estar en concordancia con la sucesión de las estaciones y las consecuencias de la vida cotidiana. Los días múltiplos del $7(14,21$, y 28) del mes lunar eran considerandos nefastos y en esos días estaba considerado prohibidos a ciertas personas realizar determinadas actividades. El intervalo de siete días en el mes babilónico supone una división del tiempo, semejante a los siete días de la semana del actual calendario gregoriano (Restrepo, 2005).

Los egipcios tenían un año que constaba de 365 días y no tenían año bisiesto. El año egipcio se dividía en doce meses de treinta días, más los cinco del Año Nuevo (Restrepo, 2005).

Para comprender mejor este fenómeno, en la figura Al.1 se representan las principales posiciones de la luna durante su recorrido. Además, se describen a continuación las diferentes fases por las que pasa el astro, tal y como las describe Jairo Restrepo en su libro "La luna. El sol nocturno en los trópicos y su influencia en la agricultura" (Restrepo, 2005). 


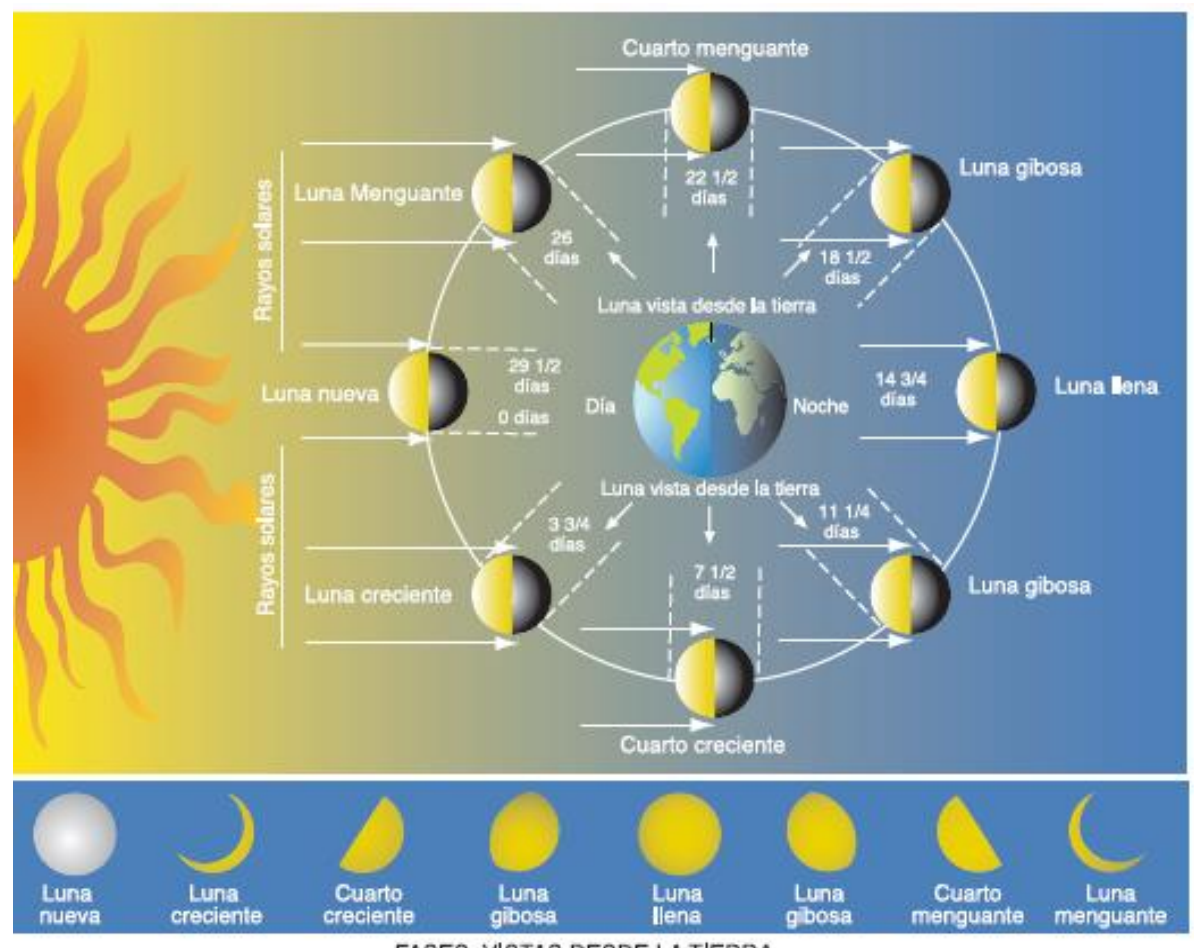

FASES VISTAS DESDE LA TIERRA

FIGURA AI.1. IMAGEN DEL CICLO LUNAR (RESTREPO, 2005).

Luna nueva o novilunio: es la fase en la que la luna se interpone entre la tierra y el sol. La luz solar cae por completo sobre la cara oculta y la cara próxima a la tierra queda totalmente a oscuras y no se ve desde la tierra. A este período también se le conoce como "conjunción". La luna y el sol pueden estar en conjunción solamente una vez por mes, pero en cada luna nueva, el sol y la luna se encuentran en un punto diferente del firmamento y solamente ocho años después vuelven a hallarse exactamente en el mismo lugar.

Primera fase del cuarto creciente: es la fase en la que la luna camina hacia la fase de cuarto creciente y se ve próxima al sol (3 ó 4 días después de la luna nueva).

Luna creciente: en esta fase, la luna ya ha recorrido un cuarto de su órbita y desde la tierra se ve la mitad iluminada. También se dice que la luna está en "cuadratura" porque las rectas que respectivamente unen a la tierra con la luna y el sol forman un ángulo de $90^{\circ}$ (este fenómeno acontece aproximadamente una semana después de la luna nueva).

Luna gibosa creciente: Tres o cuatro días después del primer cuarto el sol ilumina casi toda la cara más próxima de la luna hacia la tierra.

Luna llena o plenilunio: Cuando la luna está detrás de la tierra (pero no en su sombra) y el sol ilumina totalmente la cara de la luna más próxima a la tierra, entonces vemos una "luna llena"; este período también es conocido como el momento en que la luna se halla en oposición, es decir, la tierra se encuentra entre la luna y el sol, el cual ilumina 
con sus rayos totalmente la cara de la luna que está dirigida hacia nuestro planeta. Es el momento de la máxima luminosidad lunar, apareciendo al Este exactamente cuando el sol se está ocultando en el Oeste.

Luna gibosa menguante: es el momento cuando la luna comienza a "encogerse" o a menguar pocos días después del plenilunio. Parte de la cara iluminada comienza a desaparecer de nuestra vista.

Cuarto menguante: en este momento la luna está retrayéndose en línea con el sol. Ha recorrido tres cuartos de su órbita y solamente es visible por la mañana. La luna está nuevamente en cuadratura formando un ángulo de 90을 esta vez por el lado opuesto al anterior y el astro va tomando la forma de una "C".

Luna menguante: es el momento antes del nuevo ciclo hacia el siguiente novilunio, donde se aprecia el disco menguante alzarse justamente delante del sol para luego comenzar un nuevo ciclo.

La luna antes de concluir el ciclo completo de sus fases, para que vuelva a ser luna nueva, ha dado una vuelta completa alrededor de la tierra, mientras ha girado sobre su eje durante ese mismo tiempo, por lo que vuelve a ofrecer a la tierra la misma cara. 


\section{LA INFLUENCIA DE LAS FASES LUNARES EN ARBOLES Y PLANTAS SEGÚN LA SABIDURIA POPULAR}

La fuerza de atracción de la luna, más la del sol, sobre la superficie de la tierra en determinados momentos ejerce un elevado poder de atracción sobre todo líquido que se encuentre en la superficie terrestre, con amplitudes muy diversas según sea la naturaleza, el estado físico y la plasticidad de las sustancias sobre las que actúan estas fuerzas. Así, en determinadas posiciones de la luna el agua de los océanos asciende hasta alcanzar una altura máxima, para descender a continuación hasta un nivel mínimo, manteniéndose regular y sucesivamente esta oscilación (Restrepo, 2005).

Parece ser que este fenómeno se hace sentir en la savia de las plantas, iniciándose el proceso de su influencia desde la parte más elevada para ir descendiendo gradualmente a lo largo de todo el tallo, hasta llegar al sistema radical (Frier, 1986). Este fenómeno se observa con menor intensidad cuando está relacionado con plantas de elevado porte y recios troncos, provistos de numerosos canales de irrigación entrelazados entre sí; o en plantas de escasa altura donde es muy corta la distancia entre la capa vegetal y la raíz; pero se manifiesta muy claramente en aquellos vegetales de tallo elevado, con escasos canales para la circulación de la savia y escasa comunicación entre ellos. El influjo lunar beneficia el desarrollo y el crecimiento de forma muy acusada en muchas plantas, entre las cuales se destacan las trepadoras, buganvillas o veraneras, rosales, leguminosas, glicinias, etc. (Zürcher, 1992).

Por otro lado, también se cree que en algunos vegetales la floración sigue el ritmo del flujo y el reflujo de las mareas y ciertos árboles que se cultivan para la obtención de jugos azucarados también siguen el ritmo de las mismas, siendo abundante mientras se produce el flujo y haciéndose más escaso en el reflujo de la marea (Zürcher et al.,1998).

Botánicos japoneses, filipinos, ingleses y malayos, que durante décadas han estudiado detalladamente los fenómenos que se producen en el crecimiento de ciertos tipos de bambú, han comprobado que algunas de estas especies del sudeste asiático llegan a crecer entre 50 y 60 centímetros diarios; por ejemplo, en cierta ocasión un científico cronometró el crecimiento de 1,24 metros del bambú madake japonés en 24 horas. La acción de la luna, o más concretamente como ellos lo afirman, la acción de las mareas, se manifiesta en forma muy visible, dado que el crecimiento es mucho más rápido durante el flujo y experimenta un retraso durante el reflujo. La causa se debe a la atracción lunar, que establece un ritmo de presión y depresión de la savia en estos vegetales (O’Hara, 1996).

En las figuras Al.2 y Al.3 se muestran los flujos de savia y los periodos extensivos de "aguas arriba" y "aguas abajo" (Restrepo, 2005). 

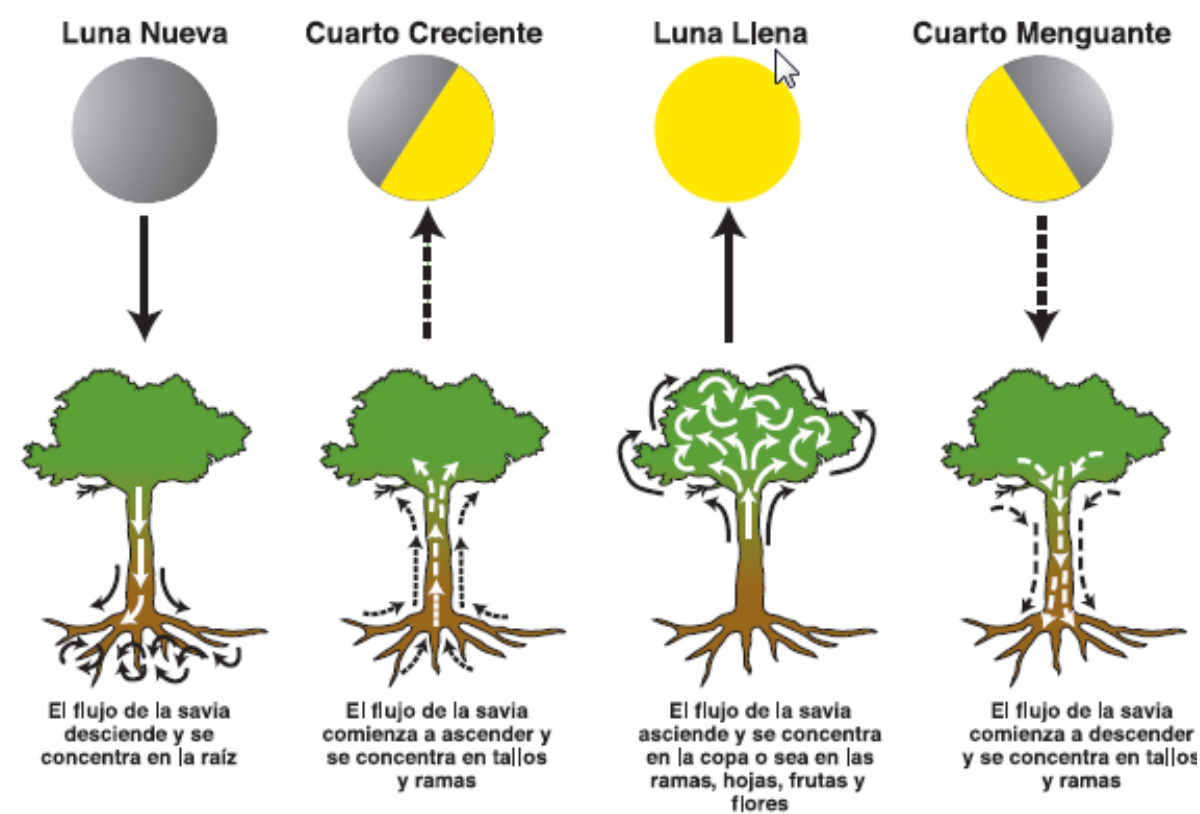

FIGURA AI.2. FLUJOS DE SAVIA SEGÚN LA FASE LUNAR (RESTREPO, 2005).

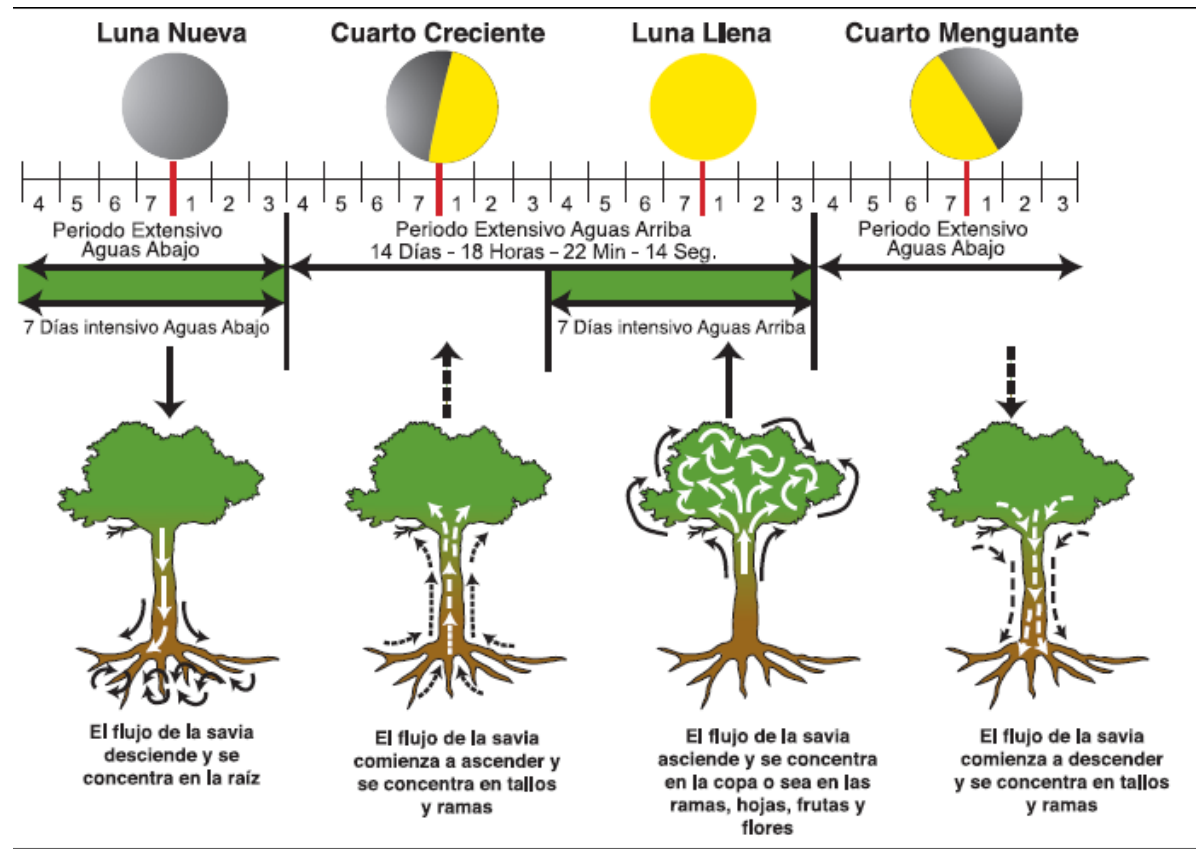

FIGURA AI.3. DETALLE DE LOS PERIODOS EXTENSIVOS DE "AGUAS ARRIBA" Y "AGUAS ABAJO" EN LA FASE LUNAR (RESTREPO, 2005).

La creencia popular considera que en el plenilunio (luna llena) todo en la tierra crece mejor y las cosas son más vivas, fuertes, elásticas y resistentes a los daños; y en el novilunio (luna nueva) la luna queda vacía, a nadie ofrece nada, ni a la tierra. La luna en creciente es considerada como la luna que conduce, proyecta, admite, construye, absorbe, inhala, almacena energía, acumula fuerza, invita al cuidado y al 
restablecimiento; y la luna menguante es considerada como la luna que aclara, seca, suda o transpira, exhala, invita a la actividad y al gasto de energía. Además, se piensa que la intensidad de la fotosíntesis es mayor en todas las plantas a partir de la luna creciente hacia el plenilunio (periodo conocido popularmente como período extensivo de "aguas arriba"), el cual está comprendido entre los tres días después de la luna creciente y los tres días después del plenilunio, fenómeno atribuido al incremento de la intensidad y duración de la iluminación lunar sobre la tierra ((Restrepo, 2005) y personas entrevistadas).

Los agricultores y leñadores comentan que cuando cortan las maderas para las construcciones en la fase de cuarto creciente hacia luna llena, las maderas duran muy poco, porque sus fibras están cargadas con el máximo de agua, que al secarse quedaban abiertas, blandas y llenas de aire. Indican también que las maderas se rajan y resisten poco a la intemperie. En cambio, si cortan las maderas en luna menguante, tres días después de luna llena hacia cuarto menguante, éstas duran más y son más resistentes al deterioro, porque las maderas tienen menos agua y al secarse sus fibras quedan cerradas, son más resistentes al tiempo y a los insectos. En este sentido, hay leñadores que limitan esta actividad solamente a seis días del ciclo lunar, los cuales comprenden los tres últimos días de la luna menguante y los tres primeros días del novilunio o luna nueva (Restrepo, 2005).

Por otro lado, asociado con esta práctica de las fases lunares, está el fenómeno de la menor circulación de savia en los árboles, debido a las bajas temperaturas de final de otoño y los meses de invierno, época en que prácticamente todos los árboles han perdido sus hojas y su actividad fotosintética se encuentra reducida al mínimo.

Cuando se trata de cortar o cosechar madera para leña, y dejarla secar para el fogón, los agricultores y ganaderos comentan que la mejor luna para realizar esta actividad es el primer cuarto creciente hacia los tres últimos días de luna llena.

El bambú, o la guadua como se le conoce más popularmente en Colombia, también es un cultivo de mucha utilidad y trayectoria en la construcción de viviendas y de instalaciones en el medio rural. Para que la madera de esta gramínea aguante a la intemperie y resista contra el apolillamiento, la tradición indica cortarla en la fase de la luna menguante, principalmente los tres últimos días de luna, prolongándose hasta los tres primeros días de luna nueva (Restrepo, 2005). Este período de seis días corresponde exactamente al momento en el que las plantas tienen la más baja concentración de savia circulando en las ramas o en la parte aérea del vegetal, motivo por el cual es el más indicado para el corte de esta madera.

Algunas personas más especializadas en el manejo de maderas finas en los países sudamericanos para la construcción, dividen la cosecha de las maderas en dos etapas: primero, limitan el período del corte de las maderas a sólo las 48 horas después de los tres primeros días de la luna menguante, y de preferencia en las horas de la madrugada. En plena oscuridad, con ausencia total de cualquier reflejo de la luz nocturna de la luna 
hacia la tierra, realizan los cortes de los árboles, que son dejados en el lugar donde se cortaron, sin cumplir ninguna actividad complementaria de quitar ramas y deshoje. (Restrepo, 2005).

Debido a la falta de paciencia y a la limitación del tiempo que muchas personas tienen para esperar por las fases lunares y el número de días que ofrecen los meses para el corte de madera, algunas veces el corte de la madera se realiza sin considerar las fases lunares.

Así, existen también dichos y lunas específicas para cortar todo tipo de maderas: mimbres, cañas y tallos de cestería (menguante de enero); para que no tuerza (luna nueva de febrero); para que no arda (nueva de marzo); para que no pudra (menguante de marzo); para que no merme (primera luna nueva de otoño).

En el libro "Vivir con la luna" (Paunger, 1996) se describen unas indicaciones acerca de las labores de tala y poda, por Ludwig Weinhold, anotadas por Michael Ober, maestro carrocero de St. Johan, Tirol y transcritas por Josef Schumutzer el 25 de diciembre de 1912.

- Para cortar madera que se mantenga compacta y sólida es bueno hacerlo durante los ocho primeros días después de la luna nueva, en diciembre, cuando cae sobre ella un signo débil.

- Para que la madera se mantenga sólida y compacta, debe cortarse en luna nueva y Escorpio.

- La tala de madera para que no se pudra se debe hacer en los dos últimos días de marzo, con cuarto menguante en Piscis

- La tala de madera para que no se queme se debe hacer el 1ำ de marzo y mejor aún después de la puesta de sol.

- La tala de madera para que no merme debe hacerse el tercer día de otoño, cuando la luna nueva tiene tres días y en un día del signo Virgo, cuando rige Cáncer.

- La madera para aserrar debe ser cortada en Pisicis con cuarto creciente, para que las tablas no se agusanen.

- Para puentes y arcos, la madera se debe cortar con cuarto menguante en Piscis o Cáncer.

- Cortar madera para que no se agriete o se abra, se debe hacer antes de la luna nueva de noviembre.

- La madera recta o de herramientas debe cortarse el 26 de febrero con cuarto menguante, pero mejor aún, cuando Cáncer cae sobre él.

- En el libro se indica que todas las afirmaciones anteriores han sido probadas y demostradas.

Según se puede apreciar, las opiniones extraídas de las costumbres populares en diferentes lugares son muy variadas, y entre ellas existen ciertas similitudes, pero también numerosas discrepancias. 


\section{EPOCA ADECUADA PARA LA CORTA DE MADERA EN EL PAIS VASCO Y NAVARRA}

Los palacios, casas-torre y caseríos que perduran en nuestro entorno muestran claramente que nuestros antepasados dominaban a la perfección los entresijos de los materiales y las técnicas de construcción que empleaban, de manera que centenares de edificios de los siglos XV y XVI permanecen aún en pie. En general, su estructura interior suele ser de madera y la exterior de piedra. Por lo tanto, la cooperación entre carpinteros y canteros era crucial para la correcta edificación.

Se cuenta que para determinar si la madera elegida para la edificación reunía las condiciones precisas, se hacía una fogata con la madera escogida, y del color de la llama emitida por cada tizón dependía cuál podía utilizarse y cuál no. La madera seleccionada, en primer lugar, debía proceder de árboles talados en su sazón y acarreados hasta casa en un carro corto. A continuación, debía dejarse secar durante el tiempo preciso, y posteriormente se procedía a labrarla.

En cuanto a las variedades de madera, en los caseríos se ha empleado casi siempre el roble y el castaño para la estructura y los cabios, y el segundo de ellos para los suelos. Asimismo, se ha empleado con profusión la encina, para las piezas curvadas, los denominados caballetes. Además, se empleaba el cerezo y el nogal para muebles; el avellano, para trenzar setos y construir tabiques con las varas, etc. En otras ocasiones se ha recurrido también al chopo, el pino albar y al haya.

J.P. Duvoisin (1838) constata con precisión en su Libro de la Agricultura la amplitud de los conocimientos existentes acerca de las diferentes clases de madera (Laborantzako Liburua edo bi aita semearen solasak laborantzaren gainean). A continuación, se muestran algunos literalmente:

El roble es el árbol más distinguido de estas tierras. Corteza, madera, bellota y leña, todo es excelente en él. Crece bien en las vaguadas (al pie de los montes) y en la ladera, no así en las cimas. Prospera allá donde ha brotado; difícilmente lo hace trasplantado.

El melojo es un tipo de roble inadecuado para carpintería. Nos resulta de provecho porque hay poca leña en nuestro entorno, pero es mejor plantar cualquier árbol antes que el melojo.

El castaño, a los cinco o seis años, es bueno para fabricar zunchos; a los dieciocho, para hacer toneles; $y$ en adelante, da fruto. De castaño se hacen bellos suelos, y otras muchas obras en las ciudades. Todos sabemos la gran valoración que tienen sus frutos tanto para personas como para los animales domésticos. El castaño demanda suelos blandos. Donde brote con profusión el helecho, crecerá el castaño con ganas. 
Veo olmos en muchos lugares, aunque aquí no llegan a ser muy grandes. Bayona por su parte está rodeada de hermosos olmos. El olmo es buena madera, para cualquier clase de obra. Crece bien en cualquier lugar, bien sea en la montaña o en el llano. Sin embargo, no le gusta la solana.

Muchos nombres tiene el álamo: álamo blanco lo llaman muchos; en estas provincias le llaman makala y los navarros chopo. Le gustan las hondonadas. Aunque es de madera blanda, su laboreo tiene gran ventaja porque se labra sin apenas esfuerzo.

El haya crece tanto en las montañas como en los valles. Es buena para navíos y para hacer aros de tamiz. También se fabrican carros de esa madera, siempre que esté bien seca. Es buena leña para quemar. De los hayucos se extrae aceite, y también sirven para engordar puercos.

El abeto es el árbol más grande y más recto de nuestras tierras. Los hay de más de cien pies de largo en el bosque del Irati. Reclama sombra durante sus primeros cinco o seis años. Por esa razón, arraiga bien en los claros del bosque. Su madera es ligera, y al ser recta y larga, resulta muy valiosa para buques y edificios. De los abetos puede extraerse asimismo una buena clase de trementina.

El pino constituye la riqueza de Gascuña. De él se extrae resina, trementina, alquitrán, madera, buena leña, frutos para el ganado. Crece tanto en la montaña como en el llano, en los pedregales como en tierra mullida; no le importan fríos ni calores. Ya quisiera ver nuestras montañas totalmente cubiertas de pinos.

El abedul no es muy bueno para maderamen de edificaciones, pero sí para fabricar utillaje, carros y carrozas. De él se fabrican utensilios idóneos. Nosotros confeccionamos cuencos, platos, escudillas, y colodras. En Rusia, extraen de él tanino, y de su savia un tipo de aguardiente. Crece tanto en laderas como en el llano.

El fresno se ve aisladamente en nuestras tierras, salvo en los matorrales; $y$, sin embargo, es la suya una de las mejores maderas: buena para la construcción y para utillaje. En suelos frescos, ligeros y espesos llega a hacerse enorme.

El arce crece en lomas y planicies. No le agradan los suelos húmedos. Por aquí no lo veo, salvo algunos aislados en viñedos, desmochados como cerezos a modo de estacas. ¿Por qué no se deja crecer un árbol tan bueno y valioso? De arce se fabrican utensilios tan buenos como de las mejores maderas de América. Nunca les ataca la carcoma.

La acacia se está extendiendo en nuestras tierras, y más aprisa se extendería si se conociera bien su valía. Sirve para cualquier cosa. Tempranamente da selectas estacas para parras. No tiene envidia de ninguna otra madera para fabricar cucharones $y$ utensilios. 
El aliso prefiere regatos y ciénagas, crece en lugares en los que no arraigan otros árboles, por lo que sanea los entornos. Por ello, no le gustan las solanas. Es bueno para navíos pero no para fabricar utensilios; resulta demasiado endeble. Se utiliza para fabricar asientos y zuecos, por ser fácil de trabajar. Del aliso se obtienen productos de escasa calidad.

Como quienquiera sabe, la madera de nogal es la más selecta para fabricar utensilios. Le gustan los lugares pedregosos.

También el cerezo tiene buena madera; arraiga bien en tierra rica.

Siempre se ha dicho que, al talar los árboles, ha de tenerse en cuenta la estación del año y la fase de la luna, y que el momento más adecuado es la menguante de invierno. Esto se explica popularmente porque en invierno las plantas entran en parada biológica, o lo que es lo mismo, detienen su proceso de crecimiento por las condiciones del entorno. A consecuencia de ello, su corteza se endurece, y ello origina que la madera talada en invierno resulte menos atacable para la carcoma. Además, conviene talar en cuarto menguante porque, por ese motivo, la madera contendrá menos agua y, por consiguiente, el secado será más fácil y completo. Si se tala durante la luna nueva, por el contrario, el secado resultará muy dificultoso, casi imposible.

No obstante, hay árboles que siguen sus propias pautas, siendo el aliso el ejemplo más notable. Talado en el momento que resulta más adecuado para el resto de los árboles, produce madera floja y propensa a la carcoma. Pero, según cuentan, tiene una particularidad que resulta increíble: al parecer, la mayor resistencia de su madera se obtiene talándola en la luna nueva de mayo. El aliso talado en su sazón se utiliza para fabricar lanzas de carro y muebles. Por otra parte, se dice que los árboles de hoja redondeada (haya, avellano, olmo, etc.) han de ser talados en la luna nueva de otoño; se cuenta que las varas de avellano cortadas en esa época resultan eternas, porque no se pudren.

Según el célebre aizkolari de Ezkurra Mikel Mindegia, conviene cortar las hayas en cuarto creciente: "cortar el haya en cuarto menguante no es bueno, la madera suele estar triste, no se seca y se oscurece; si se corta en cuarto creciente, en cambio, suele estar más blanquecina y ligera, se seca con mayor facilidad y es mucho mejor para materiales".

Mindegia vive en la localidad de Zubieta (Navarra), y al igual que allí, las leyes del cuarto de la luna se respetan en otros muchos lugares de Euskal Herria.

Tras varias conversaciones mantenidas con el citado aizkolari, además de con el carpintero José Astiz de Leitza, así como con el maderista Inaxio Larretxea de Aranaz, todos coinciden en las siguientes premisas: el avellano se ha de cortar en el cuarto creciente de noviembre; el roble, en cambio, en el cuarto menguante, y mejor aún, si es posible se ha de cortar en el cuarto menguante de San Miguel, es decir en septiembre; el aliso es también un árbol de cuarto creciente, por ejemplo, el mejor aliso para 
manufacturar mangos es aquel que se corta en el cuarto creciente de Mayo y su experiencia particular les avala esta tesis. También realizan una clasificación de la mejor época de corta indicando si el uso que se le va a dar a esa madera es para combustible o para material, ya que la fase lunar para cada uso es diferente y señalan que los viernes de menguante se deben considerar como si fueran de fase lunar creciente y al revés (esta última opinión parece que pueda estar directamente relacionada con algunas creencias o ritos de índole religioso-católicas, que en su día se amalgamaron con la sabiduría popular y ahora conforman el acervo cultural).

Según las prácticas del acervo cultural, para el apeo de las especies de limbo sensiblemente "entero", la principal, el haya, debería observarse el período de luna nueva a cuarto creciente ("ilberri"), aprovechando para tal operación a lo largo del año, a modo de épocas apropiadas, los "ilberris" de Agosto y los a partir de Octubre, en la época de otoño-invierno, el "ilberri" de Noviembre para cortar varas de avellano para que no se apolille, o el "ilberri" de Mayo para el apeo de los árboles de aliso, para procurar madera ligera y durable de esta especie.

Hay otra versión muy arraigada en la sabiduría popular tradicional que difiere en parte (contradiciendo o complementando) lo mencionado anteriormente. Mientras que los árboles de hoja perenne y de hoja redonda (haya, aliso, abedul, chopo) se talarían respetando el ciclo antes mencionado, los árboles de hoja alargada (roble, fresno, manzano, plátano) se talarían en cuarto creciente. A su vez, las especies de limbo lobulado o dentado (robles, etc.), siempre deberían apearse en luna menguante.

El precepto genérico para las coníferas sería que se deberían apear en fase lunar menguante "ilbera", y más, si el destino de esa madera fuera la de uso estructural.

Según indican, también se podría hacer una clasificación genérica, según la cual los árboles de hoja con limbo "redondeado" son los que se habrían de cortar en cuarto creciente: hayas, alisos, abedules, avellanos, fresno, etc.

Para los de cuarto menguante existiría más de un modo de clasificación. Aquellos que tienen el limbo de la hoja con borde aserrado, dentado o lobulado, ancha, o redonda, o con muescas, serían árboles de cuarto menguante: castaño, roble, olmo y aliso, por ejemplo.

En otros lugares, también hacen una clasificación parecida. En Legazpia, por ejemplo, dicen que los árboles de hoja estrecha son los que habría que cortar en cuarto creciente y todos los demás en cuarto menguante. Así pues, el haya y el fresno se cortarían en cuarto creciente y el castaño y el roble en menguante.

En la zona de Azpeitia, el maderero José Antonio Urkizu asegura que clasifican los árboles a cortar en creciente o en menguante en función de otros factores: "algunos suelen tener una coloración blanquecina junto a la corteza (la albura) y más rojiza en el interior (el duramen). 
A esto último se le denomina el magro y a la parte exterior blanquecina, el tocino, al igual que se hace con el jamón. Así, los árboles que tienen magro y tocino como el castaño, olmo y el roble, se cortan en cuarto menguante, y los demás en creciente".

Con otros árboles no indican normas tan regulares. Por ejemplo, sobre cuándo se han de cortar el cerezo y el nogal, no parece haber acuerdo, pero todos coinciden en afirmar que conviene hacerlo en invierno.

A continuación, en la tabla Al.1, se indican las especies de madera más usuales, así como la fase lunar más adecuada para su corta, según lo indicado por las personas entrevistadas. 
TABLA AI.1. CORTAS DE MADERA ADECUADAS SEGÚN FASE LUNAR Y ESPECIE.

\begin{tabular}{|c|c|}
\hline ESPECIE & FASE LUNAR ADECUADA \\
\hline Alerce & Menguante \\
\hline Encina & Menguante \\
\hline Ciruelo & Menguante \\
\hline Arce & Menguante \\
\hline Boj & Menguante \\
\hline Castaño & Menguante \\
\hline Cerezo & Menguante \\
\hline Madroño & Menguante \\
\hline Tejo & Menguante \\
\hline Roble & Menguante \\
\hline Roble americano & Menguante (Noviembre y Diciembre) \\
\hline Nogal & Menguante (Noviembre y Diciembre) \\
\hline Alamo temblón & Menguante \\
\hline Pino & Menguante \\
\hline Fresno & Menguante \\
\hline Níspero & Menguante \\
\hline Melocotonero & Menguante \\
\hline Plátano & Menguante \\
\hline Alamo & Menguante \\
\hline Eukalipto & Creciente \\
\hline Tilo & Creciente \\
\hline Acebo & Creciente \\
\hline Aliso & Creciente (Mayo) \\
\hline Avellano & Creciente (Noviembre) \\
\hline Olivo & Creciente \\
\hline Serbal de los cazadores & Creciente \\
\hline Haya & Creciente (Noviembre y Diciembre ) \\
\hline Peral & Creciente \\
\hline Abedul & Creciente \\
\hline
\end{tabular}




\section{PERSONAS ENTREVISTADAS}

\section{FERMIN LEIOZAOLA (figura Al.4)}

Etnólogo guipuzcoano nacido en Donostia-San Sebastián el 13 de noviembre de 1943. Estudió bachillerato y luego estudios técnicos en San Sebastián. Director del Departamento de Etnografía de la Sociedad de Ciencias Aranzadi. Miembro de la Sociedad de Estudios Vascos, de la Junta del Patronato del Museo Municipal de San Telmo y Casa de Oquendo de San Sebastián.

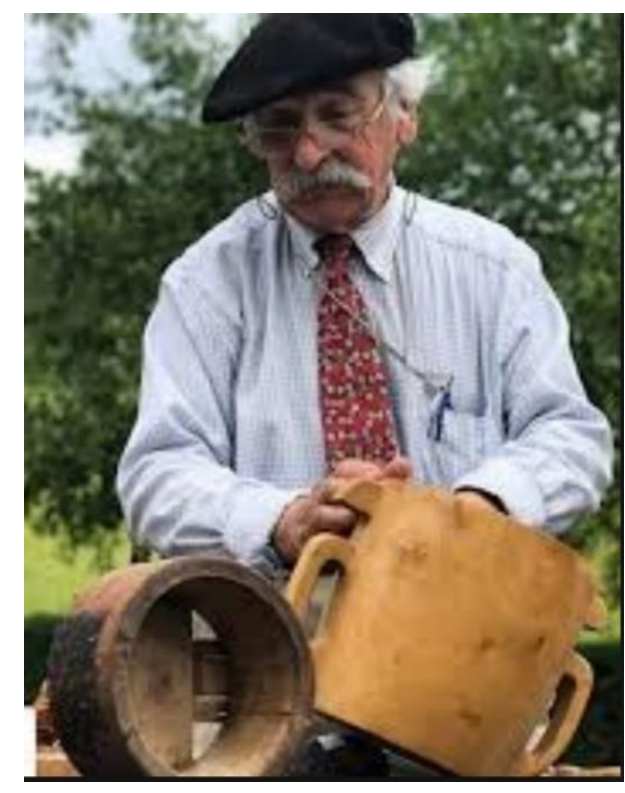

FIGURA AI.4. FERMÍN LEITZAOLA.
Secretario del Grupo Etniker (Sección Gipuzkoa) que preparó el Atlas Etnográfico del País Vasco bajo la dirección de D. José Miguel de Barandiaran. Director del Departamento de Etnografía de la S C Aranzadi, miembro de Eusko Ikaskuntza y de la RSBAP, coordinador del Euskalherriko Atlas Etnolinguistikoa y autor y coordinador de los 17 proyectos Zaharkinak realizados por la D.F.G. en Gipuzkoa.

En el documental Gutik-Zura (www.zura.eus), estrenado en el Festival Internacional de San Sebastián en 2016, nos explica la relación del fuego y la madera desde los inicios de la humanidad. 


\section{FELIPA AYERDI Y ANITA AYERDI (figura Al.5)}

Hermanas, nacidas en Leitza, localidad de Navarra, en el caserío de Goikoborda con 82 y 84 años de edad. Desde pequeñas han trabajado en el monte haciendo trabajos de caserío, concretamente con su padre, quien les llevaba a cortar madera, sobre todo en invierno. Han sabido lo que significa el trabajo desde muy niñas, y posteriormente, hacerse cargo del trabajo de la casa, de la educación de los hijos, del ganado, cuando sus maridos tenían que ir fuera a trabajar. Toda su vida se ha dedicado al cuidado de la familia y del hogar. Son la viva representación de la importancia de la mujer en el mundo rural y un claro reflejo de sus vidas dedicadas al trabajo en el monte, en el caserío y su relación con la naturaleza, junto con la gestión de los montes y campos.

Anita, además ha sido una apasionada cortando troncos. Nos cuenta que desde pequeña su padre les ha transmitido la importancia de mirar a la luna para hacer las labores de campo: cultivar, cortar leña para madera, etc.

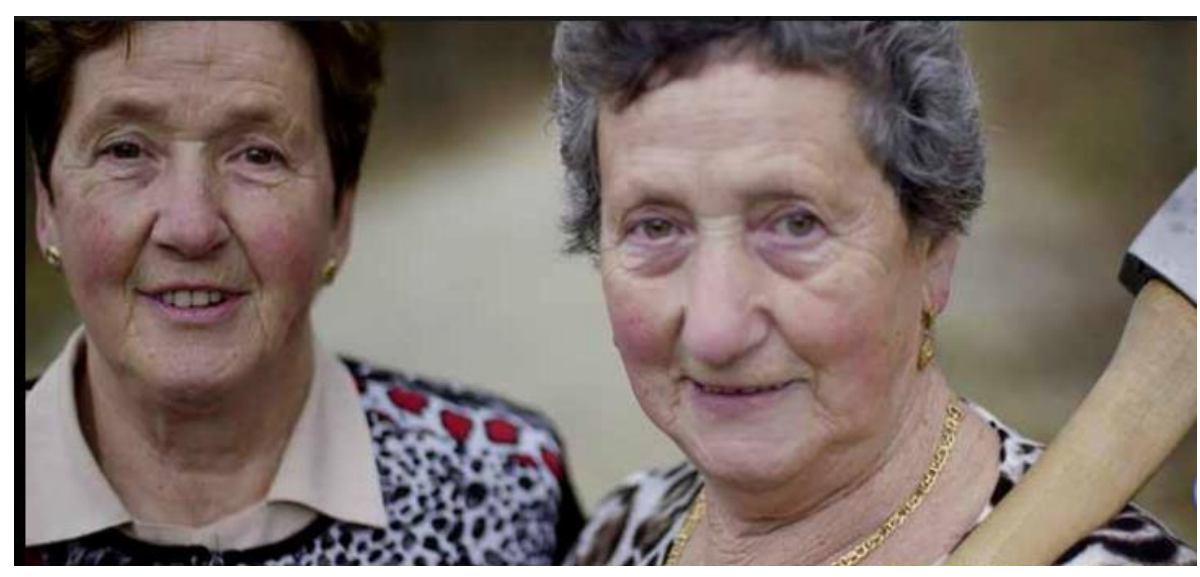

FIGURA AI.5. ANITA AYERDI Y FELIPA AYERDI. 


\section{JUANTXO BARRIOLA (figura Al.6)}

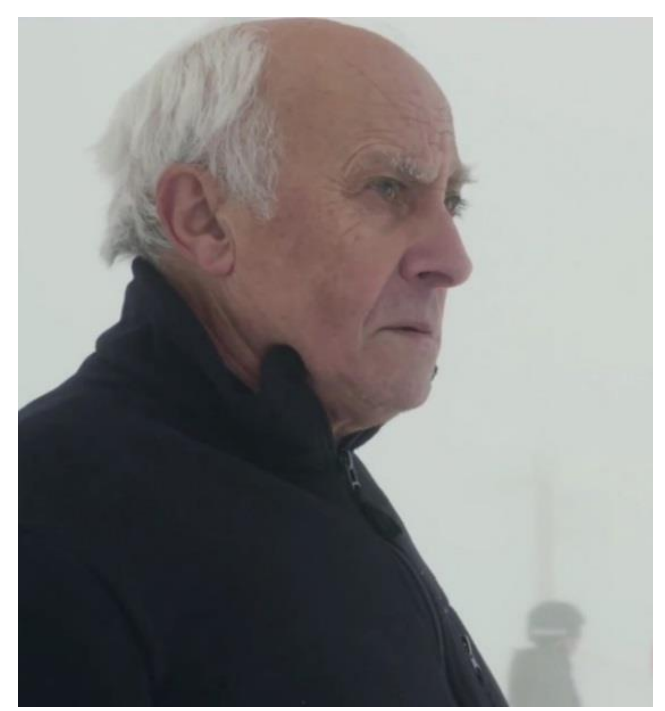

84 años y natural de Leitza (Navarra). De esfuerzo, de trabajo y de sacrificio sabe mucho Juantxo. Con solo 6 años, y con el burro, una cesta y otros niños del pueblo, ya subía a los montes navarros en busca de leña para venderla - para calentar la casa de sus padres en invierno, para la huerta o para hacer los utensilios de labranza. Muchas noches ni bajaban a Leitza y se quedaban a dormir en el monte, en chabolas. Por la mañana, por la tarde y por la noche comían habas; y limpiaban la ropa en un río, y sin secarse muchas veces, se la volvían a poner.

FIGURA AI.6. JUANTXO BARRIOLA ZABALETA.

Con 14 ó 15 años y escapando de la penuria, muchas cuadrillas se marchaban a trabajar a los montes de Francia. Juantxo lo hizo con 18 años. Decía que en su pueblo natal tenía trabajo para todo el año, pero comida, solo para medio. Así, corría el año 1953 cuando Juantxo puso rumbo a los Alpes franceses. Allí, un pequeño pueblo, Les Carroz, le esperaba para envolverle y atraparle de tal manera que, aunque consciente de que estaba pisando una tierra desconocida, la sentiría como propia y especial, muy poco después.

Se dedicaron a limpiar los árboles de las estaciones de esquí, adecentaban los terrenos, talaban los árboles y plantaban otros nuevos. Pero no lo hacían de cualquier manera porque la luna y las mareas dictaban cómo y cuándo había que talar. 


\section{MIGUEL BARRIOLA (figura Al.7)}

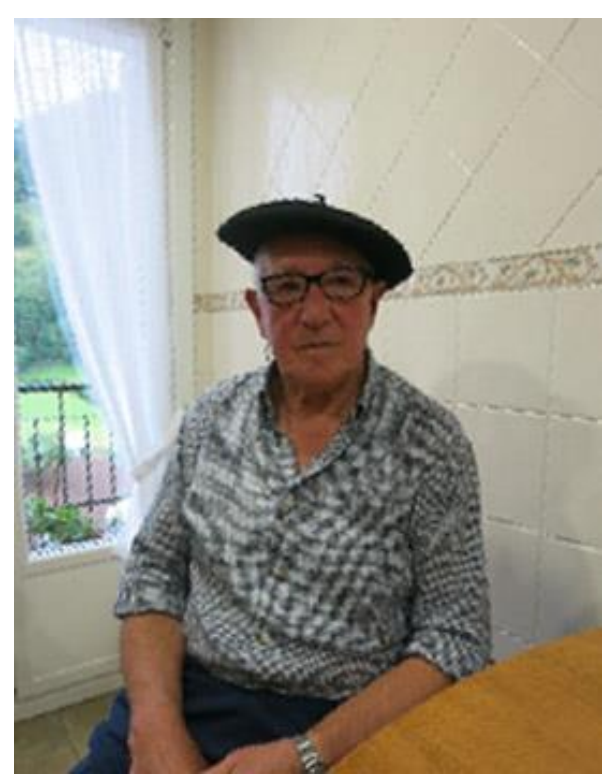

Con 84 años, nos cuenta sus historias relacionadas con la luna y la época de corta de cada una de las especies. Empezó con 16 años a trabajar en el monte. Su padre trabajaba en el monte y de niño ayudaba a su abuelo. Hasta los 30 años trabajó con su padre en la zona de Leitza y luego se fue a Francia y pasó allá un año. Pasaban toda la semana en el monte durmiendo en una chabola y el fin de semana volvían a casa. Todo el trabajo era manual. Destaca que la corta de madera se hacía limpiando todos los tocones y las raíces del árbol, no se dejaba nada en el monte. Todo lo que ha aprendido es por transmisión oral de su padre y su abuelo.

FIGURA AI.7. MIGUEL BARRIOLA ZABALETA.

Conocedor a detalle de todas las épocas de corta necesarias para cada tipo de especie, que él las clasifica atendiendo también a la forma de la hoja. Distingue entre madera para leña y madera para construcción. Ha sido también carbonero y comenta que los carboneros sí siguen a detalle las fases lunares. La madera para leña es mejor cortarla en agosto y septiembre, en creciente. Se daban cuenta de que la marea estaba subiendo o bajando cuando cortaban los árboles, sobre todo cuando cortaban la madera de haya. 


\section{MIGUEL MINDEGIA (figura Al.8)}

Aizkolari navarro nacido en Ezkurra en 1949, que vive en el caserío «Azkaretea» de Zubieta. Campeón juvenil en 1967 y de segunda categoría dos años después. Así comenzó sus desafíos con las primeras figuras logrando un puesto en la categoría absoluta. Dentro de ésta resultó campeón el año 1977 para después recuperar de nuevo el título en 1980 y triunfar desde entonces en todos los campeonatos celebrados, el séptimo el 6 de abril de 1986 en condición de super-txalpeldun con una demostración de auténtica valía. Cortó los doce troncos de haya del Irati en un tiempo de 34 minutos y 11 segundos, lo que supone mejorar el record de 1985.

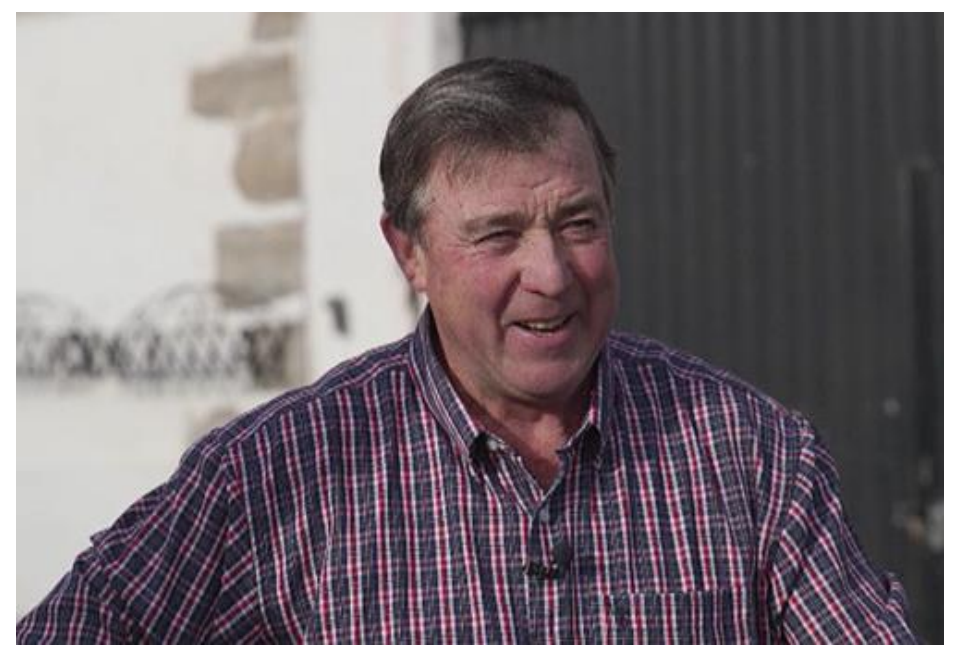

Se ha dedicado durante más de 35 años al deporte rural, temporadas en las que se ha proclamado campeón navarro en siete oportunidades, además de protagonizar grandes desafíos dentro del bello deporte de la aizkora, como demostró recientemente en Tolosa, cuando venció a Joxemari Olasagasti.

FIGURA AI.8. MIGUEL MINDEGUÍA.

Mindegia, que fue agasajado en diciembre de 2017 con la medalla de oro al mérito deportivo concedida por el Gobierno de Navarra. 


\section{PATXI ASTIBIA (figura Al.9)}

Patxi Astibia nació en el caserío de Leitza llamado Donmartinborda. Los hermanos Luziano y Pedro también fueron aizkolaris. A la edad de 14 años, comenzó a trabajar en la montaña. A la edad de 16 años ganó el campeonato juvenil español. El 3 de marzo de 1963 jugó y ganó la primera apuesta contra Esteban Sarratea de Legazpi. Desde entonces, tomó en serio el hacha y jugó con franqueza. Su duelo más recordado fue en 1968 en la plaza de toros de Tolosa, con 100.000 pesetas en juego que fueron para el de Leitza después de cortar cuatro troncos de 108 pulgadas con un tiempo de 61:09 por los 63:13 de Latasa, como recuerda Patxi Astibia, quien muestra una memoria prodigiosa. También un gran físico a sus 74 años, como demuestra con el hacha, afición que no ha abandonado pero a otro ritmo si no quiere tener dolores en la cintura.

En 1972, cuando estaba trabajando en la montaña, sufrió un grave accidente. Aunque se curó, se retiró a la edad de 34 años. Se hizo muy popular en la década de 1960, en el programa "La unión hace la fuerza".

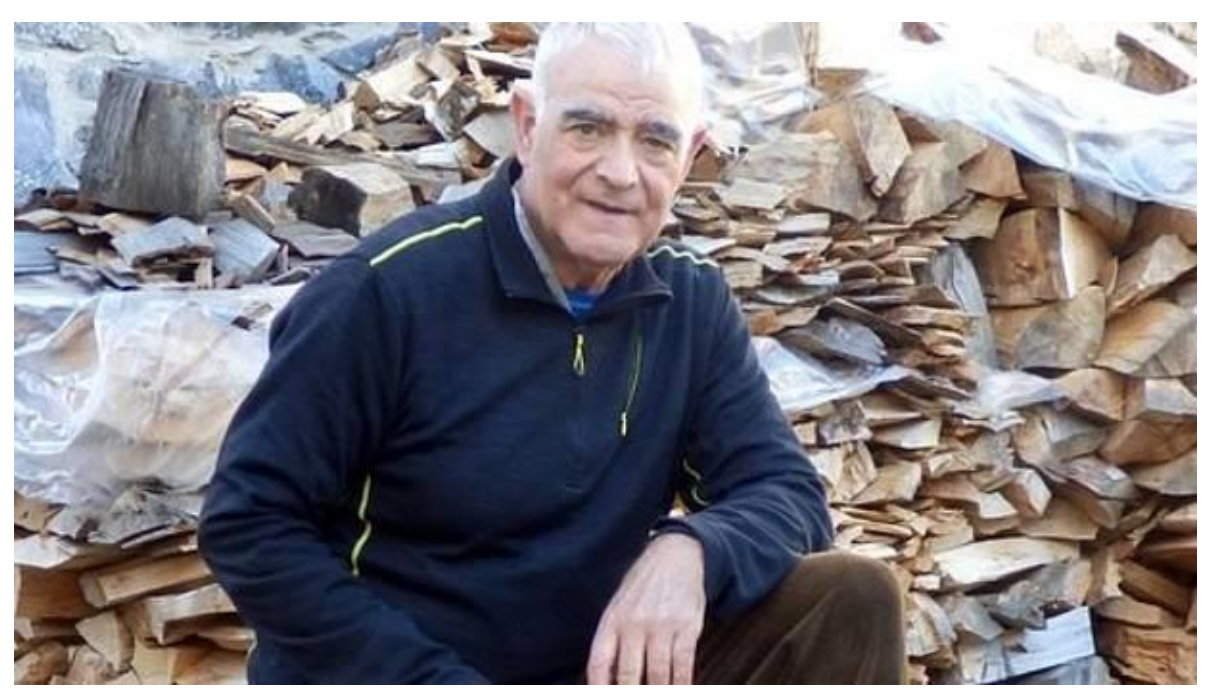

FIGURA AI.9. PATXI ASTIBIA. 


\section{JAGOBA REKONDO (figura Al.10)}

Jakoba Errekondo, nacido en 1961, es agrónomo y paisajista. Es bien conocido por su participación en diversos medios como plantas, flores, árboles y otros temas similares. Colaborador en programas de radio, ha publicado recientemente el libro "Bizibaratzea". Conocedor de la tierra y sus productos, nos invita a una reflexión importante. Considerar todo lo que la tierra nos ha dado en la historia de la humanidad, más allá de los propios frutos hortícolas.

Nos comenta que la cultura de la humanidad en toda su extensión está bañada del huerto, y lo está también nuestro idioma, en las palabras que todos utilizamos en el día a día. Su libro "Bizi baratzea" (Jagoba , 2015) explica todos estos detalles en diversas localidades de Euskal Herria donde incorpora toda la sabiduría popular relacionadas con las faenas del campo de las zonas rurales.

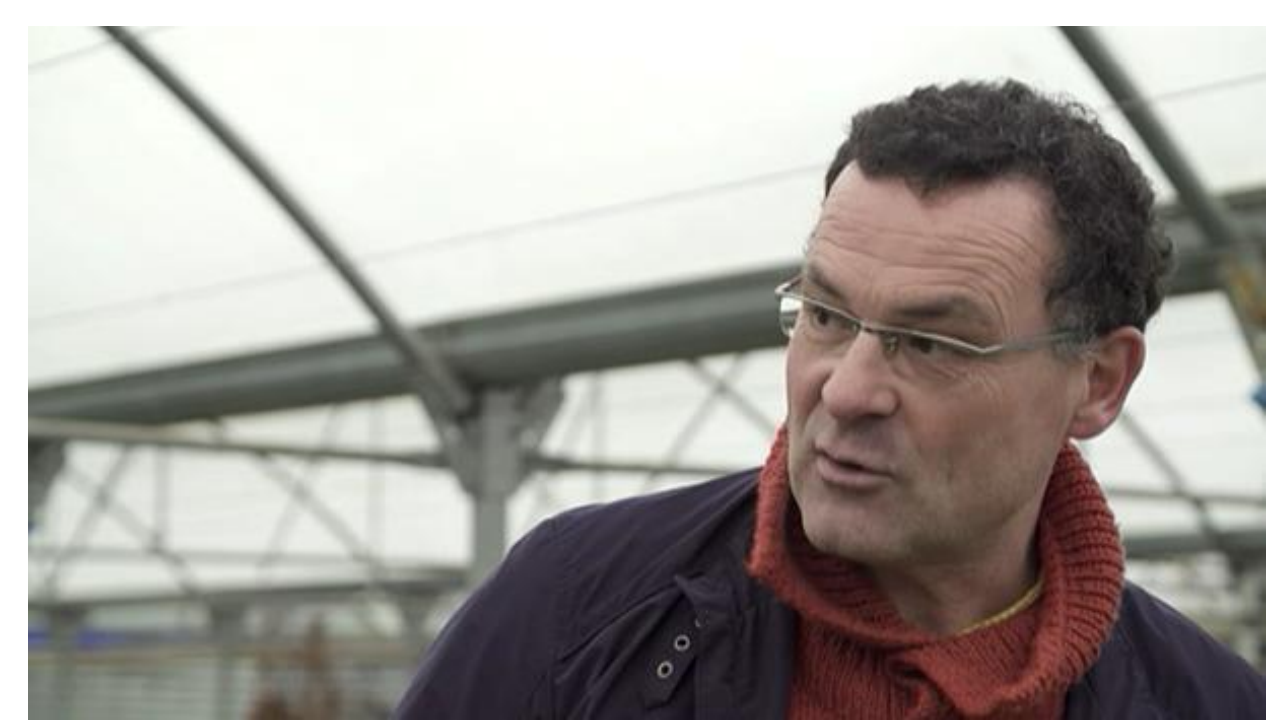

FIGURA AI.10. JAGOBA REKONDO. 


\section{ENRIQUE BILDARRAZ (figura Al.11)}

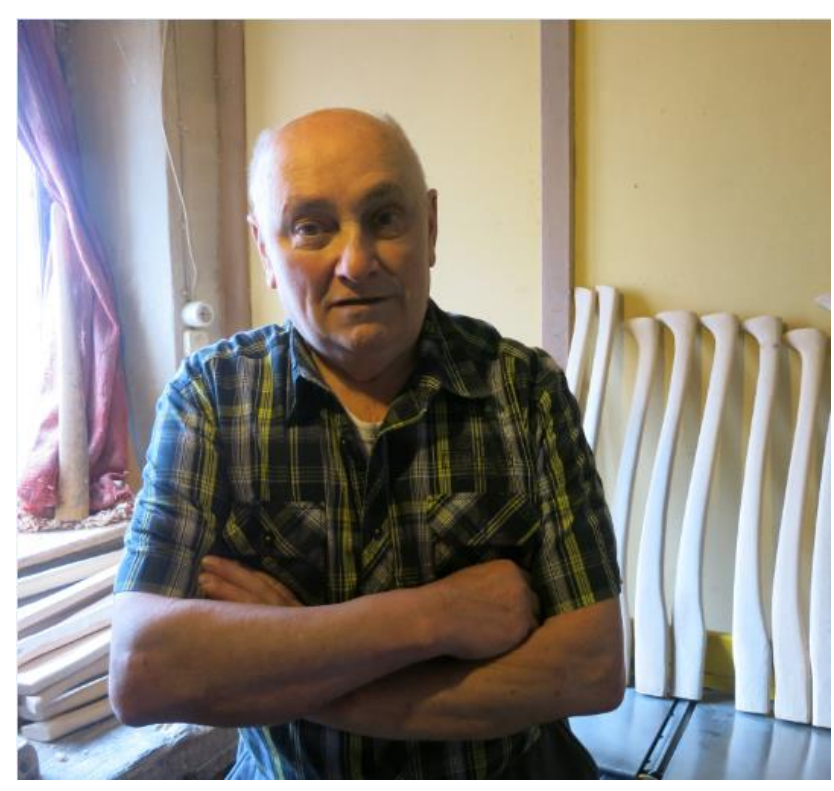

Empezó con 15 años a fabricar hachas de madera en un local debajo de su casa. Ha compaginado su trabajo con esta ilusión artesanal. Trabajó en el monte desde muy joven junto con otros 4 jóvenes en la localidad de Leitza.

Al contrario de todos sus compañeros que empezaron a trabajar en la fábrica y disfrutaban de las fábricas, él ha preferido siempre su trabajo de monte.

FIGURA AI.11. ENRIQUE BILDÁRRAZ.

Revienta la madera para empezar a trabajar y nos enseña todo el proceso para la fabricación de mangos de hachas, que hoy en día sólo se utilizan casi exclusivamente para el deporte rural, pero que han sido herramientas de trabajo en casi todos los hogares del País Vasco y Navarra.

Ha trabajado con haya y toda su vida ha pensado que la madera que ha sido derribada en creciente de Agosto es la mejor. Así la madera es más blanca y seca antes. Esta madera además dura más. Mientras que la madera que se derriba en menguante es de color más oscuro. 


\section{JOSE MIGUEL LARRAÑAGA (figura Al.12)}

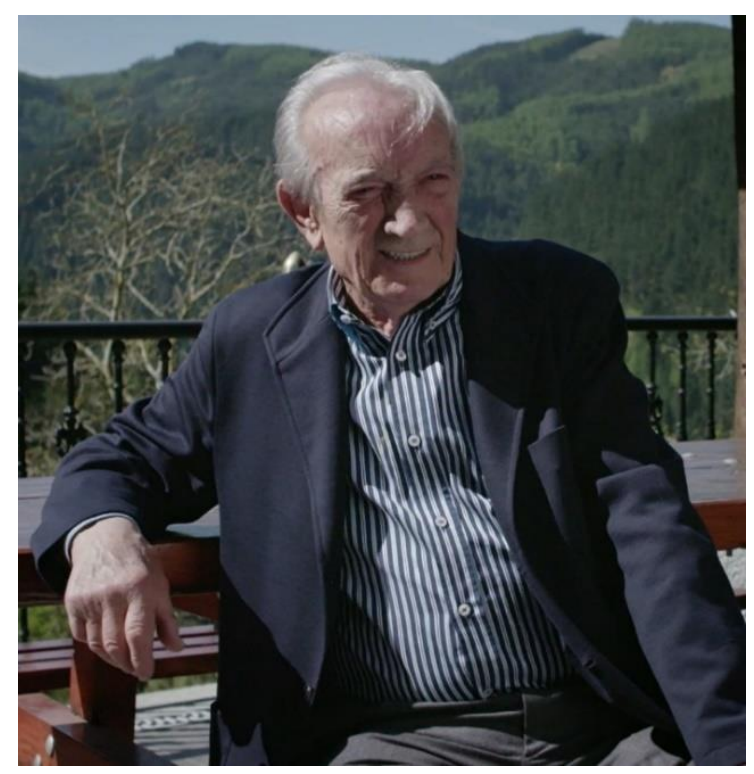

Fallecido recientemente con 93 años, dedicado toda su vida a la madera. Empezó con 17 años a trabajar en una sierra. Eran 10 hermanos en la familia y ha pasado muy malos momentos de necesidad en su vida.

Al igual que otros entrevistados, comenta que de pequeño en su caserío tenía trabajo para todo el año, pero comida solo para medio año.

FIGURA AI.12. JOSÉ MIGUEL LARRAÑAGA.

Creó su propia empresa en una pequeña sierra junto con otros dos socios y luego siguió él en solitario. Posteriormente compró otra sierra y hoy en día la familia sigue en este negocio.

Su jefe Luis le enseñó que la madera siempre debía ser derribada en menguante, y sobre todo en invierno. También le enseñó cómo se debe secar la madera y el tiempo que necesita antes de empezar a trabajarla. En toda su actividad profesional ha tenido en cuenta las fases lunares. Comenta que la madera tiene "agua" en su interior y que se debe cuidar la época en la que esta cantidad de agua es menor. Ha tenido muchos casos en los que la madera se ha podrido por no haberla derribado en su fase adecuada. 


\section{RAMON ASTIZ (figura Al.13)}

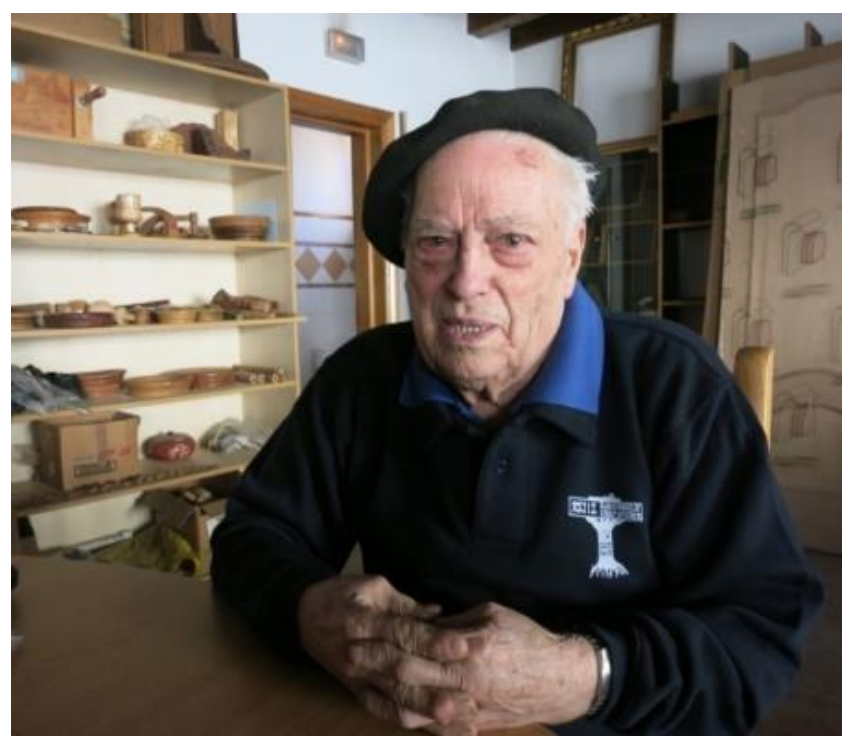

Ramón Astiz nació en Zurginenea (la casa del carpintero en euskera), en este concejo del valle de Larraun, en una familia de siete hermanos, cinco mujeres y dos hombres. Pero, a pesar del nombre del caserío, en su familia no había carpinteros. Su hermano José Mari y él mismo se iniciaron en el oficio por la inquietud y las ganas de aprender, de fabricar algo, de dar forma a las piezas que elaboraba en su cabeza, de utilizar unas manos ávidas de esculpir madera.

FIGURA AI.13 RAMÓN ASTIZ.

Su obligación con el servicio militar le llevó a Marruecos y a Ceuta, pero también allí pudo trabajar en el taller de carpintería, con lo que continuó su formación. Desde niño le gustó la lluvia porque si llovía, podía pasar horas a cubierto, tallando madera, inventando piezas, ideando maquinaria; pero, en cuanto asomaba el sol, debía ayudar en las tareas del campo.

Ramón Astiz Arrarás más que artesano es un ingeniero (sin título) que logró hacer de su afición, oficio. Todavía hoy acude a diario a la carpintería que ahora regentan sus hijos en Leitza.

Ramón era un buen conversador. Contaba al detalle su periplo vital y, de este modo, nos contaba el lugar donde comenzó a trabajar, junto a Sustraikoerreka (el río de las raíces), del que tomó el agua para generar energía con la que poner en marcha la turbina de su primera máquina. Todo lo hizo él, tras pedir consejo a Ciriaco Sótil, un amigo de Betelu. También montó la presa y el canal para llevar agua hasta la borda. Allí estuvo ocho años, hasta que en 1953 una gran riada echó al traste buena parte de su montaje. Luego se instaló en Mugiro para 12 años y más tarde, desde 1965, en Leitza, donde junto a su esposa, Maritxu Goldaraz, crió a sus trece hijos. 


\section{DONATO LARRETXEA (figura Al.14)}

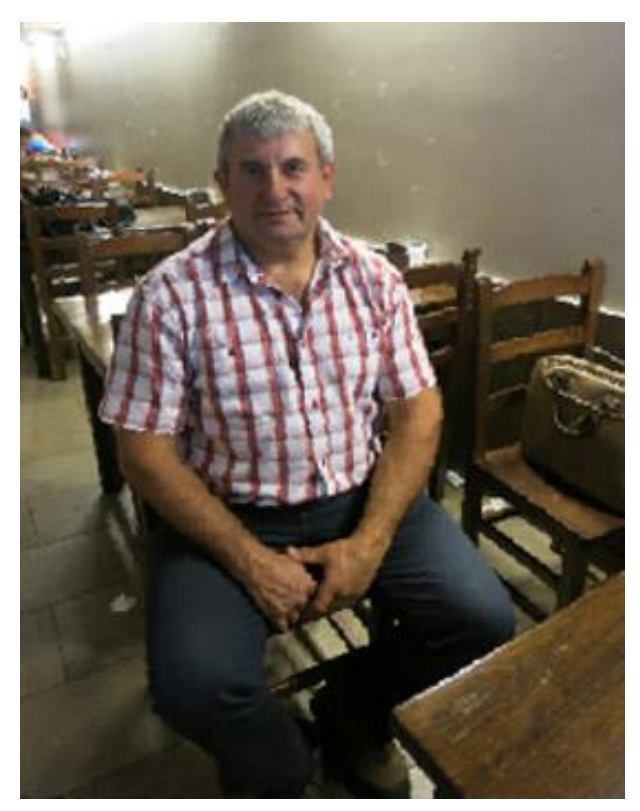

Nacido en Arantza (Navarra) en 1960, conocido como uno de los mejores cortadores de troncos. Después de vivir en Almándoz, volvió a Bera de Bidasoa a vivir. Continúa trabajando en el monte como maderista y muy joven se fue a trabajar a los montes de Francia a limpiar montes como muchos compañeros de su edad. Se ha dedicado al deporte de cortar troncos y compagina, hoy en día, aún su trabajo y empresa de madera con su afición de toda su vida que ha sido el deporte rural y el hacha.

FIGURA AI.14. DONATO LARRETXEA.

Muchos de sus clientes todavía le exigen que la madera haya sido cortada en la fase lunar adecuada. Nos comenta las diferencias terminológicas en euskera, referentes a las fases lunares ascendente ("gorapena") y descendente ("beherapena"), creciente (“Ilgora") y menguante ("ilbera”). 


\section{PANTTALEON ERRANDONEA (figura Al.15)}

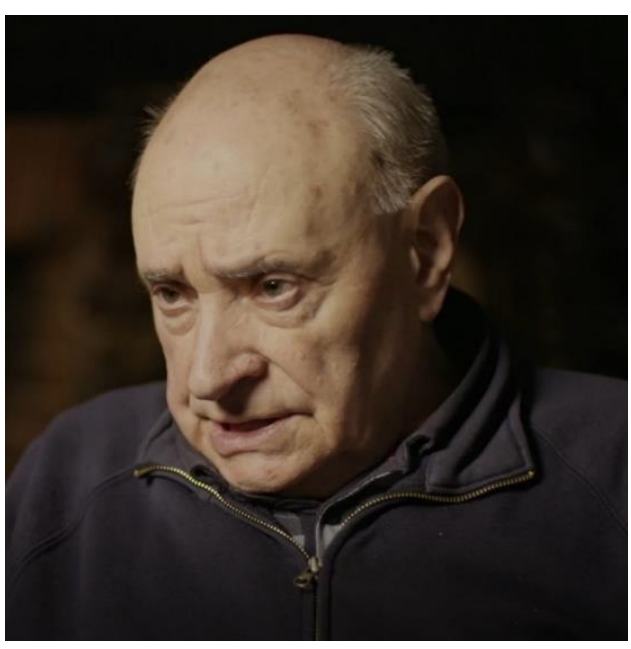

Conocido deportista con la arpana, participó en muchas exhibiciones y campeonatos. Durante años enseñó deporte rural a los jóvenes del pueblo y siempre ha estado dispuesto para participar en la vida de la localidad.

Empezó con 15 años a trabajar en el monte y estuvo, junto a más de 100 jóvenes, trabajando en los montes franceses. Pasó muchas penurias trabajando en el monte de la zona norte de Navarra, donde las condiciones eran muy malas. Libraban un día a la semana que destinaban a limpiar la ropa de monte para toda la semana.

FIGURA AI.15. PANTTALEON ERRANDONEA.

Preparaban traviesas y bajaban la madera en cables a la serrería. Todo el trabajo era manual y se fueron a Francia a trabajar porque allí había más trabajo y estaba mejor remunerado. 


\section{KONTXI Y PILAR (figura Al.16)}

Kontxi y Pilar nos cuentan alrededor del fuego de sus casas cómo han vivido su infancia en los pueblos y cómo se quedaban en casa con sus padres cuando sus hermanos iban a trabajar a Francia al monte.

Kontxi, nació en Arantza el 10 de Octubre de 1948 en el caserío Senberro del barrio de Azkilarrea.

Estudió en la escuela de Arantza hasta cumplir los 14 años y con 16 años se fue a San Juan de Luz a Francia a trabajar. Allí trabajó 2 años continúo su trabajo en otros Hotel de Hendaia durante otro año.

A la edad de 19 años se casó con Lucio Zugarramurdi que recientemente había llegado de América de trabajar, hijo de la misma localidad. Juntos regentaron el bar Eskina de Irun y tuvieron 4 hijos.

Volvieron otra vez al pueblo y tras haber trabajado como propietarios del restaurantealbergue Aterpe de la localidad, viven aquí ya jubilada.

Pilar, nació en Arantza el 13 de Octubre de 1957 en el caserío Senberro del barrio de Azkilarrea.

Estudió sus estudios de primaria en la misma localidad y desde entonces ha trabajado toda su vida en el sector de la hostelería.

Casada con Félix Iparragirre también de Arantza, tiene dos hijos y continúa trabajando en el restaurante que abrió su hermana y es dueña de la casa rural Telleri.

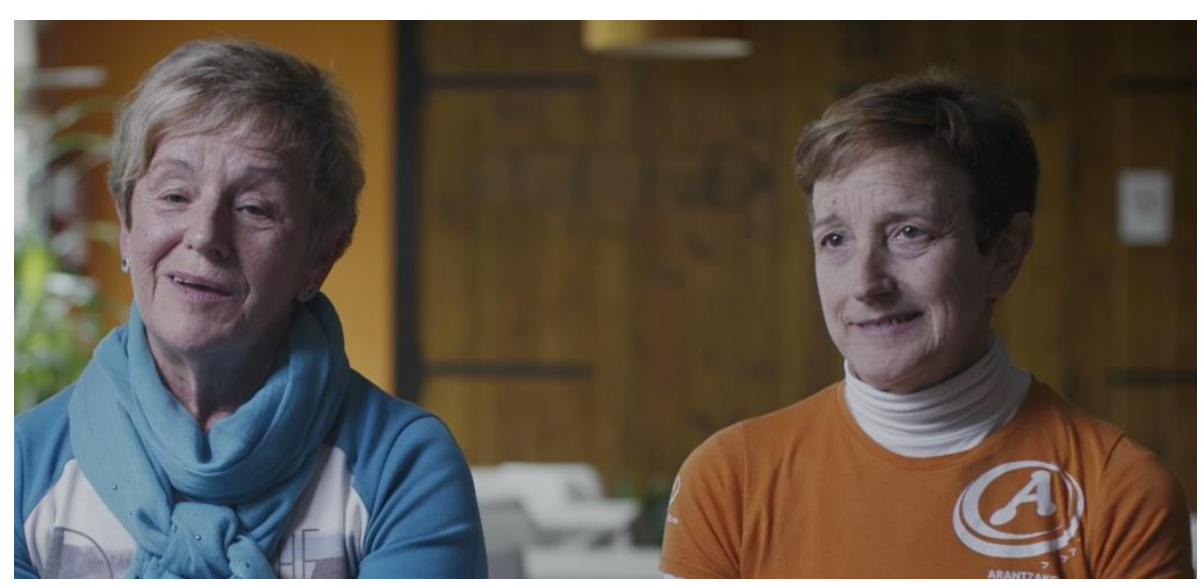

FIGURA Al.16. KONTXI Y PILAR. 


\section{JOSE MIGUEL ELOSEGI (figura Al.17)}

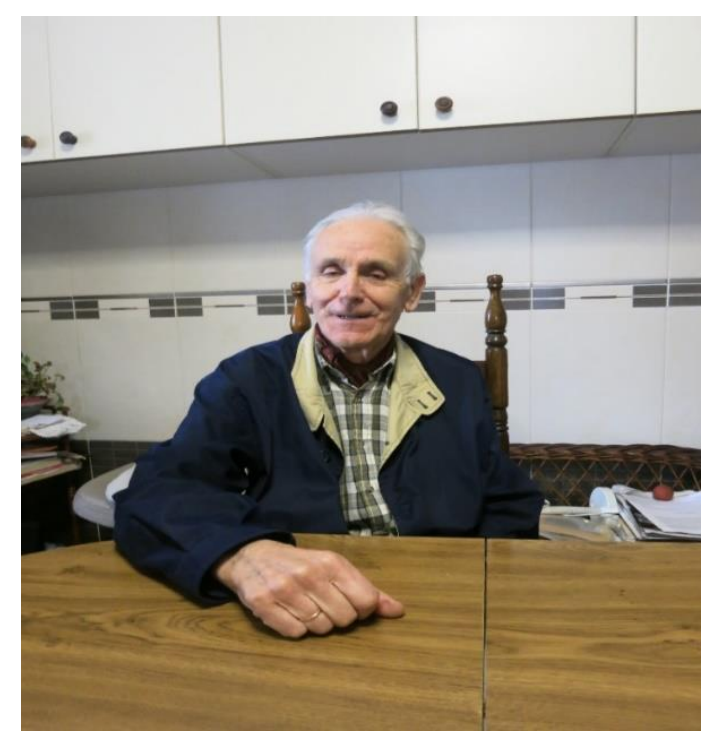

Nacido en Tolosa, pero ha vivido muchos años en Leitza.

No ha trabajado en el monte de leñador, pero es un apasionado del monte, de la biodiversidad y de la madera. Ha estado colaborando con grupos de investigación ingleses para recuperar la tradición de los árboles trasmochos, creando un grupo de trabajo donde han recuperado técnicas tradicionales y han puesto en marcha estas técnicas de trasmocheo en un periodo para 10 años.

FIGURA AI.17. MIGUEL ELOSEGI.

Entusiasta de la madera, recoge, clasifica y colabora con varias xilotecas a nivel nacional y ha hecho también sus propias colecciones de madera.

Nos comenta que debería haber unas líneas de investigación para contrarrestar tantas y tantas creencias alrededor de la influencia de la luna en la madera. Estas creencias cambian incluso de pueblo a pueblo. Nos destacó las Tablas sol lunares de Jon Alden Night. 


\section{XABI AGOTE (figura Al.18)}

Nace en San Sebastián, el 9 de septiembre de 1964. Su padre es abogado, pero tenía un barco de recreo en San Sebastián, siendo muy aficionado a la mar. Aquí toma contacto Xabier con el mar. Se apasiona con los bateles y siempre le obsesionó saber que ya no había constructores de barcos de madera. A los 18 años, acude a una escuela agrícola en Francia y allí estudia dos años. Por medio de Thalassa, el programa de la televisión francesa, se entera de la existencia de una escuela de construcción naval en Maine, en Estados Unidos. Aprender las técnicas de la construcción naval en el País Vasco era ya prácticamente imposible, al no quedar astilleros de madera por una parte y por otra, se daba cuenta de que aprender este oficio suponía dedicar años, mientras que en una escuela especializada podría avanzar más rápidamente, por lo que se fue a Estados Unidos.

Con 27 años, y a su vuelta al País Vasco, con objeto de conocer el oficio desde dentro, hace una campaña de pesca del verdel en un pesquero. Se sigue interesando en las técnicas tradicionales de construcción naval, de forma que compagina diversas actividades laborales con el estudio de viejos pecios. Para ello, unos amigos le dejan un almacén en Hondarribia (Gipuzkoa). Tomaba restos de viejos barcos encallados y estudiaba cómo estaban fabricados, qué tipo de ensamblaje tenían, cómo se construían, e incluso levantaba planos de los mismos. Recupera algunas embarcaciones que dona al Untzi Museoa (Museo Naval) de San Sebastián. Entre otras, una preciosa gabarra del barrio de Amute de Irun. Su verdadera preocupación era que aquí no se recuperaba el patrimonio naval, las técnicas y formas de construir, cosa que ya se estaba haciendo en otros países.

Con 30 años y frustrado por el nulo apoyo institucional, se dedica durante dos años a navegar, haciendo travesías trasatlánticas a vela.

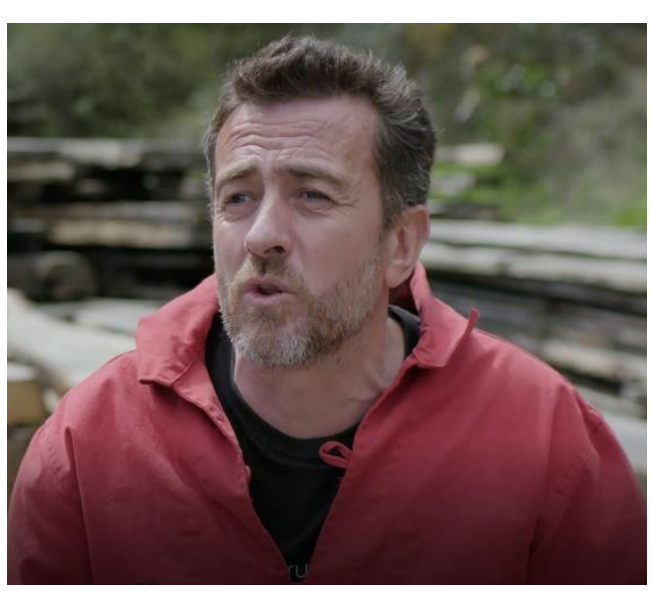

FIGURA AI.18. XABI AGOTE.
Con 32 años recibe la invitación desde The Rockland Apprenticeshop (centro especializado en construir embarcaciones tradicionales), de Maine, para construir allí una embarcación típica vasca. La construye y durante 3 semanas se dedican a navegar por el río Hudson, por los alrededores de Manhattan, en promoción, con muchos de los que habían colaborado en su construcción. Luego la traen al País Vasco como regalo de sus emigrantes y crea la sociedad Albaola. 


\section{JAIRO RESTREPO (figura Al.19)}

Nacido en Colombia y asentado en Brasil. Ingeniero Agrónomo de la Universidad Federal de Pelotas, Rio Grande del Sur, Brasil. Con tres cursos de postgrados: Ecología y Recursos Naturales; Ingeniería de Seguridad Ocupacional Agrícola y Agroecología. Ha realizado 23 cursos internacionales de actualización y perfeccionamiento en el área de agricultura orgánica. Ha publicado cuarenta trabajos científicos y artículos técnicos. En los últimos siete años ha dado a conocer dieciséis libros sobre agricultura orgánica. A nivel internacional ha dictado más de 750 conferencias en el tema de agricultura orgánica, protección ambiental, análisis cromatográfico de suelos, reciclaje, diagnóstico y planificación de fincas, desarrollo rural sostenible, incluyendo la participación en más de treinta y siete universidades e institutos de investigación de América latina, el Caribe, África, Australia y Europa, donde también ha trabajado como asesor técnico de gobiernos, ministerios y parlamentos. Cuenta con una experiencia laboral e internacional de treinta y cinco años en agricultura orgánica y desarrollo rural sostenible.

Como consultor de la Organización de las Naciones Unidas-ONU, ha trabajado con UNESCO, Panamá; OIT (Organización Internacional del Trabajo) Costa Rica, Panamá, Honduras, Guatemala y Cuba; FAO; Chile y Brasil; PNUD- Panamá y Brasil; OMS/ OPSBrasil.

Autor del libro 'La luna, el sol nocturno en los trópicos y su influencia en la agricultura' (Restrepo , 2003).

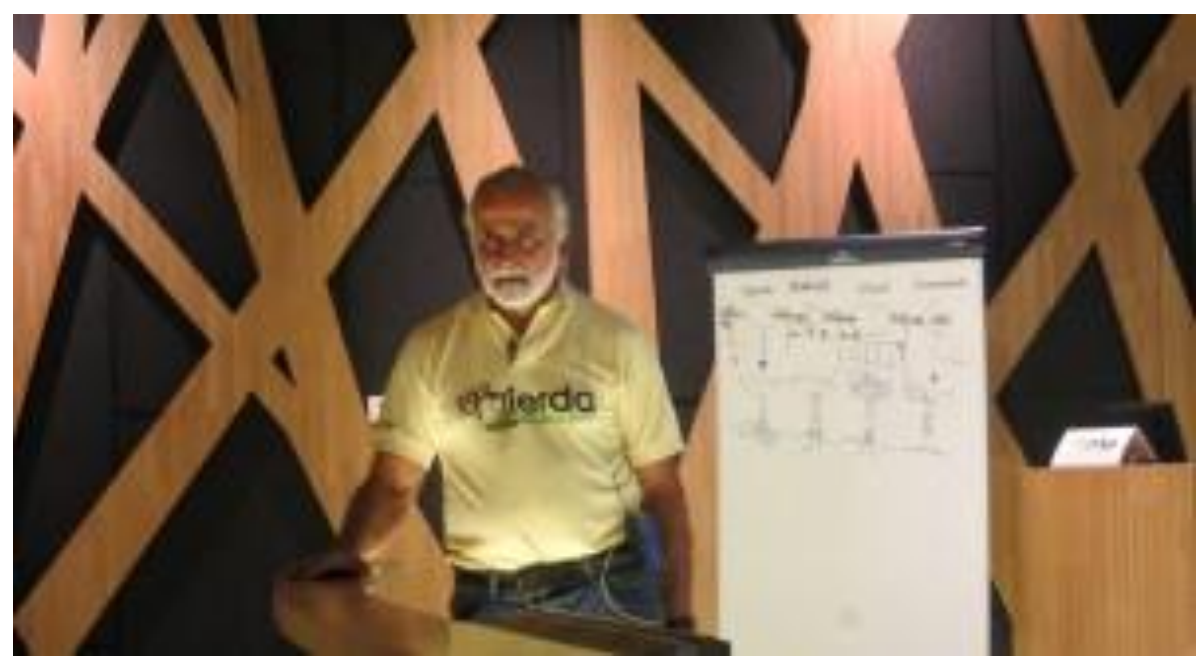

FIGURA AI.19. JAIRO RESTREPO. 


\section{ERNST ZÜRCHER (figura Al.20)}

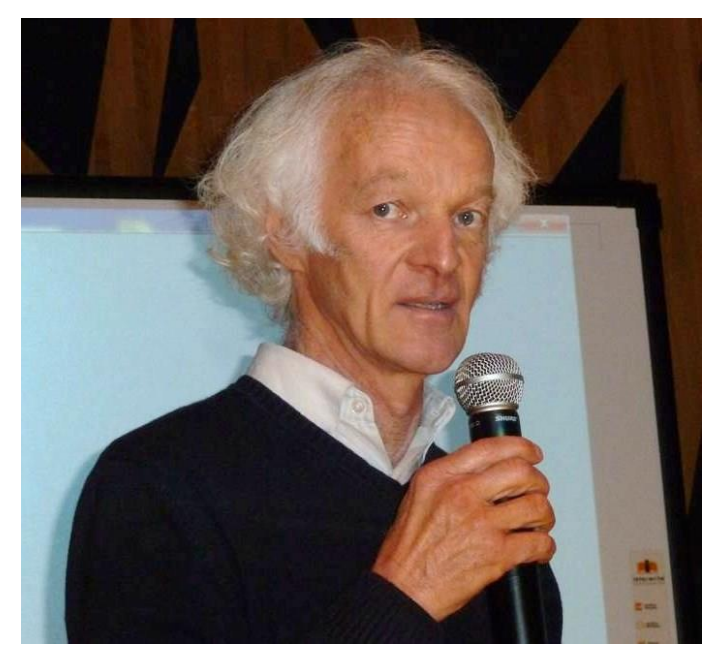

Ingeniero forestal, doctor en ciencias naturales, profesor e investigador en ciencias de la madera en la Universidad de Ciencias Aplicadas de Berna, profesor en el Instituto Federal Suizo de Tecnología de Lausana (EPFL) y en el Instituto Federal de Tecnología de Zúrich (ETHZ). Su estudio se centra más particularmente en las estructuras temporales de los árboles (cronobiología).

FIGURA AI.20. ERNST ZÜRCHER.

Autor de numerosos artículos científicos dedicados a estudiar la influencia de las fases lunares en las plantas y en los árboles, y del libro publicado en Francia con el título "Les arbres, entre visible et invisible"( Zürcher, 2016 ). 
ALVARO ARAGON (figura Al.21)

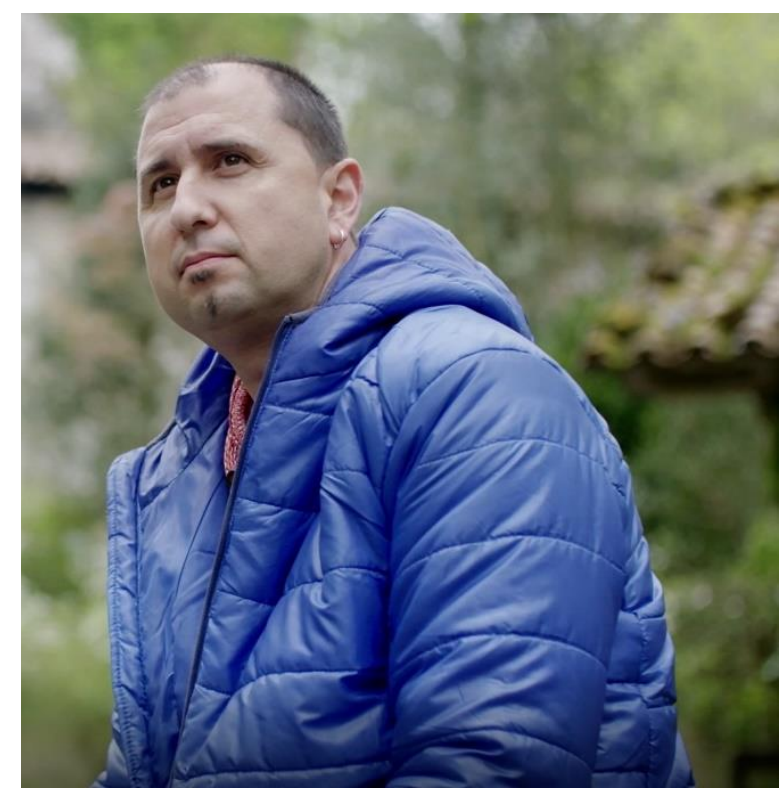

Historiador guipuzcoano, nacido en Oiartzun en 1969. Profesor de la Universidad del País Vasco-E.H.U. En 2002 se doctora con la tesis El bosque guipuzcoano en la Edad Moderna. Autor de numerosas publicaciones, libros y conferenciante en multitud de cursos y jornadas.

Nos explica, haciendo un relato histórico, la relación de los vacos con el monte, sus actividades, tradiciones, oficios, la necesidad de trabajar el campo y el monte.

FIGURA AI.21. ALVARO ARAGON. 


\section{GABRIEL SARALEGI (figura Al.22)}

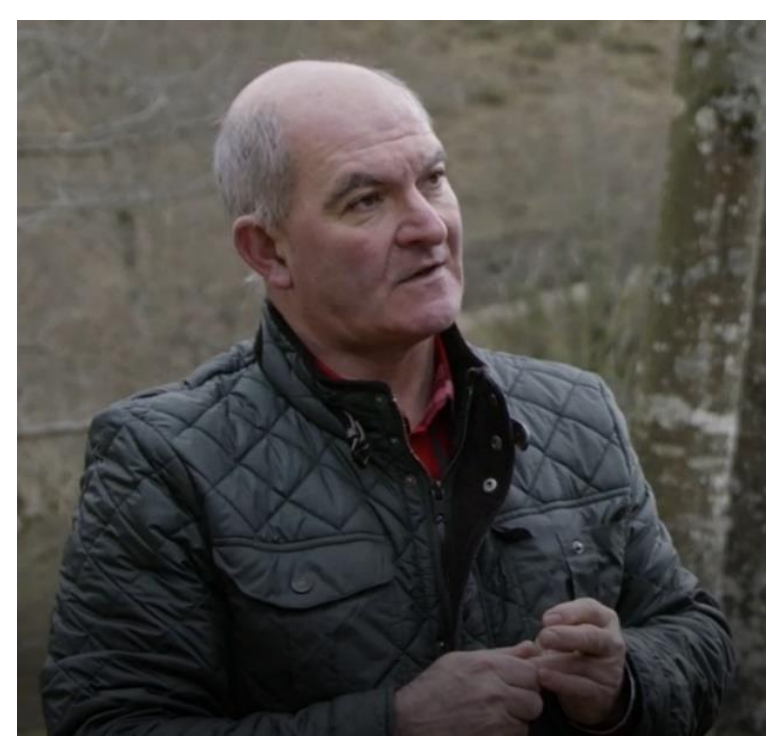

FIGURA AI.22. GABRIEL SARALEGI.
Nacido en 1956 en el caserío Arro de Leitza, Gabriel Saralegi vivió desde pequeño muy de cerca el mundo del deporte rural, sobre todo el hacha, palabras mayores en este pueblo.

$Y$ es que su padre, Esteban Saralegi, preparaba y aconsejaba a grandes aizkolaris de la época. Así, no es extraño que promoviera la afición entre sus seis hijos, cuatro chicos y dos chicas. Debutó como cortador de troncos en la plaza con 16 años, participando desde entonces en campeonatos y sobre todo exhibiciones.

Lo dejó hace 20 años porque ya le costaba recuperarse, nos comenta.

Ha destacado sobre todo en la promoción de los Herri Kirolak (Deporte Rural). Es uno de los impulsores de la Federación Navarra, además de su primer presidente en 1990. Asimismo, los Saralegi aportaron más espectáculo en el mundo de la aizkora (corte de troncos), introduciendo novedades en los años 70 como el corte en altura, desconocido hasta entonces en Europa, o el corte con una mano. 


\section{GLOSARIO}

- Probeta: Número de orden consecutivo de la probeta.

- Código: Código identificativo de la probeta.

- Aserradero: Aserradero de procedencia.

- Provincia: Provincia de procedencia.

- Monte: Monte de procedencia.

- Sección: Ancho x Grueso $\left(\mathrm{cm}^{2}\right)$.

- Longitud: Longitud real $(\mathrm{cm})$.

- Ancho: Ancho real (cm).

- Canto: Canto real $(\mathrm{cm})$.

- Peso: Peso de toda la pieza $(\mathrm{kg})$.

- Volumen: Volumen real $\left(\mathrm{m}^{3}\right)$.

- Humedad: Humedad obtenida con xilohigrómetro (\%).

- Densidad: Densidad al $\mathrm{H} \%$ de humedad $\left(\mathrm{kg} / \mathrm{m}^{3}\right)$.

- Freq 1: Frecuencia de vibración longitudinal con Fakopp (Hz), medida 1.

- $\quad$ Freq 2: Frecuencia de vibración longitudinal con Fakopp (Hz), medida 2.

- $\quad$ Freq 3: Frecuencia de vibración longitudinal con Fakopp (Hz), medida 3.

- $\quad$ Freq media: Frecuencia de vibración longitudinal con Fakopp ( $\mathrm{Hz})$, media.

- V_fvl: Velocidad de onda obtenida por vibración longitudinal (m/s).

- V_fvl_corr12\%: Velocidad de onda obtenida por vibración longitudinal corregida al $12 \%$ de humedad (m/s).

- MOE dyn_ful: Modulo de elasticidad dinámico obtenido por frecuencia de vibración longitudinal $\left(\mathrm{N} / \mathrm{mm}^{2}\right)$.

- MOE dyn_fvl corr12\%: Modulo de elasticidad dinámico obtenido por frecuencia de vibración longitudinal corregido al $12 \%$ de humedad $\left(\mathrm{N} / \mathrm{mm}^{2}\right)$.

- Valor testa-testa 1: Tiempo de paso de onda con Microsecond Timer de Fakopp ( $\mu s)$, medida 1.

- Valor testa-testa 2: Tiempo de paso de onda con Microsecond Timer de Fakopp ( $\mu$ s), medida 2.

- Valor testa-testa 3: Tiempo de paso de onda con Microsecond Timer de Fakopp ( $\mu$ s), medida 3.

- Valor testa-testa media: Tiempo de paso de onda con Microsecond Timer de Fakopp ( $\mu s)$, media.

- V_vop: Velocidad de paso de onda $(\mathrm{m} / \mathrm{s})$.

- V_vop_corr12\%: Velocidad de paso de onda corregida al $12 \%$ de humedad (m/s).

- MOEdyn_vop: Módulo de elasticidad dinámico obtenido por velocidad de onda de paso $\left(\mathrm{N} / \mathrm{mm}^{2}\right)$.

- MOEdyn_vop corr12\%: Módulo de elasticidad dinámico obtenido por velocidad de onda de paso corregido al $12 \%$ de humedad $\left(\mathrm{N} / \mathrm{mm}^{2}\right)$.

- Suma nud peor sec: Suma de nudos de la peor sección transversal en toda la pieza $(\mathrm{cm})$.

- Nud cara total: Diámetro máximo de nudo de cara en toda la pieza $(\mathrm{cm})$.

- Nud canto total: Diámetro máximo de nudo de canto en toda la pieza $(\mathrm{cm})$.

- Long fenda: Longitud máxima de fenda en toda la pieza $(\mathrm{cm})$.

- Long gema: Longitud máxima de gema en toda la pieza $(\mathrm{cm})$.

- Médula: Presencia, o no presencia, de médula en toda la pieza.

- Des fibra: Desviación de la fibra en el tercio central de la pieza (en tanto por uno).

- Des fibra porc: Desviación de la fibra en el tercio central de la pieza (\%).

- Duramen: Porcentaje de duramen (\%).

- Nudo canto: Diámetro máximo de nudo de canto en el tercio central de la pieza (cm).

- Nudo agrupado canto: Diámetro máximo de nudos agrupados de canto en el tercio central de la pieza $(\mathrm{cm})$.

- Relación nudos/canto: Proporción entre el valor máximo de Nudo canto y Nudo agrupado canto, con el canto (adimensional).

- Nudo de cara: Diámetro máximo de nudo de cara en el tercio central de la pieza $(\mathrm{cm})$. 
- Nudo agrupados cara: Diámetro máximo de nudos agrupados de cara en el tercio central de la pieza $(\mathrm{cm})$.

- Relación nudos/cara: Proporción entre el valor máximo de Nudo canto y Nudo agrupado canto, con el canto (adimensional).

- Crec 5 anillos int: Crecimiento total de los 5 anillos internos (cm).

- Creci unit 5 anillos int: Promedio del crecimiento de los 5 anillos interiores ( $\mathrm{mm} /$ anillo).

- Crec 5 anillos ext: Crecimiento total de los 5 anillos externos $(\mathrm{cm})$.

- Ancho gema: Ancho de gema en el tercio central de la pieza $(\mathrm{cm})$.

- Canto gema: Canto de gema en el tercio central de la pieza $(\mathrm{cm})$.

- Ancho fenda: Ancho fenda en el tercio central de la pieza $(\mathrm{cm})$.

- Profundidad fenda: Profundidad fenda en el tercio central de la pieza $(\mathrm{cm})$.

- Curvatura cara: Centímetros de curvatura de cara en 2 metros de longitud.

- Curvatura canto: Centímetros de curvatura de canto en 2 metros de longitud.

- Alabeo: Centímetros de alabeo en 2 metros de longitud.

- Pudrición: Presencia, o no presencia, de pudrición.

- Luz: Luz de ensayo igual a 18 veces el canto de la pieza (cm), según UNE-EN 408:2011 $+\mathrm{A} 1: 2012$

- Carga rot: Carga de rotura en el ensayo de flexión $(\mathrm{kg})$.

- MOR sin corr: Resistencia a flexión $\left(\mathrm{N} / \mathrm{mm}^{2}\right)$.

- Kh: Factor de corrección por canto (adimensional).

- MOR corr con Kh: Resistencia a flexión corregida por canto $\left(\mathrm{N} / \mathrm{mm}^{2}\right)$.

- MEOG sin corr: Módulo de elasticidad global al H\% de humedad $\left(\mathrm{N} / \mathrm{mm}^{2}\right)$.

- MOEG corr: Módulo de elasticidad global corregido al $12 \%$ de humedad $\left(\mathrm{N} / \mathrm{mm}^{2}\right)$.

- MOE sin corr: Módulo de elasticidad local al $\mathrm{H} \%$ de humedad $\left(\mathrm{N} / \mathrm{mm}^{2}\right)$.

- MOE corr: Módulo de elasticidad local corregido al $12 \%$ de humedad $\left(\mathrm{N} / \mathrm{mm}^{2}\right)$.

- Pos rotura: Distancia desde lugar de rotura hasta el centro de la pieza $(\mathrm{cm})$.

- Peso húmedo: Peso húmedo de rodaja extraída para determinación de la humedad $(\mathrm{kg})$.

- Peso seco: Peso seco de rodaja extraída para determinación de la humedad (kg).

- Humedad: Humedad de la rodaja (\%).

- Corr H: Intervalo de corrección por humedad aplicado a los módulos de elasticidad (\%).

- Canto rodaja: Canto de la rodaja extraída para la determinación de la humedad $(\mathrm{cm})$.

- Ancho rodaja: Ancho de la rodaja extraída para la determinación de la humedad $(\mathrm{cm})$.

- Espesor rodaja: Espesor de la rodaja extraída para la determinación de la humedad (cm).

- Dens anhidra: Densidad de la rodaja anhidra $\left(\mathrm{kg} / \mathrm{m}^{3}\right)$.

- DensH\%: Densidad de la rodaja a la humedad $\mathrm{H} \%\left(\mathrm{~kg} / \mathrm{m}^{3}\right)$.

- Dens12\%: Densidad de la rodaja corregida al $12 \%$ de humedad $\left(\mathrm{kg} / \mathrm{m}^{3}\right)$. 


\begin{tabular}{|c|c|c|c|c|c|c|c|c|}
\hline Probeta & Código & Aserradero & Provincia & Monte & Sección & Longitud & Ancho & Canto \\
\hline 1 & OTZ-38-1 $1^{a}$ & ERREKONDO & GIPUZKOA & OTZAURTE & $25 \times 20$ & 507,2 & 20,0 & 25,3 \\
\hline 2 & B-32-3 $3^{a}$ & LARRAÑAGA & GIPUZKOA & ALDAOLA & $15 \times 10$ & 306,1 & 9,8 & 14,9 \\
\hline 3 & B-38-3-R & LARRAÑAGA & GIPUZKOA & ALDAOLA & $15 \times 10$ & 303,2 & 10,0 & 15,0 \\
\hline 5 & OTZ-44-1 ${ }^{\underline{a}}$ & ERREKONDO & GIPUZKOA & OTZAURTE & $25 \times 20$ & 512,0 & 20,1 & 25,1 \\
\hline 6 & OTZ-25-1 $1^{a}$ & ERREKONDO & GIPUZKOA & OTZAURTE & $25 \times 20$ & 508,0 & 20,1 & 25,5 \\
\hline 7 & OTZ-30-3 & ERREKONDO & GIPUZKOA & OTZAURTE & $25 \times 20$ & 495,0 & 20,1 & 25,4 \\
\hline 8 & 19 & LARRAÑAGA & GIPUZKOA & & $25 \times 20$ & 517,0 & 19,9 & 24,9 \\
\hline 9 & 22 & LARRAÑAGA & GIPUZKOA & & $25 \times 20$ & 523,0 & 19,9 & 22,2 \\
\hline 10 & OTZ-9-1롬 & ERREKONDO & GIPUZKOA & OTZAURTE & $25 \times 20$ & 511,5 & 20,0 & 25,2 \\
\hline 11 & 30 & LARRAÑAGA & GIPUZKOA & & $25 \times 20$ & 515,0 & 19,9 & 24,9 \\
\hline 12 & 20 & LARRAÑAGA & GIPUZKOA & & $25 \times 20$ & 518,0 & 20,0 & 25,0 \\
\hline 13 & OTZ-43-1 ${ }^{\underline{a}}$ & ERREKONDO & GIPUZKOA & OTZAURTE & $25 \times 20$ & 510,0 & 20,1 & 25,4 \\
\hline 14 & 23 & LARRAÑAGA & GIPUZKOA & & $25 \times 20$ & 519,0 & 20,0 & 24,9 \\
\hline 16 & 26 & LARRAÑAGA & GIPUZKOA & & $25 \times 20$ & 515,0 & 20,1 & 24,8 \\
\hline 17 & OTZ-3-1 & ERREKONDO & GIPUZKOA & OTZAURTE & $25 \times 20$ & 509,0 & 20,2 & 25,1 \\
\hline 18 & OTZ-40-2 & ERREKONDO & GIPUZKOA & OTZAURTE & $25 \times 20$ & 504,5 & 20,3 & 25,3 \\
\hline 19 & OTZ-10-1 & ERREKONDO & GIPUZKOA & OTZAURTE & $25 \times 20$ & 516,7 & 20,1 & 25,2 \\
\hline 20 & OTZ-44-2 $2^{\underline{a}}$ & ERREKONDO & GIPUZKOA & OTZAURTE & $25 \times 20$ & 500,0 & 19,9 & 25,2 \\
\hline 21 & B-34-1 & ALEMAN & NAVARRA & BERA & $18 \times 14$ & 407,5 & 13,8 & 18,0 \\
\hline 22 & OTZ-7-1 ${ }^{\mathrm{a}}$ & ERREKONDO & GIPUZKOA & OTZAURTE & $25 \times 20$ & 527,5 & 20,5 & 25,3 \\
\hline 23 & OTZ-26-2 $2^{\mathrm{a}}$ & ERREKONDO & GIPUZKOA & OTZAURTE & $25 \times 20$ & 506,9 & 19,8 & 25,3 \\
\hline 24 & OTZ-31-1 & ERREKONDO & GIPUZKOA & OTZAURTE & $25 \times 20$ & 509,4 & 20,2 & 25,4 \\
\hline 26 & 32 & LARRAÑAGA & GIPUZKOA & & $25 \times 20$ & 526,0 & 19,9 & 24,7 \\
\hline 27 & OTZ-38-2 & ERREKONDO & GIPUZKOA & OTZAURTE & $25 \times 20$ & 505,3 & 20,0 & 25,3 \\
\hline 28 & OTZ-1-1 & ERREKONDO & GIPUZKOA & OTZAURTE & $25 \times 20$ & 505,8 & 20,3 & 25,4 \\
\hline 29 & OTZ-26-1를 & ERREKONDO & GIPUZKOA & OTZAURTE & $25 \times 20$ & 514,4 & 20,1 & 25,4 \\
\hline 30 & 27 & LARRAÑAGA & GIPUZKOA & & $25 \times 20$ & 513,0 & 19,9 & 24,9 \\
\hline 31 & 24 & LARRAÑAGA & GIPUZKOA & & $25 \times 20$ & 505,4 & 19,9 & 24,9 \\
\hline 32 & B-42-3 & ALEMAN & NAVARRA & BERA & $18 \times 14$ & 400,2 & 14,0 & 18,0 \\
\hline 33 & OTZ-28-1 ${ }^{\mathrm{a}}$ & ERREKONDO & GIPUZKOA & OTZAURTE & $25 \times 20$ & 511,0 & 20,3 & 25,3 \\
\hline 34 & 18 & LARRAÑAGA & GIPUZKOA & & $25 \times 20$ & 512,0 & 19,9 & 25,0 \\
\hline 36 & 41 & LARRAÑAGA & GIPUZKOA & & $25 \times 20$ & 518,6 & 19,9 & 24,5 \\
\hline 37 & B-35-2 & ALEMAN & NAVARRA & BERA & $18 \times 14$ & 405,5 & 14,0 & 18,0 \\
\hline 38 & OTZ-41-1aㅗ & ERREKONDO & GIPUZKOA & OTZAURTE & $25 \times 20$ & 507,4 & 20,1 & 25,4 \\
\hline 39 & OTZ-36-1 ${ }^{a}$ & ERREKONDO & GIPUZKOA & OTZAURTE & $25 \times 20$ & 509,3 & 20,2 & 25,3 \\
\hline 40 & 33 & LARRAÑAGA & GIPUZKOA & & $25 \times 20$ & 518,0 & 20,5 & 25,0 \\
\hline 41 & OTZ-44-3 & ERREKONDO & GIPUZKOA & OTZAURTE & $25 \times 20$ & 502,2 & 19,8 & 25,0 \\
\hline 42 & $\mathrm{~B}-1-1^{\mathrm{a}}$ & LARRAÑAGA & GIPUZKOA & ALDAOLA & $18 \times 14$ & 314,7 & 9,7 & 14,9 \\
\hline 43 & $\mathrm{~B}-8-1^{\mathrm{a}} \mathrm{R}$ & LARRAÑAGA & GIPUZKOA & ALDAOLA & $25 \times 20$ & 303,7 & 6,8 & 14,3 \\
\hline 44 & B-32-4-R & LARRAÑAGA & GIPUZKOA & ALDAOLA & $25 \times 20$ & 304,0 & 9,8 & 14,8 \\
\hline 45 & 2 & LARRAÑAGA & GIPUZKOA & & $25 \times 20$ & 517,0 & 20,0 & 24,9 \\
\hline 46 & $A-9-3^{a}$ & LARRAÑAGA & GIPUZKOA & ATAUN & $15 \times 10$ & 305,5 & 9,9 & 14,8 \\
\hline 47 & B-29-1 ${ }^{\mathrm{a}}-\mathrm{R}$ & LARRAÑAGA & GIPUZKOA & ALDAOLA & $15 \times 7$ & 306,9 & 6,8 & 14,7 \\
\hline 48 & $A-19-1^{a}-R$ & LARRAÑAGA & GIPUZKOA & ATAUN & $15 \times 10$ & 306,0 & 6,9 & 14,7 \\
\hline 49 & OTZ-39-1 ${ }^{\underline{a}}$ & ERREKONDO & GIPUZKOA & OTZAURTE & $25 \times 20$ & 510,2 & 20,3 & 25,4 \\
\hline 50 & B-27-2 & ALEMAN & NAVARRA & BERA & $15 \times 10$ & 404,0 & 14,0 & 17,9 \\
\hline 51 & A-33-4믄 & LARRAÑAGA & GIPUZKOA & ATAUN & $15 \times 7$ & 303,7 & 9,9 & 15,0 \\
\hline 52 & 7 & LARRAÑAGA & GIPUZKOA & & $15 \times 7$ & 514,0 & 20,1 & 25,0 \\
\hline 53 & OTZ-30-1 & ERREKONDO & GIPUZKOA & OTZAURTE & $25 \times 20$ & 508,5 & 20,4 & 25,4 \\
\hline 54 & 9 & LARRAÑAGA & GIPUZKOA & & $18 \times 14$ & 510,5 & 20,0 & 24,9 \\
\hline 55 & OTZ-4-1 & ERREKONDO & GIPUZKOA & OTZAURTE & $15 \times 10$ & 510,0 & 20,1 & 25,2 \\
\hline 56 & 1 & LARRAÑAGA & GIPUZKOA & & $25 \times 20$ & 517,5 & 19,8 & 25,0 \\
\hline 57 & 39 & LARRAÑAGA & GIPUZKOA & & $25 \times 20$ & 522,0 & 19,9 & 24,9 \\
\hline 58 & B-41-1 & ALEMAN & NAVARRA & BERA & $25 \times 20$ & 408,5 & 14,4 & 18,4 \\
\hline
\end{tabular}




\begin{tabular}{|c|c|c|c|c|c|c|c|c|}
\hline 59 & OTZ-30-2 $2^{\mathrm{a}}$ & ERREKONDO & GIPUZKOA & OTZAURTE & $25 \times 20$ & 506,7 & 20,0 & 25,3 \\
\hline 60 & OTZ-28-2 & ERREKONDO & GIPUZKOA & OTZAURTE & $25 \times 20$ & 508,0 & 20,0 & 25,5 \\
\hline 61 & B-25-4를 & LARRAÑAGA & GIPUZKOA & ALDAOLA & $25 \times 20$ & 308,0 & 9,7 & 14,8 \\
\hline 62 & L-45-1ํㅡ & ALEMAN & NAVARRA & LESAKA & $18 \times 14$ & 407,0 & 14,1 & 18,3 \\
\hline 63 & A-41-2 & LARRAÑAGA & GIPUZKOA & ATAUN & $25 \times 20$ & 304,0 & 9,9 & 15,0 \\
\hline 64 & OTZ-17-1 & ERREKONDO & GIPUZKOA & OTZAURTE & $25 \times 20$ & 508,1 & 20,2 & 25,3 \\
\hline 65 & B-14-3 & LARRAÑAGA & GIPUZKOA & ALDAOLA & $15 \times 10$ & 305,5 & 9,8 & 14,9 \\
\hline 66 & $A-3-4^{a}$ & LARRAÑAGA & GIPUZKOA & ATAUN & $18 \times 14$ & 286,4 & 9,7 & 15,0 \\
\hline 67 & OTZ-17-2 $2^{\mathrm{a}}$ & ERREKONDO & GIPUZKOA & OTZAURTE & $15 \times 10$ & 523,0 & 20,2 & 25,3 \\
\hline 68 & B-3-4 & LARRAÑAGA & GIPUZKOA & ALDAOLA & $25 \times 20$ & 304,3 & 7,0 & 15,0 \\
\hline 69 & $\mathrm{~A}-27-2^{\mathrm{a}}$ & LARRAÑAGA & GIPUZKOA & ATAUN & $15 \times 10$ & 308,1 & 9,7 & 14,8 \\
\hline 70 & A-37-1 & LARRAÑAGA & GIPUZKOA & ATAUN & $15 \times 10$ & 307,5 & 9,8 & 14,7 \\
\hline 71 & B-43-2 & LARRAÑAGA & GIPUZKOA & ALDAOLA & $25 \times 20$ & 306,0 & 9,9 & 14,9 \\
\hline 72 & A-32-3 & LARRAÑAGA & GIPUZKOA & ATAUN & $15 \times 7$ & 303,4 & 10,0 & 15,0 \\
\hline 73 & OTZ-4-2 $2^{\mathrm{a}}$ & ERREKONDO & GIPUZKOA & OTZAURTE & $15 \times 10$ & 507,0 & 20,4 & 25,1 \\
\hline 74 & OTZ-19-1 & ERREKONDO & GIPUZKOA & OTZAURTE & $15 \times 10$ & 516,3 & 20,1 & 25,5 \\
\hline 75 & B-22-2 & ALEMAN & NAVARRA & BERA & $15 \times 10$ & 406,6 & 13,8 & 17,9 \\
\hline 76 & $A-22-3^{\underline{a}}$ & LARRAÑAGA & GIPUZKOA & ATAUN & $15 \times 10$ & 306,2 & 9,8 & 14,8 \\
\hline 77 & $B-13-2^{a}$ & LARRAÑAGA & GIPUZKOA & ALDAOLA & $25 \times 20$ & 307,8 & 9,8 & 14,8 \\
\hline 78 & B-4-4a & LARRAÑAGA & GIPUZKOA & ALDAOLA & $25 \times 20$ & 308,0 & 9,8 & 14,9 \\
\hline 79 & $A-7-3^{a}$ & LARRAÑAGA & GIPUZKOA & ATAUN & $18 \times 14$ & 297,8 & 9,9 & 14,9 \\
\hline 80 & B-37-3aa & LARRAÑAGA & GIPUZKOA & ALDAOLA & $15 \times 10$ & 303,8 & 10,0 & 15,2 \\
\hline 81 & B-16-3 & ALEMAN & NAVARRA & BERA & $15 \times 10$ & 406,0 & 14,2 & 18,2 \\
\hline 82 & B-30-3 $3^{\text {a }}$ & LARRAÑAGA & GIPUZKOA & ALDAOLA & $15 \times 10$ & 303,4 & 10,0 & 15,0 \\
\hline 83 & $A-11-1^{\underline{a}}$ & LARRAÑAGA & GIPUZKOA & ATAUN & $15 \times 10$ & 305,2 & 7,0 & 14,9 \\
\hline 84 & B-40-4 & LARRAÑAGA & GIPUZKOA & ALDAOLA & $15 \times 10$ & 307,0 & 6,9 & 14,9 \\
\hline 85 & B-27-1 ${ }^{\underline{a}}$ & LARRAÑAGA & GIPUZKOA & ALDAOLA & $18 \times 14$ & 299,7 & 9,9 & 14,9 \\
\hline 86 & A-39-1 & LARRAÑAGA & GIPUZKOA & ATAUN & $15 \times 10$ & 307,8 & 6,9 & 14,9 \\
\hline 87 & A-33-2 $2^{a}$ & LARRAÑAGA & GIPUZKOA & ATAUN & $15 \times 7$ & 305,4 & 9,8 & 14,8 \\
\hline 88 & $A-8-1^{a}$ & LARRAÑAGA & GIPUZKOA & ATAUN & $15 \times 7$ & 301,2 & 9,8 & 14,9 \\
\hline 89 & $A-2-3^{a}$ & LARRAÑAGA & GIPUZKOA & ATAUN & $15 \times 10$ & 303,6 & 10,0 & 15,0 \\
\hline 90 & 44 & LARRAÑAGA & GIPUZKOA & & $15 \times 7$ & 497,0 & 20,1 & 24,8 \\
\hline 91 & $\mathrm{~A}-15-1^{\mathrm{a}}$ & LARRAÑAGA & GIPUZKOA & ATAUN & $15 \times 10$ & 306,1 & 9,8 & 15,1 \\
\hline 92 & $L-15-1^{a}-G$ & ALEMAN & NAVARRA & LESAKA & $15 \times 10$ & 405,1 & 14,0 & 18,0 \\
\hline 93 & A-39-4 & LARRAÑAGA & GIPUZKOA & ATAUN & $15 \times 10$ & 304,9 & 9,9 & 15,0 \\
\hline 94 & B-11-4 & LARRAÑAGA & GIPUZKOA & ALDAOLA & $25 \times 20$ & 303,8 & 10,0 & 15,0 \\
\hline 95 & B-36-3를 & LARRAÑAGA & GIPUZKOA & ALDAOLA & $15 \times 10$ & 305,4 & 10,0 & 15,0 \\
\hline 96 & B-29-3aㅡ & LARRAÑAGA & GIPUZKOA & ALDAOLA & $18 \times 14$ & 307,8 & 9,8 & 14,9 \\
\hline 97 & B-20-1 & LARRAÑAGA & GIPUZKOA & ALDAOLA & $15 \times 10$ & 300,8 & 9,9 & 14,8 \\
\hline 98 & A-40-4 & LARRAÑAGA & GIPUZKOA & ATAUN & $15 \times 10$ & 305,4 & 9,9 & 14,9 \\
\hline 99 & B-45-1 & ALEMAN & NAVARRA & BERA & $15 \times 10$ & 406,5 & 13,8 & 17,9 \\
\hline 100 & B-19-2 & LARRAÑAGA & GIPUZKOA & ALDAOLA & $15 \times 10$ & 311,3 & 7,0 & 14,7 \\
\hline 101 & B-6-3 $3^{a}$ & LARRAÑAGA & GIPUZKOA & ALDAOLA & $15 \times 10$ & 306,0 & 7,0 & 15,0 \\
\hline 102 & B-39-3aㅗ & LARRAÑAGA & GIPUZKOA & ALDAOLA & $15 \times 10$ & 308,8 & 9,8 & 14,9 \\
\hline 103 & B-43-1 & LARRAÑAGA & GIPUZKOA & ALDAOLA & $18 \times 14$ & 308,0 & 7,2 & 14,9 \\
\hline 104 & B-10-1 & LARRAÑAGA & GIPUZKOA & ALDAOLA & $15 \times 7$ & 308,4 & 9,9 & 14,9 \\
\hline 105 & $A-4-2^{a}$ & LARRAÑAGA & GIPUZKOA & ATAUN & $15 \times 7$ & 307,5 & 9,8 & 14,9 \\
\hline 106 & 8 & LARRAÑAGA & GIPUZKOA & & $15 \times 10$ & 515,0 & 20,2 & 25,0 \\
\hline 107 & B-23-2 $2^{a}$ & LARRAÑAGA & GIPUZKOA & ALDAOLA & $15 \times 7$ & 300,9 & 9,9 & 14,8 \\
\hline 108 & OTZ-8-2 $2^{\mathrm{a}}$ & ERREKONDO & GIPUZKOA & OTZAURTE & $15 \times 10$ & 512,0 & 20,1 & 25,1 \\
\hline 109 & $\mathrm{~A}-14-1^{a}$ & LARRAÑAGA & GIPUZKOA & ATAUN & $15 \times 10$ & 305,3 & 9,8 & 14,9 \\
\hline 110 & $A-5-1^{a}$ & LARRAÑAGA & GIPUZKOA & ATAUN & $25 \times 20$ & 300,8 & 9,9 & 15,0 \\
\hline 111 & A-45-1 & LARRAÑAGA & GIPUZKOA & ATAUN & $15 \times 10$ & 307,6 & 7,0 & 15,1 \\
\hline 112 & $A-15-2^{a}$ & LARRAÑAGA & GIPUZKOA & ATAUN & $25 \times 20$ & 303,4 & 6,9 & 14,9 \\
\hline 113 & B-38-4 & LARRAÑAGA & GIPUZKOA & ALDAOLA & $15 \times 10$ & 303,2 & 7,1 & 15,0 \\
\hline 114 & B-19-3 & LARRAÑAGA & GIPUZKOA & ALDAOLA & $15 \times 10$ & 307,6 & 7,1 & 15,0 \\
\hline 115 & B-15-4 & LARRAÑAGA & GIPUZKOA & ALDAOLA & $15 \times 7$ & 306,1 & 9,9 & 14,9 \\
\hline 116 & A-21-4 & LARRAÑAGA & GIPUZKOA & ATAUN & $15 \times 7$ & 306,2 & 6,9 & 14,9 \\
\hline
\end{tabular}




\begin{tabular}{|c|c|c|c|c|c|c|c|c|}
\hline 117 & B-42-2 & LARRAÑAGA & GIPUZKOA & ALDAOLA & $15 \times 7$ & 303,9 & 7,0 & 15,0 \\
\hline 118 & A-43-2 $2^{a}$ & LARRAÑAGA & GIPUZKOA & ATAUN & $15 \times 7$ & 302,8 & 9,9 & 14,9 \\
\hline 119 & B-24-1 & LARRAÑAGA & GIPUZKOA & ALDAOLA & $15 \times 10$ & 305,5 & 10,0 & 15,0 \\
\hline 120 & $A-17-3^{a}$ & LARRAÑAGA & GIPUZKOA & ATAUN & $15 \times 7$ & 304,7 & 9,8 & 14,9 \\
\hline 121 & A-23-4 & LARRAÑAGA & GIPUZKOA & ATAUN & $15 \times 7$ & 306,9 & 10,0 & 15,1 \\
\hline 122 & B-25-3aa & LARRAÑAGA & GIPUZKOA & ALDAOLA & $15 \times 10$ & 301,0 & 7,0 & 15,1 \\
\hline 123 & $A-13-2^{a}$ & LARRAÑAGA & GIPUZKOA & ATAUN & $15 \times 10$ & 308,1 & 7,1 & 15,0 \\
\hline 124 & A-14-4 & LARRAÑAGA & GIPUZKOA & ATAUN & $15 \times 10$ & 304,8 & 7,0 & 15,0 \\
\hline 125 & $A-9-4^{a}$ & LARRAÑAGA & GIPUZKOA & ATAUN & $15 \times 10$ & 298,7 & 7,1 & 15,1 \\
\hline 126 & A-24-4 & LARRAÑAGA & GIPUZKOA & ATAUN & $15 \times 7$ & 306,0 & 10,0 & 15,1 \\
\hline 127 & $A-7-1^{a}$ & LARRAÑAGA & GIPUZKOA & ATAUN & $15 \times 7$ & 303,5 & 6,9 & 14,9 \\
\hline 128 & $A-2-4^{a}$ & LARRAÑAGA & GIPUZKOA & ATAUN & $15 \times 7$ & 302,3 & 7,0 & 14,9 \\
\hline 129 & B-44-2 $2^{a}$ & LARRAÑAGA & GIPUZKOA & ALDAOLA & $15 \times 7$ & 304,0 & 7,0 & 15,0 \\
\hline 130 & A-18-3 & LARRAÑAGA & GIPUZKOA & ATAUN & $15 \times 10$ & 305,0 & 10,0 & 15,1 \\
\hline 131 & A-40-3a & LARRAÑAGA & GIPUZKOA & ATAUN & $15 \times 7$ & 304,1 & 7,0 & 15,1 \\
\hline 132 & A-3-3 $3^{a}$ & LARRAÑAGA & GIPUZKOA & ATAUN & $15 \times 7$ & 306,2 & 7,0 & 15,0 \\
\hline 133 & A-36-2 & LARRAÑAGA & GIPUZKOA & ATAUN & $15 \times 7$ & 305,0 & 7,1 & 15,0 \\
\hline 134 & OTZ-27-1 & ERREKONDO & GIPUZKOA & OTZAURTE & $15 \times 10$ & 505,2 & 20,0 & 25,4 \\
\hline 135 & A-35-4 & LARRAÑAGA & GIPUZKOA & ATAUN & $15 \times 7$ & 309,6 & 7,1 & 15,1 \\
\hline 136 & B-21-4 & LARRAÑAGA & GIPUZKOA & ALDAOLA & $15 \times 7$ & 309,1 & 7,1 & 15,1 \\
\hline 137 & A-33-3 & LARRAÑAGA & GIPUZKOA & ATAUN & $15 \times 7$ & 305,7 & 7,0 & 15,1 \\
\hline 138 & L-22-1 & ALEMAN & NAVARRA & LESAKA & $25 \times 20$ & 407,2 & 14,1 & 18,2 \\
\hline 139 & OTZ-8-1 & ERREKONDO & GIPUZKOA & OTZAURTE & $15 \times 7$ & 513,2 & 20,2 & 25,2 \\
\hline 140 & A-42-1 & LARRAÑAGA & GIPUZKOA & ATAUN & $15 \times 7$ & 304,9 & 10,0 & 15,0 \\
\hline 141 & B-42-1 & LARRAÑAGA & GIPUZKOA & ALDAOLA & $15 \times 7$ & 309,5 & 9,9 & 14,9 \\
\hline 142 & B-9-3 & ALEMAN & NAVARRA & BERA & $18 \times 14$ & 408,5 & 14,0 & 18,0 \\
\hline 143 & B-2-3를 & LARRAÑAGA & GIPUZKOA & ALDAOLA & $25 \times 20$ & 293,4 & 6,8 & 14,8 \\
\hline 144 & B-11-2 & LARRAÑAGA & GIPUZKOA & ALDAOLA & $15 \times 10$ & 304,5 & 6,9 & 14,8 \\
\hline 145 & OTZ-40-1 & ERREKONDO & GIPUZKOA & OTZAURTE & $15 \times 10$ & 507,2 & 20,2 & 25,4 \\
\hline 146 & $A-7-4^{a}$ & LARRAÑAGA & GIPUZKOA & ATAUN & $18 \times 14$ & 306,5 & 7,1 & 14,9 \\
\hline 147 & $A-8-4^{a}$ & LARRAÑAGA & GIPUZKOA & ATAUN & $15 \times 7$ & 304,4 & 7,0 & 15,0 \\
\hline 148 & A-21-2 & LARRAÑAGA & GIPUZKOA & ATAUN & $15 \times 7$ & 305,8 & 7,1 & 15,1 \\
\hline 149 & B-33-3 & ALEMAN & NAVARRA & BERA & $25 \times 20$ & 403,1 & 13,8 & 17,9 \\
\hline 150 & A-16-1 & LARRAÑAGA & GIPUZKOA & ATAUN & $15 \times 7$ & 301,5 & 7,0 & 15,1 \\
\hline 151 & B-26-2 & LARRAÑAGA & GIPUZKOA & ALDAOLA & $15 \times 7$ & 296,9 & 6,9 & 14,9 \\
\hline 152 & A-35-1 $1^{\underline{a}}$ & LARRAÑAGA & GIPUZKOA & ATAUN & $15 \times 7$ & 305,0 & 9,9 & 14,8 \\
\hline 153 & B-23-3aa & LARRAÑAGA & GIPUZKOA & ALDAOLA & $18 \times 14$ & 303,7 & 10,0 & 15,0 \\
\hline 154 & B-24-3aa & LARRAÑAGA & GIPUZKOA & ALDAOLA & $15 \times 7$ & 307,6 & 6,9 & 14,9 \\
\hline 155 & B-16-3 & LARRAÑAGA & GIPUZKOA & ALDAOLA & $15 \times 7$ & 307,0 & 7,0 & 15,0 \\
\hline 156 & A-25-3 & LARRAÑAGA & GIPUZKOA & ATAUN & $15 \times 10$ & 305,4 & 6,8 & 14,9 \\
\hline 157 & $\mathrm{~A}-2-2^{\mathrm{a}}$ & LARRAÑAGA & GIPUZKOA & ATAUN & $15 \times 10$ & 306,0 & 6,9 & 14,9 \\
\hline 158 & B-17-2 & LARRAÑAGA & GIPUZKOA & ALDAOLA & $15 \times 7$ & 305,6 & 7,0 & 14,9 \\
\hline 159 & B-28-2 & LARRAÑAGA & GIPUZKOA & ALDAOLA & $15 \times 7$ & 306,4 & 7,0 & 14,9 \\
\hline 160 & B-20-4 & LARRAÑAGA & GIPUZKOA & ALDAOLA & $15 \times 7$ & 305,7 & 7,1 & 15,1 \\
\hline 161 & B-17-4 & LARRAÑAGA & GIPUZKOA & ALDAOLA & $15 \times 7$ & 311,3 & 6,9 & 14,9 \\
\hline 162 & B-27-3 & ALEMAN & NAVARRA & BERA & $15 \times 7$ & 408,5 & 14,0 & 18,0 \\
\hline 163 & A-43-3aㅗ & LARRAÑAGA & GIPUZKOA & ATAUN & $15 \times 7$ & 305,0 & 7,1 & 15,1 \\
\hline 164 & B-33-2 & ALEMAN & NAVARRA & BERA & $15 \times 7$ & 400,5 & 14,0 & 18,2 \\
\hline 165 & $A-1-1^{a}$ & LARRAÑAGA & GIPUZKOA & ATAUN & $15 \times 7$ & 294,1 & 9,7 & 14,8 \\
\hline 166 & B-24-2 & ALEMAN & NAVARRA & BERA & $18 \times 14$ & 404,0 & 13,9 & 17,9 \\
\hline 167 & A-29-2 & LARRAÑAGA & GIPUZKOA & ATAUN & $15 \times 7$ & 306,0 & 7,1 & 15,1 \\
\hline 168 & B-20-2 & ALEMAN & NAVARRA & BERA & $18 \times 14$ & 406,3 & 13,9 & 18,0 \\
\hline 169 & A-38-1 & LARRAÑAGA & GIPUZKOA & ATAUN & $15 \times 10$ & 306,7 & 7,0 & 15,0 \\
\hline 170 & B-9-4 $4^{\mathrm{a}}$ & LARRAÑAGA & GIPUZKOA & ALDAOLA & $18 \times 14$ & 304,2 & 9,8 & 15,0 \\
\hline 171 & OTZ-37-1 & ERREKONDO & GIPUZKOA & OTZAURTE & $15 \times 7$ & 508,2 & 20,2 & 25,1 \\
\hline 172 & B-23-2 & LARRAÑAGA & GIPUZKOA & ALDAOLA & $18 \times 14$ & 307,3 & 6,9 & 14,8 \\
\hline 173 & L-20-2 $2^{a}$ & ALEMAN & NAVARRA & LESAKA & $15 \times 7$ & 404,2 & 14,1 & 18,1 \\
\hline 174 & $A-5-3^{\underline{a}}$ & LARRAÑAGA & GIPUZKOA & ATAUN & $15 \times 10$ & 302,7 & 7,0 & 15,0 \\
\hline
\end{tabular}




\begin{tabular}{|c|c|c|c|c|c|c|c|c|}
\hline 175 & 12 & LARRAÑAGA & GIPUZKOA & & $25 \times 20$ & 514,7 & 19,8 & 24,6 \\
\hline 176 & B-31-4a & LARRAÑAGA & GIPUZKOA & ALDAOLA & $15 \times 7$ & 298,3 & 7,0 & 15,0 \\
\hline 177 & $A-10-3^{a}$ & LARRAÑAGA & GIPUZKOA & ATAUN & $18 \times 14$ & 284,6 & 6,8 & 14,8 \\
\hline 178 & A-29-3모 & LARRAÑAGA & GIPUZKOA & ATAUN & $15 \times 7$ & 306,5 & 9,8 & 14,9 \\
\hline 179 & B-21-1 & LARRAÑAGA & GIPUZKOA & ALDAOLA & $25 \times 20$ & 314,5 & 9,9 & 14,9 \\
\hline 180 & B-22-1 ${ }^{\underline{a}}$ & LARRAÑAGA & GIPUZKOA & ALDAOLA & $15 \times 7$ & 310,9 & 7,0 & 15,0 \\
\hline 181 & $A-18-2^{a}$ & LARRAÑAGA & GIPUZKOA & ATAUN & $15 \times 7$ & 301,3 & 9,8 & 14,8 \\
\hline 182 & A-3-2 $2^{a}$ & LARRAÑAGA & GIPUZKOA & ATAUN & $15 \times 10$ & 285,5 & 9,9 & 14,9 \\
\hline 183 & B-8-4 $4^{a}$ & LARRAÑAGA & GIPUZKOA & ALDAOLA & $15 \times 10$ & 303,7 & 7,0 & 15,0 \\
\hline 184 & OTZ-16-1 & ERREKONDO & GIPUZKOA & OTZAURTE & $15 \times 7$ & 531,3 & 20,0 & 25,3 \\
\hline 185 & B-22-2 & LARRAÑAGA & GIPUZKOA & ALDAOLA & $15 \times 10$ & 293,5 & 9,9 & 15,0 \\
\hline 186 & B-27-4 & LARRAÑAGA & GIPUZKOA & ALDAOLA & $15 \times 10$ & 306,9 & 9,9 & 15,0 \\
\hline 187 & B-35-1 $1^{\underline{a}}$ & LARRAÑAGA & GIPUZKOA & ALDAOLA & $15 \times 7$ & 307,6 & 7,0 & 14,9 \\
\hline 188 & B-4-2 $2^{a}$ & LARRAÑAGA & GIPUZKOA & ALDAOLA & $25 \times 20$ & 307,0 & 7,0 & 14,9 \\
\hline 189 & 42 & LARRAÑAGA & GIPUZKOA & & $15 \times 10$ & 513,0 & 20,0 & 25,0 \\
\hline 190 & $B-5-2^{a}$ & ALEMAN & NAVARRA & BERA & $15 \times 10$ & 408,5 & 13,9 & 18,0 \\
\hline 191 & B-24-1 ${ }^{\mathrm{a}}-2$ & LARRAÑAGA & GIPUZKOA & ALDAOLA & $15 \times 7$ & 309,5 & 10,0 & 15,0 \\
\hline 192 & B-30-2 $2^{\mathrm{a}}$ & LARRAÑAGA & GIPUZKOA & ALDAOLA & $15 \times 7$ & 301,4 & 7,0 & 14,9 \\
\hline 193 & B-27-3aa & LARRAÑAGA & GIPUZKOA & ALDAOLA & $25 \times 20$ & 304,9 & 7,1 & 15,0 \\
\hline 194 & A-20-1 & LARRAÑAGA & GIPUZKOA & ATAUN & $18 \times 14$ & 300,5 & 6,9 & 14,8 \\
\hline 195 & B-43-2 & ALEMAN & NAVARRA & BERA & $15 \times 10$ & 405,0 & 13,7 & 17,9 \\
\hline 196 & B-1-2 $2^{a}$ & LARRAÑAGA & GIPUZKOA & ALDAOLA & $15 \times 7$ & 310,5 & 7,1 & 15,0 \\
\hline 197 & B-37-4 & LARRAÑAGA & GIPUZKOA & ALDAOLA & $15 \times 7$ & 307,5 & 6,8 & 14,8 \\
\hline 198 & B-32-1 ${ }^{\underline{a}}$ & LARRAÑAGA & GIPUZKOA & ALDAOLA & $15 \times 7$ & 310,0 & 6,9 & 14,8 \\
\hline 199 & $\mathrm{~A}-4-1^{\mathrm{a}}$ & LARRAÑAGA & GIPUZKOA & ATAUN & $18 \times 14$ & 305,4 & 7,1 & 15,0 \\
\hline 200 & B-15-1 & LARRAÑAGA & GIPUZKOA & ALDAOLA & $15 \times 7$ & 307,3 & 7,1 & 15,0 \\
\hline 201 & OTZ-42-2 & ERREKONDO & GIPUZKOA & OTZAURTE & $15 \times 7$ & 506,1 & 20,2 & 25,3 \\
\hline 202 & B-30-1 & ALEMAN & NAVARRA & BERA & $15 \times 7$ & 407,0 & 14,0 & 18,1 \\
\hline 203 & $A-4-3^{a}$ & LARRAÑAGA & GIPUZKOA & ATAUN & $15 \times 7$ & 297,6 & 7,0 & 14,9 \\
\hline 204 & L-25-1 & ALEMAN & NAVARRA & LESAKA & $15 \times 7$ & 410,0 & 14,0 & 18,1 \\
\hline 205 & $A-20-2^{a}$ & LARRAÑAGA & GIPUZKOA & ATAUN & $25 \times 20$ & 303,7 & 10,1 & 15,0 \\
\hline 206 & A-42-4 & LARRAÑAGA & GIPUZKOA & ATAUN & $18 \times 14$ & 304,7 & 6,9 & 15,0 \\
\hline 207 & B-18-3를 & LARRAÑAGA & GIPUZKOA & ALDAOLA & $15 \times 7$ & 304,4 & 7,1 & 15,2 \\
\hline 208 & A-31-2 & LARRAÑAGA & GIPUZKOA & ATAUN & $18 \times 14$ & 305,8 & 7,1 & 15,1 \\
\hline 209 & 6 & LARRAÑAGA & GIPUZKOA & & $15 \times 10$ & 516,0 & 20,1 & 25,0 \\
\hline 210 & B-36-1 $1^{\underline{a}}$ & LARRAÑAGA & GIPUZKOA & ALDAOLA & $15 \times 7$ & 305,8 & 6,8 & 14,8 \\
\hline 211 & A-26-2 $2^{a}$ & LARRAÑAGA & GIPUZKOA & ATAUN & $15 \times 7$ & 304,7 & 6,9 & 14,9 \\
\hline 212 & B-35-3 & ALEMAN & NAVARRA & BERA & $15 \times 7$ & 409,0 & 14,0 & 18,0 \\
\hline 213 & $A-12-4^{a}$ & LARRAÑAGA & GIPUZKOA & ATAUN & $25 \times 20$ & 304,0 & 7,1 & 15,1 \\
\hline 214 & 16 & LARRAÑAGA & GIPUZKOA & & $15 \times 7$ & 524,0 & 20,1 & 24,9 \\
\hline 215 & A-32-2 & LARRAÑAGA & GIPUZKOA & ATAUN & $15 \times 7$ & 303,5 & 7,0 & 14,9 \\
\hline 216 & A-31-4 & LARRAÑAGA & GIPUZKOA & ATAUN & $18 \times 14$ & 306,0 & 9,5 & 15,0 \\
\hline 217 & B-9-2 $2^{a}$ & ALEMAN & NAVARRA & BERA & $15 \times 7$ & 406,6 & 13,9 & 17,8 \\
\hline 218 & $L-8-1^{a}$ & ALEMAN & NAVARRA & LESAKA & $25 \times 20$ & 408,0 & 14,2 & 18,1 \\
\hline 219 & A-16-4 & LARRAÑAGA & GIPUZKOA & ATAUN & $15 \times 7$ & 304,8 & 9,9 & 15,0 \\
\hline 220 & A-44-4 & LARRAÑAGA & GIPUZKOA & ATAUN & $15 \times 10$ & 304,7 & 6,9 & 15,0 \\
\hline 221 & $L-34-1^{a}-G$ & ALEMAN & NAVARRA & LESAKA & $18 \times 14$ & 413,5 & 13,9 & 17,9 \\
\hline 222 & B-41-4 & LARRAÑAGA & GIPUZKOA & ALDAOLA & $18 \times 14$ & 303,3 & 7,0 & 15,0 \\
\hline 223 & B-13-1 & ALEMAN & NAVARRA & BERA & $15 \times 10$ & 409,8 & 14,0 & 18,0 \\
\hline 224 & $A-17-1^{a}$ & LARRAÑAGA & GIPUZKOA & ATAUN & $15 \times 7$ & 304,2 & 10,0 & 15,1 \\
\hline 225 & B-16-2 & ALEMAN & NAVARRA & BERA & $18 \times 14$ & 403,4 & 13,8 & 17,9 \\
\hline 226 & $L-2-2^{a}$ & ALEMAN & NAVARRA & LESAKA & $15 \times 7$ & 406,7 & 14,0 & 18,0 \\
\hline 227 & B-45-3 $3^{\text {a }}$ & LARRAÑAGA & GIPUZKOA & ALDAOLA & $18 \times 14$ & 306,9 & 7,0 & 15,0 \\
\hline 228 & B-40-1 & LARRAÑAGA & GIPUZKOA & ALDAOLA & $15 \times 10$ & 304,8 & 10,2 & 15,0 \\
\hline 229 & A-45-3 & LARRAÑAGA & GIPUZKOA & ATAUN & $18 \times 14$ & 299,8 & 10,0 & 15,0 \\
\hline 230 & $\mathrm{~L}-21-1^{\mathrm{a}}$ & ALEMAN & NAVARRA & LESAKA & $18 \times 14$ & 406,0 & 14,3 & 17,2 \\
\hline 231 & B-17-2 & LARRAÑAGA & GIPUZKOA & ALDAOLA & $15 \times 7$ & 306,8 & 10,1 & 15,1 \\
\hline 232 & A-26-1 & LARRAÑAGA & GIPUZKOA & ATAUN & $15 \times 10$ & 307,5 & 10,0 & 15,1 \\
\hline
\end{tabular}




\begin{tabular}{|c|c|c|c|c|c|c|c|c|}
\hline 233 & OTZ-42-1 $1^{a}$ & ERREKONDO & GIPUZKOA & OTZAURTE & $15 \times 10$ & 506,9 & 20,1 & 25,4 \\
\hline 234 & B-34-2 & LARRAÑAGA & GIPUZKOA & ALDAOLA & $18 \times 14$ & 301,4 & 9,8 & 14,9 \\
\hline 235 & L-42-1 ${ }^{a}-G$ & ALEMAN & NAVARRA & LESAKA & $15 \times 10$ & 404,0 & 13,9 & 17,8 \\
\hline 236 & 17 & LARRAÑAGA & GIPUZKOA & & $15 \times 10$ & 517,4 & 19,9 & 25,0 \\
\hline 237 & B-14-3 & ALEMAN & NAVARRA & BERA & $25 \times 20$ & 404,0 & 13,9 & 17,9 \\
\hline 238 & A-37-1 & LARRAÑAGA & GIPUZKOA & ATAUN & $15 \times 10$ & 305,0 & 7,1 & 15,1 \\
\hline 239 & B-29-2 & LARRAÑAGA & GIPUZKOA & ALDAOLA & $18 \times 14$ & 303,2 & 7,1 & 15,1 \\
\hline 240 & B-13-3믈 & LARRAÑAGA & GIPUZKOA & ALDAOLA & $25 \times 20$ & 301,1 & 7,1 & 15,1 \\
\hline 241 & $A-6-4^{a}$ & LARRAÑAGA & GIPUZKOA & ATAUN & $18 \times 14$ & 305,4 & 9,9 & 15,0 \\
\hline 242 & B-10-4 & LARRAÑAGA & GIPUZKOA & ALDAOLA & $15 \times 7$ & 304,6 & 10,0 & 15,0 \\
\hline 243 & 13 & LARRAÑAGA & GIPUZKOA & & $15 \times 7$ & 518,5 & 20,0 & 24,9 \\
\hline 244 & L-27-2 $2^{\mathrm{a}}$ & ALEMAN & NAVARRA & LESAKA & $15 \times 7$ & 402,5 & 13,9 & 18,1 \\
\hline 245 & L-30-1 & ALEMAN & NAVARRA & LESAKA & $15 \times 10$ & 407,6 & 14,0 & 18,3 \\
\hline 246 & B-33-4 & LARRAÑAGA & GIPUZKOA & ALDAOLA & $15 \times 10$ & 300,0 & 7,2 & 15,2 \\
\hline 247 & B-6-1 $1^{\mathrm{a}}$ & LARRAÑAGA & GIPUZKOA & ALDAOLA & $25 \times 20$ & 306,2 & 10,0 & 15,0 \\
\hline 248 & L-9-1 $\underline{\underline{a}}$ & ALEMAN & NAVARRA & LESAKA & $18 \times 14$ & 407,9 & 13,8 & 17,9 \\
\hline 249 & $L-5-3^{a}$ & ALEMAN & NAVARRA & LESAKA & $18 \times 14$ & 406,5 & 14,1 & 18,1 \\
\hline 250 & 31 & LARRAÑAGA & GIPUZKOA & & $15 \times 7$ & 520,0 & 19,5 & 24,8 \\
\hline 251 & L-35-2 $2^{a}$ & ALEMAN & NAVARRA & LESAKA & $15 \times 10$ & 405,5 & 14,2 & 18,1 \\
\hline 252 & B-32-2 & ALEMAN & NAVARRA & BERA & $18 \times 14$ & 407,0 & 14,0 & 17,9 \\
\hline 253 & B-12-1 & LARRAÑAGA & GIPUZKOA & ALDAOLA & $18 \times 14$ & 320,2 & 7,0 & 14,9 \\
\hline 254 & B-39-3음 & ALEMAN & NAVARRA & BERA & $25 \times 20$ & 407,6 & 13,7 & 17,9 \\
\hline 255 & L-31-2 & ALEMAN & NAVARRA & LESAKA & $18 \times 14$ & 404,5 & 14,1 & 18,1 \\
\hline 256 & B-12-2 & ALEMAN & NAVARRA & BERA & $18 \times 14$ & 404,9 & 13,7 & 17,9 \\
\hline 257 & B-44-2 $2^{\mathrm{a}}$ & ALEMAN & NAVARRA & BERA & $15 \times 7$ & 407,4 & 14,0 & 17,9 \\
\hline 258 & B-21-1aㅡ & LARRAÑAGA & GIPUZKOA & ALDAOLA & $18 \times 14$ & 304,4 & 6,9 & 15,0 \\
\hline 259 & B-12-2 & LARRAÑAGA & GIPUZKOA & ALDAOLA & $18 \times 14$ & 306,7 & 10,0 & 15,0 \\
\hline 260 & 21 & LARRAÑAGA & GIPUZKOA & & $18 \times 14$ & 512,0 & 20,0 & 24,9 \\
\hline 261 & A-13-3 & LARRAÑAGA & GIPUZKOA & ATAUN & $18 \times 14$ & 303,5 & 6,9 & 15,0 \\
\hline 262 & B-34-3 & LARRAÑAGA & GIPUZKOA & ALDAOLA & $15 \times 7$ & 304,1 & 7,0 & 15,1 \\
\hline 263 & 29 & LARRAÑAGA & GIPUZKOA & & $15 \times 10$ & 515,0 & 20,0 & 25,1 \\
\hline 264 & L-13-2 & ALEMAN & NAVARRA & LESAKA & $25 \times 20$ & 404,0 & 14,2 & 18,1 \\
\hline 265 & $A-6-3^{a}$ & LARRAÑAGA & GIPUZKOA & ATAUN & $15 \times 7$ & 300,1 & 7,2 & 15,2 \\
\hline 266 & L-19-2 & ALEMAN & NAVARRA & LESAKA & $15 \times 7$ & 402,8 & 14,2 & 18,1 \\
\hline 267 & B-37-1 & ALEMAN & NAVARRA & BERA & $25 \times 20$ & 407,3 & 13,9 & 17,9 \\
\hline 268 & $L-1-3^{a}$ & ALEMAN & NAVARRA & LESAKA & $18 \times 14$ & 404,2 & 13,9 & 17,8 \\
\hline 269 & B-36-4 $4^{a}-R$ & LARRAÑAGA & GIPUZKOA & ALDAOLA & $15 \times 7$ & 315,7 & 6,9 & 14,9 \\
\hline 270 & L-26-2 $2^{\mathrm{a}}$ & ALEMAN & NAVARRA & LESAKA & $18 \times 14$ & 403,5 & 14,0 & 17,8 \\
\hline 271 & L-33-1 & ALEMAN & NAVARRA & LESAKA & $18 \times 14$ & 406,0 & 14,1 & 17,9 \\
\hline 272 & B-14-1 & LARRAÑAGA & GIPUZKOA & ALDAOLA & $18 \times 14$ & 303,5 & 7,0 & 15,1 \\
\hline 273 & $A-11-2^{a}$ & LARRAÑAGA & GIPUZKOA & ATAUN & $15 \times 7$ & 307,3 & 10,1 & 15,0 \\
\hline 274 & A-27-3 $3^{a}$ & LARRAÑAGA & GIPUZKOA & ATAUN & $18 \times 14$ & 306,2 & 7,0 & 14,9 \\
\hline 275 & OTZ-45-1 ${ }^{\mathrm{a}}$ & ERREKONDO & GIPUZKOA & OTZAURTE & $18 \times 14$ & 507,0 & 19,9 & 24,9 \\
\hline 276 & A-19-4" & LARRAÑAGA & GIPUZKOA & ATAUN & $15 \times 7$ & 305,7 & 7,0 & 15,0 \\
\hline 277 & OTZ-6-1 $1^{\underline{a}}$ & ERREKONDO & GIPUZKOA & OTZAURTE & $15 \times 10$ & 518,0 & 20,1 & 25,4 \\
\hline 278 & 37 & LARRAÑAGA & GIPUZKOA & & $15 \times 7$ & 517,0 & 20,0 & 24,9 \\
\hline 279 & L-38-3-R & ALEMAN & NAVARRA & LESAKA & $25 \times 20$ & 407,7 & 13,8 & 18,1 \\
\hline 280 & 5 & LARRAÑAGA & GIPUZKOA & & $15 \times 7$ & 523,0 & 20,0 & 25,0 \\
\hline 281 & L-44-3 & ALEMAN & NAVARRA & LESAKA & $25 \times 20$ & 409,5 & 14,2 & 18,2 \\
\hline 282 & B-14-2 & ALEMAN & NAVARRA & BERA & $25 \times 20$ & 405,0 & 13,8 & 17,8 \\
\hline 283 & B-10-1 & ALEMAN & NAVARRA & BERA & $18 \times 14$ & 410,0 & 14,0 & 17,8 \\
\hline 284 & $A-1-2^{a}$ & LARRAÑAGA & GIPUZKOA & ATAUN & $25 \times 20$ & 304,1 & 7,1 & 15,0 \\
\hline 285 & B-19-4 & LARRAÑAGA & GIPUZKOA & ALDAOLA & $18 \times 14$ & 303,2 & 10,1 & 15,2 \\
\hline 286 & L-12-3 & ALEMAN & NAVARRA & LESAKA & $18 \times 14$ & 404,0 & 13,6 & 17,8 \\
\hline 287 & B-18-2 $2^{a}$ & LARRAÑAGA & GIPUZKOA & ALDAOLA & $18 \times 14$ & 307,6 & 9,8 & 14,8 \\
\hline 288 & B-7-1 ${ }^{a}$ & LARRAÑAGA & GIPUZKOA & ALDAOLA & $15 \times 7$ & 312,5 & 7,0 & 14,8 \\
\hline 289 & OTZ-2-1 $1^{\mathrm{a}}$ & ERREKONDO & GIPUZKOA & OTZAURTE & $15 \times 10$ & 507,0 & 20,3 & 25,1 \\
\hline 290 & B-33-1 & LARRAÑAGA & GIPUZKOA & ALDAOLA & $18 \times 14$ & 308,5 & 10,0 & 15,1 \\
\hline
\end{tabular}




\begin{tabular}{|c|c|c|c|c|c|c|c|c|}
\hline 291 & 38 & LARRAÑAGA & GIPUZKOA & & $15 \times 10$ & 514,0 & 20,0 & 24,9 \\
\hline 292 & $\mathrm{~L}-46-1^{\mathrm{a}}$ & ALEMAN & NAVARRA & LESAKA & $15 \times 7$ & 405,0 & 14,0 & 18,0 \\
\hline 293 & B-2-1 ${ }^{a}$ & LARRAÑAGA & GIPUZKOA & ALDAOLA & $25 \times 20$ & 306,8 & 10,0 & 15,2 \\
\hline 294 & B-22-3 & ALEMAN & NAVARRA & BERA & $15 \times 10$ & 409,0 & 14,1 & 18,2 \\
\hline 295 & OTZ-41-2 & ERREKONDO & GIPUZKOA & OTZAURTE & $25 \times 20$ & 507,5 & 19,9 & 25,1 \\
\hline 296 & $\mathrm{~A}-25-1^{\mathrm{a}}$ & LARRAÑAGA & GIPUZKOA & ATAUN & $18 \times 14$ & 306,6 & 7,0 & 15,0 \\
\hline 297 & 45 & LARRAÑAGA & GIPUZKOA & & $15 \times 10$ & 527,3 & 19,9 & 25,0 \\
\hline 298 & L-36-3ㄹ & ALEMAN & NAVARRA & LESAKA & $18 \times 14$ & 404,2 & 14,2 & 18,5 \\
\hline 299 & OTZ-34-1 & ERREKONDO & GIPUZKOA & OTZAURTE & $25 \times 20$ & 508,0 & 20,0 & 25,2 \\
\hline 300 & $\mathrm{~A}-22-1^{\underline{a}}$ & LARRAÑAGA & GIPUZKOA & ATAUN & $15 \times 7$ & 309,3 & 7,0 & 15,0 \\
\hline 301 & A-44-2 & LARRAÑAGA & GIPUZKOA & ATAUN & $25 \times 20$ & 305,7 & 10,0 & 15,1 \\
\hline 302 & 28 & LARRAÑAGA & GIPUZKOA & & $18 \times 14$ & 511,5 & 19,9 & 24,9 \\
\hline 303 & 35 & LARRAÑAGA & GIPUZKOA & & $25 \times 20$ & 512,0 & 20,0 & 25,0 \\
\hline 304 & $L-7-1^{\underline{a}}$ & ALEMAN & NAVARRA & LESAKA & $15 \times 7$ & 408,0 & 14,0 & 17,8 \\
\hline 305 & B-43-1-R & ALEMAN & NAVARRA & BERA & $15 \times 10$ & 356,5 & 14,0 & 18,3 \\
\hline 306 & B-37-2 & ALEMAN & NAVARRA & BERA & $25 \times 20$ & 403,5 & 14,0 & 17,9 \\
\hline 307 & B-17-1 & ALEMAN & NAVARRA & BERA & $25 \times 20$ & 406,5 & 14,2 & 18,1 \\
\hline 308 & B-28-1-R & ALEMAN & NAVARRA & BERA & $18 \times 14$ & 357,0 & 14,2 & 18,1 \\
\hline 309 & B-26-4 & LARRAÑAGA & GIPUZKOA & ALDAOLA & $18 \times 14$ & 305,6 & 10,1 & 15,2 \\
\hline 310 & 43 & LARRAÑAGA & GIPUZKOA & & $18 \times 14$ & 520,0 & 20,1 & 24,9 \\
\hline 311 & L-40-1 & ALEMAN & NAVARRA & LESAKA & $18 \times 14$ & 408,1 & 14,0 & 17,8 \\
\hline 312 & $L-10-1^{a}$ & ALEMAN & NAVARRA & LESAKA & $18 \times 14$ & 406,0 & 14,0 & 17,8 \\
\hline 313 & 4 & LARRAÑAGA & GIPUZKOA & & $15 \times 10$ & 515,2 & 20,0 & 25,0 \\
\hline 314 & B-1-2-R & ALEMAN & NAVARRA & BERA & $25 \times 20$ & 403,5 & 14,0 & 18,1 \\
\hline 315 & OTZ-45- $2^{\mathrm{a}}$ & ERREKONDO & GIPUZKOA & OTZAURTE & $18 \times 14$ & 506,0 & 20,6 & 25,4 \\
\hline 316 & OTZ-18-1 & ERREKONDO & GIPUZKOA & OTZAURTE & $18 \times 14$ & 520,5 & 20,1 & 25,1 \\
\hline 317 & L-5-2-R & ALEMAN & NAVARRA & LESAKA & $25 \times 20$ & 405,0 & 14,1 & 18,2 \\
\hline 318 & 25 & LARRAÑAGA & GIPUZKOA & & $18 \times 14$ & 510,0 & 19,8 & 25,0 \\
\hline 319 & B-42-2-R & ALEMAN & NAVARRA & BERA & $25 \times 20$ & 403,5 & 14,2 & 18,2 \\
\hline 320 & L-46-2 $2^{\mathrm{a}}$ & ALEMAN & NAVARRA & LESAKA & $25 \times 20$ & 398,0 & 14,1 & 17,8 \\
\hline 321 & B-28-4 & LARRAÑAGA & GIPUZKOA & ALDAOLA & $18 \times 14$ & 296,5 & 10,1 & 15,1 \\
\hline 322 & $A-8-3^{a}$ & LARRAÑAGA & GIPUZKOA & ATAUN & $25 \times 20$ & 295,8 & 10,1 & 15,1 \\
\hline 323 & $\mathrm{~L}-16-1^{\mathrm{a}}$ & ALEMAN & NAVARRA & LESAKA & $18 \times 14$ & 405,9 & 13,5 & 18,0 \\
\hline 324 & B-28-2 & ALEMAN & NAVARRA & BERA & $18 \times 14$ & 403,4 & 14,0 & 18,1 \\
\hline 325 & 10 & LARRAÑAGA & GIPUZKOA & & $15 \times 10$ & 521,5 & 19,8 & 24,9 \\
\hline 326 & L-39-2 ${ }^{a}$ & ALEMAN & NAVARRA & LESAKA & $15 \times 10$ & 403,0 & 14,0 & 18,0 \\
\hline 327 & B-45-4 & LARRAÑAGA & GIPUZKOA & ALDAOLA & $18 \times 14$ & 306,0 & 10,1 & 15,2 \\
\hline 328 & 3 & LARRAÑAGA & GIPUZKOA & & $18 \times 14$ & 515,0 & 20,0 & 24,9 \\
\hline 329 & $\mathrm{~L}-3-2^{\mathrm{a}}$ & ALEMAN & NAVARRA & LESAKA & $25 \times 20$ & 405,5 & 14,0 & 18,0 \\
\hline 330 & B-35-2 & LARRAÑAGA & GIPUZKOA & ALDAOLA & $18 \times 14$ & 303,2 & 10,2 & 15,1 \\
\hline 331 & 11 & LARRAÑAGA & GIPUZKOA & & $15 \times 10$ & 517,0 & 19,9 & 25,2 \\
\hline 332 & L-18-2 & ALEMAN & NAVARRA & LESAKA & $25 \times 20$ & 404,5 & 14,4 & 18,1 \\
\hline 333 & B-2-3 & ALEMAN & NAVARRA & BERA & $18 \times 14$ & 407,4 & 14,0 & 18,3 \\
\hline 334 & 14 & LARRAÑAGA & GIPUZKOA & & $15 \times 10$ & 514,0 & 20,0 & 25,0 \\
\hline 335 & L-43-3 & ALEMAN & NAVARRA & LESAKA & $25 \times 20$ & 400,8 & 13,9 & 17,9 \\
\hline 336 & $A-10-4^{a}$ & LARRAÑAGA & GIPUZKOA & ATAUN & $18 \times 14$ & 303,7 & 10,0 & 15,1 \\
\hline 337 & $\mathrm{~L}-11-3^{\mathrm{a}}$ & ALEMAN & NAVARRA & LESAKA & $18 \times 14$ & 406,7 & 14,0 & 18,0 \\
\hline 338 & L-46-3를 & ALEMAN & NAVARRA & LESAKA & $25 \times 20$ & 410,0 & 14,0 & 18,0 \\
\hline 339 & B-21-2 & ALEMAN & NAVARRA & BERA & $18 \times 14$ & 402,9 & 14,2 & 18,2 \\
\hline 340 & L-23-3르 & ALEMAN & NAVARRA & LESAKA & $15 \times 10$ & 405,0 & 13,9 & 17,8 \\
\hline 341 & B-41-2 & LARRAÑAGA & GIPUZKOA & ALDAOLA & $18 \times 14$ & 304,4 & 10,0 & 15,0 \\
\hline 342 & $B-7-2^{a}$ & LARRAÑAGA & GIPUZKOA & ALDAOLA & $18 \times 14$ & 303,8 & 9,9 & 15,1 \\
\hline 343 & B-7-2-R & ALEMAN & NAVARRA & BERA & $18 \times 14$ & 402,9 & 14,1 & 18,2 \\
\hline 344 & L-24-2 $2^{a}$ & ALEMAN & NAVARRA & LESAKA & $18 \times 14$ & 402,0 & 13,9 & 18,0 \\
\hline 345 & A-34-4 & LARRAÑAGA & GIPUZKOA & ATAUN & $15 \times 10$ & 310,7 & 10,1 & 15,1 \\
\hline 346 & $\mathrm{~A}-19-2^{\mathrm{a}}$ & LARRAÑAGA & GIPUZKOA & ATAUN & $15 \times 10$ & 300,6 & 10,1 & 15,1 \\
\hline 347 & $\mathrm{~L}-6-2^{\mathrm{a}}$ & ALEMAN & NAVARRA & LESAKA & $18 \times 14$ & 404,5 & 14,0 & 17,8 \\
\hline 348 & $B-3^{-a}$ & LARRAÑAGA & GIPUZKOA & ALDAOLA & $18 \times 14$ & 309,2 & 10,1 & 15,2 \\
\hline
\end{tabular}




\begin{tabular}{|c|c|c|c|c|c|c|c|c|}
\hline 349 & $B-4-1^{a}$ & LARRAÑAGA & GIPUZKOA & ALDAOLA & $15 \times 10$ & 306,0 & 10,1 & 15,1 \\
\hline 350 & L-14-3 $3^{a}$ & ALEMAN & NAVARRA & LESAKA & $15 \times 10$ & 398,0 & 14,0 & 18,0 \\
\hline 351 & B-32-3 & ALEMAN & NAVARRA & BERA & $18 \times 14$ & 406,0 & 14,2 & 17,9 \\
\hline 352 & $A-28-3^{a}$ & LARRAÑAGA & GIPUZKOA & ATAUN & $15 \times 10$ & 303,9 & 10,1 & 15,1 \\
\hline 353 & L-41-2 & ALEMAN & NAVARRA & LESAKA & $15 \times 10$ & 407,0 & 14,0 & 17,9 \\
\hline 354 & B-4-1-R & ALEMAN & NAVARRA & BERA & $18 \times 14$ & 358,0 & 14,0 & 18,2 \\
\hline 355 & L-14-2 $2^{\mathrm{a}}$ & ALEMAN & NAVARRA & LESAKA & $18 \times 14$ & 410,5 & 14,0 & 17,9 \\
\hline 356 & B-39-2-R & ALEMAN & NAVARRA & BERA & $15 \times 10$ & 359,3 & 14,1 & 18,1 \\
\hline 357 & 15 & LARRAÑAGA & GIPUZKOA & & $18 \times 14$ & 511,0 & 19,9 & 25,0 \\
\hline 358 & 36 & LARRAÑAGA & GIPUZKOA & & $18 \times 14$ & 514,6 & 19,7 & 24,7 \\
\hline 359 & A-36-1 & LARRAÑAGA & GIPUZKOA & ATAUN & $18 \times 14$ & 309,6 & 10,3 & 15,0 \\
\hline 360 & L-34-3 $3^{a}$ & ALEMAN & NAVARRA & LESAKA & $18 \times 14$ & 405,0 & 14,1 & 17,9 \\
\hline 361 & $A-41-1^{a}$ & LARRAÑAGA & GIPUZKOA & ATAUN & $25 \times 20$ & 302,9 & 6,9 & 14,9 \\
\hline 362 & B-4-3-R & ALEMAN & NAVARRA & BERA & $25 \times 20$ & 407,8 & 14,0 & 18,2 \\
\hline 363 & A-30-3 $3^{a}$ & LARRAÑAGA & GIPUZKOA & ATAUN & $15 \times 10$ & 306,7 & 10,1 & 15,2 \\
\hline 364 & B-8-3 & LARRAÑAGA & GIPUZKOA & ALDAOLA & $18 \times 14$ & 306,5 & 10,2 & 15,2 \\
\hline 365 & 46 & LARRAÑAGA & GIPUZKOA & & $15 \times 7$ & 628,6 & 20,5 & 25,1 \\
\hline 366 & 47 & LARRAÑAGA & GIPUZKOA & & $18 \times 14$ & 610,0 & 20,1 & 25,2 \\
\hline 367 & 48 & LARRAÑAGA & GIPUZKOA & & $15 \times 10$ & 606,0 & 20,2 & 25,1 \\
\hline 368 & 49 & LARRAÑAGA & GIPUZKOA & & $15 \times 10$ & 566,9 & 20,1 & 25,3 \\
\hline 369 & 50 & LARRAÑAGA & GIPUZKOA & & $25 \times 20$ & 612,4 & 20,5 & 25,0 \\
\hline 370 & 51 & LARRAÑAGA & GIPUZKOA & & $25 \times 20$ & 561,8 & 20,5 & 25,3 \\
\hline
\end{tabular}




\begin{tabular}{|c|c|c|c|c|c|c|c|c|}
\hline Probeta & Peso & Volumen & Humedad & Densidad & Freq 1 & Freq 2 & Freq 3 & Freq media \\
\hline 1 & 157,9 & 0,257 & 15,8 & 615,3 & 470,4 & 471,5 & 468,8 & 470,2 \\
\hline 2 & 24,0 & 0,045 & 12,5 & 537,0 & 759,5 & 768,3 & 762,6 & 763,5 \\
\hline 3 & 22,9 & 0,045 & 11,8 & 503,5 & 730,6 & 715,6 & 729,7 & 725,3 \\
\hline 4 & 171,3 & 0,258 & 16,8 & 663,2 & 478,4 & 483,6 & 475,5 & 479,2 \\
\hline 5 & 153,4 & 0,260 & 18,0 & 589,1 & 437,3 & 464,2 & 462,3 & 454,6 \\
\hline 6 & 129,4 & 0,253 & 10,6 & 512,0 & 456,7 & 457,3 & 456,5 & 456,8 \\
\hline 7 & 172,9 & 0,256 & 19,0 & 674,9 & 396 & 366,0 & 406,7 & 389,6 \\
\hline 8 & 160,9 & 0,231 & 20,0 & 696,4 & 460,1 & 462,5 & 465,9 & 462,8 \\
\hline 9 & 151,5 & 0,258 & 16,6 & 587,7 & 428,3 & 428,4 & 428,7 & 428,5 \\
\hline 10 & 143,2 & 0,255 & 19,0 & 561,2 & 441,2 & 445,9 & 444,8 & 444,0 \\
\hline 11 & 174,8 & 0,259 & 19,5 & 674,9 & 458,2 & 461,6 & 466,6 & 462,1 \\
\hline 12 & 157,7 & 0,260 & 17,8 & 605,7 & 486,5 & 480,4 & 487,0 & 484,6 \\
\hline 13 & 152,9 & 0,258 & 17,9 & 591,6 & 392,3 & 401,9 & 402,6 & 398,9 \\
\hline 14 & 154,3 & 0,257 & 15,0 & 601,1 & 393,7 & 401,3 & 398,6 & 397,9 \\
\hline 15 & 162,1 & 0,258 & 18,5 & 628,1 & 461,7 & 463,6 & 464,6 & 463,3 \\
\hline 16 & 132,9 & 0,259 & 18,1 & 512,9 & 438,0 & 437,5 & 436,4 & 437,3 \\
\hline 17 & 173,6 & 0,262 & 18,0 & 663,3 & 463,0 & 464,8 & 467,9 & 465,2 \\
\hline 18 & 150,4 & 0,251 & 15,5 & 599,8 & 491,1 & 489,7 & 494,2 & 491,7 \\
\hline 19 & 66,0 & 0,101 & 17,0 & 652,0 & 545,7 & 541,9 & 544,6 & 544,1 \\
\hline 20 & 172,3 & 0,274 & 16,9 & 629,8 & 478,9 & 480,6 & 483,0 & 480,8 \\
\hline 21 & 141,8 & 0,254 & 16,6 & 558,4 & 446,9 & 453,3 & 447,3 & 449,2 \\
\hline 22 & 180,7 & 0,261 & 15,4 & 691,4 & 408,5 & 415,2 & 417,5 & 413,7 \\
\hline 23 & 163,7 & 0,259 & 19,1 & 633,2 & 413,6 & 411,3 & 414,6 & 413,2 \\
\hline 24 & 154,6 & 0,256 & 17,1 & 604,7 & 471,0 & 462,3 & 461,6 & 465,0 \\
\hline 25 & 153,7 & 0,261 & 17,3 & 589,3 & 493,7 & 495,9 & 492,3 & 494,0 \\
\hline 26 & 148,7 & 0,263 & 18,8 & 566,2 & 461,7 & 442,5 & 444,4 & 449,5 \\
\hline 27 & 148,9 & 0,254 & 18,0 & 585,8 & 462,7 & 464,7 & 464,8 & 464,1 \\
\hline 28 & 155,2 & 0,250 & 19,1 & 619,7 & 401,6 & 408,0 & 402,9 & 404,2 \\
\hline 29 & 58,7 & 0,101 & 17,2 & 582,1 & 557,9 & 528,6 & 531,8 & 539,4 \\
\hline 30 & 153,4 & 0,262 & 17,8 & 584,5 & 455,2 & 455,2 & 456,6 & 455,7 \\
\hline 31 & 159,3 & 0,255 & 19,8 & 625,4 & 406,9 & 411,1 & 410,6 & 409,5 \\
\hline 32 & 176,7 & 0,253 & 16,6 & 698,9 & 467,8 & 469,4 & 469,3 & 468,8 \\
\hline 33 & 60,5 & 0,102 & 20 & 592,1 & 551,6 & 566,9 & 567,1 & 561,9 \\
\hline 34 & 147,7 & 0,259 & 17,6 & 570,2 & 452,9 & 454,9 & 460,5 & 456,1 \\
\hline 35 & 161,4 & 0,260 & 14,3 & 620,1 & 462,7 & 458,5 & 466,5 & 462,6 \\
\hline 36 & 122,2 & 0,265 & 17,1 & 460,3 & 337,8 & 332,0 & 335,1 & 335,0 \\
\hline 37 & 165,7 & 0,257 & 20,0 & 644,2 & 448,9 & 450,4 & 451,3 & 450,2 \\
\hline 38 & 64,8 & 0,100 & 18,0 & 646,7 & 512,9 & 502,2 & 506,2 & 507,1 \\
\hline 39 & 151,3 & 0,260 & 17,1 & 581,2 & 462,1 & 464,7 & 459,8 & 462,2 \\
\hline 40 & 135,5 & 0,254 & 18,4 & 534,2 & 454,5 & 455,6 & 450,4 & 453,5 \\
\hline 41 & 157,4 & 0,249 & 18,1 & 633,2 & 464,9 & 471,3 & 471,9 & 469,4 \\
\hline 42 & 20,9 & 0,045 & 12,0 & 459,5 & 628,9 & 626,3 & 605,8 & 620,3 \\
\hline 43 & 15,4 & 0,030 & 17,0 & 521,5 & 700,0 & 712,0 & 710,0 & 707,3 \\
\hline 44 & 25,0 & 0,044 & 14,1 & 567,0 & 786,7 & 793,3 & 798,9 & 793,0 \\
\hline 45 & 151,2 & 0,257 & 21,8 & 587,3 & 409,6 & 424,0 & 424,1 & 419,2 \\
\hline 46 & 24,7 & 0,045 & 14,5 & 551,8 & 721,7 & 717,4 & 699,6 & 712,9 \\
\hline 47 & 14,6 & 0,031 & 17,0 & 475,9 & 698,8 & 692,9 & 699,8 & 697,2 \\
\hline 48 & 17,7 & 0,031 & 17,0 & 570,3 & 715,3 & 721,0 & 716,5 & 717,6 \\
\hline 49 & 153,2 & 0,263 & 16,9 & 582,4 & 435,9 & 436,8 & 438,0 & 436,9 \\
\hline 50 & 59,4 & 0,101 & 18,0 & 586,7 & 535,7 & 538,9 & 544,6 & 539,7 \\
\hline 51 & 27,0 & 0,045 & 13,1 & 598,7 & 724,6 & 712,2 & 764,7 & 733,8 \\
\hline 52 & 172,5 & 0,258 & 20,7 & 667,9 & 348,1 & 345,3 & 348,4 & 347,3 \\
\hline 53 & 135,1 & 0,263 & 14,9 & 512,7 & 466,9 & 466,4 & 465,3 & 466,2 \\
\hline 54 & 179,5 & 0,254 & 17,9 & 706,1 & 377,0 & 382,3 & 374,5 & 377,9 \\
\hline
\end{tabular}




\begin{tabular}{|c|c|c|c|c|c|c|c|c|}
\hline 55 & 152,2 & 0,258 & 18,1 & 589,2 & 466,7 & 458,4 & 465,0 & 463,4 \\
\hline 56 & 141,3 & 0,256 & 18,3 & 551,6 & 469,2 & 442,1 & 438,7 & 450,0 \\
\hline 57 & 161,3 & 0,259 & 21,0 & 623,6 & 448,8 & 453,3 & 452,4 & 451,5 \\
\hline 58 & 68,8 & 0,108 & 20,0 & 635,6 & 574,7 & 565,6 & 551,1 & 563,8 \\
\hline 59 & & 0,256 & 12,5 & 0,0 & 866,9 & 861,6 & 855,6 & 861,4 \\
\hline 60 & 148,3 & 0,259 & 15,5 & 572,4 & 468,5 & 471,1 & 467,1 & 468,9 \\
\hline 61 & 26,3 & 0,044 & 14,8 & 594,8 & 733,7 & 734,0 & 737,0 & 734,9 \\
\hline 62 & 55,0 & 0,105 & 18,0 & 523,7 & 533,9 & 539,9 & 549,7 & 541,2 \\
\hline 63 & 29,0 & 0,045 & 14,7 & 642,4 & 702,8 & 698,2 & 687,3 & 696,1 \\
\hline 64 & 150,0 & 0,260 & 15,8 & 577,7 & 493,7 & 486,8 & 493,0 & 491,2 \\
\hline 65 & 26,1 & 0,045 & 14,4 & 585,1 & 741,5 & 744,0 & 744,0 & 743,2 \\
\hline 66 & 26,2 & 0,042 & 13,3 & 628,7 & 755,4 & 760,9 & 747,8 & 754,7 \\
\hline 67 & 154,8 & 0,267 & 11,7 & 579,2 & 419,2 & 427,7 & 418,6 & 421,8 \\
\hline 68 & 15,9 & 0,032 & 15,5 & 497,6 & 618,8 & 618,3 & 624,5 & 620,5 \\
\hline 69 & 24,5 & 0,044 & 13,3 & 553,9 & 784,9 & 784,8 & 799,2 & 789,6 \\
\hline 70 & 26,4 & 0,044 & 15,3 & 596,0 & 725,1 & 725,6 & 749,9 & 733,5 \\
\hline 71 & 20,0 & 0,045 & 13,9 & 443,1 & 669,0 & 674,5 & 672,7 & 672,1 \\
\hline 72 & 24,4 & 0,046 & 12,8 & 536,1 & 803,1 & 801,0 & 799,1 & 801,1 \\
\hline 73 & 150,2 & 0,260 & 16,2 & 578,6 & 498,1 & 490,6 & 494,3 & 494,3 \\
\hline 74 & 150,0 & 0,265 & 16,7 & 566,8 & 445,1 & 453,6 & 438,6 & 445,8 \\
\hline 75 & 59,8 & 0,100 & 16,8 & 595,4 & 543,3 & 542,5 & 542,2 & 542,7 \\
\hline 76 & 23,1 & 0,044 & 12,8 & 520,1 & 733,5 & 719,1 & 711,7 & 721,4 \\
\hline 77 & 23,6 & 0,045 & 14,8 & 528,6 & 753,4 & 750,0 & 752,2 & 751,9 \\
\hline 78 & 25,5 & 0,045 & 14,8 & 567,0 & 717,2 & 719,5 & 717,6 & 718,1 \\
\hline 79 & 27,6 & 0,044 & 15,2 & 628,3 & 744,3 & 755,7 & 747,4 & 749,1 \\
\hline 80 & 25,9 & 0,046 & 15,1 & 560,9 & 758,0 & 758,5 & 762,4 & 759,6 \\
\hline 81 & 75,2 & 0,105 & 22,0 & 716,7 & 549,5 & 536,3 & 545,5 & 543,8 \\
\hline 82 & 26,1 & 0,046 & 14,8 & 573,5 & 694,3 & 708,4 & 695,1 & 699,3 \\
\hline 83 & 16,5 & 0,032 & 18,3 & 518,3 & 664,1 & 663,6 & 666,4 & 664,7 \\
\hline 84 & 15,3 & 0,032 & 15,8 & 484,7 & 708,8 & 712,7 & 715,5 & 712,3 \\
\hline 85 & 24,6 & 0,044 & 15,1 & 556,5 & 622,4 & 637,2 & 685,3 & 648,3 \\
\hline 86 & 19,5 & 0,032 & 14,8 & 616,2 & 678,5 & 701,9 & 702,8 & 694,4 \\
\hline 87 & 24,7 & 0,044 & 12,8 & 557,6 & 759,1 & 755,1 & 735,4 & 749,9 \\
\hline 88 & 25,0 & 0,044 & 13,9 & 568,4 & 747,2 & 746,4 & 734,1 & 742,6 \\
\hline 89 & 27,4 & 0,046 & 14,8 & 601,7 & 715,6 & 714,9 & 706,5 & 712,3 \\
\hline 90 & 176,2 & 0,248 & 22,0 & 711,2 & 469,9 & 471,0 & 470,0 & 470,3 \\
\hline 91 & 26,1 & 0,045 & 11,9 & 576,2 & 708,3 & 710,9 & 700,6 & 706,6 \\
\hline 92 & 61,3 & 0,102 & 15,5 & 600,5 & 448,9 & 448,1 & 458,5 & 451,8 \\
\hline 93 & 27,6 & 0,045 & 9,5 & 609,6 & 678,7 & 678,4 & 682,1 & 679,7 \\
\hline 94 & 22,0 & 0,046 & 10,0 & 482,8 & 662,8 & 685,9 & 668,3 & 672,3 \\
\hline 95 & 25,0 & 0,046 & 13,5 & 545,7 & 762,2 & 768,8 & 757,9 & 763,0 \\
\hline 96 & 24,0 & 0,045 & 13,7 & 534,0 & 750,0 & 740,1 & 750,3 & 746,8 \\
\hline 97 & 24,1 & 0,044 & 16,1 & 546,8 & 700,2 & 706,6 & 708,0 & 704,9 \\
\hline 98 & 29,8 & 0,045 & 13,6 & 661,5 & 710,5 & 712,9 & 727,2 & 716,9 \\
\hline 99 & 69,5 & 0,100 & 21,0 & 692,1 & 481,8 & 494,8 & 480,1 & 485,6 \\
\hline 100 & 17,0 & 0,032 & 18,8 & 530,7 & 719,9 & 718,1 & 712,2 & 716,7 \\
\hline 101 & 16,5 & 0,032 & 18,4 & 513,5 & 663,8 & 667,8 & 660,5 & 664,0 \\
\hline 102 & 22,7 & 0,045 & 12,2 & 503,4 & 737,0 & 736,9 & 736,6 & 736,8 \\
\hline 103 & 14,7 & 0,033 & 13,5 & 444,9 & 733,6 & 722,8 & 710,9 & 722,4 \\
\hline 104 & 22,0 & 0,045 & 14,0 & 483,6 & 736,3 & 732,7 & 739,5 & 736,2 \\
\hline 105 & 25,8 & 0,045 & 13,3 & 574,6 & 745,3 & 733,6 & 745,2 & 741,4 \\
\hline 106 & 163,3 & 0,260 & 20,0 & 627,9 & 459,7 & 479,0 & 441,3 & 460,0 \\
\hline 107 & 24,4 & 0,044 & 13,7 & 553,4 & 800,8 & 751,1 & 748,2 & 766,7 \\
\hline 108 & 161,9 & 0,258 & 15,1 & 626,8 & 454,3 & 468,1 & 475,1 & 465,8 \\
\hline 109 & 27,2 & 0,045 & 14,6 & 610,1 & 816,6 & 811,7 & 794,2 & 807,5 \\
\hline 110 & 26,7 & 0,045 & 15,8 & 597,7 & 798,4 & 790,0 & 792,4 & 793,6 \\
\hline 111 & 19,7 & 0,033 & 15,1 & 605,9 & 674,0 & 682,0 & 670,5 & 675,5 \\
\hline 112 & 17,6 & 0,031 & 15,1 & 564,2 & 703,9 & 706,4 & 704,1 & 704,8 \\
\hline
\end{tabular}




\begin{tabular}{|c|c|c|c|c|c|c|c|c|}
\hline 113 & 17,2 & 0,032 & 14,1 & 532,7 & 747,0 & 750,4 & 744,6 & 747,3 \\
\hline 114 & 17,2 & 0,033 & 11,9 & 525,0 & 704,2 & 713,3 & 714,5 & 710,7 \\
\hline 115 & 27,9 & 0,045 & 15,7 & 617,9 & 676,1 & 701,3 & 669,9 & 682,4 \\
\hline 116 & 18,2 & 0,031 & 14,8 & 578,1 & 712,2 & 714,2 & 720,2 & 715,5 \\
\hline 117 & 15,6 & 0,032 & 10,8 & 488,9 & 661,0 & 662,9 & 670,8 & 664,9 \\
\hline 118 & 24,5 & 0,045 & 13,1 & 548,5 & 705,6 & 691,7 & 701,3 & 699,5 \\
\hline 119 & 25,7 & 0,046 & 12,1 & 560,8 & 711,3 & 716,5 & 708,3 & 712,0 \\
\hline 120 & 25,5 & 0,044 & 12,3 & 573,1 & 748,2 & 736,6 & 744,9 & 743,2 \\
\hline 121 & 29,9 & 0,046 & 12,8 & 645,2 & 653,0 & 685,1 & 676,6 & 671,6 \\
\hline 122 & 18,5 & 0,032 & 12,7 & 581,5 & 694,9 & 695,1 & 693,6 & 694,5 \\
\hline 123 & 18,5 & 0,033 & 14,1 & 563,8 & 691,1 & 710,2 & 693,1 & 698,1 \\
\hline 124 & 18,9 & 0,032 & 15,0 & 590,6 & 750,6 & 754,9 & 744,4 & 750,0 \\
\hline 125 & 19,8 & 0,032 & 13,4 & 618,3 & 674,7 & 669,7 & 661,2 & 668,5 \\
\hline 126 & 26,3 & 0,046 & 14,1 & 569,2 & 752,4 & 752,2 & 763,2 & 755,9 \\
\hline 127 & 17,6 & 0,031 & 16,7 & 564,1 & 744,6 & 763,1 & 756,6 & 754,8 \\
\hline 128 & 19,9 & 0,032 & 17,8 & 631,1 & 676,5 & 667,3 & 657,1 & 667,0 \\
\hline 129 & 17,3 & 0,032 & 17,5 & 542,0 & 671,5 & & 670,9 & 447,5 \\
\hline 130 & 23,1 & 0,046 & 12,8 & 501,6 & 751,6 & 753,5 & 752,8 & 752,6 \\
\hline 131 & 20,4 & 0,032 & 18,5 & 634,7 & 704,4 & 700,0 & 696,7 & 700,4 \\
\hline 132 & 19,5 & 0,032 & 17,5 & 606,5 & 672,6 & 678,6 & 673,1 & 674,8 \\
\hline 133 & 18,4 & 0,032 & 16,8 & 566,5 & 717,3 & 720,4 & 714,6 & 717,4 \\
\hline 134 & 150,9 & 0,257 & 14,9 & 588,0 & 482,5 & 468,7 & 503,9 & 485,0 \\
\hline 135 & 20,6 & 0,033 & 18,1 & 620,6 & 691,2 & 693,0 & 690,4 & 691,5 \\
\hline 136 & 20,9 & 0,033 & 16,6 & 630,7 & 716,8 & 719,7 & 717,9 & 718,1 \\
\hline 137 & 18,6 & 0,032 & 15,1 & 575,6 & 722,6 & 707,2 & 700,1 & 710,0 \\
\hline 138 & 62,8 & 0,104 & 18,3 & 601,0 & 487 & 500,9 & 481,6 & 489,8 \\
\hline 139 & 122,0 & 0,261 & 15,1 & 467,0 & 496,5 & 493,9 & 485,4 & 491,9 \\
\hline 140 & 30,1 & 0,046 & 14,8 & 658,1 & 628,6 & 621,7 & 615,8 & 622,0 \\
\hline 141 & 24,0 & 0,046 & 13,1 & 525,7 & 743,7 & 713,9 & 709,3 & 722,3 \\
\hline 142 & 64,2 & 0,103 & 16,0 & 623,7 & 542,1 & 559,4 & 540,6 & 547,4 \\
\hline 143 & 17,3 & 0,030 & 15,8 & 585,9 & 744,9 & 745,2 & 733,0 & 741,0 \\
\hline 144 & 14,3 & 0,031 & 11,9 & 459,9 & 741,8 & 746,9 & 758,1 & 748,9 \\
\hline 145 & 128,9 & 0,260 & 17,8 & 495,3 & 445,3 & 446,7 & 454,1 & 448,7 \\
\hline 146 & 21,2 & 0,032 & 17,1 & 653,8 & 672,2 & 680,1 & 673,5 & 675,3 \\
\hline 147 & 21,3 & 0,032 & 16,7 & 666,4 & 626,7 & 630,1 & 656,7 & 637,8 \\
\hline 148 & 19,2 & 0,033 & 16,6 & 585,6 & 775,3 & 780,8 & 7777,9 & 778,0 \\
\hline 149 & 55,4 & 0,100 & 15,6 & 556,4 & 576 & 581,3 & 580,3 & 579,2 \\
\hline 150 & 16,5 & 0,032 & 15,4 & 517,8 & 755,8 & 780,3 & 762,6 & 766,2 \\
\hline 151 & 15,9 & 0,031 & 15,8 & 520,9 & 677,0 & 678,4 & 683,1 & 679,5 \\
\hline 152 & 25,2 & 0,045 & 15,1 & 563,9 & 719,3 & 716,9 & 714,2 & 716,8 \\
\hline 153 & 26,0 & 0,046 & 15,4 & 570,7 & 740,3 & 720,3 & 735,3 & 732,0 \\
\hline 154 & 18,4 & 0,032 & 15,3 & 581,8 & 751,2 & 761,2 & 759,2 & 757,2 \\
\hline 155 & 19,7 & 0,032 & 15,2 & 611,1 & 745,5 & 746,1 & 742,5 & 744,7 \\
\hline 156 & 18,1 & 0,031 & 17,8 & 584,9 & 694,3 & 692,6 & 696,7 & 694,5 \\
\hline 157 & 17,3 & 0,031 & 13,8 & 549,9 & 656,6 & 660,4 & 652,3 & 656,4 \\
\hline 158 & 16,4 & 0,032 & 17,9 & 514,5 & 716,9 & 715,6 & 716,5 & 716,3 \\
\hline 159 & 17,0 & 0,032 & 14,2 & 532,0 & 739,1 & 744,3 & 745,2 & 742,9 \\
\hline 160 & 18,0 & 0,033 & 13,1 & 549,2 & 652,7 & 659,4 & 655,0 & 655,7 \\
\hline 161 & 18,2 & 0,032 & 15,1 & 568,7 & 705,5 & 706,1 & 704,9 & 705,5 \\
\hline 162 & 61,1 & 0,103 & 17,0 & 593,5 & 536,3 & 534,8 & 531,8 & 534,3 \\
\hline 163 & 20,1 & 0,033 & 18,3 & 614,7 & 636,6 & 643,4 & 629,2 & 636,4 \\
\hline 164 & 55,3 & 0,102 & 17,0 & 541,9 & 579,4 & 570,1 & 594,7 & 581,4 \\
\hline 165 & 23,1 & 0,042 & 12,3 & 547,1 & 741,8 & 754,5 & 792,2 & 762,8 \\
\hline 166 & 63,5 & 0,101 & 18 & 631,7 & 580,7 & 576,4 & 582,5 & 579,9 \\
\hline 167 & 17,5 & 0,033 & 14,1 & 533,4 & 735,2 & 727,4 & 730,2 & 730,9 \\
\hline 168 & 61,8 & 0,102 & 15,8 & 607,9 & 539,4 & 541,7 & 541,7 & 540,9 \\
\hline 169 & 19,2 & 0,032 & 15,4 & 596,2 & 653,1 & 635,0 & 658,1 & 648,7 \\
\hline 170 & 24,6 & 0,045 & 13,3 & 550,1 & 752,1 & 743,3 & 719,6 & 738,3 \\
\hline
\end{tabular}




\begin{tabular}{|c|c|c|c|c|c|c|c|c|}
\hline 171 & 135,3 & 0,258 & 18,4 & 525,1 & 460 & 457,9 & 479,3 & 465,7 \\
\hline 172 & 17,5 & 0,031 & 18,3 & 557,7 & 789,3 & 792,0 & 791,9 & 791,1 \\
\hline 173 & 66,1 & 0,103 & 17,5 & 640,8 & 579,1 & 579,2 & 575 & 577,8 \\
\hline 174 & 18,1 & 0,032 & 13,3 & 569,5 & 680,6 & 685,7 & 697,8 & 688,0 \\
\hline 175 & 137,7 & 0,251 & 17,5 & 549,3 & 434,5 & 433,9 & 433,9 & 434,1 \\
\hline 176 & 16,0 & 0,031 & 13,9 & 510,8 & 686,9 & 676,4 & 652,2 & 671,8 \\
\hline 177 & 17,6 & 0,029 & 16,1 & 614,5 & 762,7 & 765,7 & 768,3 & 765,6 \\
\hline 178 & 26,3 & 0,045 & 13,8 & 587,6 & 714,3 & 718,9 & 716,1 & 716,4 \\
\hline 179 & 26,4 & 0,046 & 13,9 & 569,1 & 666,9 & 689,8 & 690,1 & 682,3 \\
\hline 180 & 17,5 & 0,033 & 16,9 & 536,1 & 666,4 & 668,5 & 670,4 & 668,4 \\
\hline 181 & 22,4 & 0,044 & 14,1 & 512,6 & 759,9 & 752,9 & 758,5 & 757,1 \\
\hline 182 & 24,3 & 0,042 & 15,5 & 577,0 & 759,6 & 749,1 & 762,5 & 757,1 \\
\hline 183 & 17,5 & 0,032 & 15,5 & 548,8 & & & & 0,0 \\
\hline 184 & 157,3 & 0,269 & 14,5 & 585,1 & 456,8 & 473,9 & 469,2 & 466,6 \\
\hline 185 & 23,0 & 0,044 & 13,8 & 527,7 & 757,2 & 761,0 & 745,1 & 754,4 \\
\hline 186 & 28,1 & 0,046 & 13,5 & 616,6 & 693,1 & 688,7 & 651,0 & 677,6 \\
\hline 187 & 16,5 & 0,032 & 13,6 & 514,3 & 674,0 & 676,0 & 673,6 & 674,5 \\
\hline 188 & 18,1 & 0,032 & 15,5 & 565,3 & 710,5 & 709,1 & 709,9 & 709,8 \\
\hline 189 & 158,2 & 0,257 & 20,0 & 616,8 & $\begin{array}{l}414,6 \\
\end{array}$ & 415,2 & 423,7 & 417,8 \\
\hline 190 & 60,7 & 0,102 & 19,0 & 593,9 & 563,5 & 570,9 & 567,5 & 567,3 \\
\hline 191 & 30,8 & 0,046 & 14,7 & 663,4 & 792,7 & 772,8 & 765,5 & 777,0 \\
\hline 192 & 18,0 & 0,031 & 16,6 & 572,6 & 672,1 & 668,9 & 666,5 & 669,2 \\
\hline 193 & 18,2 & 0,032 & 13,1 & 560,5 & 711,2 & 714,9 & 713,8 & 713,3 \\
\hline 194 & 18,1 & 0,031 & 15,0 & 589,8 & 806,8 & 798,5 & 802,4 & 802,6 \\
\hline 195 & 59,3 & 0,099 & 15,9 & 597,1 & 543,3 & 555,9 & 572,5 & 557,2 \\
\hline 196 & & 0,033 & 13,4 & 0,0 & 712,0 & 716,5 & 713,5 & 714,0 \\
\hline 197 & 16,7 & 0,031 & 17,9 & 539,6 & 711,1 & 707,9 & 713,1 & 710,7 \\
\hline 198 & 17,8 & 0,032 & 16,6 & 562,3 & 680,1 & 664,2 & 656,8 & 667,0 \\
\hline 199 & 19,5 & 0,033 & 16,7 & 599,5 & 661,8 & 656,2 & 677,0 & 665,0 \\
\hline 200 & 20,2 & 0,033 & 17,6 & 617,2 & 745,9 & 747,6 & 750,5 & 748,0 \\
\hline 201 & 138,6 & 0,259 & 15,8 & 535,9 & 461 & 455,5 & 451,5 & 456,0 \\
\hline 202 & 64,8 & 0,103 & 20,0 & 628,3 & 548,8 & 554,6 & 559,2 & 554,2 \\
\hline 203 & 19,8 & 0,031 & 17,3 & 637,9 & 714,0 & 721,0 & 715,3 & 716,8 \\
\hline 204 & 60,4 & 0,104 & 18,0 & 581,4 & 496,2 & 490,2 & 497,2 & 494,5 \\
\hline 205 & 25,4 & 0,046 & 12,1 & 552,0 & 743,6 & 741,7 & 747,7 & 744,3 \\
\hline 206 & 19,5 & 0,032 & 19,7 & 618,3 & 623,5 & 622,1 & 621,2 & 622,3 \\
\hline 207 & 18,9 & 0,033 & 12,2 & 575,3 & 760,6 & 769,2 & 786,5 & 772,1 \\
\hline 208 & 19,3 & 0,033 & 17,2 & 588,7 & 751,6 & 752,5 & 751,7 & 751,9 \\
\hline 209 & 168,8 & 0,259 & 18,6 & 651,0 & 435,8 & 424,7 & 438,3 & 432,9 \\
\hline 210 & 16,9 & 0,031 & 16,7 & 549,1 & 721,8 & 715,0 & 706,1 & 714,3 \\
\hline 211 & 16,8 & 0,031 & 15,7 & 536,3 & 756,6 & 762,4 & 770,9 & 763,3 \\
\hline 212 & 64,0 & 0,103 & 18,0 & 620,9 & 539,1 & 542,3 & 538,4 & 539,9 \\
\hline 213 & 19,4 & 0,033 & 16,1 & 595,2 & 701,0 & 704,5 & 695,5 & 700,3 \\
\hline 214 & 191,5 & 0,262 & 20,0 & 730,2 & 371,1 & 373,2 & 369,4 & 371,2 \\
\hline 215 & 16,5 & 0,032 & 17,7 & 521,2 & 778,1 & 769,5 & 761,1 & 769,6 \\
\hline 216 & 26,8 & 0,044 & 14,6 & 614,6 & 671,7 & 682,4 & 664,2 & 672,8 \\
\hline 217 & 58,7 & 0,101 & 15,5 & 583,5 & 568,7 & 575,1 & 581,5 & 575,1 \\
\hline 218 & 65,5 & 0,105 & 17,0 & 624,6 & 529,8 & 543,4 & 550,1 & 541,1 \\
\hline 219 & 25,3 & 0,045 & 15,8 & 559,0 & 700,4 & 702,6 & 702,0 & 701,7 \\
\hline 220 & 20,0 & 0,032 & 16,7 & 634,2 & 669,0 & 675,3 & 670,8 & 671,7 \\
\hline 221 & 56,0 & 0,103 & 17,0 & 544,3 & 539,1 & 520,7 & 517,4 & 525,7 \\
\hline 222 & 21,1 & 0,032 & 14,7 & 662,6 & 691,3 & 684,9 & 695,3 & 690,5 \\
\hline 223 & 70,1 & 0,103 & 15,2 & 678,8 & 527,4 & 527,2 & 520,7 & 525,1 \\
\hline 224 & 24,1 & 0,046 & 14,2 & 524,7 & 668,4 & 683,3 & 684,2 & 678,6 \\
\hline 225 & 67,1 & 0,100 & 15,9 & 673,4 & 540,6 & 534,7 & 541,0 & 538,8 \\
\hline 226 & 62,8 & 0,102 & 16,9 & 612,8 & 538,7 & 540,0 & 535,8 & 538,2 \\
\hline 227 & 15,4 & 0,032 & 17,0 & 477,9 & 588,7 & 607,7 & 619,7 & 605,4 \\
\hline 228 & 21,9 & 0,047 & 16,4 & 469,6 & 655,3 & 649,8 & 665,0 & 656,7 \\
\hline
\end{tabular}




\begin{tabular}{|c|c|c|c|c|c|c|c|c|}
\hline 229 & 27,5 & 0,045 & 14,8 & 611,5 & 658,8 & 666,5 & 659,7 & 661,7 \\
\hline 230 & 65,4 & 0,100 & 20,0 & 654,9 & 539,8 & 545,5 & 588,5 & 557,9 \\
\hline 231 & 25,2 & 0,047 & 15,1 & 538,6 & 738,5 & 738,1 & 754,0 & 743,5 \\
\hline 232 & 24,4 & 0,046 & 13,5 & 525,5 & 673,6 & 671,7 & 673,8 & 673,0 \\
\hline 233 & 137,0 & 0,259 & 16,7 & 529,4 & 457,5 & 458,6 & 459,3 & 458,5 \\
\hline 234 & 26,0 & 0,044 & 14,7 & 590,8 & 798,4 & 788,5 & 788,8 & 791,9 \\
\hline 235 & 61,3 & 0,100 & 21,0 & 613,3 & 494,3 & 509,2 & 504,6 & 502,7 \\
\hline 236 & 157,9 & 0,257 & 16,3 & 613,4 & 480,9 & 482,5 & 498,1 & 487,2 \\
\hline 237 & 62,4 & 0,101 & 18,0 & 620,8 & 500,1 & 495,2 & 505,4 & 500,2 \\
\hline 238 & 20,7 & 0,033 & 15,1 & 633,0 & 698,9 & 704,4 & 703,0 & 702,1 \\
\hline 239 & 16,6 & 0,033 & 12,5 & 510,7 & 654,1 & 679,5 & 670,7 & 668,1 \\
\hline 240 & 17,5 & 0,032 & 12,1 & 542,1 & 757,9 & 749,4 & 738,1 & 748,5 \\
\hline 241 & 29,7 & 0,045 & 12,8 & 654,9 & 668,8 & 664,4 & 663,7 & 665,6 \\
\hline 242 & 23,5 & 0,046 & 13,9 & 514,3 & 713,6 & 711,3 & 713,7 & 712,9 \\
\hline 243 & 179,1 & 0,258 & 20,0 & 693,6 & 385,5 & 359,8 & 372,4 & 372,6 \\
\hline 244 & 64,7 & 0,101 & 21,0 & 638,9 & 591,5 & 571,6 & 567,0 & 576,7 \\
\hline 245 & 63,4 & 0,104 & 17,3 & 607,1 & 554,3 & 583,5 & 554,5 & 564,1 \\
\hline 246 & 18,1 & 0,033 & 17,1 & 551,3 & 754,3 & 757,7 & 758,8 & 756,9 \\
\hline 247 & 23,4 & 0,046 & 12,6 & 509,5 & 631,9 & 624,2 & 629,9 & 628,7 \\
\hline 248 & 65,1 & 0,101 & 19,1 & 646,1 & 552,8 & 534,4 & 543,4 & 543,5 \\
\hline 249 & 67,4 & 0,104 & & 649,7 & 539,8 & 542,5 & 535,5 & 539,3 \\
\hline 250 & 178,2 & 0,251 & 18,0 & 708,6 & 410,8 & 413,8 & 404,9 & 409,8 \\
\hline 251 & 65,0 & 0,104 & 18,4 & 623,7 & 474,3 & 467,7 & 460,7 & 467,6 \\
\hline 252 & 65,4 & 0,102 & 20,0 & 641,2 & 566,0 & 549,9 & 548,4 & 554,8 \\
\hline 253 & 19,4 & 0,033 & 18,4 & 580,9 & 794,7 & 797,6 & 808,9 & 800,4 \\
\hline 254 & 67,7 & 0,100 & 17,2 & 677,3 & 535,4 & 538,2 & 534,8 & 536,1 \\
\hline 255 & 65,0 & 0,103 & 21,0 & 629,6 & 544,0 & 538,2 & 546,4 & 542,9 \\
\hline 256 & 63,0 & 0,099 & 18,7 & 634,5 & 552,0 & 567,8 & 563,7 & 561,2 \\
\hline 257 & 74,0 & 0,102 & 16,3 & 724,8 & 568,2 & 569,6 & 564,7 & 567,5 \\
\hline 258 & 18,9 & 0,032 & 17,7 & 599,9 & 669,5 & 665,0 & 669,0 & 667,8 \\
\hline 259 & 25,5 & 0,046 & 13,1 & 554,3 & 768,4 & 749,0 & 761,5 & 759,6 \\
\hline 260 & 170,1 & 0,255 & 20,0 & 667,1 & 452,4 & 463,7 & 463,3 & 459,8 \\
\hline 261 & 19,1 & 0,031 & 17,6 & 608,0 & 655,7 & 658,2 & 656,6 & 656,8 \\
\hline 262 & 19,2 & 0,032 & 18,4 & 597,3 & 764,8 & 749,6 & 742,1 & 752,2 \\
\hline 263 & 164,4 & 0,259 & 23,0 & 635,9 & 414,6 & 417,4 & 416,7 & 416,2 \\
\hline 264 & 64,2 & 0,104 & 19,1 & 618,3 & 553,4 & 555,4 & 577,0 & 561,9 \\
\hline 265 & 21,1 & 0,033 & 19,1 & 642,5 & 740,8 & 737,7 & 733,2 & 737,2 \\
\hline 266 & 69,9 & 0,104 & 16,9 & 675,2 & 574,5 & 572,5 & 579,2 & 575,4 \\
\hline 267 & 67,7 & 0,101 & 15,9 & 668,0 & 500,3 & 500,6 & 503,5 & 501,5 \\
\hline 268 & 63,2 & 0,100 & & 632,0 & 503,3 & 516,2 & 518,1 & 512,5 \\
\hline 269 & 18,1 & 0,032 & 14,7 & 557,7 & 743,0 & 730,0 & 718,8 & 730,6 \\
\hline 270 & 58,5 & 0,101 & 18,9 & 581,8 & 522,5 & 502,6 & 503,7 & 509,6 \\
\hline 271 & 64,9 & 0,102 & 19,0 & 633,4 & 519,3 & 536,0 & 501,0 & 518,8 \\
\hline 272 & 18,5 & 0,032 & 14,0 & 576,7 & 673,8 & 677,4 & 670,5 & 673,9 \\
\hline 273 & 27,5 & 0,047 & 12,8 & 590,7 & 723,5 & 704,7 & 717,9 & 715,4 \\
\hline 274 & 17,7 & 0,032 & 17,9 & 554,2 & 733,0 & 742,9 & 733,4 & 736,4 \\
\hline 275 & 129,1 & 0,251 & 16,6 & 513,9 & 397,0 & 395,5 & 398,5 & 397,0 \\
\hline 276 & 19,6 & 0,032 & 18,0 & 610,6 & 652,3 & 650,8 & 665,7 & 656,3 \\
\hline 277 & 177,2 & 0,264 & 17,0 & 670,0 & 421,5 & 424,0 & 420,8 & 422,1 \\
\hline 278 & 152,3 & 0,257 & 19,1 & 591,5 & 411,1 & 413,2 & 415,3 & 413,2 \\
\hline 279 & 56,0 & 0,102 & 16,1 & 549,9 & 522,7 & 530,8 & 526,5 & 526,7 \\
\hline 280 & 153,2 & 0,262 & 19,8 & 585,9 & 461,5 & 467,5 & 470,2 & 466,4 \\
\hline 281 & 64,1 & 0,106 & 17,8 & 605,7 & 501,3 & 496,5 & 496,3 & 498,0 \\
\hline 282 & 59,3 & 0,099 & 16,0 & 596,1 & 549,4 & 542,5 & 552,8 & 548,2 \\
\hline 283 & 70,1 & 0,102 & 17,2 & 686,1 & 532,5 & 528,5 & 538,5 & 533,2 \\
\hline 284 & 17,6 & 0,032 & 12,6 & 543,4 & 690,5 & 674,5 & 679,6 & 681,5 \\
\hline 285 & 26,4 & 0,047 & 18,0 & 567,2 & 674,7 & 678,8 & 680,7 & 678,1 \\
\hline 286 & 59,0 & 0,098 & & 603,3 & 549,5 & 550,3 & 550,7 & 550,2 \\
\hline
\end{tabular}




\begin{tabular}{|c|c|c|c|c|c|c|c|c|}
\hline 287 & 24,1 & 0,045 & 12,7 & 540,2 & 709,3 & 710,2 & 710,7 & 710,1 \\
\hline 288 & 21,6 & 0,032 & 19,2 & 667,2 & 682,6 & 685,6 & 680,9 & 683,0 \\
\hline 289 & 154,5 & 0,258 & 15,2 & 598,1 & 494,4 & 495,1 & 495,0 & 494,8 \\
\hline 290 & 25,6 & 0,047 & 16,6 & 549,6 & 703,4 & 709,3 & 703,2 & 705,3 \\
\hline 291 & 151,6 & 0,256 & 18,0 & 592,3 & 411,3 & 418,7 & 418,0 & 416,0 \\
\hline 292 & 61,2 & 0,102 & 18,0 & 599,6 & 495,1 & 502,3 & 499,6 & 499,0 \\
\hline 293 & 27,5 & 0,047 & 14,9 & 589,7 & 622,0 & 623,0 & 623,2 & 622,7 \\
\hline 294 & 64,9 & 0,105 & 21,0 & 618,3 & 544,1 & 542,8 & 539,6 & 542,2 \\
\hline 295 & 146,3 & 0,253 & 17,3 & 577,1 & 454,2 & 450,2 & 455,1 & 453,2 \\
\hline 296 & 18,8 & 0,032 & 16,0 & 584,0 & 635,9 & 632,2 & 628,1 & 632,1 \\
\hline 297 & 141,8 & 0,262 & 16,8 & 540,5 & 438,6 & 438,3 & 438,4 & 438,4 \\
\hline 298 & 74,0 & 0,106 & 20,1 & 696,9 & 500,4 & 502,4 & 502,0 & 501,6 \\
\hline 299 & 143,5 & 0,256 & & 560,5 & 447,5 & 449,0 & 453,5 & 450,0 \\
\hline 300 & 17,5 & 0,032 & 14,1 & 538,9 & 630,9 & 621,6 & 620,8 & 624,4 \\
\hline 301 & 28,4 & 0,046 & 16,1 & 615,2 & 710,0 & 746,4 & 725,9 & 727,4 \\
\hline 302 & 149,7 & 0,253 & 19,0 & 590,6 & 435,0 & 432,2 & 434,2 & 433,8 \\
\hline 303 & 148,5 & 0,256 & 18,0 & 580,1 & 419,0 & 417,8 & 419,2 & 418,7 \\
\hline 304 & 60,7 & 0,102 & 20,0 & 597,0 & 486,1 & 480,6 & 482,7 & 483,1 \\
\hline 305 & 56,2 & 0,091 & 17,0 & 615,3 & 610,2 & 608,7 & 616,0 & 611,6 \\
\hline 306 & 68,6 & 0,101 & 24,0 & 678,4 & 529,0 & 529,3 & 530,5 & 529,6 \\
\hline 307 & 72,5 & 0,104 & 25,0 & 693,9 & 522,9 & 525,5 & 522,4 & 523,6 \\
\hline 308 & 61,5 & 0,092 & 21,0 & 670,3 & 573,4 & 573,4 & 567,2 & 571,3 \\
\hline 309 & 25,9 & 0,047 & 15,8 & 552,1 & 668,8 & 690,1 & 687,0 & 682,0 \\
\hline 310 & 157,7 & 0,260 & 17,0 & 605,9 & 482,9 & 464,6 & 473,2 & 473,6 \\
\hline 311 & 63,4 & 0,102 & 18,1 & 623,4 & 479,9 & 491,2 & 480,9 & 484,0 \\
\hline 312 & 65,2 & 0,101 & 20,0 & 644,4 & 522,1 & 523,4 & 525,0 & 523,5 \\
\hline 313 & 165,0 & 0,258 & 18,7 & 640,5 & 452,1 & 456,0 & 453,8 & 454,0 \\
\hline 314 & 62,5 & 0,102 & 20,0 & 611,3 & 546,5 & 545,7 & 546,0 & 546,1 \\
\hline 315 & 144,6 & 0,265 & 14,4 & 546,2 & 385,4 & 390,6 & 388,5 & 388,2 \\
\hline 316 & & 0,263 & 18,2 & 0,0 & 450,5 & 430,2 & 411,5 & 430,7 \\
\hline 317 & 71,0 & 0,104 & 15,8 & 683,1 & 545,2 & 541,1 & 539,7 & 542,0 \\
\hline 318 & 168,6 & 0,252 & 16,5 & 667,9 & 446,6 & 442,5 & 449,0 & 446,0 \\
\hline 319 & 60,8 & 0,104 & 20,0 & 583,0 & 555,1 & 560,8 & 552,6 & 556,2 \\
\hline 320 & 61,0 & 0,100 & 20,0 & 610,7 & 489,7 & 539,2 & 542,4 & 523,8 \\
\hline 321 & 25,0 & 0,045 & 14,8 & 552,9 & 724,3 & 721,5 & 715,9 & 720,6 \\
\hline 322 & 27,9 & 0,045 & 15,1 & 618,5 & 663,1 & 652,7 & 667,6 & 661,1 \\
\hline 323 & 62,5 & 0,099 & & 633,7 & 452,2 & 488,6 & 440,3 & 460,4 \\
\hline 324 & 65,6 & 0,102 & 21,0 & 641,7 & 537,2 & 532,1 & 537,0 & 535,4 \\
\hline 325 & 178,4 & 0,257 & 16,7 & 693,9 & 405,9 & 407,5 & 409,8 & 407,7 \\
\hline 326 & 62,1 & 0,102 & 22,0 & 611,5 & 545,8 & 521,5 & 530,2 & 532,5 \\
\hline 327 & 24,7 & 0,047 & 14,5 & 525,8 & 628,4 & 625,4 & 615,3 & 623,0 \\
\hline 328 & 152,1 & 0,256 & 18,2 & 593,1 & 422,3 & 425,0 & 427,7 & 425,0 \\
\hline 329 & 70,0 & 0,102 & 26,0 & 685,0 & 557,5 & 542,6 & 550,0 & 550,0 \\
\hline 330 & 27,5 & 0,047 & 19,1 & 588,9 & 706,1 & 725,4 & 717,2 & 716,2 \\
\hline 331 & 145,5 & 0,259 & 19,6 & 561,2 & 386,5 & 379,3 & 377,1 & 381,0 \\
\hline 332 & 73,5 & 0,105 & 22,0 & 697,2 & 532,6 & 526,1 & 527,0 & 528,6 \\
\hline 333 & 63,1 & 0,104 & 19,1 & 604,5 & 450,0 & 457,7 & 455,0 & 454,2 \\
\hline 334 & 141,0 & 0,257 & 17,8 & 548,6 & 484,4 & 475,6 & 476,3 & 478,8 \\
\hline 335 & 58,5 & 0,100 & 17,9 & 586,6 & 537,2 & 533,8 & 540,4 & 537,1 \\
\hline 336 & 28,9 & 0,046 & 15,6 & 630,2 & 668,4 & 666,1 & 654,8 & 663,1 \\
\hline 337 & 62,0 & 0,102 & 23,0 & 604,9 & 529,7 & 526,3 & 526,2 & 527,4 \\
\hline 338 & 65,4 & 0,103 & 20,0 & 633,0 & 526 & 517,8 & 526,1 & 523,3 \\
\hline 339 & 72,0 & 0,104 & 22,0 & 691,5 & 522,1 & 540,9 & 522,9 & 528,6 \\
\hline 340 & 70,8 & 0,100 & 23,0 & 706,6 & 469,3 & 483,2 & 488,4 & 480,3 \\
\hline 341 & 24,7 & 0,046 & 16,8 & 541,0 & 720,2 & 687,2 & 679,2 & 695,5 \\
\hline 342 & 28,5 & 0,045 & 14,2 & 627,5 & 719,8 & 702,5 & 699,1 & 707,1 \\
\hline 343 & 71,1 & 0,103 & 15,5 & 687,7 & 536,7 & 529,5 & 531,1 & 532,4 \\
\hline 344 & 60,2 & 0,101 & 10,0 & 598,5 & 531,2 & 531,9 & 539,2 & 534,1 \\
\hline
\end{tabular}




\begin{tabular}{|c|c|c|c|c|c|c|c|c|}
\hline 345 & 31,9 & 0,047 & 14,9 & 673,2 & 630,6 & 648,0 & 651,0 & 643,2 \\
\hline 346 & 27,4 & 0,046 & 15,3 & 597,7 & 736,1 & 745,3 & 743,6 & 741,7 \\
\hline 347 & 65,3 & 0,101 & 23,0 & 647,8 & 496,7 & 492,7 & 487,9 & 492,4 \\
\hline 348 & 26,2 & 0,047 & 16,6 & 551,9 & 667,7 & 664,5 & 663,1 & 665,1 \\
\hline 349 & 26,5 & 0,047 & 18,6 & 567,8 & 713,1 & 705,2 & 705,6 & 708,0 \\
\hline 350 & 62,3 & 0,100 & 30,0 & 621,2 & 507,1 & 507,4 & 506,9 & 507,1 \\
\hline 351 & 70,8 & 0,103 & 30,0 & 686,1 & 541,1 & 543,0 & 539,4 & 541,2 \\
\hline 352 & 26,2 & 0,046 & 15,8 & 565,3 & 689,9 & 669,0 & 672,3 & 677,1 \\
\hline 353 & 68,8 & 0,102 & 23,0 & 674,5 & 494,4 & 498,0 & 491,0 & 494,5 \\
\hline 354 & 64,7 & 0,091 & 23,0 & 709,3 & 583,0 & 573,1 & 583,4 & 579,8 \\
\hline 355 & 60,2 & 0,103 & 20,0 & 585,2 & 488,3 & 488,5 & 486,8 & 487,9 \\
\hline 356 & 60,1 & 0,092 & 24,0 & 655,4 & 630,6 & 632,6 & 621,3 & 628,2 \\
\hline 357 & 168,8 & 0,254 & 19,0 & 664,0 & 417,2 & 413,6 & 410,5 & 413,8 \\
\hline 358 & 140,6 & 0,250 & 17,8 & 561,5 & 445,9 & 443,1 & 447,3 & 445,4 \\
\hline 359 & 30,8 & 0,048 & 16,7 & 643,9 & 652,3 & 647,2 & 651,4 & 650,3 \\
\hline 360 & 68,4 & 0,102 & 26,0 & 669,2 & 512,6 & 512,2 & 506,5 & 510,4 \\
\hline 361 & 21,2 & 0,031 & 18,5 & 680,8 & 667,5 & 647,5 & 664,7 & 659,9 \\
\hline 362 & 73,5 & 0,104 & 16,5 & 707,4 & 485,9 & 493,5 & 487,2 & 488,9 \\
\hline 363 & 27,4 & 0,047 & 18,3 & 581,9 & 698,3 & 692,6 & 692,5 & 694,5 \\
\hline 364 & 26,8 & 0,048 & 15,5 & 564,0 & 673,7 & 673,8 & 672,0 & 673,2 \\
\hline 365 & 175,0 & 0,323 & 14,1 & 541,05 & 316,8 & 318,9 & 320,1 & 318,6 \\
\hline 366 & 173,0 & 0,308 & 13,8 & 559,91 & 333,8 & 334,1 & 333,6 & 333,8 \\
\hline 367 & 165,0 & 0,307 & 15,6 & 537,01 & 330,9 & 328,3 & 327,7 & 329,0 \\
\hline 368 & 162,0 & 0,288 & 14,8 & 561,94 & 382,2 & 376,1 & 375,5 & 377,9 \\
\hline 369 & 182,0 & 0,313 & 14,4 & 579,89 & 360,5 & 354,1 & 357,7 & 357,4 \\
\hline 370 & 173,0 & 0,291 & 13,7 & 593,73 & 342,1 & 342,7 & 342,9 & 342,6 \\
\hline
\end{tabular}




\begin{tabular}{|c|c|c|c|c|c|c|c|c|}
\hline Probeta & V_fvl & $\begin{array}{c}\text { V_fvl_corr } \\
12 \%\end{array}$ & MOEdyn_fvl & $\begin{array}{l}\text { MOE dyn_fvl } \\
\text { corr } 12 \%\end{array}$ & $\begin{array}{c}\text { Valor } \\
\text { testa-testa } 1\end{array}$ & $\begin{array}{c}\text { Valor } \\
\text { testa-testa } 2\end{array}$ & $\begin{array}{c}\text { Valor } \\
\text { testa-testa } 3\end{array}$ & \begin{tabular}{|c|} 
Valor test- \\
testa media
\end{tabular} \\
\hline 1 & 0 & 4202 & 14938 & 12283 & 1034 & 1027 & 1022 & 1027 \\
\hline 2 & 4674 & 4120 & 11598 & 9547 & 604 & 607 & 604 & 605 \\
\hline 3 & 4398 & 3891 & 10113 & 8371 & 631 & 632 & 634 & 632 \\
\hline 4 & 4907 & 4470 & 15425 & 13370 & 1006 & 1006 & 1005 & 1005 \\
\hline 5 & 4619 & 4286 & 12376 & 11040 & 1063 & 1073 & 1066 & 1067 \\
\hline 6 & 4523 & 4202 & 10728 & 9588 & 972 & 968 & 957 & 965 \\
\hline 7 & 4028 & 3749 & 10637 & 9532 & 1242 & 1242 & 1245 & 1243 \\
\hline 8 & 4841 & 4534 & 16077 & 14548 & 1068 & 1064 & 1065 & 1065 \\
\hline 9 & 4383 & 4117 & 11150 & 10136 & 1131 & 1113 & 1118 & 1120 \\
\hline 10 & 4573 & 4296 & 11699 & 10639 & 1119 & 1120 & 1119 & 1119 \\
\hline 11 & 4788 & 4504 & 15975 & 14555 & 1042 & 1046 & 1046 & 1044 \\
\hline 12 & 4943 & 4654 & 15226 & 13890 & 1088 & 1095 & 1082 & 1088 \\
\hline 13 & 4141 & 3919 & 10047 & 9239 & 1228 & 1230 & 1233 & 1230 \\
\hline 14 & 4098 & 3879 & 9644 & 8873 & 1177 & 1183 & 1179 & 1179 \\
\hline 15 & 4716 & 4473 & 14156 & 13059 & 1035 & 1039 & 1040 & 1038 \\
\hline 16 & 4412 & 4204 & 9630 & 8948 & 1062 & 1056 & 1056 & 1058 \\
\hline 17 & 4808 & 4595 & 15458 & 14430 & 1066 & 1066 & 1065 & 1065 \\
\hline 18 & 4917 & 4716 & 14841 & 13932 & 993 & 992 & 994 & 993 \\
\hline 19 & 4434 & 4260 & 12885 & 12126 & 852 & 853 & 852 & 852 \\
\hline 20 & 5073 & 4882 & 17205 & 16235 & 1009 & 1012 & 1020 & 1013 \\
\hline 21 & 4554 & 4386 & 11171 & 10553 & 1002 & 1003 & 1002 & 1002 \\
\hline 22 & 4215 & 4071 & 10830 & 10276 & 1154 & 1154 & 1154 & 1154 \\
\hline 23 & 4347 & 4201 & 11554 & 10976 & 1173 & 1165 & 1166 & 1168 \\
\hline 24 & 4699 & 4543 & 13191 & 12534 & 1032 & 1023 & 1027 & 1027 \\
\hline 25 & 4997 & 4835 & 15994 & 15216 & 996 & 998 & 1000 & 998 \\
\hline 26 & 4625 & 4479 & 12096 & 11525 & 1048 & 1050 & 1056 & 1051 \\
\hline 27 & 4761 & 4620 & 13015 & 12435 & 1029 & 1032 & 1032 & 1031 \\
\hline 28 & 4085 & 3969 & 10179 & 9743 & 1242 & 1243 & 1239 & 1241 \\
\hline 29 & 4318 & 4212 & 10714 & 10322 & 848 & 844 & 844 & 845 \\
\hline 30 & 4657 & 4550 & 12815 & 12373 & 1069 & 1071 & 1072 & 1070 \\
\hline 31 & 4194 & 4102 & 10564 & 10217 & 1136 & 1138 & 1132 & 1135 \\
\hline 32 & 4863 & 4756 & 17072 & 16512 & 1087 & 1087 & 1095 & 1089 \\
\hline 33 & 4557 & 4459 & 13503 & 13069 & 836 & 834 & 841 & 837 \\
\hline 34 & 4629 & 4562 & 12452 & 12185 & 1020 & 1020 & 1011 & 1017 \\
\hline 35 & 4712 & 4646 & 14416 & 14113 & 1068 & 1058 & 1056 & 1060 \\
\hline 36 & 3470 & 3428 & 8422 & 8267 & 1264 & 1266 & 1268 & 1266 \\
\hline 37 & 4655 & 4612 & 14191 & 13993 & 1152 & 1141 & 1141 & 1144 \\
\hline 38 & 4108 & 4075 & 10482 & 10358 & 880 & 886 & 880 & 882 \\
\hline 39 & 4732 & 4696 & 14099 & 13937 & 1056 & 1058 & 1056 & 1056 \\
\hline 40 & 4686 & 4660 & 12076 & 11979 & 1104 & 1111 & 1100 & 1105 \\
\hline 41 & 4714 & 4715 & 14065 & 14068 & 1012 & 1008 & & 673 \\
\hline 42 & 3904 & 3905 & 7216 & 7217 & 744 & 740 & 741 & 741 \\
\hline 43 & 4296 & 4304 & 10203 & 10230 & 580 & 583 & 576 & 579 \\
\hline 44 & 4821 & 4839 & 12844 & 12916 & 600 & 601 & 603 & 601 \\
\hline 45 & 4335 & 4353 & 11421 & 11492 & 1141 & 1142 & 1142 & 1141 \\
\hline 46 & 4356 & 4379 & 10352 & 10436 & 634 & 634 & 633 & 633 \\
\hline 47 & 4279 & 4306 & 8649 & 8728 & 658 & 660 & 662 & 660 \\
\hline 48 & 4392 & 4420 & 11105 & 11213 & 601 & 604 & 607 & 604 \\
\hline 49 & 4458 & 4489 & 12343 & 12472 & 1102 & 1095 & 1097 & 1098 \\
\hline 50 & 4361 & 4407 & 11480 & 11662 & 866 & 868 & 870 & 868 \\
\hline 51 & 4457 & 4516 & 11627 & 11855 & 609 & 607 & 607 & 607 \\
\hline 52 & 3570 & 3619 & 9655 & 9855 & 1254 & 1255 & 1252 & 1253 \\
\hline 53 & 4741 & 4807 & 11783 & 12028 & 1020 & 1016 & 1020 & 1018 \\
\hline 54 & 3859 & 3920 & 10133 & 10373 & 1180 & 1177 & 1179 & 1178 \\
\hline
\end{tabular}




\begin{tabular}{|c|c|c|c|c|c|c|c|c|}
\hline 55 & 4726 & 4802 & 13069 & 13384 & 1053 & 1050 & 1052 & 1051 \\
\hline 56 & 4658 & 4742 & 12350 & 12686 & 1149 & 1143 & 1142 & 1144 \\
\hline 57 & 4714 & 4801 & 14639 & 15047 & 1126 & 1105 & 1112 & 1114 \\
\hline 58 & 4606 & 4696 & 13228 & 13617 & 807 & 808 & 806 & 807 \\
\hline 59 & 8729 & 8905 & 38470 & 39635 & 1053 & 1053 & 1047 & 1051 \\
\hline 60 & 4764 & 4862 & 14514 & 14963 & 1004 & 997 & 999 & 1000 \\
\hline 61 & 4527 & 4623 & 12156 & 12545 & 627 & 626 & 627 & 626 \\
\hline 62 & 4405 & 4506 & 10385 & 10741 & 918 & 915 & 913 & 915 \\
\hline 63 & 4232 & 4330 & 11281 & 11671 & 636 & 637 & 636 & 636 \\
\hline 64 & 4991 & 5111 & 15989 & 16566 & 1060 & 1059 & 1058 & 1059 \\
\hline 65 & 4541 & 4654 & 12394 & 12858 & 630 & 631 & 630 & 630 \\
\hline 66 & 4323 & 4436 & 11771 & 12233 & 615 & 622 & 619 & 618 \\
\hline 67 & 4412 & 4536 & 11061 & 11527 & 1048 & 1046 & 1047 & 1047 \\
\hline 68 & 3777 & 3885 & 6861 & 7156 & 704 & 702 & 702 & 702 \\
\hline 69 & 4866 & 5008 & 12915 & 13482 & 579 & 580 & 579 & 579 \\
\hline 70 & 4511 & 4644 & 11947 & 12472 & 633 & 631 & 631 & 631 \\
\hline 71 & 4113 & 4234 & 7826 & 8172 & 669 & 667 & 669 & 668 \\
\hline 72 & 4861 & 5004 & 12581 & 13138 & 570 & 566 & 567 & 567 \\
\hline 73 & 5013 & 5167 & 14374 & 15040 & 1015 & 1017 & 1017 & 1016 \\
\hline 74 & 4603 & 4749 & 14142 & 14813 & 1116 & 1118 & 1119 & 1117 \\
\hline 75 & 4413 & 4554 & 11136 & 11668 & 864 & 859 & 854 & 859 \\
\hline 76 & 4418 & 4562 & 10476 & 10986 & 642 & 640 & 638 & 640 \\
\hline 77 & 4628 & 4785 & 11407 & 11983 & 606 & 607 & 604 & 605 \\
\hline 78 & 4423 & 4573 & 11190 & 11757 & 637 & 640 & 640 & 639 \\
\hline 79 & 4462 & 4626 & 12939 & 13654 & 572 & 570 & 570 & 570 \\
\hline 80 & 4616 & 4797 & 11973 & 12677 & 597 & 601 & 600 & 599 \\
\hline 81 & 4415 & 4601 & 14606 & 15527 & 870 & 872 & 877 & 873 \\
\hline 82 & 4243 & 4424 & 10104 & 10749 & 627 & 627 & 626 & 626 \\
\hline 83 & 4057 & 4232 & 8411 & 8953 & 688 & 688 & 687 & 687 \\
\hline 84 & 4374 & 4562 & 8596 & 9151 & 633 & 632 & 632 & 632 \\
\hline 85 & 3886 & 4058 & 8609 & 9181 & 661 & 660 & 657 & 659 \\
\hline 86 & 4275 & 4466 & 10961 & 11695 & 673 & 673 & 672 & 672 \\
\hline 87 & 4580 & 4786 & 11617 & 12401 & 618 & 618 & 619 & 618 \\
\hline 88 & 4473 & 4681 & 10118 & 10822 & 634 & 637 & 638 & 636 \\
\hline 89 & 4325 & 4527 & 11568 & 12377 & 626 & 626 & 627 & 626 \\
\hline 90 & 4675 & 4893 & 15304 & 16375 & 1056 & 1047 & 1054 & 1052 \\
\hline 91 & 4326 & 4530 & 10314 & 11045 & 633 & 634 & 636 & 634 \\
\hline 92 & 3661 & 3834 & 8509 & 9113 & 1000 & 1003 & 1004 & 1002 \\
\hline 93 & 4145 & 4344 & 10580 & 11343 & 668 & 666 & 670 & 668 \\
\hline 94 & 4085 & 4282 & 8144 & 8731 & 660 & 660 & 661 & 660 \\
\hline 95 & 4660 & 4885 & 11937 & 12799 & 614 & 612 & 610 & 612 \\
\hline 96 & 4597 & 4820 & 11494 & 12329 & 625 & 626 & 625 & 625 \\
\hline 97 & 4241 & 4447 & 9792 & 10504 & 648 & 649 & 644 & 647 \\
\hline 98 & 4379 & 4591 & 12855 & 13791 & 625 & 624 & 627 & 625 \\
\hline 99 & 3948 & 4140 & 11104 & 11916 & 927 & 927 & 925 & 926 \\
\hline 100 & 4462 & 4682 & 9888 & 10618 & 607 & 608 & 608 & 607 \\
\hline 101 & 4064 & 4269 & 8382 & 9016 & 678 & 680 & 678 & 678 \\
\hline 102 & 4551 & 4784 & 10376 & 11173 & 609 & 609 & 610 & 609 \\
\hline 103 & 4450 & 4681 & 8452 & 9107 & 660 & 661 & 656 & 659 \\
\hline 104 & 4541 & 4777 & 9117 & 9829 & 632 & 637 & 628 & 632 \\
\hline 105 & 4559 & 4799 & 11881 & 12816 & 608 & 608 & 604 & 606 \\
\hline 106 & 4738 & 4992 & 14351 & 15503 & 1141 & 1138 & 1141 & 1140 \\
\hline 107 & 4614 & 4863 & 13141 & 14206 & 604 & 603 & 601 & 602 \\
\hline 108 & 4770 & 5030 & 14114 & 15265 & 1020 & 1016 & 1017 & 1017 \\
\hline 109 & 4931 & 5200 & 14148 & 15307 & 595 & 595 & 596 & 595 \\
\hline 110 & 4774 & 5036 & 13758 & 14887 & 606 & 606 & 607 & 606 \\
\hline 111 & 4156 & 4384 & 10105 & 10936 & 702 & 705 & 705 & 704 \\
\hline 112 & 4277 & 4512 & 10024 & 10852 & 609 & 610 & 609 & 609 \\
\hline
\end{tabular}




\begin{tabular}{|c|c|c|c|c|c|c|c|c|}
\hline 113 & 4532 & 4782 & 11262 & 12194 & 615 & 614 & 615 & 614 \\
\hline 114 & 4372 & 4617 & 10000 & 10838 & 608 & 604 & 608 & 606 \\
\hline 115 & 4178 & 4414 & 10914 & 11838 & 650 & 649 & 648 & 649 \\
\hline 116 & 4382 & 4636 & 10669 & 11595 & 626 & 628 & 626 & 626 \\
\hline 117 & 4041 & 4276 & 8205 & 8918 & 674 & 672 & 668 & 671 \\
\hline 118 & 4236 & 4482 & 9800 & 10652 & 640 & 645 & 643 & 642 \\
\hline 119 & 4351 & 4604 & 10094 & 10974 & 627 & 627 & 628 & 627 \\
\hline 120 & 4529 & 4795 & 11767 & 12801 & 624 & 626 & 625 & 625 \\
\hline 121 & 4122 & 4367 & 10843 & 11809 & 681 & 681 & 680 & 680 \\
\hline 122 & 4181 & 4431 & 9923 & 10812 & 650 & 648 & 648 & 648 \\
\hline 123 & 4302 & 4560 & 10130 & 11039 & 655 & 650 & 652 & 652 \\
\hline 124 & 4572 & 4846 & 12284 & 13388 & 614 & 615 & 614 & 614 \\
\hline 125 & 3994 & 4234 & 9210 & 10040 & 673 & 679 & 676 & 676 \\
\hline 126 & 4626 & 4905 & 12559 & 13694 & 619 & 618 & 620 & 619 \\
\hline 127 & 4581 & 4858 & 11605 & 12654 & 592 & 590 & 592 & 591 \\
\hline 128 & 4032 & 4276 & 9649 & 10523 & 660 & 655 & 654 & 656 \\
\hline 129 & 2721 & 2885 & 4059 & 4427 & 657 & 657 & 662 & 658 \\
\hline 130 & 4591 & 4870 & 10839 & 11824 & 597 & 600 & 596 & 597 \\
\hline 131 & 4260 & 4519 & 11046 & 12055 & 648 & 643 & 639 & 643 \\
\hline 132 & 4132 & 4385 & 9575 & 10451 & 656 & 652 & 663 & 657 \\
\hline 133 & 4376 & 4645 & 10450 & 11410 & 649 & 650 & 649 & 649 \\
\hline 134 & 4901 & 5203 & 13574 & 14830 & 1014 & 1008 & 1006 & 1009 \\
\hline 135 & 4282 & 4547 & 11858 & 12956 & 661 & 661 & 669 & 663 \\
\hline 136 & 4440 & 4717 & 13596 & 14868 & 648 & 646 & 644 & 646 \\
\hline 137 & 4341 & 4613 & 10920 & 11946 & 637 & 636 & 640 & 637 \\
\hline 138 & 3989 & 4240 & 9650 & 10559 & 940 & 934 & 951 & 941 \\
\hline 139 & 5049 & 5368 & 17040 & 18653 & 1012 & 1008 & 1006 & 1008 \\
\hline 140 & 3793 & 4034 & 9592 & 10503 & 694 & 694 & 693 & 693 \\
\hline 141 & 4471 & 4756 & 10773 & 11802 & 649 & 648 & 645 & 647 \\
\hline 142 & 4472 & 4759 & 12314 & 13499 & 839 & 841 & 832 & 837 \\
\hline 143 & 4348 & 4628 & 11337 & 12429 & 607 & 609 & 609 & 608 \\
\hline 144 & 4561 & 4855 & 9810 & 10758 & 597 & 598 & 594 & 596 \\
\hline 145 & 4552 & 4846 & 9673 & 10609 & 1104 & 1110 & 1095 & 1103 \\
\hline 146 & 4139 & 4408 & 11155 & 12241 & 680 & 682 & 676 & 679 \\
\hline 147 & 3883 & 4136 & 9409 & 10327 & 718 & 718 & 715 & 717 \\
\hline 148 & 4758 & 5068 & 12615 & 13846 & 609 & 608 & 610 & 609 \\
\hline 149 & 4670 & 4974 & 12031 & 13207 & 796 & 793 & 800 & 796 \\
\hline 150 & 4620 & 4923 & 10494 & 11523 & 610 & 610 & 609 & 609 \\
\hline 151 & 4035 & 4299 & 8713 & 9568 & 621 & 618 & 615 & 618 \\
\hline 152 & 4372 & 4659 & 10921 & 11994 & 639 & 638 & 634 & 637 \\
\hline 153 & 4446 & 4738 & 11050 & 12138 & 610 & 612 & 609 & 610 \\
\hline 154 & 4658 & 4965 & 12729 & 13984 & 580 & 576 & 583 & 579 \\
\hline 155 & 4572 & 4874 & 13387 & 14711 & 616 & 615 & 615 & 615 \\
\hline 156 & 4242 & 4524 & 11000 & 12095 & 642 & 640 & 642 & 641 \\
\hline 157 & 4017 & 4285 & 8287 & 9113 & 645 & 646 & 644 & 645 \\
\hline 158 & 4378 & 4670 & 9771 & 10746 & 607 & 607 & 610 & 608 \\
\hline 159 & 4552 & 4856 & 10787 & 11866 & 620 & 620 & 618 & 619 \\
\hline 160 & 4009 & 4277 & 8724 & 9599 & 680 & 676 & 676 & 677 \\
\hline 161 & 4392 & 4689 & 10516 & 11579 & 633 & 631 & 633 & 632 \\
\hline 162 & 4365 & 4662 & 12099 & 13332 & 874 & 873 & 874 & 873 \\
\hline 163 & 3882 & 4146 & 8993 & 9910 & 686 & 685 & 684 & 685 \\
\hline 164 & 4657 & 4974 & 11963 & 13184 & 795 & 788 & 789 & 790 \\
\hline 165 & 4487 & 4795 & 11474 & 12653 & 592 & 594 & 594 & 593 \\
\hline 166 & 4685 & 5009 & 13563 & 14968 & 783 & 784 & 784 & 783 \\
\hline 167 & 4473 & 4783 & 10629 & 11731 & 632 & 632 & 627 & 630 \\
\hline 168 & 4396 & 4700 & 11702 & 12915 & 873 & 882 & 877 & 877 \\
\hline 169 & 3979 & 4255 & 8752 & 9660 & 643 & 644 & 645 & 644 \\
\hline 170 & 4492 & 4803 & 11386 & 12568 & 630 & 625 & 627 & 627 \\
\hline
\end{tabular}




\begin{tabular}{|c|c|c|c|c|c|c|c|c|}
\hline 171 & 4734 & 5062 & 11378 & 12560 & 1012 & 1017 & 1024 & 1017 \\
\hline 172 & 4862 & 5204 & 14070 & 15553 & 582 & 582 & 582 & 582 \\
\hline 173 & 4671 & 5002 & 14269 & 15784 & 802 & 805 & 804 & 803 \\
\hline 174 & 4165 & 4461 & 9728 & 10761 & 650 & 650 & 648 & 649 \\
\hline 175 & 4469 & 4786 & 10824 & 11975 & 1089 & 1082 & 1080 & 1083 \\
\hline 176 & 4008 & 4293 & 8112 & 8976 & 645 & 644 & 648 & 645 \\
\hline 177 & 4358 & 4668 & 10946 & 12112 & 586 & 585 & 583 & 584 \\
\hline 178 & 4392 & 4705 & 12571 & 13914 & 636 & 637 & 634 & 635 \\
\hline 179 & 4291 & 4598 & 10565 & 11695 & 660 & 656 & 664 & 660 \\
\hline 180 & 4156 & 4458 & 8541 & 9469 & 682 & 679 & 684 & 681 \\
\hline 181 & 4562 & 4896 & 11234 & 12463 & 608 & 607 & 606 & 607 \\
\hline 182 & 4323 & 4641 & 10792 & 11980 & 604 & 604 & 603 & 603 \\
\hline 183 & & & & & 632 & 630 & 625 & 629 \\
\hline 184 & 4958 & 5324 & 14678 & 16297 & 1051 & 1044 & 1040 & 1045 \\
\hline 185 & 4429 & 4757 & 10814 & 12014 & 584 & 582 & 582 & 582 \\
\hline 186 & 4159 & 4469 & 10214 & 11352 & 652 & 652 & 651 & 651 \\
\hline 187 & 4150 & 4459 & 8874 & 9863 & 691 & 688 & 686 & 688 \\
\hline 188 & 4358 & 4683 & 10926 & 12145 & 636 & 634 & 632 & 634 \\
\hline 189 & 4287 & 4607 & 11830 & 13150 & 1135 & 1144 & 1137 & 1138 \\
\hline 190 & 4635 & 4980 & 12800 & 14228 & 845 & 841 & 842 & 842 \\
\hline 191 & 4810 & 5169 & 15328 & 17044 & 616 & 618 & 618 & 617 \\
\hline 192 & 4034 & 4336 & 8806 & 9795 & 648 & 649 & 650 & 649 \\
\hline 193 & 4350 & 4676 & 10515 & 11695 & 633 & 636 & 633 & 634 \\
\hline 194 & 4823 & 5187 & 13644 & 15185 & 579 & 583 & 580 & 580 \\
\hline 195 & 4514 & 4856 & 12480 & 13896 & 834 & 837 & 835 & 835 \\
\hline 196 & 4434 & 4774 & 9180 & 10233 & 634 & 640 & 636 & 636 \\
\hline 197 & 4371 & 4706 & 10217 & 11389 & 608 & 606 & 606 & 606 \\
\hline 198 & 4136 & 4453 & 8956 & 9983 & 652 & 652 & 651 & 651 \\
\hline 199 & 4062 & 4376 & 9804 & 10938 & 684 & 682 & 682 & 682 \\
\hline 200 & 4597 & 4956 & 13874 & 15496 & 636 & 634 & 638 & 636 \\
\hline 201 & 4616 & 4978 & 11003 & 12296 & 1059 & 1057 & 1054 & 1056 \\
\hline 202 & 4511 & 4868 & 12884 & 14408 & 814 & 814 & 816 & 814 \\
\hline 203 & 4266 & 4604 & 11690 & 13074 & 622 & 622 & 622 & 622 \\
\hline 204 & 4055 & 4376 & 9301 & 10404 & 900 & 898 & 896 & 898 \\
\hline 205 & 4521 & 4880 & 11400 & 12753 & 590 & 588 & 589 & 589 \\
\hline 206 & 3792 & 4094 & 9047 & 10123 & 710 & 714 & 711 & 711 \\
\hline 207 & 4701 & 5077 & 12178 & 13636 & 631 & 631 & 642 & 634 \\
\hline 208 & 4599 & 4967 & 13194 & 14774 & 619 & 625 & 620 & 621 \\
\hline 209 & 4468 & 4829 & 12661 & 14192 & 1170 & 1161 & 1174 & 1168 \\
\hline 210 & 4369 & 4723 & 9973 & 11183 & 618 & 615 & 616 & 616 \\
\hline 211 & 4652 & 5032 & 11269 & 12647 & 609 & 604 & 606 & 606 \\
\hline 212 & 4417 & 4780 & 11827 & 13282 & 854 & 853 & 859 & 855 \\
\hline 213 & 4258 & 4608 & 10758 & 12083 & 661 & 660 & 657 & 659 \\
\hline 214 & 3891 & 4212 & 11112 & 12486 & 1208 & 1206 & 1200 & 1204 \\
\hline 215 & 4671 & 5059 & 12057 & 13553 & 588 & 583 & 586 & 585 \\
\hline 216 & 4117 & 4463 & 10531 & 11854 & 666 & 662 & 664 & 664 \\
\hline 217 & 4677 & 5071 & 12768 & 14380 & 817 & 819 & 820 & 818 \\
\hline 218 & 4415 & 4795 & 12053 & 13603 & 903 & 903 & 897 & 901 \\
\hline 219 & 4277 & 4648 & 10262 & 11592 & 642 & 642 & 642 & 642 \\
\hline 220 & 4093 & 4448 & 10666 & 12049 & 673 & 672 & 673 & 672 \\
\hline 221 & 4348 & 4726 & 9021 & 10196 & 872 & 876 & 873 & 873 \\
\hline 222 & 4189 & 4555 & 11856 & 13408 & 658 & 657 & 655 & 656 \\
\hline 223 & 4304 & 4682 & 13693 & 15494 & 895 & 890 & 894 & 893 \\
\hline 224 & 4129 & 4494 & 9105 & 10309 & 674 & 674 & 675 & 674 \\
\hline 225 & 4347 & 4733 & 12876 & 14586 & 850 & 850 & 853 & 851 \\
\hline 226 & 4377 & 4766 & 11406 & 12921 & 850 & 854 & 852 & 852 \\
\hline 227 & 3716 & 4046 & 6440 & 7296 & 714 & 715 & 711 & 713 \\
\hline 228 & 4003 & 4360 & 7506 & 8508 & 693 & 691 & 692 & 692 \\
\hline
\end{tabular}




\begin{tabular}{|c|c|c|c|c|c|c|c|c|}
\hline 229 & 3967 & 4321 & 9607 & 10890 & 650 & 649 & 651 & 650 \\
\hline 230 & 4530 & 4938 & 13601 & 15433 & 844 & 848 & 852 & 848 \\
\hline 231 & 4562 & 4975 & 11599 & 13170 & 632 & 630 & 638 & 633 \\
\hline 232 & 4139 & 4517 & 9042 & 10277 & 726 & 726 & 723 & 725 \\
\hline 233 & 4648 & 5073 & 11285 & 12829 & 1094 & 1090 & 1089 & 1091 \\
\hline 234 & 4774 & 5211 & 13710 & 15588 & 584 & 582 & 582 & 582 \\
\hline 235 & 4062 & 4435 & 9610 & 10931 & 936 & 932 & 930 & 932 \\
\hline 236 & 5041 & 5506 & 16026 & 18234 & 1068 & 1064 & 1063 & 1065 \\
\hline 237 & 4042 & 4416 & 9794 & 11150 & 890 & 886 & 892 & 889 \\
\hline 238 & 4283 & 4682 & 11555 & 13165 & 655 & 654 & 651 & 653 \\
\hline 239 & 4051 & 4431 & 8335 & 9502 & 670 & 673 & 669 & 670 \\
\hline 240 & 4507 & 4932 & 11049 & 12607 & 616 & 618 & 613 & 615 \\
\hline 241 & 4066 & 4449 & 10715 & 12226 & 657 & 661 & 660 & 659 \\
\hline 242 & 4343 & 4753 & 8561 & 9770 & 608 & 607 & 608 & 607 \\
\hline 243 & 3864 & 4229 & 10316 & 11776 & 1198 & 1201 & 1201 & 1200 \\
\hline 244 & 4642 & 5084 & 13686 & 15634 & 832 & 832 & 825 & 829 \\
\hline 245 & 4599 & 5040 & 13016 & 14887 & 794 & 792 & 796 & 794 \\
\hline 246 & 4542 & 4980 & 12698 & 14529 & 619 & 614 & 615 & 616 \\
\hline 247 & 3850 & 4223 & 7850 & 8987 & 732 & 727 & 728 & 729 \\
\hline 248 & 4434 & 4865 & 12786 & 14645 & 913 & 915 & 914 & 914 \\
\hline 249 & 4384 & 4812 & 12758 & 14620 & 872 & 871 & 866 & 869 \\
\hline 250 & 4262 & 4684 & 12547 & 14402 & 1137 & 1138 & 1147 & 1140 \\
\hline 251 & 3792 & 4168 & 9001 & 10334 & 914 & 920 & 918 & 917 \\
\hline 252 & 4516 & 4968 & 13287 & 15277 & 832 & 831 & 831 & 831 \\
\hline 253 & 5126 & 5640 & 15976 & 18370 & 648 & 646 & 643 & 645 \\
\hline 254 & 4371 & 4809 & 12270 & 14111 & 862 & 858 & 859 & 859 \\
\hline 255 & 4392 & 4840 & 11634 & 13410 & 828 & 826 & 828 & 827 \\
\hline 256 & 4544 & 5010 & 12968 & 14953 & 834 & 841 & 838 & 837 \\
\hline 257 & 4624 & 5098 & 15516 & 17894 & 802 & 806 & 798 & 802 \\
\hline 258 & 4066 & 4484 & 9585 & 11057 & 670 & 666 & 678 & 671 \\
\hline 259 & 4660 & 5139 & 13231 & 15268 & 609 & 609 & 610 & 609 \\
\hline 260 & 4708 & 5205 & 15358 & 17780 & 1101 & 1104 & 1102 & 1102 \\
\hline 261 & 3987 & 4409 & 9600 & 11120 & 688 & 685 & 688 & 687 \\
\hline 262 & 4575 & 5059 & 14022 & 16242 & 613 & 614 & 610 & 612 \\
\hline 263 & 4287 & 4743 & 12253 & 14198 & 1110 & 1120 & 1116 & 1115 \\
\hline 264 & 4540 & 5024 & 13120 & 15206 & 813 & 813 & 811 & 812 \\
\hline 265 & 4425 & 4897 & 12606 & 14618 & 631 & 630 & 628 & 629 \\
\hline 266 & 4635 & 5131 & 14234 & 16509 & 822 & 825 & 819 & 822 \\
\hline 267 & 4085 & 4524 & 11042 & 12816 & 920 & 914 & 915 & 916 \\
\hline 268 & 4143 & 4591 & 10786 & 12528 & 880 & 888 & 883 & 883 \\
\hline 269 & 4613 & 5112 & 11921 & 13849 & 621 & 622 & 622 & 621 \\
\hline 270 & 4112 & 4558 & 9943 & 11551 & 902 & 889 & 912 & 901 \\
\hline 271 & 4212 & 4670 & 11973 & 13917 & 888 & 886 & 889 & 887 \\
\hline 272 & 4091 & 4537 & 9048 & 10525 & 649 & 657 & 649 & 651 \\
\hline 273 & 4397 & 4880 & 10884 & 12672 & 627 & 626 & 627 & 626 \\
\hline 274 & 4510 & 5011 & 11909 & 13886 & 597 & 598 & 597 & 597 \\
\hline 275 & 4026 & 4476 & 8437 & 9848 & 1177 & 1178 & & 785 \\
\hline 276 & 4012 & 4462 & 10145 & 11844 & 680 & 678 & 680 & 679 \\
\hline 277 & 4373 & 4866 & 12123 & 14162 & 1123 & 1123 & 1125 & 1123 \\
\hline 278 & 4272 & 4756 & 10922 & 12769 & 1156 & 1155 & 1153 & 1154 \\
\hline 279 & 4294 & 4781 & 9572 & 11193 & 886 & 892 & 889 & 889 \\
\hline 280 & 4879 & 5435 & 14308 & 16745 & 1053 & 1060 & 1054 & 1055 \\
\hline 281 & 4079 & 4551 & 10255 & 12026 & 904 & 909 & 904 & 905 \\
\hline 282 & 4441 & 4958 & 11717 & 13757 & 828 & 823 & 825 & 825 \\
\hline 283 & 4372 & 4894 & 13096 & 15431 & 919 & 924 & 922 & 921 \\
\hline 284 & 4145 & 4642 & 9098 & 10728 & 634 & 634 & 628 & 632 \\
\hline 285 & 4112 & 4606 & 10340 & 12195 & 651 & 656 & 651 & 652 \\
\hline 286 & 4445 & 4980 & 12197 & 14389 & 884 & 884 & 882 & 883 \\
\hline
\end{tabular}




\begin{tabular}{|c|c|c|c|c|c|c|c|c|}
\hline 287 & 4368 & 4899 & 10804 & 12764 & 616 & 614 & 617 & 615 \\
\hline 288 & 4269 & 4790 & 12298 & 14539 & 694 & 692 & 692 & 692 \\
\hline 289 & 5018 & 5632 & 15679 & 18545 & 1018 & 1012 & 1011 & 1013 \\
\hline 290 & 4352 & 4885 & 10453 & 12364 & 625 & 627 & 624 & 625 \\
\hline 291 & 4276 & 4806 & 11054 & 13095 & 1176 & 1172 & 1176 & 1174 \\
\hline 292 & 4042 & 4543 & 9817 & 11633 & 878 & 880 & 877 & 878 \\
\hline 293 & 3821 & 4298 & 8521 & 10107 & 727 & 728 & 729 & 728 \\
\hline 294 & 4435 & 4989 & 12236 & 14518 & 890 & 890 & 890 & 890 \\
\hline 295 & 4600 & 5177 & 12039 & 14294 & 1015 & 1014 & & 676 \\
\hline 296 & 3876 & 4364 & 8742 & 10385 & 676 & 678 & 676 & 676 \\
\hline 297 & 4624 & 5207 & 11386 & 13528 & 1153 & 1176 & 1168 & 1165 \\
\hline 298 & 4055 & 4566 & 11847 & 14077 & 920 & 921 & 910 & 917 \\
\hline 299 & 4572 & 5149 & 11895 & 14134 & 1142 & 1138 & & 760 \\
\hline 300 & 3863 & 4353 & 8221 & 9777 & 711 & 710 & 708 & 709 \\
\hline 301 & 4448 & 5014 & 12846 & 15288 & 619 & 621 & 620 & 620 \\
\hline 302 & 4438 & 5010 & 13477 & 16070 & 1162 & 1170 & 1160 & 1164 \\
\hline 303 & 4287 & 4844 & 10684 & 12755 & 1174 & 1172 & 1172 & 1172 \\
\hline 304 & 3942 & 4455 & 9701 & 11583 & 972 & 969 & 966 & 969 \\
\hline 305 & 4361 & 4928 & 11384 & 13591 & 764 & 763 & 762 & 763 \\
\hline 306 & 4274 & 4830 & 12358 & 14758 & 876 & 877 & 876 & 876 \\
\hline 307 & 4257 & 4815 & 13211 & 15795 & 864 & 870 & 873 & 869 \\
\hline 308 & 4079 & 4618 & 10949 & 13107 & 796 & 794 & 794 & 794 \\
\hline 309 & 4168 & 4720 & 9852 & 11795 & 639 & 637 & 636 & 637 \\
\hline 310 & 4925 & 5579 & 15980 & 19143 & & & & 0 \\
\hline 311 & 3950 & 4477 & 10050 & 12047 & 919 & 925 & 915 & 919 \\
\hline 312 & 4251 & 4818 & 11685 & 14010 & 847 & 848 & 854 & 849 \\
\hline 313 & 4678 & 5304 & 14556 & 17461 & 1099 & 1098 & 1096 & 1097 \\
\hline 314 & 4407 & 4998 & 11789 & 14146 & 848 & 844 & 845 & 845 \\
\hline 315 & 3928 & 4456 & 9210 & 11054 & 1182 & 1183 & 1167 & 1177 \\
\hline 316 & 4484 & 5091 & 12851 & 15444 & 1164 & 1173 & 1166 & 1167 \\
\hline 317 & 4390 & 4985 & 13258 & 15936 & 841 & 843 & 840 & 841 \\
\hline 318 & 4550 & 5176 & 13981 & 16849 & 1080 & 1076 & 1077 & 1077 \\
\hline 319 & 4488 & 5112 & 11670 & 14086 & 838 & 841 & 840 & 839 \\
\hline 320 & 4169 & 4757 & 10439 & 12631 & 814 & 826 & 814 & 818 \\
\hline 321 & 4273 & 4882 & 10154 & 12309 & 630 & 631 & 634 & 631 \\
\hline 322 & 3911 & 4469 & 9854 & 11947 & 674 & 676 & 676 & 675 \\
\hline 323 & 3737 & 4277 & 8445 & 10262 & 937 & 936 & 924 & 932 \\
\hline 324 & 4320 & 4949 & 12045 & 14660 & 853 & 860 & 856 & 856 \\
\hline 325 & 4253 & 4873 & 12463 & 15171 & 1149 & 1143 & 1144 & 1145 \\
\hline 326 & 4292 & 4918 & 11289 & 13742 & 890 & 901 & 886 & 892 \\
\hline 327 & 3813 & 4373 & 7383 & 8997 & 702 & 702 & 700 & 701 \\
\hline 328 & 4378 & 5028 & 10950 & 13371 & 1080 & 1083 & 1081 & 1081 \\
\hline 329 & 4461 & 5130 & 13940 & 17053 & 823 & 835 & 825 & 827 \\
\hline 330 & 4343 & 4995 & 11522 & 14095 & 645 & 642 & 644 & 643 \\
\hline 331 & 3939 & 4542 & 8657 & 10628 & 1195 & 1200 & 1198 & 1197 \\
\hline 332 & 4276 & 4937 & 14254 & 17534 & 817 & 823 & 814 & 818 \\
\hline 333 & 3701 & 4276 & 8653 & 10653 & 1040 & 1042 & 1039 & 1040 \\
\hline 334 & 4922 & 5686 & 14211 & 17496 & 1026 & 1024 & 1024 & 1024 \\
\hline 335 & 4306 & 4975 & 10683 & 13154 & 824 & 823 & 818 & 821 \\
\hline 336 & 4028 & 4669 & 10487 & 12971 & 650 & 646 & 650 & 648 \\
\hline 337 & 4290 & 4975 & 11350 & 14047 & 868 & 848 & 852 & 856 \\
\hline 338 & 4291 & 4981 & 11558 & 14323 & 889 & 892 & 888 & 889 \\
\hline 339 & 4260 & 4948 & 13005 & 16130 & 913 & 908 & 907 & 909 \\
\hline 340 & 3890 & 4523 & 10262 & 12745 & 940 & 938 & 943 & 940 \\
\hline 341 & 4234 & 4941 & 10944 & 13659 & 637 & 637 & 638 & 637 \\
\hline 342 & 4297 & 5014 & 12167 & 15186 & 642 & 643 & 648 & 644 \\
\hline 343 & 4290 & 5007 & 12663 & 15806 & 862 & 864 & 862 & 862 \\
\hline 344 & 4294 & 5013 & 11355 & 14179 & 850 & 853 & 848 & 850 \\
\hline
\end{tabular}




\begin{tabular}{|c|c|c|c|c|c|c|c|c|}
\hline 345 & 3997 & 4672 & 10929 & 13671 & 645 & 644 & 646 & 645 \\
\hline 346 & 4459 & 5213 & 13505 & 16897 & 607 & 609 & 610 & 608 \\
\hline 347 & 3984 & 4659 & 10115 & 12660 & 882 & 884 & 885 & 883 \\
\hline 348 & 4113 & 4825 & 9786 & 12302 & 654 & 658 & 654 & 655 \\
\hline 349 & 4333 & 5085 & 11437 & 14384 & 631 & 631 & 632 & 631 \\
\hline 350 & 4037 & 4762 & 10290 & 13033 & 882 & 882 & 883 & 882 \\
\hline 351 & 4394 & 5194 & 13084 & 16615 & 868 & 870 & 862 & 866 \\
\hline 352 & 4115 & 4873 & 10227 & 13020 & 670 & 672 & 680 & 674 \\
\hline 353 & 4025 & 4770 & 11183 & 14252 & 925 & 924 & 924 & 924 \\
\hline 354 & 4152 & 4921 & 12300 & 15680 & 786 & 784 & 786 & 785 \\
\hline 355 & 4005 & 4750 & 10142 & 12939 & 909 & 903 & 906 & 906 \\
\hline 356 & 4514 & 5362 & 13438 & 17179 & 744 & 747 & 745 & 745 \\
\hline 357 & 4229 & 5026 & 11325 & 14490 & 1176 & 1183 & 1178 & 1179 \\
\hline 358 & 4584 & 5535 & 13873 & 18128 & 1059 & 1064 & 1064 & 1062 \\
\hline 359 & 4027 & 4869 & 11185 & 14645 & 669 & 670 & 667 & 668 \\
\hline 360 & 4135 & 5012 & 12642 & 16606 & 900 & 901 & 898 & 899 \\
\hline 361 & 3998 & 4897 & 10782 & 14359 & 697 & 691 & 693 & 693 \\
\hline 362 & 3987 & 4894 & 11258 & 15032 & 933 & 936 & 931 & 933 \\
\hline 363 & 4260 & 5268 & 11003 & 14835 & 650 & 649 & 648 & 649 \\
\hline 364 & 4127 & 5218 & 10051 & 13945 & 661 & 661 & 663 & 661 \\
\hline 365 & 4005 & 4578 & 11416 & 13845 & 1428 & 1431 & 1431 & 1430 \\
\hline 366 & 4073 & 4324 & 10286 & 11238 & 1373 & 1380 & 1382 & 1378 \\
\hline 367 & 3987 & 4368 & 9550 & 10915 & 1322 & 1321 & 1322 & 1321 \\
\hline 368 & 4285 & 4431 & 11209 & 11782 & 1201 & 1198 & 1200 & 1199 \\
\hline 369 & 4378 & 4655 & 11128 & 12185 & 1291 & 1292 & 1291 & 1291 \\
\hline 370 & 3849 & 4064 & 9427 & 10217 & 1326 & 1330 & 1325 & 1327 \\
\hline
\end{tabular}




\begin{tabular}{|c|c|c|c|c|c|c|c|c|}
\hline Probeta & V_vop & $\underset{12 \%}{\text { V_vop_corr }}$ & MOEdyn_vop & $\begin{array}{l}\text { MOEdyn_vop } \\
\text { corr12\% }\end{array}$ & $\begin{array}{c}\text { Suma nud } \\
\text { peor sec }\end{array}$ & $\begin{array}{c}\text { Nud cara } \\
\text { total }\end{array}$ & $\begin{array}{c}\text { Nud canto } \\
\text { total }\end{array}$ & Long fenda \\
\hline 1 & 4935 & 4348 & 15992 & 13149 & 5,7 & 1,9 & 1,9 & 507,2 \\
\hline 2 & 5060 & 4460 & 13591 & 11187 & 10,8 & 2,4 & 2,6 & 306,1 \\
\hline 3 & 4795 & 4242 & 12019 & 9949 & 12,1 & 2,7 & 2,8 & 303,2 \\
\hline 4 & 5091 & 4638 & 16606 & 14394 & 10,8 & 3,0 & 3,8 & 512,0 \\
\hline 5 & 4760 & 4416 & 13142 & 11723 & 13,1 & & 3,1 & 508,0 \\
\hline 6 & 5126 & 4762 & 13781 & 12317 & 13,7 & 3,8 & 4,0 & 495,0 \\
\hline 7 & 4159 & 3871 & 11341 & 10163 & 24,8 & 6,9 & 6,5 & 517,0 \\
\hline 8 & 4908 & 4596 & 16522 & 14951 & 9,6 & 2,7 & 2,4 & 523,0 \\
\hline 9 & 4564 & 4287 & 12090 & 10991 & 10,2 & 4,2 & 3,0 & 511,5 \\
\hline 10 & 4601 & 4323 & 11843 & 10770 & 5,0 & 3,2 & 2,3 & 515,0 \\
\hline 11 & 4959 & 4664 & 17136 & 15612 & 6,3 & 3,1 & 2,8 & 518,0 \\
\hline 12 & 4686 & 4412 & 13683 & 12482 & 6,0 & 2,4 & 2,2 & 210,0 \\
\hline 13 & 4218 & 3992 & 10426 & 9588 & 15,3 & 3,4 & 3,3 & 519,0 \\
\hline 14 & 4366 & 4133 & 10945 & 10069 & 18,9 & 4,8 & 4,4 & 515,0 \\
\hline 15 & 4904 & 4650 & 15302 & 14116 & 10,3 & 2,5 & 2,0 & 509,0 \\
\hline 16 & 4768 & 4543 & 11247 & 10450 & 13,2 & 4,0 & 3,0 & 504,5 \\
\hline 17 & 4849 & 4634 & 15722 & 14677 & 4,5 & 1,7 & 2,0 & 516,0 \\
\hline 18 & 5035 & 4829 & 15566 & 14612 & 11,8 & 5,0 & 4,4 & 500,0 \\
\hline 19 & 4781 & 4593 & 14980 & 14097 & 7,1 & 1,9 & 1,8 & 407,5 \\
\hline 20 & 5204 & 5008 & 18105 & 17085 & 6,0 & 2,1 & & 527,0 \\
\hline 21 & 5057 & 4870 & 13778 & 13016 & 20,1 & 4,2 & 3,5 & 506,9 \\
\hline 22 & 4414 & 4264 & 11877 & 11270 & 2,6 & 1,7 & 1,3 & 417,0 \\
\hline 23 & 4503 & 4353 & 12403 & 11782 & 18,0 & 4,9 & 4,8 & 400,0 \\
\hline 24 & 4919 & 4755 & 14453 & 13733 & 9,7 & 4,0 & 2,4 & 505,3 \\
\hline 25 & 5068 & 4904 & 16452 & 15653 & & 1,4 & & 505,8 \\
\hline 26 & 4893 & 4739 & 13539 & 12900 & 7,6 & 2,8 & 2,4 & 514,4 \\
\hline 27 & 4976 & 4828 & 14214 & 13580 & 14,7 & 4,6 & 3,7 & 513,0 \\
\hline 28 & 4071 & 3955 & 10110 & 9677 & 18,5 & 5,6 & 5,0 & 505,4 \\
\hline 29 & 4734 & 4619 & 12882 & 12410 & 7,5 & 2,5 & 2,8 & 400,2 \\
\hline 30 & 4773 & 4663 & 13461 & 12996 & 4,8 & 1,6 & 1,5 & 511,0 \\
\hline 31 & 4510 & 4411 & 12216 & 11815 & 23,5 & 6,8 & 5,6 & 512,0 \\
\hline 32 & 4759 & 4655 & 16353 & 15817 & 11,8 & 2,9 & 3,3 & 518,6 \\
\hline 33 & 4845 & 4741 & 15263 & 14773 & 8,4 & 3,0 & 3,4 & 405,5 \\
\hline 34 & 4989 & 4918 & 14468 & 14158 & 12,6 & 4,4 & 2,8 & 507,4 \\
\hline 35 & 4802 & 4734 & 14972 & 14657 & 6,3 & 2,1 & 1,6 & 509,3 \\
\hline 36 & 4092 & 4042 & 11708 & 11493 & 27,0 & 6,6 & 6,5 & 375,0 \\
\hline 37 & 4517 & 4475 & 13359 & 13173 & 7,8 & 3,7 & 3,6 & 517,0 \\
\hline 38 & 4592 & 4556 & 13100 & 12945 & 16,8 & 3,6 & 4,3 & 405,0 \\
\hline 39 & 4844 & 4807 & 14777 & 14607 & 8,1 & 2,6 & 2,1 & 511,9 \\
\hline 40 & 4675 & 4650 & 12022 & 11926 & 4,8 & 2,2 & 2,5 & 516,6 \\
\hline 41 & 7458 & 7460 & 35203 & 35211 & 15,7 & 8,1 & 3,7 & 500,0 \\
\hline 42 & 4243 & 4244 & 8522 & 8524 & 7,6 & 2,4 & 1,7 & 115,0 \\
\hline 43 & 5239 & 5248 & 15173 & 15213 & 3,2 & 2,3 & 1,7 & 8,0 \\
\hline 44 & 5055 & 5074 & 14122 & 14202 & 16,8 & 4,3 & 3,9 & 304,0 \\
\hline 45 & 4528 & 4547 & 12464 & 12541 & 6,4 & 2,2 & 1,8 & 517,0 \\
\hline 46 & 4821 & 4847 & 12682 & 12785 & 13,9 & 4,2 & 3,3 & 283,0 \\
\hline 47 & 4650 & 4679 & 10212 & 10307 & 3,6 & 2,2 & 1,7 & 205,0 \\
\hline 48 & 5066 & 5099 & 14779 & 14921 & 4,9 & 1,8 & 1,8 & 306,0 \\
\hline 49 & 4647 & 4679 & 13408 & 13549 & 4,6 & 2,1 & 1,6 & 510,2 \\
\hline 50 & 4654 & 4704 & 13076 & 13284 & 7,3 & 3,5 & 1,6 & 404 \\
\hline 51 & 4998 & 5063 & 14617 & 14905 & 11,6 & 3,4 & 2,5 & 303,7 \\
\hline 52 & 4100 & 4157 & 12735 & 12999 & 22,8 & 6,6 & 6,1 & 514,0 \\
\hline 53 & 4992 & 5061 & 13061 & 13333 & 9,3 & 2,2 & 2,6 & 508,0 \\
\hline 54 & 4331 & 4400 & 12766 & 13068 & 28,4 & 5,5 & 6,4 & 200,0 \\
\hline
\end{tabular}




\begin{tabular}{|c|c|c|c|c|c|c|c|c|}
\hline 55 & 4849 & 4927 & 13758 & 14090 & 14,0 & 2,7 & 2,1 & 510,0 \\
\hline 56 & 4521 & 4603 & 11636 & 11953 & 10,1 & 3,4 & 3,3 & 517,0 \\
\hline 57 & 4684 & 4772 & 14458 & 14861 & 10,3 & 2,4 & 2,4 & 522,0 \\
\hline 58 & 5062 & 5161 & 15975 & 16445 & 10,2 & 2,4 & 2,6 & 408,5 \\
\hline 59 & 4821 & 4918 & 11735 & 12090 & 11,8 & 3,1 & 2,7 & 342,0 \\
\hline 60 & 5080 & 5185 & 16504 & 17013 & 15,1 & 3,4 & 3,2 & 508,0 \\
\hline 61 & 4915 & 5020 & 14329 & 14787 & 15,1 & 4,5 & 2,3 & 308,0 \\
\hline 62 & 4446 & 4548 & 10581 & 10944 & 10,1 & 2,6 & 2,1 & 407,0 \\
\hline 63 & 4777 & 4888 & 14374 & 14871 & 5,1 & 2,5 & 1,8 & 304,0 \\
\hline 64 & 4798 & 4913 & 14774 & 15308 & 14,2 & 2,6 & 2,3 & 508,1 \\
\hline 65 & 4847 & 4967 & 14121 & 14649 & 14,5 & 3,7 & 3,4 & 305,5 \\
\hline 66 & 4629 & 4750 & 13499 & 14028 & 12,5 & 3,9 & 3,8 & 286,4 \\
\hline 67 & 4995 & 5135 & 14177 & 14773 & 17,4 & 3,3 & 3,2 & 523,0 \\
\hline 68 & 4331 & 4455 & 9022 & 9410 & 8,4 & 4,8 & 3,6 & 86,0 \\
\hline 69 & 5318 & 5474 & 15429 & 16105 & 10,9 & 2,4 & 1,6 & 308,1 \\
\hline 70 & 4868 & 5011 & 13911 & 14523 & 8,4 & 2,9 & 1,8 & 236,0 \\
\hline 71 & 4579 & 4714 & 9698 & 10127 & 10,1 & 3,1 & 3,0 & 233,0 \\
\hline 72 & 5345 & 5503 & 15210 & 15884 & 5,2 & 2,5 & 3,7 & 303,4 \\
\hline 73 & 4989 & 5143 & 14237 & 14896 & 11,8 & 3,7 & 3,0 & 507,0 \\
\hline 74 & 4619 & 4766 & 14243 & 14919 & 14,2 & 2,2 & 3,2 & 516,3 \\
\hline 75 & 4733 & 4884 & 12812 & 13424 & 15,4 & 4,0 & 3,6 & 406,6 \\
\hline 76 & 4784 & 4940 & 12285 & 12884 & 12,2 & 3,0 & 2,1 & 216,0 \\
\hline 77 & 5082 & 5253 & 13752 & 14447 & 11,2 & 2,0 & 2,2 & 187,0 \\
\hline 78 & 4820 & 4983 & 13286 & 13960 & 12,2 & 4,2 & 3,1 & 271,0 \\
\hline 79 & 5218 & 5411 & 17700 & 18678 & 6,9 & 2,1 & 3,6 & 297,8 \\
\hline 80 & 5069 & 5268 & 14441 & 15291 & 8,1 & 3,7 & 3,0 & 158,0 \\
\hline 81 & 4651 & 4846 & 16204 & 17225 & 15,4 & 3,9 & 3,6 & 406,0 \\
\hline 82 & 4841 & 5048 & 13154 & 13994 & 17,9 & 3,6 & 3,4 & 303,4 \\
\hline 83 & 4438 & 4629 & 10064 & 10713 & 5,5 & 1,6 & 1,6 & 123,0 \\
\hline 84 & 4855 & 5064 & 10592 & 11276 & 15,2 & 3,3 & 3,4 & 92,0 \\
\hline 85 & 4546 & 4747 & 11779 & 12562 & 7,8 & 2,4 & 2,2 & 210,0 \\
\hline 86 & 4576 & 4780 & 12560 & 13401 & 4,3 & 1,7 & 1,4 & 212,0 \\
\hline 87 & 4939 & 5161 & 13509 & 14420 & 6,5 & 2,3 & 2,6 & 223,0 \\
\hline 88 & 4733 & 4953 & 11329 & 12117 & 6,3 & 2,1 & 1,8 & 234,0 \\
\hline 89 & 4847 & 5073 & 14528 & 15545 & 14,1 & 3,7 & 4,6 & 303,6 \\
\hline 90 & 4723 & 4944 & 15620 & 16714 & 5,9 & 2,7 & 2,9 & 497,0 \\
\hline 91 & 4826 & 5054 & 12835 & 13744 & 6,9 & 1,7 & 1,6 & 251,0 \\
\hline 92 & 4042 & 4233 & 10371 & 11108 & 8,7 & 2,6 & 3,9 & 234,0 \\
\hline 93 & 4564 & 4784 & 12829 & 13754 & 14,8 & 3,1 & 4,0 & 304,9 \\
\hline 94 & 4601 & 4822 & 10329 & 11074 & 9,4 & 2,5 & 3,8 & 217,0 \\
\hline 95 & 4990 & 5231 & 13688 & 14676 & 11,8 & 2,6 & 3,1 & 305,4 \\
\hline 96 & 4922 & 5161 & 13175 & 14134 & 16,4 & 3,7 & 3,4 & 307,8 \\
\hline 97 & 4649 & 4875 & 11768 & 12624 & 2,0 & 1,2 & 1,5 & 111,0 \\
\hline 98 & 4884 & 5121 & 15992 & 17157 & 12,4 & 3,5 & 4,1 & 305,4 \\
\hline 99 & 4388 & 4602 & 13721 & 14725 & 6,2 & 2,2 & 1,9 & 406,5 \\
\hline 100 & 5123 & 5375 & 13032 & 13994 & 4,1 & 1,7 & 1,6 & 107,0 \\
\hline 101 & 4509 & 4737 & 10318 & 11099 & 3,8 & 2,3 & 2,7 & 37,0 \\
\hline 102 & 5068 & 5327 & 12869 & 13856 & 7,1 & 2,6 & 2,5 & 297,0 \\
\hline 103 & 4674 & 4916 & 9322 & 10045 & 7,6 & 2,4 & 2,1 & 56,0 \\
\hline 104 & 4877 & 5131 & 10518 & 11340 & 2,4 & 1,4 & 1,0 & 63,0 \\
\hline 105 & 5069 & 5335 & 14683 & 15839 & 5,3 & 1,7 & 2,0 & 303,5 \\
\hline 106 & 4518 & 4759 & 13047 & 14094 & 6,1 & 2,3 & 2,4 & 515,0 \\
\hline 107 & 4993 & 5263 & 15388 & 16634 & 8,2 & 2,0 & 2,0 & 300,9 \\
\hline 108 & 5031 & 5305 & 15701 & 16981 & 19,8 & 5,0 & 3,3 & 512,0 \\
\hline 109 & 5128 & 5409 & 15304 & 16559 & 4,4 & 2,7 & 1,7 & 275,0 \\
\hline 110 & 4961 & 5233 & 14854 & 16073 & 4,6 & 1,2 & 3,0 & 300,8 \\
\hline 111 & 4369 & 4609 & 11171 & 12090 & 4,1 & 1,3 & 2,5 & 107,0 \\
\hline 112 & 4979 & 5254 & 13587 & 14710 & 8,7 & 2,0 & 1,4 & 256,0 \\
\hline
\end{tabular}




\begin{tabular}{|c|c|c|c|c|c|c|c|c|}
\hline 113 & 4933 & 5205 & 13342 & 14447 & 4,5 & 2,5 & 2,5 & 276,0 \\
\hline 114 & 5070 & 5354 & 13449 & 14577 & 7,8 & 2,4 & 1,5 & 103,0 \\
\hline 115 & 4716 & 4983 & 13910 & 15087 & 11,9 & 3,4 & 3,6 & 271,0 \\
\hline 116 & 4886 & 5169 & 13265 & 14417 & 8,0 & 3,0 & 2,6 & 237,0 \\
\hline 117 & 4527 & 4789 & 10296 & 11190 & 6,9 & 2,8 & 2,3 & 253,0 \\
\hline 118 & 4712 & 4985 & 12122 & 13176 & 7,9 & 2,0 & 1,8 & 302,8 \\
\hline 119 & 4870 & 5153 & 12648 & 13751 & 5,4 & 2,6 & 2,0 & 305,5 \\
\hline 120 & 4875 & 5161 & 13634 & 14831 & 12,5 & 3,7 & 2,8 & 304,7 \\
\hline 121 & 4509 & 4777 & 12974 & 14129 & 9,6 & 3,1 & 2,7 & 306,9 \\
\hline 122 & 4640 & 4918 & 12223 & 13317 & 13,7 & 2,5 & 3,3 & \\
\hline 123 & 4723 & 5006 & 12210 & 13306 & 11,5 & 3,2 & 1,4 & 226,0 \\
\hline 124 & 4961 & 5259 & 14467 & 15768 & 7,0 & 2,5 & 3,0 & 295,0 \\
\hline 125 & 4419 & 4684 & 11274 & 12290 & 13,8 & 3,8 & 3,4 & 110,0 \\
\hline 126 & 4943 & 5242 & 14340 & 15636 & 11,1 & 2,4 & 2,0 & 295,0 \\
\hline 127 & 5132 & 5442 & 14564 & 15881 & 7,0 & 2,1 & 1,8 & 237,0 \\
\hline 128 & 4606 & 4884 & 12589 & 13728 & 8,7 & 4,6 & 3,7 & 251,0 \\
\hline 129 & 4615 & 4895 & 11681 & 12741 & 9,9 & 3,7 & 2,0 & 86,0 \\
\hline 130 & 5103 & 5413 & 13392 & 14609 & 9,6 & 2,9 & 2,5 & 305,0 \\
\hline 131 & 4727 & 5015 & 13603 & 14845 & 9,6 & 3,1 & 3,6 & 298,0 \\
\hline 132 & 4661 & 4945 & 12180 & 13294 & 13,9 & 3,2 & 2,9 & 175,0 \\
\hline 133 & 4697 & 4985 & 12038 & 13144 & 5,5 & 1,7 & 1,8 & 67,0 \\
\hline 134 & 5005 & 5314 & 14159 & 15469 & 2,8 & 1,6 & & 505,0 \\
\hline 135 & 4665 & 4953 & 14074 & 15377 & 9,5 & 3,4 & 3,5 & 279,0 \\
\hline 136 & 4785 & 5084 & 15794 & 17271 & 8,4 & 4,5 & 3,0 & 201,0 \\
\hline 137 & 4794 & 5095 & 13320 & 14572 & 12,9 & 2,9 & 2,5 & 225,0 \\
\hline 138 & 4324 & 4596 & 11339 & 12408 & 11,4 & 2,7 & 2,2 & 407,2 \\
\hline 139 & 5088 & 5409 & 17302 & 18940 & 13,5 & 2,3 & 2,4 & 513,2 \\
\hline 140 & 4395 & 4674 & 12880 & 14104 & 3,4 & 1,9 & 1,1 & 256,0 \\
\hline 141 & 4781 & 5086 & 12320 & 13496 & 3,4 & 1,5 & 2,5 & 236,0 \\
\hline 142 & 4879 & 5192 & 14656 & 16065 & 12,7 & 2,6 & 3,1 & 408,5 \\
\hline 143 & 4823 & 5133 & 13946 & 15291 & 11,3 & 2,6 & 2,8 & 293,4 \\
\hline 144 & 5106 & 5435 & 12296 & 13483 & 4,6 & 2,8 & 1,1 & \\
\hline 145 & 4598 & 4895 & 9873 & 10828 & 9,2 & 2,4 & 1,8 & 507,2 \\
\hline 146 & 4512 & 4805 & 13253 & 14542 & 12,6 & 3,1 & 3,0 & 306,5 \\
\hline 147 & 4245 & 4522 & 11247 & 12344 & 11,7 & 3,4 & 3,3 & 195,0 \\
\hline 148 & 5021 & 5349 & 14048 & 15420 & 5,4 & 1,2 & 1,8 & 165,0 \\
\hline 149 & 5062 & 5392 & 14138 & 15520 & 7,8 & 2,8 & 2,6 & 403,1 \\
\hline 150 & 4945 & 5269 & 12022 & 13200 & 8,5 & 2,5 & 1,8 & 251,0 \\
\hline 151 & 4804 & 5119 & 12353 & 13565 & 9,7 & 2,8 & 4,6 & 102,0 \\
\hline 152 & 4788 & 5102 & 13096 & 14382 & 6,9 & 1,5 & 1,6 & 272,0 \\
\hline 153 & 4976 & 5303 & 13842 & 15204 & 13,3 & 3,7 & 3,5 & 258,0 \\
\hline 154 & 5306 & 5656 & 16518 & 18147 & 5,5 & 1,6 & 2,2 & 307,6 \\
\hline 155 & 4989 & 5318 & 15939 & 17514 & 11,4 & 3,9 & 2,4 & 307,0 \\
\hline 156 & 4762 & 5079 & 13860 & 15240 & 12,0 & 2,3 & 3,2 & 217,0 \\
\hline 157 & 4744 & 5060 & 11556 & 12709 & 6,8 & 1,6 & 1,5 & 1111,0 \\
\hline 158 & 5026 & 5361 & 12878 & 14163 & 6,1 & 3,0 & 2,1 & \\
\hline 159 & 4947 & 5278 & 12740 & 14014 & 6,8 & 1,9 & 2,4 & 132,0 \\
\hline 160 & 4513 & 4816 & 11057 & 12166 & 10,5 & 3,3 & 2,9 & 176,0 \\
\hline 161 & 4923 & 5255 & 13210 & 14545 & 8,7 & 3,7 & 4,8 & 69,0 \\
\hline 162 & 4676 & 4994 & 13881 & 15296 & 17,0 & 4,1 & 4,0 & 408,5 \\
\hline 163 & 4453 & 4756 & 11830 & 13037 & 12,3 & 4,0 & 3,7 & 137,0 \\
\hline 164 & 5065 & 5410 & 14153 & 15598 & 6,7 & 2,2 & 2,1 & 400,5 \\
\hline 165 & 4957 & 5297 & 14002 & 15441 & 8,4 & 2,5 & 1,8 & 294,1 \\
\hline 166 & 5155 & 5512 & 16420 & 18121 & 6,0 & 2,4 & 2,0 & 404,0 \\
\hline 167 & 4855 & 5190 & 12518 & 13816 & 9,3 & 2,6 & 1,7 & 221 \\
\hline 168 & 4631 & 4952 & 12989 & 14336 & 10,1 & 3,3 & 2,8 & 406,3 \\
\hline 169 & 4762 & 5092 & 12535 & 13835 & 3,1 & 1,6 & & 154,0 \\
\hline 170 & 4849 & 5185 & 13268 & 14646 & 14,2 & 3,6 & 3,5 & \\
\hline
\end{tabular}




\begin{tabular}{|c|c|c|c|c|c|c|c|c|}
\hline 171 & 4994 & 5340 & 12663 & 13978 & 5,1 & 2,4 & 2,0 & 488,0 \\
\hline 172 & 5280 & 5652 & 16595 & 18343 & 4,4 & 1,9 & 1,5 & 157,0 \\
\hline 173 & 5029 & 5386 & 16546 & 18302 & 9,1 & 3,3 & 2,0 & 404,2 \\
\hline 174 & 4662 & 4992 & 12185 & 13478 & 9,8 & 3,1 & 3,3 & 282,0 \\
\hline 175 & 4750 & 5087 & 12227 & 13528 & 7,9 & 3,6 & 2,8 & 514,7 \\
\hline 176 & 4620 & 4949 & 10777 & 11925 & 9,3 & 2,0 & 2,5 & 71,0 \\
\hline 177 & 4868 & 5214 & 13659 & 15114 & 11,7 & 2,0 & 3,0 & 284,6 \\
\hline 178 & 4822 & 5166 & 15153 & 16772 & 7,9 & 2,2 & 2,2 & 263,0 \\
\hline 179 & 4765 & 5106 & 13026 & 14420 & 7,9 & 1,7 & 1,6 & 169,0 \\
\hline 180 & 4561 & 4892 & 10284 & 11402 & 10,1 & 2,1 & 3,1 & 215,0 \\
\hline 181 & 4964 & 5326 & 13298 & 14753 & 3,0 & 1,9 & 1,2 & 125,0 \\
\hline 182 & 4729 & 5077 & 12918 & 14339 & 9,1 & 2,7 & 2,8 & 285,5 \\
\hline 183 & 4828 & 5183 & 12379 & 13742 & 9,8 & 2,6 & 3,9 & 223,0 \\
\hline 184 & 5084 & 5459 & 15432 & 17134 & 11,8 & 2,5 & 2,7 & 531,0 \\
\hline 185 & 5037 & 5410 & 13991 & 15544 & 6,7 & 2,3 & 2,1 & 288,0 \\
\hline 186 & 4709 & 5060 & 13096 & 14555 & 6,8 & 3,4 & 3,0 & 242,0 \\
\hline 187 & 4469 & 4801 & 10291 & 11438 & 12,1 & 2,4 & 2,5 & 95,0 \\
\hline 188 & 4842 & 5203 & 13487 & 14992 & 9,9 & 3,5 & 3,0 & 246,0 \\
\hline 189 & 4505 & 4841 & 13065 & 14523 & 18,0 & 5,8 & 5,4 & 513,0 \\
\hline 190 & 4848 & 5209 & 14002 & 15565 & 7,2 & 3,3 & 3,1 & 408,5 \\
\hline 191 & 5013 & 5388 & 16656 & 18519 & 3,6 & 1,3 & 1,9 & 258,0 \\
\hline 192 & 4644 & 4992 & 11672 & 12983 & 9,2 & 2,9 & 2,9 & 88,0 \\
\hline 193 & 4809 & 5170 & 12854 & 14297 & 12,8 & 3,1 & 2,5 & 168,0 \\
\hline 194 & 5175 & 5565 & 15707 & 17480 & 6,1 & 2,1 & & 135,5 \\
\hline 195 & 4848 & 5216 & 14400 & 16034 & 11,4 & 2,7 & 4,5 & 405,0 \\
\hline 196 & 4877 & 5251 & 11106 & 12380 & 6,3 & 1,8 & 2,1 & 102,0 \\
\hline 197 & 5069 & 5457 & 13740 & 15316 & 9,0 & 3,3 & 3,5 & 203,0 \\
\hline 198 & 4757 & 5122 & 11850 & 13209 & 3,8 & 1,3 & 1,2 & 59,0 \\
\hline 199 & 4474 & 4819 & 11893 & 13269 & 6,3 & 2,8 & 2,3 & 141,0 \\
\hline 200 & 4832 & 5209 & 15326 & 17117 & 5,5 & 1,9 & 1,9 & 73,0 \\
\hline 201 & 4790 & 5165 & 11849 & 13241 & 13,6 & 4,1 & 5,4 & 506,1 \\
\hline 202 & 4996 & 5391 & 15801 & 17671 & 8 & 1,5 & 1,7 & 407,0 \\
\hline 203 & 4785 & 5163 & 14704 & 16444 & 8,0 & 2,4 & 2,5 & 123,0 \\
\hline 204 & 4566 & 4927 & 11790 & 13188 & 11,4 & 2,9 & 2,7 & 370,0 \\
\hline 205 & 5156 & 5565 & 14828 & 16588 & 5,5 & 1,4 & 1,4 & 303,7 \\
\hline 206 & 4281 & 4622 & 11532 & 12904 & 6,8 & 4,4 & 3,4 & 162,0 \\
\hline 207 & 4796 & 5180 & 12679 & 14197 & 7,5 & 3,0 & 2,8 & 265,0 \\
\hline 208 & 4922 & 5315 & 15112 & 16921 & 7,6 & 2,2 & 2,0 & 245,0 \\
\hline 209 & 4417 & 4773 & 12372 & 13868 & 3,1 & 1,7 & 1,3 & 468,0 \\
\hline 210 & 4962 & 5364 & 12863 & 14425 & 4,8 & 1,8 & 2,5 & 36,0 \\
\hline 211 & 5025 & 5436 & 13152 & 14761 & 4,0 & 2,6 & 1,7 & 177,0 \\
\hline 212 & 4782 & 5175 & 13863 & 15569 & 10,6 & 3,2 & 3,1 & 409,0 \\
\hline 213 & 4611 & 4990 & 12614 & 14168 & 11,9 & 3,0 & 2,6 & 296,0 \\
\hline 214 & 4350 & 4709 & 13890 & 15608 & 19,7 & 5,5 & 4,7 & 524,0 \\
\hline 215 & 5182 & 5612 & 14838 & 16680 & 4,7 & 2,6 & 1,8 & 279,0 \\
\hline 216 & 4608 & 4995 & 13193 & 14850 & 13,0 & 3,4 & 3,0 & 284,0 \\
\hline 217 & 4967 & 5386 & 14400 & 16218 & 9,7 & 2,8 & 3,4 & 406,6 \\
\hline 218 & 4528 & 4917 & 12678 & 14307 & 17,2 & 5,7 & 2,8 & 408,0 \\
\hline 219 & 4748 & 5159 & 12643 & 14281 & 8,6 & 3,6 & 4,1 & 229,0 \\
\hline 220 & 4530 & 4922 & 13062 & 14755 & 9,6 & 4,8 & 3,4 & 304,7 \\
\hline 221 & 4733 & 5145 & 10690 & 12082 & 10,4 & 3,0 & 2,2 & 413,5 \\
\hline 222 & 4619 & 5023 & 14417 & 16303 & 12,3 & 2,9 & 3,2 & 243,0 \\
\hline 223 & 4589 & 4992 & 15569 & 17616 & 7,6 & 3,6 & 3,5 & 409,8 \\
\hline 224 & 4511 & 4910 & 10870 & 12306 & 10,4 & 2,2 & 2,0 & 251,0 \\
\hline 225 & 4740 & 5161 & 15313 & 17347 & 16,3 & 4,5 & 3,7 & 403,4 \\
\hline 226 & 4773 & 5197 & 13563 & 15365 & 9,5 & 3,9 & 3,1 & 406,7 \\
\hline 227 & 4302 & 4685 & 8634 & 9781 & 9,8 & 2,6 & 2,4 & 104,0 \\
\hline 228 & 4405 & 4798 & 9087 & 10300 & 3,5 & 1,5 & 1,5 & \\
\hline
\end{tabular}




\begin{tabular}{|c|c|c|c|c|c|c|c|c|}
\hline 229 & 4612 & 5024 & 12985 & 14719 & 8,4 & 2,7 & 4,3 & 242,0 \\
\hline 230 & 4788 & 5219 & 15190 & 17236 & 14,6 & 2,8 & 2,2 & 364,0 \\
\hline 231 & 4844 & 5283 & 13077 & 14848 & 8,5 & 2,7 & 1,8 & 187,0 \\
\hline 232 & 4241 & 4629 & 9494 & 10791 & 7,6 & 1,6 & 1,9 & 150,0 \\
\hline 233 & 4646 & 5071 & 11276 & 12819 & 7,1 & 3,5 & 2,2 & 506,9 \\
\hline 234 & 5173 & 5646 & 16099 & 18305 & 3,9 & 1,8 & 2,4 & 254,0 \\
\hline 235 & 4332 & 4729 & 10930 & 12431 & 10,2 & 2,7 & 3,2 & 347,0 \\
\hline 236 & 4858 & 5306 & 14883 & 16934 & 6,5 & 2,2 & 2,4 & 517,4 \\
\hline 237 & 4543 & 4963 & 12372 & 14084 & 11,4 & 4,3 & 4,0 & 404,0 \\
\hline 238 & 4668 & 5103 & 13730 & 15642 & 14,7 & 3,5 & 3,8 & 256,0 \\
\hline 239 & 4521 & 4944 & 10379 & 11833 & 9,3 & 2,7 & 2,6 & 62,0 \\
\hline 240 & 4891 & 5352 & 13009 & 14843 & 12,7 & 2,8 & 3,0 & 244,0 \\
\hline 241 & 4632 & 5069 & 13908 & 15869 & 15,6 & 3,4 & 4,7 & 243,0 \\
\hline 242 & 5013 & 5486 & 11406 & 13016 & 4,5 & 1,9 & 3,1 & 299,0 \\
\hline 243 & 4321 & 4730 & 12903 & 14729 & 8,3 & 5,2 & 3,4 & 518,0 \\
\hline 244 & 4851 & 5313 & 14945 & 17073 & 9,4 & 2,5 & 2,0 & 402,5 \\
\hline 245 & 5134 & 5627 & 16221 & 18552 & 3,7 & 2,1 & 2,4 & 407,6 \\
\hline 246 & 4870 & 5340 & 14601 & 16707 & 14,8 & 3,8 & 2,4 & 300,0 \\
\hline 247 & 4200 & 4607 & 9343 & 10697 & 3,8 & 1,5 & 2,3 & 105,0 \\
\hline 248 & 4463 & 4897 & 12951 & 14835 & 8,2 & 3,5 & 2,7 & 300,0 \\
\hline 249 & 4674 & 5130 & 14502 & 16618 & 180,0 & 5,5 & 6,3 & 406,0 \\
\hline 250 & 4559 & 5009 & 14354 & 16475 & 25,2 & 4,8 & 5,7 & 300,0 \\
\hline 251 & 4420 & 4858 & 12232 & 14043 & 15,1 & 4,6 & 3,8 & 405,5 \\
\hline 252 & 4896 & 5386 & 15617 & 17956 & 6,0 & 2,8 & 1,7 & 407,0 \\
\hline 253 & 4959 & 5456 & 14955 & 17196 & 3,2 & 1,7 & 1,4 & 173,0 \\
\hline 254 & 4741 & 5217 & 14441 & 16607 & 8,7 & 4,9 & 4,3 & 407,6 \\
\hline 255 & 4889 & 5389 & 14418 & 16619 & 9,6 & 2,7 & 2,5 & 404,5 \\
\hline 256 & 4834 & 5329 & 14671 & 16917 & 8,4 & 2,6 & 2,4 & 404,7 \\
\hline 257 & 5080 & 5601 & 18726 & 21596 & 8,2 & 2,3 & 1,6 & 407,4 \\
\hline 258 & 4534 & 5000 & 11921 & 13752 & 6,8 & 3,2 & 2,6 & 36,0 \\
\hline 259 & 5033 & 5552 & 15439 & 17816 & 6,0 & 3,4 & 2,8 & 285,0 \\
\hline 260 & 4645 & 5135 & 14946 & 17303 & 4,0 & 2,0 & & 512,0 \\
\hline 261 & 4418 & 4886 & 11787 & 13652 & 11,8 & 3,5 & 2,7 & 126,0 \\
\hline 262 & 4966 & 5492 & 16525 & 19141 & 6,8 & 2,9 & 3,0 & 276,0 \\
\hline 263 & 4617 & 5108 & 14214 & 16470 & 14,9 & 4,0 & 3,8 & 515,0 \\
\hline 264 & 4973 & 5503 & 15741 & 18244 & 9,4 & 3,0 & 2,3 & 404,0 \\
\hline 265 & 4766 & 5275 & 14625 & 16959 & 9,1 & 3,3 & 2,5 & 111,0 \\
\hline 266 & 4900 & 5424 & 15907 & 18449 & 10,1 & 2,3 & 3,0 & 402,8 \\
\hline 267 & 4445 & 4923 & 13074 & 15173 & 9,8 & 2,7 & 2,0 & 407,3 \\
\hline 268 & 4574 & 5068 & 13146 & 15269 & 17,3 & 5,3 & 3,7 & 157,0 \\
\hline 269 & 5078 & 5628 & 14447 & 16783 & 10,7 & 2,6 & 2,6 & 315,7 \\
\hline 270 & 4478 & 4963 & 11791 & 13698 & 8,5 & 3,1 & 2,1 & 403,5 \\
\hline 271 & 4574 & 5071 & 14115 & 16408 & 8,4 & 3,6 & 2,2 & 406,0 \\
\hline 272 & 4657 & 5166 & 11729 & 13643 & 10,9 & 2,4 & 1,9 & 147,0 \\
\hline 273 & 4904 & 5443 & 13539 & 15763 & 8,3 & 2,2 & 2,5 & 293,0 \\
\hline 274 & 5126 & 5696 & 15385 & 17940 & 12,3 & 3,6 & 2,7 & 215 \\
\hline 275 & 6459 & 7181 & 21718 & 25349 & 9,4 & 3,5 & 2,3 & 450,0 \\
\hline 276 & 4500 & 5005 & 12760 & 14898 & 11,3 & 2,7 & 3,1 & 174,0 \\
\hline 277 & 4610 & 5129 & 13472 & 15739 & 9,1 & 2,9 & 3,1 & 453,0 \\
\hline 278 & 4477 & 4985 & 11995 & 14024 & 17,4 & 5,2 & 3,8 & 517,0 \\
\hline 279 & 4586 & 5106 & 10917 & 12765 & 14,5 & 4,5 & 3,6 & 407,7 \\
\hline 280 & 4954 & 5519 & 14755 & 17268 & 11,0 & 4,5 & 3,9 & 523,0 \\
\hline 281 & 4522 & 5044 & 12601 & 14778 & 15,1 & 4,3 & 3,8 & 409,0 \\
\hline 282 & 4907 & 5479 & 14308 & 16799 & 6,1 & 2,4 & 2,4 & 405,0 \\
\hline 283 & 4448 & 4980 & 13558 & 15975 & 7,4 & 2,3 & 1,2 & 410,0 \\
\hline 284 & 4812 & 5389 & 12260 & 14456 & 6,1 & 2,7 & 2,1 & 110,0 \\
\hline 285 & 4646 & 5204 & 13199 & 15566 & 6,7 & 2,7 & 2,9 & 144,0 \\
\hline 286 & 4574 & 5124 & 12911 & 15231 & 8,1 & 3,7 & 2,6 & 400,0 \\
\hline
\end{tabular}




\begin{tabular}{|c|c|c|c|c|c|c|c|c|}
\hline 287 & 4996 & 5604 & 14133 & 16697 & 11,1 & 3,5 & 3,8 & 307,6 \\
\hline 288 & 4512 & 5062 & 13736 & 16238 & 7,4 & 2,3 & 3,3 & 231,0 \\
\hline 289 & 5002 & 5614 & 15579 & 18427 & 1,0 & 1,0 & & 507,0 \\
\hline 290 & 4933 & 5538 & 13435 & 15891 & 7,1 & 2,0 & 1,5 & 242,0 \\
\hline 291 & 4376 & 4917 & 11573 & 13710 & 16,6 & 3,1 & 3,5 & \\
\hline 292 & 4611 & 5182 & 12776 & 15139 & 12,9 & 3,6 & 2,7 & 405,0 \\
\hline 293 & 4214 & 4740 & 10364 & 12294 & 10,6 & 2,5 & 2,5 & 249,0 \\
\hline 294 & 4596 & 5170 & 13138 & 15588 & 17,3 & 4,0 & 3,6 & 409,0 \\
\hline 295 & 7504 & 8445 & 32041 & 38040 & 17,2 & 5,9 & 3,2 & 520,0 \\
\hline 296 & 4531 & 5102 & 11947 & 14193 & 4,7 & 2,1 & 1,1 & 210,0 \\
\hline 297 & 4524 & 5094 & 10898 & 12948 & 6,6 & 2,9 & 2,3 & 527,3 \\
\hline 298 & 4408 & 4964 & 13999 & 16634 & 13,0 & 4,9 & 4,8 & 396,0 \\
\hline 299 & 6684 & 7528 & 25424 & 30211 & 6,1 & 3,2 & 2,1 & 500,0 \\
\hline 300 & 4358 & 4911 & 10466 & 12447 & 8,9 & 2,8 & 1,7 & 155,0 \\
\hline 301 & 4931 & 5559 & 15789 & 18789 & 4,5 & 2,5 & 2,1 & \\
\hline 302 & 4394 & 4961 & 13214 & 15757 & 9,7 & 4,5 & 3,9 & 511,0 \\
\hline 303 & 4366 & 4934 & 11081 & 13229 & 10,3 & 4,0 & 2,9 & 512,0 \\
\hline 304 & 4211 & 4758 & 11066 & 13212 & 9,5 & 2,8 & 3,2 & 408,0 \\
\hline 305 & 4672 & 5280 & 13068 & 15602 & 4,8 & 2,0 & 2,1 & 356,5 \\
\hline 306 & 4604 & 5204 & 14344 & 17130 & 10,4 & 3,6 & 2,0 & 403,5 \\
\hline 307 & 4678 & 5291 & 15953 & 19074 & 7,1 & 1,9 & 2,7 & 406,5 \\
\hline 308 & 4492 & 5086 & 13280 & 15896 & 8,5 & 2,2 & 1,8 & 357,0 \\
\hline 309 & 4795 & 5429 & 13038 & 15610 & 4,8 & 2,5 & 3,1 & 156,0 \\
\hline 310 & & & & & 5,9 & 3,5 & 1,6 & 520,0 \\
\hline 311 & 4437 & 5029 & 12681 & 15201 & 6,7 & 2,8 & 2,1 & 306,0 \\
\hline 312 & 4778 & 5416 & 14765 & 17703 & 8,3 & 2,7 & 3,0 & 406,0 \\
\hline 313 & 4694 & 5322 & 14655 & 17580 & 6,1 & 2,0 & 2,4 & 515,0 \\
\hline 314 & 4771 & 5411 & 13820 & 16584 & 11,8 & 2,9 & 2,7 & 403,5 \\
\hline 315 & 4298 & 4875 & 11024 & 13232 & 13,6 & 4,5 & 3,5 & 506,0 \\
\hline 316 & 4458 & 5061 & 12701 & 15264 & 4,8 & 2,5 & 1,9 & 520,0 \\
\hline 317 & 4814 & 5466 & 15940 & 19159 & 15,4 & 3,4 & 2,8 & 405,0 \\
\hline 318 & 4732 & 5384 & 15128 & 18231 & 13,7 & 2,7 & 2,9 & 510,0 \\
\hline 319 & 4805 & 5473 & 13377 & 16147 & 11,1 & 2,3 & 2,2 & 403,5 \\
\hline 320 & 4866 & 5551 & 14217 & 17202 & 17,3 & 3,1 & 3,1 & 398,0 \\
\hline 321 & 4694 & 5363 & 12253 & 14854 & 9,7 & 3,4 & 3,4 & 267,0 \\
\hline 322 & 4380 & 5004 & 12358 & 14983 & 10,7 & 2,9 & 3,0 & 222,0 \\
\hline 323 & 4354 & 4982 & 11461 & 13925 & 9,3 & 3,0 & 2,7 & 38,0 \\
\hline 324 & 4711 & 5397 & 14324 & 17433 & 8,1 & 2,3 & 2,3 & 403,4 \\
\hline 325 & 4553 & 5217 & 14287 & 17391 & 28,7 & 6,8 & 7,1 & 500,0 \\
\hline 326 & 4516 & 5175 & 12499 & 15216 & 5,7 & 3,1 & 2,0 & 403,0 \\
\hline 327 & 4363 & 5004 & 9667 & 11781 & 15,3 & 3,0 & 3,3 & 198,0 \\
\hline 328 & 4763 & 5470 & 12962 & 15828 & 24,5 & 6,3 & 6,4 & 515,0 \\
\hline 329 & 4899 & 5634 & 16816 & 20571 & 11,2 & 4,5 & 1,7 & 405,5 \\
\hline 330 & 4711 & 5417 & 13553 & 16579 & 11,1 & 2,8 & 3,2 & 229,0 \\
\hline 331 & 4317 & 4977 & 10395 & 12763 & 30,1 & 5,8 & 5,1 & 310,0 \\
\hline 332 & 4945 & 5710 & 19062 & 23448 & 6,5 & 3,1 & 4,4 & 404,0 \\
\hline 333 & 3916 & 4524 & 9688 & 11927 & 11,0 & 5,4 & 2,7 & 407,4 \\
\hline 334 & 5016 & 5796 & 14762 & 18175 & & 2,9 & 1,1 & 514,0 \\
\hline 335 & 4878 & 5636 & 13711 & 16882 & 1,5 & 4,8 & 3,4 & 328,0 \\
\hline 336 & 4682 & 5428 & 14171 & 17528 & 6,8 & 2,8 & 3,0 & 298,0 \\
\hline 337 & 4751 & 5510 & 13922 & 17230 & 7,7 & 2,3 & 3,0 & 274,0 \\
\hline 338 & 4608 & 5350 & 13331 & 16521 & 19,4 & 4,4 & 4,2 & 410,0 \\
\hline 339 & 4431 & 5147 & 14070 & 17451 & 8,0 & 3,4 & 2,9 & 402,9 \\
\hline 340 & 4307 & 5008 & 12578 & 15620 & 11,8 & 3,8 & 4,0 & 405,0 \\
\hline 341 & 4776 & 5573 & 13923 & 17377 & 6,0 & 1,8 & 2,1 & 152,0 \\
\hline 342 & 4715 & 5502 & 14652 & 18288 & 16,5 & 2,8 & 3,2 & 273,0 \\
\hline 343 & 4670 & 5451 & 15006 & 18731 & 7,5 & 2,4 & 2,0 & 402,9 \\
\hline 344 & 4728 & 5519 & 13763 & 17185 & 11,9 & 2,4 & 2,3 & 402,0 \\
\hline
\end{tabular}




\begin{tabular}{|c|c|c|c|c|c|c|c|c|}
\hline 345 & 4817 & 5630 & 15875 & 19858 & 8,2 & 4,7 & 3,3 & 304,0 \\
\hline 346 & 4939 & 5774 & 16568 & 20729 & 12,1 & 2,6 & 2,2 & 269,0 \\
\hline 347 & 4578 & 5353 & 13354 & 16715 & 17,1 & 2,9 & 2,8 & 404,5 \\
\hline 348 & 4718 & 5535 & 12878 & 16190 & 9,0 & 2,7 & 3,6 & 167,0 \\
\hline 349 & 4847 & 5688 & 14312 & 18001 & 6,3 & 2,0 & 1,8 & 228,0 \\
\hline 350 & 4511 & 5321 & 12848 & 16273 & 17,1 & 5,0 & 2,1 & 157,0 \\
\hline 351 & 4685 & 5537 & 14871 & 18883 & 11,7 & 2,9 & 3,5 & 406,0 \\
\hline 352 & 4509 & 5339 & 12277 & 15631 & 12,9 & 3,8 & 2,6 & 163,0 \\
\hline 353 & 4403 & 5218 & 13383 & 17057 & 12,3 & 2,6 & 3,5 & 122,0 \\
\hline 354 & 4559 & 5403 & 14830 & 18905 & 8,9 & 2,0 & 2,0 & 358,0 \\
\hline 355 & 4531 & 5374 & 12978 & 16557 & 5,3 & 3,4 & 2,7 & 360,0 \\
\hline 356 & 4821 & 5726 & 15325 & 19592 & 5,8 & 2,9 & 2,0 & 359,3 \\
\hline 357 & 4334 & 5151 & 11897 & 15222 & 18,4 & 4,0 & 4,5 & 511,0 \\
\hline 358 & 4844 & 5849 & 15489 & 20239 & 15,1 & 4,8 & 4,3 & 514,6 \\
\hline 359 & 4630 & 5599 & 14788 & 19363 & 4,4 & 1,6 & 1,9 & 237,0 \\
\hline 360 & 4502 & 5457 & 14987 & 19687 & 9,3 & 3,0 & 3,8 & 405,0 \\
\hline 361 & 4367 & 5349 & 12864 & 17132 & 6,4 & 1,5 & 2,5 & 189,0 \\
\hline 362 & 4369 & 5363 & 13519 & 18051 & 10,2 & 3,6 & 4,7 & 407,8 \\
\hline 363 & 4726 & 5844 & 13541 & 18258 & 5,4 & 1,9 & 1,7 & 234,0 \\
\hline 364 & 4632 & 5857 & 12665 & 17573 & 9,7 & 3,7 & 4,0 & 209,0 \\
\hline 365 & 4396 & 5024 & 13749 & 16675 & 18,9 & 7,8 & 7,3 & 628,6 \\
\hline 366 & 4426 & 4699 & 12146 & 13270 & 25,1 & 7,0 & 8,9 & 610,0 \\
\hline 367 & 4585 & 5024 & 12629 & 14436 & 32,3 & 7,8 & 7,9 & 606,0 \\
\hline 368 & 4725 & 4887 & 13631 & 14329 & 21,1 & 4,8 & 6,9 & 566,9 \\
\hline 369 & 4742 & 5043 & 13058 & 14299 & 25,8 & 6,4 & 6,5 & 612,4 \\
\hline 370 & 4234 & 4470 & 11404 & 12360 & 19,3 & 5,3 & 4,6 & 561,8 \\
\hline
\end{tabular}




\begin{tabular}{|c|c|c|c|c|c|c|c|c|}
\hline Probeta & $\begin{array}{l}\text { Long } \\
\text { gema }\end{array}$ & Médula & Des fibra & Des fibra porc & Duramen & Nudo canto & $\begin{array}{c}\text { Nudo } \\
\text { agrupado } \\
\text { canto }\end{array}$ & $\begin{array}{c}\text { Relación } \\
\text { nudos } \\
\text { /canto }\end{array}$ \\
\hline 1 & 35 & No & 0,8 & 8 & 90 & 1,9 & 4,2 & 0,210 \\
\hline 2 & 0 & No & 0,5 & 5 & 90 & 2,5 & 4,3 & 0,439 \\
\hline 3 & 0 & $\mathrm{Si}$ & 0,7 & 7 & 95 & 2,8 & 4,5 & 0,450 \\
\hline 4 & 0 & $\mathrm{Si}$ & 1,3 & 13 & 98 & 3,8 & 5,5 & 0,274 \\
\hline 5 & 107 & No & 0,4 & 4 & 90 & 2,5 & 4 & 0,199 \\
\hline 6 & 270 & No & 1,7 & 17 & 85 & 3,5 & 6,1 & 0,303 \\
\hline 7 & 127 & $\mathrm{Si}$ & 0,4 & 4 & 80 & 6,5 & 6,5 & 0,327 \\
\hline 8 & 112 & $\mathrm{Si}$ & & 0 & 85 & 2,0 & 3,5 & 0,176 \\
\hline 9 & 126 & No & 0,5 & 5 & 100 & 2,2 & 2,2 & 0,110 \\
\hline 10 & 197 & $\mathrm{Si}$ & 0,3 & 3 & 85 & 1,5 & 2,8 & 0,141 \\
\hline 11 & 362 & $\mathrm{Si}$ & 0,7 & 7 & 85 & 1,6 & 1,6 & 0,080 \\
\hline 12 & 60 & $\mathrm{Si}$ & 0,4 & 4 & 95 & 1,8 & 3,1 & 0,154 \\
\hline 13 & 211 & $\mathrm{Si}$ & 0,4 & 4 & 90 & 3,3 & 5,7 & 0,285 \\
\hline 14 & 139 & $\mathrm{Si}$ & 1,8 & 18 & 90 & 4,2 & 5,5 & 0,274 \\
\hline 15 & 326 & No & 0,1 & 1 & 95 & 2,0 & 3,7 & 0,183 \\
\hline 16 & 278 & No & 0,3 & 3 & 100 & 1,4 & 1,4 & 0,069 \\
\hline 17 & 349 & No & 0,6 & 6 & 95 & 1,8 & 3,1 & 0,154 \\
\hline 18 & 127 & No & 1,1 & 11 & 98 & 4,4 & 4,7 & 0,236 \\
\hline 19 & 137 & $\mathrm{Si}$ & 0,4 & 4 & 90 & 1,8 & 2,5 & 0,181 \\
\hline 20 & 410 & $\mathrm{Si}$ & 0,1 & 1 & 85 & & & 0,000 \\
\hline 21 & 127 & No & 0,3 & 3 & 95 & 3,5 & 6,1 & 0,308 \\
\hline 22 & 461 & No & 0,7 & 7 & 97 & & & 0,000 \\
\hline 23 & 0 & $\mathrm{Si}$ & 0,8 & 8 & 80 & 3,7 & 3,7 & 0,186 \\
\hline 24 & 505 & No & 0,1 & 1 & 80 & 2,4 & 3,6 & 0,180 \\
\hline 25 & 386 & No & 0,3 & 3 & 100 & & & 0,000 \\
\hline 26 & 193 & No & 0,2 & 2 & 95 & 2,4 & 2,4 & 0,119 \\
\hline 27 & 128 & $\mathrm{Si}$ & 0,8 & 8 & 85 & 3,7 & 3,7 & 0,186 \\
\hline 28 & 93 & $\mathrm{Si}$ & 0,6 & 6 & 97 & 5,0 & 6,5 & 0,327 \\
\hline 29 & 0 & $\mathrm{Si}$ & 0,6 & 6 & 95 & 2,8 & 2,8 & 0,200 \\
\hline 30 & 234 & No & 1,1 & 11 & 100 & 1,6 & 1,6 & 0,079 \\
\hline 31 & 0 & $\mathrm{Si}$ & 1,1 & 11 & 85 & 4,4 & 7,5 & 0,377 \\
\hline 32 & 313 & $\mathrm{Si}$ & 0,5 & 5 & 95 & 3,0 & 3,0 & 0,151 \\
\hline 33 & 0 & $\mathrm{Si}$ & 0,6 & 6 & 95 & 1,7 & 3,1 & 0,221 \\
\hline 34 & 0 & No & 0,7 & 7 & 100 & 2,3 & 2,3 & 0,114 \\
\hline 35 & 0 & No & 0,6 & 6 & 100 & 1,3 & 2,4 & 0,119 \\
\hline 36 & 0 & $\mathrm{Si}$ & 1,1 & 11 & 90 & 5,1 & 7,0 & 0,341 \\
\hline 37 & 329 & $\mathrm{Si}$ & 1,2 & 12 & 85 & 3,6 & 4,8 & 0,241 \\
\hline 38 & 64 & $\mathrm{Si}$ & 1,2 & 12 & 85 & 4,3 & 5,0 & 0,360 \\
\hline 39 & 402 & No & 0,1 & 1 & 85 & 1,7 & 1,7 & 0,085 \\
\hline 40 & 0 & $\mathrm{Si}$ & 0,7 & 7 & 100 & & & 0,000 \\
\hline 41 & 195 & $\mathrm{Si}$ & 1,0 & 10 & 80 & 3,2 & 3,2 & 0,162 \\
\hline 42 & 0 & $\mathrm{Si}$ & 1,0 & 10 & 80 & 1,7 & & 0,175 \\
\hline 43 & 0 & $\mathrm{Si}$ & 0,2 & 2 & 75 & 1,7 & & 0,250 \\
\hline 44 & 137 & $\mathrm{Si}$ & 0,5 & 5 & 75 & 3,9 & 3,9 & 0,398 \\
\hline 45 & 0 & $\mathrm{Si}$ & 0,5 & 5 & 70 & 1,8 & 2,8 & 0,140 \\
\hline 46 & 0 & $\mathrm{Si}$ & 0,6 & 6 & 100 & 2,6 & 2,6 & 0,263 \\
\hline 47 & 0 & $\mathrm{Si}$ & 0,7 & 7 & 95 & 1,4 & & 0,206 \\
\hline 48 & 0 & $\mathrm{Si}$ & 0,3 & 3 & 90 & 1,3 & & 0,188 \\
\hline 49 & 404 & No & 0,4 & 4 & 100 & 1,6 & 1,6 & 0,079 \\
\hline 50 & 0 & $\mathrm{Si}$ & 0,2 & 2 & 100 & 1,4 & 1,4 & 0,100 \\
\hline 51 & 0 & $\mathrm{Si}$ & 1,2 & 12 & 75 & 2,5 & 2,5 & 0,253 \\
\hline 52 & 0 & $\mathrm{Si}$ & & 0 & 95 & 3,1 & 11,6 & 0,577 \\
\hline 53 & 0 & $\mathrm{Si}$ & 0,4 & 4 & 100 & 2,6 & 4,6 & 0,225 \\
\hline
\end{tabular}




\begin{tabular}{|c|c|c|c|c|c|c|c|c|}
\hline 54 & 170 & $\mathrm{Si}$ & 1,1 & 11 & 90 & 6,4 & 9,9 & 0,495 \\
\hline 55 & 102 & No & 0,2 & 2 & 90 & 2,1 & 3,13 & 0,156 \\
\hline 56 & 111 & $\mathrm{Si}$ & 1,1 & 11 & 90 & 3,3 & 3,3 & 0,167 \\
\hline 57 & 244 & $\mathrm{Si}$ & 0,8 & 8 & 80 & 2,4 & 2,4 & 0,121 \\
\hline 58 & 53 & $\mathrm{Si}$ & 0,2 & 2 & 85 & 2,1 & 2,5 & 0,174 \\
\hline 59 & 0 & No & 0,7 & 7 & 95 & 2,7 & 3,4 & 0,170 \\
\hline 60 & 471 & No & 0,7 & 7 & 90 & 2,4 & 2,5 & 0,125 \\
\hline 61 & 0 & $\mathrm{Si}$ & 0,4 & 4 & 95 & 2,2 & 3,4 & 0,351 \\
\hline 62 & 0 & $\mathrm{Si}$ & 0,6 & 6 & 100 & 1,8 & 2,4 & 0,170 \\
\hline 63 & 0 & No & 1,1 & 11 & 100 & 1,8 & 3,6 & 0,364 \\
\hline 64 & 318 & No & 0,3 & 3 & 90 & 2,0 & 3,3 & 0,163 \\
\hline 65 & 0 & $\mathrm{Si}$ & 0,7 & 7 & 90 & 2,2 & 3,4 & 0,347 \\
\hline 66 & 0 & $\mathrm{Si}$ & 1,0 & 10 & 80 & 3,8 & 6,5 & 0,670 \\
\hline 67 & 523 & No & 0,3 & 3 & 90 & 3,2 & 6,4 & 0,317 \\
\hline 68 & 0 & $\mathrm{Si}$ & 0,9 & 9 & 90 & 1,7 & 1,7 & 0,243 \\
\hline 69 & 0 & No & 1,2 & 12 & 100 & 1,6 & 2,9 & 0,299 \\
\hline 70 & 0 & No & 0,1 & 1 & 100 & 1,4 & 0 & 0,143 \\
\hline 71 & 0 & No & 1,2 & 12 & 90 & 3,0 & 5,4 & 0,545 \\
\hline 72 & 0 & No & 0,3 & 3 & 90 & 2,7 & 2,7 & 0,270 \\
\hline 73 & 116 & No & 0,1 & 1 & 95 & 3,0 & 6,3 & 0,309 \\
\hline 74 & 361 & No & 0,65 & 6 & 95 & 1,8 & 2,9 & 0,144 \\
\hline 75 & 0 & $\mathrm{Si}$ & 0,3 & 3 & 100 & 2,0 & 2,8 & 0,203 \\
\hline 76 & 0 & No & 1,0 & 10 & 80 & 1,4 & 2,6 & 0,265 \\
\hline 77 & 0 & No & 0,4 & 4 & 100 & 2,1 & 3,7 & 0,378 \\
\hline 78 & 21 & No & 0,8 & 8 & 85 & 2,4 & 2,4 & 0,245 \\
\hline 79 & 0 & No & 1,0 & 10 & 90 & 3,5 & 3,5 & 0,354 \\
\hline 80 & 0 & $\mathrm{Si}$ & 0,15 & 1 & 100 & 3,0 & 3,0 & 0,300 \\
\hline 81 & 21 & $\mathrm{Si}$ & 0,8 & 8 & 85 & 2,4 & 4,9 & 0,345 \\
\hline 82 & 0 & No & 0,9 & 9 & 80 & 3,2 & 3,2 & 0,320 \\
\hline 83 & 0 & $\mathrm{Si}$ & 0,2 & 2 & 100 & 1,0 & 1,0 & 0,143 \\
\hline 84 & 0 & No & 0,7 & 7 & 95 & 2,8 & 2,8 & 0,406 \\
\hline 85 & 0 & No & 0,5 & 5 & 100 & 1,3 & 1,3 & 0,131 \\
\hline 86 & 0 & $\mathrm{Si}$ & 0,3 & 3 & 100 & 1,4 & 1,4 & 0,203 \\
\hline 87 & 0 & No & 0,6 & 6 & 100 & 1,1 & 1,1 & 0,112 \\
\hline 88 & 0 & $\mathrm{Si}$ & 0,6 & 6 & 100 & 1,1 & 1,1 & 0,112 \\
\hline 89 & 0 & $\mathrm{Si}$ & 0,5 & 5 & 90 & 4,6 & 4,6 & 0,460 \\
\hline 90 & 77 & $\mathrm{Si}$ & 0,1 & 1 & 90 & & & 0,000 \\
\hline 91 & 0 & $\mathrm{Si}$ & 0,3 & 3 & 100 & 1,6 & 2,5 & 0,255 \\
\hline 92 & 0 & No & 0,8 & 8 & 100 & 3,9 & 4,3 & 0,307 \\
\hline 93 & 0 & No & 1,2 & 12 & 70 & 4,0 & 4,0 & 0,404 \\
\hline 94 & 0 & No & 0,3 & 3 & 60 & 3,8 & 3,8 & 0,380 \\
\hline 95 & 0 & & 0,2 & 2 & 90 & 3,1 & 3,1 & 0,310 \\
\hline 96 & 0 & No & 0,4 & 4 & 100 & 3,0 & 3,0 & 0,306 \\
\hline 97 & 0 & No & 0,25 & 2 & 100 & & & 0,000 \\
\hline 98 & 190 & No & 0,5 & 5 & 70 & 3,9 & 3,9 & 0,394 \\
\hline 99 & 172 & $\mathrm{Si}$ & 0,4 & 4 & 95 & 1,9 & 3,9 & 0,283 \\
\hline 100 & 0 & $\mathrm{Si}$ & 0,6 & 6 & 100 & 1,6 & 1,6 & 0,229 \\
\hline 101 & 0 & $\mathrm{Si}$ & 0,5 & 5 & 100 & 2,2 & 2,2 & 0,314 \\
\hline 102 & 0 & No & 0,65 & 6 & 85 & 1,9 & 3,2 & 0,327 \\
\hline 103 & 0 & $\mathrm{Si}$ & 0,8 & 8 & 60 & 1,4 & 1,4 & 0,194 \\
\hline 104 & 0 & $\mathrm{Si}$ & 0,4 & 4 & 100 & & & 0,000 \\
\hline 105 & 0 & $\mathrm{Si}$ & 0,15 & 1 & 100 & 1,3 & 1,3 & 0,133 \\
\hline 106 & 415 & $\mathrm{Si}$ & 0,8 & 8 & 80 & 2,4 & 2,4 & 0,119 \\
\hline 107 & 0 & No & 0,9 & 9 & 95 & 1,3 & 1,3 & 0,131 \\
\hline 108 & 227 & No & 0,85 & 8 & 80 & 2,8 & 3,5 & 0,174 \\
\hline 109 & 0 & $\mathrm{Si}$ & 0,3 & 3 & 100 & 1,1 & 1,1 & 0,112 \\
\hline 110 & 0 & No & 0,4 & 4 & 100 & 2,3 & 4,0 & 0,404 \\
\hline 111 & 0 & & 0,3 & 3 & 100 & 1,2 & 1,2 & 0,171 \\
\hline
\end{tabular}




\begin{tabular}{|c|c|c|c|c|c|c|c|c|}
\hline 112 & 0 & No & 0,6 & 6 & 100 & 1,2 & 1,6 & 0,232 \\
\hline 113 & 142 & $\mathrm{Si}$ & 0,3 & 3 & 80 & 1,5 & 1,5 & 0,211 \\
\hline 114 & 0 & No & 0,55 & 5 & 90 & 1,7 & 4,6 & 0,648 \\
\hline 115 & 73 & No & 1,15 & 11 & 55 & 3,5 & 3,5 & 0,354 \\
\hline 116 & 45 & $\mathrm{Si}$ & 1,1 & 11 & 75 & 2,6 & 2,6 & 0,377 \\
\hline 117 & 0 & $\mathrm{Si}$ & 0,4 & 4 & 90 & 1,7 & 2,2 & 0,314 \\
\hline 118 & 0 & No & 0,7 & 7 & 100 & 1,8 & 1,8 & 0,182 \\
\hline 119 & 0 & No & 0,7 & 7 & 100 & 2,0 & 2,0 & 0,200 \\
\hline 120 & 0 & No & 0,85 & 8 & 90 & 1,7 & 1,7 & 0,173 \\
\hline 121 & 0 & No & 0,65 & 6 & 80 & 2,5 & 4,7 & 0,470 \\
\hline 122 & 0 & $\mathrm{Si}$ & 0,8 & 8 & 80 & 3,3 & 3,3 & 0,471 \\
\hline 123 & 0 & $\mathrm{Si}$ & 0,8 & 8 & 80 & 1,0 & 1,0 & 0,141 \\
\hline 124 & 0 & $\mathrm{Si}$ & 0,8 & 8 & 70 & 1,6 & 3,0 & 0,429 \\
\hline 125 & 0 & $\mathrm{Si}$ & 0,6 & 6 & 75 & 2,9 & 2,9 & 0,408 \\
\hline 126 & 0 & No & 0,8 & 8 & 85 & 1,8 & 2,9 & 0,290 \\
\hline 127 & 0 & $\mathrm{Si}$ & 0,3 & 3 & 100 & 1,7 & 2,0 & 0,290 \\
\hline 128 & 0 & $\mathrm{Si}$ & 0,4 & 4 & 95 & 3,7 & 3,7 & 0,529 \\
\hline 129 & 0 & No & 0,5 & 5 & 100 & 1,5 & 1,5 & 0,214 \\
\hline 130 & 0 & No & 0,6 & 6 & 100 & 2,3 & 2,3 & 0,230 \\
\hline 131 & 0 & $\mathrm{Si}$ & 0,6 & 6 & 70 & 3,6 & 3,6 & 0,514 \\
\hline 132 & 0 & No & 0,6 & 6 & 90 & 2,1 & 3,9 & 0,557 \\
\hline 133 & 0 & $\mathrm{Si}$ & 0,6 & 6 & 100 & 1,8 & 1,8 & 0,254 \\
\hline 134 & 462 & No & 0,4 & 4 & 95 & & & 0,000 \\
\hline 135 & 0 & $\mathrm{Si}$ & 0,55 & 5 & 80 & 2,7 & 2,7 & 0,380 \\
\hline 136 & 0 & $\mathrm{Si}$ & 0,4 & 4 & 60 & & & 0,000 \\
\hline 137 & 0 & $\mathrm{Si}$ & 0,5 & 5 & 70 & 2,5 & 2,9 & 0,414 \\
\hline 138 & 0 & $\mathrm{Si}$ & 0,35 & 3 & 95 & 1,9 & 2,9 & 0,206 \\
\hline 139 & 29 & No & 0,35 & 3 & 100 & 2,1 & 3,3 & 0,163 \\
\hline 140 & 0 & $\mathrm{Si}$ & 0,8 & 8 & 100 & 1,0 & 1 & 0,100 \\
\hline 141 & 0 & $\mathrm{Si}$ & 0,1 & 1 & 100 & 1,4 & 1,4 & 0,141 \\
\hline 142 & 53 & $\mathrm{Si}$ & 0,5 & 5 & 90 & 3,1 & 3,8 & 0,271 \\
\hline 143 & 0 & No & 1,15 & 11 & 85 & 2,5 & 3,8 & 0,559 \\
\hline 144 & 0 & $\mathrm{Si}$ & 0,2 & 2 & 100 & & 0,0 & 0,000 \\
\hline 145 & 0 & No & 0,55 & 5 & 100 & 1,2 & 1,2 & 0,059 \\
\hline 146 & 134 & No & 1,9 & 19 & 50 & 3,0 & 4,0 & 0,563 \\
\hline 147 & 0 & $\mathrm{Si}$ & 1,0 & 10 & 100 & 3,3 & 3,3 & 0,471 \\
\hline 148 & 0 & $\mathrm{Si}$ & 0,5 & 5 & & 1,6 & 1,6 & 0,225 \\
\hline 149 & 61 & $\mathrm{Si}$ & 0,45 & 4,5 & 85 & 1,6 & 1,6 & 0,116 \\
\hline 150 & 0 & No & 0,4 & 4 & 100 & 1,8 & 1,8 & 0,257 \\
\hline 151 & 0 & $\mathrm{Si}$ & 0,4 & 4 & 100 & 4,1 & 4,1 & 0,594 \\
\hline 152 & 0 & $\mathrm{Si}$ & 0,5 & 5 & 100 & 1,2 & 1,2 & 0,121 \\
\hline 153 & 0 & No & 0,75 & 7 & 90 & 2,8 & 2,8 & 0,280 \\
\hline 154 & 0 & $\mathrm{Si}$ & 0,6 & 6 & 100 & 2,2 & 3,0 & 0,435 \\
\hline 155 & 0 & $\mathrm{Si}$ & 0,7 & 7 & 80 & 2,3 & 2,3 & 0,329 \\
\hline 156 & 0 & No & 0,5 & 5 & 90 & 3,2 & 3,2 & 0,471 \\
\hline 157 & 0 & $\mathrm{Si}$ & 0,2 & 2 & 100 & 1,0 & 1,0 & 0,145 \\
\hline 158 & 0 & $\mathrm{Si}$ & 0,6 & 6 & 100 & 2,0 & 2,0 & 0,286 \\
\hline 159 & 0 & $\mathrm{Si}$ & 0,2 & 2 & 100 & 2,4 & 2,4 & 0,343 \\
\hline 160 & 0 & & 0,7 & 7 & 70 & 2,2 & 2,2 & 0,310 \\
\hline 161 & 60 & $\mathrm{Si}$ & 0,7 & 7 & 85 & 1,5 & 1,5 & 0,217 \\
\hline 162 & 335 & $\mathrm{Si}$ & 0,4 & 4 & 80 & 3,5 & 3,5 & 0,250 \\
\hline 163 & 0 & $\mathrm{Si}$ & 0,5 & 5 & 60 & 2,1 & 3,3 & 0,465 \\
\hline 164 & 00 & $\mathrm{Si}$ & 0 & 0 & 80 & 1,3 & 1,3 & 0,093 \\
\hline 165 & 0 & No & 0,3 & 3 & 100 & 1,8 & 1,8 & 0,186 \\
\hline 166 & 41 & $\mathrm{Si}$ & 0,8 & 8 & 100 & 2,0 & 3,6 & 0,259 \\
\hline 167 & 0 & No & 0,65 & 6 & 90 & 1,2 & 2,0 & 0,282 \\
\hline 168 & 0 & $\mathrm{Si}$ & 0,4 & 4 & 95 & 2,8 & 2,8 & 0,201 \\
\hline 169 & 0 & $\mathrm{Si}$ & 0,5 & 5 & 100 & & 0,0 & 0,000 \\
\hline
\end{tabular}




\begin{tabular}{|c|c|c|c|c|c|c|c|c|}
\hline 170 & 0 & No & 0,45 & 4 & 90 & 2,9 & 2,9 & 0,296 \\
\hline 171 & 398 & No & 0,6 & 6 & 90 & 2,0 & 2,4 & 0,119 \\
\hline 172 & 0 & $\mathrm{Si}$ & 0,2 & 2 & 100 & 1,5 & 1,5 & 0,217 \\
\hline 173 & 0 & $\mathrm{Si}$ & 0,3 & 3 & 100 & 1,7 & 3,5 & 0,248 \\
\hline 174 & 0 & No & 0,3 & 3 & 70 & 2,9 & 2,9 & 0,414 \\
\hline 175 & 277 & $\mathrm{Si}$ & 0,6 & 6 & 85 & 2,8 & 2,8 & 0,141 \\
\hline 176 & 0 & $\mathrm{Si}$ & 0,4 & 4 & & 1,6 & 2,6 & 0,371 \\
\hline 177 & 0 & $\mathrm{Si}$ & 0,8 & 8 & 95 & 3,0 & 4,7 & 0,691 \\
\hline 178 & 77 & No & 1,0 & 10 & 90 & 2,1 & 2,1 & 0,214 \\
\hline 179 & 0 & $\mathrm{Si}$ & 0,2 & 2 & 100 & 1,5 & 2,7 & 0,273 \\
\hline 180 & 0 & No & 0,2 & 2 & 90 & 1,0 & 1,0 & 0,143 \\
\hline 181 & 0 & $\mathrm{Si}$ & 0,3 & 3 & 100 & 1,0 & 1,0 & 0,102 \\
\hline 182 & 0 & No & 0,3 & 3 & 100 & 2,3 & 2,3 & 0,232 \\
\hline 183 & 0 & No & 0,7 & 7 & 60 & 2,4 & 2,4 & 0,343 \\
\hline 184 & 253 & No & 0,55 & 5 & 90 & 2,3 & 4,0 & 0,200 \\
\hline 185 & 0 & No & 0,45 & 4 & 100 & 1,3 & 1,3 & 0,131 \\
\hline 186 & 7 & No & 1,4 & 14 & 90 & 1,8 & 1,8 & 0,182 \\
\hline 187 & 0 & No & 0,25 & 2 & 90 & 2,1 & 2,1 & 0,300 \\
\hline 188 & 0 & $\mathrm{Si}$ & 0,6 & 6 & 100 & 2,6 & 2,6 & 0,371 \\
\hline 189 & 88 & $\mathrm{Si}$ & 0,6 & 6 & 80 & 4,1 & 7,2 & 0,360 \\
\hline 190 & 0 & $\mathrm{Si}$ & 0,8 & 8 & 80 & 3,1 & 4,0 & 0,288 \\
\hline 191 & 158 & $\mathrm{Si}$ & 0,3 & 3 & 100 & 1,0 & 1,0 & 0,100 \\
\hline 192 & 0 & $\mathrm{Si}$ & 0,4 & 4 & 100 & 1,9 & 2,5 & 0,357 \\
\hline 193 & 0 & No & 0,75 & 7 & 100 & 1,9 & 2,3 & 0,324 \\
\hline 194 & 0 & $\mathrm{Si}$ & 0,1 & 1 & 100 & & 0,0 & 0,000 \\
\hline 195 & 0 & $\mathrm{Si}$ & 0,6 & 6 & 90 & 4,5 & 6,9 & 0,504 \\
\hline 196 & 54 & $\mathrm{Si}$ & 0,5 & 5 & 70 & 1,8 & 1,8 & 0,254 \\
\hline 197 & 0 & $\mathrm{Si}$ & 0,9 & 9 & 80 & 3,5 & 3,5 & 0,515 \\
\hline 198 & 0 & $\mathrm{Si}$ & 0,35 & 3 & 100 & 1,2 & 1,2 & 0,174 \\
\hline 199 & 0 & $\mathrm{Si}$ & 0,2 & 2 & 80 & 2,3 & 3,7 & 0,521 \\
\hline 200 & 0 & $\mathrm{Si}$ & 0,3 & 3 & & 1,6 & 2,2 & 0,310 \\
\hline 201 & 0 & No & 1,15 & 11 & 90 & 4,8 & 4,8 & 0,238 \\
\hline 202 & 243 & $\mathrm{Si}$ & 0,5 & 5 & 90 & 1,5 & 2,4 & 0,171 \\
\hline 203 & 48 & $\mathrm{Si}$ & 0,3 & 3 & 90 & 2,1 & 2,1 & 0,300 \\
\hline 204 & 0 & $\mathrm{Si}$ & 0,2 & 2 & 95 & 2,1 & 4,7 & 0,336 \\
\hline 205 & 0 & No & 0,2 & 2 & 100 & 1,0 & 1,0 & 0,099 \\
\hline 206 & 280 & $\mathrm{Si}$ & 0,8 & 8 & 70 & 2,3 & 2,3 & 0,333 \\
\hline 207 & 0 & No & 0,6 & 6 & 80 & 1,0 & 1,0 & 0,141 \\
\hline 208 & 0 & $\mathrm{Si}$ & 0,1 & 1 & 80 & 1,1 & 1,1 & 0,155 \\
\hline 209 & 254 & $\mathrm{Si}$ & 1,1 & 11 & 90 & 1,4 & 1,4 & 0,070 \\
\hline 210 & 0 & $\mathrm{Si}$ & 0,1 & 1 & 90 & 1,6 & 1,6 & 0,235 \\
\hline 211 & 0 & No & 0,3 & 3 & 100 & 1,7 & 1,7 & 0,246 \\
\hline 212 & 0 & $\mathrm{Si}$ & 0,4 & 4 & 70 & 3,1 & 4,4 & 0,314 \\
\hline 213 & 0 & No & 1,2 & 12 & 80 & 2,6 & 2,6 & 0,366 \\
\hline 214 & 58 & $\mathrm{Si}$ & 0,7 & 7 & 100 & 3,9 & 5,7 & 0,284 \\
\hline 215 & 0 & $\mathrm{Si}$ & 0,45 & 4 & 100 & 1,8 & 1,8 & 0,257 \\
\hline 216 & 202 & No & 0,2 & 2 & 75 & 3,0 & 4,5 & 0,474 \\
\hline 217 & 0 & $\mathrm{Si}$ & 0,25 & 2 & 100 & 3,4 & 4,8 & 0,345 \\
\hline 218 & 0 & $\mathrm{Si}$ & 0,4 & 4 & 95 & 2,7 & 3,2 & 0,225 \\
\hline 219 & 72 & No & 0,9 & 9 & 60 & 2,8 & 2,8 & 0,283 \\
\hline 220 & 0 & $\mathrm{Si}$ & 0,55 & 5 & 70 & 2,7 & 2,7 & 0,391 \\
\hline 221 & 0 & $\mathrm{Si}$ & 0,4 & 4 & 100 & 2,2 & 4,3 & 0,309 \\
\hline 222 & 0 & No & 0,45 & 4 & 90 & 3,2 & 3,2 & 0,457 \\
\hline 223 & 371 & $\mathrm{Si}$ & 0,6 & 6 & 80 & 2,5 & 3,6 & 0,257 \\
\hline 224 & 0 & No & 0,6 & 6 & 100 & & & 0,000 \\
\hline 225 & 0 & $\mathrm{Si}$ & 0,7 & 7 & 100 & 3,7 & 3,7 & 0,268 \\
\hline 226 & 88 & $\mathrm{Si}$ & 1,0 & 10 & 95 & 3,1 & 5,5 & 0,393 \\
\hline 227 & 0 & No & 0,5 & 5 & 100 & 2,0 & 2,0 & 0,286 \\
\hline
\end{tabular}




\begin{tabular}{|c|c|c|c|c|c|c|c|c|}
\hline 228 & 0 & $\mathrm{Si}$ & 0,5 & 5 & 100 & 1,0 & 1,0 & 0,098 \\
\hline 229 & 159 & No & 1,6 & 16 & 60 & 4,3 & 4,3 & 0,430 \\
\hline 230 & 0 & $\mathrm{Si}$ & 0 & 0 & 100 & 1,8 & 3,6 & 0,252 \\
\hline 231 & 0 & No & 0,6 & 6 & 100 & 1,8 & 1,8 & 0,178 \\
\hline 232 & 0 & $\mathrm{Si}$ & 0,2 & 2 & 100 & 1,4 & 1,4 & 0,140 \\
\hline 233 & 0 & No & 0,8 & 8 & 95 & 2,2 & 2,2 & 0,109 \\
\hline 234 & 0 & $\mathrm{Si}$ & 0,4 & 4 & 80 & 2,0 & 3,0 & 0,306 \\
\hline 235 & 0 & $\mathrm{Si}$ & 0,3 & 3 & 100 & 2,1 & 2,1 & 0,151 \\
\hline 236 & 371 & $\mathrm{Si}$ & 0,6 & 6 & 98 & & & 0,000 \\
\hline 237 & 379 & $\mathrm{Si}$ & 1 & 10 & 100 & 3,9 & 4,1 & 0,295 \\
\hline 238 & 0 & No & 1,1 & 11 & 40 & 3,8 & 3,8 & 0,535 \\
\hline 239 & 0 & $\mathrm{Si}$ & 0,3 & 3 & 90 & 2,6 & 2,9 & 0,408 \\
\hline 240 & 0 & No & 0,65 & 6 & 90 & 3,0 & 3,0 & 0,423 \\
\hline 241 & 0 & $\mathrm{Si}$ & 0,8 & 8 & 95 & 4,7 & 4,7 & 0,475 \\
\hline 242 & 0 & No & 1,5 & 15 & 90 & 3,1 & 3,1 & 0,310 \\
\hline 243 & 240 & $\mathrm{Si}$ & 1,2 & 12 & 90 & 1,9 & 3,2 & 0,160 \\
\hline 244 & 0 & $\mathrm{Si}$ & 0,5 & 5 & 100 & 1,5 & 1,5 & 0,108 \\
\hline 245 & 56 & $\mathrm{Si}$ & 0,5 & 5 & 100 & 2,2 & 2,2 & 0,157 \\
\hline 246 & 0 & No & 0,6 & 6 & 100 & 1,9 & 2,6 & 0,361 \\
\hline 247 & 0 & $\mathrm{Si}$ & 0,2 & 2 & 100 & 1,2 & 1,2 & 0,120 \\
\hline 248 & 0 & $\mathrm{Si}$ & 0,6 & 6 & 85 & 2,3 & 4,1 & 0,297 \\
\hline 249 & 230 & $\mathrm{Si}$ & 0,9 & 9 & 80 & 2,9 & 4,1 & 0,291 \\
\hline 250 & 0 & $\mathrm{Si}$ & 1,0 & 10 & 90 & 5,7 & 10,1 & 0,518 \\
\hline 251 & 0 & $\mathrm{Si}$ & 0,0 & 0 & 95 & 3,8 & 0,0 & 0,268 \\
\hline 252 & 30 & $\mathrm{Si}$ & 0,6 & 6 & 90 & 1,1 & 2,1 & 0,150 \\
\hline 253 & 0 & $\mathrm{Si}$ & 0,3 & 3 & 100 & 1,4 & 1,4 & 0,200 \\
\hline 254 & 186 & $\mathrm{Si}$ & 0,5 & 5 & 85 & 3,4 & 3,4 & 0,248 \\
\hline 255 & 0 & $\mathrm{Si}$ & 0,3 & 3 & 90 & 2,3 & 2,3 & 0,163 \\
\hline 256 & 34 & $\mathrm{Si}$ & 0,25 & 2 & 95 & 2,1 & 3,2 & 0,234 \\
\hline 257 & 105 & $\mathrm{Si}$ & 1 & 10 & 90 & 1,0 & 1,8 & 0,129 \\
\hline 258 & 0 & $\mathrm{Si}$ & 0,8 & 8 & 100 & 2,6 & 3,5 & 0,507 \\
\hline 259 & 0 & No & 0,35 & 3 & 100 & 2,1 & 2,1 & 0,210 \\
\hline 260 & 190 & $\mathrm{Si}$ & 1,1 & 10 & 80 & & & 0,000 \\
\hline 261 & 0 & No & 0,9 & 9 & 100 & 2,5 & 3,4 & 0,493 \\
\hline 262 & 0 & No & 0,1 & 1 & & 2,5 & 2,5 & 0,357 \\
\hline 263 & 0 & $\mathrm{Si}$ & 0,6 & 6 & 95 & 3,2 & 4,7 & 0,235 \\
\hline 264 & 69 & $\mathrm{Si}$ & 0,4 & 4 & 100 & 2,3 & 4,2 & 0,296 \\
\hline 265 & 55 & & 0,5 & 5 & 85 & 2,5 & 2,5 & 0,347 \\
\hline 266 & 0 & $\mathrm{Si}$ & 0,25 & 2 & 90 & 2,7 & 2,7 & 0,190 \\
\hline 267 & 0 & $\mathrm{NO}$ & 1,3 & 13 & 100 & 2,0 & 2,0 & 0,144 \\
\hline 268 & 0 & $\mathrm{Si}$ & 0,8 & 8 & 100 & 2,7 & 2,7 & 0,194 \\
\hline 269 & 0 & No & 0,4 & 4 & 70 & 1,1 & 1,1 & 0,159 \\
\hline 270 & 0 & $\mathrm{Si}$ & 0,55 & 5 & 95 & 1,6 & 2,7 & 0,193 \\
\hline 271 & 0 & $\mathrm{Si}$ & 0,3 & 3 & 100 & 2,2 & 2,7 & 0,191 \\
\hline 272 & 0 & $\mathrm{Si}$ & 0,2 & 2 & 100 & 1,6 & 1,6 & 0,229 \\
\hline 273 & 0 & No & 0,3 & 3 & 95 & 2,5 & 2,5 & 0,248 \\
\hline 274 & 0 & $\mathrm{Si}$ & 1,1 & 11 & 100 & 1,1 & 1,1 & 0,157 \\
\hline 275 & 0 & $\mathrm{Si}$ & 1 & 10 & 98 & 1,9 & 2,3 & 0,116 \\
\hline 276 & 0 & No & 0,7 & 7 & & 2,5 & 2,5 & 0,357 \\
\hline 277 & 315 & $\mathrm{Si}$ & 0,7 & 7 & 90 & 1,8 & 2,4 & 0,119 \\
\hline 278 & 0 & $\mathrm{Si}$ & & 0 & 90 & 3,1 & 6,2 & 0,310 \\
\hline 279 & 46 & $\mathrm{Si}$ & 1,5 & 15 & 90 & 1,5 & 2,2 & 0,159 \\
\hline 280 & 358 & $\mathrm{Si}$ & 0,5 & 5 & 85 & 2,1 & 2,1 & 0,105 \\
\hline 281 & 171 & $\mathrm{Si}$ & 0,7 & 7 & 90 & 3,2 & 5,4 & 0,380 \\
\hline 282 & 23 & $\mathrm{Si}$ & 0,5 & 5 & 95 & 2,4 & 4,6 & 0,333 \\
\hline 283 & 108 & $\mathrm{Si}$ & 1,3 & 13 & 100 & 1,0 & 1,0 & 0,071 \\
\hline 284 & 0 & $\mathrm{Si}$ & 0,4 & 4 & 80 & 1,4 & 1,4 & 0,197 \\
\hline 285 & 0 & $\mathrm{Si}$ & 0,5 & 5 & 80 & 2,9 & 2,9 & 0,287 \\
\hline
\end{tabular}




\begin{tabular}{|c|c|c|c|c|c|c|c|c|}
\hline 286 & 0 & $\mathrm{Si}$ & 0,6 & 6 & 80 & 2,6 & 2,6 & 0,191 \\
\hline 287 & 0 & No & 0,3 & 3 & 85 & 3,8 & 7,1 & 0,724 \\
\hline 288 & 0 & $\mathrm{Si}$ & 0,4 & 4 & 100 & 1,2 & 1,2 & 0,171 \\
\hline 289 & 370 & $\mathrm{Si}$ & 1,1 & 11 & 85 & & & 0,000 \\
\hline 290 & 0 & $\mathrm{Si}$ & 0,55 & 5 & 100 & 1,5 & 2,7 & 0,270 \\
\hline 291 & 74 & $\mathrm{Si}$ & 0,6 & 6 & 90 & 3,3 & 6,6 & 0,330 \\
\hline 292 & 0 & $\mathrm{Si}$ & 0,1 & 1 & 100 & 2,7 & 2,7 & 0,193 \\
\hline 293 & 0 & $\mathrm{Si}$ & 0,9 & 9 & 100 & 2,1 & 2,8 & 0,280 \\
\hline 294 & 173 & $\mathrm{Si}$ & 0,5 & 5 & 85 & 3,1 & 5,1 & 0,362 \\
\hline 295 & 163 & $\mathrm{Si}$ & 1,2 & 12 & 95 & 3,2 & 5,4 & 0,271 \\
\hline 296 & 0 & $\mathrm{Si}$ & 0,6 & 6 & 95 & 1,1 & 1,1 & 0,157 \\
\hline 297 & 429 & $\mathrm{Si}$ & 0,35 & 3 & 95 & 2,3 & 2,3 & 0,116 \\
\hline 298 & 0 & $\mathrm{Si}$ & 1,5 & 15 & 100 & 3,1 & 3,1 & 0,218 \\
\hline 299 & 320 & No & 0,1 & 1 & 98 & 1,8 & 3,3 & 0,165 \\
\hline 300 & 0 & $\mathrm{Si}$ & 0,9 & 9 & 90 & 1,6 & 1,6 & 0,229 \\
\hline 301 & 0 & $\mathrm{Si}$ & 0,0 & 0 & 100 & & & 0,000 \\
\hline 302 & 228 & $\mathrm{Si}$ & 0,5 & 5 & 85 & 3,9 & 5,5 & 0,276 \\
\hline 303 & 220 & $\mathrm{Si}$ & 0,9 & 9 & 85 & 2,4 & 2,4 & 0,120 \\
\hline 304 & 37 & $\mathrm{Si}$ & 0,7 & 7 & 100 & 1,4 & 2,6 & 0,186 \\
\hline 305 & 0 & $\mathrm{Si}$ & 0,2 & 2 & 95 & 1,4 & 1,4 & 0,100 \\
\hline 306 & 14 & $\mathrm{Si}$ & 0,5 & 5 & 90 & 2,0 & 3,1 & 0,221 \\
\hline 307 & 182 & $\mathrm{Si}$ & 0,8 & 8 & 90 & 1,5 & 1,5 & 0,106 \\
\hline 308 & 0 & $\mathrm{Si}$ & 0,5 & 5 & 100 & 1,8 & 1,8 & 0,127 \\
\hline 309 & 0 & $\mathrm{Si}$ & 0,6 & 6 & 95 & 2,2 & 5,2 & 0,515 \\
\hline 310 & 520 & $\mathrm{Si}$ & 1,1 & 11 & 85 & & & 0,000 \\
\hline 311 & 25 & $\mathrm{Si}$ & 0,6 & 6 & 95 & 1,4 & 2,4 & 0,171 \\
\hline 312 & 39 & $\mathrm{Si}$ & 1,1 & 11 & 95 & 2,2 & 2,2 & 0,157 \\
\hline 313 & 355 & $\mathrm{Si}$ & 0,4 & 4 & 75 & 2,1 & 2,1 & 0,105 \\
\hline 314 & 0 & $\mathrm{Si}$ & 0,6 & 6 & 100 & 2,7 & 5,0 & 0,357 \\
\hline 315 & 116 & No & 1,3 & 13 & 95 & 3,1 & 3,1 & 0,150 \\
\hline 316 & 356 & No & 0,3 & 3 & 85 & 1,6 & 1,6 & 0,080 \\
\hline 317 & 31 & $\mathrm{Si}$ & 0,3 & 3 & 95 & 2,8 & 3,8 & 0,270 \\
\hline 318 & 53 & $\mathrm{Si}$ & 0,9 & 9 & 90 & 2,4 & 2,4 & 0,121 \\
\hline 319 & 0 & $\mathrm{Si}$ & 0,1 & 1 & 95 & 1,4 & 2,6 & 0,183 \\
\hline 320 & 0 & $\mathrm{Si}$ & & 0 & 100 & 3,1 & 5,0 & 0,355 \\
\hline 321 & 18 & $\mathrm{Si}$ & 0,35 & 3 & 60 & 3,4 & 3,4 & 0,337 \\
\hline 322 & 0 & No & 0,5 & 5 & 80 & 1,7 & 3,3 & 0,327 \\
\hline 323 & 0 & $\mathrm{Si}$ & 0,1 & 1 & 90 & 2,3 & 3,4 & 0,252 \\
\hline 324 & 185 & $\mathrm{Si}$ & 0,7 & 7 & 95 & 2,3 & 2,5 & 0,179 \\
\hline 325 & 320 & $\mathrm{Si}$ & 1,4 & 14 & 60 & 6,1 & 6,1 & 0,308 \\
\hline 326 & 38 & $\mathrm{Si}$ & 0,8 & 8 & 95 & 2,0 & 3,0 & 0,214 \\
\hline 327 & 0 & No & 1,5 & 15 & 95 & 1,6 & 2,3 & 0,228 \\
\hline 328 & 260 & $\mathrm{Si}$ & 0,8 & 8 & 80 & 6,4 & 6,4 & 0,320 \\
\hline 329 & 50 & $\mathrm{Si}$ & 0,5 & 5 & 90 & & & 0,000 \\
\hline 330 & 0 & No & 0,6 & 6 & 100 & 1,9 & 2,8 & 0,275 \\
\hline 331 & 250 & $\mathrm{Si}$ & 1,2 & 12 & 80 & 5,1 & 7,9 & 0,397 \\
\hline 332 & 166 & No & 0,2 & 2 & 85 & 2,3 & 2,3 & 0,160 \\
\hline 333 & 32 & $\mathrm{Si}$ & 0,7 & 7 & 90 & 2,7 & 2,7 & 0,193 \\
\hline 334 & 0 & $\mathrm{Si}$ & 0,5 & 5 & 90 & & & 0,000 \\
\hline 335 & 0 & $\mathrm{Si}$ & 0,6 & 6 & 95 & 3,4 & 6,0 & 0,432 \\
\hline 336 & 25 & No & 0,8 & 8 & 80 & 3,0 & 4,5 & 0,450 \\
\hline 337 & 161 & $\mathrm{Si}$ & 0,5 & 5 & 85 & 1,8 & 2,4 & 0,171 \\
\hline 338 & 0 & & 0,6 & 6 & 95 & 4,2 & 6,4 & 0,457 \\
\hline 339 & 0 & $\mathrm{Si}$ & 1,1 & 11 & 100 & 2,9 & 5,5 & 0,387 \\
\hline 340 & 202 & $\mathrm{Si}$ & 0,4 & 4 & 75 & 3,1 & 3,8 & 0,273 \\
\hline 341 & 0 & $\mathrm{Si}$ & 0,4 & 4 & 100 & 2,0 & 2,0 & 0,200 \\
\hline 342 & 0 & No & 1,0 & 10 & 95 & 2,4 & 4,1 & 0,414 \\
\hline 343 & 0 & $\mathrm{NO}$ & 1 & 10 & 100 & 2,0 & 3,1 & 0,220 \\
\hline
\end{tabular}




\begin{tabular}{|c|c|c|c|c|c|c|c|c|}
\hline 344 & 0 & $\mathrm{Si}$ & 0,1 & 1 & 90 & 2,3 & 3,9 & 0,281 \\
\hline 345 & 131 & $\mathrm{Si}$ & 0,4 & 4 & 50 & 3,3 & 3,3 & 0,327 \\
\hline 346 & 0 & No & 0,3 & 3 & 100 & 1,5 & 1,5 & 0,149 \\
\hline 347 & 0 & $\mathrm{Si}$ & 0,1 & 1 & 90 & 2,2 & 3,5 & 0,250 \\
\hline 348 & 0 & $\mathrm{Si}$ & 1,1 & 11 & 100 & 3,6 & 3,6 & 0,356 \\
\hline 349 & 0 & No & 0,5 & 5 & 100 & 1,6 & 2,7 & 0,267 \\
\hline 350 & 0 & No & 0,8 & 8 & 90 & 1,9 & 2,1 & 0,150 \\
\hline 351 & 406 & $\mathrm{Si}$ & 0,8 & 8 & 75 & 2,5 & 2,5 & 0,176 \\
\hline 352 & 0 & No & 0,55 & 5 & 90 & 2,0 & 2,2 & 0,218 \\
\hline 353 & 0 & $\mathrm{Si}$ & 0,6 & 6 & 100 & 3,5 & 5,9 & 0,421 \\
\hline 354 & 0 & $\mathrm{Si}$ & 0,3 & 3 & 100 & 2,0 & 4,6 & 0,329 \\
\hline 355 & 0 & $\mathrm{Si}$ & 0,3 & 3 & 95 & 1,3 & 1,3 & 0,093 \\
\hline 356 & 0 & $\mathrm{Si}$ & 0,6 & 6 & 100 & 1,8 & 3,1 & 0,220 \\
\hline 357 & 0 & $\mathrm{Si}$ & 0,8 & 8 & 95 & 3,7 & 7,0 & 0,352 \\
\hline 358 & 137 & $\mathrm{Si}$ & 0,45 & 4 & 90 & 4,3 & 6,7 & 0,340 \\
\hline 359 & 0 & No & 0,3 & 3 & 100 & 1,9 & 1,9 & 0,184 \\
\hline 360 & 0 & $\mathrm{Si}$ & 0,7 & 7 & 90 & 3,0 & 4,6 & 0,326 \\
\hline 361 & 0 & $\mathrm{Si}$ & 0,5 & 5 & 100 & 1,0 & 1,0 & 0,145 \\
\hline 362 & 0 & $\mathrm{SI}$ & 0,7 & 7 & 80 & 2,1 & 2,1 & 0,150 \\
\hline 363 & 0 & No & 0,75 & 7 & 85 & 1,2 & 1,8 & 0,178 \\
\hline 364 & 0 & No & 1,0 & 10 & 100 & 3,2 & 3,2 & 0,314 \\
\hline 365 & 436 & $\mathrm{NO}$ & 1,2 & 12 & 85 & 7,3 & 0,0 & 0,356 \\
\hline 366 & 303 & NO & 1,2 & 12 & 85 & 8,3 & 0,0 & 0,413 \\
\hline 367 & 365 & $\mathrm{SI}$ & 1,6 & 16 & 80 & 7,1 & 7,4 & 0,366 \\
\hline 368 & 100 & $\mathrm{NO}$ & 1,4 & 14 & 90 & 6,9 & 11,2 & 0,557 \\
\hline 369 & 421 & No & 0,6 & 6 & 85 & 6,4 & 11,5 & 0,561 \\
\hline 370 & 307 & No & 0,5 & 5 & 80 & 4,0 & 0,0 & 0,195 \\
\hline
\end{tabular}




\begin{tabular}{|c|c|c|c|c|c|c|c|c|}
\hline Probeta & $\begin{array}{c}\text { Nudo } \\
\text { de cara }\end{array}$ & $\begin{array}{c}\text { Nudo } \\
\text { agrupados cara }\end{array}$ & $\begin{array}{c}\text { Relación } \\
\text { nudos /cara }\end{array}$ & $\begin{array}{c}\text { Crec } 5 \\
\text { anillos int }\end{array}$ & Crec unit 5 anillos int & $\begin{array}{c}\text { Crec } 5 \\
\text { anillos ext }\end{array}$ & $\begin{array}{l}\text { Ancho } \\
\text { gema }\end{array}$ & $\begin{array}{l}\text { Canto } \\
\text { gema }\end{array}$ \\
\hline 1 & 1,9 & 2,4 & 0,095 & 2,3 & 4,6 & 1,7 & 1,9 & 2,1 \\
\hline 2 & 2,3 & 3,9 & 0,262 & 2,5 & 5,0 & 1,9 & & \\
\hline 3 & 2,7 & 4,4 & 0,293 & 3,4 & 6,8 & 1,3 & 0,0 & 0,0 \\
\hline 4 & 3,0 & 5,6 & 0,223 & 2,9 & 5,8 & 1,8 & 0,0 & 0,0 \\
\hline 5 & 3,4 & 3,4 & 0,133 & 3,7 & 7,4 & 2,4 & & \\
\hline 6 & 3,5 & 6,5 & 0,256 & & & & 1,7 & 1,6 \\
\hline 7 & 5,4 & 13,3 & 0,534 & 3,2 & 6,4 & 1,3 & & \\
\hline 8 & 2,7 & 6,1 & 0,275 & 2,8 & 5,6 & 1,6 & & \\
\hline 9 & 2,9 & 2,9 & 0,115 & 2,1 & 4,2 & 1,4 & & \\
\hline 10 & 1,7 & 3,7 & 0,149 & 3,5 & 7,0 & 3,0 & 0,4 & 0,4 \\
\hline 11 & 2,8 & 3,6 & 0,144 & 4,0 & 8,0 & 0,9 & 1,1 & 1,5 \\
\hline 12 & 2,4 & 2,4 & 0,094 & 2,7 & 5,4 & 1,7 & 0,0 & 0,0 \\
\hline 13 & 3,4 & 6,2 & 0,249 & 6,4 & 12,8 & 3,4 & 2,6 & 5,1 \\
\hline 14 & 4,8 & 6,7 & 0,270 & 5,4 & 10,8 & 1,2 & & \\
\hline 15 & 1,8 & 3,3 & 0,131 & 2,4 & 4,8 & 2,0 & 1,0 & 1,0 \\
\hline 16 & 4 & 6,1 & 0,241 & 3,3 & 6,6 & 1,5 & 0,7 & 0,8 \\
\hline 17 & 1,4 & 1,4 & 0,056 & & & & 2,2 & 2,3 \\
\hline 18 & 3,4 & 3,4 & 0,135 & 2,9 & 5,8 & 1,5 & 0,4 & 0,5 \\
\hline 19 & 1,4 & 2,9 & 0,161 & 1,4 & 2,8 & 1,0 & 1,1 & 1,1 \\
\hline 20 & 2,1 & 4,3 & 0,170 & 1,9 & 4,0 & 1,24 & 4,2 & 3,5 \\
\hline 21 & 3,5 & 4,5 & 0,178 & 3,6 & 7,2 & 1,6 & 0,7 & 0,7 \\
\hline 22 & 1,5 & 1,5 & 0,059 & & & & 2,0 & 1,9 \\
\hline 23 & 4,9 & 8,4 & 0,340 & 3,4 & 6,8 & 2,2 & 0,0 & 0,0 \\
\hline 24 & 3,6 & 5,9 & 0,233 & 2,8 & 5,6 & 2,2 & 1,1 & 1,0 \\
\hline 25 & 1,4 & 2,4 & 0,094 & 1,8 & 3,6 & 1,6 & 3,6 & 5,1 \\
\hline 26 & 2,6 & 5,1 & 0,201 & 2,9 & 5,8 & 1,6 & 0,7 & 0,7 \\
\hline 27 & 4,3 & 6,5 & 0,261 & 4,5 & 9,0 & 1,7 & & \\
\hline 28 & 3,8 & 6,5 & 0,261 & 4,3 & 8,6 & 2,2 & & \\
\hline 29 & 1,6 & 2,8 & 0,156 & 2,4 & 4,8 & 1,1 & 0,0 & 0,0 \\
\hline 30 & 1,4 & 2,4 & 0,095 & 2,4 & 4,9 & 1,1 & 1,7 & 1,3 \\
\hline 31 & 6,8 & 11,7 & 0,468 & 5,5 & 11,0 & 1,7 & & \\
\hline 32 & 2,7 & 4,9 & 0,200 & 3,9 & 7,8 & 2,8 & 0,8 & 0,7 \\
\hline 33 & 3 & 6,5 & 0,361 & 3,0 & 6,0 & 1,2 & 0,0 & 0,0 \\
\hline 34 & 4 & 7,6 & 0,299 & 3,0 & 6,0 & 1,6 & & \\
\hline 35 & 2,1 & 3,2 & 0,126 & 2,7 & 5,4 & 2,7 & & \\
\hline 36 & 4,5 & 6,7 & 0,268 & 4,9 & 9,8 & 3,0 & 0,0 & 0,0 \\
\hline 37 & 3,7 & 3,7 & 0,148 & 2,0 & 4,0 & 1,1 & 1,0 & 1,1 \\
\hline 38 & 3,2 & 4,5 & 0,253 & 2,5 & 5,0 & 1,0 & 0,0 & 0,0 \\
\hline 39 & 1,5 & 2,5 & 0,099 & 2,6 & 5,2 & 1,1 & 3,1 & 3,2 \\
\hline 40 & 1,7 & 1,7 & 0,069 & 3,0 & 6,0 & 2,6 & & \\
\hline 41 & 8,1 & 9,1 & 0,364 & & 0,0 & & 0,8 & 0,7 \\
\hline 42 & 2,0 & & 0,134 & 2,9 & 5,8 & 2,3 & 0,0 & 0,0 \\
\hline 43 & 1,7 & & 0,119 & 4,0 & 8,0 & 1,7 & & \\
\hline 44 & 3,7 & 5,4 & 0,365 & 2,3 & 4,6 & 1,2 & 0,6 & 0,9 \\
\hline 45 & 1,7 & 3,6 & 0,145 & 3,9 & 7,8 & 2,1 & & \\
\hline 46 & 4,2 & 8,0 & 0,541 & 2,7 & 5,4 & 1,3 & 0,0 & 0,0 \\
\hline 47 & 2,2 & 3,6 & 0,245 & 3,8 & 7,6 & 2,5 & 0,0 & 0,0 \\
\hline 48 & 1,7 & & 0,116 & 3,5 & 7,0 & 2,9 & & \\
\hline 49 & 1,7 & 3,3 & 0,130 & 2,8 & 5,6 & 1,6 & 2,8 & 2,7 \\
\hline 50 & 2,1 & 3,1 & 0,173 & 3,2 & 6,4 & 2,4 & 0,0 & 0,0 \\
\hline 51 & 3,4 & 6,7 & 0,447 & 3,0 & 6,0 & 2,2 & 0,0 & 0,0 \\
\hline 52 & 6,6 & 6,6 & 0,264 & 2,8 & 5,6 & 0,9 & & \\
\hline 53 & 1,8 & 1,8 & 0,071 & 2,8 & 5,6 & 2,4 & & \\
\hline 54 & 5,4 & 9,2 & 0,369 & 3,0 & 6,0 & 2,4 & 6,0 & 2,5 \\
\hline
\end{tabular}




\begin{tabular}{|c|c|c|c|c|c|c|c|c|}
\hline 55 & 2,7 & 5,0 & 0,198 & 3,5 & 7,0 & 0,9 & & \\
\hline 56 & 2,6 & 3,5 & 0,140 & 2,0 & 4,0 & 4,0 & & \\
\hline 57 & 2,4 & 2,4 & 0,096 & 3,3 & 6,6 & 1,4 & 0,7 & 0,6 \\
\hline 58 & 2,4 & 4,3 & 0,234 & 3,0 & 6,0 & 0,8 & 0,0 & 0,0 \\
\hline 59 & 2,6 & 4,3 & 0,170 & 2,2 & 4,4 & 1,7 & & \\
\hline 60 & 3,4 & 6,4 & 0,251 & 3,2 & 6,4 & 0,6 & 1,4 & 1,9 \\
\hline 61 & 4,5 & 8,0 & 0,541 & 2,2 & 4,4 & 1,8 & 0,0 & 0,0 \\
\hline 62 & 2,0 & 2,0 & 0,109 & 3,9 & 7,8 & 2,1 & 0,0 & 0,0 \\
\hline 63 & 1,8 & 2,4 & 0,160 & 2,0 & 4,0 & 1,7 & 0,0 & 0,0 \\
\hline 64 & 2,6 & 4,9 & 0,194 & 1,6 & 3,2 & 1,0 & 1,2 & 1,1 \\
\hline 65 & 3,7 & 7,5 & 0,503 & 1,9 & 3,8 & 1,0 & 0,0 & 0,0 \\
\hline 66 & 2,5 & 5,4 & 0,360 & 2,3 & 4,6 & 2,3 & 0,0 & 0,0 \\
\hline 67 & 3,3 & 6,0 & 0,237 & 2,0 & 4,0 & 1,6 & 5,2 & 6,0 \\
\hline 68 & 4,8 & 6,0 & 0,400 & 3,2 & 6,4 & 2,3 & & \\
\hline 69 & 2,2 & 4,1 & 0,277 & 3,0 & 6,0 & 1,7 & & \\
\hline 70 & 1,4 & 3,5 & 0,238 & 3,3 & 6,6 & 3,3 & 0,0 & 0,0 \\
\hline 71 & 2,3 & 4,5 & 0,302 & 3,7 & 7,4 & 2,6 & & \\
\hline 72 & 1,9 & 2,6 & 0,173 & 2,8 & 5,6 & 2,6 & & \\
\hline 73 & 3,3 & 5,8 & 0,231 & 2,4 & 4,8 & 1,4 & 0,6 & 0,6 \\
\hline 74 & 1,7 & 1,7 & 0,067 & 2,6 & 5,2 & 1,8 & 0,6 & 0,5 \\
\hline 75 & 3,5 & 5,3 & 0,296 & 2,4 & 4,8 & 1,4 & 0,0 & 0,0 \\
\hline 76 & 1,4 & 1,4 & 0,095 & 2,9 & 5,8 & 1,5 & & \\
\hline 77 & 1,7 & 3,1 & 0,209 & 2,4 & 4,8 & 1,4 & & \\
\hline 78 & 3,3 & 3,3 & 0,221 & 1,7 & 3,4 & 1,5 & & \\
\hline 79 & 1,9 & 0,0 & 0,128 & 2,6 & 5,2 & 2,6 & 0,0 & 0,0 \\
\hline 80 & 1,9 & 2,9 & 0,191 & 1,9 & 3,8 & 1,9 & & \\
\hline 81 & 3,9 & 6,0 & 0,330 & 2,3 & 4,6 & 1,2 & 0,0 & 0,0 \\
\hline 82 & 2,8 & 4,9 & 0,327 & 3,4 & 6,8 & 3,4 & & \\
\hline 83 & 1,3 & 2,3 & 0,154 & 2,8 & 5,6 & 2,3 & & \\
\hline 84 & 2,9 & 4,2 & 0,282 & 3,7 & 7,4 & 2,4 & & \\
\hline 85 & 1,8 & 1,8 & 0,121 & 3,5 & 7,0 & 2,0 & & \\
\hline 86 & 1,3 & 1,3 & 0,087 & 2,4 & 4,8 & 1,5 & & \\
\hline 87 & 2,3 & 4,1 & 0,277 & 2,7 & 5,4 & 2,5 & & \\
\hline 88 & 2,1 & 3,8 & 0,255 & 2,6 & 5,2 & 2,6 & & \\
\hline 89 & 1,5 & 1,5 & 0,100 & 2,3 & 4,6 & 1,8 & & \\
\hline 90 & 1,9 & 1,9 & 0,077 & 3,6 & 7,2 & 1,2 & & \\
\hline 91 & 1,4 & 2,8 & 0,185 & 2,6 & 5,2 & 2,9 & & \\
\hline 92 & 2,1 & 3,6 & 0,200 & 2,2 & 4,4 & 1,8 & 0,0 & 0,0 \\
\hline 93 & 3,1 & 4,4 & 0,293 & 2,4 & 4,8 & 2,4 & & \\
\hline 94 & 2,5 & 4,9 & 0,327 & 2,2 & 4,4 & 2,0 & & \\
\hline 95 & 2,6 & 3,7 & 0,247 & & & & & \\
\hline 96 & 3,7 & 8,0 & 0,537 & 3,7 & 7,4 & 2,5 & & \\
\hline 97 & 1,0 & 1,0 & 0,068 & 3,0 & 6,0 & 2,1 & & \\
\hline 98 & 2,3 & 2,3 & 0,154 & 2,6 & 5,2 & 1,8 & 1,8 & 1,6 \\
\hline 99 & 2,1 & 3,7 & 0,207 & 3,7 & 7,4 & 1,3 & 1,9 & 2,0 \\
\hline 100 & 1,7 & 3,6 & 0,245 & 2,7 & 5,4 & 1,9 & & \\
\hline 101 & 2,3 & 2,3 & 0,153 & 2,0 & 4,0 & 2,0 & & \\
\hline 102 & 2,0 & 4,0 & 0,268 & 2,4 & 4,8 & 2,1 & & \\
\hline 103 & 2,2 & 3,7 & 0,248 & 4,7 & 9,4 & 4,4 & & \\
\hline 104 & 1,4 & 2,4 & 0,161 & 3,7 & 7,4 & 1,3 & & \\
\hline 105 & 1,7 & 1,7 & 0,114 & 2,3 & 4,6 & 1,7 & & \\
\hline 106 & 2,3 & 3,8 & 0,152 & 3,1 & 6,2 & 1,1 & 2,7 & 4,2 \\
\hline 107 & 1,6 & 1,6 & 0,108 & 2,8 & 5,6 & 1,4 & & \\
\hline 108 & 3,8 & 6,7 & 0,267 & 3,0 & 6,0 & 1,8 & 0,4 & 0,3 \\
\hline 109 & 2,3 & 3,9 & 0,262 & 1,8 & 3,6 & 1,8 & & \\
\hline 110 & 1,1 & 1,1 & 0,073 & 4,1 & 8,2 & 3,5 & & \\
\hline 111 & 1,0 & 1,7 & 0,113 & 2,9 & 5,8 & 1,7 & & \\
\hline 112 & 1,6 & 3,0 & 0,201 & 2,1 & 4,2 & 1,4 & & \\
\hline
\end{tabular}




\begin{tabular}{|c|c|c|c|c|c|c|c|c|}
\hline 113 & 2,5 & 3,7 & 0,247 & 3,0 & 6,0 & 1,5 & & \\
\hline 114 & 1,2 & 2,2 & 0,147 & 2,8 & 5,6 & 1,7 & & \\
\hline 115 & 3,1 & 4,1 & 0,275 & 1,5 & 3,0 & 1,5 & & \\
\hline 116 & 2,9 & 5,4 & 0,362 & 2,0 & 4,0 & 1,5 & & \\
\hline 117 & 1,5 & 2,3 & 0,153 & 4,8 & 9,6 & 1,7 & & \\
\hline 118 & 1,7 & 3,1 & 0,208 & 2,3 & 4,6 & 1,5 & & \\
\hline 119 & 2,6 & 2,6 & 0,173 & 3,2 & 6,4 & 2,2 & & \\
\hline 120 & 3,7 & 6,9 & 0,463 & 3,4 & 6,8 & 1,8 & & \\
\hline 121 & 3,1 & 4,5 & 0,298 & 2,6 & 5,2 & 1,8 & & \\
\hline 122 & 2,5 & 6,3 & 0,417 & 2,5 & 5,0 & 2,0 & & \\
\hline 123 & 3,0 & 4,8 & 0,320 & 3,7 & 7,4 & 3,0 & & \\
\hline 124 & 2,4 & 4,0 & 0,267 & 2,3 & 4,6 & 1,6 & & \\
\hline 125 & 3,8 & 5,5 & 0,364 & 2,8 & 5,6 & 1,8 & & \\
\hline 126 & 2,4 & 4,7 & 0,311 & 2,7 & 5,4 & 1,7 & & \\
\hline 127 & 1,5 & 2,4 & 0,161 & 3,4 & 6,8 & 3,0 & & \\
\hline 128 & 4,6 & 5,2 & 0,349 & 3,0 & 6,0 & 1,7 & & \\
\hline 129 & 3,7 & 5,5 & 0,367 & 2,8 & 5,6 & 1,6 & & \\
\hline 130 & 1,1 & 1,1 & 0,073 & 3,0 & 6,0 & 2,3 & & \\
\hline 131 & 3,1 & 5,5 & 0,364 & 2,3 & 4,6 & 1,7 & & \\
\hline 132 & 3,2 & 5,4 & 0,360 & 2,4 & 4,8 & 2,4 & & \\
\hline 133 & 1,0 & 1,0 & 0,067 & 2,2 & 4,4 & 1,9 & & \\
\hline 134 & & & 0,000 & 2,7 & 5,4 & 1,4 & 1,3 & 1,4 \\
\hline 135 & 2,3 & 4,5 & 0,298 & 2,2 & 4,4 & 1,9 & & \\
\hline 136 & 2,8 & 5,3 & 0,351 & 1,3 & 2,6 & 1,7 & & \\
\hline 137 & 2,9 & 3,8 & 0,252 & 2,6 & 5,2 & 2,9 & & \\
\hline 138 & 2,6 & 6,6 & 0,363 & 3,9 & 7,8 & 1,7 & & \\
\hline 139 & 2,2 & 5,2 & 0,206 & 2,6 & 5,2 & 2,0 & & \\
\hline 140 & 1,6 & 1,6 & 0,107 & 1,4 & 2,8 & 1,6 & & \\
\hline 141 & 1,5 & 1,5 & 0,101 & 3,2 & 6,4 & 2,0 & & \\
\hline 142 & 2,2 & 3,3 & 0,183 & 2,5 & 5,0 & 1,1 & 0,4 & 0,8 \\
\hline 143 & 1,9 & 3,7 & 0,250 & 2,9 & 5,8 & 1,9 & & \\
\hline 144 & 1,5 & 1,5 & 0,101 & 3,3 & 6,6 & 2,3 & & \\
\hline 145 & 2,4 & 2,8 & 0,110 & 3,9 & 7,8 & 2,7 & & \\
\hline 146 & 2,0 & 2,0 & 0,134 & 2,4 & 4,8 & 1,6 & 1,0 & 1,0 \\
\hline 147 & 2,2 & 4,2 & 0,280 & 2,2 & 4,4 & 1,7 & & \\
\hline 148 & 1,0 & 1,0 & 0,066 & 1,9 & 3,8 & 1,5 & & \\
\hline 149 & 2,8 & 4,6 & 0,257 & 2,8 & 5,6 & 4,6 & 2,6 & 1,4 \\
\hline 150 & 2,3 & 4,8 & 0,318 & 2,4 & 4,8 & 1,4 & & \\
\hline 151 & 2,8 & 5,6 & 0,376 & 3,2 & 6,4 & 3,0 & & \\
\hline 152 & 1,4 & 2,5 & 0,169 & 3,5 & 7,0 & 1,8 & & \\
\hline 153 & 3,7 & 3,7 & 0,247 & 2,3 & 4,6 & 2,3 & & \\
\hline 154 & 1,2 & 1,2 & 0,081 & 2,7 & 5,4 & 2,0 & & \\
\hline 155 & 3,4 & 3,7 & 0,247 & 1,9 & 3,8 & 1,1 & & \\
\hline 156 & 2,2 & 5,4 & 0,362 & 2,3 & 4,6 & 1,0 & & \\
\hline 157 & 1,5 & 1,5 & 0,101 & 2,1 & 4,2 & 1,7 & & \\
\hline 158 & 2,9 & 4,9 & 0,329 & 3,9 & 7,8 & 2,6 & & \\
\hline 159 & 1,6 & 3,7 & 0,248 & 2,5 & 5,0 & 1,5 & & \\
\hline 160 & 3,3 & 7,6 & 0,503 & 2,6 & 5,2 & 2,3 & & \\
\hline 161 & 3,7 & 5,4 & 0,362 & 1,4 & 2,8 & 1,2 & & \\
\hline 162 & 3,6 & 6,3 & 0,350 & & 0,0 & & 1,9 & 1,4 \\
\hline 163 & 2,0 & 4,0 & 0,265 & 3,0 & 6,0 & 1,9 & & \\
\hline 164 & 2,2 & 4,4 & 0,242 & 3,4 & 6,8 & 1,3 & 0,0 & 0,0 \\
\hline 165 & 1,3 & 3,1 & 0,209 & 2,1 & 4,2 & 1,7 & & \\
\hline 166 & 2,2 & 3 & 0,168 & 3,9 & 7,8 & 1,2 & 0,0 & 0,0 \\
\hline 167 & 1,3 & 2,6 & 0,172 & 2,7 & 5,4 & 1,7 & & \\
\hline 168 & 3,0 & 5,6 & 0,311 & 3,0 & 6,0 & 1,9 & 0,0 & 0,0 \\
\hline 169 & & & 0,000 & 2,9 & 5,8 & 2,9 & & \\
\hline 170 & 2,6 & 5,1 & 0,340 & 3,1 & 6,2 & 2,3 & & \\
\hline
\end{tabular}




\begin{tabular}{|c|c|c|c|c|c|c|c|c|}
\hline 171 & 1,7 & 3,1 & 0,124 & 2,4 & 4,8 & 1,8 & 3,5 & 3,4 \\
\hline 172 & 1,3 & 2,7 & 0,182 & 2,5 & 5,0 & 1,7 & & \\
\hline 173 & 2,6 & 4,0 & 0,221 & 2,1 & 4,2 & 1,0 & 0,0 & 0,0 \\
\hline 174 & 2,0 & 3,0 & 0,200 & 3,9 & 7,8 & 1,4 & & \\
\hline 175 & 2,9 & 4,8 & 0,195 & 3,8 & 7,6 & 2,0 & 2,9 & 3,4 \\
\hline 176 & 2,0 & 3,7 & 0,247 & 3,2 & 6,4 & 2,1 & & \\
\hline 177 & 2,0 & 3,1 & 0,209 & 2,3 & 4,6 & 2,3 & & \\
\hline 178 & 2,2 & 4,4 & 0,295 & 2,7 & 5,4 & 1,6 & 1,2 & 1,3 \\
\hline 179 & 1,5 & 2,9 & 0,195 & 2,0 & 4,0 & 1,2 & & \\
\hline 180 & 2,0 & 0,0 & 0,133 & 3,0 & 6,0 & 1,0 & & \\
\hline 181 & 1,0 & 1,0 & 0,068 & 3,3 & 6,6 & 2,3 & & \\
\hline 182 & 2,7 & 4,4 & 0,295 & 2,9 & 5,8 & 2,1 & & \\
\hline 183 & 2,2 & 3,9 & 0,260 & 2,6 & 5,2 & 1,7 & & \\
\hline 184 & 2,4 & 4,1 & 0,162 & 2,4 & 4,8 & 2,1 & 2,1 & 1,5 \\
\hline 185 & 2,3 & 2,7 & 0,180 & 1,8 & 3,6 & 1,6 & & \\
\hline 186 & 2,4 & 4,3 & 0,287 & & & & 1,3 & 1,2 \\
\hline 187 & 2,4 & 2,5 & 0,168 & 3,2 & 6,4 & 5,2 & & \\
\hline 188 & 3,1 & 4,5 & 0,302 & 3,2 & 6,4 & 1,8 & & \\
\hline 189 & 5,8 & 8,1 & 0,324 & 4,6 & 9,2 & 1,5 & & \\
\hline 190 & 2,1 & 4,0 & 0,222 & 2,7 & 5,4 & 1,6 & 0,0 & 0,0 \\
\hline 191 & 1,2 & 2,3 & 0,153 & 2,6 & 5,2 & 1,9 & 2,0 & 1,5 \\
\hline 192 & 2,9 & 4,8 & 0,322 & 3,6 & 7,2 & 2,8 & & \\
\hline 193 & 2,0 & 3,6 & 0,240 & 2,6 & 5,2 & 2,3 & & \\
\hline 194 & 2,1 & 3,6 & 0,243 & 1,8 & 3,6 & 1,4 & & \\
\hline 195 & 1,2 & 2,2 & 0,123 & 2,3 & 4,6 & 1,5 & 0,0 & 0,0 \\
\hline 196 & 1,8 & 3,6 & 0,240 & 2,8 & 5,6 & 1,8 & 0,7 & 0,5 \\
\hline 197 & 3,2 & 4,1 & 0,277 & 1,8 & 3,6 & 1,5 & & \\
\hline 198 & 1,3 & 1,3 & 0,088 & 1,8 & 3,6 & 1,8 & & \\
\hline 199 & 2,8 & 2,8 & 0,187 & 2,8 & 5,6 & 2,1 & & \\
\hline 200 & 1,2 & 2,2 & 0,147 & & & & & \\
\hline 201 & 4,1 & 5,8 & 0,229 & 3,2 & 6,4 & 1,6 & & \\
\hline 202 & 1,5 & 3,6 & 0,199 & 2,8 & 5,6 & 0,7 & 1,7 & 2,1 \\
\hline 203 & 1,6 & 1,6 & 0,107 & 1,7 & 3,4 & 1,7 & & \\
\hline 204 & 2,6 & 4,7 & 0,260 & 4,2 & 8,4 & 1,3 & 0,0 & 0,0 \\
\hline 205 & 1,0 & 1,0 & 0,067 & 2,1 & 4,2 & 1,3 & & \\
\hline 206 & 3,1 & 3,1 & 0,207 & 2,5 & 5,0 & 2,8 & 1,3 & 2,8 \\
\hline 207 & 1,7 & 3,9 & 0,257 & 2,4 & 4,8 & 2,2 & & \\
\hline 208 & 2,2 & 3,3 & 0,219 & 2,2 & 4,4 & 1,6 & & \\
\hline 209 & 1,7 & 1,7 & 0,068 & 4,2 & 8,4 & 2,7 & & \\
\hline 210 & 2,3 & 2,3 & 0,155 & 2,2 & 4,4 & 3,1 & & \\
\hline 211 & 1,5 & 2,5 & 0,168 & 2,9 & 5,8 & 2,2 & & \\
\hline 212 & 3,2 & 3,2 & 0,178 & 3,7 & 7,4 & 1,2 & 0,0 & 0,0 \\
\hline 213 & 2,8 & 4,2 & 0,278 & 3,1 & 6,2 & 2,7 & & \\
\hline 214 & 4,2 & 6,6 & 0,265 & 3,3 & 6,6 & 1,1 & & \\
\hline 215 & 1,5 & 2,8 & 0,188 & 2,7 & 5,4 & 1,7 & & \\
\hline 216 & 3,4 & 6,6 & 0,440 & 2,7 & 5,4 & 1,5 & 1,5 & 2,1 \\
\hline 217 & 1,6 & 2,7 & 0,152 & 2,9 & 5,8 & 1,5 & 0 & 0 \\
\hline 218 & 5,3 & 8,2 & 0,453 & 3,5 & 7,0 & 0,9 & 0,0 & 0,0 \\
\hline 219 & 3,6 & 4,5 & 0,300 & 2,6 & 5,2 & 2,3 & & \\
\hline 220 & 4,8 & 4,8 & 0,320 & 2,2 & 4,4 & 2,2 & & \\
\hline 221 & 2,8 & 6,9 & 0,385 & 5,1 & 10,2 & 1,4 & 0,0 & 0,0 \\
\hline 222 & 2,8 & 4,3 & 0,287 & 2,6 & 5,2 & 1,4 & & \\
\hline 223 & 1,9 & 3,1 & 0,172 & 2,1 & 4,2 & 1,3 & 3,8 & 3,8 \\
\hline 224 & 1,9 & 3,3 & 0,219 & 2,6 & 5,2 & 2,6 & & \\
\hline 225 & 2,3 & 4,7 & 0,263 & 2,5 & 5,0 & 1,9 & 0,0 & 0,0 \\
\hline 226 & 3,6 & 3,6 & 0,200 & 2,3 & 4,6 & 2,8 & 0,3 & 0,3 \\
\hline 227 & 1,9 & 3,8 & 0,253 & 3,9 & 7,8 & 2,5 & & \\
\hline 228 & 1,5 & 1,5 & 0,100 & 4,2 & 8,4 & 2,8 & & \\
\hline
\end{tabular}




\begin{tabular}{|c|c|c|c|c|c|c|c|c|}
\hline 229 & 2,7 & 2,7 & 0,180 & 2,1 & 4,2 & 1,7 & 2,4 & 2,7 \\
\hline 230 & 2,7 & 5,9 & 0,343 & 3,5 & 7,0 & 0,6 & & \\
\hline 231 & 2,0 & 3,6 & 0,238 & 2,7 & 5,4 & 1,8 & & \\
\hline 232 & 1,6 & 3,0 & 0,199 & 3,6 & 7,2 & 2,8 & & \\
\hline 233 & 3,5 & 5,3 & 0,209 & 2,7 & 5,4 & 2,2 & & \\
\hline 234 & 1,0 & 1,0 & 0,067 & 2,9 & 5,8 & 1,7 & & \\
\hline 235 & 2,1 & 2,3 & 0,129 & 4,0 & 8,0 & 1,3 & 0,0 & 0,0 \\
\hline 236 & 2,0 & 4,0 & 0,160 & 4,9 & 9,8 & 2,8 & 1,1 & 1,2 \\
\hline 237 & 2,6 & 3,5 & 0,196 & 2,1 & 4,2 & 0,8 & 2,0 & 2,0 \\
\hline 238 & 2,2 & 4,2 & 0,278 & 2,1 & 4,2 & 2,1 & & \\
\hline 239 & 1,8 & 2,8 & 0,185 & 2,9 & 5,8 & 1,6 & & \\
\hline 240 & 2,3 & 6,7 & 0,444 & 2,3 & 4,6 & 1,6 & & \\
\hline 241 & 3,4 & 4,7 & 0,313 & 2,2 & 4,4 & 1,9 & & \\
\hline 242 & 1,9 & 3,5 & 0,233 & 2,3 & 4,6 & 3,5 & & \\
\hline 243 & 4,7 & 6,9 & 0,277 & 2,1 & 4,2 & 0,9 & & \\
\hline 244 & 2,5 & 5,0 & 0,276 & 2,8 & 5,6 & 1,3 & 0,0 & 0,0 \\
\hline 245 & 1,8 & 3,2 & 0,175 & 3,0 & 6,0 & 1,4 & 0,6 & 0,7 \\
\hline 246 & 3,8 & 6,2 & 0,408 & 3,2 & 6,4 & 1,5 & & \\
\hline 247 & 1,4 & 1,4 & 0,093 & 2,8 & 5,6 & 1,7 & & \\
\hline 248 & 2,3 & 3,2 & 0,179 & 2,4 & 4,8 & 1,4 & 0,0 & 0,0 \\
\hline 249 & 5,5 & 9,5 & 0,525 & 2,0 & 4,0 & 1,5 & 1,3 & 1,2 \\
\hline 250 & 4,0 & 7,6 & 0,306 & 4,2 & 8,4 & 2,3 & 0,0 & 0,0 \\
\hline 251 & 3,6 & 5,2 & 0,287 & 2,7 & 5,4 & 1,5 & 0,0 & 0,0 \\
\hline 252 & 2,8 & 2,8 & 0,156 & 2,4 & 4,8 & 1,1 & 0,0 & 0,0 \\
\hline 253 & 1,7 & 1,7 & 0,114 & 3,9 & 7,8 & 2,7 & & \\
\hline 254 & 3,8 & 3,8 & 0,212 & 2,0 & 4,0 & 1,6 & 0,5 & 0,9 \\
\hline 255 & 2,7 & 2,7 & 0,149 & 3,2 & 6,4 & 1,2 & 0,0 & 0,0 \\
\hline 256 & 2,2 & 2,5 & 0,140 & 2,3 & 4,6 & 1,2 & 0,0 & 0,0 \\
\hline 257 & 1,6 & 3,0 & 0,168 & 2,4 & 4,8 & 1,8 & 0,0 & 0,0 \\
\hline 258 & 2,8 & 3,7 & 0,247 & 2,9 & 5,8 & 1,5 & & \\
\hline 259 & 2,6 & 2,6 & 0,173 & 3,4 & 6,8 & 3,4 & & \\
\hline 260 & 2,0 & 4,0 & 0,161 & 3,0 & 6,0 & 3,0 & 0,4 & 0,5 \\
\hline 261 & 2,8 & 4,9 & 0,327 & 3,8 & 7,6 & 3,0 & & \\
\hline 262 & 2,4 & 4,6 & 0,305 & 2,5 & 5,0 & 2,6 & & \\
\hline 263 & 3,9 & 5,5 & 0,219 & 4,3 & 8,6 & 1,6 & & \\
\hline 264 & 3,0 & 3,0 & 0,166 & 2,5 & 5,0 & 1,5 & & \\
\hline 265 & 3,3 & 4,5 & 0,296 & 2,9 & 5,8 & 1,3 & & \\
\hline 266 & 1,9 & 1,9 & 0,105 & & 0,0 & & & \\
\hline 267 & 2,4 & 4,0 & 0,223 & 3,0 & 6,0 & 1,9 & 0,0 & 0,0 \\
\hline 268 & 5,5 & 8,0 & 0,449 & 3,1 & 6,2 & 1,6 & 0,0 & 0,0 \\
\hline 269 & 2,4 & 3,7 & 0,248 & 2,2 & 4,4 & 2,0 & & \\
\hline 270 & 3,0 & 5,2 & 0,292 & 2,9 & 5,8 & 1,8 & & \\
\hline 271 & 3,6 & 4,4 & 0,246 & 3,6 & 7,2 & 1,2 & 0,0 & 0,0 \\
\hline 272 & 2,0 & 3,7 & 0,245 & 3,3 & 6,6 & 3,5 & & \\
\hline 273 & 2,2 & 5,6 & 0,373 & 3,0 & 6,0 & 1,8 & & \\
\hline 274 & 2,5 & 3,8 & 0,255 & 3,8 & 7,6 & 2,4 & & \\
\hline 275 & 2,5 & 7,3 & 0,293 & 3,5 & 7,0 & 1,4 & 0,0 & 0,0 \\
\hline 276 & 2,7 & 4,3 & 0,287 & 3,7 & 7,4 & 2,0 & & \\
\hline 277 & 2,9 & 3,6 & 0,142 & 2,35 & 4,7 & 1,0 & 1,4 & 1,0 \\
\hline 278 & 4,0 & 4,8 & 0,193 & 4,4 & 8,8 & 1,7 & & \\
\hline 279 & 3,4 & 6,9 & 0,381 & 1,8 & 3,6 & 1,8 & 0,0 & 0,0 \\
\hline 280 & 4,1 & 4,1 & 0,164 & 3,5 & 7,0 & 1,5 & 0,5 & 0,5 \\
\hline 281 & 3,4 & 6,0 & 0,330 & 2,3 & 4,6 & 2,6 & 0,9 & 0,6 \\
\hline 282 & 1,8 & 1,8 & 0,101 & 1,3 & 2,6 & 3,2 & 0,0 & 0,0 \\
\hline 283 & 1,5 & 2,8 & 0,157 & 2,8 & 5,6 & 1,9 & 0,6 & 0,8 \\
\hline 284 & 2,4 & 6,1 & 0,407 & 3,2 & 6,4 & 2,4 & & \\
\hline 285 & 2,6 & 4,5 & 0,296 & 2,6 & 5,2 & 2,0 & & \\
\hline 286 & 2,6 & 2,6 & 0,146 & 2,1 & 4,2 & 1,1 & 0,0 & 0,0 \\
\hline
\end{tabular}




\begin{tabular}{|c|c|c|c|c|c|c|c|c|}
\hline 287 & 2,8 & 2,8 & 0,189 & 3,5 & 7,0 & 2,1 & & \\
\hline 288 & 2,3 & 3,2 & 0,216 & 3,9 & 7,8 & 3,8 & & \\
\hline 289 & & & 0,000 & 1,6 & 3,2 & 0,9 & 2,6 & 3,0 \\
\hline 290 & 1,8 & 2,9 & 0,192 & 3,9 & 7,8 & 2,2 & & \\
\hline 291 & 3,1 & 3,5 & 0,141 & 2,8 & 5,6 & 1,7 & & \\
\hline 292 & 3,3 & 5,6 & 0,311 & 3,9 & 7,8 & 1,7 & 0,0 & 0,0 \\
\hline 293 & 2,5 & 5,4 & 0,355 & 3,7 & 7,4 & 2,7 & & \\
\hline 294 & 3,1 & 4,9 & 0,269 & 2,5 & 5,0 & 1,5 & 1,0 & 0,9 \\
\hline 295 & 4,9 & 11,2 & 0,446 & 4,1 & 8,2 & 0,9 & 1,0 & 1,0 \\
\hline 296 & 2,1 & 2,1 & 0,140 & 2,6 & 5,2 & 2,2 & & \\
\hline 297 & 2,9 & 5,1 & 0,204 & 4,4 & 8,8 & 3,9 & 2,6 & 3,1 \\
\hline 298 & 4,9 & 6,0 & 0,324 & 3,7 & 7,4 & 1,6 & 0,0 & 0,0 \\
\hline 299 & 2,4 & 3,8 & 0,151 & 3,5 & 7,0 & 1,0 & 1,5 & 0,7 \\
\hline 300 & 1,6 & 2,7 & 0,180 & 2,7 & 5,4 & 1,3 & & \\
\hline 301 & 2,5 & 2,5 & 0,166 & 1,9 & 3,8 & 1,9 & & \\
\hline 302 & 3,9 & 5,4 & 0,217 & 2,6 & 5,2 & 1,7 & 0,5 & 1,3 \\
\hline 303 & 4,0 & 4,0 & 0,160 & 3,5 & 7,0 & 2,0 & 2,0 & 1,1 \\
\hline 304 & 2,3 & 3,5 & 0,197 & 3,5 & 7,0 & 1,0 & 0,0 & 0,0 \\
\hline 305 & 2,0 & 2,0 & 0,109 & 4,9 & 9,8 & 1,0 & 0,0 & 0,0 \\
\hline 306 & 2,3 & 3,4 & 0,190 & 4,2 & 8,4 & 0,8 & 0,0 & 0,0 \\
\hline 307 & 1,9 & 3,8 & 0,210 & 3,8 & 7,6 & 0,6 & 0,8 & 1,1 \\
\hline 308 & 2,2 & 3,6 & 0,199 & 5,5 & 11,0 & 2,3 & 0,0 & 0,0 \\
\hline 309 & 2,5 & 2,5 & 0,164 & 2,2 & 4,4 & 1,8 & & \\
\hline 310 & 2,1 & 2,1 & 0,084 & & 0,0 & & 1,9 & 2,4 \\
\hline 311 & 2,8 & 5,0 & 0,281 & 2,9 & 5,8 & 1,9 & 0,0 & 0,0 \\
\hline 312 & 2,3 & 3,2 & 0,180 & 3,2 & 6,4 & 1,8 & 0,0 & 0,0 \\
\hline 313 & 1,5 & 2,3 & 0,092 & 2,7 & 5,4 & 2,0 & 1,1 & 1,4 \\
\hline 314 & 2,9 & 4,1 & 0,227 & 3,6 & 7,2 & 1,2 & 0,0 & 0,0 \\
\hline 315 & 4,5 & 5,8 & 0,228 & 3,9 & 7,8 & 1,3 & 1,8 & 2 \\
\hline 316 & 2,5 & 4,0 & 0,159 & 2,3 & 4,6 & 1,2 & 2,5 & 4,2 \\
\hline 317 & 3,2 & 7,2 & 0,396 & 2,4 & 4,8 & 1,8 & 0,3 & 0,4 \\
\hline 318 & 2,3 & 2,3 & 0,092 & 3,2 & 6,4 & 1,8 & & \\
\hline 319 & 2,3 & 4,4 & 0,242 & 3,5 & 7,0 & 0,7 & 0,0 & 0,0 \\
\hline 320 & 2,7 & 4,6 & 0,258 & 3,4 & 6,8 & 1,5 & & \\
\hline 321 & 3,4 & 5,2 & 0,344 & 2,6 & 5,2 & 2,0 & & \\
\hline 322 & 2,6 & 6,7 & 0,444 & 3,5 & 7,0 & 2,7 & & \\
\hline 323 & 2,3 & 3,4 & 0,189 & 2,6 & 5,2 & 4,3 & & \\
\hline 324 & 1,7 & 2,8 & 0,155 & 4,0 & 8,0 & 1,2 & 0,5 & 0,5 \\
\hline 325 & 6,8 & 10,5 & 0,422 & 2,7 & 5,4 & 1,5 & 2,6 & 3,0 \\
\hline 326 & 2,1 & 2,1 & 0,117 & 1,8 & 3,6 & 1,3 & & \\
\hline 327 & 2,6 & 4,7 & 0,309 & 2,6 & 5,2 & 2,4 & & \\
\hline 328 & 6,3 & 10,5 & 0,422 & 3,5 & 7,0 & 1,3 & 2,4 & 2,0 \\
\hline 329 & 2,9 & 5,2 & 0,289 & 2,5 & 5,0 & 1,1 & & \\
\hline 330 & 2,1 & 2,1 & 0,139 & 3,5 & 7,0 & 3,5 & & \\
\hline 331 & 5,8 & 1,1 & 0,230 & 3,4 & 6,8 & 1,9 & 0,0 & 0,0 \\
\hline 332 & 2,1 & 4,0 & 0,221 & 3,5 & 7,0 & 0,8 & 0,6 & 0,7 \\
\hline 333 & 3,3 & 6,3 & 0,344 & 2,8 & 5,6 & 1,7 & 0,0 & 0,0 \\
\hline 334 & 2,9 & 2,9 & 0,116 & 3,1 & 6,2 & 1,2 & & \\
\hline 335 & 4,8 & 7,5 & 0,419 & 2,4 & 4,8 & 2,3 & 0,0 & 0,0 \\
\hline 336 & 2,2 & 3,9 & 0,258 & 2,4 & 4,8 & 1,5 & & \\
\hline 337 & 2,3 & 3,7 & 0,206 & 1,7 & 3,4 & 1,9 & 0,2 & 0,2 \\
\hline 338 & 4,1 & 6,3 & 0,350 & 2,1 & 4,2 & 1,1 & & \\
\hline 339 & 3,0 & 5,0 & 0,275 & 3,0 & 6,0 & 1,0 & 0,0 & 0,0 \\
\hline 340 & 3,8 & 3,8 & 0,213 & 0,6 & 1,2 & 1,6 & 0,5 & 0,3 \\
\hline 341 & 1,8 & 2,9 & 0,193 & 4,2 & 8,4 & 2,4 & & \\
\hline 342 & 2,8 & 4,3 & 0,285 & 2,8 & 5,6 & 2,4 & & \\
\hline 343 & 2,4 & 4,3 & 0,236 & 2,2 & 4,4 & 2,2 & 0,0 & 0,0 \\
\hline 344 & 2,4 & 3,6 & 0,200 & 3,0 & 6,0 & 1,0 & 0,0 & 0,0 \\
\hline
\end{tabular}




\begin{tabular}{|c|c|c|c|c|c|c|c|c|}
\hline 345 & 4,7 & 6,4 & 0,424 & 2,3 & 4,6 & 2,3 & 3,4 & 2,9 \\
\hline 346 & 1,1 & 2,1 & 0,139 & 2,9 & 5,8 & 2,9 & & \\
\hline 347 & 2,9 & 5,7 & 0,320 & 3,0 & 6,0 & 1,0 & & \\
\hline 348 & 2,7 & 3,9 & 0,257 & 2,1 & 4,2 & 2,1 & & \\
\hline 349 & 2,0 & 2,2 & 0,146 & 2,5 & 5,0 & 2,4 & & \\
\hline 350 & 2,9 & 2,9 & 0,161 & 3,8 & 7,6 & 0,8 & & \\
\hline 351 & 2,4 & 2,9 & 0,162 & 2,6 & 5,2 & 0,8 & 2,1 & 1,9 \\
\hline 352 & 3,8 & 6,6 & 0,437 & 2,7 & 5,4 & 1,9 & & \\
\hline 353 & 2,6 & 4,7 & 0,263 & 2,4 & 4,8 & 1,4 & 0,0 & 0,0 \\
\hline 354 & 2,0 & 2,3 & 0,126 & 3,5 & 7,0 & 1,0 & 0,0 & 0,0 \\
\hline 355 & 3,4 & 3,4 & 0,190 & 1,8 & 3,6 & 4,7 & 0,0 & 0,0 \\
\hline 356 & 2,5 & 2,5 & 0,138 & 3,7 & 7,4 & 1,5 & 0,0 & 0,0 \\
\hline 357 & 3,6 & 5,2 & 0,208 & 3,2 & 6,4 & 2,0 & & \\
\hline 358 & 4,4 & 5,1 & 0,206 & 3,5 & 7,0 & 2,8 & & \\
\hline 359 & 1,4 & 2,4 & 0,160 & 2,8 & 5,6 & 2,0 & & \\
\hline 360 & 2,4 & 2,4 & 0,134 & 1,3 & 2,6 & 4,4 & & \\
\hline 361 & 1,1 & 1,1 & 0,074 & 1,5 & 3,0 & 0,9 & & \\
\hline 362 & 2,3 & 4,0 & 0,220 & 2,4 & 4,8 & 1,0 & 1,2 & 2,4 \\
\hline 363 & 1,4 & 2,3 & 0,151 & 2,1 & 4,2 & 1,7 & & \\
\hline 364 & 3,7 & 5,6 & 0,368 & 2,2 & 4,4 & 1,9 & & \\
\hline 365 & 7,8 & 8,3 & 0,331 & 2,2 & 4,4 & 0,8 & 4,5 & 3,9 \\
\hline 366 & 4,5 & 7,7 & 0,306 & 2,4 & 4,8 & 1,8 & 5,0 & 4,3 \\
\hline 367 & 7,8 & 12,9 & 0,514 & 3,1 & 6,2 & 1,8 & 2,9 & 2,6 \\
\hline 368 & 4,8 & 8,1 & 0,320 & 3,2 & 6,4 & 2,2 & 0,0 & 0,0 \\
\hline 369 & 5,7 & 9,1 & 0,364 & 4,3 & 8,6 & 2,5 & 2,0 & 3,4 \\
\hline 370 & 5,3 & 9,0 & 0,356 & 3,0 & 6,0 & 1,5 & 1,5 & 1,6 \\
\hline
\end{tabular}




\begin{tabular}{|c|c|c|c|c|c|c|c|}
\hline Probeta & $\begin{array}{l}\text { Ancho } \\
\text { fenda }\end{array}$ & $\begin{array}{c}\text { Profundidad } \\
\text { fenda }\end{array}$ & $\begin{array}{c}\text { Curvatura } \\
\text { cara }\end{array}$ & $\begin{array}{c}\text { Curvatura } \\
\text { canto }\end{array}$ & Alabeo & Pudrición & Luz \\
\hline 1 & 0,2 & 1,6 & 0,2 & 0,0 & 1,0 & No & 450 \\
\hline 2 & 0,4 & 2,7 & 0,3 & 0,3 & 1,0 & No & 270 \\
\hline 3 & 0,6 & 3,0 & 0,2 & 0,3 & 1,7 & No & 270 \\
\hline 4 & 0,3 & 2,5 & 0,1 & 0,3 & 2,0 & No & 450 \\
\hline 5 & 0,4 & 2,3 & 0,1 & 0,1 & 0 & No & 450 \\
\hline 6 & 0,6 & 3,8 & 0,0 & 0,0 & 0,7 & No & 450 \\
\hline 7 & 0,1 & 0,4 & 0,2 & 0,2 & 0,1 & No & 450 \\
\hline 8 & 0,1 & 0,4 & 0,1 & 0,2 & 0,2 & No & 450 \\
\hline 9 & 0,5 & 2,8 & 0,0 & 0,1 & 0,0 & No & 450 \\
\hline 10 & 0,3 & 1,2 & 0,4 & & 0,1 & No & 450 \\
\hline 11 & 0,5 & 0,8 & 0,1 & & 0,2 & No & 450 \\
\hline 12 & 0,4 & 1,9 & 0,1 & 0,0 & 0,0 & No & 450 \\
\hline 13 & 0,3 & 1,1 & 0,1 & 0,2 & 0,2 & No & 450 \\
\hline 14 & 0,3 & 1,5 & 0,2 & & 0,3 & No & 450 \\
\hline 15 & 0,6 & 3,7 & 0,1 & & 0,0 & No & 450 \\
\hline 16 & 0,4 & 3,2 & 0,6 & 0,8 & 0,0 & No & 450 \\
\hline 17 & 0,35 & 2,4 & 0,1 & 0,0 & 0,0 & No & 450 \\
\hline 18 & 0,3 & 3,1 & 0,4 & 0,3 & 1,1 & No & 450 \\
\hline 19 & 0,2 & 0,9 & 0,0 & 0,1 & 0,3 & No & 324 \\
\hline 20 & 0,6 & 1,9 & 0,1 & 0,2 & & No & 450 \\
\hline 21 & 0,4 & 3,5 & 0,0 & 0,0 & 0,1 & No & 450 \\
\hline 22 & 0,4 & 3,5 & 0,1 & 0,0 & 0,1 & No & 450 \\
\hline 23 & 0,2 & 1,0 & 0,0 & 0,1 & 0,4 & No & 450 \\
\hline 24 & 0,2 & 1,1 & 0,1 & 0,2 & 0,1 & No & 450 \\
\hline 25 & 0,6 & 3,8 & 0,1 & 0,3 & 0,6 & No & 450 \\
\hline 26 & 0,2 & 1,9 & 0,1 & 0,0 & 0,1 & No & 450 \\
\hline 27 & 0,4 & 1,9 & 0,1 & & 0,1 & No & 450 \\
\hline 28 & 0,15 & 1,1 & 0,1 & 0,1 & 0,3 & No & 450 \\
\hline 29 & 0,15 & 1,2 & 0,0 & 0,1 & 0,15 & No & 324 \\
\hline 30 & 0,5 & 2,4 & 0,2 & 0,1 & 0,1 & No & 450 \\
\hline 31 & 0,3 & 0,8 & 0,1 & 0,1 & 1,0 & No & 450 \\
\hline 32 & 0,2 & 0,9 & 0,1 & 0,2 & 0 & No & 450 \\
\hline 33 & 0,3 & 0,7 & 0,1 & 0,3 & 0,3 & No & 324 \\
\hline 34 & 0,25 & 1,9 & 0,1 & 0,2 & 0,3 & No & 450 \\
\hline 35 & 0,3 & 2,1 & 0,0 & 0,0 & 0,1 & No & 450 \\
\hline 36 & 0,2 & 0,6 & 0,1 & 0,1 & 0,3 & No & 450 \\
\hline 37 & 0,1 & 0,4 & 0,2 & 0,2 & 0,1 & No & 450 \\
\hline 38 & 0,2 & 1,2 & 0,0 & 0,1 & 0,3 & No & 324 \\
\hline 39 & 0,3 & 2,4 & 0,2 & 0,1 & 0,1 & No & 450 \\
\hline 40 & 0,15 & 0,7 & 0,1 & 0,0 & 0,2 & No & 450 \\
\hline 41 & 0,4 & 2,5 & 0,0 & 0,0 & 1,4 & No & 450 \\
\hline 42 & 0,2 & 1,4 & 2,5 & 0,8 & 1,5 & No & 270 \\
\hline 43 & 0,1 & 0,5 & 0,0 & 0,2 & 1,2 & No & 270 \\
\hline 44 & 0,6 & 2,5 & 0,0 & 0,1 & 0,9 & No & 270 \\
\hline 45 & 0,3 & 1,0 & 0,1 & 0,2 & 0,0 & No & 450 \\
\hline 46 & 0,4 & 2,1 & 0,0 & 0,5 & 1,5 & No & 270 \\
\hline 47 & 0,25 & 1,1 & 0,1 & 0,8 & 1,8 & No & 270 \\
\hline 48 & 0,3 & 2,0 & 0,2 & 0,1 & 0,9 & $\mathrm{NO}$ & 270 \\
\hline 49 & 0,25 & 1,9 & 0,0 & 0,1 & 0,0 & No & 450 \\
\hline 50 & 0,3 & 1,0 & 0,0 & 0,1 & 0,0 & No & 324 \\
\hline 51 & 0,5 & 2,2 & 0,1 & 0,2 & 2,0 & No & 270 \\
\hline 52 & 0,2 & 0,3 & & 0,1 & 0,1 & No & 450 \\
\hline 53 & 0,7 & 3,5 & 0,1 & & 0,2 & No & 450 \\
\hline 54 & 0,2 & 0,6 & 0,0 & 0,0 & 0,0 & No & 450 \\
\hline
\end{tabular}




\begin{tabular}{|c|c|c|c|c|c|c|c|}
\hline 55 & 0,6 & 1,7 & 0,1 & 0,2 & 0,3 & No & 450 \\
\hline 56 & & & 0,1 & & 0,1 & No & 450 \\
\hline 57 & 0,4 & 1,9 & 0,1 & 0,1 & 0,0 & No & 450 \\
\hline 58 & 0,3 & 1,1 & 0,1 & 0,1 & 0 & No & 324 \\
\hline 59 & 0,2 & 1,4 & 0,0 & 0,0 & 0,0 & No & 450 \\
\hline 60 & 0,6 & 2,4 & & 0,1 & & & 450 \\
\hline 61 & 0,6 & 2,9 & 0,4 & 0,2 & 1,1 & No & 270 \\
\hline 62 & 0,2 & 0,7 & 0,1 & 0,1 & 0,6 & No & 324 \\
\hline 63 & 0,4 & 2,0 & 0,0 & 0,7 & 1,4 & No & 270 \\
\hline 64 & 0,4 & 2,6 & 0,1 & 0,1 & 0,0 & No & 450 \\
\hline 65 & 0,4 & 1,6 & 0,1 & 0,1 & 1,7 & No & 270 \\
\hline 66 & 0,4 & 1,8 & 0,4 & 0,3 & 1,5 & No & 270 \\
\hline 67 & 0,5 & 3,5 & & & 0,1 & No & 450 \\
\hline 68 & 0,1 & 0,3 & 0,4 & 0,4 & 1,4 & No & 270 \\
\hline 69 & 0,5 & 2,5 & 0,0 & 0,2 & 1,6 & No & 270 \\
\hline 70 & 0,1 & 1,0 & 1,4 & 0,9 & 0,5 & No & 270 \\
\hline 71 & 0,4 & 3,2 & 0,5 & 0,1 & 2,0 & No & 270 \\
\hline 72 & 0,1 & 0,5 & 0,6 & 0,1 & 1,1 & No & 270 \\
\hline 73 & 0,4 & 3,1 & 0,2 & 0,3 & 0,1 & No & 450 \\
\hline 74 & 0,3 & 2,5 & 0,1 & 0,1 & 0,0 & No & 450 \\
\hline 75 & 0,3 & 2,5 & 0,0 & 0,1 & 0,0 & No & 324 \\
\hline 76 & 0,4 & 2,7 & 0,1 & 0,2 & 1,8 & No & 270 \\
\hline 77 & 0,2 & 1,5 & 0,0 & 0,2 & 0,8 & No & 270 \\
\hline 78 & 0,2 & 1,5 & 0,2 & 0,2 & 1,6 & No & 270 \\
\hline 79 & 0,2 & 0,9 & 0,2 & 0,1 & 1,6 & No & 270 \\
\hline 80 & 0,0 & 0,3 & 0,3 & 0,4 & 0,0 & No & 270 \\
\hline 81 & 0,2 & 0,2 & 0,8 & 0,1 & 0,1 & No & 324 \\
\hline 82 & 0,6 & 3,4 & 0,3 & 0,3 & 1,9 & No & 270 \\
\hline 83 & 0,0 & 0,3 & 0,8 & 0,3 & 0,1 & No & 270 \\
\hline 84 & 0,2 & 1,3 & 0,1 & 0,2 & 0,7 & No & 270 \\
\hline 85 & 0,15 & 1,1 & 0,4 & 0,2 & 0,2 & No & 270 \\
\hline 86 & 0,05 & 0,3 & 0,6 & 0,2 & 0,2 & No & 270 \\
\hline 87 & 0,2 & 1,1 & 0,1 & 0,1 & 1,0 & No & 270 \\
\hline 88 & 0,2 & 1,6 & 0,3 & 0,4 & 0,2 & No & 270 \\
\hline 89 & 0,2 & 1,5 & 0,3 & 0,6 & 0,6 & No & 270 \\
\hline 90 & 0,1 & 0,3 & 0,1 & 0,2 & 0,0 & No & 450 \\
\hline 91 & 0,5 & 2,7 & 0,2 & 0,2 & 0,0 & No & 270 \\
\hline 92 & 0,2 & 1,4 & 0,2 & 0,1 & 0,1 & No & 324 \\
\hline 93 & 0,25 & 2,4 & 0,3 & 0,3 & 1,9 & No & 270 \\
\hline 94 & 0,2 & 1,8 & 0,5 & 0,7 & 0,6 & No & 270 \\
\hline 95 & 0,25 & 1,5 & 0,2 & 0,1 & 0,6 & No & 270 \\
\hline 96 & 0,5 & 3,0 & 0,1 & 0,1 & 1,2 & No & 270 \\
\hline 97 & 0,05 & 0,3 & 0,5 & 0,2 & 0,1 & No & 270 \\
\hline 98 & 0,3 & 1,7 & 0,0 & 0,1 & 0,6 & No & 270 \\
\hline 99 & 0,1 & 0,3 & 0,1 & 0,2 & 0,1 & No & 324 \\
\hline 100 & & & 0,2 & 0,2 & 0,5 & No & 270 \\
\hline 101 & & & 0,2 & 0,1 & 0,5 & No & 270 \\
\hline 102 & 0,2 & 2,2 & 0,3 & 0,1 & 0,1 & No & 270 \\
\hline 103 & 0,0 & 0,5 & 0,6 & 0,3 & 1,2 & No & 270 \\
\hline 104 & 0,0 & 0,3 & 0,3 & 0,7 & 0,0 & No & 270 \\
\hline 105 & 0,1 & 1,0 & 0,2 & 0,0 & 0,4 & No & 270 \\
\hline 106 & 0,1 & 0,7 & & & 0,0 & No & 450 \\
\hline 107 & 0,6 & 3,2 & 0,1 & 0,2 & 1,2 & No & 270 \\
\hline 108 & 0,4 & 2,7 & 0,3 & 0,0 & 0,1 & No & 450 \\
\hline 109 & 0,7 & 4,1 & 0,2 & 0,4 & 0,1 & No & 270 \\
\hline 110 & 0,1 & 1,3 & 0,7 & 0,9 & 0,2 & No & 270 \\
\hline 111 & 0,0 & 0,3 & 0,9 & 0,2 & 0,6 & No & 270 \\
\hline 112 & 0,1 & 0,8 & 0,2 & 0,7 & 0,3 & No & 270 \\
\hline
\end{tabular}




\begin{tabular}{|c|c|c|c|c|c|c|c|}
\hline 113 & 0,1 & 0,6 & 0,5 & 0,1 & 0,9 & No & 270 \\
\hline 114 & 0,0 & 0,6 & 0,0 & 0,2 & 0,6 & No & 270 \\
\hline 115 & 0,1 & 0,6 & 0,1 & 0,2 & 0,9 & No & 270 \\
\hline 116 & 0,2 & 1,8 & 0,1 & 0,2 & 2,7 & No & 270 \\
\hline 117 & 0,25 & 1,5 & 0,0 & 0,5 & 0,6 & No & 270 \\
\hline 118 & 0,4 & 2,1 & 0,0 & 0,1 & 0,8 & No & 270 \\
\hline 119 & 0,1 & 1,4 & 0,1 & 0,2 & 0,5 & No & 270 \\
\hline 120 & 0,3 & 2,5 & 0,0 & 0,3 & 1,9 & No & 270 \\
\hline 121 & 0,3 & 2,2 & 0,2 & 0,5 & 1,1 & No & 270 \\
\hline 122 & 0,2 & 1,2 & 0,2 & 0,4 & 0,5 & No & 270 \\
\hline 123 & 0,2 & 0,8 & 0,1 & 0,3 & 0,7 & No & 270 \\
\hline 124 & 0,1 & 0,8 & 0,1 & 0,2 & 1,4 & No & 270 \\
\hline 125 & 0,1 & 0,5 & 0,0 & 0,2 & 0,5 & No & 270 \\
\hline 126 & 0,3 & 2,4 & 0,2 & 0,2 & 1,1 & No & 270 \\
\hline 127 & 0,1 & 0,5 & 0,7 & 0,3 & 1,2 & No & 270 \\
\hline 128 & 0,1 & 0,5 & 0,3 & 0,4 & 1,0 & No & 270 \\
\hline 129 & & & 0,6 & 0,4 & 0,9 & No & 270 \\
\hline 130 & 0,3 & 2,2 & 0,1 & 0,4 & 0,6 & No & 270 \\
\hline 131 & 0,1 & 0,6 & 0,1 & 0,2 & 1,1 & No & 270 \\
\hline 132 & 0,1 & 0,7 & 0,4 & 0,5 & 1,0 & No & 270 \\
\hline 133 & 0,05 & 0,4 & 0,2 & 1,1 & 0,6 & No & 270 \\
\hline 134 & 0,45 & 2,9 & 0,2 & 0,2 & 0,1 & No & 450 \\
\hline 135 & 0,15 & 0,9 & 0,4 & 0,3 & 1,3 & No & 270 \\
\hline 136 & 0,1 & 0,7 & 0,1 & 0,2 & 0,6 & No & 270 \\
\hline 137 & 0,3 & 1,9 & 0,0 & 0,3 & 1,0 & No & 270 \\
\hline 138 & 0,1 & 1,0 & 0,1 & 0,3 & 0,1 & No & 324 \\
\hline 139 & 0,2 & 1,5 & 0,2 & 0,0 & 0,0 & No & 450 \\
\hline 140 & 0,2 & 1,4 & 0,2 & 0,4 & 0,8 & No & 270 \\
\hline 141 & 0,15 & 1,2 & 0,9 & 0,3 & 0,0 & No & 270 \\
\hline 142 & 0,2 & 0,5 & 0,1 & 0,1 & 0,2 & No & 324 \\
\hline 143 & 0,3 & 1,7 & 0,3 & 0,3 & 2,0 & No & 270 \\
\hline 144 & & & 1,0 & 0,5 & 0,5 & No & 270 \\
\hline 145 & 0,4 & 3,1 & 0,2 & 0,3 & 0,2 & No & 450 \\
\hline 146 & 0,1 & 1,4 & 0,6 & 0,4 & 2,1 & No & 270 \\
\hline 147 & 0,05 & 0,3 & 0,4 & 0,1 & 0,7 & No & 270 \\
\hline 148 & 0,05 & 0,4 & 0,0 & 0,3 & 1,0 & No & 270 \\
\hline 149 & 0,0 & 0,0 & 0,2 & 1,8 & 0,2 & No & 324 \\
\hline 150 & 0,1 & 0,9 & 0,2 & 0,3 & 0,3 & No & 270 \\
\hline 151 & 0,0 & 0,3 & 0,4 & 0,2 & 0,4 & No & 270 \\
\hline 152 & 0,4 & 2,7 & 0,2 & 0,8 & 0,6 & No & 270 \\
\hline 153 & 0,2 & 1,2 & 0,1 & 0,1 & 0,4 & No & 270 \\
\hline 154 & 0,1 & 0,7 & 0,1 & 0,3 & 1,2 & No & 270 \\
\hline 155 & 0,1 & 0,9 & 0,3 & 0,4 & 1,6 & No & 270 \\
\hline 156 & 0,1 & 0,8 & 0,7 & 0,6 & 1,0 & No & 270 \\
\hline 157 & 0,1 & 0,7 & 0,2 & 0,3 & 0,5 & No & 270 \\
\hline 158 & & & 0,3 & 1,1 & 0,7 & No & 270 \\
\hline 159 & 0,0 & 0,3 & 0,0 & 0,2 & 0,2 & No & 270 \\
\hline 160 & 0,2 & 1,3 & 0,4 & 0,2 & 0,9 & No & 270 \\
\hline 161 & & & 0,3 & 0,4 & 1,1 & No & 270 \\
\hline 162 & 0,2 & 0,7 & 0,2 & 0,1 & 0 & No & 324 \\
\hline 163 & 0,0 & 0,7 & 0,1 & 0,4 & 0,4 & No & 270 \\
\hline 164 & 0,4 & 1,5 & 0,1 & 0,2 & 0,0 & No & 324 \\
\hline 165 & 0,5 & 3,2 & 0,4 & 0,1 & 0,7 & No & 270 \\
\hline 166 & 0,3 & 0,9 & 0,1 & 0,2 & 0,3 & No & 324 \\
\hline 167 & 0,2 & 0,9 & 0,3 & 0,2 & 1,0 & No & 270 \\
\hline 168 & 0,2 & 1,1 & 0,2 & 0,1 & 0,2 & No & 324 \\
\hline 169 & 0,0 & 0,4 & 0,3 & 0,4 & 0,6 & No & 270 \\
\hline 170 & 0,4 & 2,1 & 0,1 & 0,1 & 0,9 & No & 270 \\
\hline
\end{tabular}




\begin{tabular}{|c|c|c|c|c|c|c|c|}
\hline 171 & 0,8 & 5,1 & 0,6 & 0,3 & 0,5 & No & 450 \\
\hline 172 & 0,0 & 0,4 & 0,3 & 0,2 & 0,5 & No & 270 \\
\hline 173 & 0,4 & 1,7 & 0,2 & 0,2 & 0,1 & No & 324 \\
\hline 174 & 0,2 & 1,3 & 0,3 & 0,2 & 0,9 & No & 270 \\
\hline 175 & 0,1 & 1,2 & 0,1 & 0,1 & 0,1 & No & 450 \\
\hline 176 & 0,0 & 0,4 & 0,4 & 0,3 & 0,4 & No & 270 \\
\hline 177 & 0,1 & 0,7 & 0,1 & 0,4 & 1,1 & No & 270 \\
\hline 178 & 0,2 & 2,0 & 0,1 & 0,2 & 1,0 & No & 270 \\
\hline 179 & 0,2 & 1,3 & 0,1 & 0,1 & 0,2 & No & 270 \\
\hline 180 & 0,0 & 0,6 & 0,9 & 0,2 & 0,7 & No & 270 \\
\hline 181 & 0,1 & 0,5 & 0,3 & 0,2 & 0,4 & No & 270 \\
\hline 182 & 0,2 & 1,5 & 0,1 & 0,3 & 0,6 & No & 270 \\
\hline 183 & 0,3 & 1,5 & 0,2 & 0,4 & 1,3 & No & 270 \\
\hline 184 & 0,7 & 4,5 & 0,1 & 0,2 & 1,0 & No & 450 \\
\hline 185 & 0,2 & 1,6 & 0,2 & 0,3 & 1,2 & No & 270 \\
\hline 186 & 0,2 & 1,3 & 0,1 & 0,1 & 0,4 & No & 270 \\
\hline 187 & 0,1 & 0,9 & 0,1 & 0,2 & 0,3 & No & 270 \\
\hline 188 & 0,1 & 0,7 & 0,2 & 0,3 & 0,8 & No & 270 \\
\hline 189 & 0,2 & 0,8 & 0,1 & 0,2 & 0,1 & No & 450 \\
\hline 190 & 0,2 & 1,0 & 0,1 & 0,1 & 0,3 & No & 324 \\
\hline 191 & 0,2 & 1,9 & 0,0 & 0,3 & 0,0 & No & 270 \\
\hline 192 & 0,0 & 0,3 & 0,5 & 0,1 & 0,9 & No & 270 \\
\hline 193 & 0,1 & 0,9 & 0,4 & 0,2 & 0,7 & No & 270 \\
\hline 194 & 0,1 & 1,1 & 0,4 & 0,2 & 0,0 & No & 270 \\
\hline 195 & 0,1 & 0,8 & 0,1 & 0,1 & 0,1 & No & 324 \\
\hline 196 & 0,0 & 0,7 & 0,7 & 0,5 & 0,5 & No & 270 \\
\hline 197 & 0,0 & 0,3 & 0,3 & 0,2 & 1,9 & No & 270 \\
\hline 198 & 0,1 & 0,4 & 0,5 & 0,4 & 0,0 & No & 270 \\
\hline 199 & 0,1 & 0,9 & 0,5 & 0,5 & 0,1 & No & 270 \\
\hline 200 & & & 0,2 & 0,3 & 0,0 & No & 270 \\
\hline 201 & 0,2 & 2,4 & 0,0 & 0,1 & 0,3 & No & 450 \\
\hline 202 & 0,2 & 0,6 & 0,1 & 0,2 & 0,2 & No & 324 \\
\hline 203 & 0,0 & 0,2 & 0,1 & 0,3 & 0,2 & No & 270 \\
\hline 204 & 0,3 & 1,4 & 0,1 & 0,2 & 0,0 & No & 324 \\
\hline 205 & 0,2 & 1,6 & 0,2 & 0,5 & 0,1 & No & 270 \\
\hline 206 & 0,0 & 0,4 & 0,0 & 0,9 & 0,8 & No & 270 \\
\hline 207 & 0,2 & 0,9 & 0,1 & 0,2 & 0,6 & No & 270 \\
\hline 208 & 0,1 & 0,7 & 0,0 & 0,3 & 0,2 & No & 270 \\
\hline 209 & 0,1 & 1,5 & 0,4 & 0,2 & 0,15 & No & 450 \\
\hline 210 & 0,0 & 0,4 & 0,6 & 0,3 & 0,2 & No & 270 \\
\hline 211 & 0,2 & 0,8 & 0,0 & 0,1 & 0,4 & No & 270 \\
\hline 212 & 0,1 & 0,4 & 0,1 & 0,1 & 0,4 & No & 324 \\
\hline 213 & 0,1 & 0,8 & 0,3 & 0,3 & 1,0 & No & 270 \\
\hline 214 & 0,1 & 0,2 & 0,1 & 0,2 & 0,1 & No & 450 \\
\hline 215 & 0,1 & 0,5 & 0,1 & 0,1 & 0,7 & No & 270 \\
\hline 216 & 0,2 & 1,5 & 0,6 & 0,5 & 0,1 & No & 270 \\
\hline 217 & 0,3 & 2,5 & 0,2 & 0,3 & 0,1 & No & 324 \\
\hline 218 & 0,1 & 0,3 & 0,2 & 0,2 & 0,0 & No & 324 \\
\hline 219 & 0,1 & 0,9 & 0,0 & 0,1 & 0,8 & No & 270 \\
\hline 220 & 0,1 & 1,3 & 0,2 & 0,1 & 0,3 & No & 270 \\
\hline 221 & 0,4 & 1,6 & 0,1 & 0,1 & 0,0 & No & 324 \\
\hline 222 & 0,1 & 0,7 & 0,2 & 0,0 & 0,5 & No & 270 \\
\hline 223 & 0,2 & 0,9 & 0,2 & 0,1 & 0,1 & No & 324 \\
\hline 224 & 0,1 & 0,9 & 0,0 & 0,2 & 0,2 & No & 270 \\
\hline 225 & 0,2 & 1,5 & 0,1 & 0,2 & 0,3 & No & 324 \\
\hline 226 & 0,3 & 1,8 & 0,1 & 0,2 & 0,5 & No & 324 \\
\hline 227 & & & 0,1 & 0,4 & 0,9 & No & 270 \\
\hline 228 & & & 0,1 & 0,2 & 0,2 & No & 270 \\
\hline
\end{tabular}




\begin{tabular}{|c|c|c|c|c|c|c|c|}
\hline 229 & 0,1 & 1,0 & 0,2 & 0,1 & 0,4 & No & 270 \\
\hline 230 & 0,2 & 0,6 & 0,2 & 0,1 & & No & 324 \\
\hline 231 & 0,1 & 1,9 & 1,0 & 0,7 & 0,1 & No & 270 \\
\hline 232 & 0,1 & 0,3 & 0,3 & 0,1 & 0,1 & No & 270 \\
\hline 233 & 0,3 & 2,1 & 0,0 & 0,0 & 0,0 & No & 450 \\
\hline 234 & 0,0 & 0,4 & 0,2 & 0,2 & 0,4 & No & 270 \\
\hline 235 & 0,1 & 0,3 & 0,1 & 0,0 & 0,0 & No & 324 \\
\hline 236 & 0,2 & 1,1 & 0,1 & 0,0 & 0,1 & No & 450 \\
\hline 237 & 0,2 & 0,5 & 0,2 & 0,4 & 0,4 & No & 324 \\
\hline 238 & 0,1 & 0,8 & 0,2 & 0,2 & 0,7 & No & 270 \\
\hline 239 & 0,1 & 0,6 & 0,5 & 0,5 & 0,6 & No & 270 \\
\hline 240 & 0,2 & 1,7 & 0,6 & 0,3 & 0,8 & No & 270 \\
\hline 241 & 0,1 & 1,0 & 0,0 & 0,1 & 0,5 & No & 270 \\
\hline 242 & 0,1 & 0,7 & 0,0 & 0,1 & 1,0 & No & 270 \\
\hline 243 & 0,1 & 0,5 & 0,1 & 0,2 & 0,0 & No & 450 \\
\hline 244 & 0,3 & 1,2 & 0,1 & 0,2 & 0,2 & No & 324 \\
\hline 245 & 0,3 & 1,7 & 0,3 & 0,1 & 0,1 & No & 324 \\
\hline 246 & 0,3 & 2,2 & 0,4 & 0,0 & 1,0 & No & 270 \\
\hline 247 & 0,1 & 0,4 & 0,1 & 0,2 & 0,5 & No & 270 \\
\hline 248 & 0,1 & 0,3 & 0,1 & 0,2 & 0,0 & No & 324 \\
\hline 249 & 0,1 & 0,3 & 0,1 & 0,1 & 0,2 & No & 324 \\
\hline 250 & 0,1 & 0,5 & 0,0 & 0,0 & 0,3 & No & 450 \\
\hline 251 & 0,1 & 0,3 & 0,3 & 0,1 & 0,1 & No & 324 \\
\hline 252 & 0,1 & 0,3 & 0,2 & 0,1 & 0,2 & No & 324 \\
\hline 253 & 0,1 & 0,4 & 0,3 & 0,3 & 0,2 & No & 270 \\
\hline 254 & 0,2 & 1,5 & 0,2 & 0,3 & 0,2 & No & 324 \\
\hline 255 & 0,3 & 0,9 & 0,2 & 0,2 & 0,0 & No & 324 \\
\hline 256 & 0,4 & 1,6 & 0,1 & 0,1 & 0,3 & No & 324 \\
\hline 257 & 0,3 & 1,4 & 0,0 & 0,1 & 0,2 & No & 324 \\
\hline 258 & & & 0,3 & 0,2 & 0,3 & No & 270 \\
\hline 259 & 0,1 & 0,7 & 0,1 & 0,1 & 0,4 & No & 270 \\
\hline 260 & 0,2 & 0,8 & & & 0,0 & No & 450 \\
\hline 261 & 0,0 & 0,4 & 0,0 & 0,1 & 0,6 & No & 270 \\
\hline 262 & 0,0 & 0,5 & 0,1 & 0,2 & 0,5 & No & 270 \\
\hline 263 & 0,2 & 1,1 & 0,1 & 0,1 & 0,2 & No & 450 \\
\hline 264 & 0,3 & 1,7 & 0,1 & 0,1 & 0,0 & No & 324 \\
\hline 265 & 0,05 & 0,3 & 0,5 & 0,4 & 0,2 & No & 270 \\
\hline 266 & 0,25 & 1,3 & 0,3 & 0,0 & 0,2 & No & 324 \\
\hline 267 & 0,3 & 0,8 & 0,2 & 0,3 & 0,2 & No & 324 \\
\hline 268 & 0,2 & 0,4 & 0,1 & 0,1 & 0,2 & No & 324 \\
\hline 269 & 0,3 & 2,2 & 0,5 & 0,4 & 0,6 & No & 270 \\
\hline 270 & 0,1 & 0,5 & 0,0 & 0,3 & 0,1 & No & 324 \\
\hline 271 & 0,1 & 0,3 & 0,2 & 0,2 & 0,2 & No & 324 \\
\hline 272 & 0,1 & 0,7 & 0,1 & 0,3 & 0,4 & No & 270 \\
\hline 273 & 0,1 & 0,6 & 0,3 & 0,1 & 0,2 & No & 270 \\
\hline 274 & 0,1 & 0,6 & 0,4 & 0,7 & 1,1 & No & 270 \\
\hline 275 & 0,3 & 1,5 & 0,0 & 0,0 & 0,3 & No & 450 \\
\hline 276 & 0,0 & 0,5 & 0,3 & 0,2 & 0,7 & No & 270 \\
\hline 277 & 0,7 & 4,4 & 0,2 & 0,1 & 0,1 & No & 450 \\
\hline 278 & 0,2 & 0,9 & 0,1 & 0,1 & 0,2 & No & 450 \\
\hline 279 & 0,2 & 0,7 & 0,1 & 0,3 & 0,2 & No & 324 \\
\hline 280 & 0,2 & 0,9 & 0,2 & 0,1 & 0,2 & No & 450 \\
\hline 281 & 0,2 & 1,1 & 0,0 & 0,3 & 0,1 & No & 324 \\
\hline 282 & 0,3 & 1,3 & 0,3 & 0,2 & 0,3 & No & 324 \\
\hline 283 & 0,2 & 1,1 & 0,1 & 0,1 & 0,3 & No & 324 \\
\hline 284 & 0,0 & 0,4 & 0,3 & 0,3 & 0,5 & No & 270 \\
\hline 285 & 0,0 & 0,4 & 0,0 & 0,2 & 0,2 & No & 270 \\
\hline 286 & 0,3 & 1,0 & 0,1 & 0,1 & 0,2 & No & 324 \\
\hline
\end{tabular}




\begin{tabular}{|c|c|c|c|c|c|c|c|}
\hline 287 & 0,4 & 3,0 & 0,1 & 0,1 & 0,4 & No & 270 \\
\hline 288 & 0,1 & 0,4 & & & 0,0 & No & 270 \\
\hline 289 & 0,7 & 4,3 & 0,2 & 0,1 & 0,6 & & 450 \\
\hline 290 & 0,2 & 2,1 & 0,2 & 0,2 & 0,4 & No & 270 \\
\hline 291 & 0,2 & 0,8 & 0,2 & 0,0 & 0,1 & No & 450 \\
\hline 292 & 0,3 & 1,7 & 0,1 & 0,3 & 0,0 & No & 324 \\
\hline 293 & 0,2 & 1,6 & 0,0 & 0,2 & 0,5 & No & 270 \\
\hline 294 & 0,2 & 0,4 & 0,0 & 0,0 & 0,2 & No & 324 \\
\hline 295 & 0,4 & 2,5 & 1,0 & 1,0 & 0,5 & No & 450 \\
\hline 296 & 0,1 & 1,2 & 0,5 & 0,6 & 0,3 & No & 270 \\
\hline 297 & 0,2 & 1,8 & 0,0 & 0,1 & 0,1 & No & 450 \\
\hline 298 & 0,3 & 0,7 & 0,1 & 0,1 & 0,3 & No & 324 \\
\hline 299 & 0,3 & 2 & 0,0 & 0,0 & 0,0 & No & 450 \\
\hline 300 & 0,2 & 1,3 & 0,5 & 0,3 & 0,8 & No & 270 \\
\hline 301 & 0,3 & 2,1 & 0,3 & 0,7 & 0,0 & No & 270 \\
\hline 302 & 0,2 & 0,9 & & & 0,0 & No & 450 \\
\hline 303 & 0,2 & 0,5 & 0,2 & 0,2 & 0,1 & No & 450 \\
\hline 304 & 0,1 & 0,7 & 0,1 & 0,1 & 0,2 & No & 324 \\
\hline 305 & 0,3 & 0,8 & 0,0 & 0,1 & 0,0 & No & 324 \\
\hline 306 & 0,1 & 0,3 & 0,2 & 0,2 & 0,2 & No & 324 \\
\hline 307 & 0,2 & 0,6 & 0,1 & 0,1 & 0,0 & No & 324 \\
\hline 308 & 0,2 & 0,4 & 0,1 & 0,1 & 0,0 & No & 324 \\
\hline 309 & 0,0 & 0,4 & 0,1 & 0,3 & 0,2 & No & 270 \\
\hline 310 & 0,5 & 0,5 & 0,3 & 0,3 & 0,1 & No & 450 \\
\hline 311 & 0,1 & 0,6 & 0,2 & 0,3 & 0,0 & No & 324 \\
\hline 312 & 0,2 & 0,6 & 0,2 & 0,3 & 0,0 & No & 324 \\
\hline 313 & 0,1 & 0,9 & 0,1 & 0,2 & 0,1 & No & 450 \\
\hline 314 & 0,3 & 0,9 & 0,0 & 0,0 & 0,2 & No & 324 \\
\hline 315 & 0,2 & & & & & & 450 \\
\hline 316 & 0,3 & 1,4 & 0,3 & 0,1 & 0,2 & No & 450 \\
\hline 317 & 0,2 & 1,5 & 0,1 & 0,0 & 0,0 & No & 324 \\
\hline 318 & 0,1 & 0,3 & & & 0,1 & No & 450 \\
\hline 319 & 0,1 & 0,3 & 0,1 & 0,1 & 0,0 & No & 324 \\
\hline 320 & 0,2 & 0,6 & & 0,1 & & No & 324 \\
\hline 321 & 0,1 & 0,5 & 0,1 & 0,1 & 0,4 & No & 270 \\
\hline 322 & 0,2 & 1,7 & 0,2 & 0,2 & 0,4 & No & 270 \\
\hline 323 & 0,0 & 0,5 & 0,2 & 0,2 & 0,0 & No & 324 \\
\hline 324 & 0,1 & 0,4 & 0,0 & 0,0 & 0,1 & No & 324 \\
\hline 325 & 0,2 & 0,5 & 0,1 & 0,2 & 0,4 & No & 450 \\
\hline 326 & 0,0 & 0,2 & 0,2 & 0,0 & 0,1 & No & 324 \\
\hline 327 & 0,1 & 0,4 & 0,3 & 0,0 & 0,4 & No & 270 \\
\hline 328 & 0,2 & 0,4 & 0,1 & 0,2 & 0,1 & No & 450 \\
\hline 329 & 0,1 & 0,3 & 0,1 & 0,1 & & No & 324 \\
\hline 330 & 0,0 & 0,3 & 0,4 & 0,2 & 0,1 & No & 270 \\
\hline 331 & 0,2 & 2,0 & 0,0 & 0,0 & 0,2 & No & 450 \\
\hline 332 & 0,1 & 0,5 & & 0,1 & 0,1 & & 324 \\
\hline 333 & 0,1 & 0,7 & 0,1 & 0,2 & 0,0 & No & 324 \\
\hline 334 & 0,3 & 1,6 & 0,1 & & 0,2 & No & 450 \\
\hline 335 & 0,1 & 0,5 & 0,2 & 0,1 & 0,0 & No & 324 \\
\hline 336 & 0,2 & 1,1 & 0,0 & 0,2 & 0,5 & No & 270 \\
\hline 337 & 0,0 & 0,3 & & 0,2 & 0,2 & No & 324 \\
\hline 338 & 0,1 & 0,3 & 0,3 & 0,1 & 0,1 & & 324 \\
\hline 339 & 0,1 & 0,3 & 0,0 & 0,0 & 0,1 & No & 324 \\
\hline 340 & 0,1 & 0,3 & 0,2 & 0,1 & 0,0 & No & 324 \\
\hline 341 & 0,1 & 0,5 & 0,0 & 0,2 & 0,3 & No & 270 \\
\hline 342 & 0,2 & 1,7 & 0,5 & 0,6 & 0,6 & No & 270 \\
\hline 343 & 0,1 & 0,6 & 0,2 & 0,3 & 0 & No & 324 \\
\hline 344 & 0,1 & 0,4 & 0,1 & 0,2 & 0,0 & No & 324 \\
\hline
\end{tabular}




\begin{tabular}{|c|c|c|c|c|c|c|c|}
\hline 345 & 0,1 & 1,3 & 0,1 & 0,1 & 0,5 & No & 270 \\
\hline 346 & 0,2 & 1,5 & 0,1 & 0,4 & 0,2 & No & 270 \\
\hline 347 & 0,1 & 0,4 & 0,2 & 0,2 & & No & 324 \\
\hline 348 & 0,0 & 0,4 & 0,2 & 0,4 & 0,1 & No & 270 \\
\hline 349 & 0,1 & 0,4 & 0,2 & 0,2 & 0,3 & No & 270 \\
\hline 350 & 0,1 & 0,2 & 0,1 & 0,1 & 0,1 & No & 324 \\
\hline 351 & 0,0 & 0,3 & 0,1 & 0,0 & 0,0 & No & 324 \\
\hline 352 & 0,1 & 0,7 & 0,7 & 0,2 & 0,5 & No & 270 \\
\hline 353 & 0,0 & 0,0 & 0,2 & 0,1 & 0,0 & No & 324 \\
\hline 354 & 0,1 & 0,3 & 0,1 & 0,1 & 0,1 & No & 324 \\
\hline 355 & 0,1 & 0,3 & 0,0 & 0,2 & 0,3 & No & 324 \\
\hline 356 & 0,2 & 0,9 & 0,1 & 0,1 & 0,1 & No & 324 \\
\hline 357 & 0,2 & 0,9 & & 0,1 & 0,0 & No & 450 \\
\hline 358 & 0,2 & 0,9 & 0,1 & 0,0 & 0,3 & No & 450 \\
\hline 359 & 0,1 & 0,7 & 0,3 & 0,5 & 0,0 & No & 270 \\
\hline 360 & 0,0 & 0,3 & 0,1 & 0,1 & 0,1 & No & 324 \\
\hline 361 & 0,1 & 0,9 & 0,5 & 0,7 & 0,6 & No & 270 \\
\hline 362 & 0,1 & 0,4 & 0,2 & 0,0 & 0,0 & No & 324 \\
\hline 363 & 0,1 & 1,0 & 0,5 & 0,2 & 0,3 & No & 270 \\
\hline 364 & 0,1 & 0,8 & 0,3 & 0,2 & 0,2 & $\mathrm{Si}$ & 270 \\
\hline 365 & 0,2 & 1,8 & 0,1 & 0,2 & 0,1 & No & 450 \\
\hline 366 & 0,3 & 2,6 & 0 & 0,1 & 0,3 & No & 450 \\
\hline 367 & 0,3 & 2,8 & 0,2 & 0,3 & 0,2 & No & 450 \\
\hline 368 & 0,4 & 2,0 & 0,1 & 0,0 & 0,2 & No & 450 \\
\hline 369 & 0,2 & 2,1 & 0,1 & 0,3 & 0,7 & No & 450 \\
\hline 370 & 0,2 & 1,9 & 0,2 & 0,2 & 0,1 & No & 450 \\
\hline
\end{tabular}




\begin{tabular}{|c|c|c|c|c|c|c|}
\hline Probeta & $\begin{array}{c}\text { Carga } \\
\text { rot }\end{array}$ & MOR sin corr & $\mathbf{K h}$ & $\begin{array}{l}\text { MOR corr } \\
\text { con } \mathrm{Kh}\end{array}$ & MOEG sin corr & MOEG corr \\
\hline 1 & 17023,86 & 58,64 & 1,00 & 58,64 & 12401,38 & 10924,56 \\
\hline 2 & 3204,62 & 38,97 & 1,00 & 38,92 & 10877,43 & 9588,61 \\
\hline 3 & 2841,98 & 33,42 & 1,00 & 33,42 & 8899,87 & 7873,60 \\
\hline 4 & 17380,28 & 60,53 & 1,00 & 60,53 & 14102,95 & 12847,26 \\
\hline 5 & 13867,49 & 46,79 & 1,00 & 46,79 & 11652,17 & 10812,23 \\
\hline 6 & 9319,37 & 31,69 & 1,00 & 31,69 & 9648,21 & 8963,63 \\
\hline 7 & 8413,88 & 30,07 & 1,00 & 30,07 & 9390,79 & 8739,60 \\
\hline 8 & 10787,38 & 48,51 & 1,00 & 48,51 & 13923,36 & 13039,37 \\
\hline 9 & 13255,83 & 46,03 & 1,00 & 46,03 & 11165,11 & 10487,63 \\
\hline 10 & 10209,96 & 36,49 & 1,00 & 36,49 & 10121,25 & 9509,10 \\
\hline 11 & 15028,56 & 53,02 & 1,00 & 53,02 & 14654,61 & 13784,93 \\
\hline 12 & 15861,24 & 53,94 & 1,00 & 53,94 & 12887,38 & 12132,59 \\
\hline 13 & 9350,83 & 33,26 & 1,00 & 33,26 & 9405,43 & 8900,83 \\
\hline 14 & 7481,60 & 26,69 & 1,00 & 26,69 & 8113,80 & 7680,62 \\
\hline 15 & 14074,49 & 48,77 & 1,00 & 48,77 & 12610,18 & 11958,16 \\
\hline 16 & 12807,59 & 43,47 & 1,00 & 43,47 & 10268,53 & 9783,28 \\
\hline 17 & 16539,83 & 57,14 & 1,00 & 57,14 & 13249,88 & 12662,30 \\
\hline 18 & 14158,54 & 49,41 & 1,00 & 49,41 & 12117,00 & 11621,53 \\
\hline 19 & 7456,70 & 52,95 & 1,00 & 52,95 & 11660,04 & 11201,88 \\
\hline 20 & 17730,47 & 59,59 & 1,00 & 59,59 & 13949,26 & 13424,80 \\
\hline 21 & 12726,65 & 44,28 & 1,00 & 44,28 & 10865,92 & 10464,74 \\
\hline 22 & 15129,73 & 51,20 & 1,00 & 51,20 & 10456,51 & 10099,99 \\
\hline 23 & 9439,54 & 34,29 & 1,00 & 34,29 & 10749,63 & 10390,87 \\
\hline 24 & 16099,37 & 55,46 & 1,00 & 55,46 & 12424,87 & 12012,11 \\
\hline 25 & 16012,21 & 53,92 & 1,00 & 53,92 & 12600,34 & 12191,97 \\
\hline 26 & 15131,00 & 51,46 & 1,00 & 51,46 & 11160,98 & 10809,92 \\
\hline 27 & 11615,39 & 41,52 & 1,00 & 41,52 & 12708,83 & 12330,85 \\
\hline 28 & 8476,14 & 30,30 & 1,00 & 30,30 & 8914,13 & 8659,82 \\
\hline 29 & 5492,52 & 38,45 & 1,00 & 38,45 & 11189,18 & 10916,09 \\
\hline 30 & 14648,80 & 49,72 & 1,00 & 49,72 & 12409,02 & 12123,58 \\
\hline 31 & 8529,05 & 30,24 & 1,00 & 30,24 & 8636,33 & 8447,11 \\
\hline 32 & 13976,44 & 51,60 & 1,00 & 51,60 & 13309,03 & 13017,97 \\
\hline 33 & 5673,07 & 39,71 & 1,00 & 39,71 & 11163,10 & 10923,99 \\
\hline 34 & 14480,71 & 49,25 & 1,00 & 49,25 & 12327,31 & 12151,16 \\
\hline 35 & 13953,09 & 47,59 & 1,00 & 47,59 & 12365,80 & 12192,56 \\
\hline 36 & 7624,79 & 26,24 & 1,00 & 26,24 & 8336,06 & 8234,04 \\
\hline 37 & 10353,15 & 36,71 & 1,00 & 36,71 & 11504,91 & 11397,96 \\
\hline 38 & 6121,31 & 44,13 & 1,00 & 44,13 & 10820,77 & 10735,45 \\
\hline 39 & 15132,84 & 51,87 & 1,00 & 51,87 & 12257,89 & 12163,77 \\
\hline 40 & 12001,37 & 43,46 & 1,00 & 43,46 & 11133,45 & 11073,72 \\
\hline 41 & 14147,64 & 50,42 & 1,00 & 50,42 & 11655,23 & 11656,95 \\
\hline 42 & 2988,28 & 36,72 & 1,00 & 36,67 & 6492,09 & 6493,12 \\
\hline 43 & 2540,00 & 48,33 & 1,01 & 47,87 & 12597,72 & 12619,90 \\
\hline 44 & 5133,00 & 63,27 & 1,00 & 63,10 & 12790,70 & 12838,61 \\
\hline 45 & 13246,49 & 47,11 & 1,00 & 47,11 & 11025,36 & 11070,91 \\
\hline 46 & 3609,25 & 44,04 & 1,00 & 43,92 & 10079,79 & 10134,58 \\
\hline 47 & 1884,80 & 33,94 & 1,00 & 33,80 & 8017,91 & 8067,25 \\
\hline 48 & 3987,49 & 70,76 & 1,00 & 70,48 & 13486,88 & 13573,69 \\
\hline 49 & 13006,81 & 43,80 & 1,00 & 43,80 & 10667,98 & 10742,48 \\
\hline 50 & 7178,10 & 50,81 & 1,00 & 50,81 & 11342,39 & 11462,44 \\
\hline 51 & 4940,00 & 58,68 & 1,00 & 58,68 & 11088,45 & 11233,95 \\
\hline 52 & 8762,51 & 30,76 & 1,00 & 30,76 & 8586,73 & 8705,37 \\
\hline 53 & 11276,09 & 37,78 & 1,00 & 37,78 & 10655,51 & 10803,33 \\
\hline 54 & 8491,70 & 30,20 & 1,00 & 30,20 & 10347,82 & 10511,44 \\
\hline
\end{tabular}




\begin{tabular}{|c|c|c|c|c|c|c|}
\hline 55 & 10764,04 & 37,19 & 1,00 & 37,19 & 12250,67 & 12447,52 \\
\hline 56 & 12354,68 & 44,03 & 1,00 & 44,03 & 10690,11 & 10883,99 \\
\hline 57 & 13760,10 & 49,18 & 1,00 & 49,18 & 12436,45 & 12667,70 \\
\hline 58 & 8972,63 & 58,44 & 1,00 & 58,44 & 12961,73 & 13215,65 \\
\hline 59 & 8177,31 & 28,17 & 1,00 & 28,17 & 10099,61 & 10303,57 \\
\hline 60 & 14107,18 & 47,84 & 1,00 & 47,84 & 11922,62 & 12168,15 \\
\hline 61 & 3416,29 & 42,55 & 1,00 & 42,43 & 10281,09 & 10500,12 \\
\hline 62 & 4924,40 & 33,11 & 1,00 & 33,11 & 8494,02 & 8688,17 \\
\hline 63 & 5554,78 & 65,98 & 1,00 & 65,98 & 10231,52 & 10467,41 \\
\hline 64 & 15201,32 & 51,85 & 1,00 & 51,85 & 12842,53 & 13151,61 \\
\hline 65 & 3271,55 & 39,79 & 1,00 & 39,73 & 9987,87 & 10236,84 \\
\hline 66 & 2871,60 & 34,81 & 1,00 & 34,81 & 9417,30 & 9663,60 \\
\hline 67 & 13027,04 & 44,43 & 1,00 & 44,43 & 11534,44 & 11857,97 \\
\hline 68 & 1869,23 & 31,40 & 1,00 & 31,40 & 7149,95 & 7355,06 \\
\hline 69 & 4140,01 & 51,56 & 1,00 & 51,42 & 15049,33 & 15489,57 \\
\hline 70 & 4728,33 & 59,08 & 1,00 & 58,84 & 11811,77 & 12158,10 \\
\hline 71 & 2143,16 & 25,80 & 1,00 & 25,77 & 6598,01 & 6792,62 \\
\hline 72 & 5184,36 & 60,97 & 1,00 & 60,97 & 13559,16 & 13959,60 \\
\hline 73 & 14283,05 & 49,01 & 1,00 & 49,01 & 12256,62 & 12635,03 \\
\hline 74 & 15674,47 & 52,89 & 1,00 & 52,89 & 11509,51 & 11873,96 \\
\hline 75 & 4865,30 & 34,94 & 1,00 & 34,94 & 10484,35 & 10818,54 \\
\hline 76 & 4765,69 & 58,74 & 1,00 & 58,59 & 10944,25 & 11300,07 \\
\hline 77 & 4446,62 & 54,81 & 1,00 & 54,66 & 12210,13 & 12621,73 \\
\hline 78 & 3643,52 & 44,31 & 1,00 & 44,25 & 10919,25 & 11288,82 \\
\hline 79 & 4655,18 & 56,04 & 1,00 & 55,97 & 10392,50 & 10775,59 \\
\hline 80 & 4524,44 & 51,82 & 1,00 & 51,82 & 11861,20 & 12326,58 \\
\hline 81 & 6667,60 & 45,01 & 1,00 & 45,01 & 13151,21 & 13704,09 \\
\hline 82 & 4255,19 & 50,04 & 1,00 & 50,04 & 9321,01 & 9717,96 \\
\hline 83 & 2874,66 & 48,94 & 1,00 & 48,88 & 9084,88 & 9475,38 \\
\hline 84 & 2130,71 & 36,80 & 1,00 & 36,75 & 8764,81 & 9142,75 \\
\hline 85 & 4239,62 & 51,04 & 1,00 & 50,97 & 9939,67 & 10380,18 \\
\hline 86 & 3313,57 & 57,24 & 1,00 & 57,16 & 10809,33 & 11292,26 \\
\hline 87 & 4480,87 & 55,23 & 1,00 & 55,09 & 11594,64 & 12116,40 \\
\hline 88 & 4617,83 & 56,16 & 1,00 & 56,09 & 10274,25 & 10750,65 \\
\hline 89 & 3445,86 & 40,52 & 1,00 & 40,52 & 10323,95 & 10805,73 \\
\hline 90 & 13450,38 & 47,98 & 1,00 & 47,98 & 13907,60 & 14557,45 \\
\hline 91 & 5294,49 & 62,70 & 1,00 & 62,70 & 11606,31 & 12154,74 \\
\hline 92 & 5989,00 & 41,92 & 1,00 & 41,92 & 8483,61 & 8885,57 \\
\hline 93 & 2731,48 & 32,45 & 1,00 & 32,45 & 7601,72 & 7967,11 \\
\hline 94 & 2803,07 & 32,96 & 1,00 & 32,96 & 7765,48 & 8138,88 \\
\hline 95 & 2891,78 & 34,01 & 1,00 & 34,01 & 11256,30 & 11798,36 \\
\hline 96 & 3497,20 & 42,53 & 1,00 & 42,47 & 10939,52 & 11470,29 \\
\hline 97 & 4301,88 & 52,49 & 1,00 & 52,35 & 10559,78 & 11072,54 \\
\hline 98 & 4311,22 & 51,90 & 1,00 & 51,83 & 12182,49 & 12774,41 \\
\hline 99 & 6066,83 & 43,57 & 1,00 & 43,57 & 11632,34 & 12200,01 \\
\hline 100 & 3145,48 & 55,02 & 1,00 & 54,80 & 10737,35 & 11266,47 \\
\hline 101 & 2164,95 & 36,37 & 1,00 & 36,37 & 7951,53 & 8353,24 \\
\hline 102 & 3213,96 & 39,09 & 1,00 & 39,03 & 10276,79 & 10803,02 \\
\hline 103 & 2992,95 & 49,54 & 1,00 & 49,48 & 8451,35 & 8888,75 \\
\hline 104 & 2868,44 & 34,53 & 1,00 & 34,49 & 8484,59 & 8926,90 \\
\hline 105 & 4437,29 & 53,96 & 1,00 & 53,89 & 13140,60 & 13830,94 \\
\hline 106 & 13851,00 & 48,38 & 1,00 & 48,38 & 11930,58 & 12569,25 \\
\hline 107 & 4849,73 & 59,18 & 1,00 & 59,02 & 10474,03 & 11040,20 \\
\hline 108 & 11889,31 & 41,40 & 1,00 & 41,40 & 12433,58 & 13109,87 \\
\hline 109 & 5400,70 & 65,68 & 1,00 & 65,59 & 16156,48 & 17040,04 \\
\hline 110 & 5333,77 & 63,36 & 1,00 & 63,36 & 14544,45 & 15340,86 \\
\hline 111 & 3683,99 & 61,07 & 1,00 & 61,07 & 8176,40 & 8624,98 \\
\hline 112 & 2438,87 & 42,13 & 1,00 & 42,07 & 9378,53 & 9895,53 \\
\hline
\end{tabular}




\begin{tabular}{|c|c|c|c|c|c|c|}
\hline 113 & 3747,80 & 62,08 & 1,00 & 62,08 & 10592,72 & 11178,05 \\
\hline 114 & 2245,88 & 37,20 & 1,00 & 37,20 & 9233,27 & 9749,90 \\
\hline 115 & 3420,96 & 41,18 & 1,00 & 41,13 & 11035,99 & 11659,20 \\
\hline 116 & 3368,04 & 58,18 & 1,00 & 58,10 & 9329,93 & 9870,75 \\
\hline 117 & 2701,90 & 45,39 & 1,00 & 45,39 & 8481,87 & 8973,75 \\
\hline 118 & 2885,56 & 34,74 & 1,00 & 34,69 & 9515,69 & 10068,38 \\
\hline 119 & 3926,79 & 46,18 & 1,00 & 46,18 & 9968,54 & 10548,52 \\
\hline 120 & 4494,87 & 54,66 & 1,00 & 54,59 & 10132,33 & 10726,39 \\
\hline 121 & 4843,00 & 56,20 & 1,00 & 56,20 & 10595,06 & 11224,57 \\
\hline 122 & 2045,10 & 33,90 & 1,00 & 33,90 & 9449,65 & 10014,50 \\
\hline 123 & 2728,36 & 45,19 & 1,00 & 45,19 & 10104,14 & 10709,32 \\
\hline 124 & 3613,95 & 60,71 & 1,00 & 60,71 & 10062,44 & 10666,18 \\
\hline 125 & 2863,77 & 46,81 & 1,00 & 46,81 & 9630,81 & 10208,65 \\
\hline 126 & 3428,74 & 39,79 & 1,00 & 39,79 & 10612,96 & 11249,73 \\
\hline 127 & 3095,67 & 53,47 & 1,00 & 53,40 & 11282,67 & 11959,62 \\
\hline 128 & 2121,37 & 36,12 & 1,00 & 36,07 & 8925,22 & 9460,73 \\
\hline 129 & 2697,24 & 45,31 & 1,00 & 45,31 & 9784,23 & 10371,28 \\
\hline 130 & 4591,37 & 53,28 & 1,00 & 53,28 & 11032,95 & 11694,92 \\
\hline 131 & 3199,95 & 53,05 & 1,00 & 53,05 & 10557,57 & 11191,01 \\
\hline 132 & 2697,24 & 45,31 & 1,00 & 45,31 & 10018,97 & 10620,10 \\
\hline 133 & 3638,85 & 60,27 & 1,00 & 60,27 & 9651,56 & 10230,65 \\
\hline 134 & 15450,35 & 52,81 & 1,00 & 52,81 & 13503,08 & 14313,26 \\
\hline 135 & 3005,40 & 49,12 & 1,00 & 49,12 & 9570,31 & 10144,52 \\
\hline 136 & 2715,91 & 44,39 & 1,00 & 44,39 & 11440,68 & 12127,11 \\
\hline 137 & 3252,87 & 53,93 & 1,00 & 53,93 & 10675,17 & 11315,68 \\
\hline 138 & 7087,83 & 48,19 & 1,00 & 48,19 & 10171,36 & 10781,64 \\
\hline 139 & 17033,20 & 58,56 & 1,00 & 58,56 & 14125,60 & 14973,13 \\
\hline 140 & 5122,10 & 60,24 & 1,00 & 60,24 & 9443,94 & 10010,58 \\
\hline 141 & 3887,88 & 46,81 & 1,00 & 46,74 & 9776,60 & 10363,19 \\
\hline 142 & 6999,11 & 48,99 & 1,00 & 48,99 & 11858,62 & 12570,13 \\
\hline 143 & 2088,68 & 37,10 & 1,00 & 37,01 & 8864,63 & 9396,50 \\
\hline 144 & 2203,86 & 38,58 & 1,00 & 38,48 & 9000,61 & 9540,64 \\
\hline 145 & 11522,00 & 38,99 & 1,00 & 38,99 & 10002,62 & 10602,78 \\
\hline 146 & 1838,10 & 30,86 & 1,00 & 30,81 & 8283,54 & 8780,55 \\
\hline 147 & 1800,75 & 30,25 & 1,00 & 30,25 & 9914,64 & 10509,51 \\
\hline 148 & 3834,96 & 62,68 & 1,00 & 62,68 & 12010,36 & 12730,98 \\
\hline 149 & 7118,96 & 51,12 & 1,00 & 51,12 & 12053,86 & 12777,09 \\
\hline 150 & 3456,76 & 57,31 & 1,00 & 57,31 & 11157,54 & 11826,99 \\
\hline 151 & 1522,16 & 26,29 & 1,00 & 26,26 & 6954,26 & 7371,51 \\
\hline 152 & 4821,65 & 58,83 & 1,00 & 58,68 & 11380,25 & 12063,06 \\
\hline 153 & 3405,40 & 40,05 & 1,00 & 40,05 & 10277,70 & 10894,36 \\
\hline 154 & 3338,47 & 57,67 & 1,00 & 57,59 & 12007,97 & 12728,44 \\
\hline 155 & 3310,46 & 55,62 & 1,00 & 55,62 & 11896,87 & 12610,68 \\
\hline 156 & 2521,36 & 44,19 & 1,00 & 44,13 & 10038,75 & 10641,07 \\
\hline 157 & 3105,01 & 53,63 & 1,00 & 53,56 & 10138,02 & 10746,30 \\
\hline 158 & 3405,40 & 57,98 & 1,00 & 57,90 & 8552,67 & 9065,83 \\
\hline 159 & 2935,36 & 49,98 & 1,00 & 49,91 & 9579,84 & 10154,63 \\
\hline 160 & 1841,22 & 30,09 & 1,00 & 30,09 & 8377,17 & 8879,80 \\
\hline 161 & 2206,97 & 38,12 & 1,00 & 38,07 & 10165,02 & 10774,92 \\
\hline 162 & 5445,83 & 38,12 & 1,00 & 38,12 & 10693,62 & 11335,23 \\
\hline 163 & 2641,20 & 43,17 & 1,00 & 43,17 & 8748,56 & 9273,47 \\
\hline 164 & 6838,81 & 46,83 & 1,00 & 46,83 & 12809,23 & 13577,77 \\
\hline 165 & 4771,91 & 59,43 & 1,00 & 59,27 & 12026,40 & 12747,98 \\
\hline 166 & 8451,23 & 60,25 & 1,00 & 60,25 & 12955,50 & 13732,83 \\
\hline 167 & 3254,43 & 53,19 & 1,00 & 53,19 & 11561,67 & 12255,37 \\
\hline 168 & 5775,79 & 40,72 & 1,00 & 40,72 & 11006,98 & 11667,39 \\
\hline 169 & 2874,66 & 48,29 & 1,00 & 48,29 & 8401,88 & 8905,99 \\
\hline 170 & 4364,14 & 52,37 & 1,00 & 52,37 & 10831,48 & 11481,37 \\
\hline
\end{tabular}




\begin{tabular}{|c|c|c|c|c|c|c|}
\hline 171 & 12991,24 & 45,02 & 1,00 & 45,02 & 11663,52 & 12363,33 \\
\hline 172 & 3654,42 & 63,98 & 1,00 & 63,81 & 11648,82 & 12347,74 \\
\hline 173 & 8441,90 & 58,03 & 1,00 & 58,03 & 14755,71 & 15641,05 \\
\hline 174 & 2443,54 & 41,05 & 1,00 & 41,05 & 10064,17 & 10668,02 \\
\hline 175 & 11582,70 & 42,63 & 1,00 & 42,63 & 10936,21 & 11592,38 \\
\hline 176 & 2560,27 & 43,01 & 1,00 & 43,01 & 8374,06 & 8876,50 \\
\hline 177 & 3329,13 & 59,14 & 1,00 & 58,98 & 10959,19 & 11616,74 \\
\hline 178 & 4776,58 & 58,09 & 1,00 & 58,01 & 12026,76 & 12748,36 \\
\hline 179 & 5118,90 & 61,63 & 1,00 & 61,54 & 12042,00 & 12764,52 \\
\hline 180 & 2656,77 & 44,63 & 1,00 & 44,63 & 8826,15 & 9355,71 \\
\hline 181 & 3526,79 & 43,47 & 1,00 & 43,36 & 10995,97 & 11655,72 \\
\hline 182 & 4635,95 & 55,81 & 1,00 & 55,74 & 11288,12 & 11965,40 \\
\hline 183 & 2149,38 & 36,11 & 1,00 & 36,11 & 9949,41 & 10546,37 \\
\hline 184 & 14732,85 & 50,75 & 1,00 & 50,75 & 11890,53 & 12603,96 \\
\hline 185 & 3761,81 & 44,69 & 1,00 & 44,69 & 9913,09 & 10507,87 \\
\hline 186 & 4580,47 & 54,41 & 1,00 & 54,41 & 10738,06 & 11382,33 \\
\hline 187 & 2429,53 & 41,37 & 1,00 & 41,31 & 8850,71 & 9381,75 \\
\hline 188 & 2323,70 & 39,56 & 1,00 & 39,51 & 9338,57 & 9898,88 \\
\hline 189 & 10153,93 & 35,82 & 1,00 & 35,82 & 10564,95 & 11198,84 \\
\hline 190 & 6457,49 & 45,53 & 1,00 & 45,53 & 11786,31 & 12493,49 \\
\hline 191 & 6054,38 & 71,20 & 1,00 & 71,20 & 15336,22 & 16256,38 \\
\hline 192 & 1993,74 & 33,95 & 1,00 & 33,90 & 8517,19 & 9028,22 \\
\hline 193 & 2227,20 & 36,89 & 1,00 & 36,89 & 10275,57 & 10892,10 \\
\hline 194 & 3830,29 & 67,06 & 1,00 & 66,88 & 14045,43 & 14888,15 \\
\hline 195 & 5019,38 & 36,31 & 1,00 & 36,31 & 11211,33 & 11884,01 \\
\hline 196 & 2863,77 & 47,43 & 1,00 & 47,43 & 8156,69 & 8646,08 \\
\hline 197 & 1487,92 & 26,43 & 1,00 & 26,36 & 9200,06 & 9752,06 \\
\hline 198 & 3176,61 & 55,61 & 1,00 & 55,46 & 9924,36 & 10519,82 \\
\hline 199 & 3237,30 & 53,62 & 1,00 & 53,62 & 10095,57 & 10701,30 \\
\hline 200 & 3150,15 & 52,18 & 1,00 & 52,18 & 12367,03 & 13109,05 \\
\hline 201 & 8943,05 & 30,50 & 1,00 & 30,50 & 10691,45 & 11332,93 \\
\hline 202 & 7588,99 & 52,54 & 1,00 & 52,54 & 12389,96 & 13133,35 \\
\hline 203 & 3610,84 & 61,48 & 1,00 & 61,40 & 12210,75 & 12943,39 \\
\hline 204 & 7090,90 & 49,09 & 1,00 & 49,09 & 10560,11 & 11193,71 \\
\hline 205 & 4627,17 & 53,88 & 1,00 & 53,88 & 11517,23 & 12208,25 \\
\hline 206 & 2154,05 & 36,71 & 1,00 & 36,71 & 7675,16 & 8135,67 \\
\hline 207 & 2729,92 & 44,03 & 1,00 & 44,03 & 10817,66 & 11466,71 \\
\hline 208 & 3285,55 & 53,70 & 1,00 & 53,70 & 11845,67 & 12556,41 \\
\hline 209 & 7266,82 & 25,51 & 1,00 & 25,51 & 11541,83 & 12234,33 \\
\hline 210 & 2526,00 & 44,87 & 1,00 & 44,75 & 10286,47 & 10903,66 \\
\hline 211 & 2550,93 & 44,06 & 1,00 & 44,00 & 10193,82 & 10805,44 \\
\hline 212 & 7217,01 & 50,52 & 1,00 & 50,52 & 11023,99 & 11685,43 \\
\hline 213 & 3473,88 & 56,78 & 1,00 & 56,78 & 9392,18 & 9955,70 \\
\hline 214 & 9363,28 & 33,13 & 1,00 & 33,13 & 11558,87 & 12252,39 \\
\hline 215 & 2136,93 & 36,38 & 1,00 & 36,34 & 10124,47 & 10731,94 \\
\hline 216 & 2950,93 & 36,53 & 1,00 & 36,53 & 9132,54 & 9680,49 \\
\hline 217 & 5760,22 & 41,53 & 1,00 & 41,53 & 11871,16 & 12583,42 \\
\hline 218 & 6384,30 & 43,58 & 1,00 & 43,58 & 11667,48 & 12367,53 \\
\hline 219 & 4336,12 & 51,51 & 1,00 & 51,51 & 10324,96 & 10944,45 \\
\hline 220 & 2070,01 & 35,28 & 1,00 & 35,28 & 9149,87 & 9698,86 \\
\hline 221 & 5898,70 & 42,05 & 1,00 & 42,05 & 11388,38 & 12071,67 \\
\hline 222 & 1926,82 & 32,37 & 1,00 & 32,37 & 10620,59 & 11257,82 \\
\hline 223 & 7061,37 & 49,43 & 1,00 & 49,43 & 11615,18 & 12312,09 \\
\hline 224 & 4339,23 & 50,36 & 1,00 & 50,36 & 7816,25 & 8285,22 \\
\hline 225 & 6980,44 & 50,13 & 1,00 & 50,13 & 11973,15 & 12691,53 \\
\hline 226 & 6571,10 & 46,00 & 1,00 & 46,00 & 10389,33 & 11012,68 \\
\hline 227 & 854,46 & 14,35 & 1,00 & 14,35 & 6143,18 & 6511,77 \\
\hline 228 & 2982,06 & 34,38 & 1,00 & 34,38 & 7460,47 & 7908,10 \\
\hline
\end{tabular}




\begin{tabular}{|c|c|c|c|c|c|c|}
\hline 229 & 3145,48 & 36,99 & 1,00 & 36,99 & 9201,73 & 9753,83 \\
\hline 230 & 7785,10 & 58,43 & 1,00 & 58,43 & 14496,48 & 15366,27 \\
\hline 231 & 4312,77 & 49,55 & 1,00 & 49,55 & 10913,08 & 11567,86 \\
\hline 232 & 3416,18 & 39,64 & 1,00 & 39,64 & 8783,88 & 9310,91 \\
\hline 233 & 14413,79 & 49,02 & 1,00 & 49,02 & 11455,45 & 12142,77 \\
\hline 234 & 4747,01 & 57,73 & 1,00 & 57,65 & 13089,92 & 13875,31 \\
\hline 235 & 6325,20 & 45,60 & 1,00 & 45,60 & 9842,83 & 10433,39 \\
\hline 236 & 14444,92 & 51,22 & 1,00 & 51,22 & 13437,69 & 14243,95 \\
\hline 237 & 3078,55 & 21,95 & 1,00 & 21,95 & 8993,17 & 9532,75 \\
\hline 238 & 2653,66 & 43,37 & 1,00 & 43,37 & 10072,77 & 10677,13 \\
\hline 239 & 1943,94 & 31,77 & 1,00 & 31,77 & 8271,30 & 8767,57 \\
\hline 240 & 1859,89 & 30,40 & 1,00 & 30,40 & 10047,56 & 10650,41 \\
\hline 241 & 4652,07 & 55,26 & 1,00 & 55,26 & 12687,97 & 13449,24 \\
\hline 242 & 1515,00 & 17,82 & 1,00 & 17,82 & 7567,08 & 8021,10 \\
\hline 243 & 12829,38 & 45,63 & 1,00 & 45,63 & 11616,66 & 12313,66 \\
\hline 244 & 8210,00 & 57,25 & 1,00 & 57,25 & 11703,99 & 12406,23 \\
\hline 245 & 6524,41 & 44,19 & 1,00 & 44,19 & 12848,59 & 13619,50 \\
\hline 246 & 2950,93 & 46,94 & 1,00 & 46,94 & 10547,19 & 11180,01 \\
\hline 247 & 1992,19 & 23,43 & 1,00 & 23,43 & 7013,28 & 7434,072 \\
\hline 248 & 6756,66 & 48,52 & 1,00 & 48,52 & 10959,69 & 11617,26 \\
\hline 249 & 6910,40 & 47,50 & 1,00 & 47,50 & 13584,08 & 14399,12 \\
\hline 250 & 10670,65 & 39,24 & 1,00 & 39,24 & 11675,59 & 12376,12 \\
\hline 251 & 5746,200 & 39,22 & 1,00 & 39,22 & 10015,15 & 10616,06 \\
\hline 252 & 7534,52 & 53,33 & 1,00 & 53,33 & 13243,11 & 14037,69 \\
\hline 253 & 4203,88 & 71,58 & 1,00 & 71,48 & 13802,07 & 14630,19 \\
\hline 254 & 6043,49 & 43,72 & 1,00 & 43,72 & 12223,16 & 12956,54 \\
\hline 255 & 7126,70 & 48,99 & 1,00 & 48,99 & 12590,75 & 13346,19 \\
\hline 256 & 6740,75 & 48,76 & 1,00 & 48,76 & 12295,43 & 13033,15 \\
\hline 257 & 8978,85 & 63,56 & 1,00 & 63,56 & 14109,48 & 14956,04 \\
\hline 258 & 3010,07 & 51,30 & 1,00 & 51,30 & 9266,29 & 9822,26 \\
\hline 259 & 5062,97 & 59,54 & 1,00 & 59,54 & 12524,58 & 13276,05 \\
\hline 260 & 15643,34 & 55,63 & 1,00 & 55,63 & 13255,07 & 14050,37 \\
\hline 261 & 1654,45 & 28,20 & 1,00 & 28,20 & 8994,64 & 9534,31 \\
\hline 262 & 2790,62 & 46,26 & 1,00 & 46,26 & 12296,14 & 13033,90 \\
\hline 263 & 9897,13 & 34,64 & 1,00 & 34,64 & 11413,34 & 12098,14 \\
\hline 264 & 7475,37 & 51,02 & 1,00 & 51,02 & 11439,87 & 12126,25 \\
\hline 265 & 2625,64 & 41,76 & 1,00 & 41,76 & 11686,06 & 12387,22 \\
\hline 266 & 8986,63 & 61,34 & 1,00 & 61,34 & 14162,84 & 15012,61 \\
\hline 267 & 4980,47 & 35,51 & 1,00 & 35,51 & 10515,77 & 11146,71 \\
\hline 268 & 5490,97 & 39,59 & 1,00 & 39,59 & 10159,76 & 10769,34 \\
\hline 269 & 2764,16 & 47,75 & 1,00 & 47,68 & 12060,16 & 12783,77 \\
\hline 270 & 6972,66 & 49,91 & 1,00 & 49,91 & 10464,78 & 11092,66 \\
\hline 271 & 6974,2 & 49,02 & 1,00 & 49,02 & 10559,73 & 11193,30 \\
\hline 272 & 3215,52 & 53,31 & 1,00 & 53,31 & 9401,93 & 9966,04 \\
\hline 273 & 4407,71 & 51,32 & 1,00 & 51,32 & 12328,26 & 13067,96 \\
\hline 274 & 3201,51 & 54,51 & 1,00 & 54,44 & 11655,47 & 12354,80 \\
\hline 275 & 10034,09 & 35,86 & 1,00 & 35,86 & 9452,69 & 10019,85 \\
\hline 276 & 2670,78 & 44,87 & 1,00 & 44,87 & 10109,38 & 10715,94 \\
\hline 277 & 13827,00 & 47,02 & 1,00 & 47,02 & 11697,95 & 12399,83 \\
\hline 278 & 8245,79 & 29,33 & 1,00 & 29,33 & 10169,20 & 10779,35 \\
\hline 279 & 4403,10 & 30,92 & 1,00 & 30,92 & 9047,63 & 9590,48 \\
\hline 280 & 12914,98 & 45,56 & 1,00 & 45,56 & 12092,48 & 12818,03 \\
\hline 281 & 5657,50 & 38,19 & 1,00 & 38,19 & 9361,74 & 9923,44 \\
\hline 282 & 6491,31 & 47,14 & 1,00 & 47,14 & 12030,15 & 12751,95 \\
\hline 283 & 3912,78 & 28,01 & 1,00 & 28,01 & 12901,17 & 13675,23 \\
\hline 284 & 3176,61 & 52,62 & 1,00 & 52,62 & 8977,84 & 9516,51 \\
\hline 285 & 3559,48 & 40,36 & 1,00 & 40,36 & 9659,07 & 10238,61 \\
\hline 286 & 6297,18 & 46,40 & 1,00 & 46,40 & 11753,58 & 12458,78 \\
\hline
\end{tabular}




\begin{tabular}{|c|c|c|c|c|c|c|}
\hline 287 & 2971,16 & 36,62 & 1,00 & 36,53 & 10177,48 & 10788,12 \\
\hline 288 & 3514,34 & 60,65 & 1,00 & 60,48 & 10577,28 & 11211,92 \\
\hline 289 & 15823,88 & 54,56 & 1,00 & 54,56 & 13596,69 & 14412,49 \\
\hline 290 & 3806,95 & 44,18 & 1,00 & 44,18 & 10886,19 & 11539,36 \\
\hline 291 & 10118,13 & 35,98 & 1,00 & 35,98 & 10514,13 & 11144,97 \\
\hline 292 & 5834,90 & 40,84 & 1,00 & 40,84 & 9989,41 & 10588,77 \\
\hline 293 & 3024,00 & 34,63 & 1,00 & 34,63 & 8570,71 & 9084,95 \\
\hline 294 & 4270,75 & 29,03 & 1,00 & 29,03 & 9661,96 & 10241,67 \\
\hline 295 & 10580,38 & 37,22 & 1,00 & 37,22 & 11682,22 & 12383,15 \\
\hline 296 & 2949,37 & 49,55 & 1,00 & 49,55 & 9575,57 & 10150,10 \\
\hline 297 & 12122,77 & 42,98 & 1,00 & 42,98 & 11260,26 & 11935,87 \\
\hline 298 & 6407,68 & 41,86 & 1,00 & 41,86 & 10705,85 & 11348,20 \\
\hline 299 & 14074,94 & 48,87 & 1,00 & 48,87 & 10796,70 & 11444,50 \\
\hline 300 & 2547,82 & 42,80 & 1,00 & 42,80 & 8577,50 & 9092,15 \\
\hline 301 & 4488,65 & 52,09 & 1,00 & 52,09 & 10844,43 & 11495,09 \\
\hline 302 & 14919,62 & 53,33 & 1,00 & 53,33 & 12331,22 & 13071,08 \\
\hline 303 & 9559,18 & 33,72 & 1,00 & 33,72 & 9694,68 & 10276,36 \\
\hline 304 & 4336,10 & 31,04 & 1,00 & 31,04 & 8958,00 & 9495,47 \\
\hline 305 & 7489,38 & 50,72 & 1,00 & 50,72 & 10730,60 & 11374,43 \\
\hline 306 & 6620,91 & 46,87 & 1,00 & 46,87 & 12314,85 & 13053,74 \\
\hline 307 & 6938,42 & 47,36 & 1,00 & 47,36 & 12611,67 & 13368,37 \\
\hline 308 & 7761,75 & 52,98 & 1,00 & 52,98 & 12198,59 & 12930,50 \\
\hline 309 & 2490,00 & 28,23 & 1,00 & 28,23 & 9198,12 & 9750,00 \\
\hline 310 & 15221,56 & 53,86 & 1,00 & 53,86 & 13109,45 & 13896,01 \\
\hline 311 & 7111,80 & 50,91 & 1,00 & 50,91 & 10662,57 & 11302,32 \\
\hline 312 & 6988,20 & 50,02 & 1,00 & 50,02 & 11705,45 & 12407,77 \\
\hline 313 & 14686,16 & 51,81 & 1,00 & 51,81 & 12816,69 & 13585,69 \\
\hline 314 & 7031,80 & 48,68 & 1,00 & 48,68 & 10543,01 & 11175,58 \\
\hline 315 & 10566,38 & 35,06 & 1,00 & 35,06 & 8287,28 & 8784,51 \\
\hline 316 & 16041,78 & 55,87 & 1,00 & 55,87 & 12577,18 & 13331,80 \\
\hline 317 & 6845,00 & 46,54 & 1,00 & 46,54 & 12826,94 & 13596,55 \\
\hline 318 & 13741,42 & 48,97 & 1,00 & 48,97 & 12515,85 & 13266,79 \\
\hline 319 & 6385,89 & 43,11 & 1,00 & 43,11 & 10854,31 & 11505,57 \\
\hline 320 & 5989,01 & 42,57 & 1,00 & 42,57 & 16264,26 & 17240,12 \\
\hline 321 & 3895,66 & 44,76 & 1,00 & 44,76 & 11018,21 & 11679,30 \\
\hline 322 & 3304,23 & 37,97 & 1,00 & 37,97 & 9307,66 & 9866,11 \\
\hline 323 & 5008,48 & 36,36 & 1,00 & 36,36 & 9061,08 & 9604,7448 \\
\hline 324 & 7501,83 & 51,93 & 1,00 & 51,93 & 12056,48 & 12779,86 \\
\hline 325 & 8194,43 & 29,44 & 1,00 & 29,44 & 9400,89 & 9964,94 \\
\hline 326 & 6566,44 & 45,97 & 1,00 & 45,97 & 10380,64 & 11003,47 \\
\hline 327 & 3310,46 & 37,54 & 1,00 & 37,54 & 7909,09 & 8383,63 \\
\hline 328 & 9402,19 & 33,44 & 1,00 & 33,44 & 9676,45 & 10257,03 \\
\hline 329 & 8236,45 & 57,66 & 1,00 & 57,66 & 13197,49 & 13989,34 \\
\hline 330 & 4054,41 & 46,13 & 1,00 & 46,13 & 11044,71 & 11707,39 \\
\hline 331 & 9416,20 & 32,86 & 1,00 & 32,86 & 8880,22 & 9413,03 \\
\hline 332 & 5775,79 & 38,87 & 1,00 & 38,87 & 11455,56 & 12142,88 \\
\hline 333 & 4378,14 & 29,65 & 1,00 & 29,65 & 7489,08 & 7938,42 \\
\hline 334 & 13118,87 & 46,28 & 1,00 & 46,28 & 12360,26 & 13101,87 \\
\hline 335 & 4649,00 & 33,14 & 1,00 & 33,14 & 10034,95 & 10637,04 \\
\hline 336 & 3758,70 & 43,62 & 1,00 & 43,62 & 10238,32 & 10852,61 \\
\hline 337 & 6245,82 & 43,72 & 1,00 & 43,72 & 10971,83 & 11630,13 \\
\hline 338 & 4975,80 & 34,83 & 1,00 & 34,83 & 11041,38 & 11703,86 \\
\hline 339 & 6183,56 & 41,74 & 1,00 & 41,74 & 10912,36 & 11567,09 \\
\hline 340 & 5039,60 & 36,33 & 1,00 & 36,33 & 14125,86 & 14973,41 \\
\hline 341 & 3978,15 & 46,78 & 1,00 & 46,78 & 12378,52 & 13121,22 \\
\hline 342 & 4059,08 & 47,58 & 1,00 & 47,58 & 10997,36 & 11657,19 \\
\hline 343 & 7701,05 & 52,36 & 1,00 & 52,36 & 11966,80 & 12684,80 \\
\hline 344 & 6211,60 & 43,79 & 1,00 & 43,79 & 9956,19 & 10553,56 \\
\hline
\end{tabular}




\begin{tabular}{|c|c|c|c|c|c|c|}
\hline 345 & 3249,76 & 37,34 & 1,00 & 37,34 & 10448,82 & 11075,74 \\
\hline 346 & 3712,01 & 42,65 & 1,00 & 42,65 & 12368,47 & 13110,57 \\
\hline 347 & 6224,03 & 44,55 & 1,00 & 44,55 & 10626,61 & 11264,20 \\
\hline 348 & 3274,66 & 37,13 & 1,00 & 37,13 & 8818,25 & 9347,34 \\
\hline 349 & 3933,01 & 45,19 & 1,00 & 45,19 & 11397,42 & 12081,26 \\
\hline 350 & 5181,24 & 36,27 & 1,00 & 36,27 & 8720,08 & 9243,28 \\
\hline 351 & 4787,48 & 33,41 & 1,00 & 33,41 & 10964,74 & 11622,62 \\
\hline 352 & 3579,71 & 41,13 & 1,00 & 41,13 & 9143,45 & 9692,059 \\
\hline 353 & 5464,50 & 38,68 & 1,00 & 38,68 & 10723,56 & 11366,97 \\
\hline 354 & 6904,17 & 47,27 & 1,00 & 47,27 & 11909,30 & 12623,85 \\
\hline 355 & 6043,50 & 42,78 & 1,00 & 42,78 & 8412,64 & 8917,40 \\
\hline 356 & 6801,45 & 46,75 & 1,00 & 46,75 & 11741,74 & 12446,24 \\
\hline 357 & 9322,81 & 33,06 & 1,00 & 33,06 & 9590,49 & 10165,91 \\
\hline 358 & 8427,89 & 30,92 & 1,00 & 30,92 & 10365,47 & 10987,40 \\
\hline 359 & 4350,00 & 49,67 & 1,00 & 49,67 & 11256,96 & 11932,37 \\
\hline 360 & 5262,18 & 36,98 & 1,00 & 36,98 & 10981,06 & 11639,92 \\
\hline 361 & 3361,82 & 58,07 & 1,00 & 57,99 & 10395,39 & 11019,11 \\
\hline 362 & 6157,10 & 42,16 & 1,00 & 42,16 & 10807,52 & 11455,97 \\
\hline 363 & 4337,68 & 49,19 & 1,00 & 49,19 & 10997,91 & 11657,78 \\
\hline 364 & 3014,74 & 33,85 & 1,00 & 33,85 & 9343,04 & 9903,62 \\
\hline 365 & 11371,03 & 38,83 & 1,00 & 38,83 & 10027,33 & 10628,97 \\
\hline 366 & 8728,27 & 30,16 & 1,00 & 30,16 & 8780,68 & 9307,53 \\
\hline 367 & 9766,39 & 33,84 & 1,00 & 33,84 & 7489,30 & 7938,65 \\
\hline 368 & 6941,53 & 23,79 & 1,00 & 23,79 & 8751,70 & 9050,36 \\
\hline 369 & 8569,52 & 29,50 & 1,00 & 29,50 & 8986,20 & 9525,37 \\
\hline 370 & 9953,16 & 33,45 & 1,00 & 33,45 & 8476,68 & 8950,92 \\
\hline
\end{tabular}




\begin{tabular}{|c|c|c|c|c|c|c|}
\hline Probeta & MOE sin corr & MOE corr & Pos Rotura & Peso húmedo & Peso seco & Humedad \\
\hline 1 & 12142,64 & 10697 & 65 & 3,280 & 3,277 & 0,09 \\
\hline 2 & 13199,74 & 11636 & 14 & 0,661 & 0,66 & 0,15 \\
\hline 3 & 13770,23 & 12182 & 35 & 0,643 & 0,64 & 0,47 \\
\hline 4 & 15245,83 & 13888 & 88 & 3,030 & 2,939 & 3,10 \\
\hline 5 & 12441,08 & 11544 & 37 & 2,690 & 2,567 & 4,79 \\
\hline 6 & 10857,47 & 10087 & 1 & 2,310 & 2,202 & 4,90 \\
\hline 7 & 10076,17 & 9377 & 72 & 2,800 & 2,665 & 5,07 \\
\hline 8 & 15523,36 & 14538 & 8 & 2,580 & 2,442 & 5,65 \\
\hline 9 & 11867,95 & 11148 & 80 & 2,500 & 2,36 & 5,93 \\
\hline 10 & 11685,44 & 10979 & 67 & 2,510 & 2,369 & 5,95 \\
\hline 11 & 16063,43 & 15110 & 33 & 3,270 & 3,083 & 6,07 \\
\hline 12 & 13801,96 & 12994 & 53 & 2,920 & 2,751 & 6,14 \\
\hline 13 & 10985,41 & 10396 & 32 & 2,700 & 2,532 & 6,64 \\
\hline 14 & & 12182 & 48 & 2,610 & 2,447 & 6,66 \\
\hline 15 & 14674,21 & 13915 & & 2,800 & 2,621 & 6,83 \\
\hline 16 & 10962,33 & 10444 & 97 & 2,330 & 2,172 & 7,27 \\
\hline 17 & 13340,58 & 12749 & 27 & 3,000 & 2,789 & 7,57 \\
\hline 18 & 13507,11 & 12955 & 129 & 2,960 & 2,743 & 7,91 \\
\hline 19 & 12351,20 & 11866 & 19 & 1,406 & 1,301 & 8,07 \\
\hline 20 & 17258,60 & 16610 & & 3,100 & 2,864 & 8,24 \\
\hline 21 & 10852,34 & 10452 & 7 & 2,490 & 2,299 & 8,31 \\
\hline 22 & 10272,90 & 9923 & 67 & 2,920 & 2,689 & 8,59 \\
\hline 23 & 11454,60 & 11072 & 81 & 2,860 & 2,632 & 8,66 \\
\hline 24 & 14078,65 & 13611 & 19 & 2,680 & 2,466 & 8,68 \\
\hline 25 & 14044,01 & 13589 & 10 & 2,980 & 2,74 & 8,76 \\
\hline 26 & 12337,56 & 11949 & 43 & 2,680 & 2,462 & 8,85 \\
\hline 27 & 14191,87 & 13770 & 64 & 2,440 & 2,238 & 9,03 \\
\hline 28 & 8270,65 & 8035 & 4 & 2,470 & 2,263 & 9,15 \\
\hline 29 & 12403,13 & 12100 & 84 & 1,318 & 1,203 & 9,56 \\
\hline 30 & 12770,17 & 12476 & 73 & 2,850 & 2,598 & 9,70 \\
\hline 31 & 8980,67 & 8784 & 42 & 2,530 & 2,304 & 9,81 \\
\hline 32 & 14963,14 & 14636 & 45 & 3,290 & 2,996 & 9,81 \\
\hline 33 & 11796,75 & 11544 & 42 & 1,549 & 1,41 & 9,86 \\
\hline 34 & 12750,73 & 12569 & 25 & 2,730 & 2,469 & 10,57 \\
\hline 35 & 13870,80 & 13676 & 62 & 2,880 & 2,604 & 10,60 \\
\hline 36 & 7722,88 & 7628 & 4 & 2,940 & 2,654 & 10,78 \\
\hline 37 & 12088,72 & 11976 & 52 & 3,030 & 2,728 & 11,07 \\
\hline 38 & 11581,27 & 11490 & 81 & 1,230 & 1,106 & 11,21 \\
\hline 39 & 13643,44 & 13539 & 170 & 3,060 & 2,751 & 11,23 \\
\hline 40 & 11909,92 & 11846 & 54 & 2,460 & 2,207 & 11,46 \\
\hline 41 & 13135,34 & 13137 & 145 & 3,030 & 2,705 & 12,01 \\
\hline 42 & 7815,95 & 7817 & 45 & 0,564 & 0,5035 & 12,02 \\
\hline 43 & 20789,76 & 20826 & 10 & 0,433 & 0,386 & 12,18 \\
\hline 44 & 15729,58 & 15789 & 45 & 0,672 & 0,598 & 12,37 \\
\hline 45 & 12129,14 & 12179 & 82 & 2,590 & 2,304 & 12,41 \\
\hline 46 & 12196,85 & 12263 & 67 & 0,646 & 0,574 & 12,54 \\
\hline 47 & 10187,62 & 10250 & 37 & 0,366 & 0,325 & 12,62 \\
\hline 48 & 16540,32 & 16647 & 58 & 0,441 & 0,392 & 12,64 \\
\hline 49 & 10652,11 & 10727 & 17 & 2,840 & 2,520 & 12,70 \\
\hline 50 & 12588,14 & 12721 & 17 & 1,316 & 1,164 & 13,06 \\
\hline 51 & 14399,32 & 14588 & 54 & 0,715 & 0,631 & 13,31 \\
\hline 52 & 9834,74 & 9971 & 50 & 3,44 & 3,034 & 13,38 \\
\hline 53 & 10424,69 & 10569 & 65 & 2,380 & 2,099 & 13,39 \\
\hline 54 & 10182,01 & 10343 & 29 & 2,810 & 2,474 & 13,58 \\
\hline
\end{tabular}




\begin{tabular}{|c|c|c|c|c|c|c|}
\hline 55 & 13254,89 & 13468 & 63 & 2,630 & 2,315 & 13,61 \\
\hline 56 & 11052,84 & 11253 & 75 & 2,480 & 2,179 & 13,81 \\
\hline 57 & 13855,44 & 14113 & 108 & 2,900 & 2,547 & 13,86 \\
\hline 58 & 13848,01 & 14119 & 52 & 1,445 & 1,268 & 13,96 \\
\hline 59 & 9775,81 & 9973 & 50 & 2,570 & 2,254 & 14,02 \\
\hline 60 & 13646,09 & 13927 & 40 & 2,880 & 2,525 & 14,06 \\
\hline 61 & 14341,62 & 14647 & 36 & 0,735 & 0,644 & 14,13 \\
\hline 62 & 8482,59 & 8676 & 6,0 & 1,200 & 1,05 & 14,29 \\
\hline 63 & 10787,80 & 11037 & 43 & 0,823 & 0,72 & 14,31 \\
\hline 64 & 14597,51 & 14949 & 32 & 2,970 & 2,596 & 14,41 \\
\hline 65 & 13452,26 & 13788 & 24 & 0,711 & 0,621 & 14,49 \\
\hline 66 & 14730,31 & 15116 & 0 & 0,745 & 0,65 & 14,62 \\
\hline 67 & 12470,03 & 12820 & 37 & 2,590 & 2,256 & 14,80 \\
\hline 68 & 9421,65 & 9692 & 22 & 0,394 & 0,343 & 14,87 \\
\hline 69 & 17370,87 & 17879 & 29 & 0,693 & 0,603 & 14,93 \\
\hline 70 & 13757,82 & 14161 & 45 & 0,762 & 0,663 & 14,93 \\
\hline 71 & 9129,44 & 9399 & 34 & 0,569 & 0,495 & 14,95 \\
\hline 72 & 12722,85 & 13099 & 5 & 0,615 & 0,535 & 14,95 \\
\hline 73 & 11956,43 & 12326 & 72 & 2,830 & 2,459 & 15,09 \\
\hline 74 & 12647,83 & 13048 & 210 & 3,250 & 2,822 & 15,17 \\
\hline 75 & 12291,27 & 12683 & 36 & 1,259 & 1,093 & 15,19 \\
\hline 76 & 13609,66 & 14052 & 55 & 0,665 & 0,577 & 15,25 \\
\hline 77 & 12731,24 & 13160 & 13 & 0,653 & 0,566 & 15,37 \\
\hline 78 & 11077,45 & 11452 & 19 & 0,705 & 0,611 & 15,38 \\
\hline 79 & 12521,03 & 12983 & 0 & 0,767 & 0,663 & 15,69 \\
\hline 80 & 13541,05 & 14072 & & 0,728 & 0,628 & 15,92 \\
\hline 81 & 14623,78 & 15239 & 92 & 1,549 & 1,333 & 16,20 \\
\hline 82 & 12524,40 & 13058 & 59 & 0,665 & 0,572 & 16,26 \\
\hline 83 & 10258,61 & 10700 & 23 & 0,421 & 0,362 & 16,30 \\
\hline 84 & 10064,94 & 10499 & & 0,328 & 0,282 & 16,31 \\
\hline 85 & 11759,77 & 12281 & 26 & 0,744 & 0,639 & 16,43 \\
\hline 86 & 12956,94 & 13536 & 71 & 0,488 & 0,419 & 16,47 \\
\hline 87 & 12450,15 & 13010 & 35 & 0,699 & 0,600 & 16,50 \\
\hline 88 & 11274,87 & 11798 & 26 & 0,652 & 0,559 & 16,64 \\
\hline 89 & 11686,50 & 12232 & 38 & 0,742 & 0,636 & 16,67 \\
\hline 90 & 17176,83 & 17979 & 73 & 3,240 & 2,777 & 16,67 \\
\hline 91 & 12505,71 & 13097 & 28 & 0,663 & 0,568 & 16,73 \\
\hline 92 & 8465,63 & 8867 & 48 & 1,360 & 1,165 & 16,74 \\
\hline 93 & 8109,50 & 8499 & 22 & 0,695 & 0,595 & 16,81 \\
\hline 94 & 9019,55 & 9453 & 36 & 0,549 & 0,470 & 16,81 \\
\hline 95 & 13682,03 & 14341 & 40 & 0,653 & 0,559 & 16,82 \\
\hline 96 & 11776,46 & 12348 & 33 & 0,631 & 0,540 & 16,85 \\
\hline 97 & 10418,34 & 10924 & 23 & 0,721 & 0,617 & 16,86 \\
\hline 98 & 13236,84 & 13880 & 10 & 0,811 & 0,694 & 16,86 \\
\hline 99 & 11885,08 & 12465 & 1 & 1,551 & 1,327 & 16,88 \\
\hline 100 & 11196,79 & 11749 & 37 & 0,373 & 0,319 & 16,93 \\
\hline 101 & 8336,48 & 8758 & 18 & 0,405 & 0,346 & 17,05 \\
\hline 102 & 10844,45 & 11400 & 2 & 0,602 & 0,514 & 17,12 \\
\hline 103 & 10154,87 & 10680 & 103 & 0,307 & 0,262 & 17,18 \\
\hline 104 & 10838,30 & 11403 & 74 & 0,572 & 0,488 & 17,21 \\
\hline 105 & 14106,50 & 14848 & 31 & 0,666 & 0,568 & 17,25 \\
\hline 106 & 12989,85 & 13685 & 91 & 2,820 & 2,403 & 17,35 \\
\hline 107 & 13298,28 & 14017 & 54 & 0,715 & 0,609 & 17,41 \\
\hline 108 & 13695,78 & 14441 & 33 & 2,660 & 2,265 & 17,44 \\
\hline 109 & 20683,42 & 21815 & 39 & 0,659 & 0,561 & 17,47 \\
\hline 110 & 14232,27 & 15012 & 5 & 0,726 & 0,618 & 17,48 \\
\hline 111 & 9797,69 & 10335 & 22 & 0,430 & 0,366 & 17,49 \\
\hline 112 & 9973,65 & 10523 & 9 & 0,463 & 0,394 & 17,51 \\
\hline
\end{tabular}




\begin{tabular}{|c|c|c|c|c|c|c|}
\hline 113 & 12057,62 & 12724 & 49 & 0,456 & 0,388 & 17,53 \\
\hline 114 & 10110,39 & 10676 & 51 & 0,401 & 0,341 & 17,60 \\
\hline 115 & 12350,60 & 13048 & 98 & 0,780 & 0,663 & 17,65 \\
\hline 116 & 10152,97 & 10741 & 14 & 0,417 & 0,354 & 17,80 \\
\hline 117 & 9390,15 & 9935 & 26 & 0,364 & 0,309 & 17,80 \\
\hline 118 & 12055,18 & 12755 & 23 & 0,688 & 0,584 & 17,81 \\
\hline 119 & 11510,10 & 12180 & 62 & 0,648 & 0,550 & 17,82 \\
\hline 120 & 11274,87 & 11936 & 59 & 0,706 & 0,599 & 17,86 \\
\hline 121 & 12731,13 & 13488 & 63 & 0,848 & 0,719 & 17,94 \\
\hline 122 & 9502,80 & 10071 & 15 & 0,420 & 0,356 & 17,98 \\
\hline 123 & 11955,14 & 12671 & 70 & 0,446 & 0,378 & 17,99 \\
\hline 124 & 11985,75 & 12705 & 70 & 0,472 & 0,400 & 18,00 \\
\hline 125 & 10822,63 & 11472 & 65 & 0,452 & 0,383 & 18,02 \\
\hline 126 & 12633,86 & 13392 & 5 & 0,707 & 0,599 & 18,03 \\
\hline 127 & 12585,25 & 13340 & 11 & 0,432 & 0,366 & 18,03 \\
\hline 128 & 12622,39 & 13380 & 35 & 0,458 & 0,388 & 18,04 \\
\hline 129 & 11788,88 & 12496 & 58 & 0,438 & 0,371 & 18,06 \\
\hline 130 & 12860,82 & 13632 & 24 & 0,660 & 0,559 & 18,07 \\
\hline 131 & 13033,73 & 13816 & 51 & 0,483 & 0,409 & 18,09 \\
\hline 132 & 10754,10 & 11399 & 9 & 0,424 & 0,359 & 18,11 \\
\hline 133 & 10779,65 & 11426 & 38 & 0,430 & 0,364 & 18,13 \\
\hline 134 & 14990,53 & 15890 & & 2,770 & 2,344 & 18,17 \\
\hline 135 & 11256,45 & 11932 & 4 & 0,520 & 0,440 & 18,18 \\
\hline 136 & 13465,12 & 14273 & 78 & 0,525 & 0,444 & 18,24 \\
\hline 137 & 13205,11 & 13997 & 43 & 0,466 & 0,394 & 18,27 \\
\hline 138 & 10370,51 & 10993 & 24 & 1,300 & 1,099 & 18,29 \\
\hline 139 & 16136,21 & 17104 & 2 & 2,900 & 2,451 & 18,32 \\
\hline 140 & 9518,99 & 10090 & 3 & 0,800 & 0,676 & 18,34 \\
\hline 141 & 11657,51 & 12357 & 72 & 0,670 & 0,566 & 18,37 \\
\hline 142 & 11576,25 & 12271 & 39 & 1,350 & 1,140 & 18,42 \\
\hline 143 & 11812,24 & 12521 & 15 & 0,469 & 0,396 & 18,43 \\
\hline 144 & 11190,24 & 11862 & 36 & 0,366 & 0,309 & 18,45 \\
\hline 145 & 10194,84 & 10807 & 116 & 2,150 & 1,815 & 18,46 \\
\hline 146 & 12891,38 & 13665 & 2 & 0,551 & 0,465 & 18,49 \\
\hline 147 & 9368,10 & 9930 & 11 & 0,525 & 0,443 & 18,51 \\
\hline 148 & 15708,80 & 16651 & 18 & 0,448 & 0,378 & 18,52 \\
\hline 149 & 13306,74 & 14105 & 43 & 1,203 & 1,015 & 18,52 \\
\hline 150 & 12795,97 & 13564 & 39 & 0,390 & 0,329 & 18,54 \\
\hline 151 & 6931,67 & 7348 & 30 & 0,441 & 0,372 & 18,55 \\
\hline 152 & 12324,39 & 13064 & 36 & 0,690 & 0,582 & 18,56 \\
\hline 153 & 12083,40 & 12808 & 53 & 0,696 & 0,587 & 18,57 \\
\hline 154 & 13490,02 & 14299 & 4 & 0,453 & 0,382 & 18,59 \\
\hline 155 & 13954,50 & 14792 & 6 & 0,491 & 0,414 & 18,60 \\
\hline 156 & 10459,43 & 11087 & 3 & 0,509 & 0,429 & 18,65 \\
\hline 157 & 11339,76 & 12020 & 45 & 0,407 & 0,343 & 18,66 \\
\hline 158 & 9024,49 & 9566 & 31 & 0,426 & 0,359 & 18,66 \\
\hline 159 & 9472,82 & 10041 & 39 & 0,413 & 0,348 & 18,68 \\
\hline 160 & 11388,88 & 12072 & 25 & 0,419 & 0,353 & 18,70 \\
\hline 161 & 12650,46 & 13409 & 11 & 0,475 & 0,400 & 18,75 \\
\hline 162 & 13025,25 & 13807 & 54 & 1,472 & 1,239 & 18,81 \\
\hline 163 & 8370,41 & 8873 & 21 & 0,499 & 0,420 & 18,81 \\
\hline 164 & 14413,69 & 15279 & 10 & 1,162 & 0,978 & 18,81 \\
\hline 165 & 13536,97 & 14349 & 56 & 0,668 & 0,562 & 18,86 \\
\hline 166 & 15461,24 & 16389 & 38 & 1,339 & 1,126 & 18,92 \\
\hline 167 & 14838,11 & 15728 & 63 & 0,396 & 0,333 & 18,92 \\
\hline 168 & 12960,32 & 13738 & 60 & 1,282 & 1,078 & 18,92 \\
\hline 169 & 8134,88 & 8623 & 38 & 0,465 & 0,391 & 18,93 \\
\hline 170 & 11880,00 & 12593 & 10 & 0,647 & 0,544 & 18,93 \\
\hline
\end{tabular}




\begin{tabular}{|c|c|c|c|c|c|c|}
\hline 171 & 12225,81 & 12959 & 82 & 2,280 & 1,917 & 18,94 \\
\hline 172 & 13006,77 & 13787 & 6 & 0,444 & 0,373 & 19,03 \\
\hline 173 & 16772,47 & 17779 & 12 & 1,410 & 1,184 & 19,09 \\
\hline 174 & 12048,75 & 12772 & 37 & 0,418 & 0,351 & 19,09 \\
\hline 175 & 11250,16 & 11925 & 83 & 2,070 & 1,738 & 19,10 \\
\hline 176 & 9344,48 & 9905 & 56 & 0,349 & 0,293 & 19,11 \\
\hline 177 & 11474,65 & 12163 & 8 & 0,430 & 0,361 & 19,11 \\
\hline 178 & 13027,57 & 13809 & 7 & 0,828 & 0,695 & 19,14 \\
\hline 179 & 12225,61 & 12959 & 35 & 0,697 & 0,585 & 19,15 \\
\hline 180 & 10661,18 & 11301 & 5 & 0,353 & 0,296 & 19,26 \\
\hline 181 & 11876,24 & 12589 & 10 & 0,655 & 0,549 & 19,31 \\
\hline 182 & 11918,84 & 12634 & 31 & 0,697 & 0,584 & 19,35 \\
\hline 183 & 9831,15 & 10421 & 12 & 0,407 & 0,341 & 19,35 \\
\hline 184 & 13328,71 & 14128 & 64 & 2,700 & 2,262 & 19,36 \\
\hline 185 & 11782,27 & 12489 & 2 & 0,689 & 0,577 & 19,41 \\
\hline 186 & 10921,43 & 11577 & 45 & 0,682 & 0,571 & 19,44 \\
\hline 187 & 10485,18 & 11114 & 9 & 0,387 & 0,324 & 19,44 \\
\hline 188 & 11147,24 & 11816 & 50 & 0,479 & 0,401 & 19,45 \\
\hline 189 & 12121,99 & 12849 & & 2,800 & 2,344 & 19,45 \\
\hline 190 & 12587,54 & 13343 & 11 & 1,314 & 1,100 & 19,45 \\
\hline 191 & 16934,40 & 17950 & & 0,773 & 0,647 & 19,47 \\
\hline 192 & 10409,66 & 11034 & 55 & 0,429 & 0,359 & 19,50 \\
\hline 193 & 13043,66 & 13826 & 16 & 0,429 & 0,359 & 19,50 \\
\hline 194 & 16684,73 & 17686 & 27 & 0,471 & 0,394 & 19,54 \\
\hline 195 & 12921,07 & 13696 & 53 & 1,307 & 1,093 & 19,58 \\
\hline 196 & 9563,80 & 10138 & 48 & 0,353 & 0,295 & 19,66 \\
\hline 197 & 9894,73 & 10488 & 3 & 0,426 & 0,356 & 19,66 \\
\hline 198 & 10118,96 & 10726 & 35 & 0,426 & 0,356 & 19,66 \\
\hline 199 & 11254,82 & 11930 & 7 & 0,443 & 0,370 & 19,73 \\
\hline 200 & 14259,52 & 15115 & 47 & 0,496 & 0,414 & 19,81 \\
\hline 201 & 8699,53 & 9222 & 125 & 2,530 & 2,111 & 19,85 \\
\hline 202 & 13112,62 & 13899 & 44 & 1,283 & 1,07 & 19,91 \\
\hline 203 & 13882,22 & 14715 & 35 & 0,530 & 0,442 & 19,91 \\
\hline 204 & 10719,35 & 11363 & 19 & 1,240 & 1,034 & 19,92 \\
\hline 205 & 13753,96 & 14579 & 49 & 0,686 & 0,572 & 19,93 \\
\hline 206 & 8634,65 & 9153 & 23 & 0,469 & 0,391 & 19,95 \\
\hline 207 & 14781,47 & 15668 & 58 & 0,390 & 0,325 & 20,00 \\
\hline 208 & 13655,39 & 14475 & 45 & 0,468 & 0,390 & 20,00 \\
\hline 209 & 13070,93 & 13855 & 218 & 3,200 & 2,665 & 20,08 \\
\hline 210 & 12657,90 & 13417 & 20 & 0,436 & 0,363 & 20,11 \\
\hline 211 & 11656,03 & 12355 & 54 & 0,423 & 0,352 & 20,17 \\
\hline 212 & 11418,75 & 12104 & 21 & 1,314 & 1,093 & 20,22 \\
\hline 213 & 11824,22 & 12534 & 31 & 0,529 & 0,440 & 20,23 \\
\hline 214 & 12690,56 & 13452 & 92 & 3,270 & 2,719 & 20,26 \\
\hline 215 & 11630,92 & 12329 & 63 & 0,409 & 0,340 & 20,29 \\
\hline 216 & 9819,21 & 10408 & 26 & 0,738 & 0,613 & 20,39 \\
\hline 217 & 13443,13 & 14250 & 45 & 1,267 & 1,052 & 20,44 \\
\hline 218 & 11645,06 & 12344 & 14 & 1,470 & 1,219 & 20,59 \\
\hline 219 & 10440,34 & 11067 & 5 & 0,695 & 0,576 & 20,66 \\
\hline 220 & 10333,14 & 10953 & 24 & 0,508 & 0,421 & 20,67 \\
\hline 221 & 11920,56 & 12636 & 20 & 1,160 & 0,961 & 20,71 \\
\hline 222 & 11445,53 & 12132 & 44 & 0,518 & 0,429 & 20,75 \\
\hline 223 & 12308,63 & 13047 & 22 & 1,714 & 1,419 & 20,79 \\
\hline 224 & 8169,32 & 8659 & 18 & 0,725 & 0,60 & 20,83 \\
\hline 225 & 14842,14 & 15733 & 41 & 1,598 & 1,322 & 20,88 \\
\hline 226 & 11324,25 & 12004 & 49 & 1,320 & 1,092 & 20,88 \\
\hline 227 & 6909,53 & 7324 & 62 & 0,382 & 0,316 & 20,89 \\
\hline 228 & 8201,74 & 8694 & 40 & 0,578 & 0,478 & 20,92 \\
\hline
\end{tabular}




\begin{tabular}{|c|c|c|c|c|c|c|}
\hline 229 & 10050,39 & 10653 & 42 & 0,705 & 0,583 & 20,93 \\
\hline 230 & 14058,69 & 14902 & 57 & 1,400 & 1,157 & 21,00 \\
\hline 231 & 11502,93 & 12193 & 40 & 0,690 & 0,570 & 21,05 \\
\hline 232 & 10434,55 & 11061 & 48 & 0,665 & 0,549 & 21,13 \\
\hline 233 & 11715,19 & 12418 & 8 & 2,360 & 1,948 & 21,15 \\
\hline 234 & 14427,89 & 15294 & 36 & 0,670 & 0,553 & 21,16 \\
\hline 235 & 9260,09 & 9816 & 40 & 1,270 & 1,048 & 21,18 \\
\hline 236 & 14836,66 & 15727 & 68 & 2,680 & 2,211 & 21,21 \\
\hline 237 & 9154,15 & 9703 & 15 & 1,335 & 1,101 & 21,25 \\
\hline 238 & 13255,06 & 14050 & 12 & 0,500 & 0,412 & 21,31 \\
\hline 239 & 9271,54 & 9828 & 28 & 0,392 & 0,323 & 21,36 \\
\hline 240 & 11601,98 & 12298 & 11 & 0,408 & 0,336 & 21,43 \\
\hline 241 & 11782,27 & 12489 & 0 & 0,799 & 0,658 & 21,43 \\
\hline 242 & 12392,10 & 13136 & 65 & 0,606 & 0,499 & 21,44 \\
\hline 243 & 12709,38 & 13472 & & 2,960 & 2,437 & 21,46 \\
\hline 244 & 12528,27 & 13280 & 54 & 1,440 & 1,185 & 21,52 \\
\hline 245 & 14141,21 & 14990 & 48 & 1,390 & 1,143 & 21,61 \\
\hline 246 & 12717,55 & 13481 & 38 & 0,444 & 0,365 & 21,64 \\
\hline 247 & 7892,80 & 8366 & 37 & 0,690 & 0,567 & 21,69 \\
\hline 248 & 11738,86 & 12443 & 5 & 1,440 & 1,183 & 21,72 \\
\hline 249 & 13250,33 & 14045 & 63 & 1,550 & 1,273 & 21,76 \\
\hline 250 & 11763,02 & 12469 & 32 & 3,130 & 2,568 & 21,88 \\
\hline 251 & 10178,93 & 10790 & 3 & 1,380 & 1,132 & 21,91 \\
\hline 252 & 14005,51 & 14846 & 56 & 1,330 & 1,090 & 22,02 \\
\hline 253 & 14889,76 & 15783 & 7 & 0,482 & 0,395 & 22,03 \\
\hline 254 & 13035,64 & 13818 & 98 & 1,357 & 1,112 & 22,03 \\
\hline 255 & 13311,85 & 14111 & 21 & 1,370 & 1,121 & 22,21 \\
\hline 256 & 13305,68 & 14104 & 43 & 1,440 & 1,178 & 22,24 \\
\hline 257 & 15687,13 & 16628 & 39 & 1,725 & 1,411 & 22,25 \\
\hline 258 & 9107,61 & 9654 & 3 & 0,494 & 0,404 & 22,28 \\
\hline 259 & 14475,83 & 15344 & 56 & 0,713 & 0,583 & 22,30 \\
\hline 260 & 13992,59 & 14832 & 69 & 3,130 & 2,554 & 22,55 \\
\hline 261 & 9305,74 & 9864 & 36 & 0,521 & 0,425 & 22,59 \\
\hline 262 & 14762,92 & 15649 & 30 & 0,510 & 0,416 & 22,60 \\
\hline 263 & 12141,09 & 12870 & 58 & 2,900 & 2,365 & 22,62 \\
\hline 264 & 11820,69 & 12530 & 53 & 1,430 & 1,166 & 22,64 \\
\hline 265 & 13298,83 & 14097 & 1 & 0,476 & 0,388 & 22,68 \\
\hline 266 & 15279,85 & 16197 & 61 & 1,530 & 1,247 & 22,69 \\
\hline 267 & 11565,69 & 12260 & 56 & 1,457 & 1,187 & 22,75 \\
\hline 268 & 10203,32 & 10816 & 14 & 1,33 & 1,083 & 22,81 \\
\hline 269 & 12844,45 & 13615 & 75 & 0,409 & 0,333 & 22,82 \\
\hline 270 & 10277,03 & 10894 & 63 & 1,200 & 0,977 & 22,82 \\
\hline 271 & 10216,94 & 10830 & 41 & 1,370 & 1,115 & 22,87 \\
\hline 272 & 9975,24 & 10574 & 36 & 0,429 & 0,349 & 22,92 \\
\hline 273 & 13131,76 & 13920 & 27 & 0,722 & 0,587 & 23,00 \\
\hline 274 & 15114,73 & 16022 & 40 & 0,458 & 0,372 & 23,12 \\
\hline 275 & 9504,24 & 10074 & 46 & 2,300 & 1,867 & 23,19 \\
\hline 276 & 12021,98 & 12743 & 78 & 0,483 & 0,392 & 23,21 \\
\hline 277 & 13195,28 & 13987 & 50 & 2,930 & 2,377 & 23,26 \\
\hline 278 & 10834,77 & 11485 & $16 / 10$ & 2,760 & 2,238 & 23,32 \\
\hline 279 & 9664,66 & 10245 & 47 & 1,110 & 0,900 & 23,33 \\
\hline 280 & 12667,73 & 13428 & 75 & 2,900 & 2,350 & 23,40 \\
\hline 281 & 9756,70 & 10342 & 60 & 1,400 & 1,133 & 23,57 \\
\hline 282 & 12755,70 & 13521 & 55 & 1,338 & 1,082 & 23,66 \\
\hline 283 & 14389,46 & 15253 & 76 & 1,496 & 1,207 & 23,94 \\
\hline 284 & 9726,85 & 10310 & 51 & 0,403 & 0,325 & 24,00 \\
\hline 285 & 9969,22 & 10567 & 56 & 0,785 & 0,633 & 24,01 \\
\hline 286 & 12507,37 & 13258 & 52 & 1,290 & 1,040 & 24,04 \\
\hline
\end{tabular}




\begin{tabular}{|c|c|c|c|c|c|c|}
\hline 287 & 10768,26 & 11414 & 30 & 0,699 & 0,563 & 24,16 \\
\hline 288 & 10353,18 & 10974 & 4 & 0,549 & 0,442 & 24,21 \\
\hline 289 & 15680,56 & 16621 & 147 & 2,890 & 2,326 & 24,25 \\
\hline 290 & 12871,62 & 13644 & 46 & 0,661 & 0,532 & 24,25 \\
\hline 291 & 10466,55 & 11095 & 19 & 2,720 & 2,187 & 24,37 \\
\hline 292 & 9001,13 & 9541 & 15 & 1,280 & 1,029 & 24,39 \\
\hline 293 & 10530,87 & 11163 & 110 & 0,712 & 0,572 & 24,48 \\
\hline 294 & 9061,91 & 9606 & 1 & 1,357 & 1,090 & 24,50 \\
\hline 295 & 12913,75 & 13689 & 74 & 2,760 & 2,216 & 24,55 \\
\hline 296 & 10525,73 & 11157 & 3 & 0,471 & 0,378 & 24,60 \\
\hline 297 & 13351,88 & 14153 & 64 & 2,370 & 1,902 & 24,61 \\
\hline 298 & 11427,98 & 12114 & 7 & 1,620 & 1,300 & 24,62 \\
\hline 299 & 10699,99 & 11342 & 76 & 2,450 & 1,966 & 24,62 \\
\hline 300 & 10039,05 & 10641 & 44 & 0,399 & 0,320 & 24,69 \\
\hline 301 & 12039,45 & 12762 & 52 & 0,832 & 0,667 & 24,74 \\
\hline 302 & 12739,60 & 13504 & 48 & 3,030 & 2,426 & 24,90 \\
\hline 303 & 10280,81 & 10898 & 65 & 2,750 & 2,200 & 25,00 \\
\hline 304 & 11897,57 & 12611 & 80 & 1,290 & 1,032 & 25,00 \\
\hline 305 & 11428,38 & 12114 & 55 & 1,350 & 1,08 & 25,00 \\
\hline 306 & 13020,56 & 13802 & 68 & 1,509 & 1,207 & 25,02 \\
\hline 307 & 13561,73 & 14375 & 44 & 1,649 & 1,318 & 25,11 \\
\hline 308 & 13729,72 & 14554 & 54 & 1,480 & 1,182 & 25,21 \\
\hline 309 & 11424,26 & 12110 & 46 & 0,685 & 0,547 & 25,23 \\
\hline 310 & 14689,07 & 15570 & 77 & 2,840 & 2,267 & 25,28 \\
\hline 311 & 10692,34 & 11334 & 30 & 1,450 & 1,157 & 25,32 \\
\hline 312 & 12329,17 & 13069 & 16 & 1,360 & 1,085 & 25,35 \\
\hline 313 & 13671,00 & 14491 & 51 & 2,830 & 2,257 & 25,39 \\
\hline 314 & 10688,37 & 11330 & 36 & 1,446 & 1,153 & 25,41 \\
\hline 315 & 7874,01 & 8346 & 80 & 2,540 & 2,025 & 25,43 \\
\hline 316 & 12953,27 & 13730 & 75 & 2,940 & 2,342 & 25,53 \\
\hline 317 & 14016,46 & 14857 & 20 & 1,440 & 1,147 & 25,54 \\
\hline 318 & 13463,86 & 14272 & 126 & 2,890 & 2,298 & 25,76 \\
\hline 319 & 10785,69 & 11433 & 60 & 1,303 & 1,035 & 25,89 \\
\hline 320 & 10972,28 & 11631 & 6 & 1,300 & 1,031 & 26,09 \\
\hline 321 & 12968,89 & 13747 & & 0,683 & 0,541 & 26,25 \\
\hline 322 & 8889,90 & 9423 & 2 & 0,779 & 0,617 & 26,26 \\
\hline 323 & 8534,17 & 9046 & 39 & 1,430 & 1,131 & 26,44 \\
\hline 324 & 11524,85 & 12216 & 55 & 1,529 & 1,208 & 26,57 \\
\hline 325 & 9507,15 & 10078 & 23 & 3,090 & 2,441 & 26,59 \\
\hline 326 & 10056,38 & 10660 & 53 & 1,290 & 1,019 & 26,59 \\
\hline 327 & 8802,66 & 9331 & 64 & 0,622 & 0,491 & 26,68 \\
\hline 328 & 9239,13 & 9793 & 156 & 2,400 & 1,892 & 26,85 \\
\hline 329 & 12655,13 & 13414 & 19 & 1,430 & 1,126 & 27,00 \\
\hline 330 & 11972,91 & 12691 & 50 & 0,762 & 0,600 & 27,00 \\
\hline 331 & 8779,35 & 9306 & 82 & 2,350 & 1,846 & 27,30 \\
\hline 332 & 13124,88 & 13912 & 7 & 1,680 & 1,318 & 27,47 \\
\hline 333 & 7688,86 & 8150 & 45 & 1,385 & 1,086 & 27,53 \\
\hline 334 & 14338,01 & 15198 & & 2,640 & 2,070 & 27,54 \\
\hline 335 & 10242,97 & 10858 & 28 & 1,190 & 0,933 & 27,55 \\
\hline 336 & 11909,76 & 12624 & 36 & 0,820 & 0,641 & 27,93 \\
\hline 337 & 10969,88 & 11628 & 35 & 1,290 & 1,008 & 27,98 \\
\hline 338 & 12064,50 & 12788 & 52 & 1,400 & 1,093 & 28,09 \\
\hline 339 & 10748,14 & 11393 & 38 & 1,593 & 1,243 & 28,16 \\
\hline 340 & 9481,55 & 10050 & 43 & 1,470 & 1,146 & 28,27 \\
\hline 341 & 13494,60 & 14304 & 42 & 0,749 & 0,582 & 28,69 \\
\hline 342 & 11080,32 & 11745 & 14 & 0,843 & 0,655 & 28,70 \\
\hline 343 & 11981,69 & 12701 & 18 & 1,529 & 1,188 & 28,70 \\
\hline 344 & 10089,06 & 10694 & 36 & 1,250 & 0,971 & 28,73 \\
\hline
\end{tabular}




\begin{tabular}{|c|c|c|c|c|c|c|}
\hline 345 & 12487,37 & 13237 & 5 & 0,821 & 0,637 & 28,89 \\
\hline 346 & 13931,93 & 14768 & 48 & 0,718 & 0,557 & 28,90 \\
\hline 347 & 10570,19 & 11204 & 52 & 1,350 & 1,047 & 28,94 \\
\hline 348 & 9947,18 & 10544 & 49 & 0,697 & 0,539 & 29,31 \\
\hline 349 & 12904,69 & 13679 & 54 & 0,683 & 0,528 & 29,36 \\
\hline 350 & 8607,38 & 9124 & 56 & 1,440 & 1,108 & 29,96 \\
\hline 351 & 11755,56 & 12461 & 0 & 1,505 & 1,156 & 30,19 \\
\hline 352 & 8518,59 & 9030 & 11 & 0,746 & 0,572 & 30,42 \\
\hline 353 & 10986,59 & 11646 & 20 & 1,450 & 1,111 & 30,51 \\
\hline 354 & 12600,55 & 13357 & 65 & 1,582 & 1,212 & 30,53 \\
\hline 355 & 8039,75 & 8522 & 22 & 1,370 & 1,049 & 30,60 \\
\hline 356 & 14411,56 & 15276 & 16 & 1,504 & 1,150 & 30,78 \\
\hline 357 & 9689,81 & 10271 & 117 & 2,850 & 2,178 & 30,85 \\
\hline 358 & 10683,05 & 11324 & 7,6 & 3,000 & 2,260 & 32,74 \\
\hline 359 & 10800,22 & 11448 & 24 & 0,876 & 0,659 & 32,93 \\
\hline 360 & 12371,65 & 13114 & 58 & 1,640 & 1,231 & 33,23 \\
\hline 361 & 12076,62 & 12801 & 40 & 0,577 & 0,429 & 34,50 \\
\hline 362 & 12128,22 & 12856 & 66 & 1,633 & 1,212 & 34,74 \\
\hline 363 & 11036,11 & 11698 & 19 & 0,757 & 0,558 & 35,66 \\
\hline 364 & 10522,79 & 11154 & 14 & 0,749 & 0,541 & 38,45 \\
\hline 365 & 10672,15 & 11312 & 15 & 3,051 & 2,416 & 26,28 \\
\hline 366 & 10235,98 & 10850 & 19 & 2,607 & 2,206 & 18,18 \\
\hline 367 & 9008,91 & 9549 & 22 & 2,193 & 1,804 & 21,56 \\
\hline 368 & 10122,50 & 10468 & 24 & 2,224 & 1,927 & 15,41 \\
\hline 369 & 10545,81 & 11179 & 23 & 2,452 & 2,072 & 18,34 \\
\hline 370 & 8826,47 & 9320 & 3 & 2,640 & 2,245 & 17,59 \\
\hline
\end{tabular}




\begin{tabular}{|c|c|c|c|c|c|c|c|}
\hline Probeta & Corr H & Canto rodaja & Ancho rodaja & Espesor rodaja & Dens anhidra & DensH\% & Dens $12 \%$ \\
\hline 1 & $-11,91$ & 25,8 & 20,6 & 9,4 & 656 & 657 & 696 \\
\hline 2 & $-11,85$ & 15,0 & 10,0 & 8,3 & 530 & 531 & 562 \\
\hline 3 & $-11,53$ & 15,0 & 10,0 & 8,2 & 520 & 523 & 553 \\
\hline 4 & $-8,90$ & 25,3 & 20,1 & 9,3 & 621 & 641 & 669 \\
\hline 5 & $-7,21$ & 25,2 & 20,0 & 9,2 & 554 & 580 & 601 \\
\hline 6 & $-7,10$ & 25,4 & 20,4 & 8,5 & 500 & 524 & 543 \\
\hline 7 & $-6,93$ & 25,0 & 20,1 & 8,5 & 624 & 656 & 678 \\
\hline 8 & $-6,35$ & 22,2 & 19,7 & 8,6 & 649 & 686 & 708 \\
\hline 9 & $-6,07$ & 24,8 & 19,3 & 9,0 & 548 & 580 & 598 \\
\hline 10 & $-6,05$ & 24,9 & 19,8 & 9,1 & 528 & 559 & 576 \\
\hline 11 & $-5,93$ & 25,1 & 20,1 & 9,3 & 657 & 697 & 718 \\
\hline 12 & $-5,86$ & 25,4 & 20,5 & 9,0 & 587 & 623 & 641 \\
\hline 13 & $-5,36$ & 24,9 & 19,9 & 9,3 & 549 & 586 & 602 \\
\hline 14 & $-5,34$ & 24,7 & 20,0 & 9,2 & 538 & 574 & 590 \\
\hline 15 & $-5,17$ & 25,0 & 20,0 & 8,8 & 596 & 636 & 653 \\
\hline 16 & $-4,73$ & 25,5 & 20,3 & 9,1 & 461 & 495 & 506 \\
\hline 17 & $-4,43$ & 25,4 & 20,3 & 8,7 & 622 & 669 & 684 \\
\hline 18 & $-4,09$ & 25,0 & 20,3 & 9,5 & 569 & 614 & 627 \\
\hline 19 & $-3,93$ & 18,0 & 13,7 & 8,7 & 606 & 655 & 668 \\
\hline 20 & $-3,76$ & 25,1 & 20,3 & 9,1 & 618 & 669 & 681 \\
\hline 21 & $-3,69$ & 25,1 & 19,8 & 9,3 & 497 & 539 & 549 \\
\hline 22 & $-3,41$ & 25,5 & 20,2 & 9,3 & 561 & 610 & 620 \\
\hline 23 & $-3,34$ & 25,0 & 19,9 & 9,4 & 563 & 612 & 622 \\
\hline 24 & $-3,32$ & 25,4 & 20,3 & 8,7 & 550 & 597 & 607 \\
\hline 25 & $-3,24$ & 25,5 & 20,5 & 8,9 & 589 & 641 & 651 \\
\hline 26 & $-3,15$ & 25,5 & 20,2 & 9,2 & 520 & 566 & 574 \\
\hline 27 & $-2,97$ & 25,0 & 20,0 & 8,5 & 527 & 574 & 583 \\
\hline 28 & $-2,85$ & 25,0 & 20,0 & 8,1 & 559 & 610 & 619 \\
\hline 29 & $-2,44$ & 18,0 & 14,0 & 9,1 & 525 & 575 & 582 \\
\hline 30 & $-2,30$ & 25,4 & 20,2 & 9,4 & 539 & 591 & 598 \\
\hline 31 & $-2,19$ & 24,9 & 19,9 & 8,5 & 547 & 601 & 607 \\
\hline 32 & $-2,19$ & 24,5 & 20,0 & 9,3 & 657 & 722 & 730 \\
\hline 33 & $-2,14$ & 18,1 & 14,0 & 9,4 & 592 & 650 & 657 \\
\hline 34 & $-1,43$ & 25,4 & 20,1 & 9,2 & 526 & 581 & 585 \\
\hline 35 & $-1,40$ & 25,2 & 20,0 & 8,8 & 587 & 649 & 654 \\
\hline 36 & $-1,22$ & 24,9 & 20,1 & 8,4 & 631 & 699 & 704 \\
\hline 37 & $-0,93$ & 25,0 & 19,9 & 9,3 & 590 & 655 & 658 \\
\hline 38 & $-0,79$ & 17,9 & 14,0 & 7,9 & 559 & 621 & 624 \\
\hline 39 & $-0,77$ & 25,2 & 20,3 & 9,5 & 566 & 630 & 632 \\
\hline 40 & $-0,54$ & 25,0 & 20,1 & 8,9 & 493 & 550 & 552 \\
\hline 41 & 0,01 & 25,2 & 20,0 & 9,5 & 565 & 633 & 633 \\
\hline 42 & 0,02 & 14,8 & 9,7 & 8,3 & 423 & 473 & 473 \\
\hline 43 & 0,18 & 14,4 & 6,8 & 8,0 & 493 & 553 & 552 \\
\hline 44 & 0,37 & 14,8 & 9,9 & 8,3 & 492 & 553 & 552 \\
\hline 45 & 0,41 & 24,9 & 19,9 & 8,6 & 541 & 608 & 607 \\
\hline 46 & 0,54 & 14,8 & 10,0 & 8,0 & 485 & 546 & 544 \\
\hline 47 & 0,62 & 6,8 & 14,8 & 7,7 & 419 & 472 & 471 \\
\hline 48 & 0,64 & 14,8 & 6,9 & 7,5 & 511 & 576 & 574 \\
\hline 49 & 0,70 & 25,6 & 20,3 & 8,8 & 551 & 621 & 619 \\
\hline 50 & 1,06 & 17,9 & 14,0 & 8,7 & 534 & 604 & 600 \\
\hline 51 & 1,31 & 14,9 & 10,0 & 8,2 & 516 & 585 & 581 \\
\hline 52 & 1,38 & 25,1 & 20,1 & 9,0 & 668 & 758 & 752 \\
\hline 53 & 1,39 & 25,1 & 20,1 & 9,0 & 462 & 524 & 521 \\
\hline 54 & 1,58 & 25,0 & 19,9 & 8,3 & 599 & 681 & 675 \\
\hline
\end{tabular}




\begin{tabular}{|c|c|c|c|c|c|c|c|}
\hline 55 & 1,61 & 25,1 & 19,9 & 9,0 & 515 & 585 & 580 \\
\hline 56 & 1,81 & 25,2 & 20,1 & 8,6 & 500 & 569 & 564 \\
\hline 57 & 1,86 & 24,7 & 19,8 & 9,0 & 579 & 659 & 653 \\
\hline 58 & 1,96 & 18,5 & 14,4 & 8,7 & 547 & 623 & 617 \\
\hline 59 & 2,02 & 25,2 & 20,0 & 10,1 & 443 & 505 & 500 \\
\hline 60 & 2,06 & 25,3 & 20,0 & 8,9 & 561 & 640 & 633 \\
\hline 61 & 2,13 & 14,9 & 9,9 & 8,4 & 520 & 593 & 587 \\
\hline 62 & 2,29 & 18,2 & 14,0 & 8,8 & 468 & 535 & 529 \\
\hline 63 & 2,31 & 15,0 & 9,9 & 8,8 & 551 & 630 & 623 \\
\hline 64 & 2,41 & 25,3 & 20,1 & 9,1 & 561 & 642 & 634 \\
\hline 65 & 2,49 & 14,9 & 9,8 & 8,1 & 525 & 601 & 594 \\
\hline 66 & 2,62 & 14,9 & 9,8 & 8,1 & 550 & 630 & 622 \\
\hline 67 & 2,80 & 25,2 & 20,1 & 9,0 & 495 & 568 & 560 \\
\hline 68 & 2,87 & 15,0 & 7,0 & 7,8 & 419 & 481 & 474 \\
\hline 69 & 2,93 & 14,9 & 9,8 & 8,7 & 475 & 546 & 538 \\
\hline 70 & 2,93 & 14,9 & 9,9 & 8,8 & 511 & 587 & 578 \\
\hline 71 & 2,95 & 15,0 & 10,0 & 8,2 & 402 & 463 & 456 \\
\hline 72 & 2,95 & 15,0 & 10,0 & 7,7 & 463 & 532 & 525 \\
\hline 73 & 3,09 & 25,4 & 20,5 & 9,5 & 497 & 572 & 563 \\
\hline 74 & 3,17 & 25,5 & 20,1 & 9,5 & 580 & 667 & 657 \\
\hline 75 & 3,19 & 18,0 & 13,9 & 8,8 & 496 & 572 & 563 \\
\hline 76 & 3,25 & 14,9 & 9,9 & 8,4 & 466 & 537 & 528 \\
\hline 77 & 3,37 & 14,6 & 10,0 & 8,4 & 462 & 532 & 523 \\
\hline 78 & 3,38 & 14,8 & 9,8 & 8,5 & 496 & 572 & 562 \\
\hline 79 & 3,69 & 14,9 & 9,9 & 8,0 & 562 & 650 & 638 \\
\hline 80 & 3,92 & 15,3 & 10,2 & 8,3 & 485 & 562 & 551 \\
\hline 81 & 4,20 & 18,2 & 14,2 & 8,0 & 645 & 749 & 733 \\
\hline 82 & 4,26 & 15,0 & 10,0 & 7,9 & 483 & 561 & 549 \\
\hline 83 & 4,30 & 14,9 & 7,0 & 7,9 & 439 & 511 & 500 \\
\hline 84 & 4,31 & 14,9 & 6,9 & 7,1 & 386 & 449 & 440 \\
\hline 85 & 4,43 & 15,0 & 10,0 & 8,7 & 490 & 570 & 557 \\
\hline 86 & 4,47 & 14,9 & 7,0 & 7,8 & 515 & 600 & 586 \\
\hline 87 & 4,50 & 15,0 & 9,9 & 8,5 & 475 & 554 & 541 \\
\hline 88 & 4,64 & 14,8 & 9,9 & 8,8 & 434 & 506 & 494 \\
\hline 89 & 4,67 & 15,0 & 10,0 & 8,0 & 530 & 618 & 604 \\
\hline 90 & 4,67 & 25,0 & 19,9 & 9,3 & 600 & 700 & 684 \\
\hline 91 & 4,73 & 15,0 & 9,9 & 8,1 & 472 & 551 & 538 \\
\hline 92 & 4,74 & 18,0 & 14,0 & 8,5 & 544 & 635 & 620 \\
\hline 93 & 4,81 & 15,0 & 9,9 & 7,6 & 527 & 616 & 601 \\
\hline 94 & 4,81 & 15,0 & 10,0 & 7,5 & 418 & 488 & 476 \\
\hline 95 & 4,82 & 15,0 & 9,9 & 8,0 & 471 & 550 & 536 \\
\hline 96 & 4,85 & 14,8 & 9,8 & 8,0 & 465 & 544 & 531 \\
\hline 97 & 4,86 & 14,9 & 10,1 & 8,8 & 466 & 544 & 531 \\
\hline 98 & 4,86 & 14,9 & 9,9 & 8,2 & 574 & 670 & 654 \\
\hline 99 & 4,88 & 18,0 & 13,9 & 8,7 & 610 & 713 & 695 \\
\hline 100 & 4,93 & 14,7 & 7,0 & 7,3 & 425 & 497 & 484 \\
\hline 101 & 5,05 & 15,0 & 7,0 & 7,6 & 434 & 508 & 495 \\
\hline 102 & 5,12 & 14,8 & 9,9 & 8,2 & 428 & 501 & 488 \\
\hline 103 & 5,18 & 14,9 & 7,1 & 6,8 & 364 & 427 & 416 \\
\hline 104 & 5,21 & 14,7 & 10,0 & 8,8 & 377 & 442 & 431 \\
\hline 105 & 5,25 & 14,9 & 9,9 & 7,9 & 487 & 572 & 557 \\
\hline 106 & 5,35 & 25,1 & 20,2 & 8,7 & 545 & 639 & 622 \\
\hline 107 & 5,41 & 15,0 & 9,9 & 7,8 & 526 & 617 & 601 \\
\hline 108 & 5,44 & 25,1 & 20,1 & 8,5 & 528 & 620 & 603 \\
\hline 109 & 5,47 & 14,9 & 10,0 & 7,6 & 495 & 582 & 566 \\
\hline 110 & 5,48 & 15,0 & 9,9 & 8,1 & 514 & 604 & 587 \\
\hline 111 & 5,49 & 15,0 & 7,1 & 6,9 & 498 & 585 & 569 \\
\hline 112 & 5,51 & 14,9 & 7,0 & 8,1 & 466 & 548 & 533 \\
\hline
\end{tabular}




\begin{tabular}{|c|c|c|c|c|c|c|c|}
\hline 113 & 5,53 & 15,0 & 7,2 & 7,7 & 467 & 548 & 533 \\
\hline 114 & 5,60 & 15,0 & 7,0 & 7,3 & 445 & 523 & 509 \\
\hline 115 & 5,65 & 15,0 & 9,9 & 8,4 & 532 & 625 & 608 \\
\hline 116 & 5,80 & 14,9 & 6,9 & 7,3 & 472 & 556 & 540 \\
\hline 117 & 5,80 & 15,0 & 7,0 & 6,9 & 427 & 502 & 488 \\
\hline 118 & 5,81 & 15,0 & 10,0 & 8,4 & 463 & 546 & 530 \\
\hline 119 & 5,82 & 15,0 & 10,0 & 8,1 & 453 & 533 & 518 \\
\hline 120 & 5,86 & 14,8 & 9,9 & 8,4 & 487 & 574 & 557 \\
\hline 121 & 5,94 & 15,1 & 10,0 & 8,8 & 541 & 638 & 619 \\
\hline 122 & 5,98 & 15,1 & 7,0 & 7,0 & 481 & 568 & 551 \\
\hline 123 & 5,99 & 15,1 & 7,1 & 7,6 & 464 & 547 & 531 \\
\hline 124 & 6,00 & 14,9 & 7,0 & 7,7 & 498 & 588 & 570 \\
\hline 125 & 6,00 & 15,1 & 7,2 & 7,2 & 489 & 577 & 560 \\
\hline 126 & 6,00 & 15,1 & 10,1 & 7,9 & 497 & 587 & 569 \\
\hline 127 & 6,00 & 14,9 & 6,9 & 7,6 & 468 & 553 & 536 \\
\hline 128 & 6,00 & 14,9 & 7,0 & 7,4 & 503 & 593 & 575 \\
\hline 129 & 6,00 & 15,0 & 7,1 & 7,5 & 464 & 548 & 532 \\
\hline 130 & 6,00 & 15,1 & 10,0 & 8,5 & 436 & 514 & 499 \\
\hline 131 & 6,00 & 15,1 & 7,1 & 7,4 & 516 & 609 & 590 \\
\hline 132 & 6,00 & 15,0 & 7,1 & 7,1 & 475 & 561 & 544 \\
\hline 133 & 6,00 & 15,0 & 7,1 & 7,4 & 462 & 546 & 529 \\
\hline 134 & 6,00 & 25,4 & 20,1 & 9,6 & 478 & 565 & 548 \\
\hline 135 & 6,00 & 15,1 & 7,1 & 7,5 & 547 & 647 & 627 \\
\hline 136 & 6,00 & 15,1 & 7,2 & 7,0 & 583 & 690 & 668 \\
\hline 137 & 6,00 & 15,1 & 7,1 & 7,5 & 490 & 580 & 561 \\
\hline 138 & 6,00 & 18,1 & 14,1 & 8,4 & 513 & 606 & 587 \\
\hline 139 & 6,00 & 25,5 & 20,5 & 8,3 & 565 & 668 & 647 \\
\hline 140 & 6,00 & 15,0 & 10,0 & 8,0 & 563 & 667 & 646 \\
\hline 141 & 6,00 & 14,8 & 10,0 & 8,4 & 455 & 539 & 522 \\
\hline 142 & 6,00 & 18,0 & 14,0 & 8,7 & 520 & 616 & 596 \\
\hline 143 & 6,00 & 14,9 & 7,0 & 7,5 & 506 & 600 & 580 \\
\hline 144 & 6,00 & 14,8 & 6,9 & 7,6 & 398 & 472 & 456 \\
\hline 145 & 6,00 & 25,3 & 20,0 & 9,1 & 394 & 467 & 452 \\
\hline 146 & 6,00 & 14,9 & 7,1 & 8,0 & 549 & 651 & 630 \\
\hline 147 & 6,00 & 15,0 & 7,1 & 7,9 & 527 & 624 & 604 \\
\hline 148 & 6,00 & 15,1 & 7,1 & 7,5 & 470 & 557 & 539 \\
\hline 149 & 6,00 & 17,9 & 14,0 & 8,7 & 466 & 552 & 534 \\
\hline 150 & 6,00 & 15,1 & 7,1 & 7,4 & 415 & 492 & 476 \\
\hline 151 & 6,00 & 14,9 & 7,0 & 7,9 & 451 & 535 & 518 \\
\hline 152 & 6,00 & 14,7 & 9,9 & 8,3 & 482 & 571 & 553 \\
\hline 153 & 6,00 & 15,0 & 10,0 & 8,3 & 471 & 559 & 541 \\
\hline 154 & 6,00 & 14,9 & 7,1 & 7,3 & 495 & 587 & 567 \\
\hline 155 & 6,00 & 15,0 & 7,1 & 7,2 & 540 & 640 & 619 \\
\hline 156 & 6,00 & 14,9 & 6,9 & 8,1 & 515 & 611 & 591 \\
\hline 157 & 6,00 & 14,9 & 7,0 & 7,6 & 433 & 513 & 496 \\
\hline 158 & 6,00 & 14,9 & 7,1 & 7,9 & 430 & 510 & 493 \\
\hline 159 & 6,00 & 14,9 & 7,1 & 7,5 & 439 & 521 & 503 \\
\hline 160 & 6,00 & 15,1 & 7,1 & 7,2 & 457 & 543 & 525 \\
\hline 161 & 6,00 & 15,0 & 7,0 & 8,3 & 459 & 545 & 527 \\
\hline 162 & 6,00 & 18,0 & 14,0 & 9,2 & 534 & 635 & 613 \\
\hline 163 & 6,00 & 15,1 & 7,1 & 7,8 & 502 & 597 & 576 \\
\hline 164 & 6,00 & 18,0 & 14,1 & 8,3 & 464 & 552 & 533 \\
\hline 165 & 6,00 & 14,8 & 9,9 & 8,0 & 479 & 570 & 550 \\
\hline 166 & 6,00 & 18,0 & 14,0 & 8,6 & 520 & 618 & 596 \\
\hline 167 & 6,00 & 15,0 & 7,1 & 7,0 & 447 & 531 & 513 \\
\hline 168 & 6,00 & 18,0 & 14,0 & 8,4 & 509 & 606 & 585 \\
\hline 169 & 6,00 & 15,0 & 7,1 & 7,9 & 465 & 553 & 534 \\
\hline 170 & 6,00 & 15,0 & 9,8 & 7,8 & 474 & 564 & 545 \\
\hline
\end{tabular}




\begin{tabular}{|c|c|c|c|c|c|c|c|}
\hline 171 & 6,00 & 25,3 & 20,4 & 8,7 & 427 & 508 & 490 \\
\hline 172 & 6,00 & 14,8 & 7,0 & 7,2 & 500 & 595 & 574 \\
\hline 173 & 6,00 & 18,2 & 14,1 & 8,4 & 549 & 654 & 631 \\
\hline 174 & 6,00 & 15,0 & 7,1 & 7,0 & 471 & 561 & 541 \\
\hline 175 & 6,00 & 25,0 & 20,1 & 7,6 & 455 & 542 & 523 \\
\hline 176 & 6,00 & 15,0 & 7,2 & 6,4 & 424 & 505 & 487 \\
\hline 177 & 6,00 & 14,8 & 7,0 & 7,2 & 484 & 576 & 556 \\
\hline 178 & 6,00 & 14,9 & 9,8 & 8,7 & 547 & 652 & 629 \\
\hline 179 & 6,00 & 15,0 & 10,0 & 8,1 & 481 & 574 & 553 \\
\hline 180 & 6,00 & 15,0 & 7,0 & 6,8 & 415 & 494 & 476 \\
\hline 181 & 6,00 & 14,8 & 10,0 & 8,2 & 452 & 540 & 520 \\
\hline 182 & 6,00 & 14,9 & 10,0 & 8,1 & 484 & 578 & 556 \\
\hline 183 & 6,00 & 15,0 & 7,0 & 7,3 & 445 & 531 & 511 \\
\hline 184 & 6,00 & 25,1 & 19,8 & 9,1 & 500 & 597 & 575 \\
\hline 185 & 6,00 & 15,0 & 9,8 & 8,5 & 462 & 551 & 531 \\
\hline 186 & 6,00 & 15,0 & 10,0 & 7,7 & 494 & 590 & 569 \\
\hline 187 & 6,00 & 14,9 & 7,2 & 7,0 & 431 & 515 & 496 \\
\hline 188 & 6,00 & 14,9 & 6,9 & 8,1 & 482 & 575 & 554 \\
\hline 189 & 6,00 & 25,0 & 20,0 & 8,7 & 539 & 644 & 620 \\
\hline 190 & 6,00 & 17,9 & 14 & 8,8 & 499 & 596 & 574 \\
\hline 191 & 6,00 & 15,0 & 10,1 & 7,7 & 555 & 663 & 638 \\
\hline 192 & 6,00 & 14,9 & 7,0 & 7,6 & 453 & 541 & 521 \\
\hline 193 & 6,00 & 15,1 & 7,2 & 7,1 & 465 & 556 & 535 \\
\hline 194 & 6,00 & 14,9 & 7,0 & 7,7 & 491 & 586 & 564 \\
\hline 195 & 6,00 & 17,9 & 13,7 & 8,7 & 512 & 613 & 589 \\
\hline 196 & 6,00 & 15,0 & 7,2 & 7,0 & 390 & 467 & 449 \\
\hline 197 & 6,00 & 14,8 & 6,9 & 7,8 & 447 & 535 & 514 \\
\hline 198 & 6,00 & 14,9 & 7,0 & 7,8 & 438 & 524 & 504 \\
\hline 199 & 6,00 & 15,0 & 7,1 & 7,0 & 496 & 594 & 571 \\
\hline 200 & 6,00 & 15,0 & 7,3 & 6,9 & 548 & 656 & 631 \\
\hline 201 & 6,00 & 25,4 & 20,3 & 9,5 & 431 & 516 & 496 \\
\hline 202 & 6,00 & 18,0 & 13,9 & 8,1 & 528 & 633 & 608 \\
\hline 203 & 6,00 & 14,9 & 7,1 & 7,8 & 536 & 642 & 617 \\
\hline 204 & 6,00 & 18,0 & 14,0 & 8,7 & 472 & 566 & 543 \\
\hline 205 & 6,00 & 15,0 & 10,0 & 8,2 & 465 & 558 & 536 \\
\hline 206 & 6,00 & 15,0 & 7,0 & 7,1 & 524 & 629 & 604 \\
\hline 207 & 6,00 & 15,1 & 7,1 & 6,6 & 459 & 551 & 529 \\
\hline 208 & 6,00 & 15,1 & 7,2 & 6,9 & 520 & 624 & 599 \\
\hline 209 & 6,00 & 25,1 & 20,1 & 10,0 & 528 & 634 & 609 \\
\hline 210 & 6,00 & 14,9 & 7,0 & 8,0 & 435 & 523 & 501 \\
\hline 211 & 6,00 & 14,9 & 6,9 & 7,9 & 433 & 521 & 500 \\
\hline 212 & 6,00 & 18,0 & 14,0 & 8,6 & 504 & 606 & 581 \\
\hline 213 & 6,00 & 15,1 & 7,2 & 8,2 & 494 & 593 & 569 \\
\hline 214 & 6,00 & 24,9 & 20,1 & 8,9 & 610 & 734 & 704 \\
\hline 215 & 6,00 & 14,9 & 6,9 & 7,2 & 459 & 553 & 530 \\
\hline 216 & 6,00 & 15,0 & 9,9 & 8,0 & 516 & 621 & 595 \\
\hline 217 & 6,00 & 17,8 & 13,7 & 8,9 & 485 & 584 & 559 \\
\hline 218 & 6,00 & 18,2 & 14,2 & 9,2 & 513 & 618 & 592 \\
\hline 219 & 6,00 & 14,9 & 9,9 & 8,4 & 465 & 561 & 537 \\
\hline 220 & 6,00 & 15,0 & 7,0 & 7,6 & 528 & 637 & 609 \\
\hline 221 & 6,00 & 17,9 & 14,0 & 9,7 & 395 & 477 & 456 \\
\hline 222 & 6,00 & 15,0 & 7,0 & 7,3 & 560 & 676 & 646 \\
\hline 223 & 6,00 & 18,0 & 14,0 & 9,2 & 612 & 739 & 707 \\
\hline 224 & 6,00 & 15,1 & 10,1 & 8,9 & 442 & 534 & 511 \\
\hline 225 & 6,00 & 17,7 & 13,8 & 9,6 & 564 & 681 & 651 \\
\hline 226 & 6,00 & 18,0 & 14,0 & 8,8 & 492 & 595 & 569 \\
\hline 227 & 6,00 & 15,0 & 7,0 & 7,8 & 386 & 466 & 446 \\
\hline 228 & 6,00 & 14,9 & 10,1 & 8,2 & 387 & 468 & 447 \\
\hline
\end{tabular}




\begin{tabular}{|c|c|c|c|c|c|c|c|}
\hline 229 & 6,00 & 15,0 & 10,0 & 7,7 & 505 & 610 & 583 \\
\hline 230 & 6,00 & 17,3 & 14,2 & 8,6 & 548 & 663 & 633 \\
\hline 231 & 6,00 & 15,1 & 10,0 & 8,2 & 460 & 557 & 532 \\
\hline 232 & 6,00 & 15,0 & 10,0 & 8,4 & 436 & 528 & 504 \\
\hline 233 & 6,00 & 25,1 & 20,0 & 9,0 & 431 & 522 & 498 \\
\hline 234 & 6,00 & 14,8 & 9,9 & 7,6 & 497 & 602 & 574 \\
\hline 235 & 6,00 & 17,9 & 14,0 & 8,7 & 481 & 583 & 556 \\
\hline 236 & 6,00 & 25,0 & 20,0 & 8,5 & 520 & 631 & 602 \\
\hline 237 & 6,00 & 18,0 & 13,9 & 8,9 & 494 & 600 & 572 \\
\hline 238 & 6,00 & 15,1 & 7,1 & 7,4 & 519 & 630 & 601 \\
\hline 239 & 6,00 & 15,1 & 7,2 & 7,1 & 418 & 508 & 484 \\
\hline 240 & 6,00 & 15,1 & 7,2 & 6,9 & 448 & 544 & 518 \\
\hline 241 & 6,00 & 15,0 & 9,9 & 8,3 & 534 & 648 & 618 \\
\hline 242 & 6,00 & 15,0 & 10,0 & 8,9 & 374 & 454 & 433 \\
\hline 243 & 6,00 & 24,9 & 20,0 & 8,6 & 569 & 691 & 658 \\
\hline 244 & 6,00 & 18,2 & 14,0 & 8,9 & 523 & 635 & 605 \\
\hline 245 & 6,00 & 18,2 & 14,1 & 8,8 & 506 & 616 & 586 \\
\hline 246 & 6,00 & 15,2 & 7,3 & 6,5 & 506 & 616 & 586 \\
\hline 247 & 6,00 & 15,0 & 10,1 & 8,6 & 435 & 530 & 504 \\
\hline 248 & 6,00 & 17,9 & 13,9 & 8,9 & 534 & 650 & 619 \\
\hline 249 & 6,00 & 18,2 & 14,1 & 9,1 & 545 & 664 & 631 \\
\hline 250 & 6,00 & 24,9 & 20,0 & 9,1 & 567 & 691 & 657 \\
\hline 251 & 6,00 & 18,1 & 14,0 & 8,7 & 513 & 626 & 595 \\
\hline 252 & 6,00 & 18,0 & 14,0 & 8,1 & 534 & 652 & 619 \\
\hline 253 & 6,00 & 14,9 & 7,0 & 7,6 & 498 & 608 & 578 \\
\hline 254 & 6,00 & 17,8 & 13,8 & 8,6 & 526 & 642 & 610 \\
\hline 255 & 6,00 & 18,1 & 14,1 & 8,9 & 494 & 603 & 572 \\
\hline 256 & 6,00 & 18,0 & 14,0 & 9,1 & 514 & 628 & 596 \\
\hline 257 & 6,00 & 18,0 & 14,2 & 9,3 & 594 & 726 & 688 \\
\hline 258 & 6,00 & 15,0 & 7,1 & 8,0 & 474 & 580 & 550 \\
\hline 259 & 6,00 & 15,0 & 10,0 & 7,8 & 498 & 609 & 578 \\
\hline 260 & 6,00 & 25,1 & 20,0 & 9,0 & 565 & 693 & 656 \\
\hline 261 & 6,00 & 15,0 & 7,1 & 8,1 & 493 & 604 & 572 \\
\hline 262 & 6,00 & 15,1 & 7,1 & 7,1 & 547 & 670 & 635 \\
\hline 263 & 6,00 & 25,0 & 20,0 & 8,7 & 544 & 667 & 631 \\
\hline 264 & 6,00 & 18,4 & 14,2 & 8,6 & 519 & 636 & 603 \\
\hline 265 & 6,00 & 15,1 & 7,2 & 6,8 & 525 & 644 & 609 \\
\hline 266 & 6,00 & 18,2 & 14,1 & 9,0 & 540 & 662 & 627 \\
\hline 267 & 6,00 & 18,0 & 13,9 & 8,8 & 539 & 662 & 626 \\
\hline 268 & 6,00 & 18,0 & 14,0 & 8,4 & 512 & 628 & 594 \\
\hline 269 & 6,00 & 14,9 & 7,0 & 7,0 & 456 & 560 & 530 \\
\hline 270 & 6,00 & 18,0 & 14,0 & 8,1 & 479 & 588 & 556 \\
\hline 271 & 6,00 & 18,0 & 14,1 & 8,0 & 549 & 675 & 638 \\
\hline 272 & 6,00 & 15,1 & 7,1 & 7,4 & 440 & 541 & 511 \\
\hline 273 & 6,00 & 15,0 & 10,3 & 8,3 & 458 & 563 & 532 \\
\hline 274 & 6,00 & 14,9 & 7,0 & 7,5 & 476 & 585 & 553 \\
\hline 275 & 6,00 & 25,1 & 20,0 & 8,8 & 423 & 521 & 492 \\
\hline 276 & 6,00 & 15,0 & 7,0 & 7,3 & 511 & 630 & 595 \\
\hline 277 & 6,00 & 25,1 & 19,8 & 9,3 & 514 & 634 & 598 \\
\hline 278 & 6,00 & 24,4 & 19,9 & 9,5 & 485 & 598 & 564 \\
\hline 279 & 6,00 & 18,1 & 13,9 & 8,5 & 421 & 519 & 490 \\
\hline 280 & 6,00 & 25,0 & 20,1 & 9,6 & 487 & 601 & 567 \\
\hline 281 & 6,00 & 18,1 & 14,1 & 8,9 & 499 & 616 & 581 \\
\hline 282 & 6,00 & 18,0 & 13,9 & 9,0 & 481 & 594 & 560 \\
\hline 283 & 6,00 & 17,8 & 14,1 & 8,7 & 553 & 685 & 644 \\
\hline 284 & 6,00 & 15,1 & 7,2 & 7,0 & 427 & 530 & 498 \\
\hline 285 & 6,00 & 15,1 & 10,0 & 8,5 & 493 & 612 & 575 \\
\hline 286 & 6,00 & 17,9 & 13,9 & 8,4 & 498 & 617 & 580 \\
\hline
\end{tabular}




\begin{tabular}{|c|c|c|c|c|c|c|c|}
\hline 287 & 6,00 & 14,8 & 9,7 & 8,6 & 456 & 566 & 532 \\
\hline 288 & 6,00 & 14,9 & 7,0 & 7,8 & 543 & 675 & 634 \\
\hline 289 & 6,00 & 25,4 & 20,3 & 9,0 & 501 & 623 & 585 \\
\hline 290 & 6,00 & 15,2 & 10,1 & 7,8 & 444 & 552 & 518 \\
\hline 291 & 6,00 & 25,0 & 20,0 & 9,0 & 486 & 604 & 567 \\
\hline 292 & 6,00 & 17,9 & 14,0 & 8,5 & 483 & 601 & 564 \\
\hline 293 & 6,00 & 15,1 & 10,1 & 8,0 & 469 & 584 & 547 \\
\hline 294 & 6,00 & 18,2 & 14,1 & 8,5 & 500 & 622 & 583 \\
\hline 295 & 6,00 & 25,4 & 20,1 & 9,5 & 457 & 569 & 533 \\
\hline 296 & 6,00 & 15,0 & 7,1 & 7,6 & 467 & 582 & 545 \\
\hline 297 & 6,00 & 25,0 & 20,0 & 8,9 & 427 & 533 & 499 \\
\hline 298 & 6,00 & 18,2 & 14,2 & 8,7 & 578 & 721 & 675 \\
\hline 299 & 6,00 & 25,2 & 20,1 & 8,5 & 457 & 569 & 533 \\
\hline 300 & 6,00 & 15,0 & 7,1 & 6,8 & 442 & 551 & 516 \\
\hline 301 & 6,00 & 15,1 & 10,1 & 8,4 & 521 & 649 & 608 \\
\hline 302 & 6,00 & 25,0 & 19,9 & 8,9 & 548 & 684 & 640 \\
\hline 303 & 6,00 & 24,9 & 20,0 & 9,5 & 465 & 581 & 543 \\
\hline 304 & 6,00 & 17,7 & 13,9 & 8,4 & 499 & 624 & 584 \\
\hline 305 & 6,00 & 18,1 & 14,0 & 8,9 & 479 & 599 & 560 \\
\hline 306 & 6,00 & 17,9 & 14,0 & 8,9 & 541 & 677 & 633 \\
\hline 307 & 6,00 & 18,1 & 14,2 & 8,8 & 583 & 729 & 681 \\
\hline 308 & 6,00 & 18,0 & 14,2 & 8,8 & 526 & 658 & 615 \\
\hline 309 & 6,00 & 15,1 & 10,0 & 8,0 & 453 & 567 & 530 \\
\hline 310 & 6,00 & 24,9 & 19,9 & 8,7 & 526 & 659 & 615 \\
\hline 311 & 6,00 & 17,8 & 13,9 & 9,1 & 514 & 644 & 601 \\
\hline 312 & 6,00 & 17,8 & 13,9 & 8,5 & 516 & 647 & 604 \\
\hline 313 & 6,00 & 24,9 & 20,1 & 8,5 & 531 & 665 & 621 \\
\hline 314 & 6,00 & 18,1 & 14,0 & 9,4 & 484 & 607 & 566 \\
\hline 315 & 6,00 & 25,7 & 20,7 & 8,0 & 476 & 597 & 557 \\
\hline 316 & 6,00 & 25,3 & 20,2 & 9,0 & 509 & 639 & 596 \\
\hline 317 & 6,00 & 18,2 & 14,2 & 8,1 & 548 & 688 & 641 \\
\hline 318 & 6,00 & 25,0 & 19,9 & 8,6 & 537 & 675 & 629 \\
\hline 319 & 6,00 & 18,0 & 14,2 & 8,8 & 460 & 579 & 539 \\
\hline 320 & 6,00 & 17,9 & 13,9 & 8,7 & 476 & 601 & 558 \\
\hline 321 & 6,00 & 15,2 & 10,1 & 8,0 & 440 & 556 & 516 \\
\hline 322 & 6,00 & 15,2 & 10,2 & 7,8 & 510 & 644 & 598 \\
\hline 323 & 6,00 & 18,1 & 13,9 & 9,4 & 478 & 605 & 561 \\
\hline 324 & 6,00 & 18,0 & 14,0 & 9,4 & 510 & 645 & 598 \\
\hline 325 & 6,00 & 25,1 & 20,3 & 8,8 & 544 & 689 & 639 \\
\hline 326 & 6,00 & 17,9 & 14,0 & 8,4 & 484 & 613 & 568 \\
\hline 327 & 6,00 & 15,2 & 10,2 & 7,9 & 401 & 508 & 471 \\
\hline 328 & 6,00 & 25,0 & 20,0 & 8,4 & 450 & 571 & 529 \\
\hline 329 & 6,00 & 18,0 & 14,0 & 8,1 & 552 & 701 & 648 \\
\hline 330 & 6,00 & 15,1 & 10,2 & 8,1 & 481 & 611 & 565 \\
\hline 331 & 6,00 & 25,2 & 19,9 & 8,4 & 438 & 558 & 515 \\
\hline 332 & 6,00 & 17,9 & 14,0 & 8,6 & 612 & 780 & 719 \\
\hline 333 & 6,00 & 18,0 & 14,0 & 8,7 & 495 & 632 & 583 \\
\hline 334 & 6,00 & 25,0 & 20,0 & 9,0 & 460 & 587 & 541 \\
\hline 335 & 6,00 & 17,9 & 13,9 & 8,3 & 452 & 576 & 531 \\
\hline 336 & 6,00 & 15,1 & 10,0 & 8,4 & 505 & 646 & 595 \\
\hline 337 & 6,00 & 18,0 & 14,0 & 8,3 & 482 & 617 & 567 \\
\hline 338 & 6,00 & 17,9 & 14,0 & 8,9 & 490 & 628 & 577 \\
\hline 339 & 6,00 & 18,2 & 14,2 & 8,6 & 559 & 717 & 659 \\
\hline 340 & 6,00 & 17,8 & 14,0 & 8,7 & 529 & 678 & 623 \\
\hline 341 & 6,00 & 15,0 & 10,1 & 8,1 & 474 & 610 & 559 \\
\hline 342 & 6,00 & 15,2 & 9,9 & 8,5 & 512 & 659 & 604 \\
\hline 343 & 6,00 & 18,2 & 14,2 & 8,6 & 535 & 688 & 630 \\
\hline 344 & 6,00 & 17,9 & 14,0 & 8,1 & 478 & 616 & 564 \\
\hline
\end{tabular}




\begin{tabular}{|c|c|c|c|c|c|c|c|}
\hline 345 & 6,00 & 15,0 & 10,0 & 8,0 & 531 & 684 & 626 \\
\hline 346 & 6,00 & 15,1 & 10,0 & 7,0 & 527 & 679 & 622 \\
\hline 347 & 6,00 & 17,8 & 14,0 & 8,5 & 494 & 637 & 583 \\
\hline 348 & 6,00 & 15,1 & 10,1 & 7,9 & 447 & 579 & 528 \\
\hline 349 & 6,00 & 15,0 & 10,1 & 7,4 & 471 & 609 & 556 \\
\hline 350 & 6,00 & 17,9 & 14,0 & 9,1 & 486 & 631 & 575 \\
\hline 351 & 6,00 & 17,9 & 14,1 & 8,8 & 520 & 678 & 616 \\
\hline 352 & 6,00 & 15,1 & 10,1 & 8,1 & 463 & 604 & 548 \\
\hline 353 & 6,00 & 17,7 & 13,8 & 8,6 & 529 & 690 & 626 \\
\hline 354 & 6,00 & 18,2 & 14,0 & 8,7 & 547 & 714 & 648 \\
\hline 355 & 6,00 & 18,0 & 14,0 & 8,6 & 484 & 632 & 573 \\
\hline 356 & 6,00 & 18,1 & 14,0 & 9,0 & 504 & 659 & 598 \\
\hline 357 & 6,00 & 25,0 & 20,0 & 9,0 & 484 & 633 & 574 \\
\hline 358 & 6,00 & 24,7 & 20,0 & 9,2 & 497 & 660 & 592 \\
\hline 359 & 6,00 & 15,0 & 10,2 & 8,3 & 519 & 690 & 618 \\
\hline 360 & 6,00 & 18,0 & 14,0 & 8,8 & 555 & 740 & 661 \\
\hline 361 & 6,00 & 14,9 & 7,0 & 8,2 & 502 & 675 & 599 \\
\hline 362 & 6,00 & 18,1 & 14,0 & 9,1 & 526 & 708 & 628 \\
\hline 363 & 6,00 & 15,3 & 10,2 & 8,0 & 447 & 606 & 535 \\
\hline 364 & 6,00 & 15,4 & 10,3 & 8,0 & 426 & 590 & 512 \\
\hline 365 & 6,00 & 25,2 & 20,5 & 8,3 & 563 & 712 & 661 \\
\hline 366 & 6,00 & 25,2 & 20,1 & 8,3 & 525 & 620 & 601 \\
\hline 367 & 6,00 & 25,1 & 20,2 & 7,2 & 494 & 601 & 572 \\
\hline 368 & 3,41 & 25,3 & 20,0 & 7,2 & 529 & 610 & 600 \\
\hline 369 & 6,00 & 25,0 & 20,6 & 8,2 & 491 & 581 & 562 \\
\hline 370 & 5,59 & 25,3 & 20,5 & 8,0 & 541 & 636 & 618 \\
\hline
\end{tabular}


ANEXO III. PUBLICACIONES 
Con el objeto de demostrar la calidad de esta tesis doctoral, se indican 2 artículos científicos, publicados en revistas indexadas, que muestran los resultados más relevantes de la misma.

\section{ARTÍCULO 1}

Autores: Barriola M.J., Aira J.R., Villanueva J.L.

Título: "Analytical models of the mechanical properties of Japanese larch (Larix kaempferi (Lamb.) Carr.) based on non-destructive testing and visual grading parameters"

DOI: $10.1080 / 17480272.2019 .1626481$

Revista: Wood Material Science \& Engineering

ISSN: 1748-0272 (print), 1748-0280 (online)

Índice de impacto: 0,390

Base de indexación:

SJR Cuartil: Q2 Categoría: Materials Science (miscellaneous)

Enlace web: https://www.tandfonline.com/loi/swoo20

\section{ARTÍCULO 2}

Autores: Barriola M.J., Aira J.R., Lafuente E.

Título: "Visual grading criteria for Japanese larch (Larix kaempferi (Lamb.) Carr.) structural timber from Spain"

DOI: 10.1007/s11676-019-01025-5

Revista: Journal of Forestry Research

ISSN: 1007-662X (print), 1993-0607 (online)

Índice de impacto: 1,155

Base de indexación: JCR Cuartil: Q3 Categoría: Forestry

Enlace web: https://link.springer.com/journal/11676 